\title{
Estimação da relação ar-combustível e do tipo de combustível utilizando o sinal de pressão no cilindro em um motor ciclo Otto alimentado com misturas de etanol e gasolina
}

Tese apresentada à Escola de Engenharia de São Carlos da Universidade de São Paulo, como parte dos requisitos para obtenção do título de Doutor em Ciências

Área de Concentração: Dinâmica das Máquinas e Sistemas

ORIENTADOR: Prof. Dr. Luís Carlos Passarini

ESTE EXEMPLAR TRATA-SE DA VERSÃO CORRIGIDA. A VERSÃO ORIGINAL ENCONTRA-SE DISPONÍVEL JUNTO AO DEPARTAMENTO DE ENGENHARIA MECÂNICA DA EESC-USP.

São Carlos

2015 


\section{AUTORIZO A REPRODUÇÃO TOTAL OU PARCIAL DESTE TRABALHO, POR QUALQUER MEIO CONVENCIONAL OU ELETRÔNICO, PARA FINS DE ESTUDO E PESQUISA, DESDE QUE CITADA A FONTE.}

Costa, Fabiano Tadeu Mathias
Estimação da relação ar-combustível e do tipo de combustível utilizando o sinal de pressão no cilindro em um motor ciclo otto alimentado com misturas de etanol e gasolina / Fabiano Tadeu Mathias Costa; orientador Luís Carlos Passarini. São Carlos, 2015.

Tese (Doutorado) - Programa de Pós-Graduação em Engenharia Mecânica e Área de Concentração em Dinâmica de Máquinas e Sistemas -- Escola de Engenharia de São Carlos da Universidade de São Paulo, 2015.

1. método dos momentos. 2. método da razão de pressões. 3. veículos flexíveis. 4. sensibilidade ao tipo de combustível. 5. análise estatística. 6. modelagem de motores. I. Título. 


\section{FOLHA DE JULGAMENTO}

Candidato: Engenheiro FABIANO TADEU MATHIAS COSTA.

Título da tese: "Estimação da relação ar-combustível e do tipo de combustível utilizando o sinal de pressão no cilindro em um motor ciclo Otto alimentado com misturas de etanol e gasolina".

Data da defesa: 13/05/2015

\section{Comissão Julgadora:}

Prof. Associado Luis Carlos Passarini (Orientador)

(Escola de Engenharia de São Carlos/EESC)

Prof. Dr. Antonio Moreira dos Santos

(Escola de Engenharia de São Carlos/EESC)

Prof. Dr. Délson Luiz Módolo

(Universidade Estadual Paulista "Júlio de Mesquita Filho"/UNESP-Bauru)

Prof. Dr. Márcio Turra de Ávila

(Universidade Federal de São Carlos/UFSCar)

Prof. Dr. Rodolfo Ipolito Meneguette Prof. Dr. Rodolfo Ipolito Meneguette
(Instituto Federal de Educação. Ciência e Tecnologia de São Paulo - Campus Catanduva)

Coordenador do Programa de Pós-Graduação em Engenheira Mecânica:

Prof. Associado Gherhardt Ribatski

Presidente da Comissão de Pós-Graduação: Prof. Associado Paulo Sergio Lima Segantine

\section{Resultado:}
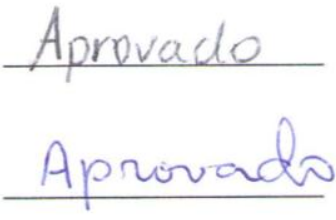

Aprovado
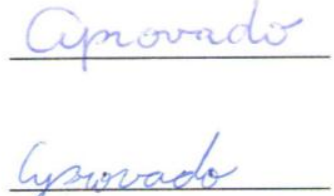



\section{AGRADECIMENTOS}

Ao Conselho Nacional de Desenvolvimento Científico e Tecnológico - CNPQ, pela bolsa de estudos concedida.

Ao Prof. Dr. Luís Carlos Passarini pela oportunidade e orientação.

Em especial ao Dr. Armando José Dal Bem pela enorme ajuda no cumprimento dos requisitos do programa de doutorado e pelo incansável empenho para viabilizar a realização dos experimentos.

Ao mestrando Marcos Ferreira Polito pela ajuda na montagem da bancada experimental e pelo empenho na realização dos experimentos.

Ao técnico Hélio José Donizete Trebi pela construção e manipulação de diversas peças da bancada experimental de forma tão detalhista, precisa e competente. Também, pelos momentos em que me ajudou mesmo estando sobrecarregado de tarefas.

Ao Prof. Dr. Antônio Moreira dos Santos por disponibilizar o Laboratório de Motores da EESC.

Ao Eng. e Dr. Gustavo Rodrigues de Sousa pela disponibilidade e empenho durante a montagem da bancada experimental.

Ao técnico Roberto Carlos Pratavieira e ao Especialista em laboratório Jorge Nicolau dos Santos pela dedicação e empenho na solução dos problemas que surgiram durante o desenvolvimento dos VIs de aquisição de dados e dos componentes da bancada experimental.

Ao técnico Roberto Aparecido Lourenço pelo apoio e suporte técnico durante a realização dos experimentos.

Ao técnico José Roberto Bogni pela disponibilização do banho termostático e pelas inúmeras soldas realizadas nas ferragens da bancada experimental. 
Aos amigos do Laboratório de Eletrônica Embarcada e da EESC, Jaime Marini Júnior, Gilberto Hirotsugu Azevedo Koike, Rodrigo de Oliveira Preti e Marcus Vinícius Ivo da Silva.

Ao Instituto Federal de Educação Ciência e Tecnologia de São Paulo - IFSP campus Catanduva pelo incentivo a minha qualificação profissional.

Ao bibliotecário Eduardo Graziosi Silva pela enorme contribuição na adequação deste trabalho às normas da ABNT.

A minha mãe Marly Terezinha Santana Costa e a minha família. 


\section{RESUMO}

COSTA, F. T. M. Estimação da relação ar-combustível e do tipo de combustível utilizando o sinal de pressão no cilindro em um motor ciclo Otto alimentado com misturas de etanol e gasolina. 2015. $166 \mathrm{f}$. Tese (Doutorado) - Escola de Engenharia de São Carlos, Universidade de São Paulo, São Carlos, 2015.

A pesquisa realizada tratou do estudo de modelos de estimação da relação ar-combustível e de identificação do tipo de combustível usando o sinal da pressão no cilindro em um motor quatro tempos automotivo, alimentado com gasolina brasileira tipo $C$, etanol e misturas destes combustíveis. Foi montada uma bancada dinamométrica para realização de testes em um motor originalmente projetado para operar com etanol e que possui relação de compressão de 13,44:1. Durante os testes do motor foram coletados dados referentes às variáveis de desempenho e emissões de gases de exaustão. Os dados coletados em plena carga foram analisados utilizando parâmetros estatísticos e confrontados com os resultados esperados segundo a literatura. As variáveis independentes disponibilizadas nos testes do motor foram utilizadas em conjunto com a aplicação do método dos momentos e da razão de pressões no sinal da pressão no cilindro para o desenvolvimento de novos modelos de estimação da relação ar-combustível e de identificação do tipo de combustível. Os modelos obtidos na presente pesquisa mostraram-se capazes de estimar a relação ar-combustível, sendo sensíveis à variação da composição do combustível nesta estimativa, e de identificar o tipo de combustível utilizado no motor.

Palavras-chave: Método dos momentos. Método da razão de pressões. Veículos flexíveis. Sensibilidade ao tipo de combustível. Análise estatística. 


\begin{abstract}
COSTA, F. T. M. Estimation of the air-fuel ratio and type of fuel in-cylinder pressure signal in an Otto-cycle engine fueled with ethanol and gasoline blends. 2015. $166 \mathrm{f}$. Tese (Doutorado) - Escola de Engenharia de São Carlos, Universidade de São Paulo, São Carlos, 2015.

This research addressed the study of models for estimating the air-fuel ratio and identifying the type of fuel by in-cylinder pressure signal in a four stroke automotive engine fueled with Brazilian gasoline $\mathrm{C}$ type, ethanol, and blends of these fuels. A dynamometer was assembled for tests in an engine originally designed to operate with ethanol and with a 13.44:1 compression ratio. During the engine tests, data were collected related to the performance and exhaustion gas emission variables. Data collected at full load were analyzed using statistical parameters and compared with the expected results according to the literature. The independent variables provided by the engine tests were used together with application of the method of moments and the pressure ratio for in-cylinder pressure in order to develop new models for estimating the air-fuel ratio and to identify the fuel type. The models obtained in this research proved to be capable of estimating the air-fuel ratio, being sensitive to the variation in the type of fuel used in such estimations, and of identifying the type of fuel used in the engine.
\end{abstract}

Keywords: Method of moments. Method of pressure ratio. Flex-fuel vehicles. Fuel sensitivity. Statistical analysis. 


\section{LISTA DE FIGURAS}

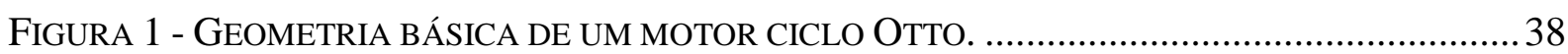

FIGURA 2 - CICLO INDICADO DE UM MOTOR DE IGNIÇÃO POR CENTELHA.................................... 40

FIGURA 3 - LICENCIAMENTO NO BRASIL DE AUTO VEÍCULOS NOVOS POR COMBUSTÍVEL............54

FIGURA 4 - PRESSÃO NO CILINDRO EM FUNÇÃO DA POSIÇÃO DO PISTÃO. ...................................55

FIGURA 5 - SEQUÊNCIA DE EVENTOS DO CICLO DE OPERAÇÃO DE UM MOTOR QUATRO TEMPOS

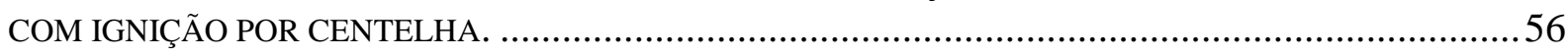

FIGURA 6 - EFEITOS DA RELAÇÃO COMBUSTÍVEL-AR $(\varnothing)$ SOBRE O DIAGRAMA P -V . .................57

FIGURA 7 - A - PRESSÃO NO CILINDRO VERSUS ÂNGULO DA ÁRVORE DE MANIVELAS. B EFEITOS DO AVANÇO DA CENTELHA SOBRE O TORQUE...........................................................5

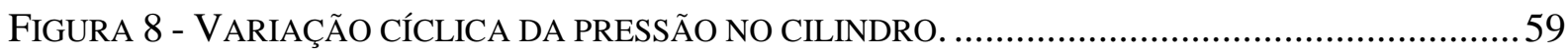

FIGURA 9 - EFEITO DA OCORRÊNCIA DE KNOCKING SOBRE O TRAÇO DA PRESSÃO NO CILINDRO. 60

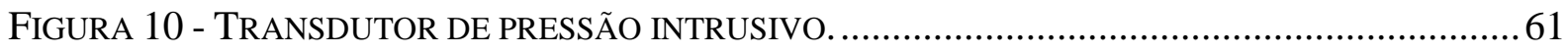

FIGURA 11 - TRANSDUTOR DE PRESSÃO NO CILINDRO NÃO INTRUSIVO....................................61

FIGURA 12 - DiAgRAMA DE BLOCOS DE UM SISTEMA DE CONTROLE DE MOTORES BASEADO NA

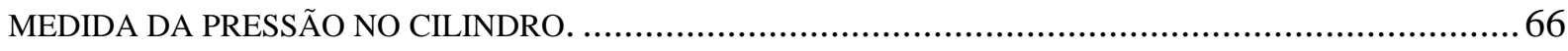

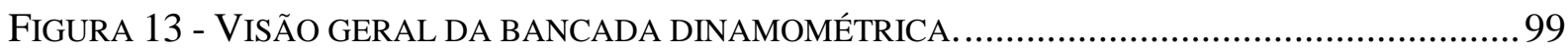

FIGURA 14 - DiAGRAMA DE COMUNICAÇÃO DA BANCADA DINAMOMÉTRICA............................ 100

FIGURA 15 - CONTROLADOR DE ROTAÇÃO DO DINAMÔMETRO E EQUIPAMENTOS AO SEU REDOR.

FIGURA 16 - UTILIZAÇÃO DO APARELHO TM131 PARA MEDIÇÃO DOS GASES DE EXAUSTÃO... 104

FIGURA 17 - VISUAL DA TELA DE MEDIÇÃO DO PROGRAMA SOFGAS.................................... 105

FIGURA 18 - CIRCUITO DO BUFFER DE TENSÃO COM UM DIVISOR DE TENSÃO EM UMA DAS SAÍDAS.

FIGURA 19 - INSTALAÇÃO NA BANCADA DINAMOMÉTRICA DO BUFFER E DIVISOR DE TENSÃO PARA O SINAL DO TRANSDUTOR DE ROTAÇÃO - PMS.

FIGURA 20 - TERMOPAR DO TIPO K INSTALADO NO DUTO DO COLETOR DE ADMISSÃO DO PRIMEIRO CILINDRO.

FIGURA 21 - TERMOPAR DO TIPO K INSTALADO NO DUTO DO PRIMEIRO CILINDRO DO COLETOR DE ESCAPE. 
FIGURA 22 - TERMOPAR DO TIPO K INSTALADO ENTRE AS SONDAS LAMBDAS NO DUTO DO COLETOR DE ESCAPE DO PRIMEIRO CILINDRO.

FIGURA 23 - CiRCUITO ELÉTRICO DO AMPLIFICADOR DE TERMOPAR DO TIPO K.

FIGURA 24 - INSTALAÇÃO NA BANCADA DINAMOMÉTRICA DOS AMPLIFICADORES DE TERMOPARES DO TIPO K.

FIGURA 25 - CIRCUITO DO TRANSDUTOR DE PRESSÃO UTILIZADO NO COLETOR DE ADMISSÃO. 112

FIGURA 26 - SISTEMA DE MEDIDAS DA PRESSÃO DO COLETOR DE ADMISSÃO INSTALADO NA

BANCADA DINAMOMÉTRICA.

FIGURA 27 - CÂMARA DE COMBUSTÃO DO MOTOR VW AT1000 8V COM ORIFÍCIO PARA TOMADA DA PRESSÃO NO CILINDRO.

FIGURA 28 - TRANSDUTOR DE PRESSÃO INSTALADO NA CÂMARA DE COMBUSTÃO DO PRIMEIRO CILINDRO DO MOTOR VW AT1000 8V.

FIGURA 29 - AMPLIFICADOR DE CARGA 3059 HICF-AMPLIFIER.

FIGURA 30 - RESERVATÓRIO DE COMBUSTÍVEL E BALANÇA DIGITAL UTILIZADOS NO SISTEMA DE MEDIÇÃO DE CONSUMO.

FigURA 31 - PAINEL FRONTAL DO VI PARA MEDIÇÃO DO CONSUMO DE COMBUSTÍVEL. 118

FIGURA 32 - DiAgRAMA DE BLOCOS DO VI PARA MEDIÇÃo DE CONSUMO DE COMBUSTÍVEL. . 118

FIGURA 33 - PAINEL FRONTAL DO VI DE AQUISIÇÃO DE DADOS. 120

FIGURA 34 - DiAGRAMA DE BLOCOS DO VI DE AQUISIÇÃO DE DADOS.

FIGURA 35 - SISTEMA DE GERENCIAMENTO ELETRÔNICO REPROGRAMÁVEL DA MARCA FUELTECH, MODELO RACEPRO-1FI.

FIGURA 36 - POTÊNCIA CORRIGIDA DO MOTOR EM FUNÇÃO DO FATOR $A$ E DO TIPO DE COMBUSTÍVEL (2000 E 3000 RPM, REGIME DE PLENA CARGA, MBT).

FIGURA 37 - CONSUMO ESPECÍFICO DO MOTOR EM FUNÇÃO DO FATOR $\Lambda$ E DO TIPO DE COMBUSTÍVEL (2000 E 3000 RPM, REGIME DE PLENA CARGA, MBT).

FIGURA 38 - EFICIÊNCIA DE CONVERSÃO DE COMBUSTÍVEL EM FUNÇÃO DO FATOR $A$ E DO TIPO DE COMBUSTÍVEL (2000 E 3000 RPM, REGIME DE PLENA CARGA, MBT). 143

FIGURA 39 - EMISSÃO DE $C O$ EM FUNÇÃO DO FATOR $A$ E DO TIPO DE COMBUSTÍVEL (2000 E 3000 RPM, REGIME DE PLENA CARGA, MBT).

FIGURA 40 - EMISSÃO DE $H C$ EM FUNÇÃO DO FATOR $A$ E DO TIPO DE COMBUSTÍVEL (2000 E 3000 RPM, REGIME DE PLENA CARGA, MBT).

FIGURA 41 - EMISSÃO DE $\mathrm{CO}_{2}$ DO MOTOR EM FUNÇÃO DO FATOR $A$ E DO TIPO DE COMBUSTÍVEL (2000 E 3000 RPM, REGIME DE PLENA CARGA, MBT). 148 
FIGURA 42 - CURVA GERADA PELO MÉTODO DA RAZÃO DE PRESSÕES NO CILINDRO (3000 RPM, REGIME DE PLENA CARGA, MBT, COMBUSTÍVEL E26).

FIGURA 43 - RESÍDUOS, E SEUS RESPECTIVOS INTERVALOS DE CONFIANÇA, RESULTANTES DA ESTIMAÇÃO DO FATOR $\Lambda$ UTILIZANDO O MODELO 4, MÉDIA DOS 20 CICLOS DE PRESSÃO NO CILINDRO E JANELA 2 PARA O COMBUSTÍVEL E26 EM CONDIÇÕES DE CARGAS COMBINADAS... 166

FIGURA 44 - RESULTADOS OBTIDOS NA ESTIMAÇÃO DO FATOR $\Lambda$ UTILIZANDO O MODELO 4, MÉDIA DE 20 CICLOS DE PRESSÃO NO CILINDRO E JANELA 2 PARA O COMBUSTÍVEL E26 EM CONDIÇÕES DE CARGAS COMBINADAS.

FIGURA 45 - RESULTADOS OBTIDOS NA ESTIMAÇÃO DO FATOR $\Lambda$ UTILIZANDO O MODELO 9, MÉDIA DE 20 CICLOS DE PRESSÃO NO CILINDRO E JANELA 4 PARA O COMBUSTÍVEL E26 EM CONDIÇÕES DE CARGAS COMBINADAS.

FIGURA 46 - RESULTADOS OBTIDOS NA ESTIMAÇÃO DO FATOR $\Lambda$ UTILIZANDO O MODELO 1, MÉDIA DE 20 CICLOS DE PRESSÃO NO CILINDRO E JANELA 1 PARA O COMBUSTÍVEL E26 EM CONDIÇÕES DE CARGAS COMBINADAS.

FIGURA 47 - RESÍDUOS, E SEUS RESPECTIVOS INTERVALOS DE CONFIANÇA, RESULTANTES DA ESTIMAÇÃO DO FATOR $A$ UTILIZANDO O MODELO 4, MÉDIA DE 20 CICLOS DE PRESSÃO NO CILINDRO, E JANELA 3 PARA O COMBUSTÍVEL E56 EM CONDIÇÕES DE CARGAS COMBINADAS.. 175

FIGURA 48 - RESULTADOS OBTIDOS NA ESTIMAÇÃO DO FATOR $\Lambda$ UTILIZANDO O MODELO 4, MÉDIA DE 20 CICLOS DE PRESSÃO NO CILINDRO E JANELA 3 PARA O COMBUSTÍVEL E56 EM CONDIÇÕES DE CARGAS COMBINADAS.

FIGURA 49 - RESULTADOS OBTIDOS NA ESTIMAÇÃO DO FATOR 4 UTILIZANDO O MODELO 8, MÉDIA DE 20 CICLOS DE PRESSÃO NO CILINDRO E JANELA 3 PARA O COMBUSTÍVEL E56 EM CONDIÇÕES DE CARGAS COMBINADAS.

FIGURA 50 - RESULTADOS OBTIDOS NA ESTIMAÇÃO DO FATOR $\Lambda$ UTILIZANDO O MODELO 1 , MÉDIA DE 20 CICLOS DE PRESSÃO NO CILINDRO E JANELA 1 PARA O COMBUSTÍVEL E56 EM CONDIÇÕES DE CARGAS COMBINADAS.

FIGURA 51 - RESÍDUOS, E SEUS RESPECTIVOS INTERVALOS DE CONFIANÇA, RESULTANTES DA ESTIMAÇÃO DO FATOR $\Lambda$ UTILIZANDO O MODELO 4, MÉDIA DE 20 CICLOS DE PRESSÃO NO CILINDRO E JANELA 3 PARA O COMBUSTÍVEL E70 EM CONDIÇÕES DE CARGAS COMBINADAS... 184

FIGURA 52 - RESULTADOS OBTIDOS NA ESTIMAÇÃO DO FATOR $\Lambda$ UTILIZANDO O MODELO 4, MÉDIA DE 20 CICLOS DE PRESSÃO NO CILINDRO E JANELA 3 PARA O COMBUSTÍVEL E70 EM CONDIÇÕES DE CARGAS COMBINADAS.

FIGURA 53 - RESULTADOS OBTIDOS NA ESTIMAÇÃO DO FATOR $\Lambda$ UTILIZANDO O MODELO 6 , MÉDIA DE 20 CICLOS DE PRESSÃO NO CILINDRO E JANELA 3 PARA O COMBUSTÍVEL E70 EM CONDIÇÕES DE CARGAS COMBINADAS.

FIGURA 54 - RESULTADOS OBTIDOS NA ESTIMAÇÃO DO FATOR $\Lambda$ UTILIZANDO O MODELO 1 , MÉDIA DE 20 CICLOS DE PRESSÃO NO CILINDRO E JANELA 1 PARA O COMBUSTÍVEL E70 EM CONDIÇÕES DE CARGAS COMBINADAS. 
FIGURA 55 - RESÍDUOS, E SEUS RESPECTIVOS INTERVALOS DE CONFIANÇA, RESULTANTES DA ESTIMAÇÃO DO FATOR $A$ UTILIZANDO O MODELO 4, MÉDIA DE 20 CICLOS DE PRESSÃO NO CILINDRO E JANELA 1 PARA O COMBUSTÍVEL E100 EM CONDIÇÕES DE CARGAS COMBINADAS. 193

FIGURA 56 - RESULTADOS OBTIDOS NA ESTIMAÇÃO DO FATOR $\Lambda$ UTILIZANDO O MODELO 4 , MÉDIA DE 20 CICLOS DE PRESSÃO NO CILINDRO E JANELA 1 PARA O COMBUSTÍVEL E100 EM CONDIÇÕES DE CARGAS COMBINADAS.

FIGURA 57 - RESULTADOS OBTIDOS NA ESTIMAÇÃO DO FATOR $A$ UTILIZANDO O MODELO 8, MÉDIA DE 20 CICLOS DE PRESSÃO NO CILINDRO E JANELA 1 PARA O COMBUSTÍVEL E100 EM CONDIÇÕES DE CARGAS COMBINADAS.

FIGURA 58 - RESULTADOS OBTIDOS NA ESTIMAÇÃO DO FATOR $\Lambda$ UTILIZANDO O MODELO 1 , MÉDIA DE 20 CICLOS DE PRESSÃO NO CILINDRO E JANELA 1 PARA O COMBUSTÍVEL E100 EM CONDIÇÕES DE CARGAS COMBINADAS.

FIGURA 59 - RESÍDUOS, E SEUS RESPECTIVOS INTERVALOS DE CONFIANÇA, RESULTANTES DA ESTIMAÇÃO DO FATOR $\Lambda$ UTILIZANDO O MODELO 4, MÉDIA DE 20 CICLOS DE PRESSÃO NO CILINDRO E JANELA 4 PARA O CONJUNTO COM TODOS OS COMBUSTÍVEIS - ETOTAL EM CONDIÇÕES DE CARGAS COMBINADAS, INTERVALOS DAS AMOSTRAS: 0-60: E26; 61-120: E56; 121-180: E70; 181-240: E100.

FIGURA 60 - RESULTADOS OBTIDOS NA ESTIMAÇÃO DO FATOR $A$ UTILIZANDO O MODELO 4 , MÉDIA DE 20 CICLOS DE PRESSÃO NO CILINDRO E JANELA 4 PARA O CONJUNTO COM TODOS OS COMBUSTÍVEIS - ETOTAL EM CONDIÇÕES DE CARGAS COMBINADAS.

FIGURA 61 - RESULTADOS OBTIDOS NA ESTIMAÇÃO DO FATOR $\Lambda$ UTILIZANDO O MODELO 8, MÉDIA DE 20 CICLOS DE PRESSÃO NO CILINDRO E JANELA 4 PARA O CONJUNTO COM TODOS OS COMBUSTÍVEIS - ETOTAL EM CONDIÇÕES DE CARGAS COMBINADAS.

FIGURA 62 - RESULTADOS OBTIDOS NA ESTIMAÇÃO DO FATOR $\Lambda$ UTILIZANDO O MODELO 1, MÉDIA DE 20 CICLOS DE PRESSÃO NO CILINDRO E JANELA 1 PARA O CONJUNTO COM TODOS OS COMBUSTÍVEIS - ETOTAL EM CONDIÇÕES DE CARGAS COMBINADAS.

FIGURA 63 - RESÍDUOS, E SEUS RESPECTIVOS INTERVALOS DE CONFIANÇA, RESULTANTES DA IDENTIFICAÇÃO DA FRAÇÃO MÁSSICA DE ETANOL UTILIZANDO O MODELO 4, MÉDIA DE 20 CICLOS DE PRESSÃO NO CILINDRO E JANELA 4 EM CONDIÇÕES DE CARGAS COMBINADAS, INTERVALOS DAS AMOSTRAS: 0-60: E26; 61-120: E56; 121-180: E70; 181-240: E100. 220

FIGURA 64 - RESULTADOS OBTIDOS NA ESTIMAÇÃO DA FRAÇÃO MÁSSICA DE ETANOL UTILIZANDO O MODELO 4, MÉDIA DE 20 CICLOS DE PRESSÃO NO CILINDRO E JANELA 4 EM CONDIÇÕES DE CARGAS COMBINADAS.

FIGURA 65 - RESULTADOS OBTIDOS NA ESTIMAÇÃO DA FRAÇÃO MÁSSICA DE ETANOL UTILIZANDO O MODELO 8, MÉDIA DE 20 CICLOS DE PRESSÃO NO CILINDRO E JANELA 4 EM CONDIÇÕES DE CARGAS COMBINADAS.

FIGURA 66 - RESULTADOS OBTIDOS NA ESTIMAÇÃO DA FRAÇÃO MÁSSICA DE ETANOL UTILIZANDO O MODELO 1, MÉDIA DE 20 CICLOS DE PRESSÃO NO CILINDRO E JANELA 4 EM CONDIÇÕES DE CARGAS COMBINADAS. 
FIGURA D1 - INSTALAÇÃO DOS BRAÇOS E PRATOS NO DINAMÔMETRO.

FIGURA D2 - CORREÇÃO DAS DIFERENÇAS DE MASSAS ENTRE OS BRAÇOS E PRATOS INSTALADOS.

FIGURA D3 - VISOR DA BANLANÇA DINAMOMÉTRICA COM O PONTEIRO NO ZERO DA ESCALA 1.

FIGURA D4 - TORQUE EM FUNÇÃO DA MASSA OBSERVADA NA BALANÇA DINAMOMÉTRICA (KG RED).

FIGURA D5 - FATOR DA POTÊNCIA EM FUNÇÃO DA MASSA OBSERVADA NA BALANÇA

FIGURA E1 - DIAGRAMA DO CONJUNTO CILINDRO-PISTÃO-BIELA DE UM MOTOR. 299

FIGURA E2 - VOLUMES QUE COMPÕE O VOLUME TOTAL DA CÂMARA DE COMBUSTÃO. 300

FIGURA E3 - DIREÇÕES DOS DIÂMETROS MEDIDOS NOS CILINDROS. 301

FIGURA E4 - PROCEDIMENTO DE MEDIÇÃO DO DIÂMETRO DO CILINDRO. 301

FigURA E5 - PROCEDIMENTO DE MEDIÇÃo DA ALTURA $H_{F}$ 303

FIGURA E6 - ARRANJO MONTADO PARA MEDIR O VOLUME DA CAVIDADE DO CABEÇOTE. ........308

FIGURA E7 - ARRANJO MONTADO PARA MEDIR O VOLUME $V_{P I S}$ 311

FIGURA F1 - CIRCUITO DO SISTEMA DE CALIBRAÇÃO DO TRANSDUTOR DE TEMPERATURA NTC 4053.

FiguRA F2 - TENSÃO DE SAÍdA $\left(V_{S}\right)$ EM FUNÇÃO DA TEMPERATURA $(Y)$. 



\section{LISTA DE TABELAS}

TABELA 1 - PROPRIEDADES DA GASOLINA TÍPICA E DO ETANOL................................................. 45

TABELA 2 - EMISSÕES EVITADAS DE $\mathrm{CO}_{2}$ UTILIZANDO O ETANOL COMO COMBUSTÍVEL.............46

TABEla 3 - DURAÇÃO DA COMBUSTÃO E AVANÇO DA CENTELHA PARA MISTURAS GASOLINAETANOL.

TABELA 4 - RELAÇÕES DE COMPRESSÃO ÓTIMAS EM FUNÇÃO DA PORCENTAGEM DE ETANOL NA GASOLINA.

TABELA 5 - REDUÇÕES NO CONSUMO ESPECÍFICO E NOS TEORES DE EMISSÕES UTILIZANDO MISTURA ETANOL-GASOLINA (50\%).

TABELA 6 - RELAÇÃO DE COMPRESSÃO DOS 10 VEÍCULOS FLEX FUEL MAIS VENDIDOS NO BRASIL.

TABELA 7 - ARRANJO DOS DADOS OBSERVADOS EM UM EXPERIMENTO COM DOIS FATORES.......83

TABELA 8 - ANÁLISE DE VARIÂNCIA PARA UM PLANEJAMENTO COM DOIS FATORES. 86

TABELA 9 - EXEMPLO DE APLICAÇÃO DO MÉTODO SME E DO PROCEDIMENTO DE TUKEY NA PRESENÇA DE INTERAÇÃO ENTRE FATORES PRINCIPAIS (FATOR $\Lambda$ E TIPO DE COMBUSTÍVEL)........89

TABELA 10 - ANÁLISE DE VARIÂNCIA PARA TESTAR A SIGNIFICÂNCIA NA REGRESSÃO MÚLTIPLA.

TABELA 11 - PRINCIPAIS CARACTERÍSTICAS DO DINAMÔMETRO SHENCK, MODELO W260... 101

TABELA 12 - CARACTERÍSTICAS NOMINAIS DO MOTOR VW AT 10008 VÁLVULAS A ETANOL SEGUNDO VOLKSWAGEN DO BRASIL LTDA. (2003)

TABELA 13 - ABERTURA E FECHAMENTO DAS VÁLVULAS DE ADMISSÃO E ESCAPE.

TABELA 14 - ESPECIFICAÇÕES TÉCNICAS DO ANALISADOR DE GASES TM131 COM ANALISADOR OPCIONAL DE $N O_{X}$.

TABELA 15 - ESPECIFICAÇÕES TÉCNICAS DO TRANSDUTOR 8QP 500CA.

TABELA 16 - CARACTERÍSTICAS DO AMPLIFICADOR DE CARGA HICF CALIBRADO.

TABELA 17 - VARIÁVEIS COLETADAS POR MEIO DO VI DE AQUISIÇÃO DE DADOS

TABELA 18 - VARIÁVEIS MONITORADAS PELO SISTEMA RACEPRO-1FI.

TABELA 19 - RESUMO DO DELINEAMENTO DO EXPERIMENTO 1 EM CARGA PARCIAL (33\% DE ABERTURA DA BORBOLETA DE ACELERAÇÃO). AS “OBSERVAÇÕES” SE REFEREM AOS DADOS DAS VARIÁVEIS DO MOTOR COLETADAS DURANTE O EXPERIMENTO.

TABELA 20- RESUMO DO DELINEAMENTO DO EXPERIMENTO 1 - WOT. AS “OBSERVAÇÕES” SE REFEREM AOS DADOS DAS VARIÁVEIS DO MOTOR COLETADAS DURANTE O EXPERIMENTO. ..... 125 
TABELA 22 - FRAÇÃO MÁSSICA DE ETANOL UTILIZADA NAS MISTURAS COMBUSTÍVEIS ENSAIADAS NOS EXPERIMENTO 1.

TABELA 23 - RELAÇÃO DE COMPRESSÃO REFERENTE A CADA CILINDRO DO MOTOR. 138

TABELA 24 - PROPRIEDADES DOS COMBUSTÍVEIS UTILIZADOS. 138

TABELA 25 - RESULTADOS ALCANÇADOS COM OS NOVE MODELOS DE ESTIMAÇÃO DO FATOR $A$ UTILIZANDO O COMBUSTÍVEL E26 (REGIME DE PLENA CARGA, MÉDIA DE 20 CICLOS DE PRESSÃO NO CILINDRO E JANELAS 1, 2, 3 E 4). (CONTINUA).....

TABELA 26 - RESULTADOS ALCANÇADOS COM OS NOVE MODELOS DE ESTIMAÇÃO DO FATOR $A$ UTILIZANDO O COMBUSTÍVEL E26 (DUAS CARGAS COMBINADAS, MÉDIA DE 20 CICLOS DE PRESSÃO NO CILINDRO E JANELAS 1, 2, 3 E 4). (CONTINUA).

TABELA 27 - COEFICIENTES INDIVIDUAIS DAS REGRESSÕES LINEARES MÚLTIPLAS DOS MODELOS QUE APRESENTARAM OS MENORES RMS PARA O COMBUSTÍVEL E26.

TABELA 28 - RESULTADOS ALCANÇADOS COM OS NOVE MODELOS DE ESTIMAÇÃO DO FATOR $A$ UTILIZANDO O COMBUSTÍVEL E56 (REGIME DE PLENA CARGA, MÉDIA DE 20 CICLOS DE PRESSÃO NO CILINDRO E JANELAS 1, 2, 3 E 4). (CONTINUA).

TABELA 29 - RESULTADOS ALCANÇADOS COM OS NOVE MODELOS DE ESTIMAÇÃO DO FATOR $A$ UTILIZANDO O COMBUSTÍVEL E56 (DUAS CARGAS COMBINADAS, MÉDIA DE 20 CICLOS DE PRESSÃO NO CILINDRO E JANELAS 1, 2, 3 E 4). (CONTINUA)

TABELA 30 - COEFICIENTES INDIVIDUAIS DAS REGRESSÕES LINEARES MÚLTIPLAS DOS MODELOS QUE APRESENTARAM OS MENORES RMS PARA O COMBUSTÍVEL E56.

TABELA 31 - RESULTADOS ALCANÇADOS COM OS NOVE MODELOS DE ESTIMAÇÃO DO FATOR $\Lambda$ UTILIZANDO O COMBUSTÍVEL E70 (REGIME DE PLENA CARGA, MÉDIA DE 20 CICLOS DE PRESSÃO NO CILINDRO E JANELAS 1, 2, 3 E 4). (CONTINUA). 178

TABELA 32 - RESULTADOS ALCANÇADOS COM OS NOVE MODELOS DE ESTIMAÇÃO DO FATOR $A$ UTILIZANDO O COMBUSTÍVEL E70 (DUAS CARGAS COMBINADAS, MÉDIA DE 20 CICLOS DE PRESSÃO NO CILINDRO E JANELAS 1, 2, 3 E 4). (CONTINUA) .................................................. 180

TABELA 33 - COEFICIENTES INDIVIDUAIS DAS REGRESSÕES LINEARES MÚLTIPLAS DOS MODELOS QUE APRESENTARAM OS MENORES RMS PARA O COMBUSTÍVEL E70.

TABELA 34 - RESULTADOS ALCANÇADOS COM OS NOVE MODELOS DE ESTIMAÇÃO DO FATOR $\Lambda$ UTILIZANDO O COMBUSTÍVEL E100 (REGIME DE PLENA CARGA, MÉDIA DE 20 CICLOS DE PRESSÃO NO CILINDRO E JANELAS 1, 2, 3 E 4). (CONTINUA)

TABELA 35 - RESULTADOS ALCANÇADOS COM OS NOVE MODELOS DE ESTIMAÇÃO DO FATOR $A$ UTILIZANDO O COMBUSTÍVEL E100 (DUAS CARGAS COMBINADAS, MÉDIA DE 20 CICLOS DE PRESSÃO NO CILINDRO E JANELAS 1, 2, 3 E 4). (CONTINUA).

TABELA 36 - COEFICIENTES INDIVIDUAIS DAS REGRESSÕES LINEARES MÚLTIPLAS DOS MODELOS QUE APRESENTARAM OS MENORES RMS PARA O COMBUSTÍVEL E100. 
TABELA 37 - RESULTADOS ALCANÇADOS COM OS NOVE MODELOS DE ESTIMAÇÃO DO FATOR $\Lambda$ UTILIZANDO TODOS OS DADOS DOS COMBUSTÍVEIS EM ESTUDO (ETOTAL =E26, E56, E70 E E100, REGIME DE PLENA CARGA, MÉDIA DE 20 CICLOS DE PRESSÃO NO CILINDRO E JANELAS 1, 2, 3 E 4). (CONTINUA)

TABELA 38 - RESULTADOS ALCANÇADOS COM OS NOVE MODELOS DE ESTIMAÇÃO DO FATOR 4 UTILIZANDO TODOS OS DADOS DOS COMBUSTÍVEIS EM ESTUDO (ETOTAL = E26, E56, E70 E E100, DUAS CARGAS COMBINADAS, MÉDIA DE 20 CICLOS DE PRESSÃO NO CILINDRO E JANELAS 1, 2, 3 E 4). (CONTINUA).

TABELA 39 - COMPARAÇÃO ENTRE OS RESULTADOS DO MODELO 1 NA ESTIMATIVA DO FATOR $\Lambda$ (E26, E56, E70, E100 E ETOTAL (TODOS OS COMBUSTÍVEIS JUNTOS), PLENA CARGA E DUAS CARGAS COMBINADAS, MÉDIA DE 20 CICLOS DE PRESSÃO NO CILINDRO E MELHOR JANELA)...200

TABELA 40 - COMPARAÇÃO ENTRE OS RESULTADOS DO MODELO 2 NA ESTIMATIVA DO FATOR $\Lambda$ (E26, E56, E70, E100 E ETOTAL (TODOS OS COMBUSTÍVEIS JUNTOS), PLENA CARGA E DUAS CARGAS COMBINADAS, MÉDIA DE 20 CICLOS DE PRESSÃO NO CILINDRO E MELHOR JANELA)...201

TABELA 41 - COMPARAÇÃO ENTRE OS RESULTADOS DO MODELO 4 NA ESTIMATIVA DO FATOR $\Lambda$ (E26, E56, E70, E100 E ETOTAL (TODOS OS COMBUSTÍVEIS JUNTOS), PLENA CARGA E DUAS CARGAS COMBINADAS, MÉDIA DE 20 CICLOS DE PRESSÃO NO CILINDRO E MELHOR JANELA)...202

TABELA 42 - COMPARAÇÃO ENTRE OS RESULTADOS DO MODELO 8 NA ESTIMATIVA DO FATOR $A$ (E26, E56, E70, E100 E ETOTAL (TODOS OS COMBUSTÍVEIS JUNTOS), PLENA CARGA E DUAS CARGAS COMBINADAS, MÉDIA DE 20 CICLOS DE PRESSÃO NO CILINDRO E MELHOR JANELA). ..204

TABELA 43 - COMPARAÇÃO ENTRE OS RESULTADOS DO MODELO 9 NA ESTIMATIVA DO FATOR $\Lambda$ (E26, E56, E70, E100 E ETOTAL (TODOS OS COMBUSTÍVEIS JUNTOS), PLENA CARGA E DUAS CARGAS COMBINADAS, MÉDIA DE 20 CICLOS DE PRESSÃO NO CILINDRO E MELHOR JANELA). ..204

TABELA 44 - COEFICIENTES INDIVIDUAIS DAS REGRESSÕES LINEARES MÚLTIPLAS DOS MODELOS QUE APRESENTARAM OS MENORES RMS PARA O CONJUNTO DE DADOS COM TODOS OS COMBUSTÍVEIS (ETOTAL).

TABELA 45 - FRAÇÃO MÁSSICA DE ETANOL UTILIZADA NAS MISTURAS COMBUSTÍVEIS EM ESTUDO.

TABELA 46 - RESULTADOS ALCANÇADOS COM OS NOVE MODELOS DE IDENTIFICAÇÃO DO TIPO DE COMBUSTÍVEL UTILIZANDO OS DADOS DE TODOS OS COMBUSTÍVEIS - ETOTAL (REGIME DE PLENA CARGA, MBT, MÉDIA DE 20 CICLOS DE PRESSÃO NO CILINDRO E JANELAS 1, 2, 3 E 4) (CONTINUA).

TABELA 47 - RESULTADOS ALCANÇADOS COM OS NOVE MODELOS DE IDENTIFICAÇÃO DO TIPO DE COMBUSTÍVEL UTILIZANDO OS DADOS DE TODOS OS COMBUSTÍVEIS - ETOTAL (DUAS CARGAS COMBINADAS, MBT, MÉDIA DE 20 CICLOS DE PRESSÃO NO CILINDRO E JANELAS 1, 2, 3 E 4) (CONTINUA).

TABELA 48 - COEFICIENTES INDIVIDUAIS DAS REGRESSÕES LINEARES MÚLTIPLAS DOS MODELOS QUE APRESENTARAM OS MENORES RMS NA IDENTIFICAÇÃO DA FRAÇÃO MÁSSICA DE ETANOL. 219 
TABELA A1 - DADOS COLETADOS DURANTE O EXPERIMENTO 1 A 2000 RPM, PLENA CARGA E MBT.

TABELA A2 - DAdOS COLETADOS DURANTE O EXPERIMENTO 1 A 3000 RPM, PLENA CARGA E MBT.

TABELA A3 - DADOS COLETADOS DURANTE O EXPERIMENTO 1 A 2000 RPM, CARGA PARCIAL E MBT.

TABELA A4 - DADOS COLETADOS DURANTE O EXPERIMENTO 1 A 3000 RPM, CARGA PARCIAL E MBT.

TABELA A5 - ANOVA DA POTÊNCIA CORRIGIDA DO MOTOR (EXPERIMENTO 1: 2000 RPM, PLENA CARGA E MBT).

TABELA A6 - VALORES DE POTÊNCIA CORRIGIDA DO MOTOR OBTIDOS NO EXPERIMENTO $1 \mathrm{~A}$ 2000 RPM, PLENA CARGA E MBT.

TABELA A7 - RESUMO DOS RESULTADOS OBTIDOS COM A APLICAÇÃO DO MÉTODO SME TUKEY PARA A POTÊNCIA CORRIGIDA DO EXPERIMENTO 1 (2000 RPM, PLENA CARGA E MBT).

TABELA A8 - ANOVA DA POTÊNCIA CORRIGIDA DO MOTOR (EXPERIMENTO 1: 2000 RPM, PLENA CARGA E MBT).

TABELA A9 - VALORES DE POTÊNCIA CORRIGIDA DO MOTOR OBTIDOS NO EXPERIMENTO 1 A 3000 RPM, PLENA CARGA E MBT.

TABELA A10 - RESUMO DOS RESULTADOS OBTIDOS COM A APLICAÇÃO DO MÉTODO SME -

TUKEY PARA A POTÊNCIA CORRIGIDA DO EXPERIMENTO 1 (3000 RPM, PLENA CARGA E MBT).

TABELA A11 - ANOVA DA POTÊNCIA CORRIGIDA DO MOTOR (EXPERIMENTO 1: 2000 RPM, PLENA CARGA E MBT).

TABELA A12 - VALORES DE CONSUMO HORÁRIO DO MOTOR OBTIDOS NO EXPERIMENTO 1 A 2000 RPM, PLENA CARGA E MBT.

TABELA A13 - VALORES DE CONSUMO ESPECÍFICO DO MOTOR OBTIDOS NO EXPERIMENTO 1 A 2000 RPM, PLENA CARGA E MBT.

TABELA A14 - RESUMO DOS RESULTADOS OBTIDOS COM A APLICAÇÃO DO MÉTODO SME TUKEY PARA A POTÊNCIA CORRIGIDA DO EXPERIMENTO 1 (2000 RPM, PLENA CARGA E MBT).

TABELA A15 - ANOVA DA POTÊNCIA CORRIGIDA DO MOTOR (EXPERIMENTO 1: 3000 RPM, PLENA CARGA E MBT).

TABELA A16 - VALORES DE CONSUMO HORÁRIO DO MOTOR OBTIDOS NO EXPERIMENTO 1 A 3000 RPM, PLENA CARGA E MBT. 
TABELA A17 - VALORES DE CONSUMO ESPECÍFICO DO MOTOR OBTIDOS NO EXPERIMENTO 1 A 3000 RPM, PLENA CARGA E MBT.

TABELA A18 - RESUMO DOS RESULTADOS OBTIDOS COM A APLICAÇÃO DO MÉTODO SME TUKEY PARA A POTÊNCIA CORRIGIDA DO EXPERIMENTO 1 (3000 RPM, PLENA CARGA E MBT).

TABELA A19 - ANOVA DA EFICIÊNCIA DE CONVERSÃO DE COMBUSTÍVEL (EXPERIMENTO 1: 2000 RPM, PLENA CARGA E MBT).

TABELA A20 - VALORES DE POTÊNCIA CORRIGIDA DO MOTOR OBTIDOS NO EXPERIMENTO 1 A 2000 RPM, PLENA CARGA E MBT.

TABELA A21 - RESUMO DOS RESULTADOS OBTIDOS COM A APLICAÇÃO DO MÉTODO SME TUKEY PARA A EFICIÊNCIA DE CONVERSÃO DE COMBUSTÍVEL DO EXPERIMENTO 1 (2000 RPM, PLENA CARGA E MBT)

TABELA A22 - ANOVA DA EFICIÊNCIA DE CONVERSÃO DE COMBUSTÍVEL (EXPERIMENTO 1: 3000 RPM, PLENA CARGA E MBT).

TABELA A23 - VALORES DE POTÊNCIA CORRIGIDA DO MOTOR OBTIDOS NO EXPERIMENTO 1 A 3000 RPM, PLENA CARGA E MBT.

TABELA A24 - RESUMO DOS RESULTADOS OBTIDOS COM A APLICAÇÃO DO MÉTODO SME TUKEY PARA A EFICIÊNCIA DE CONVERSÃO DE COMBUSTÍVEL DO EXPERIMENTO 1 (3000 RPM, PLENA CARGA E MBT)

TABELA A25 - ANOVA DA EMISSÃO DE CO (EXPERIMENTO 1: 2000 RPM, PLENA CARGA E MBT).

TABELA A26 - VALORES DE EMISSÃO DE CO OBTIDOS NO EXPERIMENTO 1 A 2000 RPM, PLENA CARGA E MBT.

TABELA A27 - RESUMO DOS RESULTADOS OBTIDOS COM A APLICAÇÃO DO MÉTODO SME TUKEY PARA A EMISSÃO DE CO DO EXPERIMENTO 1 (2000 RPM, PLENA CARGA E MBT).

TABELA A28 - ANOVA DA EMISSÃO DE CO (EXPERIMENTO 1: 3000 RPM, PLENA CARGA E MBT).

TABELA A29 - VALORES DE EMISSÃO DE CO OBTIDOS NO EXPERIMENTO 1 A 3000 RPM, PLENA CARGA E MBT.

TABELA A30 - RESUMO DOS RESULTADOS OBTIDOS COM A APLICAÇÃO DO PROCEDIMENTO DE TUKEY PARA ANÁLISE DAS MÉDIAS DOS NÍVEIS DO FATOR $\Lambda$, CONSIDERANDO OS DADOS DE EMISSÃO DE CO (EXPERIMENTO 1: 3000 RPM, PLENA CARGA E MBT).

TABELA A31- ANOVA DA EMISSÃO DE HC DO MOTOR (EXPERIMENTO 1: 2000 RPM, PLENA CARGA E MBT)

TABELA A32 - VALORES DE EMISSÃO DE HC DO MOTOR OBTIDOS NO EXPERIMENTO 1 A 2000 RPM, PLENA CARGA E MBT. 
TABELA A33 - RESUMO DOS RESULTADOS OBTIDOS COM A APLICAÇÃO DO PROCEDIMENTO DE TUKEY PARA ANÁLISE DAS MÉDIAS DOS NÍVEIS DO FATOR $\Lambda$, CONSIDERANDO OS DADOS DE EMISSÃO DE HC (EXPERIMENTO 1: 2000 RPM, PLENA CARGA E MBT).

TABELA A34 - RESUMO DOS RESULTADOS OBTIDOS COM A APLICAÇÃO DO PROCEDIMENTO DE TUKEY PARA ANÁLISE DAS MÉDIAS DOS NÍVEIS DO FATOR $\Lambda$, CONSIDERANDO OS DADOS DE EMISSÃO DE HC (EXPERIMENTO 1: 2000 RPM, PLENA CARGA E MBT).

TABELA A35 - ANOVA DA EMISSÃO DE HC DO MOTOR (EXPERIMENTO 1: 3000 RPM, PLENA CARGA E MBT).

TABELA A36 - VALORES DE EMISSÃO DE HC DO MOTOR OBTIDOS NO EXPERIMENTO 1 A 3000 RPM, PLENA CARGA E MBT.

TABELA A37 - RESUMO dOS RESULTADOS OBTIDOS COM A APLICAÇÃO DO MÉTODO SME -

TUKEY PARA A EMISSÃO DE HC DO EXPERIMENTO 1 (3000 RPM, PLENA CARGA E MBT)........ 260

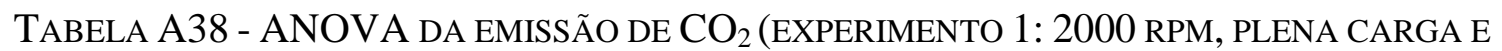
MBT).

TABELA A39 - VALORES DE EMISSÃO DE CO CO $_{2}$ OBTIDOS NO EXPERIMENTO 1 A 2000 RPM, PLENA CARGA E MBT.

TABELA A40 - RESUMO DOS RESULTADOS OBTIDOS COM A APLICAÇÃO DO PROCEDIMENTO DE TUKEY PARA ANÁLISE DAS MÉDIAS DOS NÍVEIS DO FATOR $\Lambda$, CONSIDERANDO OS DADOS DE EMISSÃO DE $\mathrm{CO}_{2}$ (EXPERIMENTO 1: 2000 RPM, PLENA CARGA E MBT).

TABELA A41 - ANOVA DA EMISSÃO DE $\mathrm{CO}_{2}$ (EXPERIMENTO 1: 3000 RPM, PLENA CARGA E MBT)

TABELA A42 - VALORES DE EMISSÃO DE $\mathrm{CO}_{2}$ OBTIDOS NO EXPERIMENTO 1 A 3000 RPM, PLENA CARGA E MBT.

TABELA A43 - RESUMO DOS RESUlTAdOS OBTIDOS COM A APLICAÇÃO DO MÉTODO SME TUKEY PARA A EMISSÃO DE $\mathrm{CO}_{2}$ DO EXPERIMENTO 1 (3000 RPM, PLENA CARGA E MBT). ..... 264

TABELA B1 - COMPOSIÇÃO EM MASSA DA GASOLINA TIPO C COM 20\% DE ÁlCOOL ETÍLICO ANIDRO.

TABELA B2 - NÚMERO DE MOLES DE CADA COMPONENTE EM 1KG DE GASOLINA TIPO $C$ COM $20 \%$ DE ÁLCOOL ETÍLICO ANIDRO.

TABELA B3 - DENSIDADES Do ÁlCOOL ETíliCo ANIDRO, DO OCTANO E DO UNDECANO.......... 279

TABela B4 - PoRCENTAGEM EM MASSA DE $C_{11} H_{24}$ EM CADA TIPO DE COMBUSTÍvel.............. 285

TABELA C1 - PoDER CALORÍFICO SUPERIOR DOS COMBUSTíveIS E100, G100, E60G40 E E40G60. 288

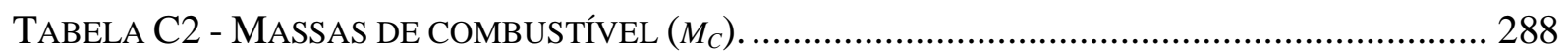

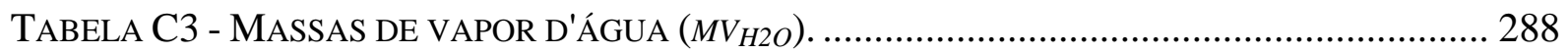


TABELA D1 - TORQUE E FATOR DA POTÊNCIA EM FUNÇÃO DA MASSA APLICADA NA BALANÇA

TABELA E1 - DiÂMETROS $\left(D_{C I L}\right)$ REFERENTES A CADA CILINDRO DO MOTOR...........................302

TABELA E2 - ALTURAS HF REFERENTES A CADA CILINDRO DO MOTOR....................................304

TABELA E3 - ALtURAS TOTAIS $\left(H_{F}+C_{P I S}\right)$ REFERENTES A CADA CILINDRO DO MOTOR. ...........305

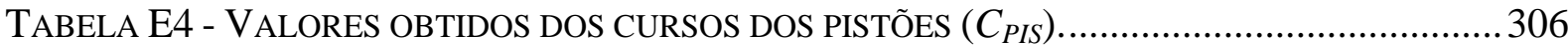

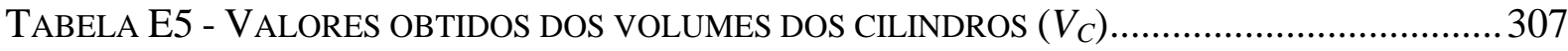

TABELA E6 - VOLUMES DAS CAVIDADES DO CABEÇOTE REFERENTES A CADA CILINDRO DO MOTOR

TABELA E7 - ESPESSURAS DA JUNTA DO CABEÇOTE $\left(H_{J}\right)$ REFERENTES A CADA CILINDRO DO MOTOR

TABELA E8 - VALORES OBTIDOS DOS VOLUMES DA JUNTA DO CABEÇOTE $\left(V_{\text {JUNTA }}\right)$

TABELA E9 - VOLUMES DAS CAVIDADES (PISTÃO E FOLGAS) REFERENTES A CADA CILINDRO DO MOTOR

TABELA E10 - VALORES OBTIDOS DOS VOLUMES DAS CÂMARAS DE COMBUSTÃO $\left(V_{C C}\right) \ldots \ldots . . . .312$

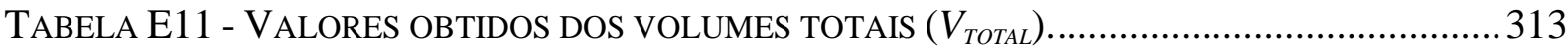

TABELA E12 - VALORES OBTIDOS DAS TAXAS DE COMPRESSÃO DO MOTOR $\left(\mathrm{T}_{\mathrm{R}}\right) \ldots \ldots \ldots \ldots \ldots \ldots . . . . . . . . .314$

TABELA F1 - TENSÕES DE SAÍDA (+VS) EM FUNÇÃO DAS TEMPERATURAS ATRIBUÍDAS AO ELEMENTO SENSOR DO TRANSDUTOR NTC 4053

TABELA F2 - VALORES DE $V R E F$ E $R_{l}$ OBTIDOS DURANTE AS TRÊS REPETIÇÕES DA MEDIÇÃO DE

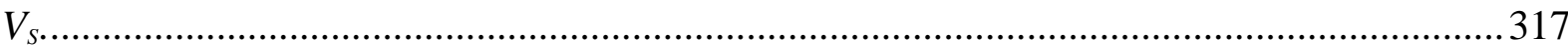

TABELA G1 - PRocEDIMENTOS PRELIMINARES ADOTADOS NA SALA DE ENSAIOS....................319

TABELA G2 - PROCEDIMENTOS PRELIMINARES ADOTADOS NA SALA DE MONITORAMENTO..... 319 



\section{LISTA DE ABREVIATURAS E SIGLAS}

A/C Relação ar-combustível

AEAC Álcool etílico anidro carburante

AEHC Álcool etílico hidratado carburante

ANP Agência Nacional do Petróleo, Gás Natural e Biocombustíveis

APC Ângulo da árvore de manivelas em que ocorre o pico de pressão no cilindro

APMI Antes do ponto morto inferior

APMS Antes do ponto morto superior

CC Corrente contínua

CI Circuito integrado

CONAMA Conselho Nacional de Meio Ambiente

DP Diferença de pressão

DPMS Depois do ponto morto superior

E26 Gasolina brasileira tipo $C$ (25\% em volume de AEAC)

E56 Mistura combustível com etanol (55,78\% em massa) e E26

E70 Mistura combustível com etanol (70,52\% em massa) e E26

E100 Etanol (100\% de AEHC)

INPM Instituto Nacional de Pesos e Medidas

IPI Imposto sobre produtos industrializados

KS Knock sensor (sensor de detonação)

MBT Maximum Brake Torque Timing (Mínimo avanço da centelha para melhor torque)

PC Pico de pressão no cilindro

PFC Parâmetro de fase da combustão

PMI Ponto Morto Inferior

PMS Ponto Morto Superior

PROCONVE Programa de Controle da Poluição do ar por Veículos Automotores

QME Quadrado médio dos erros

QMR Quadrado médio da regressão

RAC Relação ar-combustível

RBF Radial Basis Function (função de base radial)

RGE Recirculação de gases de exaustão 
RPS Rotações por segundo

RPM Rotações por minuto

SAFR Relação ar-combustível estequiométrica

SGTP Sistema de gerenciamento da razão de pressões

SME $\quad$ Efeitos simples principais

SQE Soma dos quadrados dos erros

SQT Soma dos quadrados total

SQX Soma dos quadrados dos desvios das médias das variáveis $\mathrm{X}$

SQY Soma dos quadrados dos desvios das médias das variáveis Y

TA Temperatura do ar tomada no coletor de admissão

TE Temperatura dos gases tomada no coletor de exaustão

TI Tempo de injeção de combustível

TP Razão de pressões

TRMP Tempo relativo médio de processamento

UCE Unidade de controle eletrônico

VAA Válvula de admissão aberta

VAF Válvula de admissão fechada

VEA Válvula de exaustão aberta

VEF Válvula de exaustão fechada

VI Instrumento virtual 


\section{LISTA DE SÍMBOLOS}

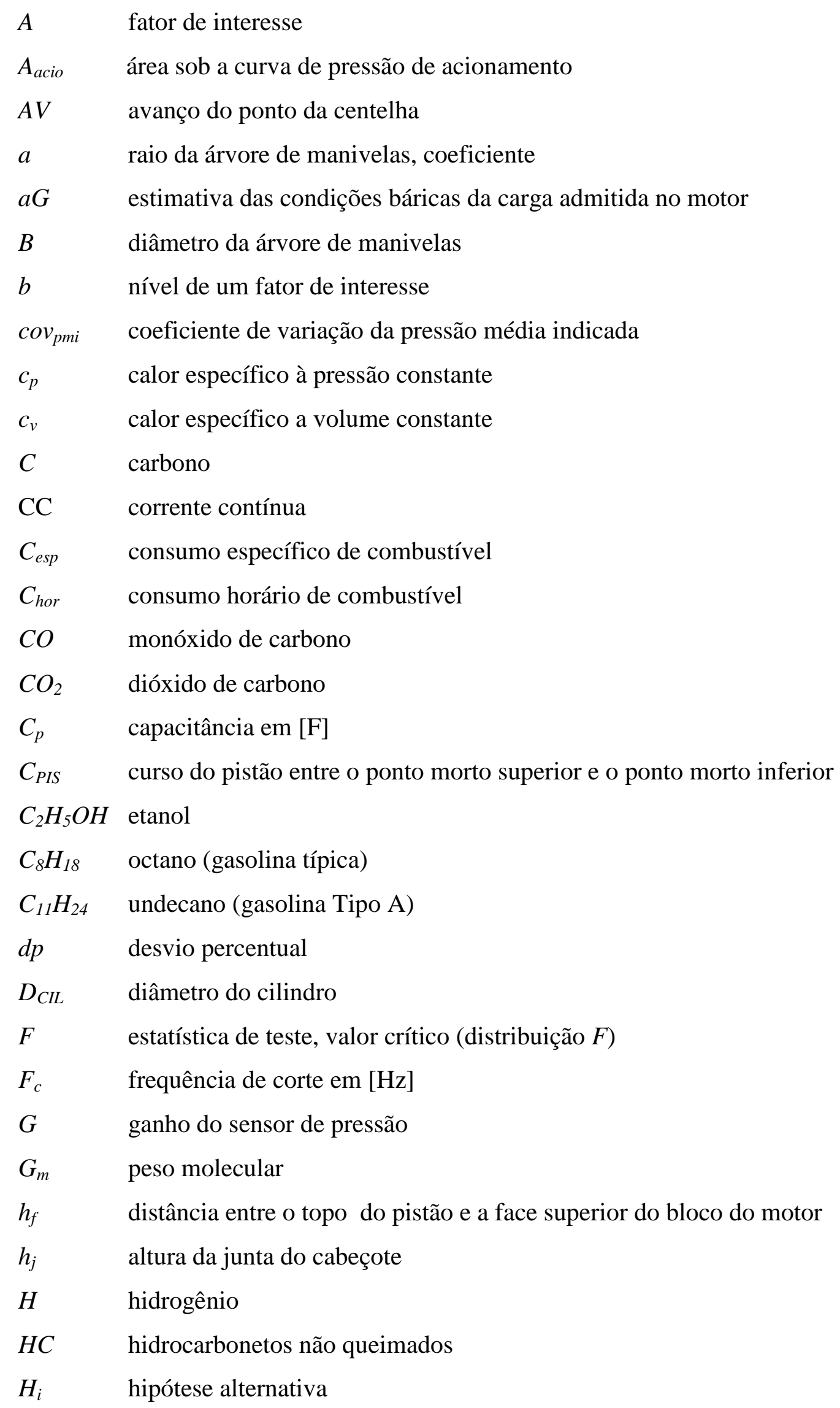




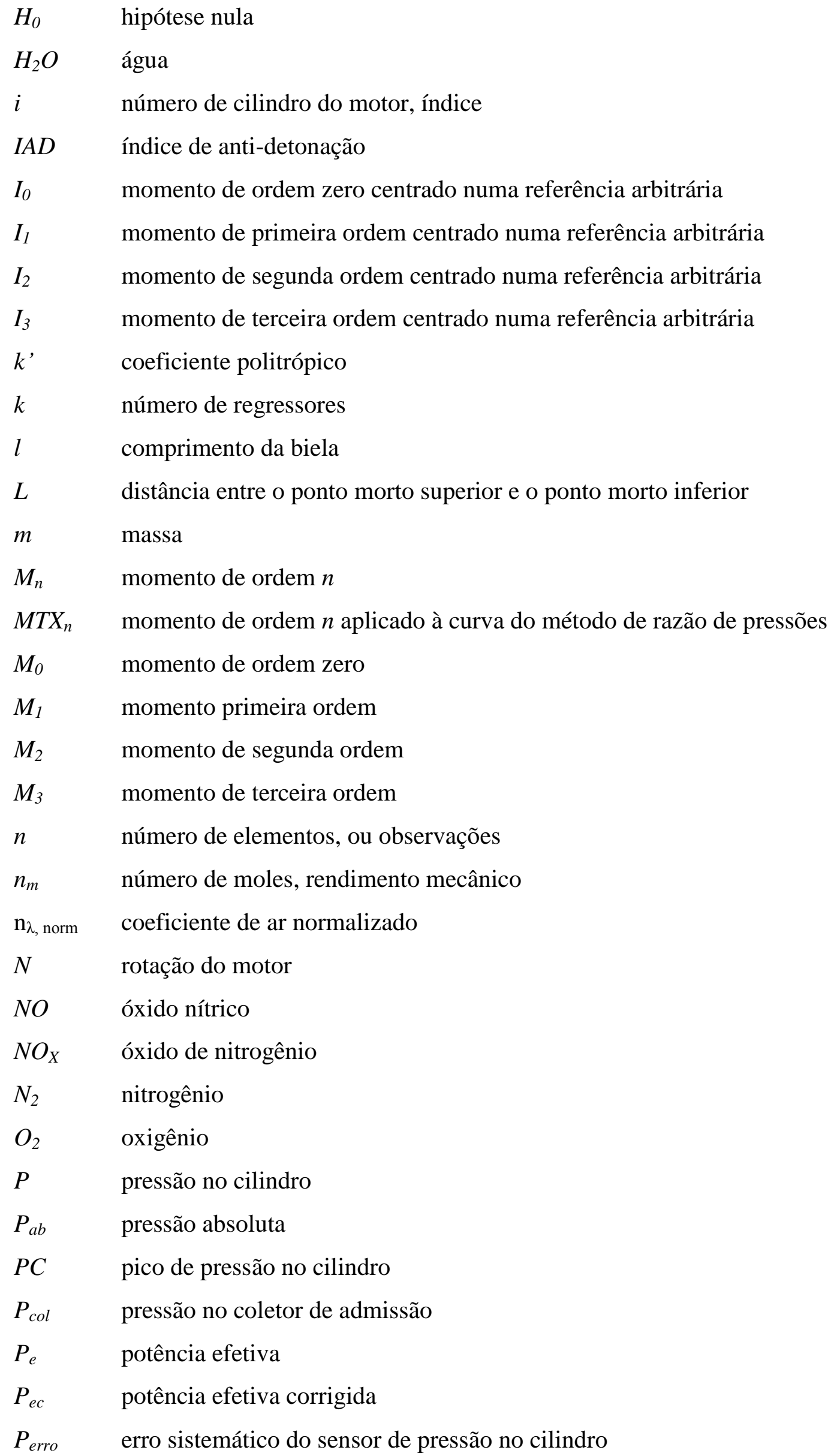




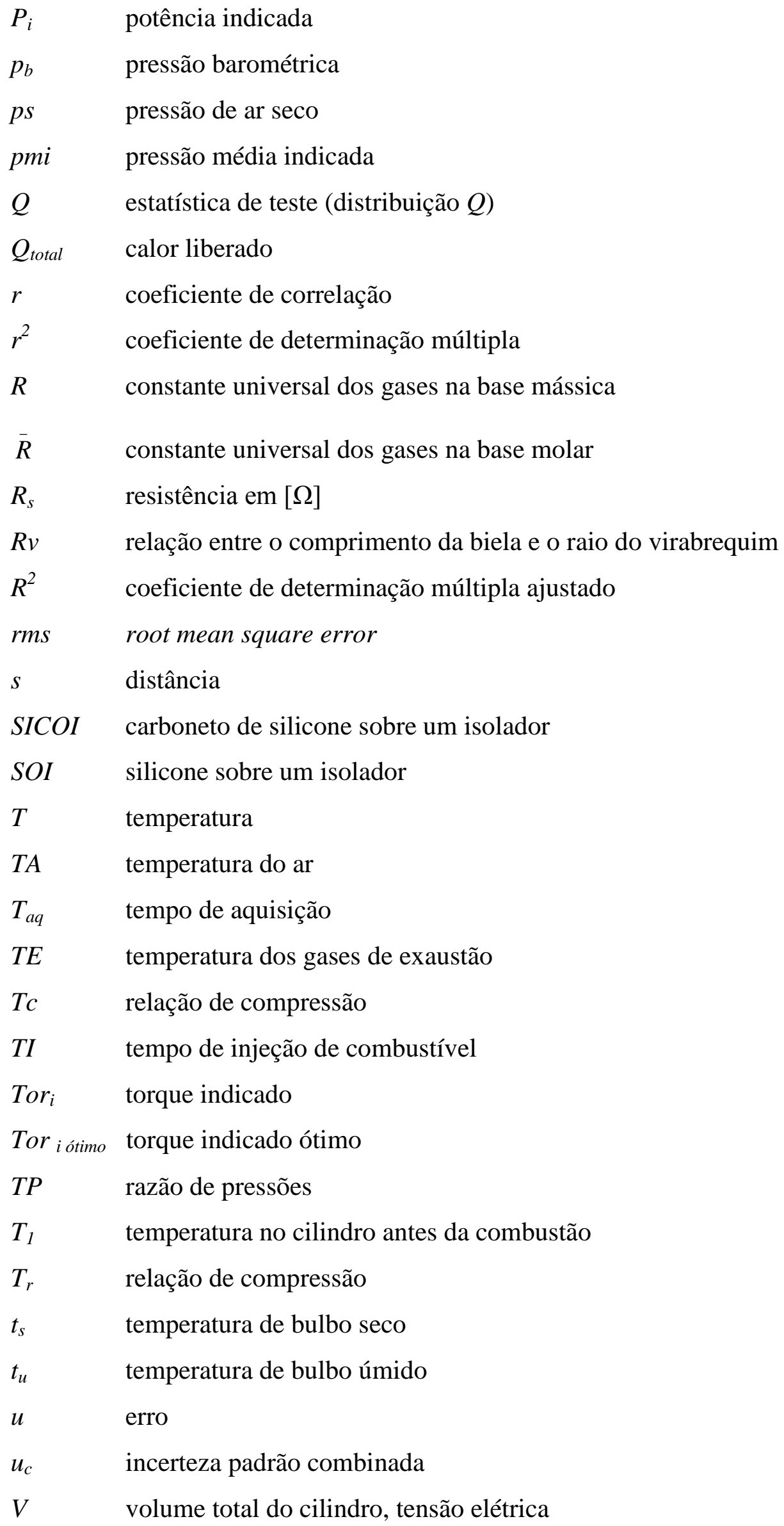




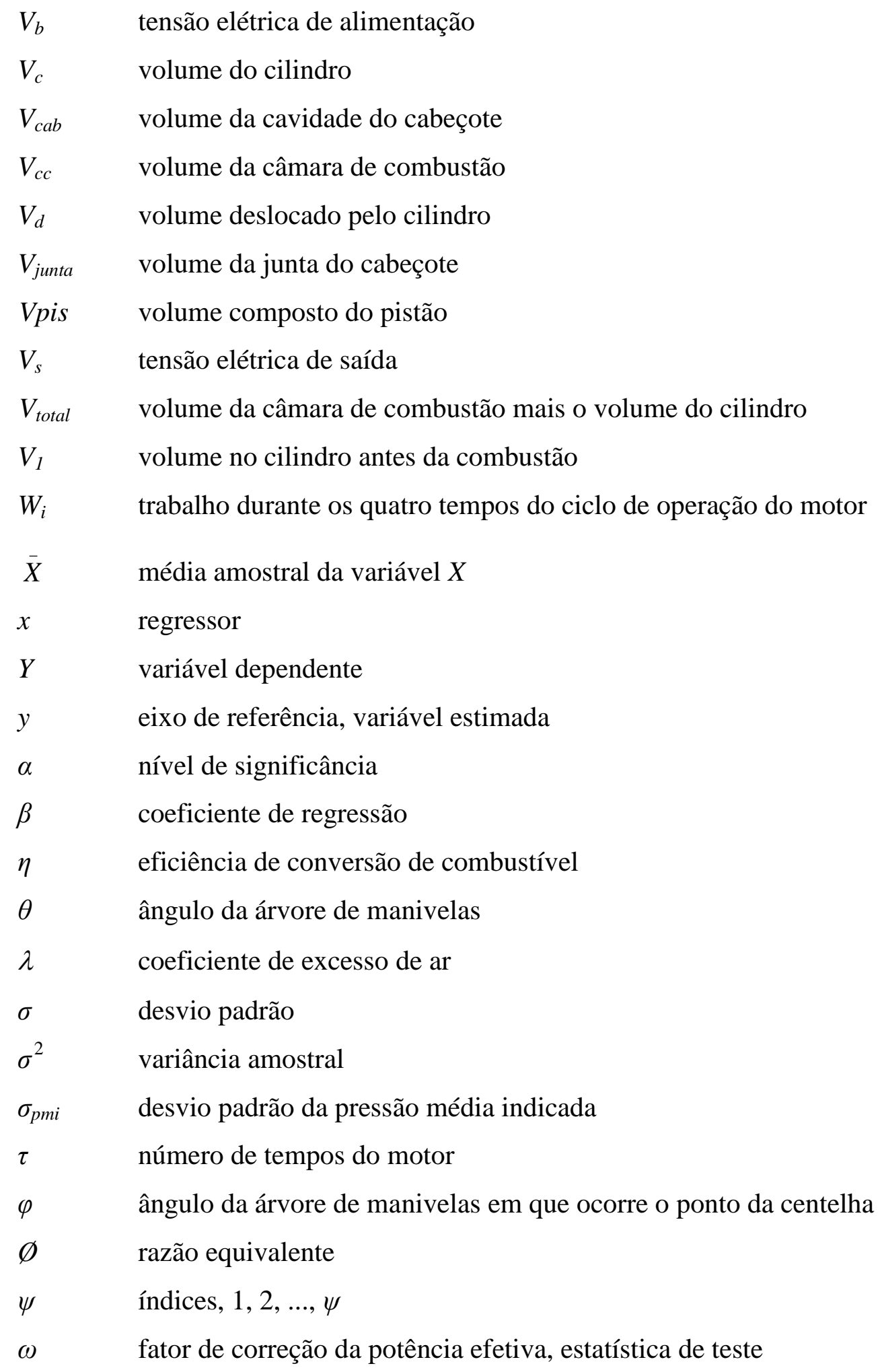




\section{SUMÁRIO}

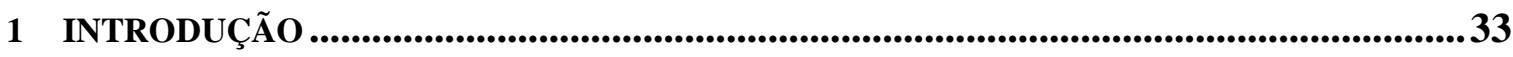

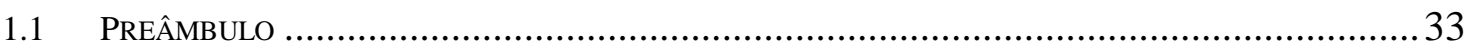

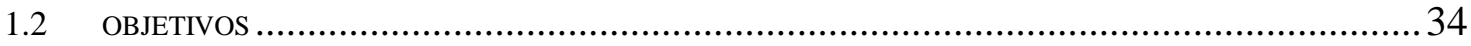

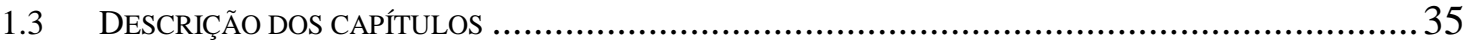

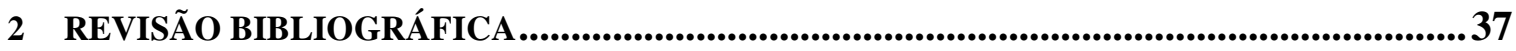

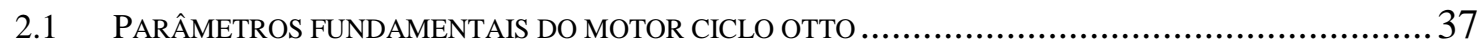

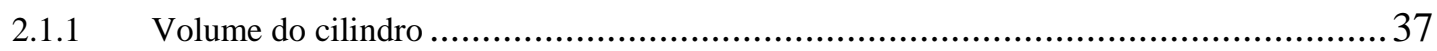

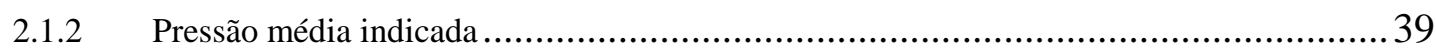

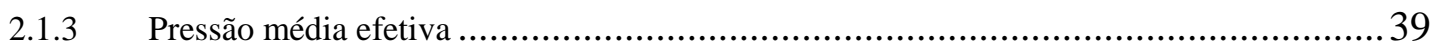

2.1.4 Rendimento mecânico ............................................................... 42

2.1.5 Coeficiente de variação da pressão média indicada.......................................... 42

2.1.6 Calor liberado durante a combustão....................................................... 42

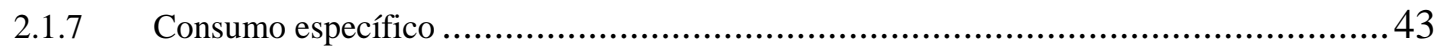

2.1.8 Eficiência na conversão de combustível ..................................................4 43

Fator $\lambda$ e razão equivalente ............................................................... 43

2.1.10 Avanço do ponto da centelha ....................................................... 44

2.2 PROPRIEDADES FÍSICO-QUÍMICAS DOS COMBUSTÍVEIS GASOLINA E ETANOL ..........................44

2.3 Misturas DE ETANOL E GASOLINA COMO COMbUStíveis EM MOTORES OTTO......................46

2.4 SiSTEMAS DE CONTROLE ELETRÔNICO DE MOTORES BICOMBUSTÍVEL ..............................5.52

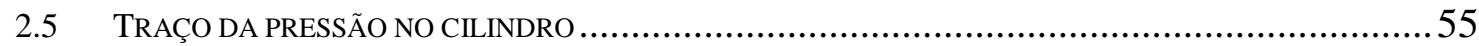

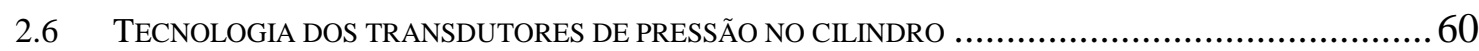

2.6.1 Estimativa do erro sistemático e do drift do sinal dos transdutores de pressão no cilindro.63

2.7 ESTADO DA ARTE DA UTILIZAÇÃO DA PRESSÃO NO CILINDRO NOS SISTEMAS ELETRÔNICOS DE CONTROLE DE MOTORES OTTO 65

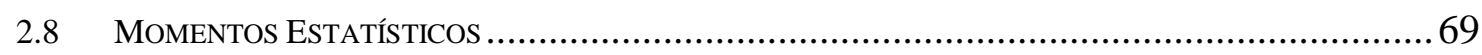

2.9 ESTADO DA ARTE DOS MÉTODOS PARA ESTIMAÇÃO DA RELAÇÃO AR-COMBUSTÍVEL QUE UTILIZAM A PRESSÃO NO CILINDRO

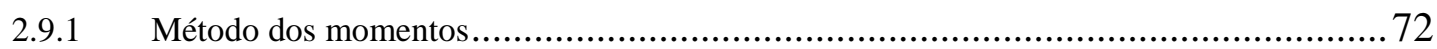

2.9.2 Método da razão de pressões............................................................. 75

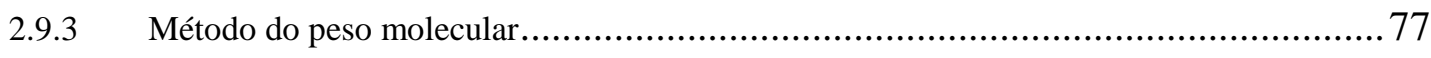

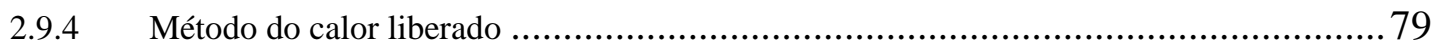


2.9.5 Método do torque indicado

2.9.6 Análise comparativa dos métodos de estimação apresentados ............................... 80

2.10 CONCEITOS FUNDAMENTAIS DA ESTATÍSTICA E TÉCNICAS ESTATÍSTICAS DE ANÁLISE

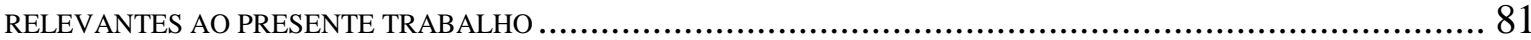

2.10.1 Variáveis aleatórias ...................................................................... 81

2.10.2 Medidas de posição e dispersão ............................................................. 82

2.10.3 Análise de variância ou ANOVA .......................................................... 82

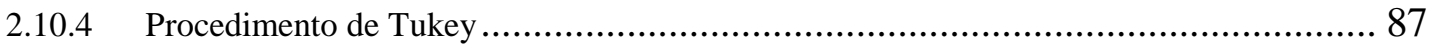

2.10.5 Método dos efeitos simples principais (SME) ....................................... 87

2.10.6 Regressões lineares ................................................................ 89

2.10.7 Regressão linear simples .......................................................... 90

2.10.8 Análise dos modelos de regressão linear múltipla .......................................... 93

2.10.9 Raiz quadrada do erro quadrático médio ................................................ 95

3 MATERIAIS E MÉTODOS $. . \ldots \ldots \ldots \ldots \ldots \ldots \ldots \ldots \ldots \ldots \ldots \ldots \ldots \ldots \ldots \ldots \ldots \ldots \ldots \ldots \ldots \ldots \ldots \ldots \ldots \ldots \ldots \ldots \ldots \ldots \ldots \ldots \ldots \ldots \ldots \ldots \ldots \ldots . . \ldots 7$

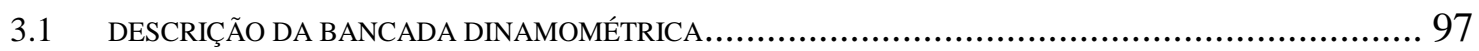

3.1.1 Características dos principais componentes da bancada dinamométrica................... 101

Sistema de aquisição de dados ......................................................... 119

3.2 DELINEAMENTO DOS EXPERIMENTOS E MÉTODOS UTILIZADOS ............................... 123

3.2.1 Delineamento dos experimentos..................................................... 123

3.2.2 Variáveis obtidas nos experimentos ...................................................... 125

3.2.3 Obtenção das misturas de combustíveis ................................................... 126

3.2.4 Procedimentos adotados durante os experimentos ....................................... 127

Cálculo das variáveis de desempenho do motor ....................................... 128

3.2.6 Análise dos dados coletados no experimento 1 ........................................ 129

3.2.7 Obtenção e análise dos modelos estatísticos de estimação do fator $\lambda$ e de identificação do

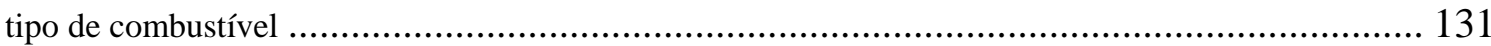

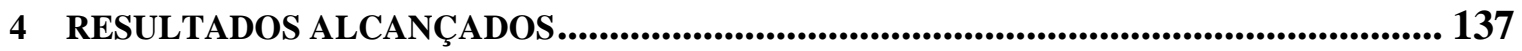

4.1 ANÁLISE DOS EXPERIMENTOS .......................................................... 137

4.1.1 Resultados do experimento para obtenção da relação de compressão do motor VW AT1000 $8 \mathrm{~V}$

4.1.2 Resultados dos cálculos para obtenção da relação ar-combustível e do poder calorífico inferior para cada tipo de combustível utilizado nos experimentos 
4.1.3 Análise do desempenho do motor VW AT1000 8V operando com E100, E70, E56 e E26.

4.1.4 Análise das emissões do motor VW AT1000 8V operando com E100, E70, E56 e E26 .144

4.1.5 Síntese dos resultados experimentais e discussões relativas ao desempenho geral do motor operando com diferentes misturas de etanol e gasolina

4.2 ANÁLISE DOS MODELOS OBTIDOS PARA ESTIMAÇÃO DO FATOR LAMBDA

4.2.1 Análise dos modelos obtidos para estimação do fator $\lambda$ utilizando o combustível E26 ... 151

4.2.2 Análise dos modelos obtidos para estimação do fator $\lambda$ utilizando o combustível E56 ... 168

4.2.3 Análise dos modelos obtidos para estimação do fator $\lambda$ utilizando o combustível E70 ... 177

4.2.4 Análise dos modelos obtidos para estimação do fator $\lambda$ utilizando o combustível E100.. 186

4.2.5 Análise dos modelos obtidos para estimação do fator $\lambda$ utilizando todos os combustíveis em estudo (E26, E56, E70 e E100).

4.3 ANÁLISE DOS MODELOS OBTIDOS PARA IDENTIFICAÇÃO DO TIPO DE COMBUSTÍVEL .... 209

4.3.1 Modelo 2

4.3.2 Modelo 3

4.3.3 Modelo 4 215

4.3.4 Modelo 5 216

4.3.5 Modelo 6 216

4.3.6 Modelo 7

4.3.7 Modelo 8

4.3.8 Modelo 9

5 CONCLUSÕES

5.1 SUGESTÕES DE TRABALHOS FUTUROS

REFERÊNCIAS.

APÊNDICE A - DADOS COLETADOS NO EXPERIMENTOS 1 E ALGORITMOS

DESENVOLVIDOS NO PRESENTE TRABALHO

APÊNDICE B - RELAÇÕES AR-COMBUSTÍVEL E CÁLCULO DA PORCENTAGEM EM MASSA DE GASOLINA TIPO A EM CADA TIPO DE COMBUSTÍVEL

APÊNDICE C - CÁLCULO DO PODER CALORÍFICO INFERIOR 
APÊNDICE E - OBTENÇÃO DA RELAÇÃO DE COMPRESSÃO DO MOTOR VW AT $10008 \mathrm{~V}$ 299

APÊNDICE F - CALIBRAÇÃO DO TRANSDUTOR DE TEMPERATURA DO LÍQUIDO DE ARREFECIMENTO

APÊNDICE G - PROCEDIMENTOS ADOTADOS PARA PRESERVAR OS EQUIPAMENTOS DA BANCADA DINAMOMÉTRICA 319

ANEXO A - ESPECIFICAÇÕES TÉCNICAS DO AMPLIFICADOR OPERACIONAL LM224A321

ANEXO B - ESPECIFICAÇÕES TÉCNICAS DO AMPLIFICADOR PARA TERMOPARES AD595AQ 325

ANEXO C - ESPECIFICAÇÕES TÉCNICAS DOS TRANSDUTORES DE PRESSÃO MPXH6115AC6T1 E MPX4250GP 327

ANEXO D - TABELA PARA O PROCEDIMENTO DE TUKEY 333 


\section{INTRODUÇÃO}

\subsection{PREÂMBULO}

Os veículos flexíveis, ou veículos flex fuel, apresentam como característica a capacidade de funcionar com etanol, gasolina ou misturas destes combustíveis. A tecnologia flex fuel foi introduzida no Brasil em meados do ano 2003 e alcançou em 2014 a marca de 88,2\% do mercado nacional de veículos (ASSOCIAÇÃO NACIONAL DOS FABRICANTES DE VEÍCULOS AUTOMOTORES, 2014).

A relação de compressão dos motores de 4 tempos usados nos veículos flexíveis elevouse desde o seu surgimento, alcançando valores médios de 12,33:1, intensificando as pesquisas sobre os benefícios proporcionados ao desempenho, às emissões de gases poluentes e à redução do consumo de combustível. Apesar da elevação da relação de compressão nos veículos comerciais, as investigações mais recentes sobre os seus benefícios nos motores flex fuel ainda se limitam a faixa entre 10:1 e 12:1, de acordo com Costa e Sodré (2011).

O desenvolvimento da tecnologia flex fuel surgiu com a possibilidade de identificação do tipo de combustível fornecido ao motor do veículo. Teixeira (2005) ressalta que esta tecnologia só se tornou competitiva para aplicação no mercado brasileiro após o desenvolvimento de um sensor lógico (software) capaz de identificar o tipo de combustível por meio do sinal do sensor de oxigênio (sonda lambda). Ahn et al. (2010) verificaram que os erros acumulados na identificação do tipo de combustível ao se utilizar o sinal do sensor de oxigênio são elevados em relação a métodos baseados no sinal do transdutor de pressão dentro do cilindro do motor.

Desde o surgimento dos veículos flexíveis, as investigações sobre a utilização do sinal de transdutores de pressão dentro do cilindro do motor tomaram um novo impulso, buscando principalmente a identificação do tipo de combustível, a estimação mais rápida e precisa de variáveis do motor, como a relação ar-combustível, e o diagnóstico a bordo.

Existem diversos métodos de estimação de variáveis do motor baseados na pressão no cilindro que ainda não foram investigados quanto à sua adequação à tecnologia flex fuel. Dentre estes métodos, podem-se destacar os métodos dos Momentos e da Razão de Pressões utilizados para estimar a relação ar-combustível, conforme relatados por Powell (1993). Neste contexto, o presente estudo pretende investigar a capacidade dos métodos dos Momentos e da Razão de pressões na identificação do tipo de combustível e da relação ar-combustível em um 
motor 4 tempos com relação de compressão de 13,44:1, alimentado com etanol, gasolina brasileira e misturas destes combustíveis.

\subsection{OBJETIVOS}

O objetivo principal do presente trabalho é a investigação sobre a estimação da relação arcombustível e a detecção do tipo de combustível utilizando o sinal da pressão no cilindro em um motor Otto alimentado com etanol, gasolina e mistura destes combustíveis.

Os objetivos específicos desta pesquisa são:

I. Analisar estatisticamente o desempenho (potência, consumo específico e eficiência de conversão de combustível) e as emissões de gases poluentes (CO, $\mathrm{CO}_{2}$ e $\mathrm{HC}$ ), confrontando os resultados obtidos com a literatura, a partir dos dados coletados em plena carga de um motor 4 tempos automotivo comercial, originalmente projetado para operar com etanol, com relação de compressão de 13,44:1, operando com etanol, gasolina brasileira tipo $C$ e misturas destes combustíveis;

II. investigar se o modelo baseado no Método dos Momentos, proposto originalmente por Gilkey e Powell (1985), é capaz de estimar o fator $\lambda$ a partir dos dados da pressão no cilindro para cada um dos combustíveis testados;

III. verificar se o modelo de estimação do fator $\lambda$ baseado no Método dos Momentos, proposto originalmente por Gilkey e Powell (1985), é sensível à variação da composição da mistura combustível quando obtido por um conjunto de dados composto por todos os combustíveis em estudo;

IV. verificar se o modelo baseado no Método dos Momentos, proposto originalmente por Gilkey e Powell (1985), é capaz de identificar o tipo de combustível a partir dos dados da pressão no cilindro;

V. propor modelos originais de estimação do fator $\lambda$ e de identificação do tipo de combustível incluindo variáveis do motor a partir do modelo proposto originalmente por Gilkey e Powell (1985);

VI. verificar se os modelos propostos para estimação do fator $\lambda$ são sensível à variação da composição da mistura combustível;

VII. investigar se a aplicação do Método dos Momentos nas curvas geradas pelo Método das Razões de Pressão, proposto originalmente por Gassenfeit e Powell 
(1989), é capaz de gerar modelos de estimação do fator $\lambda$, se estes modelos são sensíveis à variação da composição da mistura combustível, e de gerar modelos de identificação do tipo de combustível.

\subsection{DESCRIÇÃO DOS CAPÍTULOS}

Esta tese está organizada da seguinte maneira: o Capítulo 1 apresenta a introdução e os objetivos a serem alcançadas nesta pesquisa; o Capítulo 2 trata dos conceitos fundamentais e das pesquisas de interesse realizadas anteriormente; o Capítulo 3 relata todos os materiais e procedimentos utilizados no desenvolvimento deste estudo; o Capítulo 4 aborda os resultados alcançados e o Capítulo 5 versa sobre as conclusões do presente estudo e de apontamentos para pesquisas futuras. 


\section{REVISÃO BIBLIOGRÁFICA}

Neste capítulo são apresentados os estudos relevantes para a elaboração do presente trabalho.

\subsection{PARÂMETROS FUNDAMENTAIS DO MOTOR CICLO OTTO}

Nesta seção serão apresentados os parâmetros e conceitos necessários para o desenvolvimento do presente trabalho e para o entendimento de alguns estudos encontrados na revisão bibliográfica.

\subsubsection{Volume do cilindro}

Segundo Heywood (1988), a partir da geometria básica de um motor pode-se obter o volume do cilindro como uma função da posição angular da árvore de manivelas.

A Figura 1, segundo Tunestal (2000), mostra a geometria básica de um motor ciclo Otto, em que $B$ é o diâmetro do cilindro, $L$ é a distância entre o PMS (ponto morto superior) e o PMI (ponto morto inferior) ou, também, definido como o comprimento do percurso do pistão durante um tempo do ciclo de operação, $a$ é o raio da árvore de manivelas, $V_{c}$ é o volume da câmara de combustão, $\theta$ é o ângulo da árvore de manivelas, $y$ é o eixo de referência em que ocorre o deslocamento do pistão, $l$ é o comprimento da biela e $s$ é a distância entre centro do eixo da árvore de manivelas e o centro do pino munhão, na articulação de conexão entre a biela e o pistão. 


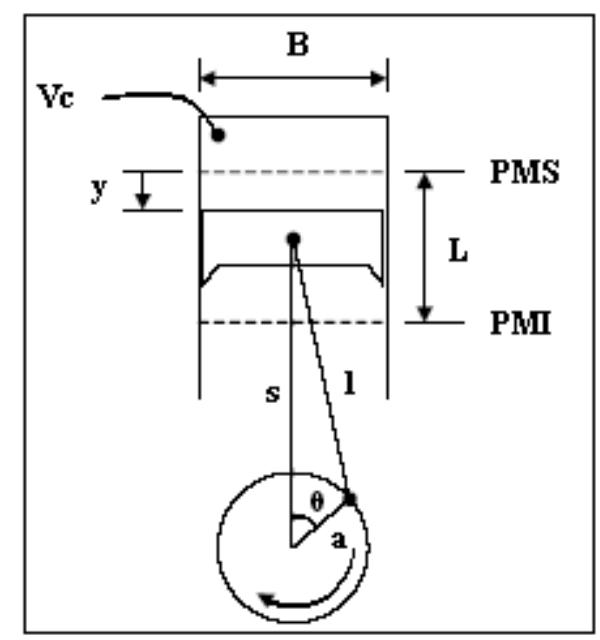

Figura 1 - Geometria básica de um motor ciclo Otto.

Fonte: Tunestal (2000).

As equações (1) e (2), encontradas em Heywood (1988), representam, respectivamente, a relação de compressão, $T_{r}$, e a relação entre o comprimento da biela e o raio da árvore de manivelas, $R \mathrm{v}$, em que $V_{d}$ é o volume deslocado pelo pistão. A partir destas equações é possível obter o volume do cilindro em função do ângulo da árvore de manivelas, como mostra a equação (3). Esta equação pode ser aproximada pela equação (4), considerando que o valor de $\operatorname{sen}^{2} \theta$ é muito pequeno em relação a $R v^{2}$ e, portanto, pode ser desprezado.

$$
\begin{gathered}
T_{r}=\frac{V_{d}+V_{c}}{V_{c}} \\
R v=\frac{l}{a} \\
V=V_{c}\left\{1+0,5\left(T_{r}-1\right)\left[R v+1-\cos \theta-\sqrt{R v^{2}-\operatorname{sen}^{2} \theta}\right]\right\} \\
V=V_{c}\left[1+0,5\left(T_{r}-1\right)(1-\cos \theta)\right]
\end{gathered}
$$




\subsubsection{Pressão média indicada}

Obert (1950) define pressão média indicada como a pressão hipoteticamente constante que seria necessária, dentro do cilindro, durante o curso de expansão para desenvolver uma potência equivalente à potência indicada.

A pressão média indicada (pmi), segundo Tunestal et al. (1999), é representada pela equação (5), em que Wi é o trabalho durante os quatro tempos do ciclo de operação e $p$ é a pressão no cilindro. As unidades estão no Sistema Internacional de Unidades (SI).

$$
p m i=\frac{W_{i}}{V_{d}}=\frac{\oint p d V}{V_{d}} \quad[P a]
$$

\subsubsection{Pressão média efetiva}

Analogamente, a potência média efetiva, segundo Obert (1950), é a pressão hipoteticamente constante que seria necessária, dentro do cilindro, durante o tempo de expansão para desenvolver uma potência equivalente à potência no eixo (potência medida em um dinamômetro).

\subsubsection{Potência efetiva}

De acordo com Obert (1950), potência efetiva é a potência no eixo do motor (medida em um dinamômetro).

\subsubsection{Potência indicada}

Segundo Obert (1950), potência indicada é a potência total desenvolvida dentro do cilindro. Essa potência é obtida pelo ciclo indicado, que é representado pelo diagrama de pressão versus volume de um motor de ignição por centelha.

De acordo com Martins (2006), a Figura 2 apresenta o ciclo indicado de um motor de ignição por centelha, na qual a área representada por "bombagem" corresponde à região em que o motor trabalha como uma bomba de vácuo para fornecer aos cilindros uma mistura à baixa pressão e a área representada por "inerente" corresponde à região em que o motor produz trabalho. 


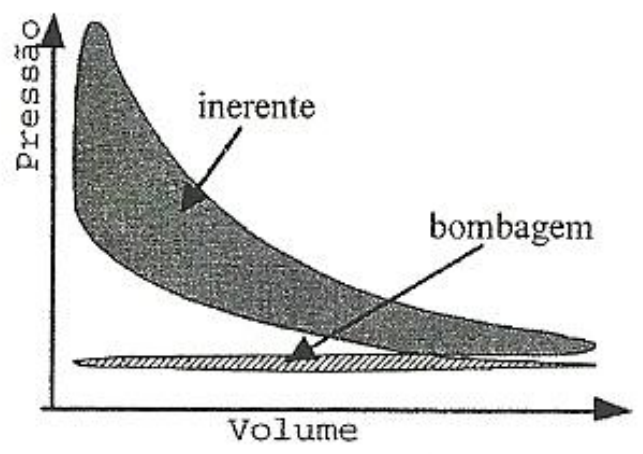

Figura 2 - Ciclo indicado de um motor de ignição por centelha.

Fonte: Martins (2006).

A potência indicada $\left(\mathrm{P}_{\mathrm{i}}\right)$, no SI, é dada pela equação (6), em que $\tau$ é o número de tempos do motor (motor ciclo Otto quatro tempos: $\tau=4$ ), pmi é a pressão média indicada calculada de acordo com a equação (5), $V_{d}$ é o volume deslocado pelo movimento do pistão dentro do cilindro, $i$ é o número de cilindros do motor e $N$ é o número de revoluções do motor na unidade de tempo.

$$
P_{i}=\frac{2}{\tau} p m i * i * V_{d} * N \quad[W]
$$

\subsubsection{Potência corrigida}

Segundo Martins (2006), a pressão barométrica, a umidade do ar e a temperatura ambiente afetam significativamente a potência efetiva dos motores. Fatores de correção devem ser utilizados para comparar as medições de motores que foram ensaiados em condições diferentes.

A Associação Brasileira de Normas Técnicas (ABNT) regulamenta a correção da potência efetiva dos motores ciclo Otto e ciclo Diesel por meio da norma NBR ISO 1585.

A potência efetiva corrigida para os motores ciclo Otto é apresentada pela equação (7).

$$
P_{e c}=\omega P e
$$

em que:

$$
\begin{aligned}
& P_{e c}=\text { potência corrigida; } \\
& \omega=\text { fator de correção, e } \\
& P_{e}=\text { potência efetiva. }
\end{aligned}
$$


As condições atmosféricas do ensaio devem respeitar alguns limites para a temperatura de bulbo seco e para a pressão de ar seco, como mostra a equação (8). A pressão de ar seco é baseada em uma pressão total de $100 \mathrm{kPa}$ e uma pressão de vapor de $1 \mathrm{kPa}$.

$$
\begin{aligned}
& 288 k \leq T \leq 308 k \\
& 80 k P a \leq p_{s} \leq 110 k P a
\end{aligned}
$$

em que:

$p_{s}=$ pressão do ar seco em $[\mathrm{kPa}]$, no local do ensaio, e

$T=$ temperatura absoluta em $[\mathrm{K}]$, na entrada do motor.

O fator de correção, $\omega$, para os motores ciclo Otto é representado pela equação (9).

$$
\omega=\left(\frac{99}{p_{s}}\right)^{1,2}\left(\frac{T}{298}\right)^{0,6}
$$

O fator $\omega$ só é válido dentro dos limites estabelecidos pela equação (10), e impostas pelas relações estabelecidas em (8).

$$
0,93 \leq \omega \leq 1,07
$$

Se estes limites forem excedidos, o valor da potência corrigida deve ser informado em conjunto com as condições de temperatura e pressão do ensaio.

A pressão de ar seco é obtida pela subtração da pressão de vapor d'água da pressão barométrica, como mostra a equação (11).

$$
p_{s}=p_{b}-\frac{1}{7,5}\left[e^{\left(21,106-\frac{53455}{t u+273}\right)}-0,49(t s-t u) \frac{p_{b}}{100}\right]
$$

em que:

$$
\begin{aligned}
& p_{b}=\text { pressão barométrica em }[\mathrm{kPa}] \\
& t u=\text { temperatura de bulbo úmido em }\left[{ }^{\circ} \mathrm{C}\right], \mathrm{e} \\
& t s=\text { temperatura de bulbo seco em }\left[{ }^{\circ} \mathrm{C}\right] .
\end{aligned}
$$




\subsubsection{Rendimento mecânico}

Segundo Obert (1950), rendimento mecânico, $\eta_{m}$, é a razão entre a potência efetiva e a potência indicada, como mostra a equação (12).

$$
\eta_{m}=\frac{P_{e}}{P_{i}}
$$

\subsubsection{Coeficiente de variação da pressão média indicada}

O coeficiente de variação da pressão média indicada (cov pmi), de acordo com Tunestal et al. (1999), é a relação entre o desvio padrão da pressão média indicada $\left(\sigma_{p m i}\right)$ e a própria $p m i$, como mostra a equação (13).

$$
\operatorname{cov} p m i=\frac{\sigma_{p m i}}{p m i}
$$

\subsubsection{Calor liberado durante a combustão}

Os equacionamentos apresentados por Tunestal (2000) permitem calcular o calor liberado $\left(Q_{\text {total }}\right)$ durante a combustão. Estas equações desprezam as perdas de calor para as paredes dos cilindros e os efeitos de fendas (perdas de calor ocasionadas pelo escoamento de uma fração dos gases produzidos durante a combustão pelas frestas entre o pistão, cilindro e anéis, assim como entre o bloco do motor e o cabeçote, etc.). O calor liberado pode ser escrito de acordo com a equação (14).

$$
\partial Q_{\text {total }}=\frac{c_{v}}{R} V d p+\frac{c_{p}}{R} p d V
$$

em que:

$c_{v}=$ calor específico a volume constante;

$c_{p}=$ calor específico à pressão constante;

$R=$ constante universal dos gases em base mássica;

$p=$ pressão no cilindro, $\mathrm{e}$

$V=$ volume total dos cilindros do motor. 


\subsubsection{Consumo específico}

O consumo específico $\left(C_{e s p}\right)$, de acordo com Heywood (1988), é calculado dividindo-se consumo horário pela potência efetiva do motor, como mostra a equação (15).

$$
C_{\text {esp }}=\frac{C_{\text {hor }}}{\text { Potência }} \quad[g / k W h]
$$

é comum, no cotidiano, adotarem-se as seguintes unidades: $\left[C_{e s p}\right]=\mathrm{g} / \mathrm{kWh},\left[C_{h o r}\right]=\mathrm{g} / \mathrm{h}$ e $\left[P_{e}\right]$ $=\mathrm{kW}$.

\subsubsection{Eficiência na conversão de combustível}

A eficiência na conversão de combustível, $\eta$, de acordo com Heywood (1988), é a definição de eficiência do motor mais utilizada porque emprega grandezas facilmente medidas para definir a energia usada do combustível suprida para o motor. É representada pela equação (16), em que $C_{e s p}$ é o consumo específico de combustível em [g/kWh] e PCI é o poder calorífico inferior do combustível em $[\mathrm{MJ} / \mathrm{kg}]$.

$$
\eta=\frac{3600}{C_{e s p} P C I}
$$

Segundo Heywood (1988), a eficiência na conversão de combustível quantifica mais precisamente a eficiência do motor diferindo das eficiências térmica e da combustão.

\subsubsection{Fator $\lambda$ e razão equivalente}

O coeficiente de excesso de ar $(\lambda)$, ou fator $\lambda$, e a razão equivalente $(\varnothing)$ detectam a proximidade da razão ar-combustível da mistura do valor estequiométrico.

As equações (17) e (18), adaptadas a partir de Heywood (1988) e Ribbens (1993), representam $\lambda$ e $\varnothing$, respectivamente, em que a mistura ar-combustível estequiométrica é a quantidade de ar teoricamente necessária e suficiente para oxidar toda a massa de combustível. O oxigênio presente no ar é o responsável pela oxidação do combustível.

$$
\lambda=\frac{\text { mistura ar-combustível utilizada }}{\text { mistura ar-combustível estequiométrica }}
$$




$$
\phi=\frac{\text { mistura combustível-ar utilizada }}{\text { mistura combustivel-ar estequiométrica }}
$$

Dependendo dos valores de $\lambda$ e $\emptyset$, a mistura será classificada em rica (mistura arcombustível deficiente de ar, quando $\lambda<1,0$ ou $\emptyset>1$ ), pobre (mistura ar-combustível com excesso de ar, quando $\lambda>1$ ou $\emptyset<1$ ) e quimicamente correta (quando $\lambda=1,0$ ou $\emptyset=1,0$ ).

\subsubsection{Avanço do ponto da centelha}

Segundo Heywood (1988), existe, para uma dada mistura ar-combustível dentro do cilindro numa dada condição de operação do motor, um avanço do ponto da centelha ótimo em relação ao PMS do seu respectivo cilindro, que resulta no máximo torque. Se este avanço do ponto da centelha estiver relativamente adiantado ou atrasado em relação ao ângulo medido no eixo de giro da árvore de manivelas, o torque será reduzido.

A ocorrência de knocking, de acordo com Heywood (1988), pode ser provocada pelo avanço da centelha para um muito distante do PMS.

Os sistemas de gerenciamento eletrônico de motores utilizam valores de avanço do ponto da centelha, obtidos durante os procedimentos de calibração do motor, para obter os torques máximos, corrigidos em função da ocorrência de knocking e emissões de gases poluentes, em especial os hidrocarbonetos não queimados $(H C)$.

\subsection{PROPRIEDADES FÍSICO-QUÍMICAS DOS COMBUSTÍVEIS GASOLINA E ETANOL}

Nesta seção serão apresentadas as características do etanol e da gasolina que são os combustíveis de interesse do presente trabalho.

A Tabela 1 apresenta as propriedades físico-químicas do etanol e da gasolina, de acordo com Celik (2008).

No presente trabalho, optou-se por calcular a composição química da gasolina a partir dos dados apresentados por Samaniego (2007). A aproximação da gasolina tipo A pelo isooctano (2,2,4 - trimetilpentano) (Tabela 1) difere bastante da composição calculada neste estudo, apresentada no Apêndice B, e que equivale ao undecano $\left(C_{11} H_{24}\right)$. 
Tabela 1 - Propriedades da gasolina típica e do etanol.

\begin{tabular}{lcc}
\hline Combustível & Gasolina & Etanol \\
\hline Fórmula química & $C_{8} H_{18}$ & $C_{2} H_{5} O H$ \\
Relação $C / H$ & 0,445 & 0,333 \\
Massa molecular $[\mathrm{kg} / \mathrm{mol}]$ & 114,18 & 46,07 \\
Poder calorífico inferior $[\mathrm{MJ} / \mathrm{kg}]$ & 44 & 26,9 \\
Relação A/C estequiométrica & 14,6 & 9 \\
Temperatura de autoignição $\left[{ }^{\circ} \mathrm{C}\right]$ & 257 & 425 \\
Calor latente de vaporização & & \\
[kJ/kg] & 305 & 840 \\
Octanagem $(\mathrm{RON})$ & $88-100$ & 108,6 \\
Octanagem (MON) & $80-90$ & 89,7 \\
Ponto de congelamento $\left[{ }^{\circ} \mathrm{C}\right]$ & -40 & -114 \\
Ponto de ebulição $\left[{ }^{\circ} \mathrm{C}\right]$ & $27-225$ & 78 \\
Massa específica $\left[\mathrm{kg} / \mathrm{m}^{3}\right.$ ] & 765 & 785 \\
\hline
\end{tabular}

Fonte: Celik (2008).

O etanol da Tabela 1 refere-se ao álcool etílico anidro carburante (AEAC).

Bayraktar (2005) afirma que o etanol é um combustível parcialmente oxidado porque contém um átomo de oxigênio em sua molécula, como pode ser visto na Tabela 1. Por esta razão, o etanol tem poder calorífico e relação ar-combustível menores do que a gasolina. Em relação à gasolina mais combustível será necessário para obter a mesma potência ou torque quando etanol ou misturas etanol-gasolina são usadas.

De acordo com Celik (2008), o alto calor de vaporização do etanol, em relação à gasolina, reduz o pico de temperatura dentro do cilindro e as emissões de NOx. Este alto calor de vaporização pode prover um resfriamento da carga ar-combustível na entrada do motor aumentando a densidade da mistura, fazendo que relativamente maior massa de arcombustível entre no motor.

Celik (2008) afirma que as características antidetonantes e o alto calor de vaporização do etanol permitem aos motores Otto trabalharem com relações de compressão relativamente maiores.

Devido à menor quantidade de átomos de carbono em sua molécula - relação $C / H$ - Celik (2008) aponta uma redução das emissões de $\mathrm{CO}_{2}$ quando se utiliza etanol como combustível.

Macedo, Seabra e Silva (2008) estudaram os efeitos do uso de etanol nas emissões de $\mathrm{CO}_{2}$. Os resultados mostraram que o etanol, produzido a partir da cana-de-açúcar, pode reduzir as emissões de $\mathrm{CO}_{2}$ em relação ao uso da gasolina, considerando todo o seu ciclo de produção. A Tabela 2 mostra a quantidade de emissões evitadas pelo uso de etanol hidratado ou anidro no Brasil em substituição aos combustíveis de origem fóssil. 
Tabela 2 - Emissões evitadas de $\mathrm{CO}_{2}$ utilizando o etanol como combustível.

\begin{tabular}{|c|c|c|c|c|c|c|c|}
\hline \multicolumn{8}{|c|}{ Emissões evitadas $\left[\mathrm{kg} \mathrm{CO}_{2}{\left.\text { eq } \mathrm{m}^{-3}\right]}\right.$ ] } \\
\hline Período & \multicolumn{2}{|c|}{2002} & \multicolumn{2}{|c|}{$2005 / 2006$} & \multicolumn{3}{|c|}{ Previsão em 2020} \\
\hline Combustível & $\mathrm{AEHC}$ & E25 & $\mathrm{AEHC}$ & E25 & $\mathrm{AEHC}$ & VFF & E25 \\
\hline Emissões evitadas & 2049 & 2256 & 1979 & 2111 & 1979 & 1805 & 2111 \\
\hline \multicolumn{8}{|c|}{$\begin{array}{l}\text { AEHC - } 100 \% \text { álcool etílico hidratado carburante } \\
\text { álcool etílico anidro carburante e } 75 \% \text { gasolina em volume } \\
\text { VFF - veículos bicombustível fabricados no Brasil }\end{array}$} \\
\hline
\end{tabular}
Fonte: Macedo, Seabra e Silva (2008).

Moreira e Goldemberg (1999) afirmam que a combustão do etanol produz mais acetaldeídos do que a combustão da gasolina. Porém, as emissões de acetaldeídos originadas do etanol são menos agressivas a vida humana e ao meio ambiente do que os formaldeídos originados da queima da gasolina.

Segundo Heywood (1988), o índice de octano é uma medida da resistência dos combustíveis a detonação. Esta resistência pode ser medida utilizando o método de pesquisa $(R O N)$ ou o método motor $(M O N)$. Estes métodos se diferem pela temperatura na entrada do motor, rotação do motor, avanço da centelha e relação de compressão durante a medição.

O índice de anti-detonação (IAD), apresentado na equação (19) de acordo com Heywood (1988), também é um indicativo da qualidade de um combustível em resistir à detonação.

$$
I A D=\frac{R O N+M O N}{2}
$$

Considerando os valores de $R O N$ e $M O N$ apresentados na Tabela 1 e obtendo o IAD da gasolina e do etanol, pode-se afirmar que o etanol é mais resistente a detonação do que a gasolina.

Segundo Bayraktar (2005), a pressão de vapor Reid (teste Reid) do etanol é menor do que da gasolina e isso causa problemas na partida a frio.

Segundo Obert (1950), o teste Reid padroniza a vaporização por meio da determinação da pressão de vapor em um volume de ar que ocupa quatro vezes o volume de combustível.

\subsection{MISTURAS DE ETANOL E GASOLINA COMO COMBUSTÍVEIS EM MOTORES OTTO}

Segundo Dal Bem (2008), o advento do PROÁLCOOL, no ano de 1975, impulsionou a utilização do etanol como combustível, principalmente devido aos incentivos fiscais oferecidos pelo governo brasileiro aos proprietários de automóveis movidos a etanol. 
Entretanto, com a retirada gradativa desses incentivos e a ocorrência de um desabastecimento desse combustível nos últimos anos da década de 1980, houve grande desconforto e insegurança por parte dos consumidores brasileiros que passaram a dar novamente preferência aos veículos movidos à gasolina.

Dal Bem (2008) também relata o ressurgimento do interesse do consumidor brasileiro no etanol a partir do final da década de 1990, quando os preços desse combustível voltaram a ser competitivos em relação aos da gasolina. Naquela época surgiu uma prática popular dos consumidores misturarem gasolina e etanol em seus carros até então movidos à gasolina, o que aliada à antiga insegurança quanto ao uso do etanol, devido aos desabastecimentos anteriores, motivou a produção em série de veículos flexíveis, capazes de serem movidos com gasolina, etanol e ou misturas de ambos.

Os motores destes veículos flexíveis podem ser alimentados com misturas de AEHC e gasolina tipo $C$ (25\% AEAC e $75 \%$ gasolina tipo $A$, em volume, de acordo com Agência Nacional do Petróleo, Gás Natural e Biocombustíveis (2009)). Segundo Agência Nacional do Petróleo, Gás Natural e Biocombustíveis (2009), o AEHC possui um teor alcoólico relativo a sua composição, em massa, na faixa de 92,6 a 93, $8^{\circ}$ INPM. Portanto, as misturas nos motores flexíveis brasileiros são formadas por água, etanol e gasolina.

Kyriakides et al. (2013) investigaram a estabilidade de várias misturas de água, etanol e gasolina e as emissões de uma mistura com 10\% de água, $60 \%$ de gasolina e $40 \%$ de etanol e obtiveram como resultado uma redução significativa nas emissões de $N O_{x}$. Os autores atribuem o resultado à queima mais lenta da mistura dentro do cilindro e uma provável redução no pico de temperatura durante o processo de combustão.

Não só no Brasil, mas em vários outros países têm sido relatados vários estudos considerando a aplicação do etanol misturado à gasolina para atenuação do consumo de gasolina e também redução das emissões de poluentes.

Hsieh et al. (2002) estudaram as emissões de poluentes num motor Otto operando com diferentes misturas de gasolina e etanol. Os resultados destes autores mostraram que o aumento da quantidade de etanol reduz o poder calorífico da mistura e aumenta o índice de octano da mistura de combustíveis. A pressão de vapor Reid aumentou com a adição de até $10 \%$ de etanol na mistura e decresceu nas misturas com 20 e $40 \%$ de etanol. O consumo específico e o torque do motor aumentaram ligeiramente com o aumento da quantidade de etanol, enquanto as emissões de $H C$ e $C O$ caíram drasticamente devido ao empobrecimento da mistura. A combustão melhorou e, consequentemente, as emissões de $\mathrm{CO}_{2}$ aumentaram. Quanto às emissões de $N O_{X}$, os resultados foram inconclusivos, aparentemente mostraram-se 
mais dependentes das condições de operação do motor do que da adição de etanol nas misturas de combustíveis.

He et al. (2003) também investigaram as emissões de um motor Otto. Os resultados destes autores indicaram que misturas com $10 \%$ de etanol tiveram pouco efeito na redução das emissões, mas misturas com $30 \%$ de etanol reduziram drasticamente as emissões de CO, THC e $N O_{x}$. Além disso, a adição de etanol na gasolina aumentou o número de octanos da mistura. Por outro lado, com o aumento da quantidade de etanol, as emissões de etanol não queimado e acetaldeídos aumentaram. Para contornar este problema He et al. (2003) sugerem usar um catalisador trivalente $P t / R h$, que poderia efetivamente converter as emissões de acetaldeídos, mas advertem que a eficiência na conversão de etanol não queimado será baixa.

Em outra investigação, Wu et al. (2004) testaram um motor Otto sob várias relações arcombustível variando a rotação e a carga admitida por um motor com relação de compressão de 9,5:1 e verificaram que, sem alterar o tempo de injeção de combustível e mantendo a abertura da válvula borboleta fixa, a relação ar-combustível é deslocada para misturas pobres à medida que a quantidade de etanol aumenta na mistura combustível. Com a relação arcombustível ligeiramente pobre foram encontrados o máximo torque e o menor consumo específico. O aumento da quantidade de etanol também reduziu as emissões de $H C$ e $C O$, a que os autores atribuíram a presença de oxigênio proveniente do etanol $\left(\mathrm{C}_{2} \mathrm{H}_{5} \mathrm{OH}\right)$.

Melo et al. (2012) estudaram o desempenho e as emissões de gases poluentes utilizando um motor flex fuel comercializado no Brasil, com relação de compressão de 10,35:1, e constataram que as emissões de $\mathrm{CO}_{2}$ aumentam com a elevação da quantidade de etanol, assim como o consumo específico, devido à redução do poder calorífico inferior na mistura combustível. As emissões de CO reduziram quando houve adição de etanol na mistura justificada por eles pela presença de oxigênio no etanol. O combustível com $100 \%$ de etanol (H100) apresentou a maior eficiência energética.

Entre outros resultados apresentados por Melo et al. (2012), pode-se destacar a medição da duração da combustão para os diversos combustíveis investigados. A Tabela 3 apresenta estes valores de duração da combustão. Pode-se observar nesta tabela que, praticamente, não existem diferenças significativas entre os valores de duração da combustão dos cinco combustíveis analisados (H0, H30, H50, H80 e H100 - 100\% de etanol na mistura combustível), considerando as condições de ensaio utilizadas. 
Tabela 3 - Duração da combustão e avanço da centelha para misturas gasolina-etanol.

\begin{tabular}{lcc}
\hline \multicolumn{1}{c}{ Combustível } & $\begin{array}{c}3875 \mathrm{rpm}-105 \mathrm{Nm} \\
\text { Ponto da centelha } \\
{\left[{ }^{\circ} \mathrm{APMS}\right]}\end{array}$ & $\begin{array}{c}\text { Duração da combustão } \\
{\left[{ }^{\circ}\right]}\end{array}$ \\
\hline H0 (gasolina brasileira tipo $C)$ & 22 & 25 \\
H30 (30\% de etanol) & 24 & 24 \\
H50 (50\% de etanol) & 28 & 24 \\
H80 (80\% de etanol) & 29 & 24 \\
H100 (100\% de etanol) & 30 & 24 \\
\hline
\end{tabular}

Fonte: Melo et al. (2012).

Um dos parâmetros mais importantes para o desenvolvimento de motores alimentados com misturas de etanol e gasolina é a adequação da relação de compressão para reduzir as emissões e aumentar a eficiência da combustão.

Abdel-Rahman e Osman (1997) estudaram as misturas de etanol e gasolina sob diferentes relações de compressão utilizando um motor com relação de compressão variável. Os resultados obtidos por estes autores mostraram que para cada mistura há uma relação de compressão ótima na qual se obtém a máxima potência indicada. As relações de compressão ótimas em função da porcentagem de etanol na gasolina são mostradas na Tabela 4. Estas relações de compressão são representativas apenas quando se considera as características do motor, os parâmetros de operação, a qualidade e as propriedades dos combustíveis utilizados pelos autores.

Tabela 4 - Relações de compressão em função da porcentagem de etanol na gasolina.

\begin{tabular}{cc}
\hline Quantidade de etanol na gasolina [\%] & Relação de compressão \\
\hline 10 & $8: 1$ \\
20 & $10: 1$ \\
30 & $12: 1$ \\
\hline
\end{tabular}

Fonte: Abdel-Rahman e Osman (1997).

Costa e Sodré (2011) também investigaram os efeitos da relação de compressão sobre o desempenho de um motor flex fuel com relação de compressão alterada em três níveis: 10:1, 11:1 e 12:1 e alimentado com etanol e gasolina brasileira tipo $C$ (22\% de álcool etílico anidro carburante). Os resultados de desempenho do motor, utilizando os dois combustíveis estudados, indicaram que a elevação da relação de compressão aumenta a pressão dentro do cilindro e, consequentemente, o torque do motor. O aumento da relação de compressão também reduziu o consumo específico quando utilizado o etanol como combustível. O 
combustível E22 apresentou melhora menos significativa do torque com o aumento da relação de compressão devido ao controle de knocking por meio da redução do avanço da centelha.

Bayraktar (2005) investigou os efeitos da adição de etanol (de zero a 12\%) a gasolina sobre o desempenho e as emissões de um motor Otto de compressão variável (entre 7,75:1 e $8,25: 1)$. A potência efetiva e a eficiência efetiva aumentam com o aumento da quantidade de etanol na mistura de combustível. Os autores atribuíram o resultado à melhora da combustão, que também proporcionou uma redução nas emissões de $C O$. Esta melhora na combustão aumentou a pressão e a temperatura no cilindro. As emissões de $N O_{X}$ aumentam com a elevação da relação de compressão devido ao aumento na temperatura dentro do cilindro. Os resultados experimentais mostraram que entre as várias misturas analisadas, a de 7,5\% de etanol produziu melhores resultados do ponto de vista do desempenho do motor e das emissões de $C O$. Porém, comparações teóricas realizadas por Bayraktar (2005) por meio de um modelo matemático mostraram que a mistura contendo $16,5 \%$ em volume de etanol deveria ter sido a mais adequada para seu motor Otto.

Topgül et al. (2006) estudaram os efeitos de misturas combustíveis (entre 10 e $60 \%$ de etanol na gasolina) em um motor Otto variando a relação de compressão (8:1, 9:1 e 10:1). Estes autores concluíram que suas misturas etanol-gasolina aumentaram ligeiramente o torque e diminuíram as emissões de $\mathrm{CO}$ e $H C$. Além disso, eles observaram que suas misturas com etanol permitiram trabalhar com relações de compressão mais altas sem ocorrência de knocking. A explicação foi o etanol possuir maior número de octanos que a gasolina.

Yücesu et al. (2006) também estudaram o desempenho e as emissões de um motor Otto variando a relação de compressão (entre 8:1 e 13:1). Os resultados dos experimentos apontaram para aumento do torque do motor e também das emissões de HC quando a relação de compressão aumenta. Com misturas com 40 e $60 \%$ de etanol houve redução nas emissões de $H C$ e $C O$ do motor. $\mathrm{O}$ aumento da quantidade de etanol mostrou vantagem porque o motor pode operar com o avanço da centelha mais adiantado sem ocorrência de knocking e porque maior torque foi obtido.

Um desafio na utilização de etanol e de misturas etanol-gasolina nos motores Otto é a partida a frio. Nesse sentido, Liao et al. (2005) estudaram a combustão de misturas de etanol e gasolina em baixas temperaturas em uma câmara de combustão fechada, com pressão de 1 bar, simulando condições de partida a frio de um motor de ignição por centelha. Eles observaram que para realizar uma partida a frio confiável, como ocorre em um motor a gasolina na mesma temperatura, o motor a etanol-gasolina não precisou ser alimentado com mistura ar-combustível muito mais rica, especialmente em uma faixa de temperatura ao redor 
do ponto de ebulição do etanol, pois a adição de etanol na gasolina resultou em uma melhora da evaporação da mistura. Liao et al. (2005) também investigaram as velocidades de chama e, verificaram que as misturas etanol-gasolina contendo 15\% e 30\% de etanol apresentam uma propagação de chama mais rápida do que a gasolina, atingindo o máximo pico de pressão de combustão a uma razão equivalente $\emptyset=1,3$. Segundos os autores, esta taxa é inferior à encontrada para a gasolina, que apresenta maior pico de pressão de combustão em razão equivalente $\varnothing=1,6$. As taxas equivalentes encontradas são maiores do que a unidade porque, para os autores, os combustíveis testados encontravam-se parcialmente evaporados nas condições de temperatura e pressão dos testes.

Chen et al. (2011) investigaram as emissões e a estabilidade de um motor alimentado com misturas de etanol e gasolina (E5, E10, E20, E30 e E40 - 40\% de etanol) durante a partida a frio.

De acordo com Chen et al. (2011), na partida a frio e nos instantes posteriores, o motor Otto (com relação de compressão de 9,8:1) necessitou de uma mistura ar-combustível mais rica para manter a ignição. As emissões de $H C$ e $C O$ foram elevadas devido à baixa temperatura do catalisador, que ainda estava inoperante. O tempo de injeção de combustível manteve-se praticamente o mesmo para todos os combustíveis analisados. O fator excesso de ar progrediu $2 \%$ para o E5, 4\% para o E10, 9\% para o E20, 14\% para o E30 e 19\% para o E40.

Os resultados dos ensaios realizados por Chen et al. (2011) indicaram que o motor afinado originalmente para a gasolina foi capaz de operar de forma estável, durante três minutos após a partida a frio, com misturas contendo até 30\% de etanol. Acima de $30 \%$ de etanol, na mistura combustível, o empobrecimento da mistura ar-combustível gerou dificuldades na partida a frio e na estabilidade do motor nos instantes posteriores. As emissões de $H C, N O_{x}$ e $C O$ foram reduzidas para misturas contendo entre 20 e $40 \%$ de etanol.

Além dos estudos sobre motores de veículos comerciais, existem outros sobre a aplicação das misturas de etanol e gasolina em pequenos motores utilizados em diversas atividades profissionais e domésticas como, por exemplo, o estudo realizado por Celik (2008) utilizando um pequeno motor de baixa eficiência e dotado de carburador, originalmente projetado para operar com gasolina. Os resultados indicaram que o aumento da relação de compressão (de 6:1 para 10:1) e a adição de etanol a gasolina (mistura de 50\% de etanol e gasolina) aumentaram a potência do motor em aproximadamente $29 \%$ quando comparado com a utilização de $100 \%$ de gasolina como combustível. Além disso, o consumo específico de 
combustível e as emissões de $\mathrm{CO}, \mathrm{CO}_{2}, \mathrm{HC}$ e $\mathrm{NO}_{X}$ foram reduzidas, conforme mostra a Tabela 5.

Tabela 5 - Reduções no consumo específico e nos teores de emissões utilizando mistura etanol-

\begin{tabular}{cc}
\multicolumn{2}{c}{ gasolina (50\%). } \\
\hline Variáveis do motor & Redução em relação ao motor a gasolina [\%] \\
\hline Consumo específico de combustível & 3 \\
Emissões de CO & 53 \\
Emissões de $\mathrm{CO}_{2}$ & 10 \\
Emissões de $\mathrm{HC}$ & 12 \\
Emissões de $\mathrm{NO}_{\mathrm{x}}$ & 19 \\
\hline
\end{tabular}

Fonte: Celik (2008)

A variação cíclica é um importante parâmetro no projeto dos motores Otto. Ceviz e Yüksel (2005) estudaram este parâmetro em um motor Otto dotado de carburador e alimentado com misturas de etanol e gasolina. O coeficiente de variação da pressão média indicada (cov pmi) foi utilizado para quantificar a variação cíclica. Os resultados mostraram que o valor do cov pmi decresceu com adição de até $10 \%$ de etanol na mistura. Acima de $10 \%$ de etanol o valor do cov pmi voltou a aumentar.

\subsection{SISTEMAS DE CONTROLE ELETRÔNICO DE MOTORES BICOMBUSTÍVEL}

Os sistemas de gerenciamento eletrônico do motor, de acordo com Rovai (2005), podem ser divididos em dois grupos: injeção na borboleta de aceleração (monoponto) e injeção nos dutos de admissão (multiponto). Os sistemas monoponto possuem um só injetor para alimentar o motor e utilizam pressão a montante do injetor em torno de 1,0 bar, enquanto que os sistemas multiponto possuem um injetor para cada cilindro do motor e pressão a montante dos injetores em torno de 3,0 bar.

Segundo Rovai (2005) os veículos bicombustíveis necessitam da tecnologia de gerenciamento eletrônico do motor. Esta tecnologia visa basicamente controlar a quantidade de combustível injetada e o momento ideal do disparo da centelha na vela de ignição em cada ciclo. Estes controles se fazem necessários devido às diferenças das propriedades físicoquímicas entre as misturas de combustíveis utilizadas quando queimadas no mesmo motor de combustão interna.

Dal Bem (2008) descreve os sistemas de gerenciamento eletrônico de motores. A relação ar-combustível é calculada inicialmente a partir das informações vindas dos diversos sensores do motor (rotação, pressão de admissão, temperatura do ar, etc.) e compensadas em função 
das condições de operação do motor e corrigida usando um sensor de oxigênio (sonda lambda), localizado no sistema de exaustão. O sistema identifica a ocorrência de detonação pelo sinal do sensor de detonação e corrige o momento da centelha de forma adaptativa para minimizar a ocorrência deste fenômeno.

De acordo com Alves (2007) a Bosch foi a primeira empresa a investir no desenvolvimento de veículos bicombustíveis a partir de 1980. O primeiro protótipo desta empresa foi apresentado em 1994, mas apesar do grande interesse demonstrado por parte das montadoras, não existia ainda a motivação comercial necessária para que se iniciasse a comercialização em série do produto. Em 1999, a empresa Magneti Marelli apresentou a tecnologia flex fuel (SFS - Software Flex fuel Sensor), totalmente desenvolvida no Brasil. O sistema basicamente modificou o programa de computador inserido no módulo de gerenciamento eletrônico do motor para rodar rotinas corretivas de tempo de injeção e ponto da centelha, alimentadas pelo sinal da sonda lambda. Porém, só a partir do ano 2000 com a redução do preço do álcool, aumento nos preços do petróleo, os consumidores agindo por conta própria e com a decisão do governo de reduzir a alíquota de IPI dos veículos flex fuel, a produção em série destes veículos passou a ser viável no Brasil. Isto resultou no lançado, em abril de 2003, do primeiro automóvel flex fuel, o Gol 1.6 Total Flex da Volkswagen.

Segundo Alves (2007) os veículos flex fuel, quando comparados aos automóveis tradicionais a gasolina, oferecem flexibilidade aos seus proprietários com relação à escolha do combustível a ser utilizado, permitindo a opção pela alternativa mais econômica cada vez que o automóvel é reabastecido.

Alves (2007) acrescenta que o sucesso do automóvel flex fuel no mercado brasileiro é inédito no mundo, e tem sido citado como um exemplo de substituição do combustível fóssil por fontes renováveis de energia, ao mesmo tempo em que reduz o dano de emissões de gases poluentes ao meio ambiente.

Teixeira (2005) apresenta um histórico do desenvolvimento da tecnologia flex fuel e ressalta que o protótipo apresentado pela Bosch em 1994 utilizava um sensor físico para identificar o tipo de combustível no tanque do veículo. O custo deste sensor tornava a produção de veículos bicombustível pouco competitiva no mercado brasileiro. Para baratear esta tecnologia, a empresa Magneti Marelli eliminou o sensor no tanque de combustível do veículo e desenvolveu suas rotinas para o software diretamente inserido no sistema de gerenciamento eletrônico do motor. A identificação do combustível é feita por um sensor lógico no software, baseado no sistema de controle de um motor convencional, em que a sonda lambda detecta os gases provenientes da queima do combustível para inferir sobre a 
variação da mistura. Esta tecnologia se difundiu em praticamente todas as empresas do mercado brasileiro responsáveis pela fabricação de sistemas de gerenciamento eletrônico de motores.

A Figura 3 exibe os dados sobre veículos licenciados no Brasil de acordo com o tipo de combustível. Pode-se notar a aceitação da tecnologia bicombustível, no mercado brasileiro, pelo avanço acentuado de licenciamentos de veículos flex fuel (ou bicombustíveis) desde o ano de 2003, atingindo no ano de 2014 a marca de 88,2\% do total de veículos licenciados.

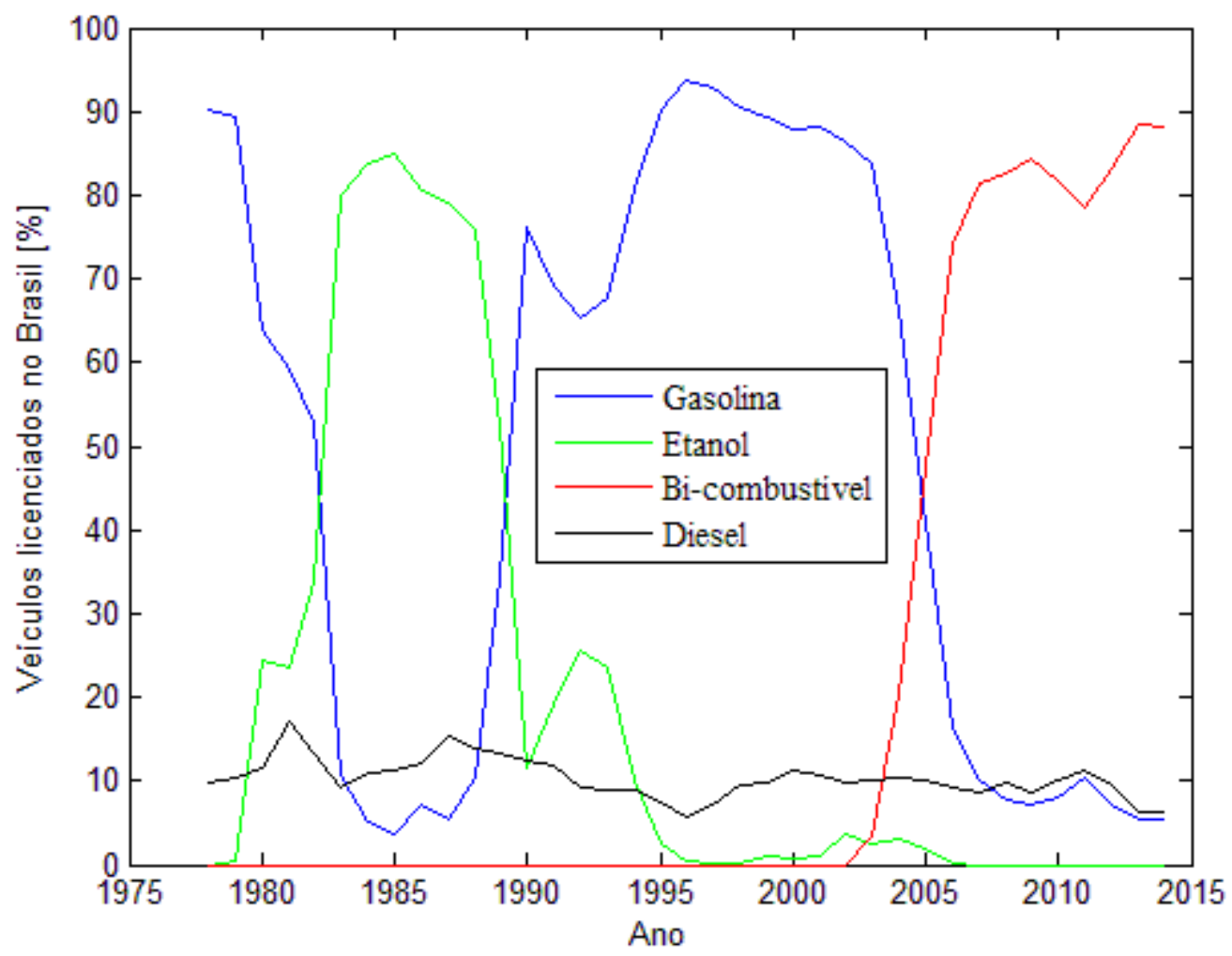

Figura 3 - Licenciamento no Brasil de auto veículos novos por combustível.

Fonte: Adaptado de Associação Nacional dos Fabricantes de Veículos Automotores (2014).

Um fator importante a ser considerado no desenvolvimento dos veículos flex fuel é a relação de compressão dos motores. O primeiro veículo flex fuel comercializado no Brasil, Gol 1.6 Total Flex da Volkswagen, apresentava relação de compressão de 10:1, enquanto que os veículos flexíveis atuais apresentam relação de compressão entre 10,35:1 e 13,00:1 (média ponderada, pelo número de veículos comercializados no Brasil, de 12,33:1), como mostra a Tabela 6. Esta tabela foi elaborada consultando os veículos mais vendidos no Brasil, de acordo com Associação Nacional dos Fabricantes de Veículos Automotores (2014), e consultando os valores das relações de compressão nos manuais dos fabricantes destes veículos. 
Tabela 6 - Relação de compressão dos 10 veículos flex fuel mais vendidos no Brasil.

\begin{tabular}{cc}
\hline \multicolumn{2}{c}{10 veículos mais vendidos no Brasil } \\
Modelo & Relação de compressão \\
\hline 1.0 flex & 12,70 \\
1.0 flex & 12,15 \\
1.4 flex & 12,35 \\
1.0 flex & 13,00 \\
1.0 flex & 12,60 \\
1.4 flex & 10,35 \\
1.0 flex & 12,80 \\
1.0 flex & 12,15 \\
1.4 flex & 12,40 \\
1.6 flex & 12,10 \\
Média ponderada & 12,33 \\
\hline
\end{tabular}

\subsection{TRAÇO DA PRESSÃO NO CILINDRO}

O ciclo de operação de um motor ciclo Otto, pode ser ilustrado por meio do diagrama ( $\mathrm{P}$ V) que relaciona o traço da pressão no cilindro e o volume deslocado pelo pistão, como mostra a Figura 4.

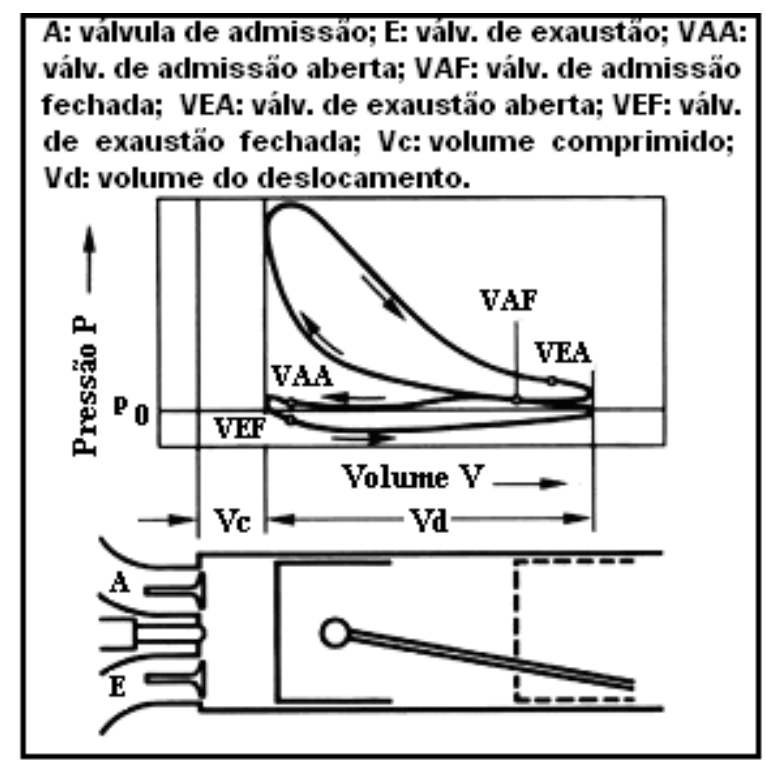

Figura 4 - Pressão no cilindro em função da posição do pistão. Fonte: BOSCH (1988).

A Figura 5 ilustra outra forma de apresentação da pressão no cilindro, de acordo com Heywood (1988). Nesta figura a pressão no cilindro está em função da posição angular da árvore de manivelas, em que VAA é a válvula de admissão aberta, VAF é a válvula de admissão fechada, VEA é a válvula de exaustão aberta, VEF é a válvula de exaustão fechada 
e MC (ou AV) é o avanço da centelha. O trecho grifado na Figura 5 como combustão representa a duração do processo de queima do combustível que pode variar de acordo com o projeto de cada motor e com a condição de operação, geralmente este trecho estende-se entre 40 e 60 graus a partir do ponto da centelha. A curva pontilhada representa a pressão de acionamento que é a pressão resultante do movimento do pistão sem a ocorrência de combustão.

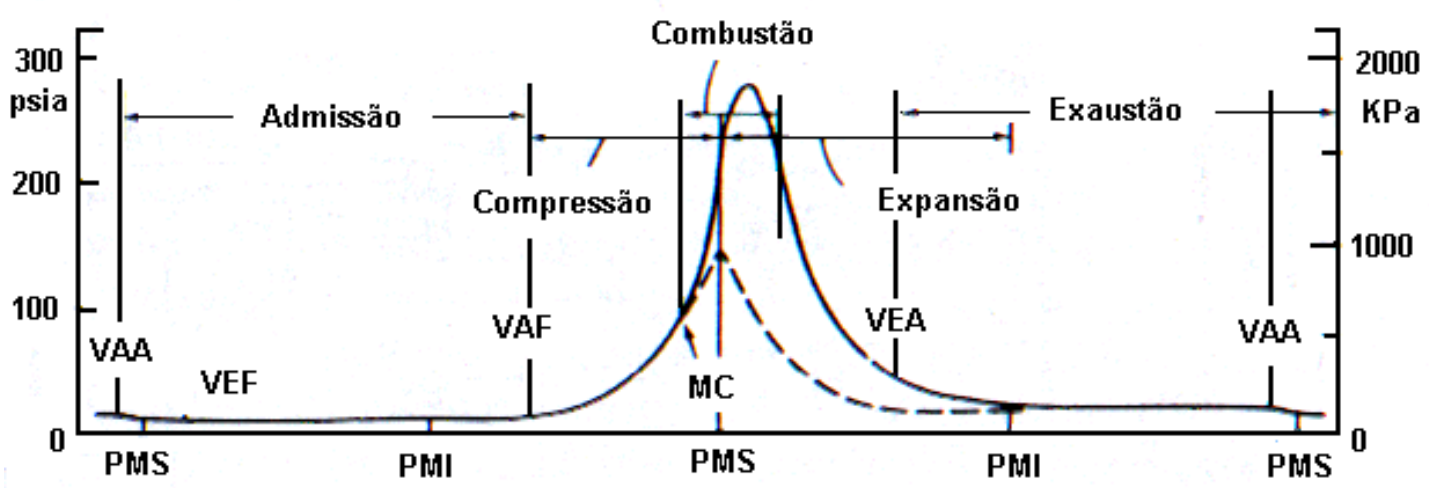

Figura 5 - Sequência de eventos do ciclo de operação de um motor quatro tempos com ignição por centelha.

Fonte: Heywood (1988).

A identificação do cruzamento de válvulas pode ser feita observando a Figura 5.

O cruzamento de válvulas é o espaço angular no qual as válvulas de admissão e de exaustão encontram-se abertas simultaneamente dentro de um mesmo cilindro. Geralmente, a válvula de admissão é aberta um pouco antes do PMS, ainda durante a exaustão, e a válvula de exaustão é fechada um pouco depois do PMS, durante a admissão. Este espaço angular é representado pelo trecho compreendido entre VAA e VEF. É importante observar que a válvula de admissão é fechada um pouco depois do PMI, durante a compressão, enquanto que a válvula de exaustão é aberta um pouco antes do PMI, durante a expansão. Em baixas rotações o cruzamento de válvulas permite que parte dos gases da combustão entre no coletor de admissão, visto que a pressão no interior do cilindro é mais elevada. Estes gases da combustão, gases residuais, retornam para o cilindro quando o pistão inicia seu curso durante a admissão. Em altas rotações o arrasto provocado pela exaustão dos gases da combustão, durante o cruzamento de válvulas, facilita a entrada da mistura fresca no cilindro aumentando a eficiência volumétrica do motor (HENRY, 2001).

O traço da pressão no cilindro (Figura 5) é afetado por diversas variáveis do motor.

Segundo Taylor (1968), a variação da relação ar-combustível (A/C) ou da relação combustível-ar (C/A) provoca variações na velocidade e na temperatura da chama e, 
consequentemente, na temperatura da parede do cilindro. Estas variações provocam alterações na duração do processo de queima do combustível.

A Figura 6 mostra os efeitos da variação da relação C/A no digrama $P-V$, em que as curvas $1,2,3$ e 4 representam $\varnothing$ igual a $1,17,0,8,1,8$ e 0,735 , respectivamente. Nesta figura pode-se observar que aumentando o valor de $\varnothing$ aumenta-se o pico de pressão no cilindro, porém, se $\varnothing$ é aumentado de forma exagerada (curva 3), a reação não ocorre completamente devido à falta de ar para queimar completamente o combustível que se encontra em excesso na mistura, e o pico de pressão não aumenta.

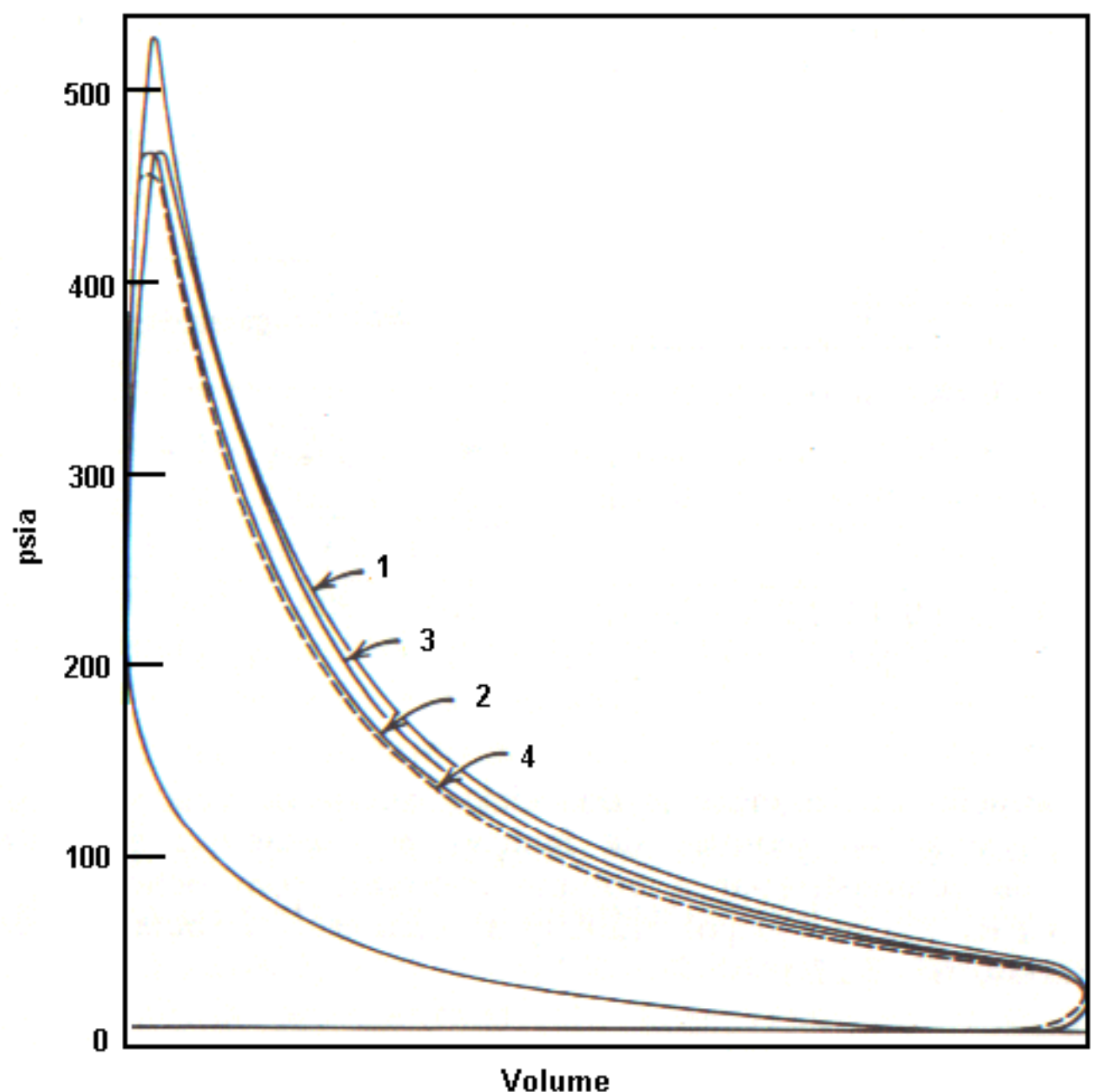

Figura 6 - Efeitos da relação combustível-ar $(\varnothing)$ sobre o diagrama P -V. Fonte: Taylor (1968).

Segundo Heywood (1988) o avanço da centelha afeta o traço da pressão no cilindro, como mostra a Figura 7. Nesta figura pode-se observar três situações distintas em relação ao avanço da centelha. A primeira, quando o avanço da centelha ( $M C$ ou $A V)$ ocorre muito antes do PMS (50 $\mathrm{APMS})$ o pico de pressão ocorre mais cedo no tempo de expansão, porém o 
trabalho do pistão sobre os gases, durante a compressão, é maior. A segunda, quando o avanço da centelha ocorre muito próximo do PMS $\left(10^{\circ} \mathrm{APMS}\right.$ - antes do ponto morto superior) o pico de pressão ocorre mais adiante no tempo de expansão, porém, o trabalho do pistão sobre os gases é menor, mas o pico de pressão também é bem menor que no caso anterior, reduzindo o torque do motor. A terceira, quando o avanço da centelha ocorre em um ponto intermediário, entre os dois casos anteriores, a 30 $\mathrm{APMS}$, o trabalho do pistão sobre o gás e o torque gerado são otimizados resultando no mínimo avanço da centelha para melhor torque (MBT - maximum brake torque timing).

Heywood (1988) relata que o avanço da centelha ótimo depende das condições de operação e do projeto do motor, assim como das propriedades do combustível, do ar e da mistura queimada.

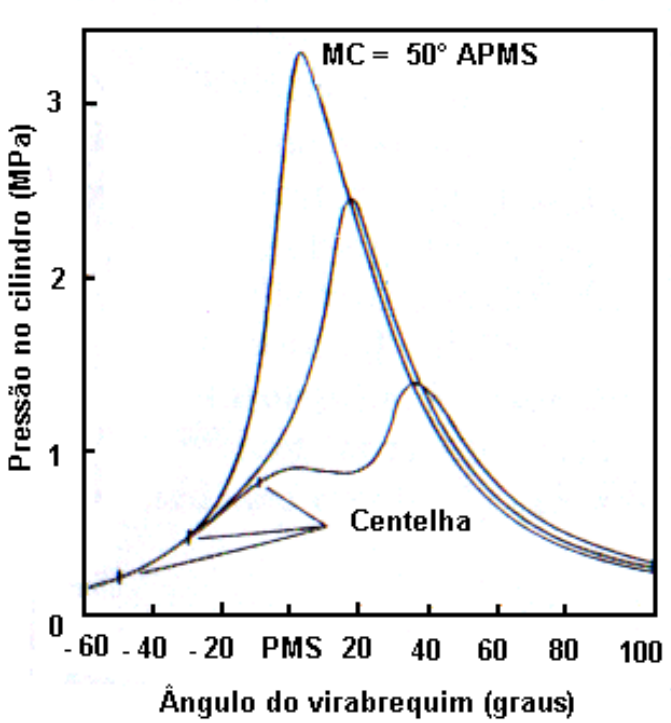

(A)

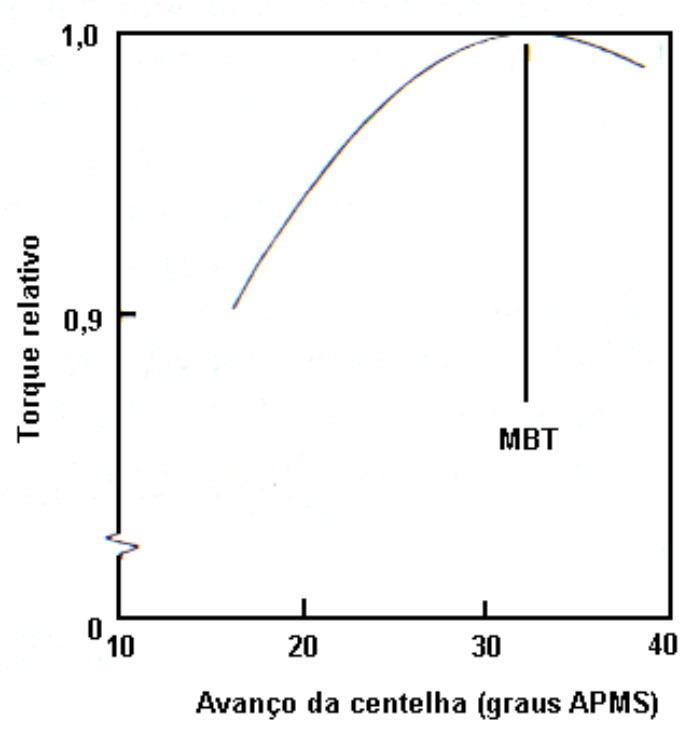

(B)

Figura 7 - A - Pressão no cilindro versus ângulo da árvore de manivelas. B - Efeitos do avanço da centelha sobre o torque.

Fonte: Heywood (1988).

A Figura 8 ilustra a influência da variação cíclica da combustão sobre o traço da pressão no cilindro. Segundo Heywood (1988) esta variação é analisada por meio de fotografias tiradas da câmara de combustão, que mostram a evolução da chama e a dispersão da fração de volume inflamado desde o início da combustão. Esta dispersão na taxa de queima ocorre devido a três fatores:

- Variação em cada ciclo na movimentação dos gases dentro do cilindro durante a combustão; 
- variação em cada ciclo nas quantidades de combustível, ar e de gases de exaustão cilindro a cilindro, e

- variação em cada ciclo na composição da mistura, especialmente nas proximidades da vela de ignição devido às variações na mistura entre o combustível, ar, gases de exaustão e gases residuais (gases queimados no ciclo anterior e que não são eliminados durante a exaustão).

A contribuição de cada um destes fatores na variação cíclica ainda não está definida, entretanto, de acordo com Sellnau et al. (2000) o desequilíbrio da relação A/C cilindro a cilindro pode comprometer o controle das operações dos motores causando problemas de dirigibilidade, aumentando os índices de emissão de poluentes e reduzindo a potência gerada.

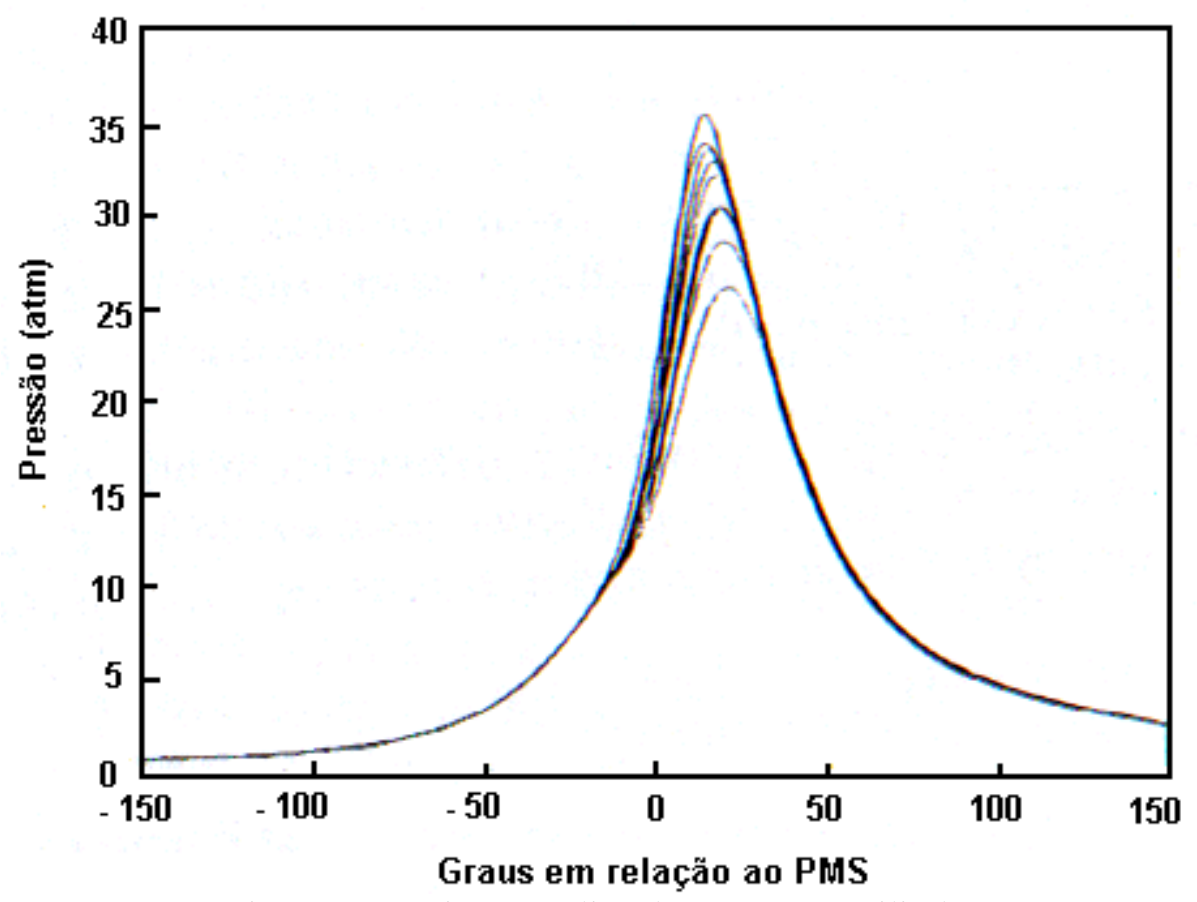

Figura 8 - Variação cíclica da pressão no cilindro.

Fonte: Heywood (1988).

A ocorrência de knocking afeta significativamente o traço da pressão no cilindro. De acordo com Heywood (1988), knocking ocorre quando os motores apresentam combustão anormal caracterizada por pressões locais muito altas, que se propagam na forma de ondas pela câmara de combustão acompanhadas pelo aumento da transferência de calor. Este fenômeno é causado por diversos fatores (avanço da centelha, relação de compressão, temperatura na câmara de combustão, etc.) e, dependendo de sua intensidade e/ou frequência pode ocasionar danos ao motor. 
A Figura 9 apresenta três traços da pressão no cilindro, sendo que no primeiro a combustão ocorre normalmente, no segundo ocorre knocking de maneira branda e no terceiro ocorre knocking de maneira severa.

Outros efeitos sobre o traço da pressão no cilindro, como relação de compressão, pressão de descarga, pressão de admissão e rotação podem ser estudados em detalhes consultando Taylor (1968).

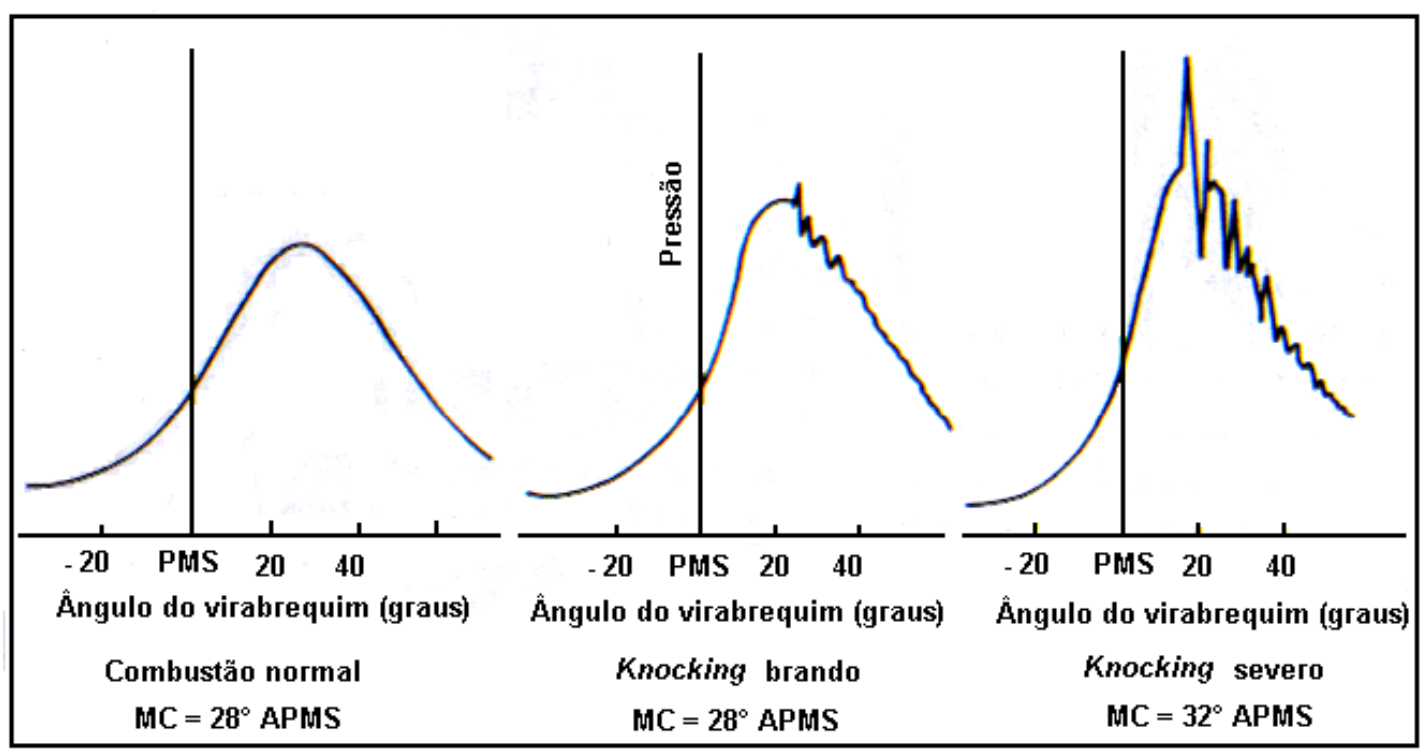

Figura 9 - Efeito da ocorrência de knocking sobre o traço da pressão no cilindro.

Fonte: Heywood (1988).

\subsection{TECNOLOGIA DOS TRANSDUTORES DE PRESSÃO NO CILINDRO}

Segundo Powell (1993) a obtenção do traço completo da pressão no cilindro só foi possível a partir da década de 1960 com o surgimento dos transdutores eletrônicos de pressão. Estes transdutores permitiram o avanço das pesquisas, principalmente, sobre o controle da relação ar-combustível e do avanço da centelha.

Sellnau et al. (2000) classificou os transdutores de pressão no cilindro em dois tipos, quanto a sua forma e localização no motor:

- Intrusivos: são instalados no motor atravessando as paredes do cabeçote até alcançar a câmara de combustão, como mostra a Figura 10, e

- Não intrusivos: são instalados no motor incorporados, geralmente, à vela de ignição, como mostra a Figura 11. 
Os transdutores intrusivos são os mais comuns, apresentando alto custo. Sua instalação, às vezes, não é possível ou requer grandes adaptações no cabeçote do motor. Em alguns motores, estes transdutores precisam atravessar as galerias de água para alcançarem a câmara de combustão, o que pode provocar sérios problemas na durabilidade do cabeçote.

Os transdutores não intrusivos são mais recentes, mais baratos e não requerem nenhum tipo de alteração na geometria do cabeçote.

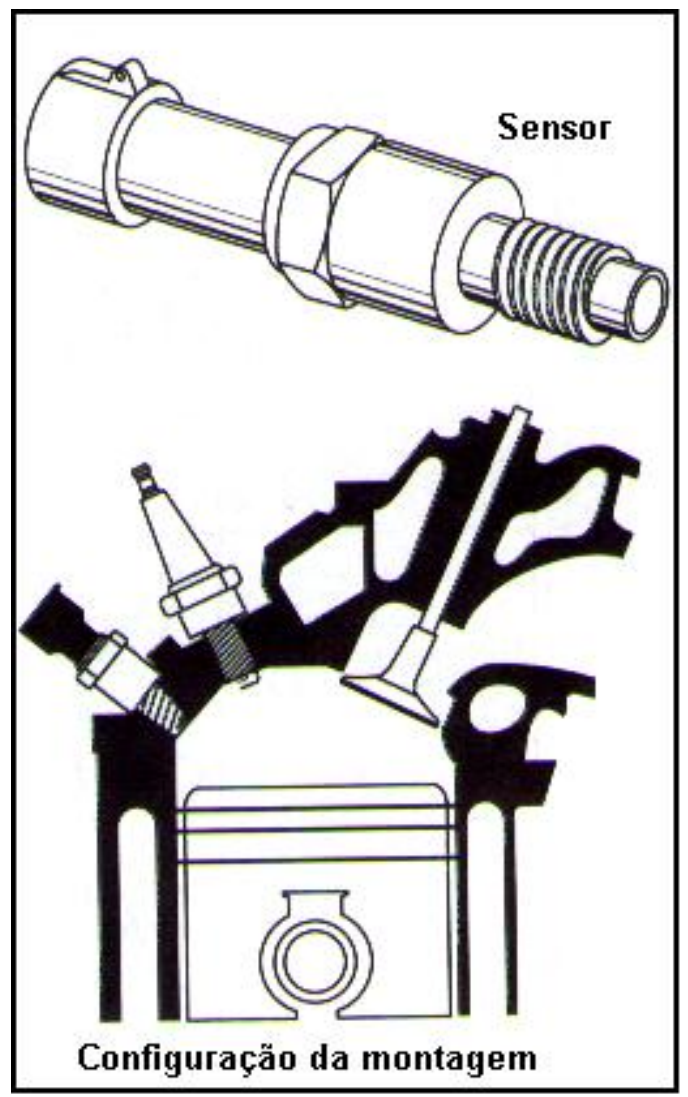

Figura 10 - Transdutor de pressão intrusivo. Fonte: Ribbens (1993).

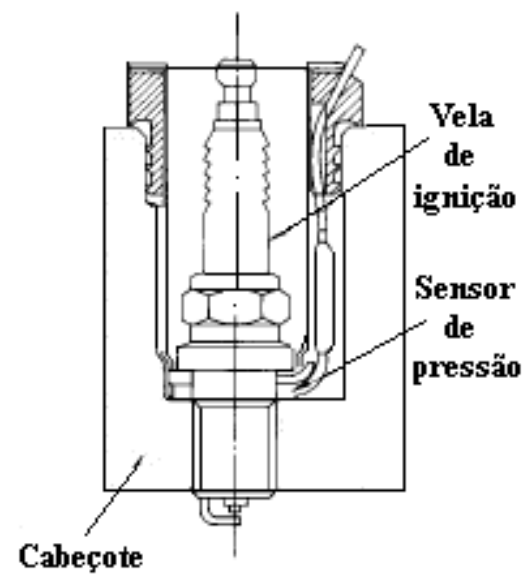

Figura 11 - Transdutor de pressão no cilindro não intrusivo.

Fonte: Hata et al. (1988). 
Tunestal (2000) fez uma classificação dos transdutores de pressão no cilindro quanto aos tipos de materiais utilizados na sua construção:

- transdutores de pressão constituídos por fibras ópticas, e

- transdutores de pressão constituídos por cristais piezelétricos.

Atkins et al. (1994) e Wlodarczyk et al. (1998) desenvolveram transdutores de pressão no cilindro empregando fibras ópticas. Estes transdutores diferem apenas quanto ao formato e quanto aos componentes geradores de luz (LED ou laser).

Nos transdutores desenvolvidos por Wlodarczyk et al. (1998) um LED gera luz que se propaga por uma fibra óptica até se encontrar com um diafragma metálico, que se deforma proporcionalmente à variação da pressão no cilindro. A luz refletida pelo referido diafragma retorna por outra fibra óptica até um fotodiodo onde é feita a sua captação. Um circuito eletrônico controla a intensidade da luz do LED, amplifica, filtra o sinal do fotodiodo e providencia uma função de referência entre a intensidade da luz refletida e a pressão no cilindro.

Os erros sistemáticos dos transdutores desenvolvidos por Wlodarczyk et al. (1998) (erros caracterizados pela medida de um valor constante, a mais ou a menos, sobre qualquer valor real da medida) são provocados por fenômenos mecânicos causados por stress térmico, envelhecimento e dobramento das fibras ópticas. Estes transdutores foram incorporados às velas de ignição dos motores e foi previsto apresentar custo relativamente baixo (estimado entre US\$7 e US\$9 cada) e boa durabilidade, porém, as pesquisas sobre suas aplicações nos sistemas de controle de motores ainda não são significativas.

Sellnau et al. (2000) e Berg et al. (1998) desenvolveram transdutores de pressão no cilindro constituídos por materiais piezelétricos que possuem a propriedade de gerar um sinal elétrico quando submetidos a uma variação de pressão. Quando uma força é aplicada ao cristal piezelétrico seus elétrons se redistribuem de tal forma que um dos seus lados fica positivo e o outro fica negativo. Sellnau et al. (2000) desenvolveram e testaram um transdutor piezelétrico de pressão no cilindro não intrusivo, acoplado à vela de ignição, enquanto Berg et al. (1998) desenvolveram transdutores intrusivos de pressão no cilindro por meio da utilização de dois compostos piezelétricos (carboneto de silício sobre um isolador, SiCOI, e silício sobre um isolador, SOI). Segundo Berg et al. (1998) estes compostos apresentam custos relativamente baixos, podendo viabilizar a utilização do sinal da pressão no cilindro nos sistemas eletrônicos de controle de motores. Os erros sistemáticos destes transdutores serão 
provocados por variações na temperatura (elevação da temperatura) e por efeitos associados à eletrônica dos amplificadores.

\subsubsection{Estimativa do erro sistemático e do drift do sinal dos transdutores de pressão no cilindro}

Gilkey e Powell (1985) propuseram um método de estimação do erro sistemático (erro caracterizado pelo valor constante, a mais ou a menos, sobre qualquer valor real da medida) e do drift (escorregamento do sinal provocado por variações nas características elétricas do amplificador de sinais) para os transdutores piezelétricos de pressão no cilindro.

Os efeitos que o erro sistemático ou o drift provocam nos transdutores de pressão no cilindro, de acordo com Gilkey e Powell (1985), estão associados a variações de temperatura sobre os transdutores ou sobre a eletrônica dos amplificadores de sinal. Apesar de provocarem pequenas alterações sobre a forma do sinal de pressão no cilindro, o erro sistemático e o drift afetam significativamente o cálculo dos momentos estatísticos (caracterizados como quantidades numéricas utilizadas para quantificar uma distribuição de frequências ou de probabilidades fornecendo informações resumidas destas distribuições).

A estimativa do erro sistemático e do drift reduz os requisitos de precisão e os custos dos transdutores de pressão no cilindro, sendo que esta estimativa pode ser feita utilizando o equacionamento a seguir, desenvolvido por Gilkey e Powell (1985).

Primeiramente, assume-se a hipótese de que a mistura ar-combustível é um gás perfeito submetido a uma compressão adiabática e internamente reversível (processo isoentrópico). Esta hipótese permite aplicar a lei dos gases ideais, de acordo com as equações (20) e (21).

$$
P(\theta)=m \stackrel{-}{R} \frac{T(\theta)}{V(\theta)}
$$

em que:

$$
\begin{aligned}
& P(\theta)=\text { pressão dentro do cilindro em }[\mathrm{Pa}] ; \\
& m=\text { massa de ar admitida no motor }[\mathrm{kg}] ; \\
& \bar{R}=\text { constante universal dos gases }[\mathrm{kJ} / \mathrm{kgK}] ; \\
& T(\theta)=\text { temperatura do ar admitido no motor }[\mathrm{K}], \mathrm{e} \\
& V(\theta)=\text { volume do ar admitido no motor }\left[\mathrm{m}^{3}\right] .
\end{aligned}
$$




$$
\frac{T(\theta)}{T_{1}}=\left(\frac{V_{1}}{V(\theta)}\right)^{K^{\prime}-1}
$$

em que:

$k^{\prime}=$ coeficiente politrópico da mistura ar-combustível (pode ser considerado aproximadamente igual a 1,3 para a gasolina tipo $A$, para mistura ar-combustível, ou igual a 1,4, considerando apenas o ar);

$V_{1}=$ volume antes da combustão em $\left[\mathrm{m}^{3}\right]$, e

$T_{1}=$ temperatura antes da combustão $[\mathrm{K}]$.

A combinação das equações (20) e (21) permite obter a equação (22).

$$
P(\theta)=\frac{a}{V(\theta)^{K}} ; a=m \stackrel{-}{R} T_{1} V_{1}^{K^{\prime}-1}
$$

Posteriormente assume-se a hipótese de que o transdutor de pressão tem um ganho $(G)$ e um erro sistemático (e/ou um drift) $\left(P_{\text {erro }}\right)$ desconhecido, de acordo com a equação (23).

$$
P(\theta)_{\text {medido }}=G P(\theta)+P_{\text {erro }}
$$

A combinação das equações (22) e (23) permite obter a equação (24).

$$
P(\theta)_{\text {medido }}=a G V(\theta)^{-K^{\prime}}+P_{\text {erro }}
$$

Sendo o volume da mistura ar-combustível $(V)$ uma função conhecida a partir do ângulo de manivela pode-se obter o termo $a G$ (que é uma estimativa das condições báricas da carga admitida no motor) e o erro sistemático $\left(P_{\text {erro }}\right)$ utilizando os dados de pressão no cilindro durante a fase de compressão do ciclo do motor, por meio de uma regressão linear. Esta regressão linear fornece dois coeficientes que representam os termos $a G$ e $P_{\text {erro }}$.

A subtração do termo $P_{\text {erro }}$ do sinal da pressão no cilindro elimina os efeitos do erro sistemático e do drift sobre o cálculo dos momentos. 


\subsection{ESTADO DA ARTE DA UTILIZAÇÃO DA PRESSÃO NO CILINDRO NOS SISTEMAS ELETRÔNICOS DE CONTROLE DE MOTORES OTTO}

Segundo Dudek e Sain (1989) os sistemas de controle de motores baseados no sinal da pressão no cilindro permitem controlar em malha fechada as "métricas" (ou taxas) obtidas a partir da forma do traço da pressão no cilindro e quantificar diversas variáveis do motor como, por exemplo, a relação ar-combustível (relação A/C) e o avanço do ponto da centelha, em uma faixa de controle muito maior do que os sistemas baseados nos sensores de oxigênio. Estes sistemas permitem que o motor opere próximo do limite de mistura ar-combustível pobre $(\lambda \approx 1,5)$, ou dentro de uma faixa de máxima economia de combustível, oferecendo substancial redução nas emissões de $C O$ e $N O_{x}$. O principal interesse em operar o motor no limite pobre, além da redução do consumo de combustível, é a possibilidade de redução das emissões de $N O_{x}$ a ponto de eliminar o sistema de RGE (recirculação de gases de exaustão) e o ródio (responsável pela redução dos óxidos de nitrogênio) como substrato dos catalisadores trivalentes. A eliminação do sistema de RGE permite simplificar os sistemas de controle, enquanto que a eliminação do ródio reduz os custos dos catalisadores.

As vantagens apresentadas pela utilização dos transdutores de pressão no cilindro em relação aos sensores de oxigênio levaram ao surgimento de novos sistemas de controle de motores baseados no sinal da pressão no cilindro.

Ribbens (1993) afirma que a evolução da pressão no cilindro durante o processo de combustão é a mais importante variável para a identificação das condições de operação dos motores de combustão interna. A medida da pressão no cilindro fornece um sinal em tempo real do processo de combustão que pode ser usado para o controle de diversas variáveis dos motores.

A Figura 12 apresenta um diagrama de blocos, elaborado por Ribbens (1993), que exibe algumas das possíveis utilizações da pressão no cilindro (detecção de knocking, controle da quantidade de RGE, determinação da relação $\mathrm{A} / \mathrm{C}$ e do avanço do ponto da centelha $A V$ ) dentro de um sistema eletrônico de controle de motores. 


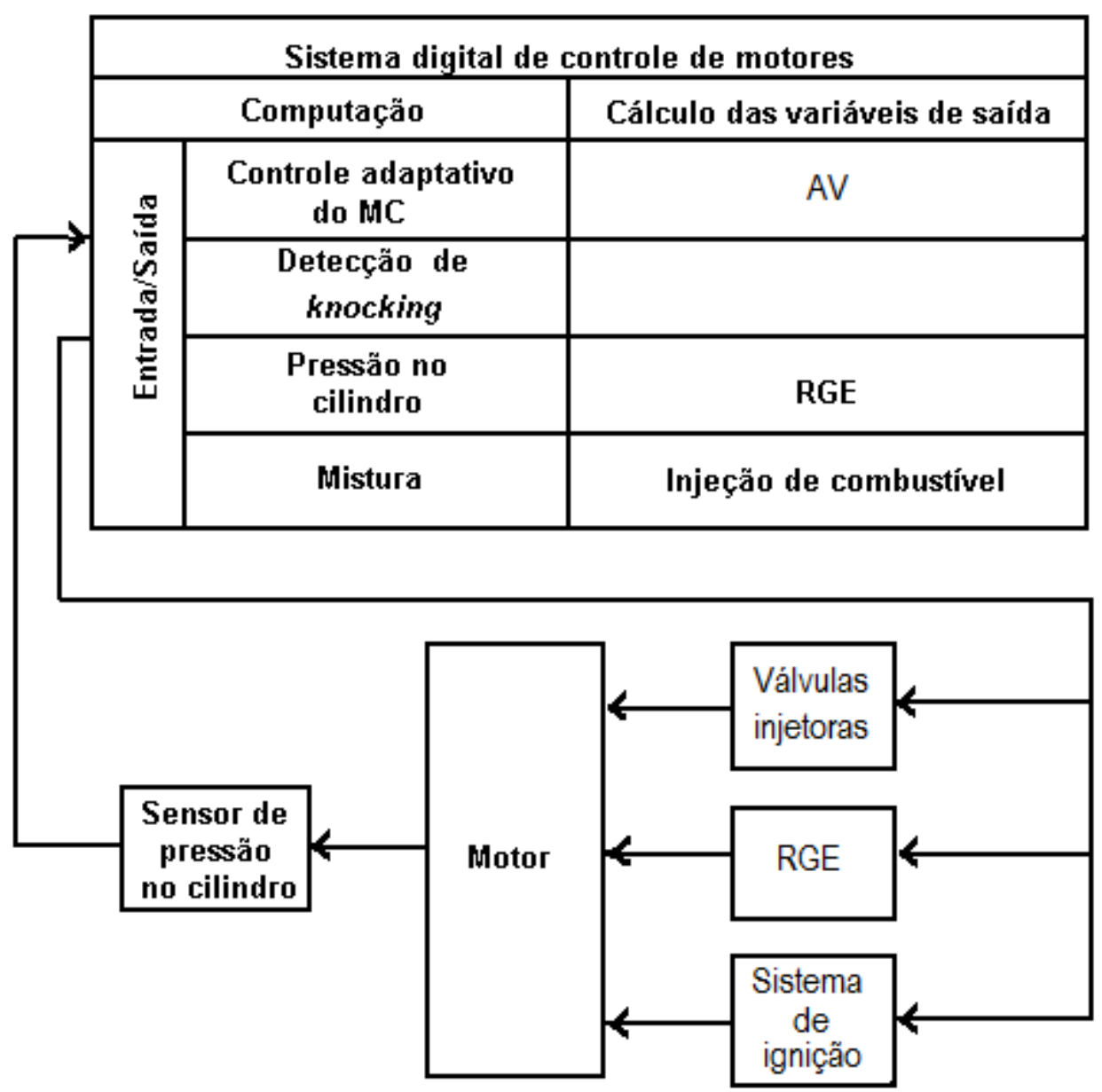

Figura 12 - Diagrama de blocos de um sistema de controle de motores baseado na medida da pressão no cilindro.

Fonte: Ribbens (1993).

Entre os beneficios da utilização do sinal da pressão no cilindro em um sistema eletrônico de controle de motores Otto, Müller e Isermann (2001) destacam:

- Controle do avanço da centelha;

- detecção de knocking;

- detecção de falhas na combustão e misfiring;

- determinação da posição angular da árvore de manivelas;

- controle da quantidade de recirculação de gases de exaustão ou sua substituição por meio do controle da mistura próxima do limite pobre;

- controle e balanceamento da relação A/C cilindro a cilindro;

- estimação da massa de ar admitida;

- obtenção do torque indicado;

- calibração simplificada do motor, e 
- maior economia de combustível.

Além dos beneficios enumerados por Müller e Isermann (2001), Hata et al. (1988) afirmam que o sinal da pressão no cilindro pode ser utilizado para estabelecer o limite de estabilidade (vibração tolerável pelos componentes mecânicos do motor) em que o motor pode operar em condições de mistura pobre. Este limite pode ser estabelecido por meio de uma análise estatística do pico de pressão, possibilitando o controle da relação $\mathrm{A} / \mathrm{C}$ no limite pobre sem comprometer a dirigibilidade e a durabilidade do motor.

Tunestal et al. (1999) verificaram que a pressão no cilindro permite controlar os motores durante a fase de aquecimento (warm-up) por meio de modelos baseados no calor liberado durante a combustão.

Yoon et al. (2000) concluíram que a localização do pico de pressão no cilindro é um parâmetro de identificação do avanço da centelha e que esse pico da pressão reflete os efeitos da variação da relação A/C durante a combustão.

Klein e Eriksson (2002), utilizando a pressão no cilindro conseguiram estimar a relação de compressão por meio de diferentes métodos em um motor com relação de compressão variável (Saab Variable Compression Engine).

Apesar das vantagens da utilização do sinal da pressão no cilindro em relação ao uso do sensor de oxigênio, os sistemas de controle eletrônico de motores baseados na pressão no cilindro têm se restringido ao campo das pesquisas acadêmicas devido ao custo elevado dos transdutores comerciais de pressão no cilindro. Porém, CONSUMERS... (2001, p.5) reporta que o consórcio AENEAS (ㅁpplication and Evaluation of a Novel Engine management system base on intelligent control Algorithms and utilising innovative Sensor technology $=\mathrm{em}$ tradução livre: aplicação e avaliação de um moderno sistema de gerenciamento de motores baseado em algoritmos inteligentes de controle e utilização de tecnologia inovadora de sensores), formado por Kistler Instruments (indústria de instrumentos de medição), DaimlerChrysler (indústria de automóveis) e Ricardo (centro independente de consultoria em engenharia automotiva), desenvolveu um sistema avançado de gerenciamento de motores baseado no sinal da pressão no cilindro, de tecnologia piezelétrica de baixo custo (constituídos de carboneto de silício sobre isolante, SiCOI, ou de silício sobre isolante, SOI).

O sistema de gerenciamento de motores apresentado na reportagem de CONSUMERS... (2001, p.5) foi avaliado em motores Otto e Diesel e, aplicado tanto em automóveis quanto em caminhões. Foram desenvolvidos algoritmos de controle e diagnóstico que permitiram a substituição de praticamente todos os sensores convencionais empregados atualmente 
naqueles motores por transdutores de pressão no cilindro. Estes algoritmos foram capazes de estimar a massa de ar admitida, identificar o melhor momento da centelha, controlar a relação ar-combustível (inclusive na fase de aquecimento do motor), diagnosticar falhas e ocorrência de knocking. Em contrapartida a aplicação dos algoritmos exigiu maiores recursos computacionais da UCE. Os resultados da aplicação do inovador sistema de gerenciamento foram redução do consumo de combustível, redução das emissões de poluentes, redução no desbalanceamento da relação A/C cilindro a cilindro - que proporcionaram uma operação mais suave do motor e consequentemente maior conforto ao motorista. A expectativa do custo do novo sistema de gerenciamento, considerando uma produção de 750 mil motores de quatro cilindros cada, é de 56 euros incluindo os quatro sensores de pressão e o aumento na capacidade de processamento da UCE, contra 67 euros do sistema tradicional constituído pelo sensor de oxigênio, sensor $K S$ e sensor de massa de ar.

CONSUMERS... (2001, p.5) não reportou os métodos de obtenção das variáveis do motor, baseados na pressão no cilindro, utilizados no sistema de gerenciamento dos motores.

Dudek e Sain (1989) afirmam que os modelos mais atuais orientados para controle de motores que utilizam a pressão no cilindro se apoiam em métodos (ou submodelos) de estimação da relação A/C a partir do traço da pressão no cilindro.

Yilmaz (2009) e Ahn et al. (2010) desenvolveram um sistema de gerenciamento eletrônico para um motor sobrealimentado com injeção direta de combustível e comando de válvulas variável tendo como base o sinal da pressão no cilindro. Este sistema de gerenciamento permite a identificação da quantidade de etanol na mistura combustível em função do resfriamento da carga, durante as fases de admissão e compressão, proporcionado pela diferença entre os calores latentes de vaporização das misturas combustíveis. O método utilizado por Yilmaz (2009) e Ahn et al. (2010) não se aplica a motores com injeção indireta no coletor (no pé da válvula de admissão) porque necessita de uma segunda injeção de combustível durante a fase de compressão do motor para coletar informações sobre o comportamento do traço da pressão no cilindro.

Ahn et al. (2010) verificaram que os sistemas de gerenciamento eletrônico de motores baseados no sinal do sensor de oxigênio apresentam erros entre 9 e 12,5\% na identificação do tipo de combustível (quantidade de etanol na mistura), enquanto que os sistemas baseados no sinal da pressão no cilindro podem reduzir estes erros para uma faixa entre 2,8 e $7 \%$.

Até o presente momento não há relatos da utilização do método dos momentos e da razão de pressões para a identificação do tipo de combustível e para estimação do fator $\lambda$ para misturas de combustíveis. 


\subsection{MOMENTOS ESTATÍSTICOS}

Os Momentos Estatísticos serão detalhados nesta seção, pois são a base dos modelos estatísticos desenvolvidos no presente estudo.

Manzoli (1959) afirma que as primeiras publicações sobre os momentos datam do século XIX e se referiam a problemas matemáticos do cálculo de probabilidades. O uso dos momentos não se restringe a estes problemas, pois pode ser empregado em praticamente todos os ramos da ciência. O nome "Momentos" originou-se da analogia entre as equações que definem o primeiro e segundo momentos de uma função e os conceitos de centro de gravidade e momento de inércia, respectivamente.

Os momentos podem ser caracterizados como quantidades numéricas utilizadas para quantificar uma distribuição de frequências ou de probabilidades fornecendo informações resumidas destas distribuições.

Mood e Graybill (1963) definem os momentos de ordem $n\left(M_{n}\right)$ de acordo com a equação (25). Os momentos centrados em um ponto (ou referência - $a$ ) arbitrário qualquer são definidos pela equação (26), enquanto que os momentos centrados na media são definidos pela equação (27). A média de $X$ é obtida pela equação (28). Os momentos de primeira ordem centrados na média são iguais a zero (MOOD; GRAYBILL, 1963).

$$
M_{n}=\int_{-\infty}^{+\infty} X^{n} f(X) d X
$$

em que:

$X=$ variável de interesse, $\mathrm{e}$

$Y=f(X)$.

$$
\begin{gathered}
M_{n}=\int_{-\infty}^{+\infty}(X-a)^{n} f(X) d X \\
M_{n}=\int_{-\infty}^{+\infty}(X-\bar{X})^{n} f(X) d X
\end{gathered}
$$




$$
\bar{X}=\frac{\int_{-\infty}^{+\infty}(X) f(X) d X}{\int_{-\infty}^{+\infty} f(X) d X}
$$

De acordo com Mood e Graybill (1963) se o eixo $X$ fosse uma barra com densidade variável, o momento de primeira ordem $\left(M_{1}\right)$ centrado em um ponto arbitrário seria o centro de gravidade desta barra, por isso o $M_{1}$ também é chamado de média da variável $X$, já que a média pode ser pensada como um valor central da variável $X$. Por esta razão $M_{1}$ é frequentemente referido como um parâmetro de localização, informando onde o centro da distribuição (no sentido de centro de gravidade) está sobre o eixo $X$.

Segundo Mood e Graybill (1963) o momento de segunda ordem $\left(M_{2}\right)$ centrado na média é conhecido como variância de $X$. A variância representa uma medida do espalhamento ou dispersão de uma distribuição. Se a maior parte da área sob a curva que representa a distribuição analisada estiver próxima da média, o valor de $M_{2}$ (ou a variância) será pequeno. Se a área sob a curva estiver esparramada em uma grande extensão, o valor de $M_{2}$ será grande. $M_{2}$ é necessariamente positivo uma vez que é a integral ou somatório de quantidades positivas. $M_{2}$ será zero somente quando a distribuição estiver concentrada em um único ponto como, por exemplo, quando a distribuição é discreta e só há um resultado possível. $M_{2}$ só fornece a informação de quanto a distribuição está próxima da média.

O momento de terceira ordem centrado na média $\left(M_{3}\right)$, de acordo com Mood e Graybill (1963) é conhecido como uma medida da assimetria (assimetria é o grau de deformação da distribuição em relação à média). $M_{3}$ será igual à zero para uma distribuição simétrica, porém outras distribuições não simétricas também resultam em $M_{3}$ igual à zero.

Mood e Graybill (1963) afirmam que um momento em particular ou um número pequeno de momentos fornecem poucas informações sobre a distribuição, enquanto que, um conjunto inteiro de momentos $\left(M_{1}, M_{2}, \ldots, M_{n}\right)$ determina exatamente uma distribuição, mesmo que não se tenha nenhuma informação prévia sobre ela.

Kuttatharmmakul et al. (2001) testaram os momentos estatísticos (método dos momentos - MM) e o método de máxima verossimilhança (MMV) para estimar a média e o desvio padrão de uma população normal com poucas e moderadas amostras. Os resultados mostraram que o MMV apresenta maior eficiência em relação ao MM, especialmente nas condições em que se têm poucas amostras. 
Porém, segundo Montgomery e Runger (2003) o método de máxima verossimilhança pode apresentar algumas complicações durante o seu uso e nem sempre é possível maximizar a função de verossimilhança para obter os parâmetros do estimador.

Portugal (2009) afirma que o grande obstáculo à utilização prática do método de máxima verossimilhança consiste na frequente incapacidade de se obter uma solução explícita para a maioria dos problemas em questão. Por este motivo o método dos momentos tem sido amplamente utilizado em estudos científicos atuais. Entre os exemplos encontrados na literatura destacam-se:

- Putko et al. (2001) implementaram uma aproximação do método dos momentos estatísticos para propagação de erros e otimização de um código de dinâmica dos fluídos computacional;

- Jindo, Hung e Nishitani (2003) calcularam quantidades termodinâmicas de metais e ligas por meio dos momentos estatísticos;

- Heim, Olejnik e Pawlak (2005) empregaram os momentos estatísticos para descrever o processo de moagem de matérias-primas usado em escala industrial na fabricação de azulejos;

- Dorini e Cunha (2008) utilizaram o método dos momentos para aproximar uma equação de transporte linear aleatória;

- Hung e Thanh (2011) investigaram a influência da temperatura e da pressão sobre as propriedades do dióxido de cério (também conhecido como óxido cérico $\mathrm{CeO}_{2}$ ) utilizando o método dos momentos estatísticos;

- Hung, Hai e Binh (2013) utilizaram o método dos momentos para estudar o comportamento das curvas de fusão de metais com defeitos em altas pressões e temperaturas variadas.

\subsection{ESTADO DA ARTE DOS MÉTODOS PARA ESTIMAÇÃO DA RELAÇÃO AR- COMBUSTÍVEL QUE UTILIZAM A PRESSÃO NO CILINDRO}

Nesta seção serão apresentados os principais métodos usados para obtenção da razão equivalente $\emptyset$ ou do fator $\lambda$ a partir do sinal da pressão no cilindro.

O traço da pressão no cilindro é afetado pela relação ar-combustível (relação A/C) assim como por outras variáveis do motor. Na literatura diversos trabalhos relatam métodos que permitem a separação dos efeitos da relação A/C dos outros efeitos sobre o traço da pressão 
no cilindro. Estes métodos permitem estimar o coeficiente de excesso de ar ( $\lambda$, ou fator $\lambda)$ ou a razão equivalente $(\varnothing)$.

Além dos métodos apresentados nas próximas seções, outros métodos utilizados para estimação da relação A/C podem ser analisados nos estudos apresentados por Fiorini, Gassenfeit e Powell (1988) e Chauvin et al. (2006), métodos estes que utilizam a transformada rápida de Fourier e o filtro de Kalman para estimar a relação A/C, respectivamente.

\subsubsection{Método dos momentos}

Gilkey e Powell (1985) utilizaram com sucesso os quatro primeiros momentos estatísticos para estimar a razão equivalente $(\varnothing)$. Estes momentos $\left(I_{0}, I_{1}, I_{2}\right.$ e $\left.I_{3}\right)$ foram centrados em uma referência arbitrária (ângulo da árvore de manivelas em que ocorre o momento da centelha, $\theta_{\text {ref }}$ ), como mostram as equações (29), (30), (31) e (32).

$$
I_{0}=\int_{\theta_{\text {inicial }}}^{\theta_{\text {fral }}}\left(P(\theta)-P_{\text {erro }}(\theta)\right) d \theta
$$

em que:

$I_{0}=$ momento estatístico;

$P(\theta)=$ pressão medida no cilindro;

$P_{\text {erro }}(\theta)=$ erro sistemático do sensor de pressão;

$\theta_{\text {inicial }}=$ ângulo da árvore de manivelas em que se inicia a coleta de dados, e

$\theta_{\text {final }}=$ ângulo da árvore de manivelas em que se encerra esta coleta.

$$
\begin{gathered}
I_{1}=\int_{\theta_{\text {ivicial }}}^{\theta_{\text {frial }}}\left(P(\theta)-P_{\text {erro }}(\theta)\right)\left(\theta-\theta_{\text {ref }}\right) d \theta \\
I_{2}=\int_{\theta_{\text {inicial }}}^{\theta_{\text {frual }}}\left(P(\theta)-P_{\text {erro }}(\theta)\right)\left(\theta-\theta_{\text {ref }}\right)^{2} d \theta
\end{gathered}
$$




$$
I_{3}=\int_{\theta_{\text {inicial }}}^{\theta_{\text {final }}}\left(P(\theta)-P_{\text {erro }}(\theta)\right)\left(\theta-\theta_{\text {ref }}\right)^{3} d \theta
$$

As integrais que compõe os momentos foram calculadas por somas de Riemann.

$\mathrm{O}$ segundo e o terceiro momento $\left(I_{2}\right.$ e $\left.I_{3}\right)$ foram trocados por momentos $\left(M_{2}\right.$ e $\left.M_{3}\right)$

centrados em $\bar{\theta}$, como mostram as equações (33), (34) e (35). Estas trocas evitam que os efeitos da escolha de uma posição angular de referência arbitrária determinem um mesmo valor dos momentos para formas diferentes do traço da pressão no cilindro.

$$
\begin{gathered}
\bar{\theta}=\frac{I_{1}}{I_{0}} \\
M_{2}=I_{2}-2 \bar{\theta} I_{1}+\bar{\theta}^{2} I_{0} \\
M_{3}=I_{3}-3 \bar{\theta} I_{2}+3 \bar{\theta}^{3} I_{0}
\end{gathered}
$$

Gilkey e Powell (1985) concluíram que a pressão no cilindro é fortemente influenciada pela relação A/C nas fases de compressão e expansão do ciclo motor. Dentro destas fases foi criada uma "janela" de dados da pressão no cilindro para computação dos momentos. Esta janela compreende os dados da pressão no cilindro a partir do ângulo da árvore de manivelas em que ocorre o disparo da centelha $(\varphi)$ até $120^{\circ}$ após o disparo da centelha $\left(\varphi+120^{\circ}\right)$.

Os momentos computados por Gilkey e Powell (1985) foram normalizados para evitar que variações na magnitude do traço da pressão no cilindro, provocadas por alterações no ganho dos sensores, fossem interpretadas como mudanças ocorridas nas variáveis do motor. Entre os métodos de normalização avaliados, a área da pressão de acionamento foi a que forneceu os melhores resultados, produzindo momentos que variavam linearmente com as variáveis do motor, principalmente com relação a $\emptyset$.

A curva da pressão de acionamento (curva de pressão dentro do cilindro sem a ocorrência de combustão), o momento normalizado (por exemplo, $M_{2}$ normalizado - $M_{2}^{\prime}$ ) e a área abaixo da curva da pressão de acionamento foram obtidas pelas equações (36), (37) e (38), respectivamente. 


$$
P(\theta)_{\text {acionameno }}=a G V(\theta)^{-k}
$$

em que:

$P(\theta)_{\text {acionamento }}=$ pressão de acionamento $[\mathrm{Pa}] ;$

$a G=$ termo proporcional à pressão no coletor de admissão;

$V=$ volume varrido $\left[\mathrm{m}^{3}\right]$;

$\theta=$ ângulo da árvore de manivelas [graus], e

$k^{\prime}=$ coeficiente politrópico da mistura ar-combustível.

$$
A_{\text {acio }}=a G \int_{\theta_{\text {inicial }}}^{\theta_{\text {frinal }}} V(\theta)^{-k} d \theta
$$

em que:

$A_{\text {acio }}=$ área debaixo da curva de acionamento.

$$
M_{2}^{\prime}=\frac{M_{2}}{A_{\text {acionameno }}}
$$

Entre as formulações propostas por Gilkey e Powell (1985) para estimar $\varnothing$, a que apresentou melhor resultado foi a combinação linear entre os momentos normalizados de segunda e terceira ordem com a rotação do motor e a pressão no coletor de admissão, como mostra a equação (39).

$$
\phi, \phi^{*}=a_{1} N+a_{2} P_{c o l}+a_{3} M_{2}+a_{4} M_{3}+a_{5}
$$

em que:

$\emptyset=$ razão equivalente;

$\emptyset^{*}=$ razão equivalente considerando a recirculação de gases de exaustão;

$N=$ rotação do motor;

$M_{2}=$ momento de segunda ordem;

$M_{3}=$ momento de terceira ordem;

$P_{c o l}=$ pressão no coletor de admissão estimada pelo termo $a G$ que é diretamente relacionado com a pressão do ar na entrada do motor, e 
$a_{1}, a_{2}, a_{3}, a_{4}$ e $a_{5}=$ coeficientes da regressão linear múltipla.

A equação (39) apresentou um erro rms (erro médio quadrático ou root mean square error) na estimativa de $\emptyset$ e de $\emptyset^{*}$ nas condições ensaiadas por ciclo a ciclo de 0,052 e 0,0291, respectivamente (GILKEY; POWELL, 1985). O erro $r m s$ considerando a média de 20 ciclos do motor foi de 0,0487 na estimativa de $\varnothing$ e de 0,0219 na estimativa de $\varnothing^{*}$.

Gilkey e Powell (1985) justificaram que o modelo descrito pela equação (39) pode ter o erro rms elevado a 0,080 devido a erros na medição da posição da árvore de manivelas. Estes erros adicionariam um $P_{\text {erro }}$ desconhecido no cálculo dos momentos. Porém, segundo aqueles autores o modelo poderia ser recalibrado utilizando um sensor de oxigênio (sonda lambda), para identificar o valor de $\varnothing$ para as misturas estequiométricas, ou por um método de estimação do pico da pressão no cilindro que permitisse alcançar facilmente uma resolução de $1^{\circ}$ na posição angular da árvore de manivelas, dispensando a utilização do sensor de oxigênio.

O modelo para estimação de $\emptyset$, sem corrigir os erros na medida da posição da árvore de manivelas, foi implementado por Gilkey e Powell (1985) em um microprocessador Intel 8096 (com micro controlador MCS 96) de $12 \mathrm{MHz}$ e sua execução consumiu 4 ms, para um motor monocilindro, o que comprova a possibilidade de implementação deste modelo, uma vez que um ciclo de trabalho a $5000 \mathrm{rpm}$ ocorre em $24 \mathrm{~ms}$.

O Método dos Momentos também foi estudado por Arsie, Pianese e Rizzo (1998), Costa (2005) e Arsie et al. (2014).

Costa (2005) produziu algoritmos para calcular os momentos em qualquer ordem desejada, para normalização dos momentos por diversos métodos e para calcular regressões lineares múltiplas de modo a obter os modelos lineares de estimação de $\emptyset$ ou do fator $\lambda$.

Sellnau et al. (2000) apontam que o Método dos Momentos não foi estendido para a estimação de outras variáveis do motor, como, por exemplo, o avanço do ponto da centelha.

\subsubsection{Método da razão de pressões}

A literatura indica que a energia adicionada pela combustão do combustível pode ser um bom indicador da razão equivalente $(\varnothing)$ ou do fator $\lambda$. Uma das maneiras de medir esta energia foi reportada por Powell (1993), por meio da razão entre dois trechos distintos do traço da pressão no cilindro. O primeiro trecho deve ser tomado no tempo de compressão do motor, enquanto que o segundo trecho deve ser tomado no tempo de expansão do motor. Os 
dois trechos do traço da pressão no cilindro devem ser tomados em posições angulares simétricas da árvore de manivelas.

A razão entre estes dois trechos do traço da pressão no cilindro foi denominada como razão de pressões $(T P)$, como mostra a equação (40).

A razão de pressões está diretamente relacionada com a fração de massa queimada $(F M Q)$ durante a combustão, como mostra a equação (41).

$$
\begin{gathered}
T P=\frac{\text { trecho do } \text { traço }}{\text { trecho }} \text { do } \text { traço } d a \quad \text { pressão no cilindro (exp ansão) } \\
\text { pressão no cilindro (compressão) } \\
F M Q=T P-1
\end{gathered}
$$

Gassenfeit e Powell (1989) analisaram o método da razão de pressões propondo a equação (42). Os trechos do traço da pressão no cilindro foram tomados entre $60 \mathrm{e}$ $120^{\circ}$ APMS (antes do ponto morto superior), durante o tempo de compressão, e entre 60 e $120^{\circ}$ DPMS (depois do ponto morto superior), durante o tempo da expansão, obtendo-se um valor médio da razão de pressões. O erro sistemático do sensor de pressão no cilindro e o termo $a G$ (designados pelos autores como $P_{c o l}$ ) foram estimados de acordo com as formulações apresentadas na seção 2.6.1 do Capítulo 2, intitulada Estimativa do erro sistemático e do drift do sinal dos transdutores de pressão no cilindro.

$$
\phi=a_{1} N+a_{2} P_{c o l}+a_{3} T P+a_{4}
$$

em que:

$\emptyset=$ razão equivalente;

$N=$ rotação do motor;

$P_{c o l}=$ pressão no coletor de admissão estimada pelo termo $a G$ que é diretamente relacionado com a pressão do ar na entrada do motor;

$T P=$ razão de pressões, e

$a_{1}, a_{2}, a_{3}, a_{4}$ e $a_{5}=$ coeficientes da regressão linear múltipla.

Os resultados na estimação de $\emptyset$, de acordo com Gassenfeit e Powell (1989), utilizando uma média de 10 ciclos de pressão no cilindro (10 ciclos de trabalho do motor) para diversas condições de operação do motor, apresentaram um erro de $2,4 \%$ na faixa de $0,8<\emptyset<1,1$. Já o erro apresentado ciclo a ciclo (ciclos de trabalho do motor considerados individualmente) 
aumentou para 3,3\%, utilizando uma amostragem de pressão a cada 2 graus de giro da árvore de manivelas, e para 4\%, utilizando uma amostragem de pressão a cada 16 graus de giro da árvore de manivelas.

Powell (1993) comparou os resultados fornecidos pelos métodos dos momentos e da razão de pressões, considerando que a recirculação dos gases de exaustão foi prevista nestes dois algoritmos, e concluiu que o erro na estimativa de $\varnothing$ ciclo a ciclo utilizando o método da razão de pressões foi aproximadamente $20 \%$ maior do que utilizando o método dos momentos. Porém, o esforço de computação requerido pelo método dos momentos foi 10 vezes maior do que o requerido pelo método da razão de pressões.

Diversas aplicações e variantes do método da razão de pressões, para controle da relação A/C podem ser encontradas na literatura como, por exemplo, os estudos realizados por Leonhardt, Müller e Isermann (1999) e por Sellnau et al. (2000). No presente trabalho o método dos momentos será aplicado, originalmente, nas curvas geradas pelo método da razão de pressões.

\subsubsection{Método do peso molecular}

As informações apresentadas nesta seção baseiam-se nos estudos realizados por Patrick e Powell (1990) que desenvolveram um método para estimar a razão equivalente $(\varnothing)$ que é insensível a variações na temperatura da mistura ar-combustível. Este método depende apenas da composição química do combustível, ou mais precisamente, da proporção de átomos de hidrogênio para os de carbono $(H / C)$. Quando ocorre a combustão o número de moléculas do produto da combustão aumenta em relação ao número de moléculas da mistura arcombustível e, consequentemente, o peso molecular $\left(G_{m}\right)$ também se altera.

A equação (43) comprova esse aumento considerando-se a combustão completa da gasolina típica $\left(C_{8} H_{18}\right)$ em que o número de moléculas aumenta de 59,5 para 64. Essa variação no número de moléculas depende da relação $\mathrm{A} / \mathrm{C}$, da composição do combustível e da reação de combustão ser ou não completa.

$$
\mathrm{C}_{8} \mathrm{H}_{18}+12,5 \mathrm{O}_{2}+12,5(3,76) \mathrm{N}_{2} \rightarrow 8 \mathrm{CO}_{2}+9 \mathrm{H}_{2} \mathrm{O}+47 \mathrm{~N}_{2}
$$

Considerando a mistura ar-combustível como um gás ideal, pode-se calcular o número de moles antes e depois da combustão a partir da pressão no cilindro, da temperatura antes e depois da combustão e da aplicação da lei dos gases ideais. As medições da pressão no 
cilindro e da temperatura nos coletores de admissão e escape antes e depois da combustão são feitas em posições angulares simétricas, antes e depois do PMS, ou seja, o volume da mistura ar-combustível é constante. A equação (44) mostra a relação obtida aplicando a lei dos gases ideais antes e depois da combustão considerando o volume constante.

$$
\frac{n_{m 1}}{n_{m 2}}=\frac{P_{1} \cdot T_{2}}{P_{2} \cdot T_{1}}
$$

em que:

$n_{m l}=$ número de moles antes da combustão;

$n_{m 2}=$ número de moles depois da combustão;

$P_{1}=$ pressão no cilindro antes da combustão;

$P_{2}=$ pressão no cilindro depois da combustão;

$T_{1}=$ temperatura no coletor de admissão, e

$T_{2}=$ temperatura no coletor de escape;

Assumindo que a massa $(m)$ contida dentro do cilindro não varia ao longo de todo o processo, pode-se considerar que a razão do número de moles é equivalente à razão média dos pesos moleculares, comparados antes e depois da combustão, como mostra a equação (45). A partir da razão dos pesos moleculares pode-se estimar a razão equivalente $(\varnothing)$ por meio de uma regressão linear múltipla.

$$
\frac{G_{m 2}}{G_{m 1}}=\frac{m / n_{m 2}}{m / n_{m 1}}=\frac{n_{m 1}}{n_{m 2}}
$$

O método dos Pesos Moleculares, de acordo com Patrick e Powell (1990), apresentou um erro de 4,85\% na faixa de $0,8<\emptyset<1,3$, utilizando uma média de 10 ciclos para diversas condições de operação do motor. Patrick e Powell (1990) apontaram as variações na composição do combustível e incertezas na quantidade de RGE como candidatas às principais fontes de erros deste algoritmo.

Powell (1993) analisou os resultados desse método e verificou que o seu desempenho poderia ser significativamente melhorado por meio da inclusão de um algoritmo de estimação da temperatura da mistura ar-combustível dentro do cilindro. 


\subsubsection{Método do calor liberado}

Esta seção se baseia nos estudos realizados por Tunestal et al. (2003) que desenvolveram um método para estimar a relação A/C em função do calor liberado pela combustão. Foram elaborados dois modelos de velocidade de chama, um laminar e o outro turbulento, aos quais foi incorporado o calor liberado pela combustão. Após um extenso equacionamento matemático foi obtida uma relação direta com a relação ar-combustível, como mostra a equação (46).

$$
A / C=c \frac{\Delta \theta_{b}}{Q_{\text {total }}} p_{0}^{1+\mu} T_{0}^{\beta-1} N^{-\eta}
$$

em que:

$c, \mu, \beta$ e $\eta=$ coeficientes da regressão linear múltipla;

$\Delta \theta_{b}=$ deslocamento do ângulo da árvore de manivelas desde o início até o final do processo de queima do combustível;

$Q_{\text {total }}=$ calor total liberado durante a combustão;

$p_{0}=$ pressão no cilindro durante a admissão;

$T_{0}=$ temperatura no cilindro durante a admissão, e

$N=$ rotação do motor.

Um dos diferenciais desse método é a utilização de dois métodos para estimação do erro sistemático do sensor de pressão no cilindro que admitem, como hipótese, o tempo de compressão como um processo politrópico. O primeiro método considera o coeficiente politrópico $\left(k^{\prime}\right)$ conhecido, sendo que o modelo de estimação acaba sendo o resultado de uma aproximação linear obtida pelo método dos mínimos quadrados. No segundo método $k$ é uma incógnita e é estimado por uma aproximação não linear obtida pelo método dos mínimos quadrados não lineares. Também foi utilizado o método das diferenças finitas de Newton para simplificar os cálculos das derivadas existentes neste modelo de estimação. O segundo método é mais exato que o primeiro, uma vez que o valor de $k^{\prime}$ (razão entre os calores específicos) varia de acordo com a temperatura da mistura ar-combustível.

Os resultados obtidos com o método do calor liberado apresentaram um erro de $4 \%$ na estimativa da A/C. Porém, para valores da mistura A/C acima de 18 a estimativa sofreu um forte desvio, devido à proximidade com o limite de mistura pobre. 


\subsubsection{Método do torque indicado}

Müller e Isermann (2001) desenvolveram um método de estimação de $\lambda$ baseado na avaliação da pressão média indicada $(p m i)$ ou do torque indicado proporcional $\left(p m i \sim\right.$ Tor $\left._{i}\right)$, ambos calculados nos tempos de compressão e expansão. O valor de $\lambda$ (equação (47)) é obtido

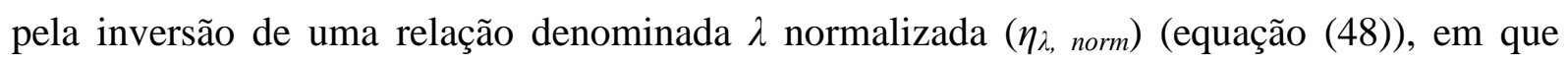
$\bar{T}_{i}$ é o torque indicado e $\overline{\text { Tor }}_{\text {otimo }}$ é o torque indicado ótimo, ambos obtidos da média dos torques de todos os cilindros (ou de cilindro a cilindro).

$$
\begin{gathered}
\eta_{\lambda, \text { norm }}=\frac{\overline{\text { Tor }}_{i}}{\overline{\overline{T o r}_{\text {ótimo }}}} \\
\lambda=\frac{1}{\eta_{\lambda, \text { norm }}}
\end{gathered}
$$

O $\overline{T o r}_{\text {ótimo }}$ é obtido de dados experimentais, considerando $\lambda$ igual a 1 e ponto da centelha ótimo (MBT), por meio de duas variáveis de entrada, massa de ar no cilindro (carga) e rotação do motor $(N)$. O $\overline{\text { Tor }}_{i}$ pode ser calculado por meio dos dados fornecidos pelos transdutores de pressão no cilindro. A eficiência de $\lambda$ normalizada ( $\lambda$-Eficiência) é uma função de $\eta_{\lambda, \text { norm }}$, que só pode ser invertida para $\lambda>0,9$, restringindo a faixa de estimação da relação A/C para valores de $\lambda$ maiores que 0,9 .

Este método apresentou, nas condições ensaiadas, boa precisão na estimação e balanceamento da relação $\mathrm{A} / \mathrm{C}$ cilindro a cilindro, para $\lambda>0,9$. Diferencia-se dos métodos anteriores por não propor a substituição do sensor de oxigênio (sonda lambda), mas sim de utilizá-lo em conjunto com os sensores de pressão no cilindro, auxiliando a obtenção do torque indicado à medida que o motor sofre desgastes não previstos nos experimentos que deram origem aos dados de torque ótimo.

\subsubsection{Análise comparativa dos métodos de estimação apresentados}

Comparando-se os métodos descritos nas seções 2.9.1 a 2.9.5 infere-se que o método dos momentos se destaca em relação aos outros métodos apresentados devido a sua maior exatidão na estimação da relação ar-combustível. Apesar de ser mais exigente quanto aos 
requisitos computacionais do que o método da razão de pressões, ele é bem menos exigente do que o método do calor liberado e já foi implementado com sucesso em um sistema de controle baseado na pressão no cilindro por Gilkey e Powell (1985).

No presente trabalho o método dos momentos será utilizado para obter modelos de estimação do fator $\lambda$ e da fração mássica de etanol (FMDE - identificação do tipo de combustível). Este método também será aplicado à curva obtida pelo método da razão de pressões durante a obtenção dos modelos de estimação do fator $\lambda$ e da $F M D E$.

\subsection{CONCEITOS FUNDAMENTAIS DA ESTATÍSTICA E TÉCNICAS ESTATÍSTICAS DE ANÁLISE RELEVANTES AO PRESENTE TRABALHO}

Os modelos estatísticos estão compreendidos dentro da Estatística Descritiva, que permite descrever um determinado fenômeno por meio do cálculo de alguns coeficientes que constituem o modelo estatístico do fenômeno. Porém, para a construção de um modelo estatístico é necessário seguir alguns passos e conhecer alguns conceitos e definições fundamentais, que serão descritos nas próximas subseções juntamente com uma breve revisão teórica.

\subsubsection{Variáveis aleatórias}

Segundo Montgomery e Runger (2003) uma variável aleatória é uma função que confere um número real a cada resultado no espaço amostral de um experimento.

Montgomery e Runger (2003) explicam que a variável aleatória pode ser contínua quando tem um intervalo (finito ou infinito) de números reais para sua faixa como, por exemplo, medidas de comprimento, tensão e temperatura, ou pode ser discreta quando tem uma faixa finita (ou infinita contável), como por exemplo, o número de arranhões em uma superfície.

Montgomery e Runger (2003) afirmam que em alguns casos em que a variável aleatória é discreta, porém com uma faixa de valores possíveis muito grande, pode-se analisar esta variável como sendo uma variável aleatória contínua.

Quanto à pressão no cilindro pode-se inferir que se trata de uma variável aleatória contínua, mas que durante o processo de medição e aquisição são coletados valores discretos da pressão no cilindro. 


\subsubsection{Medidas de posição e dispersão}

A principal medida de posição é a média amostral $(\bar{x})$.

Montgomery e Runger (2003) definem a média amostral como uma medida de localização e tendência central dos dados da amostra (subconjunto de observações selecionadas a partir de uma população), como mostra a equação (49).

$$
\bar{x}=\frac{\sum_{i=1}^{n} x_{i}}{n}
$$

em que:

$n=$ número de elementos da amostra de dados $x_{i}$

Quanto às medidas de dispersão ou variabilidade destacam-se o desvio padrão $(\sigma)$ e a variância amostral $\left(\sigma^{2}\right)$.

Montgomery e Runger (2003) definem a variância amostral e o desvio padrão da amostra de acordo com as equações (50) e (51), respectivamente. Quanto maior for a variância maior será a variabilidade da amostra.

$$
\begin{gathered}
\sigma^{2}=\frac{\sum_{i=1}^{n}\left(x_{i}-\bar{x}\right)^{2}}{n-1} \\
\sigma=\sqrt{\frac{\sum_{i=1}^{n}\left(x_{i}-\bar{x}\right)^{2}}{n-1}}
\end{gathered}
$$

\subsubsection{Análise de variância ou ANOVA}

Os conceitos e informações presentes nesta seção se referem aos estudos apresentados por Montgomery e Runger (2003).

A análise de variância (ANOVA) é utilizada para comparar médias quando houver mais de dois níveis em um único fator. 
ANOVA é muito utilizada para análise de dados experimentais.

Nesta seção será descrito o procedimento de ANOVA para dois fatores. ANOVA para outros números de fatores é encontrada em detalhes em Montgomery e Runger (2003).

A Tabela 7 apresenta o arranjo de um experimento com dois fatores $A$ e $B$ e vários níveis, chamados de tratamentos, $a$ e $b$. Cada nível, ou tratamento, dos dois fatores recebe como resposta uma variável aleatória $\left(x_{i j \psi}\right)$. Neste caso o número de repetições do experimento, $n$, é igual nos dois tratamentos. A coleta dos dados deve ser feita de forma aleatória.

Tabela 7 - Arranjo dos dados observados em um experimento com dois fatores.

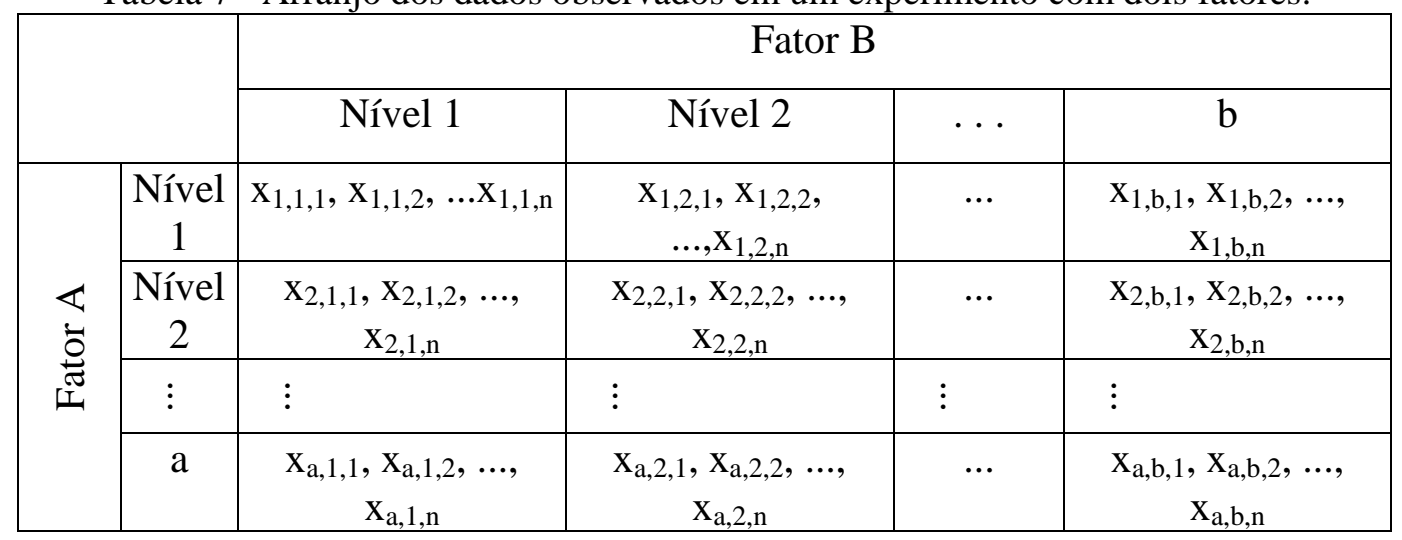

As observações da Tabela 7 podem se descritas pelo modelo linear estatístico apresentado pela equação (52).

$$
x_{i j \psi}=\mu+A_{i}+B_{j}+(A B)_{i j}+\varepsilon_{i j \psi}
$$

em que:

$$
\begin{aligned}
& x_{i j \psi}=\text { variável aleatória referente à } i j \psi \text {-ésima observação; } \\
& \mu=\text { média global; } \\
& A_{i}=\text { efeito do } i \text {-ésimo tratamento do fator } A ; \\
& B_{j}=\text { efeito do } j \text {-ésimo tratamento do fator } B ; \\
& (A B)_{i j}=\text { efeito da interação entre } A \text { e } B \\
& \varepsilon_{i j \psi}=\text { componente do erro aleatório; } \\
& i=1,2, \ldots, a \\
& j=1,2, \ldots, b, \text { e } \\
& \psi=1,2, \ldots, n .
\end{aligned}
$$

Supondo que os fatores $A$ e $B$ sejam fatores fixos, ou seja, os níveis $a$ e $b$ são especificamente escolhidos pelo experimentalista e as interferências estão restritas somente a 
estes níveis, a análise de variância poderá ser usada para testar as hipóteses sobre os efeitos principais dos fatores $A$ e $B$ e a interação $A B$ considerando o modelo linear estatístico como sendo um modelo de efeitos fixos.

As hipóteses testadas são:

1. Hipóteses para o fator $A$ :

$$
\begin{array}{ll}
H_{0}: A_{1}=A_{2}=\ldots=A_{a}=0 & \text { (nenhum efeito principal do fator } A \text { ); } \\
H_{1}: \text { no mínimo um } A i \neq 0 & \text { (fator } A \text { afeta a variável aleatória). }
\end{array}
$$

2. Hipóteses para o fator $B$ :

$$
\begin{array}{ll}
H_{0}: B_{1}=B_{2}=\ldots=B_{a}=0 & \text { (nenhum efeito principal do fator } B \text { ); } \\
H_{1}: \text { no mínimo um } B j \neq 0 & \text { (fator } B \text { afeta a variável aleatória). }
\end{array}
$$

3. Hipóteses para interação entre os fatores $A B$ :

$$
H_{0}:(A B)_{11}=(A B)_{12}=\ldots=(A B)_{a b}=0 \quad \text { (nenhum efeito principal da }
$$

interação do fator $A$ com o fator $B$ );

$H_{1}$ : no mínimo um $(A B)_{i j} \neq 0$ (interação $A B$ afeta a variável aleatória).

em que:

$H_{0}=$ hipótese nula;

$H_{1}=$ hipótese alternativa;

Índices $1,2, i$ e $j=$ representam os níveis dos fatores (tratamentos).

Analisando as hipóteses formuladas para realização da ANOVA, pode-se constatar que ela permite verificar se os efeitos dos fatores $A$ e $B$ são significativos sobre a variável aleatória e se existe interação entre os efeitos destes fatores.

Para obter as somas dos quadrados é necessário efetuar alguns somatórios e obter algumas médias.

As equações (53), (54), (55) e (56), respectivamente, representam a soma das observações no $i$-ésimo tratamento do fator $A\left(x_{i . .}\right)$, a soma das observações no $j$-ésimo tratamento do fator $B(x . j$.$) , a soma das observações na i j$-ésima célula da Tabela 7 (xij.) e a soma de todas as observações $(x \ldots)$.

$$
x_{i . .}=\sum_{j=1}^{b} \sum_{\psi=1}^{n} x_{i j k} \quad i=1,2, \ldots, a
$$




$$
\begin{gathered}
x_{. j .}=\sum_{i=1}^{a} \sum_{\psi=1}^{n} x_{i j k} \quad j=1,2, \ldots, b \\
x_{i j .}=\sum_{\psi=1}^{n} x_{i j k} \quad i=1,2, \ldots, a \text { e } j=1,2, \ldots, b \\
x_{\ldots}=\sum_{i=1}^{a} \sum_{j=1}^{b} \sum_{\psi=1}^{n} x_{i j \psi}
\end{gathered}
$$

As médias das linhas $\left(\bar{x}_{i . .}\right)$, das colunas $\left(\bar{x}_{. j .}\right)$, das células $\left(\bar{x}_{i j .}\right)$ e a média global $\left(\bar{x}_{\ldots}\right)$ são apresentadas pelas equações (57), (58), (59) e (60), respectivamente.

$$
\begin{gathered}
\bar{x}_{i . .}=\frac{x_{i . .}}{b n} \quad i=1,2, \ldots, a \\
\bar{x}_{. j .}=\frac{x_{. j .}}{a n} \quad j=1,2, \ldots, b \\
\bar{x}_{i j .}=\frac{x_{i j .}}{n} \quad i=1,2, \ldots, a \text { e } j=1,2, \ldots, b \\
\overline{\mathrm{x}}_{\ldots}=\frac{x_{\ldots .}}{a b n}
\end{gathered}
$$

A soma dos quadrados total, $S Q T$, pode ser escrita de acordo com a equação (61).

$$
S Q T=S Q A+S Q B+S Q A B+S Q E
$$

em que:

$S Q A=$ soma dos quadrados devido às linhas ou fator $A$;

$S Q B=$ soma dos quadrados devido às colunas ou fator $B$;

$S Q A B=$ soma dos quadrados devido à interação entre $A$ e $B, \mathrm{e}$

$S Q E=$ soma dos quadrados devido ao erro.

As equações (62), (63), (64) e (65) representam $S Q T, S Q A, S Q B$ e $S Q A B$, respectivamente. 


$$
\begin{gathered}
S Q T=\sum_{i=1}^{a} \sum_{j=1}^{b} \sum_{\psi=1}^{n} x_{i j \psi}^{2}-\frac{x_{\ldots}^{2}}{a b n} \\
S Q A=\sum_{i=1}^{a} \frac{x_{i . .}^{2}}{b n}-\frac{x_{\ldots}^{2}}{a b n} \\
S Q B=\sum_{j=1}^{b} \frac{x_{. j .}^{2}}{a n}-\frac{x_{\ldots}^{2}}{a b n} \\
S Q A B=\sum_{i=1}^{a} \sum_{j=1}^{b} \frac{x_{i j}^{2}}{n}-\frac{x_{\ldots}^{2}}{a b n}-S Q A-S Q B
\end{gathered}
$$

A soma dos quadrados do erro pode ser obtida utilizando a equação (66).

$$
S Q E=S Q T-S Q A-S Q B-S Q A B
$$

O número total de graus de liberdade é dado por ( $\left.\mathrm{a}^{*} \mathrm{~b}^{*} \mathrm{n}-1\right)$. Os fatores $A$ e $B$ possuem $(a$ 1) e $(b-1)$ graus de liberdade, respectivamente. O efeito da interação $A B$ possui $(a-1)(b-1)$ graus de liberdade. Dentro de cada uma das $a b$ células da Tabela 7 existem $(n-1)$ graus de liberdade entre as $n$ repetições. As observações dentro de cada célula podem diferir somente devido ao erro aleatório. O erro possui $a^{*} b *(n-1)$ graus de liberdade.

Os quadrados médios são obtidos dividindo-se cada soma dos quadrados pelo seu respectivo número de graus de liberdade.

A Tabela 8 sintetiza o procedimento de aplicação da análise de variância para um planejamento com dois fatores.

Tabela 8 - Análise de variância para um planejamento com dois fatores.

\begin{tabular}{lcccc}
\hline Fonte de Variação & SQs & GL & MQs & F \\
\hline Tratamento A & SQA & $a-1$ & SQA/(a-1) & MQA/MQE \\
Tratamento B & SQB & $b-1$ & SQB/(b-1) & MQB/MQE \\
Interação AB & SQAB & $(a-1)(b-1)$ & SQAB/(a-1)(b-1) & MQAB/MQE \\
Erro & SQE & $a b(n-1)$ & SQE/ab(n-1) & \\
Total & SQT & $a b n-1$ & & \\
\hline
\end{tabular}


A estatística de teste $F$, obtida na ANOVA, deve ser maior que o valor crítico $F_{\text {crítico, }}$, obtido nas tabelas da distribuição $F$, para que os fatores apresentem efeitos significativos sobre a variável aleatória em estudo.

\subsubsection{Procedimento de Tukey}

Segundo Benjamini e Braun (2002) o procedimento de Tukey aborda o problema de comparações múltiplas. Neste procedimento são analisados diversos grupos de médias (níveis de um fator). Considerando que todos estes grupos foram retirados de uma população de média, $\mu$, e variância, $\sigma^{2}$, e possuem o mesmo número de observações, $n$, e a mesma variância, pode-se obter um conjunto simultâneo de intervalos de confiança para todos os pares de médias dos grupos da forma $\left(\mu_{i}-\mu_{j}\right)$ usando a distribuição $Q$. A equação (67) descreve o conjunto de intervalos de confiança. A estatística de teste, $w$, pode ser escrita conforme a equação (68).

$$
\begin{gathered}
\bar{x}_{i}-\bar{x}_{j}-w \leq \bar{\mu}_{i}-\bar{\mu}_{j} \leq \bar{x}_{i}-\bar{x}_{j}+w \\
w=Q_{\alpha, k, k_{Q M E}} \sqrt{Q M E / n}
\end{gathered}
$$

em que:

$Q_{\alpha, k, k Q M E}=$ estatística da distribuição $Q$ (Anexo D), com nível de confiança, $\alpha$, e graus de liberdade do fator, $k$, e do erro ( $d f$ na tabela do Anexo D), $\mathrm{k}_{\mathrm{QME}}$;

$Q M E=$ quadrado médio dos erros (estimador da variância).

Os pares de intervalos de confiança são significativamente diferentes entre si, quando não se sobrepõe uns aos outros, ou seja, quando a diferença entre as duas médias de um par é maior que a estatística de teste, $w$.

O procedimento de Tukey também é conhecido como o teste de Tukey da diferença honestamente significativa (honestly significant difference - HSD).

\subsubsection{Método dos efeitos simples principais $(S M E)$}

Após a aplicação da ANOVA pode-se utilizar o procedimento de Tukey para comparar as diferenças entres as médias de cada nível dos fatores principais, entretanto, quando há 
interação entre os fatores principais a utilização do procedimento de Tukey para comparação das médias dos níveis é questionável (HUCK, 2012).

De acordo com Huck (2012), havendo interação entre os fatores pode-se realizar a comparação das médias dos níveis utilizando o método dos efeitos simples principais (SME).

Na utilização do método SME, segundo Huck (2012), os dados de cada nível de um fator de interesse são separados para aplicação da ANOVA com 1 fator. Após a aplicação da ANOVA pode-se utilizar o procedimento de Tukey para comparar as médias dos níveis do fator de interesse.

Pode-se utilizar o estudo do presente trabalho para exemplificar o método SME considerando a análise de um parâmetro de desempenho do motor que apresente interação entre os fatores principais (fator $\lambda$ e tipo de combustível). Neste caso deve-se escolher um dos fatores principais para a análise das médias, por exemplo, o fator $\lambda$. A escolha do fator $\lambda$ resultará em uma análise sobre as diferenças entre os tipos de combustível em cada nível do fator $\lambda$. A Tabela 9 apresenta um resumo deste exemplo de aplicação do método SME seguido do procedimento de Tukey, ou seja, a indicação final (SIM ou NÃO) será se os tipos de combustível se diferenciam ou não em cada nível do fator $\lambda$. 
Tabela 9 - Exemplo de aplicação do método $S M E$ e do procedimento de Tukey na presença de

\begin{tabular}{|c|c|c|}
\hline \multicolumn{3}{|c|}{$\begin{array}{c}\text { SME - Tukey - Potência, xxx rpm, carga, avanço } \\
\text { da centelha }\end{array}$} \\
\hline Nível I & \multicolumn{2}{|c|}{ Combustível 1} \\
\hline Nível II & \multicolumn{2}{|c|}{ Combustível 2} \\
\hline Nível III & \multicolumn{2}{|c|}{ Combustível 3} \\
\hline Nível IV & \multicolumn{2}{|c|}{ Combustível 4} \\
\hline Fator Lambda & Níveis & Diferem entre si \\
\hline \multirow{6}{*}{0,9} & I - II & Não \\
\hline & I -III & Não \\
\hline & I - IV & Sim \\
\hline & II - III & Não \\
\hline & II - IV & Sim \\
\hline & III - IV & Sim \\
\hline \multirow{6}{*}{1} & I - II & Não \\
\hline & I -III & Não \\
\hline & I - IV & Sim \\
\hline & II - III & Não \\
\hline & II - IV & Sim \\
\hline & III - IV & Sim \\
\hline \multirow{6}{*}{1,1} & I - II & Não \\
\hline & I -III & Não \\
\hline & I - IV & Sim \\
\hline & II - III & Não \\
\hline & II - IV & Sim \\
\hline & III - IV & Sim \\
\hline
\end{tabular}

\subsubsection{Regressões lineares}

Nas subseções a seguir serão abordadas as regressões lineares simples e múltiplas, de acordo com a teoria apresentada por Hoffmann e Vieira (1977).

A regressão linear simples pode ser obtida utilizando o comando polyfit do software Matlab $^{\circledR}$, de acordo com as formulações descritas nesta seção.

Para obter os coeficientes de uma regressão linear múltipla pode-se utilizar o algoritmo apresentado por Costa (2005), desenvolvido de acordo com as formulações descritas nas próximas seções. 


\subsubsection{Regressão linear simples}

O modelo estatístico de uma regressão linear simples entre duas variáveis $X$ e $Y$, admitindo que $Y$ é a variável dependente e que $X$ é a variável independente, ou seja, $Y$ é uma função linear de $X$, é definido pela equação (69). Para estabelecer uma regressão linear simples admite-se que a média do erro $\left(u_{i}\right)$ é nula.

$$
Y_{i}=a_{1}+a_{2} X_{i}+u_{i}
$$

As estimativas $\hat{a}_{1}$ e $\hat{a}_{2}$ dos coeficientes $a_{1}$ e $a_{2}$ são feitas considerando o método dos mínimos quadrados. O método dos mínimos quadrados adota como estimativa dos coeficientes os valores que minimizam a soma dos quadrados dos erros ( $S Q E)$, como mostra a equação (70). A função $S Q E$ será mínima quando suas derivadas parciais em relação à $\hat{a}_{1}$ e $\hat{a}_{2}$ forem nulas, como mostram as equações (71) e (72). A solução do sistema gerado pelas equações (71) e (72) permite obter os valores de $\hat{a}_{1}$ e $\hat{a}_{2}$ como mostram as equações (73) e (74).

$$
\begin{gathered}
S Q E=\sum_{i=1}^{n} u_{i}^{2}=\sum_{i=1}^{n}\left(Y_{i}-\hat{a}_{1}-\hat{a}_{2} X_{i}\right)^{2} \\
\frac{\partial S Q E}{\partial \hat{a}_{1}}=-2 \sum_{i=1}^{n}\left(Y_{i}-\hat{a}_{1}-\hat{a}_{2} X_{i}\right)=0 \\
\frac{\partial S Q E}{\partial \hat{a}_{2}}=2 \sum_{i=1}^{n}\left(Y_{i}-\hat{a}_{1}-\hat{a}_{2} X_{i}\right)\left(X_{i}\right)=0 \\
\hat{a}_{2}=\frac{n \sum X Y-\left(\sum X\right)\left(\sum Y\right)}{n \sum X^{2}-\left(\sum X\right)^{2}} \\
\hat{a}_{1}=\frac{\left(\sum X^{2}\right)\left(\sum Y\right)-\left(\sum X\right)\left(\sum X Y\right)}{n \sum X^{2}-\left(\sum X\right)^{2}}=\bar{Y}-\hat{a}_{2} \bar{X}
\end{gathered}
$$


A equação (75) mostra a reta de regressão estimada.

$$
\hat{Y}=\hat{a}_{1}+\hat{a}_{2} X
$$

\subsubsection{Regressão linear múltipla}

O modelo estatístico de uma regressão linear múltipla apresenta uma variável dependente $(Y)$ como função linear de duas ou mais variáveis independentes $\left(X_{i}\right)$, como mostram as equações (76) e (77). Para estabelecer uma regressão linear múltipla admite-se que a média do erro $\left(u_{i}\right)$ seja nula.

$$
\begin{gathered}
Y_{i}=a_{1}+a_{2} X_{1 i}+a_{3} X_{2 i}+\ldots+a_{n} X_{n i}+u_{i} \\
Y_{i}=a_{1}+\sum_{j=1}^{n} a_{j} X_{j i}+u_{i}
\end{gathered}
$$

Para simplificar os cálculos de uma regressão linear múltipla utilizam-se variáveis centradas na média, como mostra a equação (78), onde $x_{i j}$ é a variável $X_{i j}$ centrada na média. Neste caso, o modelo estatístico da regressão linear múltipla é representado pela equação (79), ou em notação matricial pela equação (80).

$$
\begin{gathered}
x_{i j}=X_{i j}-\bar{X}_{i} \\
Y_{i}=a_{1}+a_{2} x_{1 i}+a_{3} x_{2 i}+\ldots+a_{n} x_{n i}+u_{i} \\
y=X a+u
\end{gathered}
$$

As estimativas $\hat{a}_{n}$ dos coeficientes $a_{n i}$ da regressão linear múltipla são feitas considerando o método dos mínimos quadrados. A soma dos quadrados dos erros $(S Q R)$ para a regressão linear múltipla será mínima quando os valores de $\hat{a}_{n}$ tornarem sua diferencial identicamente 
nula, como mostra a equação (81), obtendo o sistema de equações normais apresentado na equação (82).

$$
\begin{gathered}
d S Q R=-2\left(d \hat{a^{\prime}}\right) X^{\prime} y+2\left(d \hat{a^{\prime}}\right) X^{\prime} X \hat{a}=0 \\
X^{\prime} X \hat{a}=X^{\prime} y
\end{gathered}
$$

Se a matriz $X^{\prime} X$ não for singular, pode-se obter a sua inversa $\left(X^{\prime} X\right)^{-1}$ e, multiplicando a equação (82) por esta inversa obtém-se a estimativa $\hat{a} \operatorname{dos}$ parâmetros $a_{n}$, como mostra a equação (83).

$$
\hat{\mathrm{a}}=\left(X^{\prime} X\right)^{-1} X^{\prime} y
$$

Construindo as matrizes $X^{\prime} X$ e $X^{\prime} y$, pode-se obter as estimativas $\hat{a}$ dos parâmetros $a_{n}$ como mostram as equações (84) e (85).

$$
\begin{aligned}
X^{\prime} X=\left[\begin{array}{ccccc}
n & 0 & 0 & \cdots & 0 \\
0 & \sum x_{1 j}^{2} & \sum x_{1 j} x_{2 j} & \cdots & \sum x_{1 j} x_{i j} \\
0 & \sum x_{1 j} x_{2 j} & \sum x_{2 j}^{2} & \cdots & \sum x_{2 j} x_{i j} \\
\vdots & \vdots & \vdots & & \vdots \\
0 & \sum x_{1 j} x_{i j} & \sum x_{2 j} x_{i j} & \cdots & \sum x_{i j}^{2}
\end{array}\right] \\
X^{\prime} y=\left[\begin{array}{c}
\sum Y_{j} \\
\sum x_{1 j} Y_{j} \\
\sum x_{2 j} Y_{j} \\
\vdots \\
\sum x_{i j} Y_{j}
\end{array}\right]
\end{aligned}
$$

A reta ajustada pela regressão linear múltipla é apresentada na equação (86). 


$$
\hat{Y}=\hat{a}_{1}+\sum_{i=1}^{j} \hat{a}_{i} x_{i}
$$

\subsubsection{Análise dos modelos de regressão linear múltipla}

Nas subseções desta seção serão utilizados os estudos apresentados por Montgomery e Runger (2003)

Para verificar a adequação dos modelos de regressão linear múltipla são utilizados testes de hipóteses relativos aos coeficientes dos modelos.

Estes testes requerem que os termos de erro no modelo de regressão sejam normal e independentemente distribuídos com média zero e variância $\sigma^{2}$.

\subsubsection{Teste de significância da regressão}

O teste de significância da regressão permite determinar se existe uma relação linear entre a variável de resposta $Y$ e os seus regressores $X_{1}, X_{2}, \ldots, X_{n}$.

As hipóteses verificadas neste teste são:

$$
\begin{aligned}
& H_{0}: a_{1}=a_{2}=\ldots=a_{n}=0 \\
& H_{1}: a_{i} \neq 0 \text { para no mínimo um } \mathrm{i}
\end{aligned}
$$

em que:

$$
\begin{aligned}
& H_{0}=\text { hipótese nula; } \\
& H_{l}=\text { hipótese alternativa; } \\
& a_{i}, \mathrm{i}=1,2, \ldots, n=\text { coeficientes da regressão linear múltipla. }
\end{aligned}
$$

A rejeição de $H_{0}$ implica que existe pelo menos um regressor, $X_{1}, X_{2}, \ldots, X_{n}$, que contribui significativamente para o modelo e que existe uma relação linear entre os regressores e a variável de resposta.

Para rejeitar $H_{0}$ é necessário que o valor da estatística do teste, $F$, seja maior que o valor crítico $F_{\alpha, k, n-p},(\alpha=$ nível de significância, $k=$ número de regressores, $n=$ número de observações de $Y$ e $p=$ número de parâmetros da regressão linear múltipla). 
O procedimento do teste de significância da regressão é expresso de forma semelhante a uma tabela de ANOVA, como mostra a Tabela 10, em que $Q M R$ é o quadrado médio da regressão e $Q M E$ é o quadrado médio dos erros.

Tabela 10 - Análise de variância para testar a significância na regressão múltipla.

\begin{tabular}{lcccc}
\hline \multicolumn{1}{c}{$\begin{array}{c}\text { Fonte de } \\
\text { variação }\end{array}$} & $\begin{array}{c}\text { Soma } \\
\text { Quadrática }\end{array}$ & $\begin{array}{c}\text { Graus de } \\
\text { liberdade }\end{array}$ & $\begin{array}{c}\text { Média } \\
\text { Quadrática }\end{array}$ & $\mathrm{F}$ \\
\hline Regressão & $\mathrm{SQR}$ & $\mathrm{k}$ & QMR & QMR/QME \\
Erro ou resíduo & $\mathrm{SQE}$ & $\mathrm{n}-\mathrm{p}$ & QME & \\
Total & $\mathrm{SQT}$ & $\mathrm{n}-1$ & & \\
\hline
\end{tabular}

O valor da soma quadrática da regressão, $S Q R$, é dado pela equação (87), em que o índice $j$ expressa a numeração das observações das variáveis $y$.

$$
S Q R=\hat{a^{\prime}} X^{\prime} y-\frac{\left(\sum_{j}^{n} y_{j}\right)^{2}}{n}
$$

A equação (88) expressa à soma quadrática do erro, $S Q E$.

$$
S Q E=y^{\prime} y-\frac{\left(\begin{array}{c}
\sum_{j}^{n} y_{j} \\
j
\end{array}\right)^{2}}{n}-\left[\hat{a}^{\prime} X^{\prime} y-\frac{\left(\sum_{j}^{n} y_{j}\right)^{2}}{n}\right]
$$

A soma quadrática total, $S Q T$, pode ser escrita de acordo com a equação (89).

$$
\mathrm{SQT}=\mathrm{SQE}+\mathrm{SQR}
$$

O valor crítico $F_{\text {crítico }}$ é obtido a partir das tabelas de distribuição $F$.

\subsubsection{Coeficiente de determinação múltipla ajustado}

O coeficiente de determinação múltipla, $r^{2}$, é definido de acordo com a equação (90), em que os valores de $S Q R, S Q E$ e $S Q T$, são as somas quadráticas da regressão linear múltipla. 


$$
r^{2}=\frac{S Q R}{S Q T}=1-\frac{S Q E}{S Q T}
$$

O valor de $r^{2}$ é uma medida da quantidade de redução na variabilidade de $y$, obtida pelo uso dos regressores $a_{1}, a_{2}, \ldots, a_{i}$.

Um valor grande de $r^{2}$ não significa que o modelo de regressão seja bom. A adição de variáveis ao modelo sempre aumenta o valor de $r^{2}$. Modelos com grandes valores de $r^{2}$ podem resultar em previsões pobres de novas observações ou estimativas pobres da resposta média.

Existem vários critérios que podem ser utilizados em substituição a do $r^{2}$ para comparar diferentes modelos de regressão.

Dentre estes critérios, o coeficiente de determinação ajustado $\left(R^{2}\right)$, baseado no coeficiente de determinação $r^{2}$, pode ser escrito de acordo com a equação (91).

$$
R^{2}=1-\frac{n-1}{n-p}\left(1-r^{2}\right)
$$

O valor de $R^{2}$ pode diminuir à medida que o valor de $p$ aumenta, se a diminuição em ( $n$ 1) $\left(1-r^{2}\right)$ não for compensada pela perda de um grau de liberdade em $(n-p)$.

\subsubsection{Raiz quadrada do erro quadrático médio}

Conforme encontrado em Costa (2005), a raiz quadrada do erro quadrático médio ou root mean square error (rms) pode ser utilizado para comparar modelos de regressão, sendo obtido pela equação (92).

$$
r m s=\sqrt{\frac{\sum_{i=1}^{n}(\hat{y}-y)^{2}}{n}}
$$

O rms é uma medida do desvio entre os valores calculados e os valores originais. em que:

$y-y=$ resíduo da estimativa;

$\mathrm{n}=$ números de estimativas. 


\section{MATERIAIS E MÉTODOS}

Neste capítulo serão apresentadas a bancada experimental e as características de seus componentes, os métodos utilizados para obtenção, cálculo e análise dos dados dos experimentos e os métodos e ferramentas utilizadas para obtenção e análise dos modelos de estimação do fator $\lambda$ e de identificação do tipo de combustível.

\subsection{DESCRIÇÃO DA BANCADA DINAMOMÉTRICA}

Os ensaios do motor foram realizados no Laboratório de Motores de Combustão integrado ao Núcleo de Engenharia Térmica e Fluídos (NETEF) da Escola de Engenharia Mecânica de São Carlos, utilizando um dinamômetro de corrente de Foucault da marca Schenck, modelo W260 de 260 kW com 100 rpm de resolução. Os demais componentes instalados para a realização dos ensaios foram:

- Motor VW, modelo AT 1000 8V com 61,2 CV de potência e relação de compressão de 14,1:1 $\pm 0,5$, com bomba d'água e motor de partida originais de fábrica e com bateria $12 \mathrm{~V}$ (chumbo ácido) e alternador adaptado;

- sistema de arrefecimento para o motor, composto por dois radiadores, modelos VW AP 2000 e VW AT 1000, com acionamento elétrico externo;

- transdutor de temperatura do líquido de arrefecimento, modelo MTE-4053;

- bomba de combustível externa, modelo Delphi GM EFI, e regulador de pressão, modelo LP-47716/202 (3 bar);

- tubulação de escapamento redimensionada para possibilitar a instalação de tomadas de pressão, temperaturas, gases de exaustão e para instalação da sonda lambda de banda larga Bosch, modelo LSU 4.2 ( $n^{\circ} 0258007$ 057), no duto do primeiro cilindro;

- controlador da sonda lambda de banda larga da marca FuelTech, modelo WB-O2, com resolução de $0,01 \lambda$, faixa de medição de $0,65-4,00 \lambda$ e tempo de resposta da sonda menor que $100 \mathrm{~ms}$;

- sistema de medição dos gases de exaustão composto pelo medidor da marca Tecnomotor, modelo TM 131 e por um notebook (PC-compatível - computador de monitoramento 2) para aquisição de dados via porta serial, utilizando o software SOFTGAS; 
- $\quad$ sistema de admissão de ar composto por uma câmara de ressonância, medidor de vazão mássica de ar, modelo Ford 98AB-128579-B2B, psicrômetro marca Asahi Style com escalas de temperatura de bulbo seco e úmido de -10 a $50^{\circ} \mathrm{C}$ e por um barômetro WI 71353 com resolução de $1 \mathrm{mmHg}$;

- buffer de tensão com divisor de tensão em uma das saídas, desenvolvido no presente trabalho para reprodução do sinal do transdutor de rotação - PMS (ponto morto superior) em duas saídas diferentes, uma com tensão adequada ao sistema de aquisição e outra com tensão idêntica à tensão de entrada para o sistema de gerenciamento eletrônico do motor;

- adaptador instalado no coletor de admissão para tomadas de pressão e temperatura;

- amplificador de termopares do tipo K com compensação de junta fria, desenvolvido no presente trabalho com base no amplificador AD595AQ, com faixa de medição de $0-1250{ }^{\circ} \mathrm{C}$ e ganho de $10 \mathrm{mV} /{ }^{\circ} \mathrm{C}$;

- transdutor de pressão absoluta da marca Motorola, modelo MPXH6115AC6T1 (15 a $115 \mathrm{kPa}$ ), instalado no coletor de admissão e transdutor de pressão relativa da marca Motorola, modelo MPX4250GP (0 a $250 \mathrm{kPa}$ ) instalado no coletor de escape;

- pistola de ponto indutiva digital para medição do avanço da centelha em função do PMS marca PlanaTC, modelo PP-2000, como resolução de $0,1^{\circ}$;

- transdutor de pressão no cilindro (0-150 bar) da marca AVL, modelo 8QP 500CA com resolução de 0,004 bar e frequência natural de $100 \mathrm{kHz}$, instalado na câmara de combustão do primeiro cilindro do motor;

- amplificador de carga marca AVL, modelo 3059 HICF, para conversão da carga elétrica do transdutor de pressão no cilindro em um sinal de tensão;

- sistema de medição de consumo composto por uma balança digital marca Toledo, modelo XP32001L com resolução de 0,1 g, computador PC-compatível para aquisição via porta serial e algoritmo de aquisição desenvolvido em linguagem gráfica LabVIEW ${ }^{\circledR}$;

- sistema de aquisição de dados (pressão no cilindro e nos coletores de admissão e escape, sinal do transdutor de rotação - PMS, vazão mássica de ar, temperatura do líquido de arrefecimento, da admissão e dos gases de exaustão) composto por um módulo de condicionamento de sinais NI SCXI-1000 da National Instruments, um 
computador PC-compatível (computador de monitoramento 1) com uma placa de aquisição PCI-6035E da National Instruments e algoritmo desenvolvido no presente estudo em linguagem gráfica LabVIEW ${ }^{\circledR}, \mathrm{e}$

- sistema de gerenciamento eletrônico reprogramável do motor marca FuelTech, modelo RacePro-1Fi. Esse sistema permite a variação dos valores de tempo de injeção de combustível e momento da centelha, assim como é capaz de monitorar variáveis das condições de funcionamento do motor (temperatura do motor, avanço da centelha, tempo de injeção e pressão no coletor de admissão).

A Figura 13 mostra uma visão geral da bancada dinamométrica, enquanto que a Figura 14 mostra um diagrama de blocos com os sistemas relevantes desta bancada.

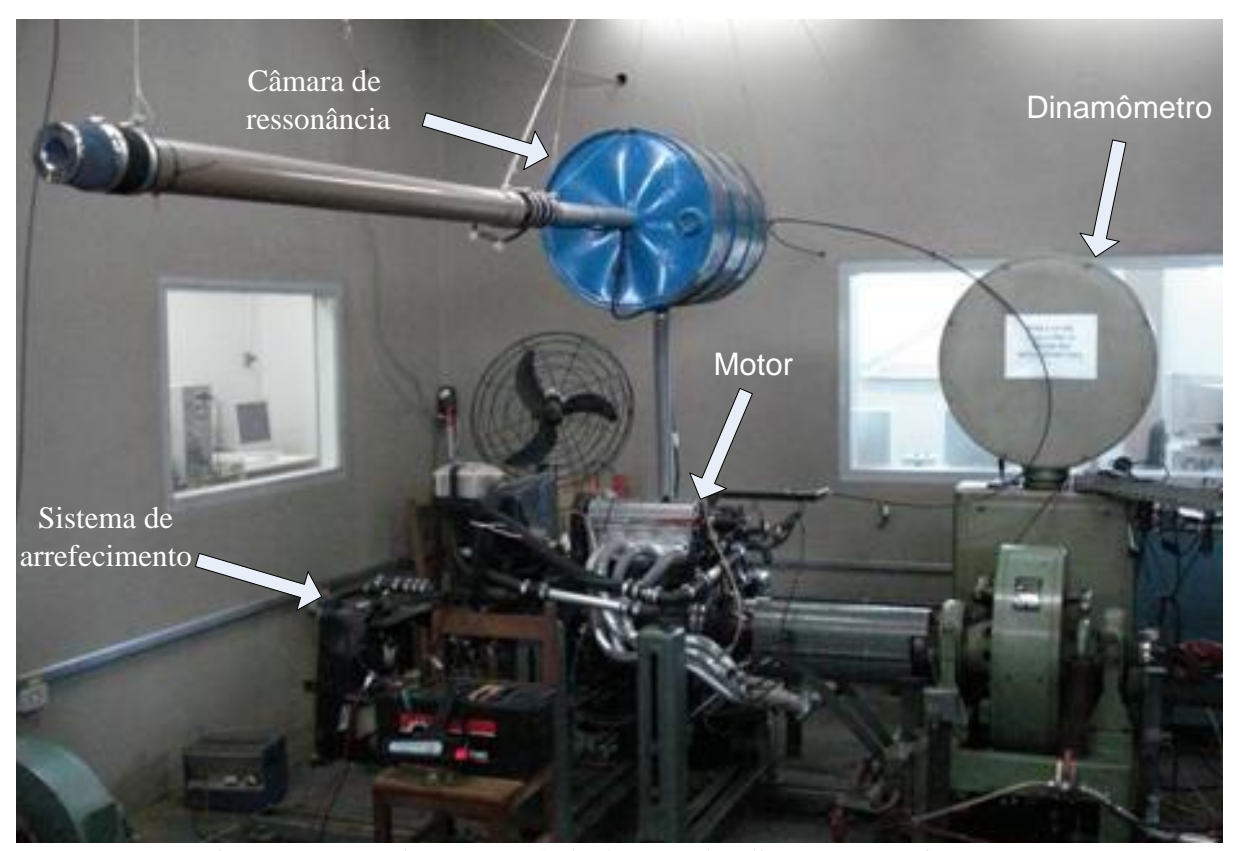

Figura 13 - Visão geral da bancada dinamométrica.

De acordo com a Figura 14 os valores (representados pelas linhas cinzas) das medições do fator lambda, da pressão barométrica, do avanço da centelha, do torque do motor e das temperaturas de bulbo seco e de bulbo úmido foram anotados em uma planilha impressa para esta finalidade. Posteriormente, esta planilha foi digitalizada. As demais medições (representadas pelas linas azuis e vermelhas) foram coletados utilizando os computadores de monitoramento 1 e 2 . 


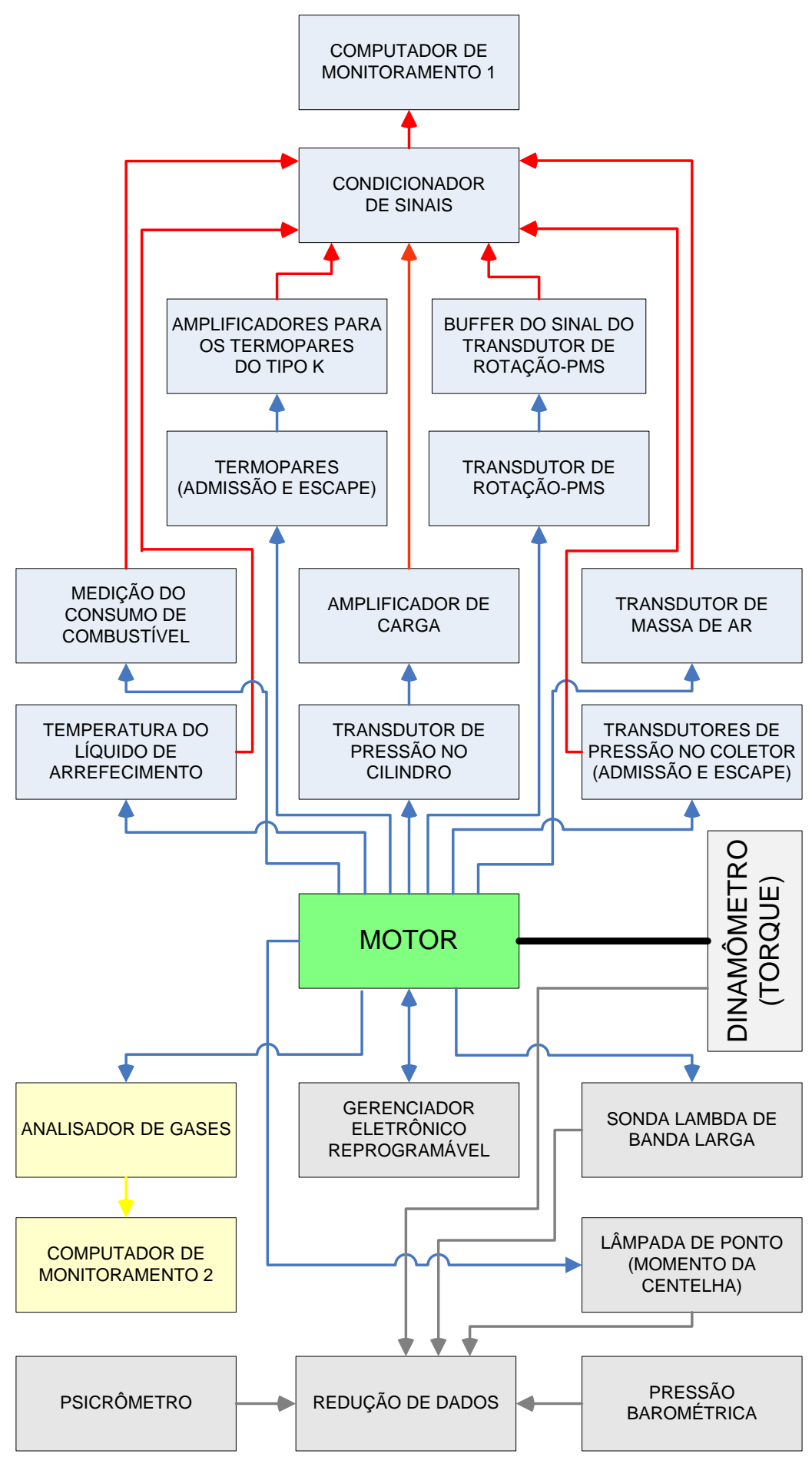

Figura 14 - Diagrama de comunicação da bancada dinamométrica. 


\subsubsection{Características dos principais componentes da bancada dinamométrica}

\subsubsection{Dinamômetro}

O dinamômetro de corrente de Foucault da marca SHENCK utilizado nos experimentos, modelo W260 fabricado em 1968, encontra-se instalado no Laboratório de Motores de Combustão integrado ao Núcleo de Engenharia Térmica e Fluídos (NETEF) da Escola de Engenharia de São Carlos. As principais características deste equipamento encontram-se na Tabela 11.

Tabela 11 - Principais características do dinamômetro SHENCK, modelo W260.

\begin{tabular}{lc}
\hline Rotação máxima & $7500[\mathrm{rpm}]$ \\
Torque máximo a 7500rpm & $211,508[\mathrm{Nm}]$ \\
Escala 1 (utilizada) & 0 a $25 \mathrm{~kg}$ red \\
Controle de rotação (utilizado) & Rotação constante (Erro: $\pm 10 \mathrm{rpm}$ ) \\
\hline
\end{tabular}

Por motivos de segurança a rotação do motor durante os experimentos não excedeu os $3000 \mathrm{rpm}$.

A Figura 15 mostra o controlador de rotação do dinamômetro SHENCK, modelo W260, que foi utilizado na função de rotação constante ("n = const."), e os equipamentos instalados ao seu redor.

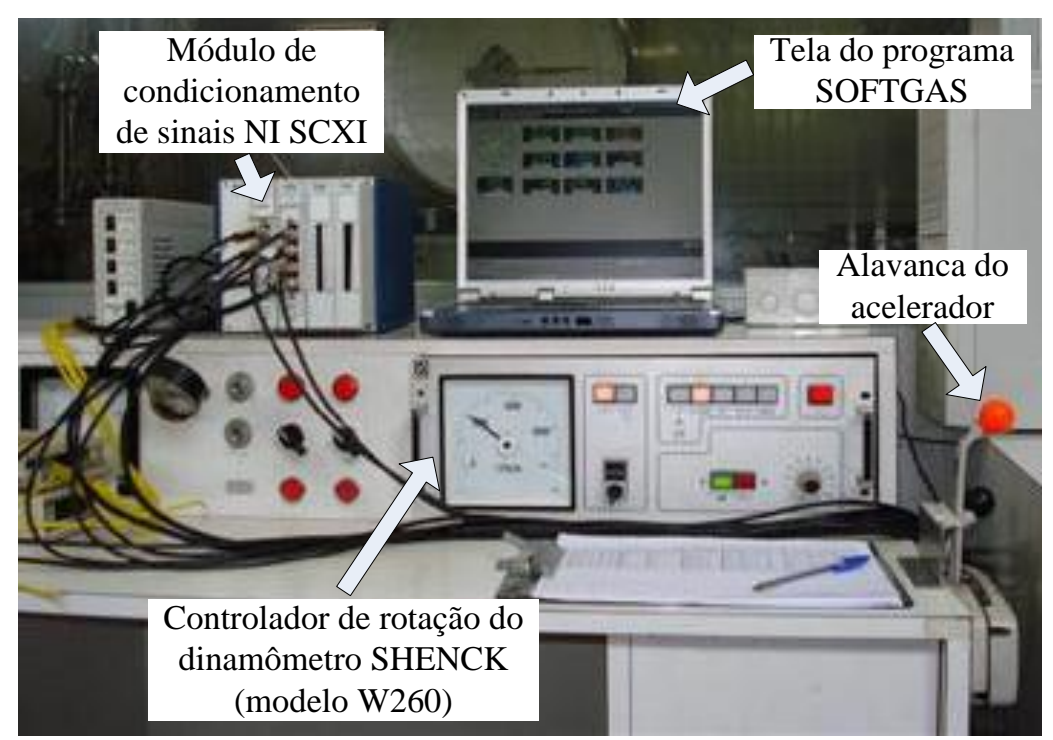

Figura 15 - Controlador de rotação do dinamômetro e equipamentos ao seu redor. 
Para facilitar os cálculos durante os experimentos foi determinado um parâmetro, chamado de fator da potência, que multiplicado pela rotação da árvore de manivelas resulta na potência do motor em $\mathrm{kW}$. O desenvolvimento deste parâmetro encontra-se no Apêndice $\mathrm{D}$, assim como o procedimento de calibração do dinamômetro que resultou nas equações que fornecem o torque e o fator da potência para os diversos valores observados na balança dinamométrica (em $\mathrm{kg}$ red).

As equações (93) e (94) representam o torque e o fator da potência do motor em função dos valores observados (em kg red) na balança dinamométrica, respectivamente. Os valores entre parênteses nestas equações representam o erro padrão das retas de regressão linear, com nível de confiança de $95 \%$.

$$
\begin{gathered}
\text { Torque }[\mathrm{Nm}]=7,2858 \text { kgred }+2,1845 \quad(0,7831) \\
\text { Fator da Potência }=0,763 \text { kgred }+0,2288 \quad(0,082)
\end{gathered}
$$

A potência do motor pode ser obtida diretamente pela equação (95).

$$
\text { Potência }[k W]=\frac{\text { Fator } \quad d a}{\text { Potência } \quad * \quad r p m}
$$

\subsubsection{Características do motor}

As principais características nominais originais do motor VW AT 1000 8V a etanol ensaiado em dinamômetro são apresentados na Tabela 12 .

Os dados nominais apresentados na Tabela 12 são fornecidos pelo fabricante do motor VW AT 1000 8V nos manuais do proprietário e de serviço de manutenção.

A expressão Cross-flow (fluxo cruzado), utilizada para designar o fluxo de gases na Tabela 12, significa que a entrada e a saída de gases ocorrem em lados opostos do motor.

Devido à instalação de um transdutor de pressão na câmara de combustão do primeiro cilindro a relação de compressão deste motor foi medida antes da realização dos experimentos. Os procedimentos para obtenção dos valores da relação de compressão e suas incertezas padrões encontram-se no Apêndice E. 
Tabela 12 - Características nominais do motor VW AT 10008 Válvulas a etanol segundo Volkswagen do Brasil Ltda. (2003)

\begin{tabular}{|c|c|}
\hline Potência máxima - rotação (CV-rpm) & $61,2-5000$ \\
\hline Torque máximo - rotação (Nm - rpm) & $95-3500$ \\
\hline Cilindrada $\left(\mathrm{cm}^{3}\right)$ & 999 \\
\hline Número de cilindros & 4 \\
\hline Relação de compressão & $14,1: 1 \pm 0,5$ \\
\hline Diâmetro dos cilindros (mm) & 67,1 \\
\hline Curso do pistão (mm) & 70,6 \\
\hline Fluxo dos gases & Cross-Flow \\
\hline Sistema de gerenciamento eletrônico & $\begin{array}{c}\text { Multiponto sequencial com } \\
\text { sonda lambda e controle de } \\
\text { detonação - } \\
\text { Bosch Motronic MP 9.0 }\end{array}$ \\
\hline $\begin{array}{l}\text { Sequência de Ignição (ordem de } \\
\text { explosão) }\end{array}$ & $1-3-4-2$ \\
\hline Avanço inicial em marcha lenta & $6^{\circ}$ APMS \\
\hline Vela de ignição & $\begin{array}{l}3 \text { eletrodos de massa - } \\
\text { modelo WR 8LTC }\end{array}$ \\
\hline Distribuidor & $\begin{array}{c}\text { Instalado no cabeçote - } \\
\text { acionado pelo comando de } \\
\text { válvulas } \\
\text { (ignição dinâmica) }\end{array}$ \\
\hline Rotação em marcha lenta (rpm) & $850 \pm 50$ \\
\hline
\end{tabular}

Os ângulos de abertura e fechamento das válvulas de admissão e escape do motor VW AT 1000 8V são apresentados na Tabela 13. Os valores destes ângulos foram obtidos com um goniômetro mecânico, da marca Digimess, colocado no eixo da polia de distribuição do motor, verificando o momento de abertura e fechamento das válvulas no interior do cabeçote.

Tabela 13 - Abertura e fechamento das válvulas de admissão e escape.

\begin{tabular}{cccc}
\hline Válvula & Abre & Fecha & $\begin{array}{c}\text { Ângulo de Permanência } \\
\text { [Graus] }\end{array}$ \\
\hline Admissão & PMS & $17^{\circ}$ & 197 \\
& $\left(0^{\circ}\right)$ & $\begin{array}{c}\text { DPMI } \\
\left(197^{\circ}\right)\end{array}$ & \\
Escape & $24^{\circ}$ APMI & PMS & 204 \\
\hline
\end{tabular}

Os ângulos entre parênteses apresentados na Tabela 13 são relativos à posição absoluta da árvore de manivelas em relação ao ponto morto superior (PMS) do $1^{\circ}$ cilindro do motor. 


\subsubsection{Sistema de medição dos gases de exaustão}

A tomada de gases de exaustão foi realizada no duto de escapamento do primeiro cilindro do motor VW, próximo da montagem da sonda lambda.

Os gases foram conduzidos, por uma mangueira de silicone de $1 / 2$ polegada, passando por dois filtros de combustível automotivos da marca Tecfill, modelos AG 68, para redução dos vapores d'água, até um aparelho de medição por infravermelho não dispersivo da marca Tecnomotor, modelo TM 131. A Figura 16 mostra a utilização deste aparelho durante as medições dos gases de exaustão.

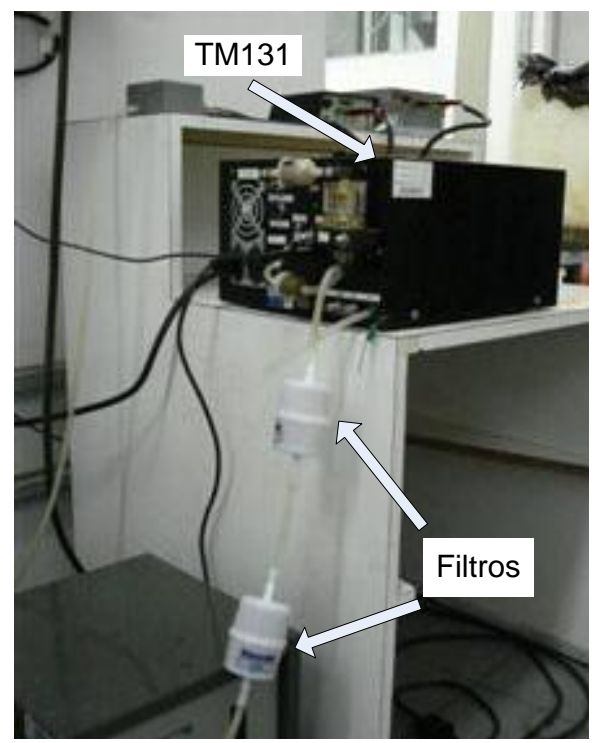

Figura 16 - Utilização do aparelho TM131 para medição dos gases de exaustão.

As especificações técnicas do aparelho TM131 são apresentadas na Tabela 14.

Tabela 14 - Especificações técnicas do analisador de gases TM131 com analisador opcional de $N O_{x}$.

\begin{tabular}{|c|c|c|c|}
\hline Gás & Medida mínima & Medida máxima & Resolução \\
\hline $\mathbf{O}_{2}$ & $\mathbf{0}(\%)$ & $25(\%)$ & $0,01(\%)$ \\
\hline $\mathrm{CO}$ & $0(\%)$ & $15(\%)$ & $0,01(\%)$ \\
\hline $\mathrm{CO}_{2}$ & $\mathbf{0}(\%)$ & $20(\%)$ & $0,1(\%)$ \\
\hline HC (Hexano) & $\mathbf{0}(\mathbf{p p m})$ & $20.000(\mathbf{p p m})$ & 1 (ppm) \\
\hline HC (Propano) & 0 (ppm) & $40.000(\mathrm{ppm})$ & 1 (ppm) \\
\hline $\mathrm{NO}_{\mathrm{x}}$ & $\mathbf{0}(\mathbf{p p m})$ & $5.000(\mathrm{ppm})$ & $1(\mathrm{ppm})$ \\
\hline
\end{tabular}


A leitura dos valores medidos pelo medidor TM131 foram anotadas em planilhas impressas para esta finalidade e também adquiridas em um notebook, via porta serial, utilizando o software SOFTGAS, da marca Tecnomotor.

A Figura 17 mostra a tela do programa SOFTGAS durante a realização de uma medida dos gases de exaustão.

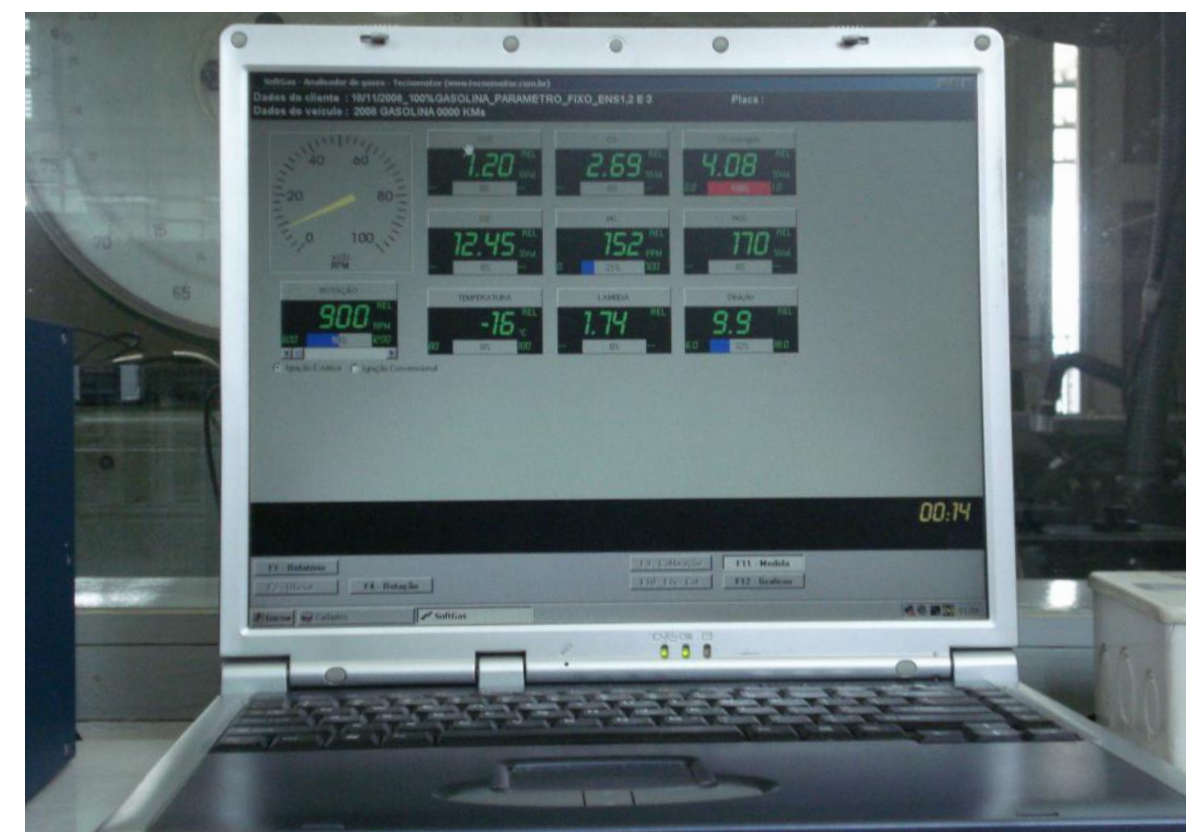

Figura 17 - Visual da tela de medição do programa SOFGAS.

\subsubsection{Transdutor de temperatura do líquido de arrefecimento}

O transdutor de temperatura, modelo MTE-4053, foi utilizado para monitorar a temperatura do líquido de arrefecimento do motor durante os experimentos.

As características e os procedimentos adotados para obter a curva de calibração deste transdutor são apresentados no Apêndice F.

A curva de ajuste da tensão de saída deste transdutor $\left(+V_{s}\right)$ em função da temperatura pode ser escrita de acordo com a equação (96) extraída do Apêndice F. O erro padrão, com nível de confiança de 95\%, é apresentado entre parênteses na equação (96).

$$
\begin{gathered}
\text { Temperatura }=-1,268 V_{s}^{5}+14,522 V_{s}^{4}-64,627 V_{s}^{3}+141,46 V_{s}^{2}-175,74 V_{s}+146,43 \\
(0,9046)
\end{gathered}
$$




\subsubsection{Buffer e divisor de tensão para o sinal do transdutor de rotação - PMS}

O sinal do transdutor de rotação - PMS (conhecido popularmente como sensor de efeito Hall com 1+3 janelas (ou armaduras)), original do sistema de gerenciamento eletrônico Motronic MP 9.0, foi utilizado para determinar a posição da árvore de manivelas em cada ciclo de pressão no cilindro.

As aquisições iniciais do sinal deste transdutor apresentaram tensões de até $+15 \mathrm{~V} \mathrm{CC}$.

O módulo de condicionamento de sinais utilizado nos experimentos, NI SCXI-1000 da National Instruments, possui canais de entrada de até $+10 \mathrm{~V}$ CC. Portanto, foi necessário construir um divisor de tensão (divisor de tensão resistivo ou divisor de resistência) para tornar a tensão do sinal do transdutor de rotação - PMS compatível com as especificações de entrada deste módulo.

Segundo Regazzi, Pereira e Silva Júnior (2005) um divisor de tensão resistivo, constituído por dois resistores em série, apresenta tensão na saída proporcional à razão entre a resistência de interesse e a resistência total do circuito, conforme a equação (97), em que $R_{1}$ e $R_{2}$ são as resistências dos resistores, $V s_{2}$ é a tensão na saída e $V b$ é a tensão de alimentação. $O$ circuito do divisor de tensão resistivo pode ser visto na Figura 18 em conjunto com um buffer de tensão.

$$
V_{s_{2}}=\frac{V_{b} R_{2}}{\left(R_{1}+R_{2}\right)}
$$

O divisor de tensão construído consiste de dois resistores em série, com resistências de 10 $\mathrm{k} \Omega$, e faz com que a tensão na saída seja a metade da tensão na entrada. A entrada deste circuito é o sinal do transdutor de rotação - PMS.

Para isolar o sinal do transdutor de rotação - PMS adquirido pelo módulo NI SCXI-1000 do mesmo sinal adquirido pelo sistema de gerenciamento eletrônico RacePro-1Fi (ou Motronic MP 9.0) foi desenvolvido um buffer de tensão (circuito seguidor de tensão).

Segundo Boylestad e Nashelsky (1998) um buffer de tensão, construído a partir de um amplificador operacional, permite que um ou mais sinais de saída sejam criados a partir de um sinal de entrada sem que o sinal de entrada seja afetado pelos sinais de saída (ganho de tensão unitário, $V_{\text {entrada }}=V_{\text {saída }}$ ). O buffer de tensão fornece corrente aos sinais de saída isoladamente da corrente do sinal de entrada. 
A Figura 18 apresenta o circuito construído para fazer o buffer e o divisor de tensão para o sinal do transdutor de rotação - PMS, em que “+E” corresponde à entrada do sinal deste sensor, $+V s_{1}$ corresponde à saída com tensão idêntica ao do sinal de entrada (conectada ao sistema de gerenciamento eletrônico RacePro-1Fi ou Motronic MP 9.0), “+ $V s_{2}$ ” corresponde à saída com tensão igual à metade do sinal de entrada (conectada ao módulo NI SCXI-1000) e $V b$ corresponde à tensão da bateria. Este circuito é constituído por um amplificador operacional, modelo LM324A, e por dois resistores (10 k $\Omega$ ).

As principais especificações técnicas do amplificador operacional LM324A encontram-se no Anexo A.

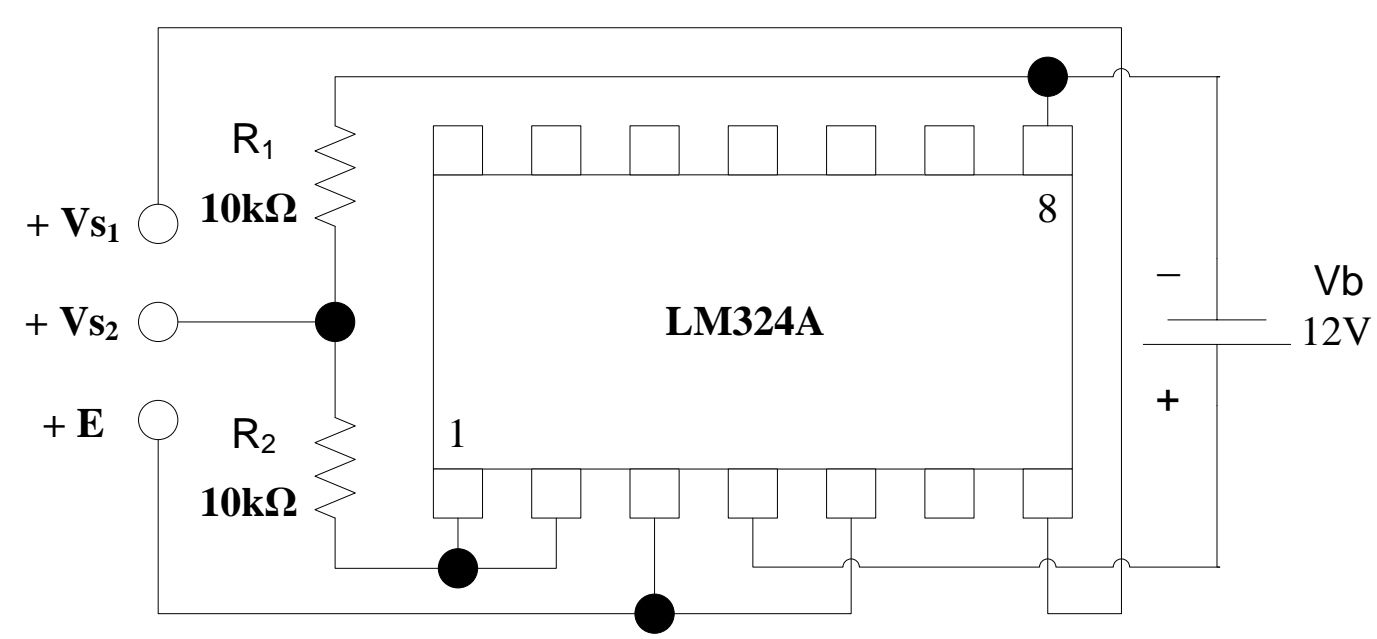

Figura 18 - Circuito do buffer de tensão com um divisor de tensão em uma das saídas.

A Figura 19 mostra uma fotografia da instalação do buffer e do divisor de tensão na bancada dinamométrica. 


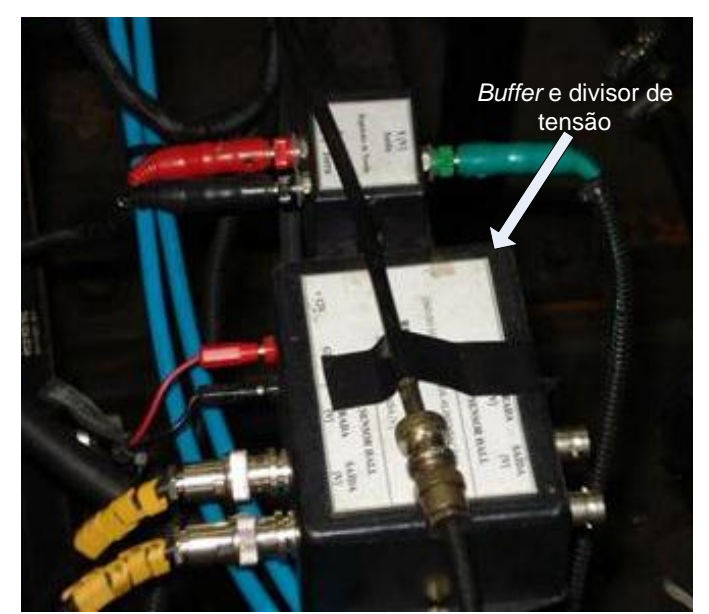

Figura 19 - Instalação na bancada dinamométrica do buffer e divisor de tensão para o sinal do transdutor de rotação - PMS.

\subsubsection{Amplificador para termopar do tipo K com compensação de junta fria}

Para adquirir os dados de temperatura nos coletores de admissão e escape foram instalados três termopares do tipo $K$ e construídos três amplificadores para os sinais dos termopares com compensação de junta fria, utilizando o circuito integrado (CI) AD595AQ.

Regazzi, Pereira e Silva Júnior (2005) descrevem as características fundamentais dos termopares do tipo $K$ que são constituídos por uma liga metálica de chromel-alumel e apresentam faixa de operação de -200 até $1250^{\circ} \mathrm{C}$.

$\mathrm{O}$ primeiro termopar foi instalado no duto coletor de admissão do primeiro cilindro. Na Figura 20 pode-se observar que este termopar encontra-se próximo do cabeçote e pouco antes da posição do spray da válvula eletromagnética injetora de combustível.

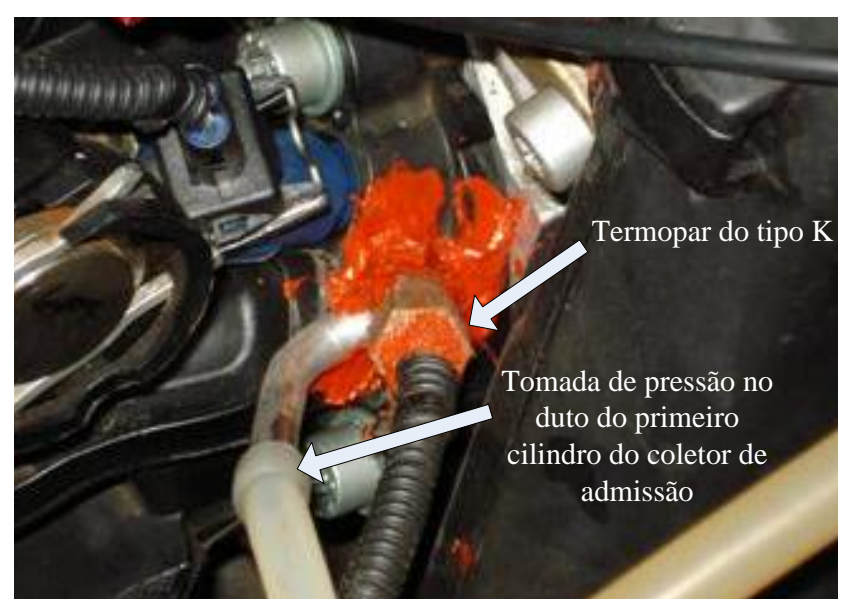

Figura 20 - Termopar do tipo K instalado no duto do coletor de admissão do primeiro cilindro.

O segundo termopar foi instalado no duto do coletor de escape do primeiro cilindro, distante do cabeçote na mesma proporção da posição do primeiro termopar (no coletor de 
admissão) até o cabeçote, como mostra a Figura 21. As posições dos termopares, nos coletores de admissão e escape, seguiram as recomendações de Patrick e Powell (1990), para obtenção de dados de temperatura dos gases de um motor gerenciado por um sistema eletrônico baseado no sinal da pressão no cilindro.

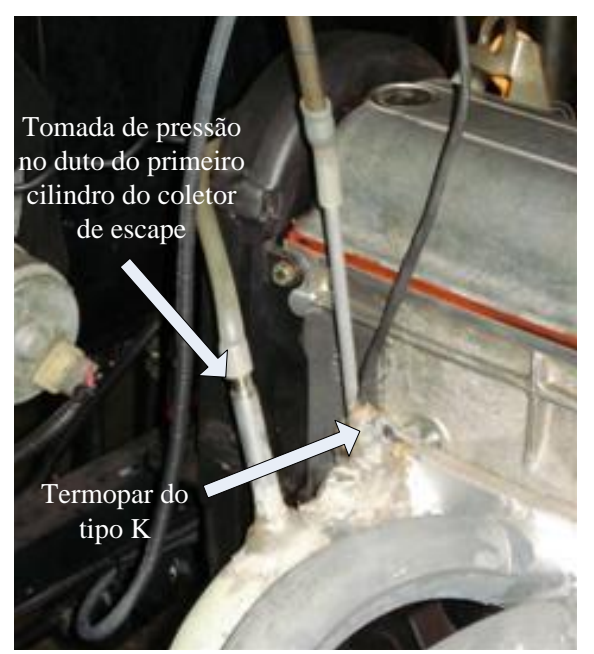

Figura 21 - Termopar do tipo K instalado no duto do primeiro cilindro do coletor de escape.

Para monitorar a temperatura próxima à sonda lambda de banda larga Bosch, modelo LSU 4.2 que suporta temperaturas de até $850^{\circ} \mathrm{C}$, foi instalado o terceiro termopar. Este termopar foi posicionado entre a sonda lambda original do sistema Motronic MP 9.0 e a sonda lambda de banda larga, como mostra a Figura 22.

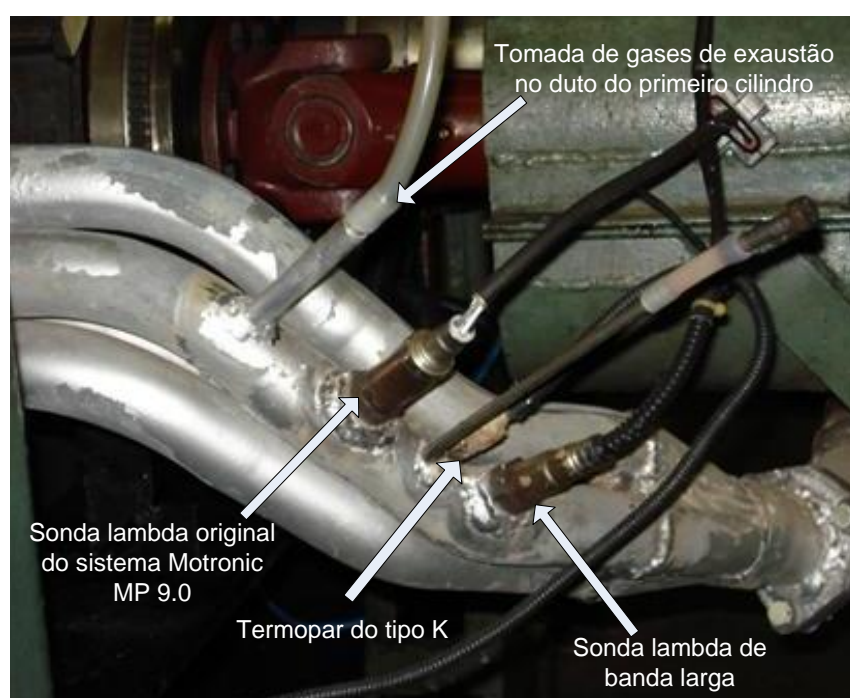

Figura 22 - Termopar do tipo K instalado entre as sondas lambdas no duto do coletor de escape do primeiro cilindro.

Os amplificadores para os sinais dos termopares foram construídos segundo o diagrama elétrico apresentado na Figura 23. Neste circuito pode-se observar que a alimentação foi feita 
com uma fonte de $15 \mathrm{~V} \mathrm{CC}$ e que o sinal de saída do CI AD595AQ foi filtrado por um filtro de segunda ordem (filtro $R C$ de segunda ordem) do tipo passa-baixa com frequência de corte de aproximadamente $16 \mathrm{kHz}$.

Esta frequência de corte foi estabelecida com o intuito de verificar se os circuitos construídos seriam afetados pelas frequências em que ocorrem knocking no motor.

Este filtro RC de segunda ordem é constituído por dois pares em paralelo de resistores (10 $\mathrm{k} \Omega$ ) e capacitores $(1 \mathrm{nF})$ em série. De acordo com Boylestad e Nashelsky (1998) a frequência de corte é calculada segundo a equação (98), em que $F_{c}$ é a frequência de corte em [Hz], $R_{S}$ é a resistência em $[\Omega]$ e $C_{p}$ é a capacitância em $[\mathrm{F}]$.

$$
F_{c}=\frac{1}{2 \pi R_{s} C_{p}}
$$

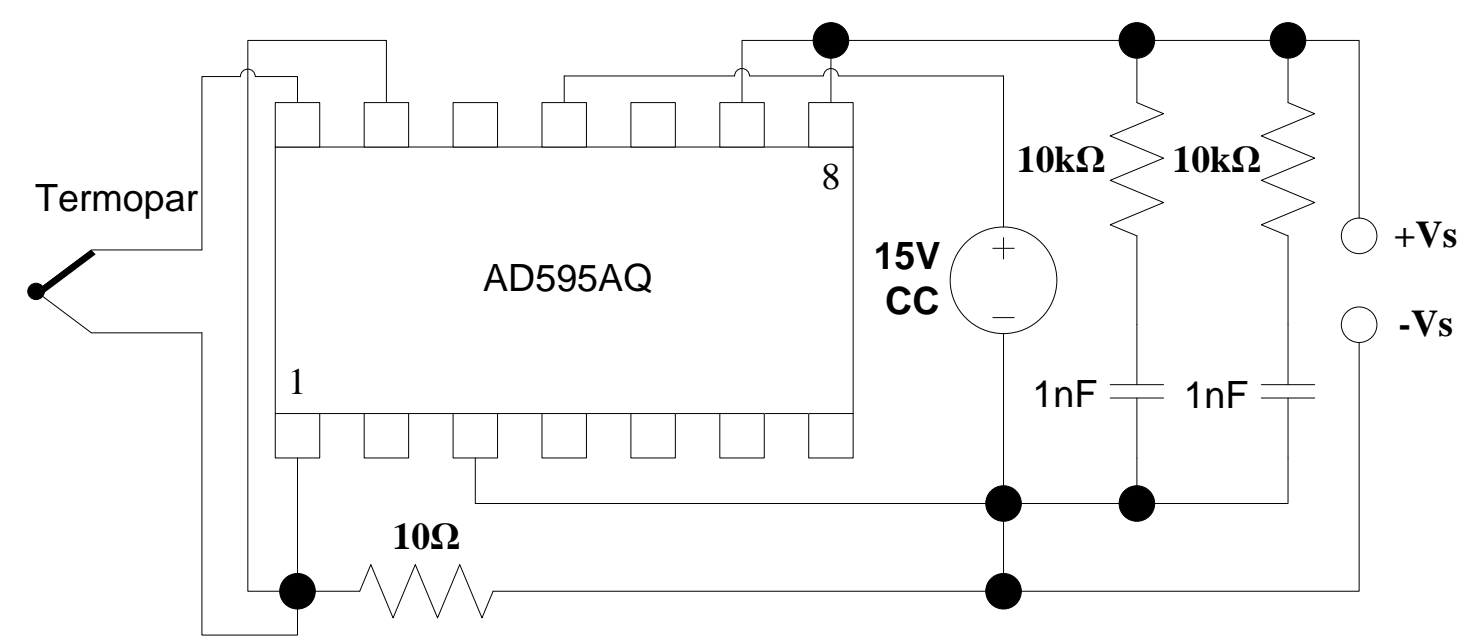

Figura 23 - Circuito elétrico do amplificador de termopar do tipo K.

A equação (99) representa a temperatura (Temp, em $\left.{ }^{\circ} \mathrm{C}\right)$ em função da tensão na saída do CI AD595AQ $\left(V_{s}\right)$. Esta equação foi elaborada a partir dos dados apresentados no manual deste CI e apresenta coeficiente de determinação $\left(r^{2}\right)$ de 0,9993. O erro padrão, com nível de confiança de 95\%, encontra-se entre parênteses na equação (99).

$$
\text { Temp }=8 * 10^{-8} \mathrm{~V}_{\mathrm{s}}^{2}+0,0976 \mathrm{~V}_{\mathrm{s}} \quad(2,382)
$$

Não foram obtidas as curvas experimentais dos circuitos construídos para os amplificadores de termopares do tipo K devido à falta de equipamentos adequados para a realização das medições de temperatura em função da tensão de saída destes circuitos. 
O Anexo B apresenta as principais especificações técnicas do amplificador de termopares AD595AQ.

A Figura 24 mostra a fotografia da instalação dos amplificadores de termopares do tipo k construídos na bancada dinamométrica.

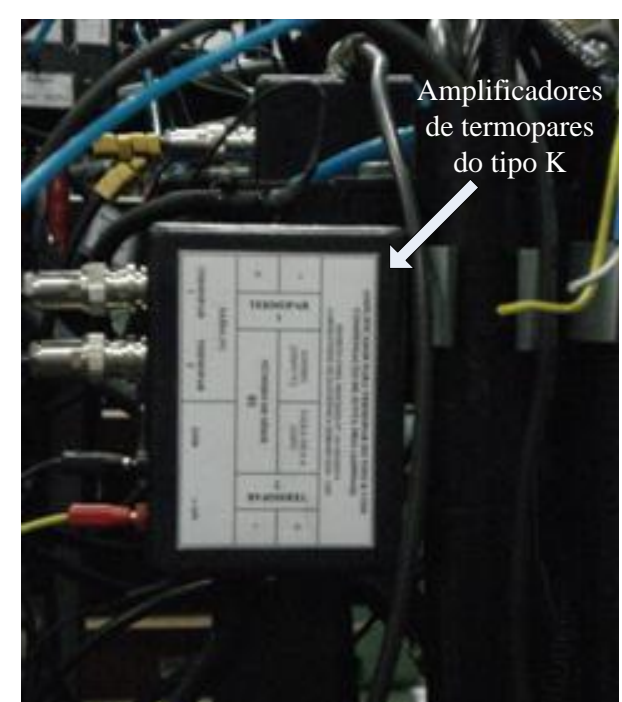

Figura 24 - Instalação na bancada dinamométrica dos amplificadores de termopares do tipo K.

\subsubsection{Transdutores de pressão nos coletores de admissão e de escape}

Foram medidas, nos dutos do primeiro cilindro do motor, a pressão absoluta no coletor de admissão e a pressão relativa no coletor de escape.

A pressão no coletor de admissão é fundamental para realizar a correção da potência do motor em plena carga.

As tomadas de pressão nos coletores de admissão e escape podem ser vistas nas Figuras 20 (26, também) e 21 , respectivamente.

Para medir a pressão absoluta no coletor de admissão foi utilizado um transdutor de pressão da marca Motorola, modelo MPXH6115AC6T1, com faixa de medição de 15 a 115 $\mathrm{kPa}$.

Para medir a pressão relativa no coletor de escape foi utilizado um transdutor de pressão da marca Motorola, modelo MPX4250GP, com faixa de medição de 0 a $250 \mathrm{kPa}$.

O Anexo C apresenta as principais especificações técnicas destes transdutores de pressão absoluta e relativa.

A Figura 25 apresenta o circuito elétrico construído de acordo com as recomendações do fabricante para obter a pressão absoluta do coletor de admissão. 
Neste circuito pode-se observar que a alimentação foi feita com uma fonte de 5V CC e que o sinal de saída do circuito foi filtrado por um filtro RC de segunda ordem do tipo passa baixa com frequência de corte de aproximadamente $16 \mathrm{kHz}$.

Este filtro RC de segunda ordem é constituído por um par em paralelo de resistor (10 k $\Omega$ ) em série com capacitor $(1 \mathrm{nF})$.

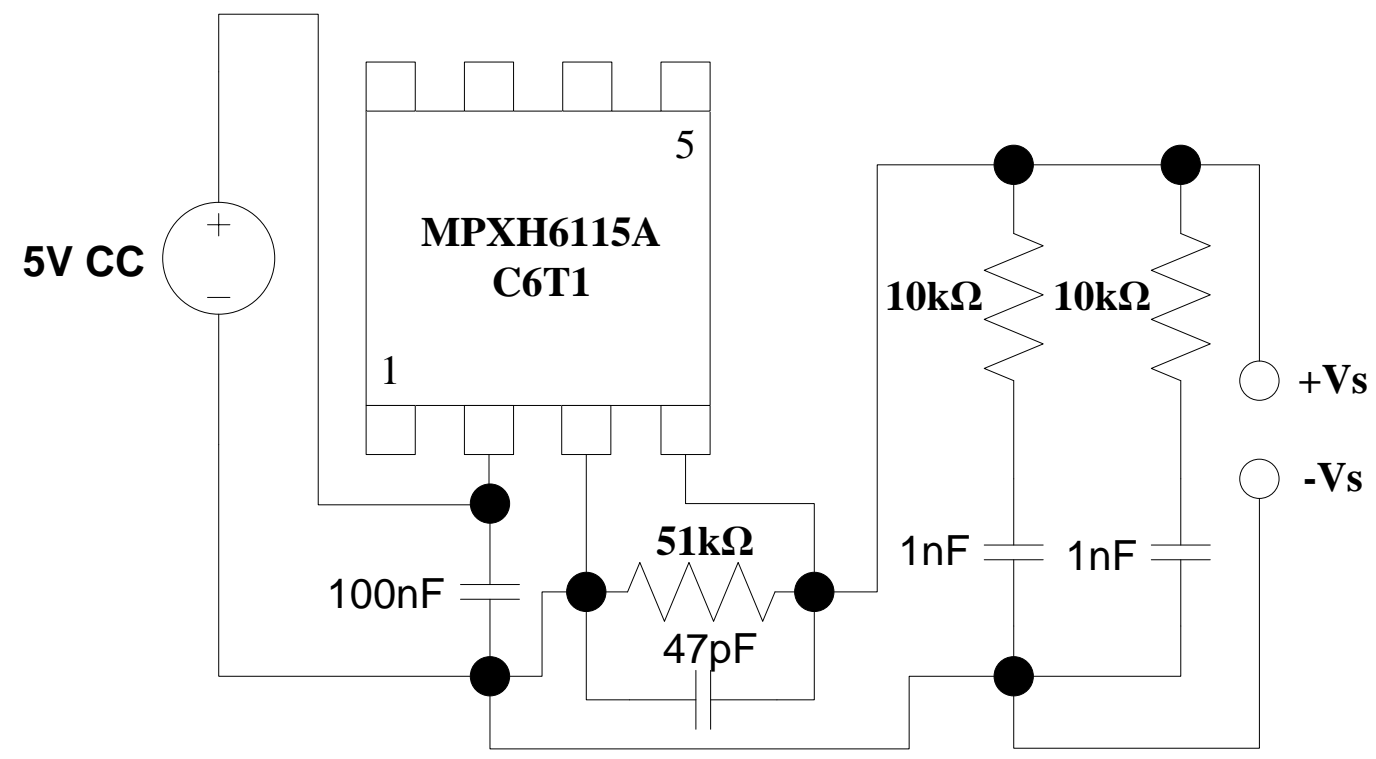

Figura 25 - Circuito do transdutor de pressão utilizado no coletor de admissão.

A equação (100) representa a pressão absoluta em $\mathrm{kPa}\left(P_{a b}\right)$ medida em função da tensão de saída $\left(V_{s}\right)$ do transdutor de pressão MPXH6115AC6T1. O valor de 1,5, expresso entre parênteses, representa o erro da medida segundo o fabricante.

$$
P_{a b}=\left(\frac{V_{s}}{0,045}\right)+10,5556 \quad(1,5) \quad[k P a]
$$

O circuito elétrico construído para obter a pressão relativa do coletor de escape é semelhante ao apresentado na Figura 25, substituindo apenas o transdutor de pressão absoluta MPXH6115AC6T1 pelo transdutor de pressão relativa MPX4250GP.

A equação (101) representa a pressão relativa em $\mathrm{kPa}\left(P_{r e l}\right)$ fornecida em função da tensão de saída $\left(V_{s}\right)$ do transdutor de pressão MPX4250GP. O valor de 0,06, expresso entre parênteses, representa o erro da medida segundo o fabricante.

$$
P_{r e l}=\left(\frac{V_{s}}{0,01845}\right)+10,8401 \quad(3,45) \quad[k P a]
$$


A Figura 26 mostra uma fotografia da instalação do sistema de medição da pressão absoluta do coletor de admissão na bancada dinamométrica.

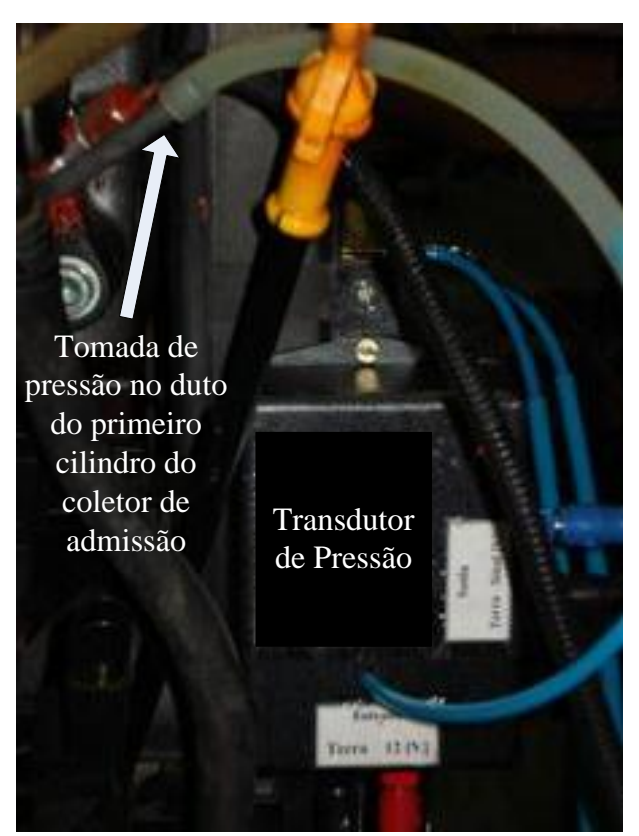

Figura 26 - Sistema de medição da pressão do coletor de admissão instalado na bancada dinamométrica.

\subsubsection{Amplificador de carga do transdutor de pressão no cilindro}

O sistema de medição da pressão no cilindro é composto por um transdutor piezelétrico de pressão, modelo 8QP 500CA, e por um amplificador de carga, modelo $3059 \mathrm{HICF}$, ambos da marca AVL.

A Tabela 15 apresenta as principais características do transdutor piezelétrico de pressão 8QP 500CA.

A tomada de pressão no cilindro foi obtida furando a parede do cabeçote do motor, com uma broca de 1,7 mm de diâmetro, até atingir a câmara de combustão do primeiro cilindro, como mostra a Figura 27. Esta posição do furo foi escolhida em função de ser a única região segura e acessível para a instalação do adaptador do transdutor de pressão.

No lado externo da parede furada foi produzida uma rosca métrica de $8 \mathrm{~mm}$ para receber o adaptador do transdutor de pressão. A Figura 28 apresenta uma fotografia do adaptador com o transdutor de pressão instalado no motor. 
Tabela 15 - Especificações técnicas do transdutor 8QP 500CA.

\begin{tabular}{lc}
\hline Faixa de medição [bar] & $0-150$ \\
Resolução $[\mathrm{bar}]$ & 0,004 \\
Frequência natural $[\mathrm{kHz}]$ & 100 \\
Sensibilidade (nominal) $[\mathrm{pC} / \mathrm{bar}]$ & 11,69 \\
Coeficiente de sensibilidade à temperatura $\left[\% /{ }^{\circ} \mathrm{C}\right]$ & 0,01 \\
Capacitância $[\mathrm{pF}]$ & 3,1 \\
Linearidade $[\%$ do fundo de escala] & $<0,6$ \\
Máxima temperatura de operação sem refrigeração $\left[{ }^{\circ} \mathrm{C}\right]$ & 200 \\
Massa $[\mathrm{g}]$ & 14 \\
\hline
\end{tabular}

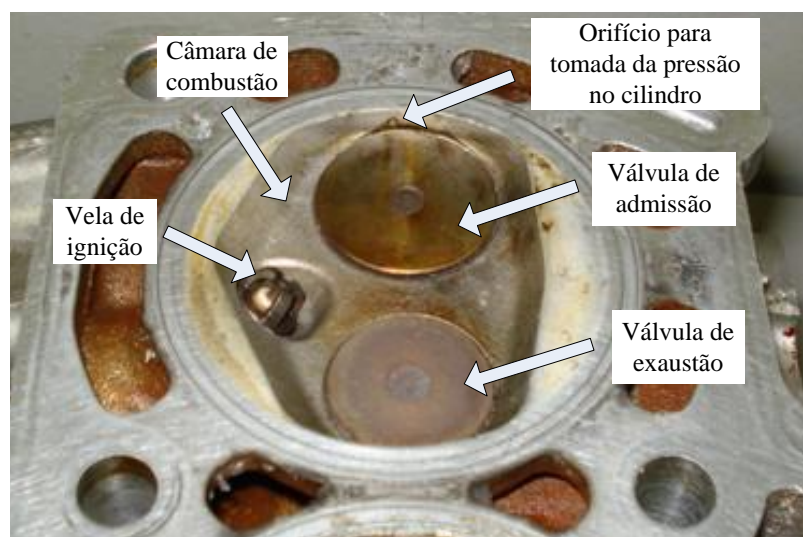

Figura 27 - Câmara de combustão do motor VW AT1000 8V com orifício para tomada da pressão no cilindro.

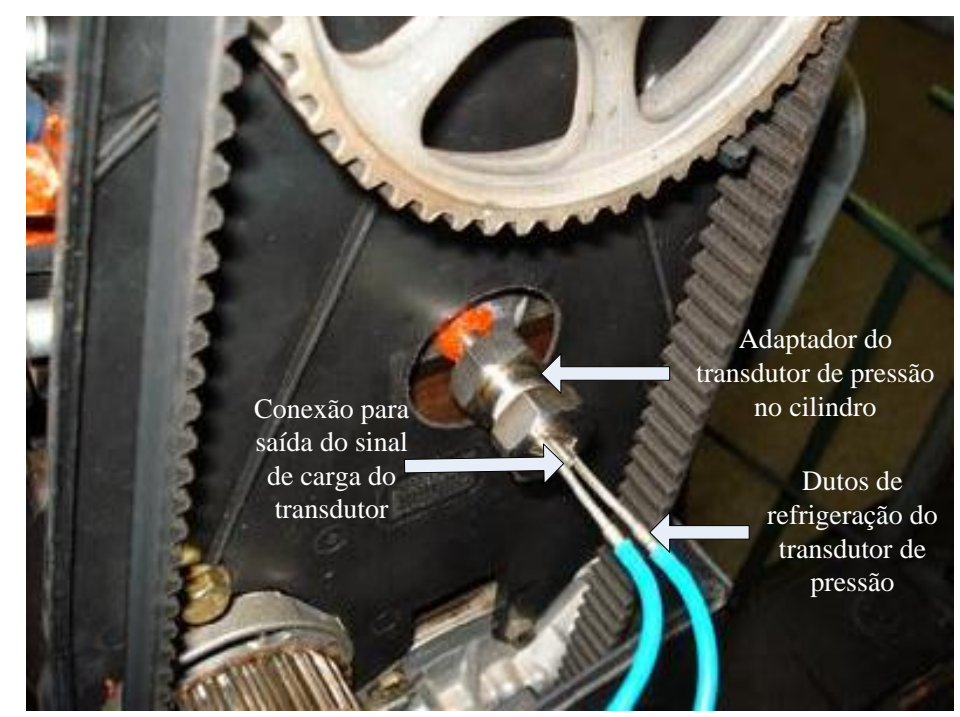

Figura 28 - Transdutor de pressão instalado na câmara de combustão do primeiro cilindro do motor VW AT1000 8V. 
O sinal do transdutor de pressão no cilindro foi amplificado por um amplificador de carga da marca AVL, modelo 3059 HICF. Este amplificador foi calibrado, antes do inicio dos experimentos, utilizando um calibrador de carga da marca AVL, modelo 3054-A01. A Figura 29 apresenta a bancada que engloba o amplificador e o calibrador de carga utilizado.

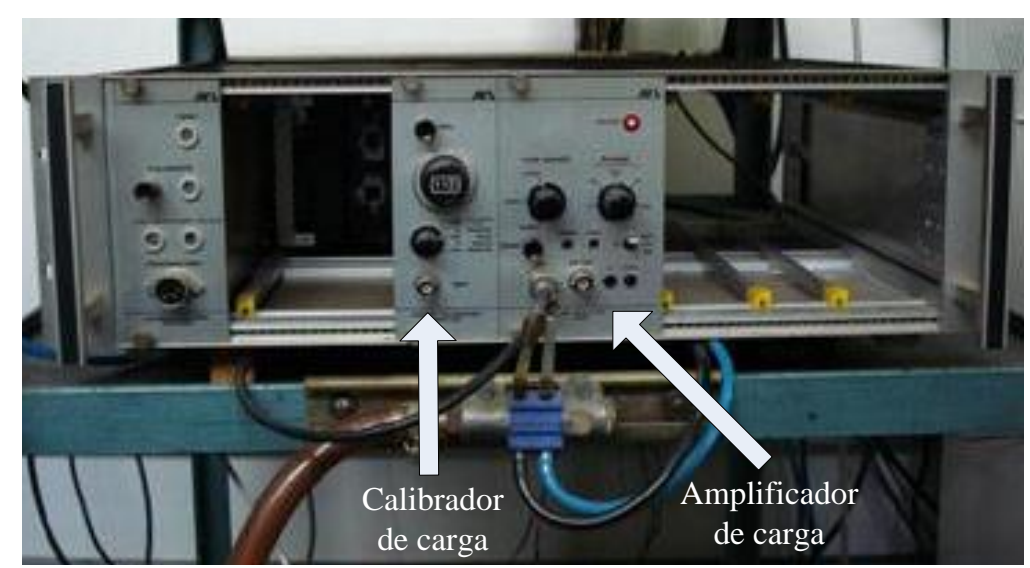

Figura 29 - Amplificador de carga 3059 HICF-Amplifier.

A Tabela 16 apresenta as principais características e resultados do procedimento de calibração do amplificador de carga 3039 HICF.

\begin{tabular}{lc} 
Tabela 16 - Características do amplificador de carga HICF calibrado. \\
\hline Pressão máxima estimada (A) [bar] & 100 \\
Sensibilidade do transdutor (B) [pC/bar] & 11,69 \\
Carga de calibração (C=A*B) [nC] & 1,169 \\
Tensão requerida (D) [V] & 5 \\
Ganho do amplificador (D/A) [V/bar] & 0,05 \\
Posição do Seletor "RANGE" [pC/V] & 100 (100pC até 10nC) \\
Frequência de corte $[\mathrm{kHz}]$ & 100 \\
Entrada do sinal do transdutor & Canal "IN" \\
Temperatura de operação [ $\left.{ }^{\circ} \mathrm{C}\right]$ & $0-60$ \\
Seletor de medida "TIME CONST" & "LONG" (sem filtro) \\
\hline
\end{tabular}

O seletor "RANGE" determina a faixa de medição do amplificador HICF, enquanto que o seletor "TIME CONST" permite a saída do sinal amplificado do transdutor de pressão no cilindro para o sistema de aquisição de dados. A carga de calibração pode ser obtida, segundo o manual do fabricante, devido à boa linearidade do transdutor de pressão, multiplicando a pressão máxima (estimada) pelo ganho do transdutor. O ganho do amplificador (conversor carga/tensão) é de $0,05 \mathrm{~V} / \mathrm{bar}$. 
A faixa de medição selecionada (seletor "RANGE") foi de 100 pC até $10 \mathrm{nC}$ e a carga de calibração é de 1,169 pC o que permite obter medidas de pressão acima de 100 bar sem atingir o fundo de escala do amplificador (aproximadamente 855 bar (10 nC/11,69 pC), que é a maior pressão medida pelo transdutor).

De acordo com as instruções da AVL, fabricante do amplificador HICF, este aparelho é sensível à umidade, o que resulta em um drift (escorregamento) do sinal amplificado. Para evitar ou minimizar este efeito o amplificador foi mantido ligado e alojado em uma sala com condicionador de ar.

Outra medida adotada para evitar a ocorrência de drift no sinal amplificado foi utilizar o seletor "TIME CONST" na posição "GND" antes de ser efetuada a aquisição do sinal amplificado. Na posição "GND" o amplificador descarrega o seu capacitor interno reduzindo os efeitos de escorregamento do sinal.

O drift que não pode ser evitado com os cuidados descritos nesta seção foi corrigido utilizando o parâmetro do erro sistemático da pressão no cilindro, $P_{\text {erro }}$, calculado de acordo com a descrição feita na seção 2.6.1 do Capítulo 2. A subtração deste erro do sinal do transdutor de pressão no cilindro elimina o erro sistemático juntamente com o drift.

O procedimento de cálculo do parâmetro do erro sistemático foi descrito na seção 2.61.

\subsubsection{Sistema de medição de consumo}

O consumo de combustível do motor foi medido em $[\mathrm{g} / \mathrm{s}]$ utilizando uma balança digital da marca Toledo ${ }^{\circledR}$, modelo XP32001L, com faixa de medição de 32,1 kg e resolução de $0,1 \mathrm{~g}$, um computador PC-compatível para aquisição das medidas via porta serial e um algoritmo de monitoração e aquisição de dados desenvolvido em linguagem gráfica LabVIEW ${ }^{\circledR}$.

A Figura 30 apresenta o reservatório colocado sobre a balança digital para a medição da massa de combustível consumida pelo motor. 


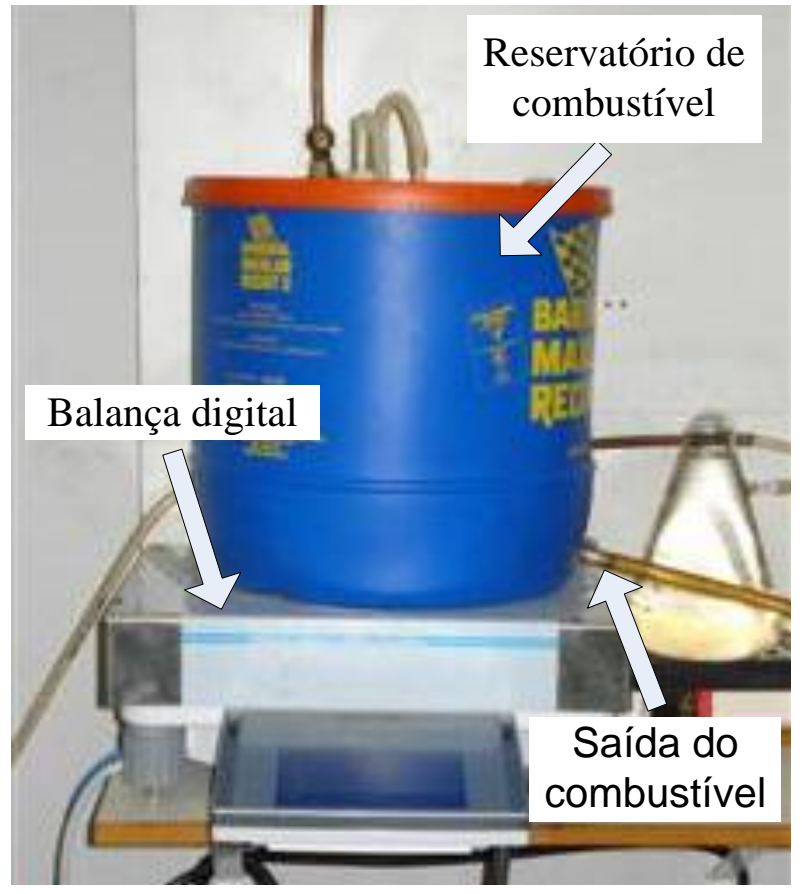

Figura 30 - Reservatório de combustível e balança digital utilizados no sistema de medição de consumo,

O algoritmo de comunicação da balança digital com o PC-compatível, via porta serial, foi desenvolvido em linguagem gráfica LabVIEW ${ }^{\circledR}$ pelo grupo técnico do Núcleo de Engenharia Térmica e Fluídos (NETEF) do Departamento de Engenharia Mecânica da Escola de Engenharia de São Carlos.

Este algoritmo de comunicação foi utilizado no presente estudo no desenvolvimento de outro algoritmo (VI - virtual instrument: instrumento virtual) capaz de medir o consumo horário de combustível.

As Figuras 31 e 32 apresentam o painel frontal e o diagrama de blocos do VI desenvolvido no presente trabalho, respectivamente. Este VI permite visualizar os tempos de aquisição, massa de combustível e consumo horário de combustível em $[\mathrm{g} / \mathrm{s}]$ e $[\mathrm{kg} / \mathrm{h}]$, estabelecer o intervalo entre as medidas em [s] e salvar os valores adquiridos pelo VI de massa de combustível em [g], tempo entre cada medida em [s] e o consumo horário de combustível em [g/s]. 


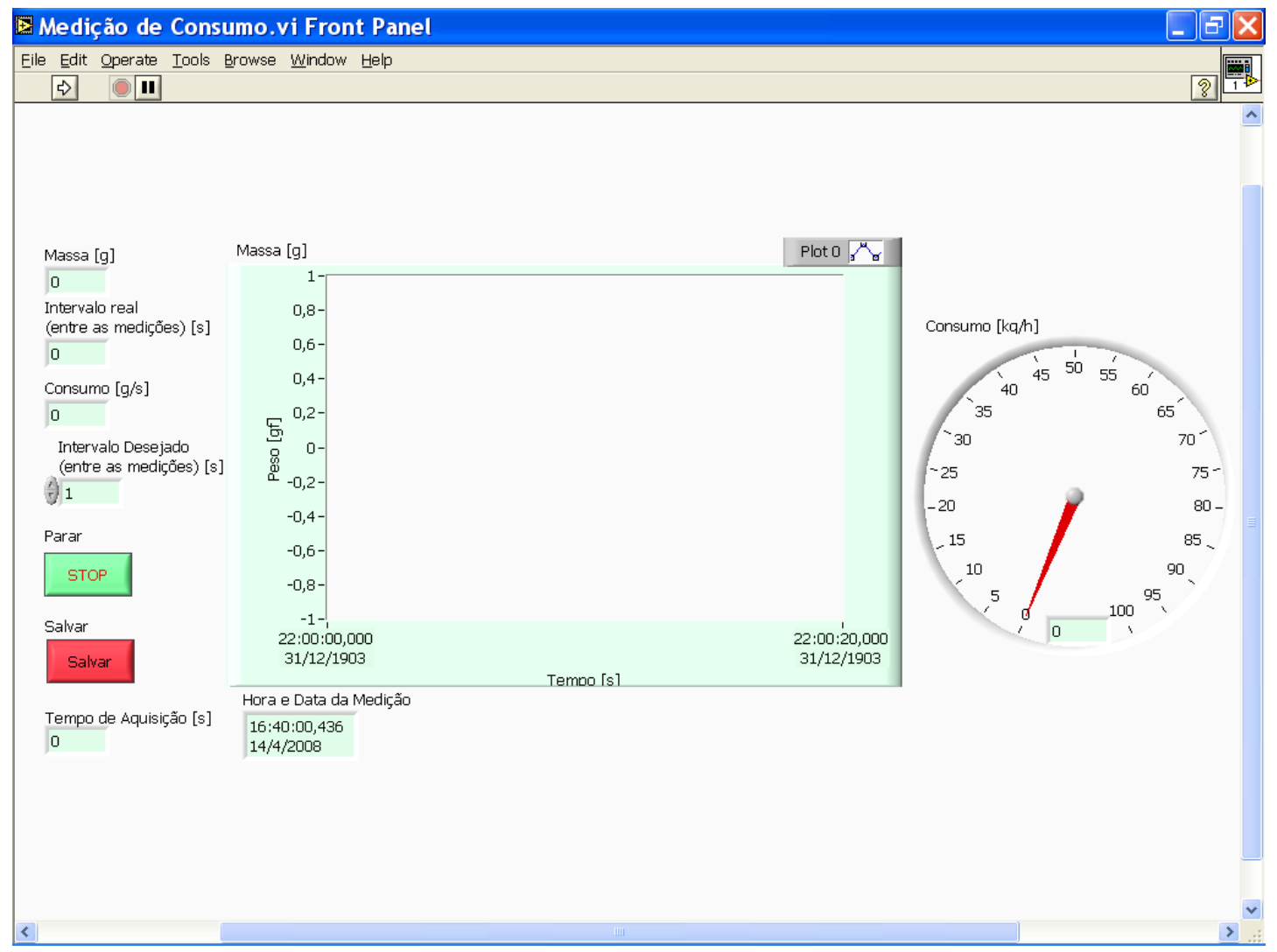

Figura 31 - Painel frontal do VI para medição do consumo de combustível.

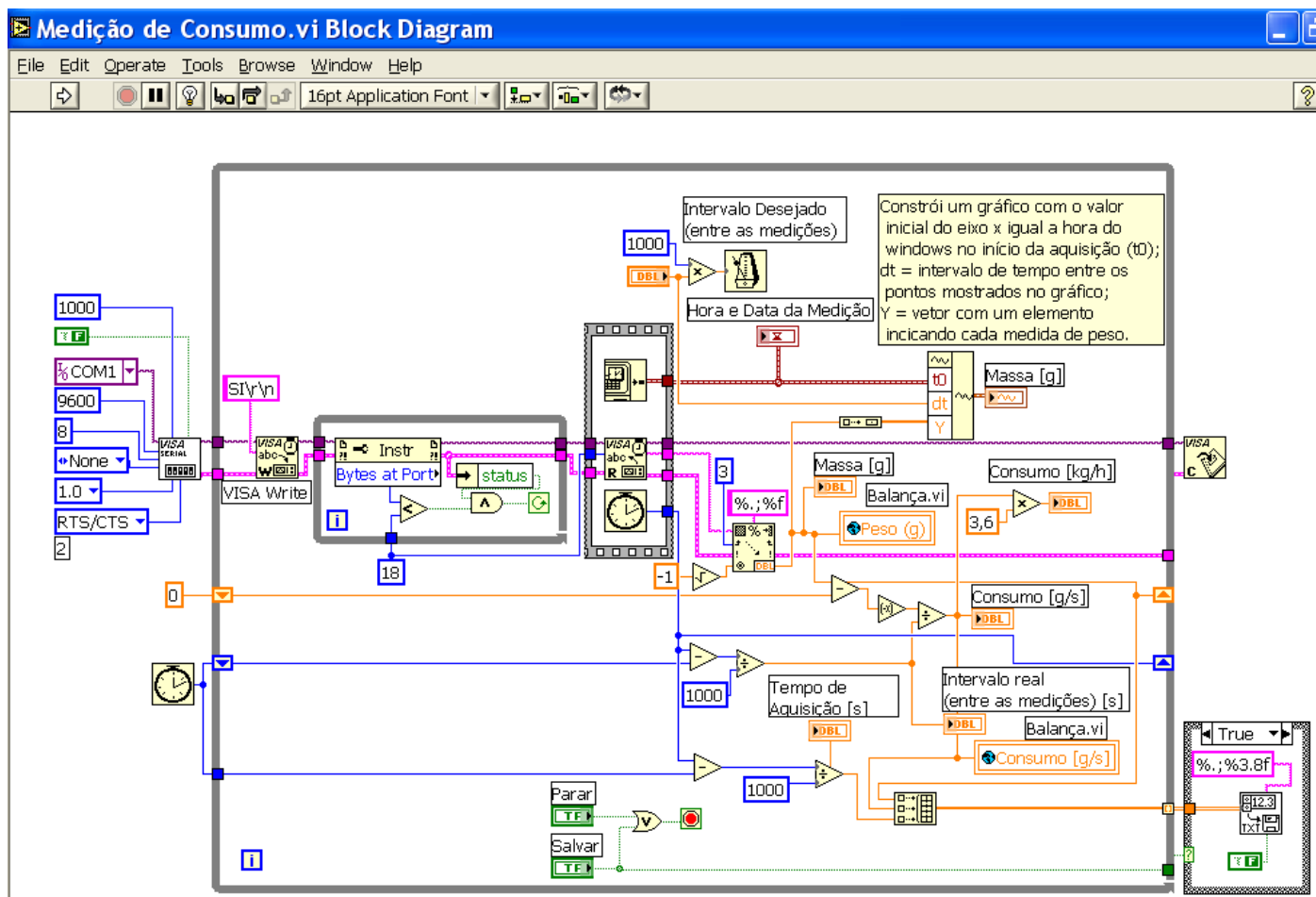

Figura 32 - Diagrama de blocos do VI para medição de consumo de combustível. 


\subsubsection{Sistema de aquisição de dados}

Um módulo de condicionamento de sinais NI SCXI-1000 da National Instruments foi utilizado em conjunto com uma placa de aquisição PCI-6035E da National Instruments, instalada em um computador PC-compatível, e com um algoritmo (VI) desenvolvido em linguagem gráfica LabVIEW ${ }^{\circledR}$, desenvolvido neste estudo, para realizar a aquisição de dados provenientes do motor VW durante as medições.

A placa de aquisição de dados PCI-6035E possui frequência de amostragem máxima de $200 \mathrm{kS} / \mathrm{s}$ (kilo samples per second: amostras por segundo).

O VI de aquisição de dados permite visualizar a magnitude do espectro de frequências do sinal de pressão no cilindro e o consumo de combustível. Outras oito variáveis do funcionamento do motor podem ser visualizadas e salvas por este VI em um arquivo com extensão "txt". A Tabela 17 apresenta estas variáveis e as suas respectivas unidades.

\begin{tabular}{|c|c|}
\hline Variáveis & Unidades \\
\hline Pressão no cilindro & bar \\
\hline Pressão no coletor de admissão & bar \\
\hline Pressão no coletor de escape & bar \\
\hline Temperatura de admissão & ${ }^{\circ} \mathrm{C}$ \\
\hline Temperatura de escape & ${ }^{\circ} \mathrm{C}$ \\
\hline Temperatura do líquido de arrefecimento & ${ }^{\circ} \mathrm{C}$ \\
\hline Massa de ar & $\mathrm{g} / \mathrm{s}$ \\
\hline Onda Hall (sinal do transdutor de rotação-PMS) & $\mathrm{V}$ \\
\hline
\end{tabular}

No VI de aquisição de dados foram estabelecidos a taxa de amostragem, igual a $40 \mathrm{kS} / \mathrm{s}$, e o tempo de aquisição $\left(T_{a q}\right)$, igual a 3,72 s, obtido de acordo com a equação (102). Este tempo resultou em aproximadamente 60 e 90 ciclos de combustão salvos para os tratamentos de $2000 \mathrm{rpm}$ e $3000 \mathrm{rpm}$, respectivamente.

$$
T_{a q}=\frac{2 \text { número } \text { de ciclos }}{\text { rotação por segundo }}=\frac{2(60+2)}{2000 / 60}=\frac{124}{33,33}=3,72 \mathrm{~s}
$$

As Figuras 33 e 34 apresentam o painel frontal e o diagrama de blocos do VI desenvolvido, respectivamente. 
A equação da vazão mássica de ar $\left(m_{a r}\right)$ foi inserida neste algoritmo seguindo as recomendação da Ford, fabricante do transdutor de vazão mássica de ar. Esta equação é representada pela equação (103).

$$
m_{a r}=1,0549 V_{s}^{3}+0,8097 V_{s}^{2}+1,8578 V_{s}+0,6661
$$

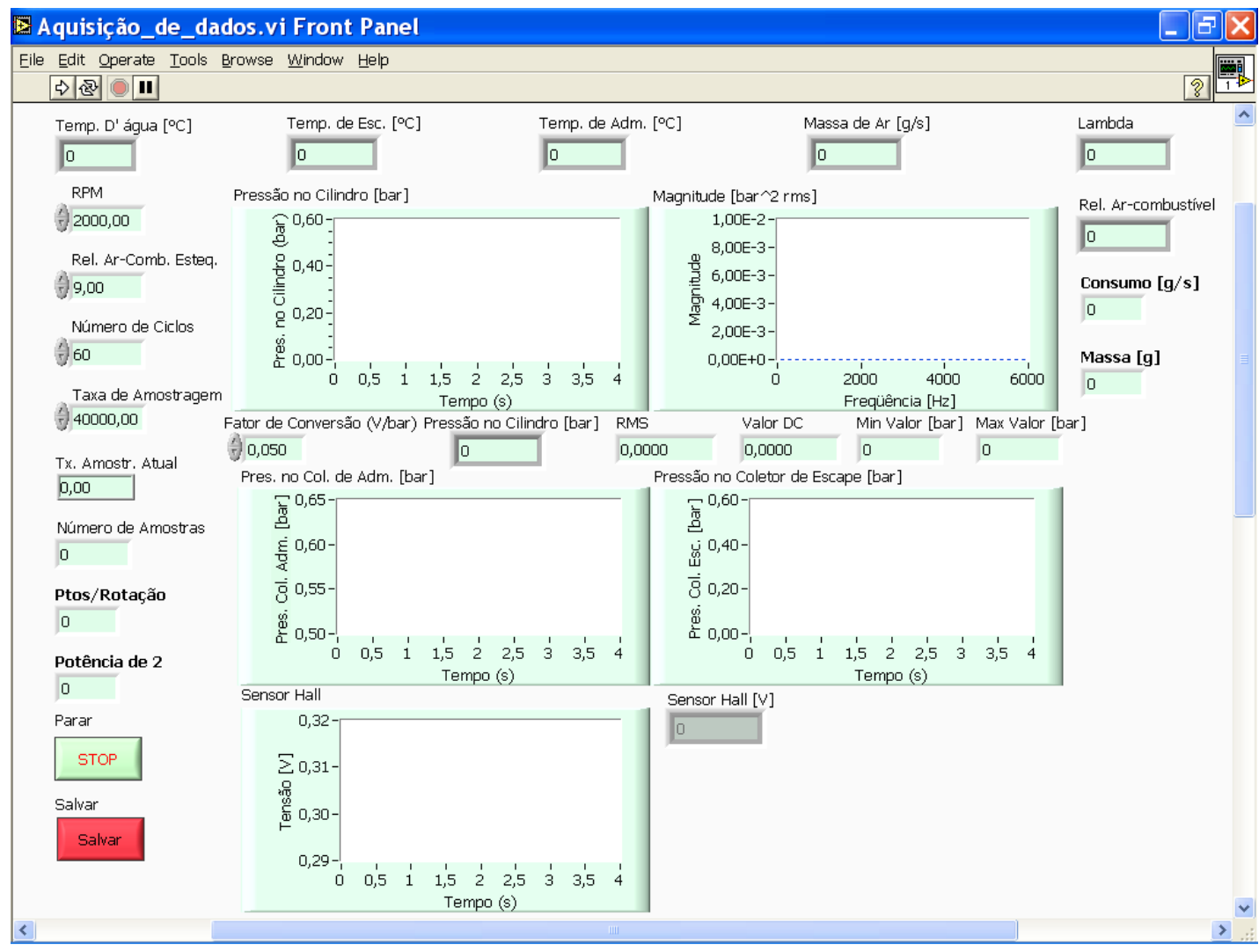

Figura 33 - Painel frontal do VI de aquisição de dados. 


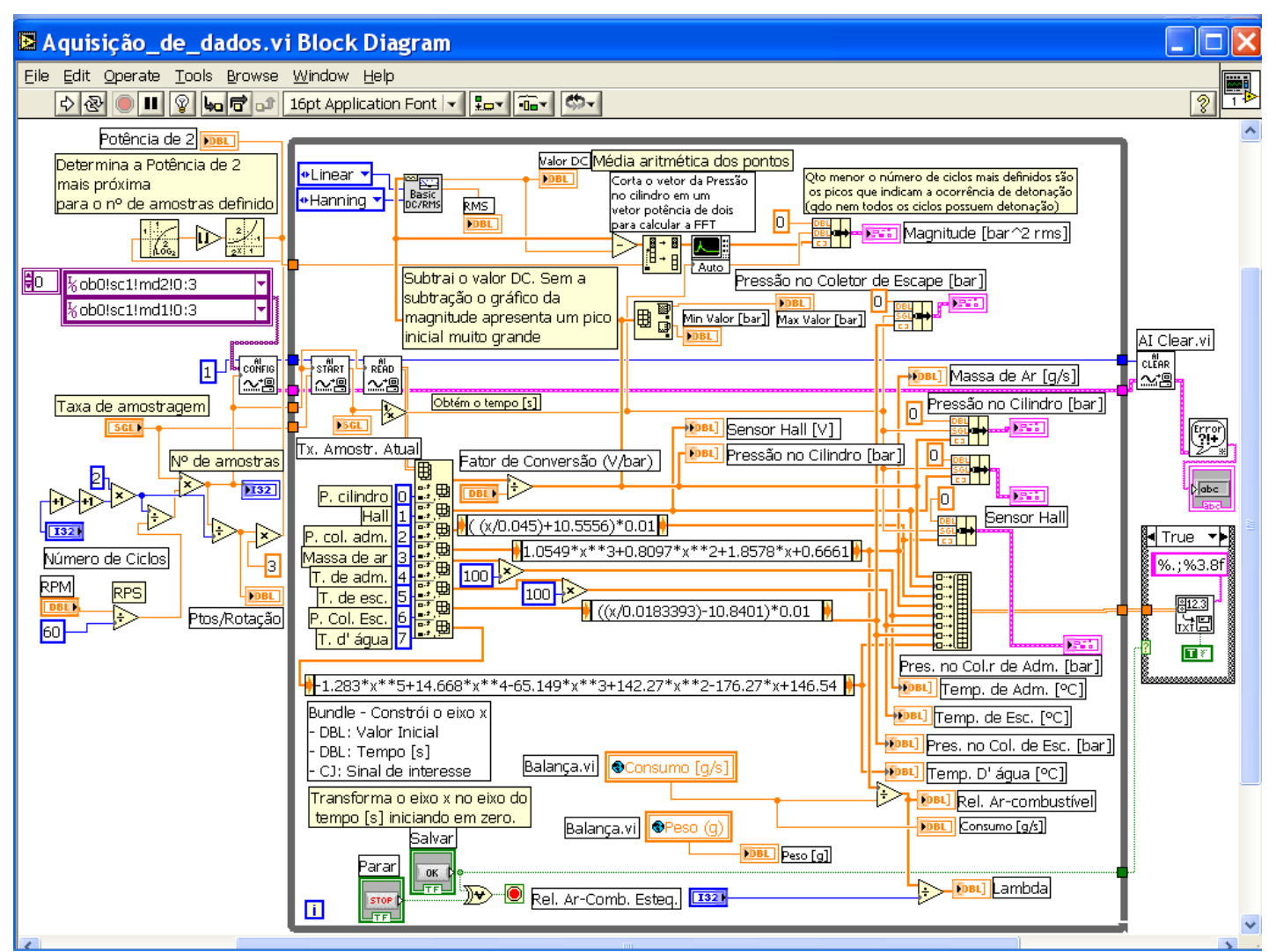

Figura 34 - Diagrama de blocos do VI de aquisição de dados.

\subsubsection{Sistema de gerenciamento eletrônico reprogramável do motor}

O fator lamba e o avanço da centelha foram estabelecidos durante os experimentos utilizando um sistema de gerenciamento eletrônico reprogramável do motor da marca FuelTech, modelo RacePro-1Fi. A Figura 35 mostra a fotografia deste sistema em funcionamento durante os testes do motor. 


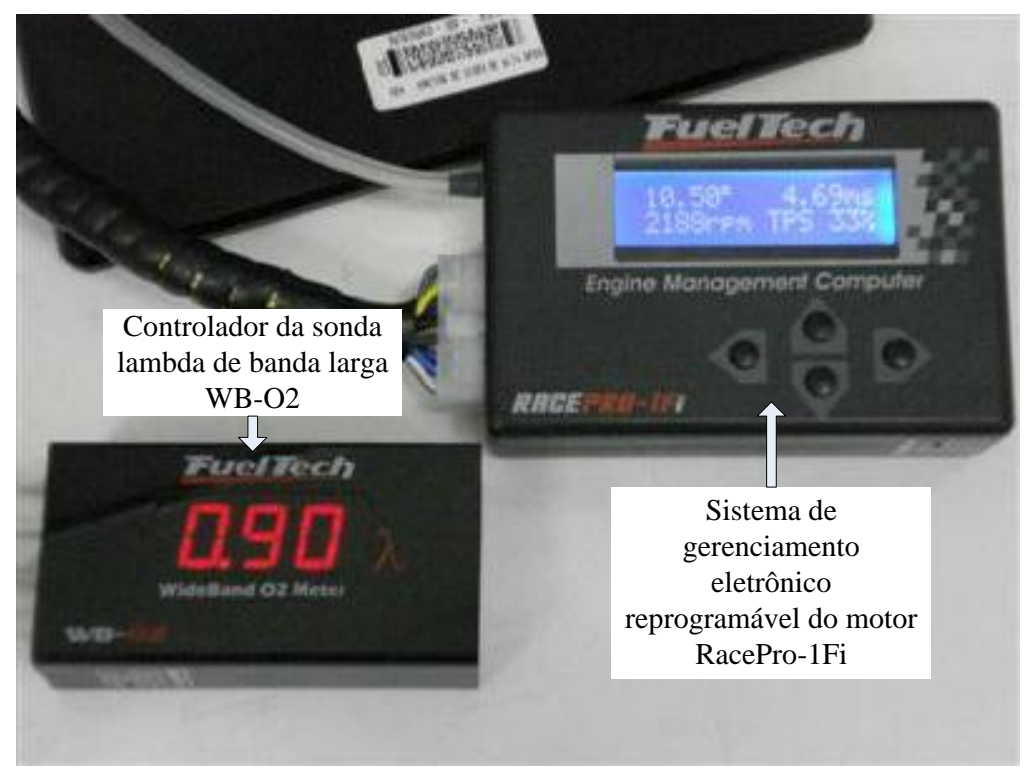

Figura 35 - Sistema de gerenciamento eletrônico reprogramável da marca FuelTech, modelo RacePro$1 \mathrm{Fi}$.

Neste sistema, as válvulas eletromagnéticas injetoras de combustível são disparadas simultaneamente em cada rotação do motor e o sistema de ignição é do tipo dinâmico, utiliza distribuidor instalado no comando de válvulas com transdutor de rotação-PMS e bobina com módulo de potência de ignição (bobina da marca Bosch, código F000ZS0104, de três fios).

O RacePro-1Fi permite a variação dos valores de tempo de injeção de combustível e momento da centelha e monitora diversas variáveis do funcionamento do motor como mostra a Tabela 18.

Tabela 18 - Variáveis monitoradas pelo sistema RacePro-1Fi.

\begin{tabular}{lc}
\hline Momento da centelha & ${ }^{\circ} \mathrm{APMS}$ \\
Tempo de injeção & $\mathrm{ms}$ \\
Rotação & $\mathrm{rpm}$ \\
Abertura das válvulas eletromagnéticas de injeção de combustível & $\%$ \\
Posição da válvula borboleta & $\%$ \\
Pressão no coletor de admissão (transdutor interno) & $\mathrm{bar}$ \\
Temperatura de admissão & ${ }^{\circ} \mathrm{C}$ \\
Temperatura do líquido de arrefecimento & ${ }^{\circ} \mathrm{C}$ \\
Tensão da bateria & $\mathrm{V}$ \\
\hline
\end{tabular}

As alterações feitas durante as medições nos tempos de injeção, modificando o fator lambda, e no avanço da centelha foram conseguidas por meio das funções de ajuste rápido do mapa principal de injeção e ajuste rápido da ignição, respectivamente. O mapa principal de injeção e de ignição tiveram seus valores zerados. 


\subsection{DELINEAMENTO DOS EXPERIMENTOS E MÉTODOS UTILIZADOS}

\subsubsection{Delineamento dos experimentos}

Os experimentos foram realizados ensaiando um motor VW AT1000 8V na bancada dinamométrica apresentada na seção 3.1.

Os quatro tipos de combustíveis descritos a seguir foram utilizados durante os experimentos realizados neste estudo:

- E100: álcool etílico hidratado carburante com teor alcoólico de 92,79 INPM, ou simplesmente etanol,

- E26: gasolina brasileira tipo $C, 23,76 \%$ em massa de álcool etílico anidro carburante $\left(\mathrm{AEHC}-\mathrm{C}_{2} \mathrm{H}_{5} \mathrm{OH}\right)$ com $76,24 \%$ de gasolina tipo A $\left(\mathrm{C}_{11} \mathrm{H}_{24}\right)$, ou $25 \%$ em volume de etanol na gasolina tipo A;

- E56: mistura mássica de 40\% de etanol 92,79 INPM com 60\% de gasolina tipo C, $\mathrm{e}$

- E70: mistura mássica de 60\% de etanol 92,79 INPM com 40\% de gasolina tipo C.

A porcentagem de etanol, em massa, contida em cada uma das misturas de combustíveis, E26, E56 e E70, pode ser obtida utilizando os resultados apresentados no Apêndice B.

As misturas E56 e E70 foram escolhidas com o intuito de que as diferenças nas quantidades de etanol fossem de 30\% em massa em relação aos combustíveis E26 e E100, respectivamente.

Os avanços da centelha utilizados durante os experimentos foram escolhidos para obtenção do máximo torque do motor (MBT), ou seja, o valor do ponto da centelha foi adiantado até encontrar a maior indicação de força na balança dinamométrica, sem ocorrência de knocking para garantir a integridade do motor.

Os fatores $\lambda$ utilizados durante os experimentos foram escolhidos utilizando um espaçamento constante $(\Delta \lambda=0,1)$, partindo de uma mistura ar-combustível rica $(0,9)$ até misturas pobres $(1,3)$.

Inicialmente o motor VW AT 1000 8V foi testado com o seu sistema original de gerenciamento eletrônico (Motronic MP 9.0) e alimentado com E100, variando a rotação e a abertura da válvula borboleta. 
Posteriormente, foi delineado e realizado o experimento 1 em dois regimes de carga, utilizando o sistema de gerenciamento eletrônico reprogramável RacePro-1Fi:

- Experimento 1 em regime de carga parcial (33\% de abertura máxima da válvula borboleta): delineado em função dos fatores: tipo de combustível (E26, E56, E70 e E100), fator $\lambda(0,9,1,0,1,1,1,2$ e 1,3) e rotação do motor (2000 rpm e 3000 rpm).

A Tabela 19 apresenta um resumo deste delineamento;

Tabela 19 - Resumo do delineamento do experimento $1 \mathrm{em}$ carga parcial (33\% de abertura da borboleta de aceleração). As "Observações" se referem aos dados das variáveis do motor coletadas durante o experimento.

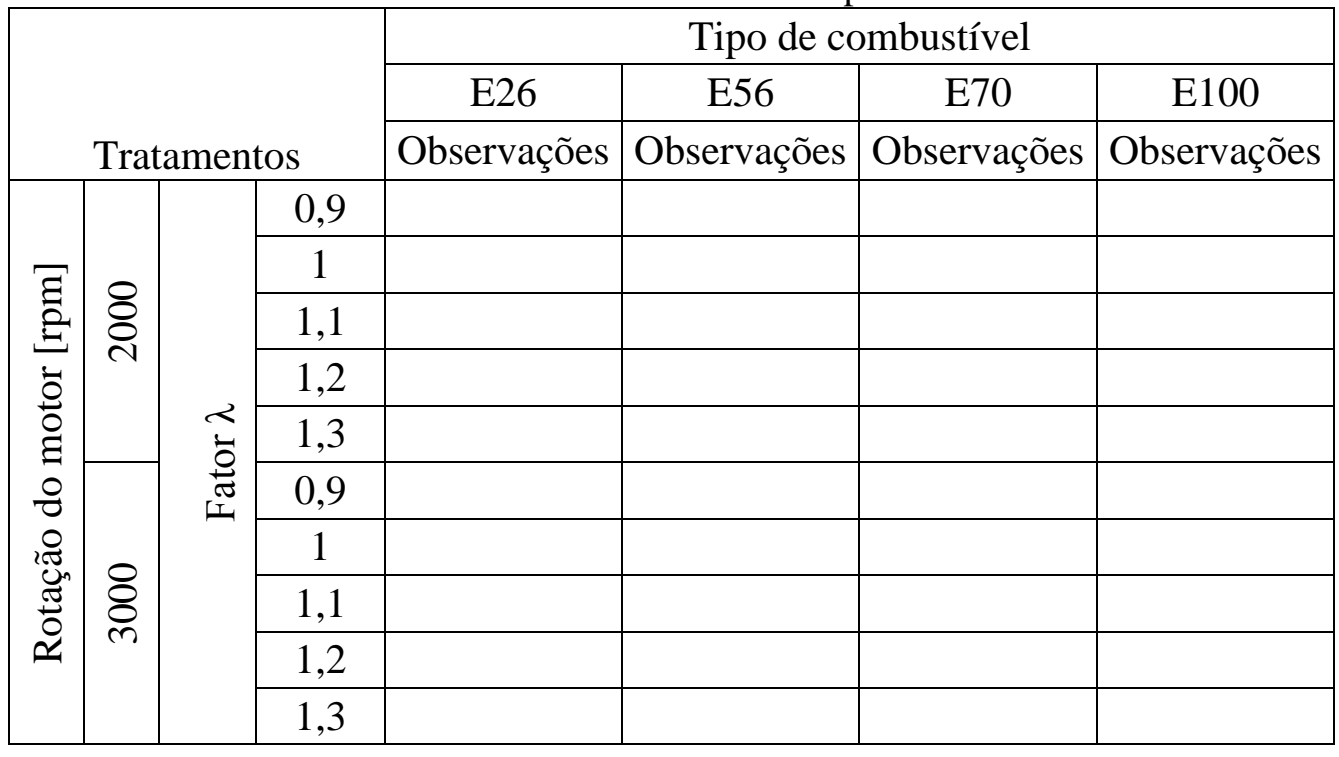

- Experimento 1 em regime de plena carga (abertura máxima da válvula borboleta WOT): delineado em função dos fatores: tipo de combustível (E26, E56, E70 e E100), fator $\lambda(0,9,1,0,1,1,1,2$ e 1,3) e rotação do motor (2000 rpm e 3000 rpm).

A Tabela 20 apresenta um resumo deste delineamento; 
Tabela 20- Resumo do delineamento do experimento 1 - WOT. As "Observações" se referem aos dados das variáveis do motor coletadas durante o experimento.

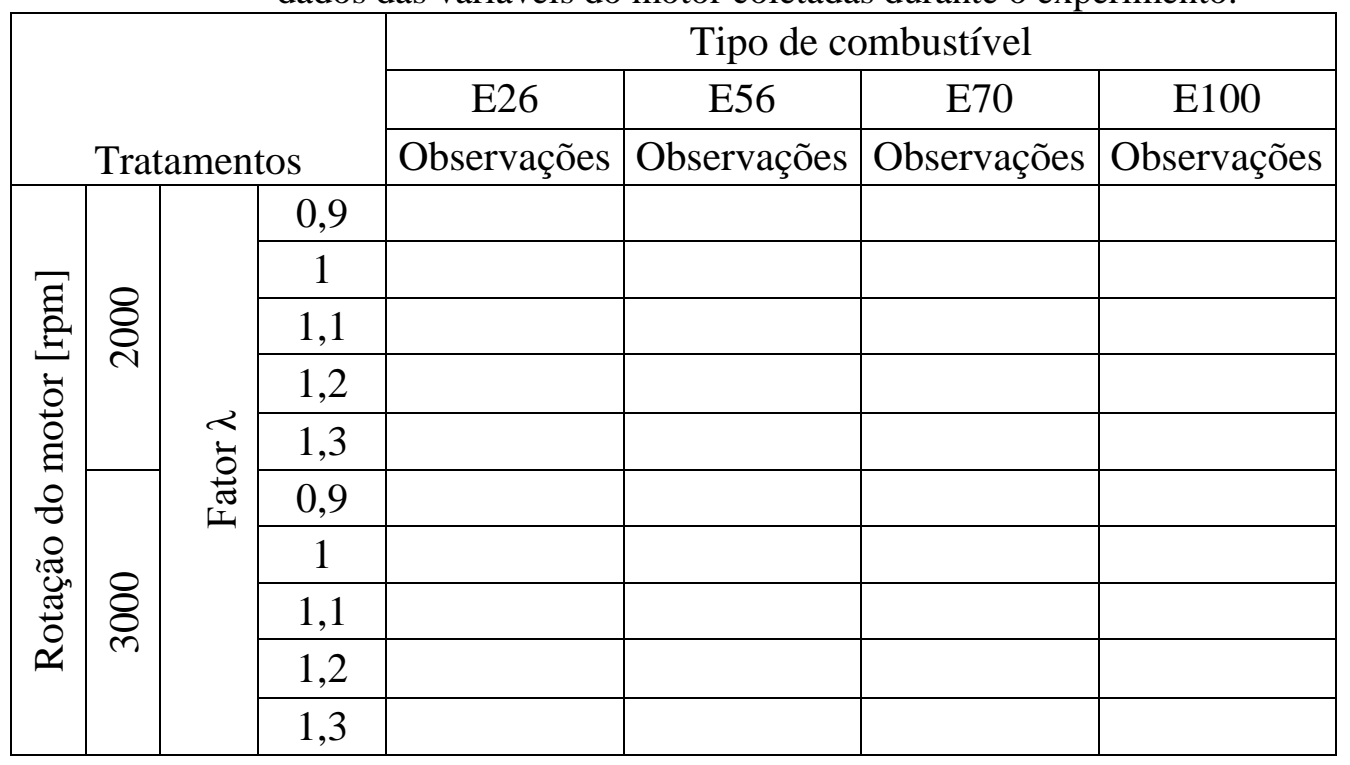

O experimento 1, em regime de carga parcial e de plena carga, foi repetido três vezes cada. Este experimento foi realizado com o intuito de coletar dados para serem utilizados para estimar o fator $\lambda$ e identificar o tipo de combustível.

Durante os testes do motor foram realizados outros experimentos delineados com o avanço da centelha fixo, com ocorrência de knocking e com avanço da centelha progressivo. Estes experimentos não foram utilizados na presente pesquisa com o intuito de focar apenas no experimento 1 , que é mais adequado para realização das estimativas do fator $\lambda$ e identificação do tipo de combustível.

\subsubsection{Variáveis obtidas nos experimentos}

A Tabela 21 apresenta as dezenove variáveis obtidas durante o experimento 1 (nos dois regimes de carga do motor utilizados). Algumas destas variáveis preenchem os campos "Observações" das Tabelas 19 e 20. 
Tabela 21 - Variáveis coletadas durante os experimentos.

\begin{tabular}{|c|c|c|}
\hline Variáveis & Unidades & Equipamento de medição \\
\hline Pressão no cilindro & bar & Amplificador $\mathrm{HICF}$ \\
\hline Pressão no coletor de admissão & bar & $\begin{array}{l}\text { Circuito do transdutor } \\
\text { MPXH6115AC6T1 }\end{array}$ \\
\hline Pressão no coletor de escape & bar & Circuito do transdutor MPX4250GP \\
\hline Temperatura de admissão & ${ }^{\circ} \mathrm{C}$ & Amplificador de termopar do tipo K \\
\hline Temperatura de escape & ${ }^{\circ} \mathrm{C}$ & Amplificador de termopar do tipo K \\
\hline Temperatura do motor & ${ }^{\circ} \mathrm{C}$ & Transdutor de temperatura \\
\hline Massa de ar & $\mathrm{g} / \mathrm{s}$ & Transdutor de massa de ar \\
\hline Onda Hall (rotação - PMS) & V & Buffer de tensão \\
\hline Força (balança dinamométrica) & $\mathrm{kg}$ red & Dinamômetro \\
\hline Temperatura de bulbo seco & ${ }^{\circ} \mathrm{C}$ & Psicrômetro \\
\hline Temperatura de bulbo úmido & ${ }^{\circ} \mathrm{C}$ & Psicrômetro \\
\hline Pressão barométrica & $\mathrm{mmHg}$ & Barômetro \\
\hline Avanço da centelha & ${ }^{\circ} \mathrm{APMS}$ & Pistola indutiva de ponto \\
\hline Tempo de injeção & $\mathrm{ms}$ & RacePro-1Fi \\
\hline $\mathrm{CO}$ & $\%$ Vol. & TM131 \\
\hline $\mathrm{CO}_{2}$ & $\%$ Vol. & TM131 \\
\hline $\mathrm{O}_{2}$ & $\%$ Vol. & TM131 \\
\hline $\mathrm{HC}$ & ppm & TM131 \\
\hline
\end{tabular}

\subsubsection{Obtenção das misturas de combustíveis}

As duas misturas de combustíveis foram obtidas por porcentagens em massa de cada combustível que as compõe. Assim, a primeira mistura foi composta por $60 \%$ em massa de etanol 92,79 INPM e 40\% em massa de gasolina brasileira do tipo $C$ (contendo 23,76\% em massa de álcool em sua composição), enquanto que a segunda mistura foi composta por $40 \%$ em massa de etanol 92,79 INPM e 60\% em massa de gasolina brasileira do tipo $C$.

As massas de cada combustível foram medidas usando uma balança digital da marca Toledo $^{\circledR}$, modelo XP32001L, com faixa de medição de $32,1 \mathrm{~kg}$ e resolução de $1 \mathrm{~g}$.

Os poderes caloríficos superiores do etanol 92,79 INPM, da gasolina brasileira do tipo $C$ e das duas misturas foram obtidos por meio de ensaios, em um calorímetro da marca IKA ${ }^{\circledR}$, modelo C5000 control, realizados no Núcleo de Engenharia Térmica e Fluídos (NETEF) da Escola de Engenharia de São Carlos. A determinação do poder calorífico inferior foi realizada por cálculos apresentados no Apêndice C.

As relações ar-combustível (A/C) de cada tipo de combustível foram obtidas no Apêndice B. 
O teor alcoólico dos lotes de etanol utilizados nos experimentos foi fornecido pelo laboratório de análises da empresa Virgolino de Oliveira S.A. Açúcar e Álcool por intermédio do Dr. Armando José Dal Bem. Estes teores são apresentados no Apêndice B.

Os lotes de etanol utilizados nos experimentos foram integralmente doados pelo Dr. Armando José Dal Bem do grupo Virgolino de Oliveira S.A. Açúcar e Álcool.

A gasolina brasileira do tipo $C$ utilizada nos experimentos foi comprada em um posto de venda de combustíveis localizado na cidade de São Carlos.

\subsubsection{Procedimentos adotados durante os experimentos}

Para preservar os equipamentos da bancada dinamométrica antes do início das medições realizadas em cada experimento foram adotados diversos procedimentos apresentados no Apêndice G.

Para evitar distorções nos experimentos todas as medições foram iniciadas somente depois de o motor estar devidamente aquecido (depois das ventoinhas, do sistema de arrefecimento, serem ligadas pela segunda vez).

Durante os experimentos, as aberturas da válvula borboleta, utilizadas em dois níveis (33\% e 100\%), foram obtidas utilizando a indicação de posição da válvula borboleta do sensor TPS, original do sistema Motronic MP 9.0, no sistema RacePro-1Fi para alterar a posição da alavanca do acelerador do motor.

O sistema de controle do dinamômetro foi responsável por manter a rotação constante nos dois níveis (2000 rpm e $3000 \mathrm{rpm}$ ) empregados durante os experimentos.

O sistema RacePro-1Fi foi utilizado para alcançar os valores de lambda nos gases de exaustão, definidos em cada tratamento do experimento, alterando os valores de tempo de injeção das válvulas eletromagnéticas de injeção de combustível. O controlador da sonda lambda de banda larga WB-O2 ficou encarregado de mostrar se os valores de lambda realmente foram alcançados.

O avanço da centelha foi modificado em cada experimento utilizando o RacePro-1Fi e conferido com o emprego de uma pistola indutiva de ponto. No experimento com avanço da centelha para máximo torque (MBT) o valor do avanço da centelha foi modificado até encontrar a maior indicação de força na balança dinamométrica, sem ocorrência de knocking para garantir a integridade do motor.

As trocas de combustíveis durante os experimentos foram realizadas deixando o motor em funcionamento até o esgotamento completo do combustível substituído. 
Não foi possível controlar a temperatura ambiente durante os experimentos, mas procurou-se ao máximo possível evitar a influência da temperatura ambiente nos resultados.

As coletas das variáveis do motor só foram realizadas quando o sistema de refrigeração do motor encontrava-se com as ventoinhas do sistema de arrefecimento desligadas.

\subsubsection{Cálculo das variáveis de desempenho do motor}

Foram obtidas e analisadas três variáveis de desempenho do motor após o encerramento do experimento 1 (em regimes de plena carga e carga parcial).

\subsubsection{Torque e potência do motor}

O torque $[\mathrm{Nm}]$ e a potência do motor $[\mathrm{kW}]$ foram obtidos por meio das equações (93) e (95) apresentados na seção 3.1.1.1, respectivamente.

\subsubsection{Consumo específico}

O consumo específico $\left(C_{e s p}\right)$ [g/kWh] foi calculado dividindo o consumo horário $[\mathrm{g} / \mathrm{h}]$ pela potência do motor [kW], como mostra a equação (104).

$$
C_{\text {esp }}=\frac{C_{\text {hor }}}{\text { Potência }} \quad[g / k W h]
$$

\subsubsection{Eficiência de conversão de combustível}

Como descrito no capítulo de revisão bibliográfica, a eficiência de conversão de combustível $(\eta)$ é representada pela equação (105), em que $C_{e s p}$ é o consumo específico de combustível em [g/kWh] e PCI é o poder calorífico inferior do combustível em $[\mathrm{MJ} / \mathrm{kg}]$.

$$
\eta=\frac{3600}{C_{e s p} P C I}
$$




\subsubsection{Análise dos dados coletados no experimento 1}

Todos os ensaios realizados em plena carga tiveram a potência corrigida segundo a norma técnica NBR ISO 1585 antes de serem analisados.

A NBR ISO 1585 não prevê correção da potência para ensaios realizados em cargas parciais, portanto, os dados de potência obtidos em carga parcial não foram corrigidos. Entretanto, conforme dito anteriormente, procurou-se realizar o experimento dentro de condições atmosféricas muito próximas.

Os dados do experimento 1 em carga parcial não foram analisados quanto aos parâmetros de desempenho e emissões de gases poluentes devido à impossibilidade de controlar a temperatura ambiente e de corrigir a potência obtida.

As seis variáveis analisadas foram as três variáveis de desempenho do motor (potência, consumo específico e eficiência de conversão de combustível) e os teores dos três gases $(C O$, $\mathrm{CO}_{2}$ e $\mathrm{HC}$ ) coletados na exaustão do motor.

Para inferir sobre a influência de cada fator sobre estas variáveis foi utilizada ANOVA (análise de variância).

As formulações teóricas utilizadas para aplicação de ANOVA nos dois experimentos analisados, para testar hipóteses sobre os efeitos de cada fator e as interações entre eles, foram descritas no capítulo de revisão bibliográfica de acordo com Montgomery e Runger (2003).

Para aplicar ANOVA nos experimentos realizados assumiu-se a hipótese de que eles foram completamente aleatorizados.

As tabelas de resumo dos delineamentos dos experimentos, Tabelas 19 e 20, apresentam os fatores a serem analisados utilizando ANOVA. A influência destes fatores e suas interações sobre as variáveis analisadas serão resumidas no capítulo de Resultados Alcançados. As tabelas de ANOVA obtidas para a análise dos dados do motor serão exibidas no Apêndice A2.

As variáveis analisadas no experimento 1 em plena carga podem ser descritas, segundo Montgomery e Runger (2003), pelo modelo estatístico linear descrito pela equação (106).

$$
Y_{i j \psi}=\mu+A_{i}+B_{j}+(A B)_{i j}+\varepsilon_{i j \psi}
$$

em que:

$A=$ efeito do fator $A$;

$B=$ efeito do fator $B$; 
$A B=$ efeito da interação entre os fatores $A$ e $B ;$

Índices $i, j, \psi=$ representam os níveis dos fatores (tratamentos);

$\varepsilon=$ erro aleatório com distribuição normal, média zero e variância $\sigma^{2}$.

As hipóteses que serão testadas no próximo capítulo para o experimento 1 são:

1. Hipóteses para o fator $A$ :
$H_{0}: A_{1}=A_{2}=\ldots=A_{a}=0 \quad$ (nenhum efeito principal do fator $A$ );
$H_{1}$ : no mínimo um $A i \neq 0 \quad$ (fator $A$ afeta a variável aleatória).

2. Hipóteses para o fator $B$ :

$$
\begin{array}{ll}
H_{0}: B_{1}=B_{2}=\ldots=B_{a}=0 & \text { (nenhum efeito principal do fator } B \text { ); } \\
H_{1}: \text { no mínimo um } B j \neq 0 & \text { (fator } B \text { afeta a variável aleatória). }
\end{array}
$$

3. Hipóteses para interação entre os fatores $A B$ :

$$
H_{0}:(A B)_{11}=(A B)_{12}=\ldots=(A B)_{a b}=0 \text { (nenhum efeito principal da }
$$

interação do fator $A$ com o fator $B)$;

$$
H_{1} \text { : no mínimo um }(A B)_{i j} \neq 0 \quad \text { (interação } A B \text { afeta a variável aleatória). }
$$

em que:

$$
\begin{aligned}
& A=\text { fator } A, \text { que é o fator } \lambda ; \\
& B=\text { fator } B, \text { que é o tipo de combustível; } \\
& H_{0}=\text { hipótese nula; } \\
& H_{1}=\text { hipótese alternativa; }
\end{aligned}
$$

Índices 1,2 , i e $j=$ representam os níveis dos fatores (tratamentos).

O nível de significância $(\alpha)$ utilizado em todas as análises foi de $0,05(5 \%)$.

Os valores críticos de $F_{0,05}$, numerador, denominador foram obtidos utilizando as tabelas da distribuição $F$ apresentadas por Montgomery e Runger (2003).

Para inferir sobre as diferenças das médias de cada nível dos fatores, após a aplicação de ANOVA (sem ocorrência de interação entre os fatores principais $(A$ e $B)$ ), foi utilizado o procedimento de Tukey, apresentado no capítulo de revisão bibliográfica de acordo com Benjamini e Braun (2002).

Na presença de interação entre os fatores principais $(A$ e $B)$ foi aplicado o método dos efeitos simples principais (SME), relatado por Huck (2012), antes da utilização do procedimento de Tukey. O método SME foi descrito no Capítulo 2. 
Na aplicação do método $S M E$ foi priorizada a influência dos tipos de combustível sobre cada fator $\lambda$, ou seja, optou-se pela verificação da capacidade de se diferenciar os quatro tipos de combustíveis em cada um dos fatores $\lambda$ utilizados durante o experimento 1 em plena carga.

O nível de significância $(\alpha)$ utilizado no procedimento de Tukey foi de 0,05 (5\%).

Os valores de $Q_{0,05}$, numerador, denominador foram obtidos utilizando as tabelas do procedimento de Tukey apresentadas no Anexo D.

Os resultados da aplicação do procedimento de Tukey e do método SME serão exibidos no Apêndice A2.

O algoritmo 1 do Apêndice A3 foi elaborado para realizar todas as análises estatísticas dos parâmetros de desempenho e das emissões do motor.

Para a realização das análises estatísticas, as variáveis: abertura da válvula borboleta e rotação foram fixadas com o intuito de se analisar apenas os efeitos dos fatores principais de interesse (fator $\lambda$ e tipo de combustível) sobre os variáveis do motor.

A energia disponível, apresentada nas Tabela A1 e A2, foi obtida de acordo com a equação (107). Trata-se de uma variável auxiliar na interpretação dos resultados de desempenho do motor que não será utilizada nas análises estatísticas.

$$
\text { Energia disponível }=\frac{C_{h o r} P_{C I}}{1000} \quad[M J / s]
$$

Os fatores $\lambda$ utilizados para as análises foram obtidos pela leitura da sonda lambda de banda larga WB-O2.

Um segundo fator $\lambda, \lambda c$, foi obtido pela combinação da massa de ar, relação de estequiometria e consumo de combustível. O $\lambda c$, exibido nas Tabelas A1 e A2, não foi utilizado devido à impossibilidade de se efetuar a calibração do transdutor de massa de ar.

\subsubsection{Obtenção e análise dos modelos estatísticos de estimação do fator $\lambda$ e de identificação do tipo de combustível}

Antes de obter os modelos estatísticos foi necessário corrigir o escorregamento do sinal amplificado do transdutor de pressão no cilindro utilizando o parâmetro $P_{\text {erro }}$, descrito no Capítulo 2.

Os traços de pressão no cilindro utilizados na construção dos modelos foram escolhidos aleatoriamente, ou seja, não foi utilizada nenhuma ferramenta de seleção de dados (filtros, algoritmos de pré-seleção, etc.). O objetivo deste procedimento foi evitar que apenas ciclos 
semelhantes fossem escolhidos para representar um dada condição de operação do motor, descaracterizando a variação cíclica da pressão no cilindro.

Os momentos estatísticos, calculados e normalizados a partir do sinal da pressão no cilindro de acordo com as equações expressas na seção 2.9.1 do Capítulo 2, foram obtidos utilizando médias de 20 ciclos de pressão no cilindro, para permitir a comparação dos resultados com os relatos apresentados na literatura.

Foram obtidos momentos de segunda $\left(M_{2}\right)$ até a quinta ordem $\left(M_{5}\right)$ utilizando as seguintes janelas de pressão no cilindro (trechos do traço da pressão no cilindro):

- Janela 1: início no avanço da centelha e continuando por 120 graus (proposta por Gilkey e Powell (1985));

- janela 2: início no avanço da centelha e continuando até o instante em que a válvula de exaustão se abre $\left(\right.$ vea $\left.=516^{\circ}\right)$;

- janela 3: início no instante em que a válvula de admissão se fecha $\left(\right.$ vaf $\left.=197^{\circ}\right)$ até o instante em que a válvula de exaustão se abre, e

- janela 4: início em $5^{\circ} \mathrm{APMS}$ e continuando por $40^{\circ} \mathrm{DPMS}$ (compreende, aproximadamente, a região em que ocorre o pico de pressão no cilindro).

Os momentos foram normalizados pela área sob a curva da pressão de acionamento, como apresentado na seção 2.9.1, para evitar que uma mudança no ganho do sensor (troca de sensor) seja interpretada como resultado de uma alteração nas variáveis do motor, afetando a magnitude do traço de pressão no cilindro.

Os valores do volume no cilindro foram obtidos segundo as formulações apresentadas na seção 2.1.1 (aproximação do cálculo do volume no cilindro apresentada por Tunestal (2000)), e os valores de $a G$ segundo as formulações apresentadas na seção 2.6.1.

As unidades de pressão e de volume no cilindro foram fixadas em bar $\mathrm{e} \mathrm{m}^{3}$, respectivamente.

Os modelos de estimação do fator $\lambda$ e de identificação do tipo de combustível (ou estimação da fração mássica de etanol - FMDE) foram delineados a partir do primeiro modelo apresentado por Gilkey e Powell (1985), baseado no coeficiente que estima as condições báricas da carga admitida no motor $(a G)$, na rotação real do motor ( $N$ - determinada pelo sinal do transdutor de rotação - PMS) e nos momentos de segunda $\left(M_{2}\right)$ e terceira ordem $\left(M_{3}\right)$. 
O modelo 1 utilizado para a estimativa do fator $\lambda$ e para a estimativa da fração mássica de etanol - FMDE pode ser visualizado nas equações 108 e 109, respectivamente.

$$
\lambda=a_{1}+a_{2} a G+a_{3} N+a_{4} M_{2}+a_{5} M_{3}
$$

Modelo 1:

$$
F M D E=a_{1}+a_{2} a G+a_{3} N+a_{4} M_{2}+a_{5} M_{3}
$$

A Tabela 22 indica a fração mássica de etanol $(F M D E)$ em cada mistura combustível utilizada neste estudo. A fração mássica de etanol foi obtida dividindo a porcentagem mássica de etanol (Apêndice B) por uma constante de valor cem.

Tabela 22 - Fração mássica de etanol utilizada nas misturas combustíveis ensaiadas nos experimento 1.

\begin{tabular}{lcccc}
\hline & \multicolumn{4}{c}{ Combustíveis } \\
\multicolumn{1}{c}{ Parâmetros } & E26 & E56 & E70 & E100 \\
\hline Porcentagem mássica de $C_{11} H_{24}[\%]$ & 73,71 & 44,22 & 29,48 & 0 \\
Fração mássica de etanol & 0,2629 & 0,5578 & 0,7052 & 1 \\
\hline
\end{tabular}

A partir do modelo 1 foram analisadas outras variáveis independentes que poderiam contribuir para a estimação do fator $\lambda$ e identificação do tipo de combustível. Dentre estas variáveis destacam-se:

- o tempo de injeção de combustível (TI, em s);

- o pico de pressão no cilindro ( $P C$, em bar);

- o avanço da centelha ( $A V$, em graus);

- os momentos de segunda e terceira ordem obtidos a partir da aplicação do método da razão de pressões no cilindro (janela 5: $120^{\circ}$ APMS até $60^{\circ}$ APMS e janela 6: $60^{\circ} \mathrm{DPMS}$ até $\left.120^{\circ} \mathrm{DPMS}\right)$;

- a temperatura do ar, tomada no coletor de admissão $\left(T A\right.$, em $\left.{ }^{\circ} \mathrm{C}\right)$, e

- a temperatura dos gases de exaustão, tomada no coletor de escape (TE, em $\left.{ }^{\circ} \mathrm{C}\right)$.

Além das variáveis independentes do motor foram utilizados os momentos de segunda e terceira ordem elevados ao quadrado para compor novos modelos. 
Utilizando as variáveis independentes disponíveis foram elaborados além do modelo 1 mais oito modelos originais de estimação do fator $\lambda$ e identificação do tipo de combustível (FMDE), como mostram as equações (110 a 117).

Modelo 2: $\quad$ FMDE ou $\lambda=a_{1}+a_{2} a G+a_{3} N+a_{4} M_{2}+a_{5} M_{3}+a_{6} T I$

Modelo 3: $\quad F M D E$ ou $\lambda=a_{1}+a_{2} a G+a_{3} N+a_{4} M_{2}+a_{5} M_{3}+a_{6} T I+a_{7} P C$

Modelo 4: FMDE ou $\lambda=a_{1}+a_{2} a G+a_{3} N+a_{4} M_{2}+a_{5} M_{3}+a_{6} T I+a_{7} P C+$ $+a_{8} A V$

Modelo 5:

$F M D E$ ou $\lambda=a_{1}+a_{2} a G+a_{3} N+a_{4} M_{2}+a_{5} M_{3}+a_{6} T I+a_{7} P C+$

Modelo 6:

$a_{8} A V+a_{9} M T X_{2}+a_{10} M T X_{3}$

$F M D E$ ou $\lambda=a_{1}+a_{2} a G+a_{3} N+a_{4} M_{2}+a_{5} M_{3}+a_{6} T I+a_{7} P C+$

$a_{8} A V+a_{9} M_{4}+a_{10} M_{5}$

FMDE ou $\lambda=a_{1}+a_{2} a G+a_{3} N+a_{4} M_{2}+a_{5} M_{3}+a_{6} T I+a_{7} P C+$

Modelo 7: $\quad a_{8} A V+a_{9} M_{4}+a_{10} M_{5}+a_{11} T A$

Modelo 8:

$F M D E$ ou $\lambda=a_{1}+a_{2} a G+a_{3} N+a_{4} M_{2}+a_{5} M_{3}+a_{6} T I+a_{7} P C+$

$a_{8} A V+a_{9} M_{4}+a_{10} M_{5}+a_{11} T A+a_{12} T E$

Modelo 9: $F M D E$ ou $\lambda=a_{1}+a_{2} a G+a_{3} N+a_{4} M_{2}+a_{5} M_{3}+a_{6} T I+a_{7} P C+$

$a_{8} A V+a_{9} M_{2}^{2}+a_{10} M_{3}^{2}$

Cada um dos modelos desenvolvidos a partir do modelo 1 teve o acréscimo de apenas uma variável independente em relação ao seu antecessor. Isto permitiu verificar se a variável acrescida melhora ou não as estimativas do fator $\lambda$ e da $F M D E$. 
A capacidade de cada variável independente em estimar o fator $\lambda$ e de identificar o tipo de combustível (estimar a FMDE) foi realizada comparando os resultados do modelo atual com o seu antecessor, ou com outro modelo de interesse.

O modelo 6 foi desenvolvido para verificar se um número maior de momentos poderia melhorar a eficiência da estimativa do fator $\lambda$ e da FMDE, considerando o relato de Mood e Graybill (1963), que um número grande de momentos define exatamente o comportamento de uma distribuição.

A influência de cada variável independente sobre as estimativas do fator $\lambda$ ou da FMDE foi analisada de acordo com os valores obtidos de erro médio quadrático ( $r m s)$, de coeficiente de determinação múltipla $\left(r^{2}\right)$ e de coeficiente de determinação múltipla ajustado $\left(R^{2}\right)$.

Todos os coeficientes, $a_{n}$, dos modelos foram obtidos por meio de uma regressão linear múltipla (realizada por um algoritmo de regressão desenvolvido por Costa (2005)). A regressão linear múltipla foi analisada utilizando o teste de significância da regressão.

Se o resultado do teste de significância da regressão linear múltipla indicar que a estatística de teste, $F$, é maior que o valor crítico, $F_{\alpha, k, n-p}$, deve-se rejeitar a hipótese $H_{0}$ e afirmar que existe pelo menos um regressor $\left(a_{n}\right)$ que contribui para a estimativa do fator $\lambda$ ou da FMDE e que os regressores apresentam uma relação linear com a variável dependente (fator $\lambda$ ou FMDE).

A análise dos resultados obtidos com os nove modelos em todas as estimativas, utilizando os dados em regime de plena carga, foi complementada com os resultados obtidos utilizando dados em regime de plena carga em conjunto com os dados em regime de carga parcial, ou seja, em duas cargas combinadas.

A estimativa do fator $\lambda$ foi realizada para cada combustível individualmente e para um conjunto de dados composto por todos os combustíveis testados (Etotal: dados dos combustíveis E26, E56, E70 e E100). A sensibilidade à variação do tipo de combustível foi verificada utilizando os desvios percentuais $(d p)$ entre os $r m s$ das estimativas do fator $\lambda$ obtidas individualmente para cada combustível e as obtidas para o conjunto de dados Etotal. Esta verificação foi feita para confirmar se a afirmação feita por Gilkey e Powell (1985), de que o modelo 1 é pouco sensível à variação do tipo de combustível, é verdadeira.

$\mathrm{Na}$ estimativa da FMDE, independentemente da condição de carga analisada, os dados utilizados foram compostos pelo conjunto de dados de todos os combustíveis em estudo (Etotal). Os dados utilizados para obtenção dos nove modelos foram obtidos considerando o avanço da centelha para o máximo torque, MBT, ou seja, a identificação do tipo de combustível será processada considerando que o sistema eletrônico de controle do motor 
ajusta o avanço da centelha, durante a mudança do tipo de combustível, para obter o máximo torque. Durante esta mudança de combustível ocorre um empobrecimento (adição de etanol na mistura rica em gasolina) ou um enriquecimento da mistura (adição de gasolina na mistura rica em etanol) operante no motor. 


\section{RESULTADOS ALCANÇADOS}

Neste capítulo serão apresentados e discutidos os resultados dos experimentos descrito no Capítulo 3 e a verificação da capacidade do Método dos Momentos em estimar o fator $\lambda$ e identificar o tipo de combustível operante no motor VW AT1000 8V.

Os quatro combustíveis utilizados nos experimentos, como descrito no Capítulo 3 e no Apêndice B, foram:

- E100 - 100\% de AEHC, álcool etílico hidratado carburante com teor alcoólico de 92,79 INPM, designado neste trabalho de etanol;

- $\quad$ E26 - 26,29\% de etanol e 73,71\% de gasolina tipo A, em massa (75\% de gasolina tipo $C$ e $25 \%$ de AEAC - álcool etílico anidro carburante, em volume);

- $\quad$ E70 - mistura de 70,52\% de etanol e $29,48 \%$ de gasolina tipo A, em massa, e

- $\quad$ E56 - mistura de 55,78\% de etanol e 44,22\% de gasolina tipo A, em massa.

Este capítulo foi dividido em três partes: análise dos experimentos, análise dos modelos obtidos para estimar o fator $\lambda$ e análise dos modelos obtidos para identificar o tipo de combustível.

\subsection{ANÁLISE DOS EXPERIMENTOS}

\subsubsection{Resultados do experimento para obtenção da relação de compressão do motor VW AT1000 8V}

A relação de compressão do motor VW AT1000 8V foi medida antes da realização dos experimentos, conforme mostra a Tabela 23. Os procedimentos para obtenção dos valores da relação de compressão e suas incertezas encontram-se no Apêndice E.

De acordo com a Tabela 23, pode-se afirmar que a relação de compressão média do motor $\left(T_{r}\right)$ é de 13,44:1 (0,04), em que o número expresso entre parênteses é o valor numérico de $u_{c}$ (incerteza padrão combinada) expresso na unidade do resultado mencionado (neste caso de dimensão um). 
Tabela 23 - Relação de compressão referente a cada cilindro do motor.

\begin{tabular}{lc}
\hline Cilindro & Relação de compressão (incerteza padrão combinada) \\
\hline Primeiro & $13,42(0,01)$ \\
Segundo & $13,52(0,01)$ \\
Terceiro & $13,52(0,03)$ \\
Quarto & $13,28(0,03)$ \\
Média & $13,44(0,04)$ \\
\hline
\end{tabular}

\subsubsection{Resultados dos cálculos para obtenção da relação ar-combustível e do poder calorífico inferior para cada tipo de combustível utilizado nos experimentos}

Os cálculos realizados para obtenção das relações ar-combustível $(A / C)$ de cada tipo de combustível estão apresentados no Apêndice B.

A determinação do poder calorífico inferior foi realizada por cálculos apresentados no Apêndice C.

A Tabela 24 apresenta a relação ar-combustível, o poder calorífico inferior $(P C I)$, o produto entre $P C I$ e a relação combustível-ar $(C / A)$ e a porcentagem em massa de gasolina tipo $A\left(C_{11} H_{24}\right)$ para cada tipo de combustível utilizado nos experimentos, de acordo com os Apêndices B e C.

Tabela 24 - Propriedades dos combustíveis utilizados.

\begin{tabular}{lcccc}
\hline Combustível & Relação A/C & PCI [MJ/kg] & PCI*C/A [MJ/kg] & \% Massa de $\mathrm{C}_{11} \mathrm{H}_{24}$ \\
\hline E100 & $8,30: 1$ & 25,09 & 3,023 & 0 \\
E70 & $10,32: 1$ & 29,04 & 2,813 & 29,48 \\
E56 & $11,34: 1$ & 31,61 & 2,788 & 44,22 \\
E26 & $13,36: 1$ & 38,38 & 2,872 & 73,71 \\
\hline
\end{tabular}

\subsubsection{Análise do desempenho do motor VW AT1000 8V operando com E100, E70, E56 e E26}

Os dados coletados nos experimentos foram organizados em tabelas e apresentados em gráficos, com o objetivo de facilitar o entendimento e a visualização dos resultados alcançados.

De acordo com o Capítulo 3, o experimento 1 pode ser descrito da seguinte forma:

- Motor VW AT1000 8V operando com os combustíveis E100, E70, E56 e E26 em 2000 e 3000 rpm, plena carga (borboleta com 82,5 - curso máximo) e avanço da centelha buscando o máximo torque possível para cada combustível; 
- Motor VW AT1000 8V operando com os combustíveis E100, E70, E56 e E26 em 2000 e 3000 rpm, carga parcial (borboleta com abertura de 33\% do valor máximo) e avanço da centelha buscando o máximo torque possível para cada combustível.

O experimento 1 foi realizado visando identificar a influência do fator $\lambda$ e do tipo de combustível sobre o traço da pressão no cilindro e sobre as variáveis de desempenho e emissões do motor.

As análises de desempenho do motor foram fundamentadas em três variáveis: potência, consumo específico e eficiência de conversão de combustível.

As Tabelas A1 e A2 do Apêndice A1 apresentam resumos dos dados coletados e calculados durante o Experimento 1 para análise das variáveis do motor, a 2000 e 3000 rpm em regime de plena carga com máximo torque.

As tabelas das análises estatísticas (incertezas expandidas, análise de variância (ANOVA), método SME e procedimento de Tukey) para cada variável estudada do motor encontram-se no Apêndice A2.

Conforme descrito no Capítulo 3, todos os ensaios realizados em plena carga tiveram a potência corrigida segundo a norma técnica NBR ISO 1585, antes de serem analisados.

\subsubsection{Análise dos efeitos do fator $\lambda$ e do tipo de combustível a 2000 e $3000 \mathrm{rpm}$, regime de plena carga e MBT sobre a potência corrigida do motor}

O intervalo de confiança para cada média de potência corrigida pode ser visualizado na Figura 36, em função do fator $\lambda$ e do tipo de combustível.

(a) $2000 \mathrm{rpm}$

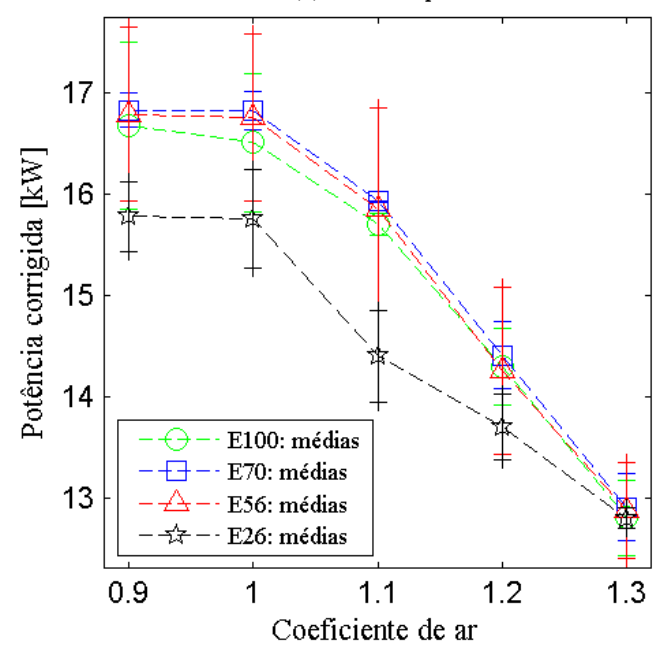

(b) $3000 \mathrm{rpm}$

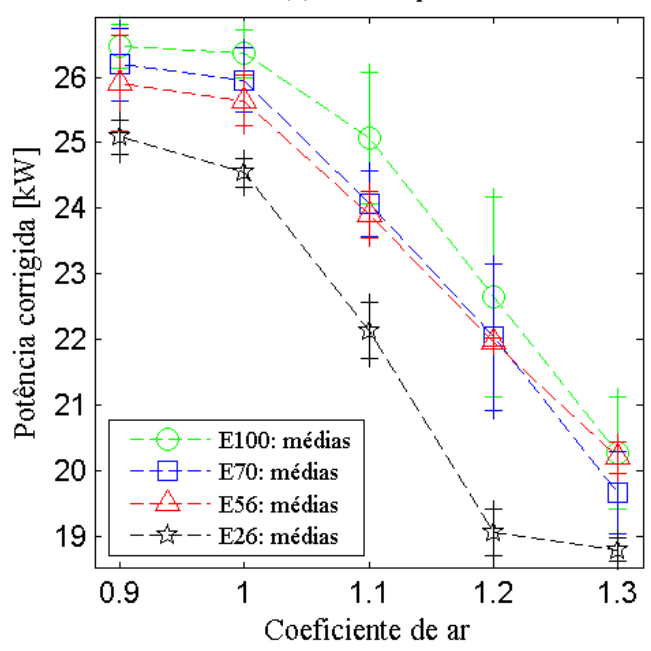

Figura 36 - Potência corrigida do motor em função do fator $\lambda$ e do tipo de combustível (2000 e 3000 rpm, regime de plena carga, MBT). 
A equação 118 adaptada a partir de Heywood (1988) permite constatar que a razão entre o torque do motor e a eficiência de conversão de combustível $(\eta)$, para uma mesma rotação do motor $(N)$, é uma função do poder calorífico inferior $(P C I)$, do fluxo mássico de $\operatorname{ar}\left(m_{a}\right)$ e da relação combustível-ar (C/A). A equação 118 pode ser reescrita em função da potência do motor, considerando que a potência é o produto do torque pela velocidade angular do motor.

$$
\frac{\text { Torque }}{\eta}=\frac{m_{a} * P C I * C / A}{2 * \pi * N}
$$

De acordo com a literatura o torque do motor é pouco sensível à variação da composição da mistura etanol-gasolina (HSIEH et al., 2002). Considerando a literatura, a relação apresentada na equação 118 e verificando os produtos entre $P C I$ e $C / A$ apresentados na Tabela 24, espera-se que não sejam observadas grandes variações entre os torques desenvolvidos pelos combustíveis testados, em condições fixas de operação do motor. Diferenças mais significativas entre os torques devem ser resultado da eficiência de conversão de cada combustível utilizado.

Analisando os dados apresentados na Figura 36 e os resultados das análises estatísticas, apresentados no Apêndice A2, constata-se que o combustível E26 apresentou as menores médias de potência corrigida em todas as condições de operação do motor. Os valores das médias de potência corrigida do motor para o E26 apresentaram diferenças estatisticamente significativas em relação aos demais combustíveis em todas as condições de operação no motor, exceto para a rotação de $2000 \mathrm{rpm}$ com fator $\lambda$ igual a 1,3.

O combustível E26 apresentou diferenças significativas nas médias de potência corrigida do motor por apresentar o menor poder antidetonante entre os combustíveis testados, não permitindo manter o mesmo avanço da centelha dos demais combustíveis sem a ocorrência de knocking. O menor poder antidetonante do E26 se deve à menor quantidade de etanol na sua composição, sendo que a literatura reconhece o efeito antidetonante da adição de etanol às gasolinas (VILANOVA, 2007). Estas afirmações justificam-se em razão da relação de compressão do motor VW AT 1000 8V (13,44:1) ser considerada muito elevada para um motor operando com gasolina tipo $C$ (E26). Pela literatura, o aumento da adição de etanol (40 a 60\%) à gasolina permite que um motor com relação de compressão mais elevada (13:1) opere com maior avanço do ponto da centelha sem a ocorrência de knocking (YÜCESU et al., 2006). 
A literatura constata que o knocking ocorre em função da temperatura e da riqueza local da mistura, sendo mais frequente na proximidade da mistura estequiométrica (MARTINS, 2006), portanto, a potência corrigida do motor com o E26 se aproxima dos demais combustíveis para fator $\lambda$ igual a 1,3 (a $2000 \mathrm{rpm}$ ) porque é possível se manter o ponto da centelha mais adiantado sem a ocorrência de knocking.

A 2000 rpm o combustível E70 apresentou a maior média de potência corrigida do motor, seguindo pelos combustíveis E56 e E100, enquanto que a $3000 \mathrm{rpm}$ a maior média de potência corrigida do motor foi obtida pelo combustível E100, seguido pelos combustíveis E70 e E56 (para fator $\lambda$ entre 0,9 e 1,1, tendo se igualado em $\lambda$ igual a 1,2 e E56 superado o E70 em $\lambda$ igual a 1,3). Estes resultados estão de acordo com a literatura, pois a maior taxa de vaporização da mistura gasolina-etanol favorece a obtenção de maiores potências em plena carga e baixas rotações (até $2500 \mathrm{rpm}$ ), superando os resultados de potência obtidos utilizando apenas o etanol, e se invertendo em rotações superiores a 2500 rpm (SOTO PAU, 1999).

Em todos os casos houve redução da potência corrigida do motor à medida que uma mesma mistura ar-combustível foi sendo empobrecida. Nas condições ensaiadas os maiores valores de potência registrada do motor foram encontrados para fator $\lambda$ igual a 0,9 .

\subsubsection{Análise dos efeitos do fator $\lambda$ e do tipo de combustível a 2000 e 3000 rpm, regime de plena carga e MBT sobre o consumo específico do motor}

De acordo com as formulações apresentadas no capítulo de Revisão Bibliográfica, o consumo específico foi obtido a partir da relação entre os dados de consumo horário e potência corrigida do motor.

O intervalo de confiança, obtido a partir da incerteza expandida, $U$, para cada média de consumo específico pode ser visualizado na Figura 37, em função do fator $\lambda$ e do tipo de combustível. 
(a) $2000 \mathrm{rpm}$

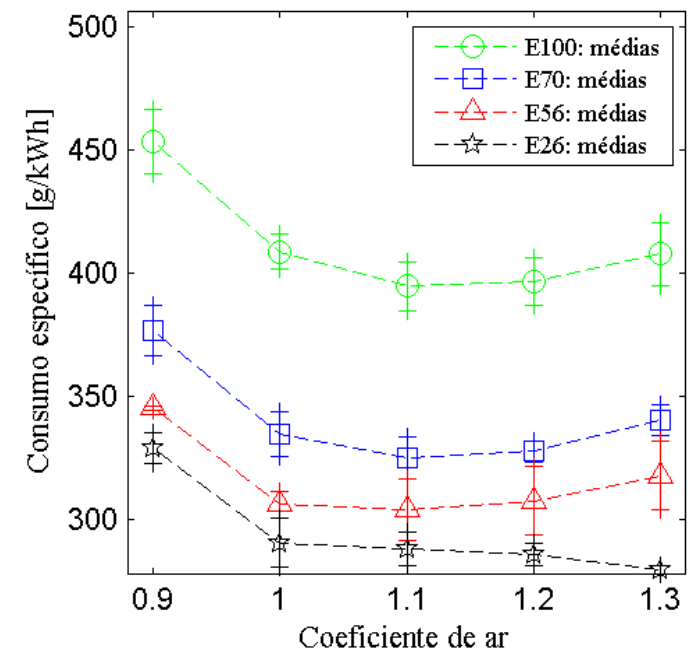

(b) $3000 \mathrm{rpm}$

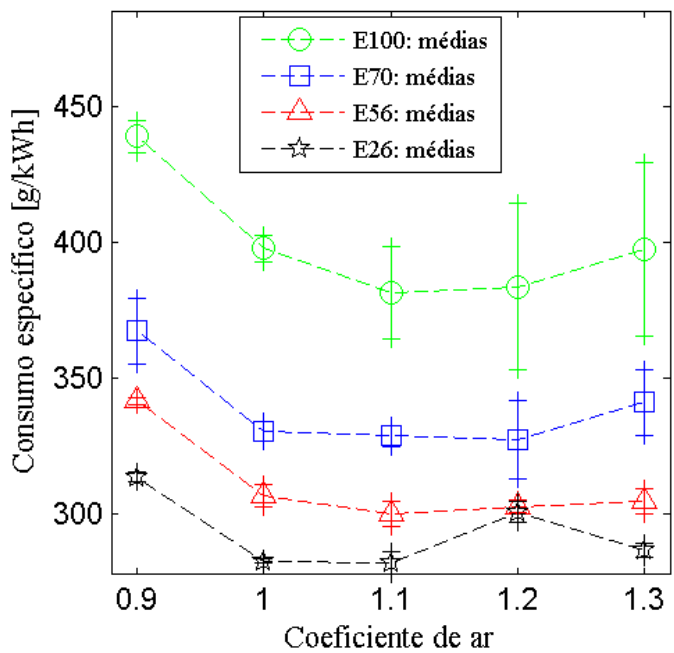

Figura 37 - Consumo específico do motor em função do fator $\lambda$ e do tipo de combustível (2000 e 3000 rpm, regime de plena carga, MBT).

Na literatura o consumo específico do motor $\left(C_{e s p}\right)$ é expresso como o inverso do produto entre o poder calorífico inferior $(P C I)$ e a eficiência de conversão de combustível $(\eta)$ (HEYWOOD, 1988). A adição de etanol à gasolina reduz o PCI da mistura combustível aumentando significativamente o consumo específico (MELO et al., 2012).

Como previsto na literatura os dados apresentados na Figura 37 e os resultados das análises estatísticas, apresentados no Apêndice A2, confirmam que em todas as condições de operação do motor há diferenças significativas nos valores de consumo específico entre todos os combustíveis, exceto entre E56 e E26 a $3000 \mathrm{rpm}$ (para fatores $\lambda$ iguais a 1,2 e 1,3). A maior média de consumo específico foi registrada pelo combustível E100, em todas as condições de operação do motor, seguido pelos combustíveis E70, E56 e E26. Quanto menor o PCI do combustível analisado, ou seja, quanto maior a quantidade de etanol na mistura combustível, maior foi o seu consumo específico.

Como mencionado na análise da potência corrigida do motor, o combustível E26 não manteve o avanço do ponto da centelha dos demais combustíveis porque apresenta menor poder antidetonante, facilitando a ocorrência de knocking e provocando uma redução significativa da potência do motor. Esta redução na potência, como uma consequência da redução na eficiência de conversão de combustível, afeta significativamente o consumo específico do combustível E26. A $3000 \mathrm{rpm}$ e fator $\lambda$ igual a 1,2 a queda na eficiência de conversão de combustível reduziu significativamente a potência do motor e, consequentemente, aumentou o seu consumo específico. Esta condição de operação do motor 
foi revista durante os testes do motor, mas não foi possível aumentar o avanço do ponto da centelha na mesma magnitude com que foi aumentado para o fator $\lambda$ igual a 1,3.

Todos os combustíveis analisados apresentaram a maior média de consumo específico em $\lambda$ igual a 0,9 . Neste caso a eficiência de conversão de combustível foi reduzida porque a mistura ar-combustível está rica.

Nas condições de ensaio analisadas, o consumo específico sofreu reduções até atingir fatores $\lambda$ pobres, 1,1 ou 1,2 dependendo do combustível utilizado. Ao atingir o valor mínimo os combustíveis E100, E70 e E56 apresentaram um ligeiro aumento no consumo específico, em misturas ar-combustível mais pobres devido à queda na eficiência da conversão do combustível.

\subsubsection{Análise dos efeitos do fator $\lambda$ e do tipo de combustível a 2000 e $3000 \mathrm{rpm}$, regime de plena carga e MBT sobre a eficiência de conversão de combustível}

A eficiência de conversão de combustível foi obtida de acordo com as formulações apresentadas no capítulo de Revisão Bibliográfica.

O intervalo de confiança, resultante da incerteza expandida, para cada média de eficiência de conversão de combustível pode ser visualizado na Figura 38, em função do fator $\lambda$ e do tipo de combustível.

(a) $2000 \mathrm{rpm}$

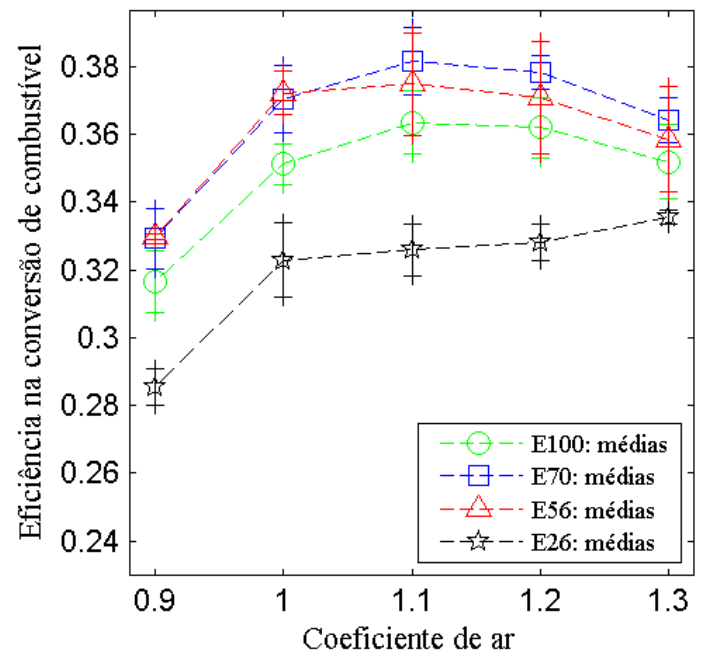

(b) $3000 \mathrm{rpm}$

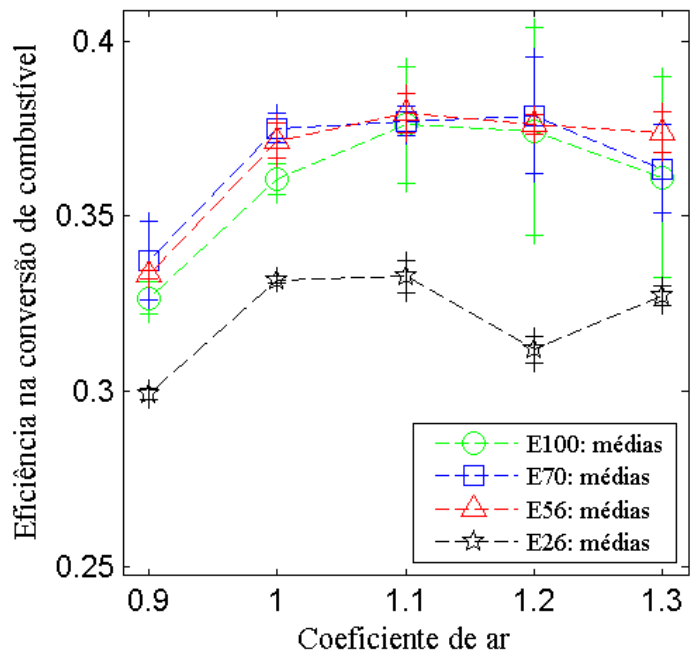

Figura 38 - Eficiência de conversão de combustível em função do fator $\lambda$ e do tipo de combustível (2000 e 3000 rpm, regime de plena carga, MBT).

$\mathrm{Na}$ literatura a eficiência de conversão é obtida pelo inverso do produto entre o consumo específico e o poder calorífico inferior (HEYWOOD, 1988). 
Os resultados das análises estatísticas, apresentados no Apêndice A2, e os dados apresentados na Figura 38 mostram que o combustível E26 apresentou as menores médias de eficiência de conversão de combustível. O maior poder calorífico inferior $(P C I)$ do E26, em relação aos demais combustíveis, e a impossibilidade de utilização de avanços do ponto da centelha adequados para este combustível nas condições ensaiadas, devido à relação de compressão elevada, tornaram o produto do consumo específico pelo PCI mais alto do que nos demais combustíveis, reduzindo a sua eficiência de conversão de combustível.

Em todos os casos o combustível E100 apresentou médias de eficiência de conversão de combustível inferiores às misturas E70 e E56, possivelmente devido a menor vaporização do E100.

Considerando a rotação de $2000 \mathrm{rpm}$ e valores de $\lambda$ superiores a 1,0 o combustível E70 apresentou as maiores médias de eficiência de conversão de combustível.

De acordo com os resultados das análises estatísticas a 3000 rpm os combustíveis E70 e E56 não apresentaram diferenças significativas entre as médias de eficiência de conversão de combustível.

\subsubsection{Análise das emissões do motor VW AT1000 8V operando com E100, E70, E56 e E26}

As análises de emissões do motor foram fundamentadas em três gases: $\mathrm{CO}, \mathrm{HC}$ e $\mathrm{CO}_{2}$.

As análises estatísticas dos parâmetros de emissões seguiram os mesmos critérios estabelecidos para as análises estatísticas dos parâmetros de desempenho do motor VW AT1000 8V.

\subsubsection{Análise dos efeitos do fator $\lambda$ e do tipo de combustível a 2000 e $3000 \mathrm{rpm}$, regime de plena carga e MBT sobre as emissões de $C O$}

A Figura 39 apresenta os intervalos de confiança para cada média de emissão de monóxido de carbono (CO), com nível de confiança de 95\%, em função do fator $\lambda$ e do tipo de combustível. 
(a) $2000 \mathrm{rpm}$

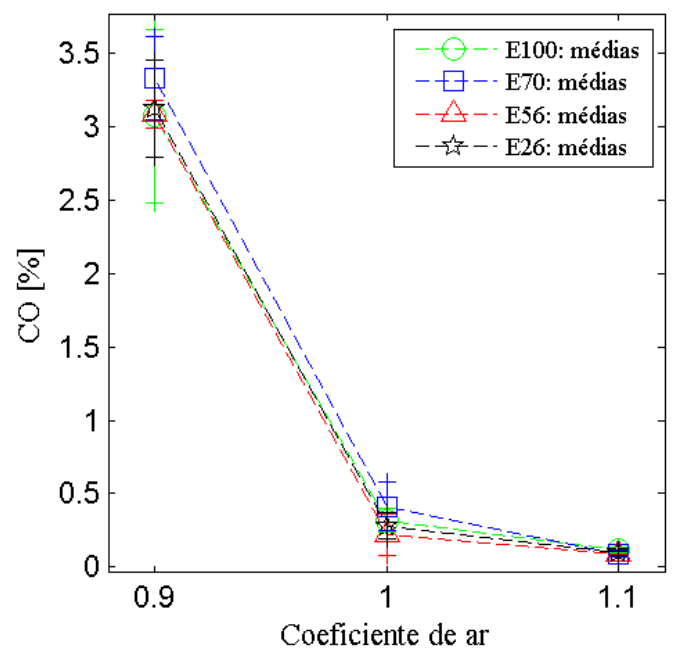

(b) $3000 \mathrm{rpm}$

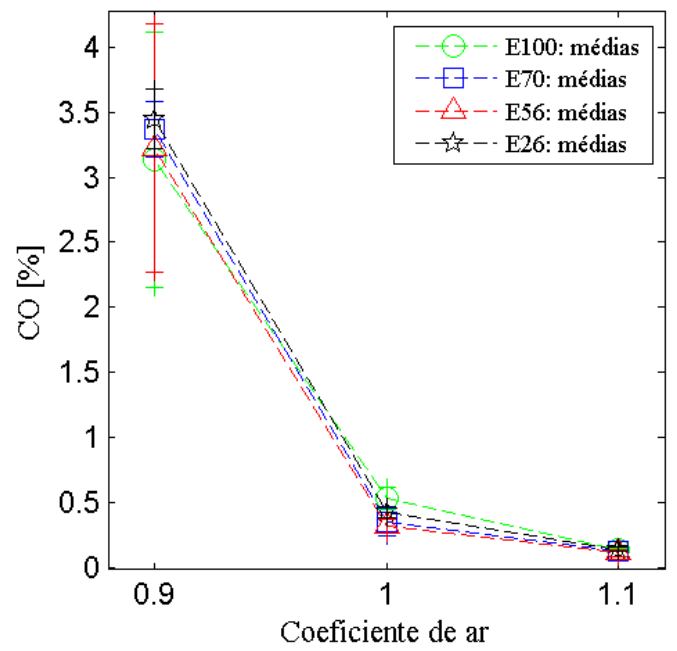

Figura 39 - Emissão de $C O$ em função do fator $\lambda$ e do tipo de combustível (2000 e 3000 rpm, regime de plena carga, MBT).

Os resultados das análises estatísticas, apresentados no Apêndice A2, mostram que o fator $\lambda$ afeta significativamente as emissões de $C O$ e que os combustíveis praticamente não apresentam diferenças estatisticamente significativas nas emissões de $C O$. Este resultado está de acordo com a literatura que reconhece que as emissões de $C O$ são primariamente controladas pela mistura ar-combustível (HEYWOOD, 1988).

De acordo com os dados apresentados na Figura 39 e com os resultados das análises estatísticas, apresentados no Apêndice A2, o maior valor médio registrado de emissão de $C O$, para todos os combustíveis analisados, ocorreu em mistura rica, $\lambda$ igual a 0,9 , e caiu sensivelmente quando a mistura se tornou estequiométrica, $\lambda$ igual a 1,0. A redução continuou, de forma menos acentuada, até $\lambda$ igual a 1,1. A partir de $\lambda$ igual a 1,2 as emissões se tornaram estáveis ou com reduções da ordem de um centésimo (que representa a resolução do aparelho de medição utilizado). Estes resultados estão de acordo com o relato de Martins (2006) que afirma que a emissão de $C O$ depende da riqueza da mistura, ou seja, quanto mais rica for a mistura, maior será a emissão de $C O$, devido à falta de oxigênio suficiente para oxidar todo o carbono presente no combustível. Também é previsto pela literatura que para misturas mais pobres as emissões de $C O$ variem muito pouco com a relação ar-combustível (HEYWOOD, 1988).

Os maiores valores registrados de potência corrigida do motor e de emissão de $C O$ foram encontrados em $\lambda$ igual a 0,9 (em regime de plena carga e em 2000 e 3000 rpm). Este resultado indica que este valor de $\lambda$ é ou está próximo da mistura de máxima potência. Brunetti (2012) explica que a mistura de máxima potência é uma mistura levemente rica que 
em uma determinada posição do acelerador e numa dada rotação produz a máxima potência do motor, aumentando a probabilidade das emissões de $C O$.

Além da riqueza da mistura, Martins (2006) relata que a queda de pressão no momento da abertura da válvula de escape é acompanhada de uma redução na temperatura dentro do cilindro que inibe a reação envolvendo o $\mathrm{CO}\left(\mathrm{CO}+\mathrm{OH} \rightarrow \mathrm{CO}_{2}+\mathrm{H}\right)$, que ainda não foi transformado em dióxido de carbono $\left(\mathrm{CO}_{2}\right)$ durante o período de expansão do motor.

Quanto à saúde humana, a literatura descreve que o monóxido de carbono é altamente tóxico porque apresenta grande afinidade com a hemoglobina do sangue podendo ocasionar asfixia e morte se a carboemoglobina atingir uma concentração de 50\% no sangue (PENIDO FILHO, 1991).

\subsubsection{Análise dos efeitos do fator $\lambda$ e do tipo de combustível a 2000 e $3000 \mathrm{rpm}$, regime de plena carga e MBT sobre as emissões de $H C$}

O intervalo de confiança, resultante da incerteza expandida, para cada média de emissão de $H C$ pode ser visualizado na Figura 40, em função do fator $\lambda$ e do tipo de combustível.

(a) $2000 \mathrm{rpm}$

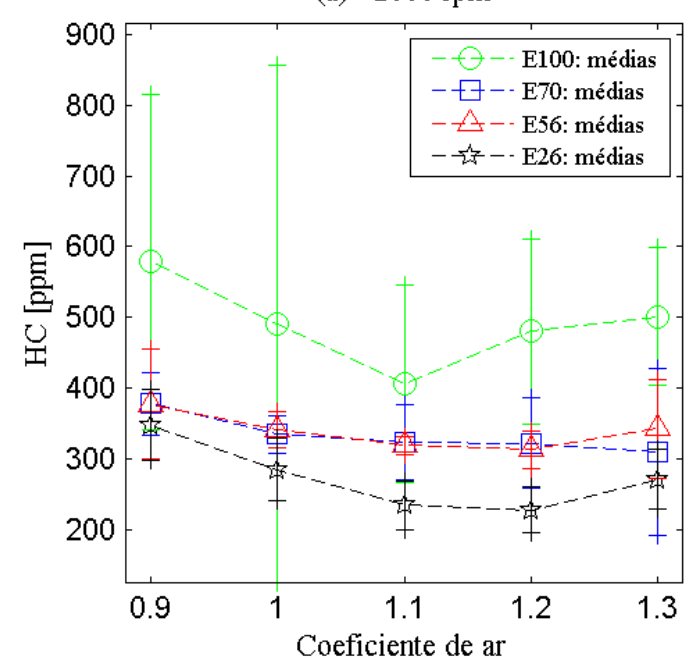

(b) $3000 \mathrm{rpm}$

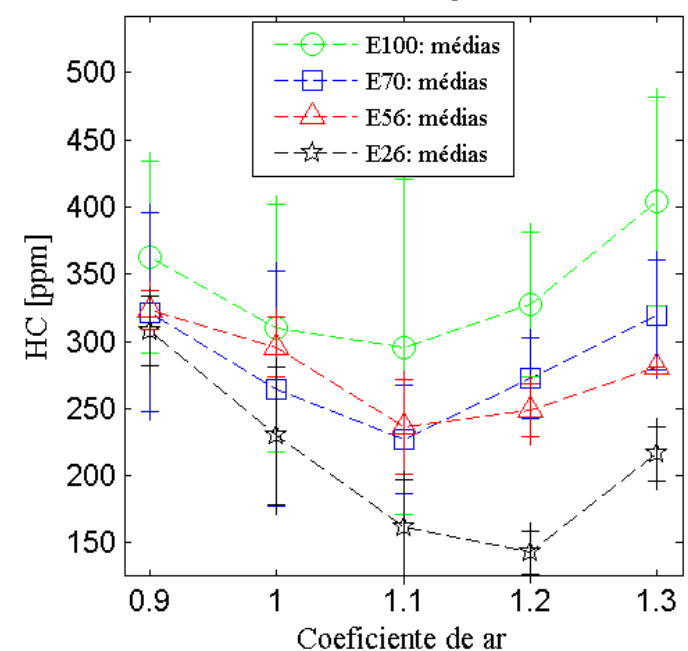

Figura 40 - Emissão de $H C$ em função do fator $\lambda$ e do tipo de combustível (2000 e 3000 rpm, regime de plena carga, MBT).

De acordo com os resultados das análises estatísticas, apresentados no Apêndice A2, constata-se que o fator $\lambda$ e o tipo de combustível afetam significativamente as emissões de $H C$ em todas as condições ensaiadas. A literatura explica que a relação ar-combustível (HEYWOOD, 1988) e a composição da mistura gasolina-etanol (CELIK, 2008) afetam significativamente as emissões de $H C$. 
Os dados apresentados na Figura 40 e os resultados das análises estatísticas, apresentados no Apêndice A2, mostram que as médias de emissão de $H C$ para todos os combustíveis testados diminuem a partir de $\lambda$ igual a 0,9 , atingem seu valor mínimo em $\lambda$ pobre e voltam a aumentar com o maior empobrecimento da mistura, exceto para o combustível E70 a 2000 rpm que apresentou redução nas emissões de $H C$ desde $\lambda$ igual 0,9 até $\lambda$ igual a 1,3 . Os maiores valores médios registrados de emissão de $H C$ foram encontrados em $\lambda$ igual a 0,9 , exceto para o combustível E100 a 3000 rpm (maior valor médio registrado em $\lambda$ igual a 1,3)

Estes resultados estão em conformidade com o relato de Heywood (1988), que afirma que as emissões de $H C$ crescem rapidamente quando a mistura se afasta da região de estequiometria em direção à região de mistura rica, o mesmo ocorrendo, em menor escala, quando a mistura se torna pobre.

Heywood (1988) explica que as emissões de $H C$ estão relacionadas à combustão incompleta do combustível, a extinção da chama nas paredes frias da câmara de combustão, a dificuldade da chama penetrar nas fendas existentes no motor (entre o pistão, os anéis de vedação do pistão e as paredes do cilindro, assim como ao redor das velas de ignição e do eletrodo central da vela) e a absorção de parte do combustível pelo filme de óleo lubrificante que se forma nas paredes do cilindro (este combustível é desabsorvido durante a combustão, mas uma parte não chega a ser queimada, contribuindo para as emissões de $H C$ ).

Quanto aos efeitos das emissões de $H C$ à saúde humana, Martins (2006) explica que o $H C$ associado aos óxidos de nitrogênio produz o smog fotoquímico, mas também podem provocar irritações nos olhos, náuseas, dores de cabeça e problemas respiratórios. Os $H C$ aromáticos, de acordo com Martins (2006), são considerados cancerígenos.

O combustível E26 apresentou as menores médias de emissão de $H C$ porque foi testado em condições de ponto da centelha atrasado em relação aos demais combustíveis. Estes resultados estão de acordo com a literatura, que explica que a ignição atrasada reduz as emissões de HC (PENIDO FILHO, 1991).

O combustível E100 apresentou as maiores médias de emissão de $H C$ seguido pelos combustíveis E70 e E56 (em posições alternadas em função das condições de operação do motor). E70 e E56 não apresentaram diferenças estatisticamente significativas nas emissões de $H C$.

Os resultados apresentaram-se semelhantes aos relatados por Celik (2008), pois os combustíveis com maior quantidade mássica de etanol apresentaram os maiores valores médios de emissão de $H C$. 
Celik (2008) atribui o aumento das emissões de $H C$, nos combustíveis com maior teor de etanol, à redução da temperatura no cilindro ao término do período de admissão, devido ao elevado calor de vaporização do etanol. A redução da temperatura da câmara acaba provocando falhas na combustão nas proximidades das paredes da câmara de combustão.

\subsubsection{Análise dos efeitos do fator $\lambda$ e do tipo de combustível a 2000 e $3000 \mathrm{rpm}$, regime de plena carga e MBT sobre as emissões de $\mathrm{CO}_{2}$}

$\mathrm{O}$ intervalo de confiança para cada média de emissão de $\mathrm{CO}_{2}$ pode ser visualizado na Figura 41, em função do fator $\lambda$ e do tipo de combustível.

(a) $2000 \mathrm{rpm}$

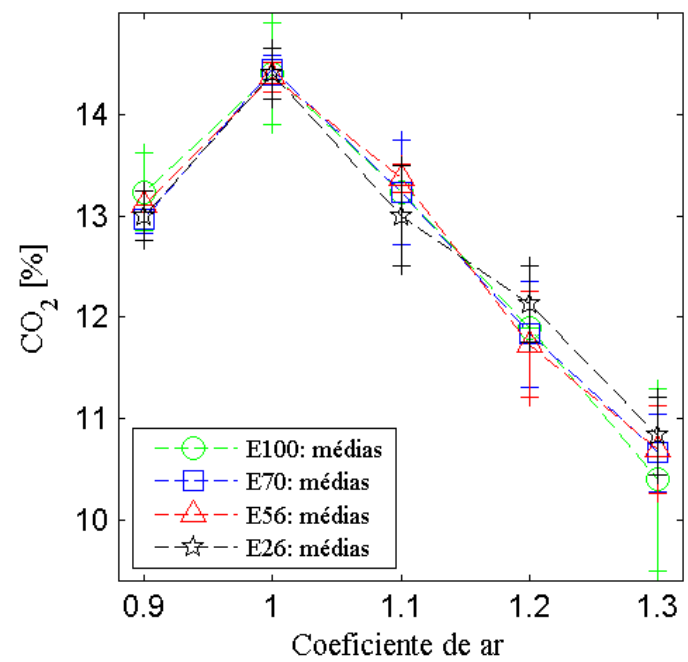

(b) $3000 \mathrm{rpm}$

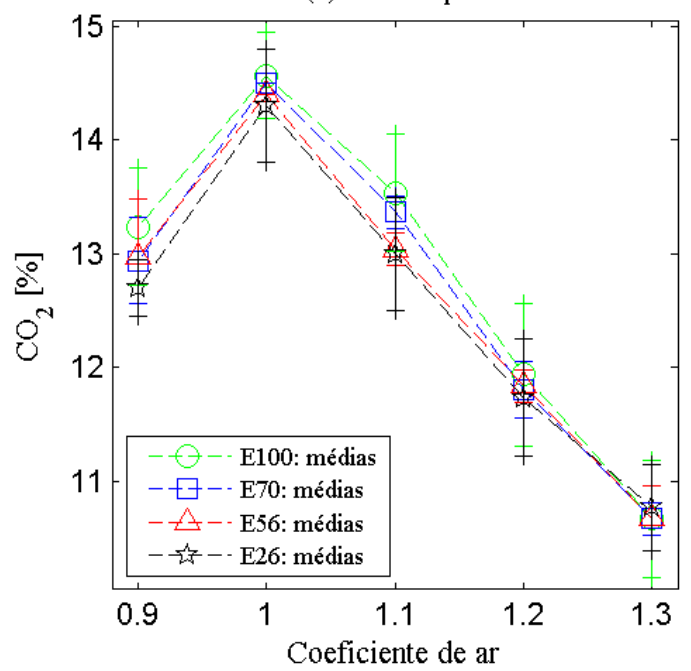

Figura 41 - Emissão de $\mathrm{CO}_{2}$ do motor em função do fator $\lambda$ e do tipo de combustível (2000 e 3000 rpm, regime de plena carga, MBT).

Os resultados das análises estatísticas, apresentadas no Apêndice A2, permitem constatar que as emissões de $\mathrm{CO}_{2}$ são afetadas significativamente pelo fator $\lambda$ e praticamente não são afetadas pela variação do tipo de combustível.

As médias de emissão de $\mathrm{CO}_{2}$, considerando todos os combustíveis analisados, apresentaram maior valor registrado na razão estequiométrica ( $\lambda$ igual a 1,0 ).

Os resultados apresentados na Figura 41 e nas análises estatísticas (Apêndice A2) mostram que a emissão de $\mathrm{CO}_{2}$ ocorre de maneira inversa à emissão de $C O$ para fatores $\lambda$ menores do que 1,0 (inclusive). Este resultado encontra-se de acordo com Vilanova (2007) e Hsieh et al. (2012) que afirmam que a emissão de $\mathrm{CO}_{2}$ é semelhante à emissão de $C O$, mas na proporcionalidade inversa à mistura (para $\lambda<1)$. 
Acima de $\lambda$ igual a 1,0 a emissão de $\mathrm{CO}_{2}$ sofre redução acentuada à medida que a mistura ar-combustível vai sendo empobrecida. A redução das emissões de $\mathrm{CO}_{2}$ também ocorre quando a mistura ar-combustível é enriquecida.

A emissão de $\mathrm{CO}_{2}$ está relacionada com a emissão de $\mathrm{CO}$ pelo fato de que é a oxidação do $\mathrm{CO}$ que origina o $\mathrm{CO}_{2}$, conforme Martins (2006).

\subsubsection{Síntese dos resultados experimentais e discussões relativas ao desempenho geral do motor operando com diferentes misturas de etanol e gasolina}

A análise das variáveis de desempenho e emissões do motor VW AT1000 8V nas condições ensaiadas pode ser resumida em função dos tipos de combustíveis, da seguinte forma:

- E26:

$\checkmark$ quanto ao desempenho: apresentou as menores médias de potência corrigida, de consumo específico e de eficiência de conversão de combustível, e

$\checkmark$ quanto às emissões: apresentou as menores médias de emissões de $H C$, decréscimo significativo das emissões de $C O$ a partir do valor máximo $(\lambda=0,9)$ até $\lambda$ igual a 1,0 (com redução menos significativa, ou estabilização das emissões, para $\lambda$ mais pobres), pico de emissão de $\mathrm{CO}_{2}$ em $\lambda$ igual a 1 com reduções significativas para misturas ricas ou pobres.

- E100:

quanto ao desempenho: apresentou as maiores médias de potência corrigida a $3000 \mathrm{rpm}$, mas a $2000 \mathrm{rpm}$ apresentou médias de potência inferiores às das misturas E70 e E56, apresentou as maiores médias de consumo específico e médias de eficiência de conversão de combustível inferiores às das misturas E70 e E56, e

$\checkmark$ quanto às emissões: apresentou as maiores médias de emissões de $H C \mathrm{e}$ comportamento semelhante ao E26 quanto às emissões de $\mathrm{CO}$ e $\mathrm{CO}_{2}$. 
- E70:

$\checkmark$ quanto ao desempenho: apresentou as maiores médias de potência corrigida a $2000 \mathrm{rpm}$, e inferiores às do E100 a $3000 \mathrm{rpm}$ (mas semelhantes às do E56), as médias de consumo específico ficaram entre as médias dos combustíveis E100 e E56, apresentou as maiores médias de eficiência de conversão de combustível a 3000 rpm (juntamente com o combustível E56), assim como a $2000 \mathrm{rpm}$ para $\lambda$ superiores a 1,0, e

$\checkmark$ quanto às emissões: apresentou médias de emissões de $H C$ inferiores às do E100, superiores às do E26 e semelhantes às do E56, quanto às emissões de $\mathrm{CO}$ e $\mathrm{CO}_{2}$ apresentou comportamento semelhante ao E26.

- E56:

quanto ao desempenho: apresentou médias de potência corrigida inferiores às do E70 a 2000 rpm e às do E100 a 3000 rpm (mas semelhantes às do E70), médias de consumo específico superiores apenas as do E26 e as maiores médias de eficiência de conversão de combustível a $3000 \mathrm{rpm}$ (juntamente com o combustível E70), mas inferiores às do E70 a $2000 \mathrm{rpm}$ para $\lambda$ superiores a 1,0, e

$\checkmark$ quanto às emissões: apresentou médias de emissões de $H C$ inferiores às do E100, superiores às do E26 e semelhantes às do E70, quanto às emissões de $\mathrm{CO}$ e $\mathrm{CO}_{2}$ apresentou comportamento semelhante ao E26.

É importante registrar que os resultados encontrados estão coerentes com a literatura e que o motor VW AT 1000 8V foi capaz de operar com os quatro combustíveis em estudo (E26, E56, E70 e E100) sem ocorrência de knocking, apesar da relação de compressão elevada $(13,44: 1)$. A variação no avanço da centelha foi suficiente para garantir o bom funcionamento do motor em todas as condições de operação experimentadas, porém, no caso do E26 a necessidade de atrasar muito o ponto de ignição comprometeu o seu desempenho. 


\subsection{ANÁLISE DOS MODELOS OBTIDOS PARA ESTIMAÇÃO DO FATOR LAMBDA}

A literatura já demonstrou que os modelos utilizando o método dos momentos, aplicado ao sinal da pressão no cilindro, apresentados por Gilkey e Powell (1985), Arsie, Pianese e Rizzo (1998), Costa (2005) e Arsie et al. (2014) se mostraram capazes de estimar o fator $\lambda$ (ou a relação ar-combustível ou a relação combustível-ar) de motores alimentados com etanol ou com gasolina.

Nesta seção será analisada a capacidade do método dos momentos em estimar o fator $\lambda$ em um motor operando com quatro combustíveis distintos (E100, E70, E56 e E26).

As análises desta seção abordarão os resultados apresentados pelos nove modelos de estimação do fator $\lambda$, apresentados no Capítulo 3, na seção 3.2.7, obtidos primeiramente considerando os dados individuais de cada combustível testado e em seguida por um conjunto de dados composto por todos os combustíveis testados

\subsubsection{Análise dos modelos obtidos para estimação do fator $\lambda$ utilizando o combustível E26}

A Tabela 25 apresenta os resultados alcançados com os nove modelos propostos para estimação do fator $\lambda$, utilizando a média de 20 ciclos e as janelas 1, 2, 3 e 4 de pressão no cilindro aplicada aos dados em regime de plena carga, enquanto que a Tabela 26 apresenta os resultados utilizando os dados de duas cargas combinadas (regime de plena carga mais regime de carga parcial com borboleta aberta em 33\%). 
Tabela 25 - Resultados alcançados com os nove modelos de estimação do fator $\lambda$ utilizando o combustível E26 (regime de plena carga, média de 20 ciclos de pressão no cilindro e janelas 1, 2, 3 e 4). (continua)

\begin{tabular}{|c|c|c|c|c|c|}
\hline \multicolumn{6}{|c|}{$\begin{array}{l}\text { Combustível: E26 (regime de plena carga) } \\
\text { Média de } 20 \text { ciclos de pressão no cilindro }\end{array}$} \\
\hline \multirow{2}{*}{ Modelo } & \multirow{2}{*}{ Parâmetros } & \multicolumn{4}{|c|}{ Janelas } \\
\hline & & 1 & 2 & 3 & 4 \\
\hline \multirow{5}{*}{ Modelo 1} & $\mathrm{~F}$ & 33,29 & 11,39 & 36,50 & 49,73 \\
\hline & $\mathrm{F}_{0,05 ; 4 ; 25}$ & 2,76 & 2,76 & 2,76 & 2,76 \\
\hline & $r^{2}$ & 0,8419 & 0,6456 & 0,8538 & 0,8884 \\
\hline & $\mathrm{R}^{2}$ & 0,8166 & 0,5889 & 0,8304 & 0,8705 \\
\hline & rms & 0,0562 & 0,0842 & 0,0541 & 0,0473 \\
\hline \multirow{5}{*}{ Modelo 2} & $\mathrm{~F}$ & 602,09 & 500,29 & 305,54 & 279,11 \\
\hline & $\mathrm{F}_{0,05 ; 5 ; 24}$ & 2,62 & 2,62 & 2,62 & 2,62 \\
\hline & $\mathrm{r}^{2}$ & 0,9921 & 0,9905 & 0,9845 & 0,9831 \\
\hline & $\mathrm{R}^{2}$ & 0,9904 & 0,9885 & 0,9813 & 0,9796 \\
\hline & $\mathrm{rms}$ & 0,0126 & 0,0138 & 0,0176 & 0,0184 \\
\hline \multirow{5}{*}{ Modelo 3} & $\mathrm{~F}$ & 583,29 & 399,55 & 301,45 & 417,43 \\
\hline & $\mathrm{F}_{0,05 ; 6 ; 23}$ & 2,53 & 2,53 & 2,53 & 2,53 \\
\hline & $r^{2}$ & 0,9935 & 0,9905 & 0,9874 & 0,9909 \\
\hline & $\mathrm{R}^{2}$ & 0,9918 & 0,9880 & 0,9842 & 0,9885 \\
\hline & rms & 0,0114 & 0,0138 & 0,0158 & 0,0135 \\
\hline \multirow{5}{*}{ Modelo 4} & $\mathrm{~F}$ & 640,50 & 595,87 & 567,21 & 618,75 \\
\hline & $\mathrm{F}_{0,05 ; 7 ; 22}$ & 2,46 & 2,46 & 2,46 & 2,46 \\
\hline & $r^{2}$ & 0,9951 & 0,9948 & 0,9945 & 0,9949 \\
\hline & $\mathrm{R}^{2}$ & 0,9936 & 0,9931 & 0,9927 & 0,9933 \\
\hline & $\mathrm{rms}$ & 0,0099 & 0,0102 & 0,0105 & 0,0101 \\
\hline \multirow{5}{*}{ Modelo 5} & $\mathrm{~F}$ & 526,95 & 449,77 & 466,74 & 469,20 \\
\hline & $\mathrm{F}_{0,05 ; 9 ; 20}$ & 2,39 & 2,39 & 2,39 & 2,39 \\
\hline & $r^{2}$ & 0,9958 & 0,9951 & 0,9953 & 0,9953 \\
\hline & $\mathrm{R}^{2}$ & 0,9939 & 0,9929 & 0,9931 & 0,9932 \\
\hline & $\mathrm{rms}$ & 0,0092 & 0,0099 & 0,0097 & 0,0097 \\
\hline \multirow{5}{*}{ Modelo 6} & $\mathrm{~F}$ & 545,20 & 550,09 & 487,14 & 671,49 \\
\hline & $\mathrm{F}_{0,05 ; 9 ; 20}$ & 2,39 & 2,39 & 2,39 & 2,39 \\
\hline & $r^{2}$ & 0,9959 & 0,9960 & 0,9955 & 0,9967 \\
\hline & $\mathrm{R}^{2}$ & 0,9941 & 0,9942 & 0,9934 & 0,9952 \\
\hline & $\mathrm{rms}$ & 0,0090 & 0,0090 & 0,0095 & 0,0081 \\
\hline
\end{tabular}


Tabela 25 - Resultados alcançados com os nove modelos de estimação do fator $\lambda$ utilizando o combustível E26 (regime de plena carga, média de 20 ciclos de pressão no cilindro e janelas 1, 2, 3 e 4). (conclusão)

Combustível: E26 (regime de plena carga)

Média de 20 ciclos de pressão no cilindro

\begin{tabular}{clcccc} 
Modelo & Parâmetros & \multicolumn{4}{c}{ Janelas } \\
& & 1 & 2 & 3 & 4 \\
\hline \multirow{2}{*}{ Modelo 7 } & $\mathrm{F}$ & 469,26 & 471,87 & 417,89 & 579,39 \\
& $\mathrm{~F}_{0,05 ; 10 ; 19}$ & 2,38 & 2,38 & 2,38 & 2,38 \\
& $\mathrm{R}^{2}$ & 0,9960 & 0,9960 & 0,9955 & 0,9967 \\
& $\mathrm{rms}$ & 0,9938 & 0,9939 & 0,9931 & 0,9950 \\
& $\mathrm{~F}$ & 0,0090 & 0,0090 & 0,0095 & 0,0081 \\
& $\mathrm{~F}_{0,05 ; 1 ; 18}$ & 497,11 & 486,10 & 461,95 & 585,01 \\
Modelo 88 & $\mathrm{r}^{2}$ & 2,38 & 2,38 & 2,38 & 2,38 \\
& $\mathrm{R}^{2}$ & 0,9967 & 0,9966 & 0,9965 & 0,9972 \\
& $\mathrm{rms}$ & 0,9947 & 0,9946 & 0,9943 & 0,9955 \\
& $\mathrm{~F}$ & 0,0081 & 0,0082 & 0,0084 & 0,0075 \\
& $\mathrm{~F}_{0,05 ; 9 ; 20}$ & 564,00 & 447,38 & 441,16 & 437,79 \\
Modelo 9 9 & 2,39 & 2,39 & 2,39 & 2,39 \\
& $\mathrm{r}^{2}$ & 0,9961 & 0,9951 & 0,9950 & 0,9949 \\
& $\mathrm{R}^{2}$ & 0,9943 & 0,9928 & 0,9927 & 0,9927 \\
& $\mathrm{rms}$ & 0,0089 & 0,0099 & 0,0100 & 0,0101 \\
\hline
\end{tabular}


Tabela 26 - Resultados alcançados com os nove modelos de estimação do fator $\lambda$ utilizando o combustível E26 (duas cargas combinadas, média de 20 ciclos de pressão no cilindro e janelas 1, 2, 3 e 4). (continua)

\begin{tabular}{|c|c|c|c|c|c|}
\hline \multicolumn{6}{|c|}{$\begin{array}{l}\text { Combustível: E26 (duas cargas combinadas) } \\
\text { Média de } 20 \text { ciclos de pressão no cilindro }\end{array}$} \\
\hline \multirow{2}{*}{ Modelo } & \multirow{2}{*}{ Parâmetros } & \multicolumn{4}{|c|}{ Janelas } \\
\hline & & 1 & 2 & 3 & 4 \\
\hline \multirow{5}{*}{ Modelo 1} & $\mathrm{~F}_{0,05 ; 4 ; 55}$ & 2,55 & 2,55 & 2,55 & 2,55 \\
\hline & $\mathrm{F}$ & 93,89 & 18,70 & 50,04 & 90,57 \\
\hline & $r^{2}$ & 0,8723 & 0,5763 & 0,7844 & 0,8682 \\
\hline & $\mathrm{R}^{2}$ & 0,8630 & 0,5455 & 0,7688 & 0,8586 \\
\hline & $\mathrm{rms}$ & 0,0505 & 0,0921 & 0,0657 & 0,0513 \\
\hline \multirow{5}{*}{ Modelo 2} & $\mathrm{~F}_{0,05 ; 5 ; 54}$ & 2,39 & 2,39 & 2,39 & 2,39 \\
\hline & $\mathrm{F}$ & 397,06 & 193,82 & 175,93 & 181,79 \\
\hline & $\mathrm{r}^{2}$ & 0,9735 & 0,9472 & 0,9422 & 0,9439 \\
\hline & $\mathrm{R}^{2}$ & 0,9711 & 0,9423 & 0,9368 & 0,9387 \\
\hline & $\mathrm{rms}$ & 0,0230 & 0,0325 & 0,0340 & 0,0335 \\
\hline \multirow{5}{*}{ Modelo 3} & $\mathrm{~F}_{0,05 ; 6 ; 53}$ & 2,28 & 2,28 & 2,28 & 2,28 \\
\hline & $\mathrm{F}$ & 331,20 & 164,36 & 155,42 & 225,35 \\
\hline & $r^{2}$ & 0,9740 & 0,9490 & 0,9462 & 0,9623 \\
\hline & $\mathrm{R}^{2}$ & 0,9711 & 0,9432 & 0,9401 & 0,9580 \\
\hline & $\mathrm{rms}$ & 0,0228 & 0,0319 & 0,0328 & 0,0275 \\
\hline \multirow{5}{*}{ Modelo 4} & $\mathrm{~F}_{0,05 ; 7 ; 52}$ & 2,20 & 2,20 & 2,20 & 2,20 \\
\hline & $\mathrm{F}$ & 311,06 & 337,37 & 335,94 & 321,34 \\
\hline & $r^{2}$ & 0,9767 & 0,9785 & 0,9784 & 0,9774 \\
\hline & $\mathrm{R}^{2}$ & 0,9735 & 0,9756 & 0,9755 & 0,9744 \\
\hline & $\mathrm{rms}$ & 0,0216 & 0,0208 & 0,0208 & 0,0213 \\
\hline \multirow{5}{*}{ Modelo 5} & $\mathrm{~F}_{0,05 ; 9 ; 50}$ & 2,08 & 2,08 & 2,08 & 2,08 \\
\hline & $\mathrm{F}$ & 250,59 & 252,53 & 252,21 & 287,29 \\
\hline & $r^{2}$ & 0,9783 & 0,9785 & 0,9784 & 0,9810 \\
\hline & $\mathrm{R}^{2}$ & 0,9744 & 0,9746 & 0,9746 & 0,9776 \\
\hline & $\mathrm{rms}$ & 0,0208 & 0,0207 & 0,0208 & 0,0195 \\
\hline \multirow{5}{*}{ Modelo 6} & $\mathrm{~F}_{0,05 ; 9 ; 50}$ & 2,08 & 2,08 & 2,08 & 2,08 \\
\hline & $\mathrm{F}$ & 258,46 & 273,12 & 251,28 & 245,90 \\
\hline & $\mathrm{r}^{2}$ & 0,9790 & 0,9801 & 0,9784 & 0,9779 \\
\hline & $\mathrm{R}^{2}$ & 0,9752 & 0,9765 & 0,9745 & 0,9739 \\
\hline & $\mathrm{rms}$ & 0,0205 & 0,0200 & 0,0208 & 0,0210 \\
\hline
\end{tabular}


Tabela 26 - Resultados alcançados com os nove modelos de estimação do fator $\lambda$ utilizando o combustível E26 (duas cargas combinadas, média de 20 ciclos de pressão no cilindro e janelas 1, 2, 3 e 4). (conclusão)

\begin{tabular}{|c|c|c|c|c|c|}
\hline \multicolumn{6}{|c|}{$\begin{array}{l}\text { Combustível: E26 (duas cargas combinadas) } \\
\text { Média de } 20 \text { ciclos de pressão no cilindro }\end{array}$} \\
\hline \multirow{2}{*}{ Modelo } & \multirow{2}{*}{ Parâmetros } & \multicolumn{4}{|c|}{ Janelas } \\
\hline & & 1 & 2 & 3 & 4 \\
\hline \multirow{5}{*}{ Modelo 7} & $\mathrm{~F}_{0,05 ; 10 ; 49}$ & 2,04 & 2,04 & 2,04 & 2,04 \\
\hline & $\mathrm{F}$ & 231,72 & 243,13 & 225,46 & 218,22 \\
\hline & $r^{2}$ & 0,9793 & 0,9802 & 0,9787 & 0,9780 \\
\hline & $\mathrm{R}^{2}$ & 0,9751 & 0,9762 & 0,9744 & 0,9736 \\
\hline & $\mathrm{rms}$ & 0,0204 & 0,0199 & 0,0206 & 0,0210 \\
\hline \multirow{5}{*}{ Modelo 8} & $\mathrm{~F}_{0,05 ; 11 ; 48}$ & 2,01 & 2,01 & 2,01 & 2,01 \\
\hline & $\mathrm{F}$ & 237,02 & 248,52 & 224,16 & 213,83 \\
\hline & $r^{2}$ & 0,9819 & 0,9827 & 0,9809 & 0,9800 \\
\hline & $\mathrm{R}^{2}$ & 0,9778 & 0,9788 & 0,9765 & 0,9754 \\
\hline & $\mathrm{rms}$ & 0,0190 & 0,0186 & 0,0195 & 0,0200 \\
\hline \multirow{5}{*}{ Modelo 9} & $\mathrm{~F}_{0,05 ; 9 ; 50}$ & 2,08 & 2,08 & 2,08 & 2,08 \\
\hline & $\mathrm{F}$ & 243,31 & 326,15 & 253,53 & 391,04 \\
\hline & $r^{2}$ & 0,9777 & 0,9833 & 0,9786 & 0,9860 \\
\hline & $\mathrm{R}^{2}$ & 0,9737 & 0,9802 & 0,9747 & 0,9835 \\
\hline & $\mathrm{rms}$ & 0,0211 & 0,0183 & 0,0207 & 0,0167 \\
\hline
\end{tabular}

Os resultados dos valores críticos, $F_{\alpha, k, n-p}$, apresentados nas Tabela 25 e 26, foram menores que as estatísticas de teste, $F$, nos nove modelos estudados. Portanto, pode-se afirmar que existe pelo menos um regressor $\left(a_{n}\right)$ em cada um dos modelos analisados que contribui significativamente para a estimativa do fator $\lambda$.

Observando a Tabela 25, constata-se que as janelas 2 e 3 não apresentaram os menores rms para nenhum dos modelos em estudo.

Na Tabela 26 pode-se constatar que apenas a janela 3 não apresentou o menor rms para nenhum dos modelos em estudo.

\subsubsection{Modelo 1}

O modelo 1 apresentou o menor rms com a janela 4 (0,0473, Tabela 25), e quando este mesmo modelo foi obtido utilizando os dados de cargas combinadas a melhor janela passou a ser a janela $1(r m s=0,0505$ contra $r m s=0,0513$ para a janela 4, Tabela 26). Quanto menor for o rms obtido menor será a magnitude média dos erros estimados, e quanto mais próximo de zero for o valor do rms melhor será a qualidade dos valores estimados. Portanto, deve-se selecionar sempre a janela que obteve o menor rms. 
É importante ressaltar que a janela 4 é a que apresenta a menor porção de um ciclo completo do sinal do transdutor de pressão no cilindro, ou seja, é a janela que apresenta o menor requisito computacional entre todas as janelas propostas.

Para obter uma estimativa mais precisa do fator $\lambda$ poder-se-ia utilizar janelas distintas de pressão no cilindro para cada faixa de operação do motor (cargas combinadas e plena carga), mas isto tornaria o sistema de controle do motor bastante complexo e dependente de um modelo de previsão da carga ou de um sensor de posição da válvula borboleta. Deve-se salientar que os sistemas de controle baseados no sinal da pressão no cilindro visam à utilização do menor número possível de transdutores.

Os resultados obtidos com o uso do modelo 1 permitem dizer que a afirmação de Gilkey e Powell (1985), sobre a melhor estimativa do fator $\lambda$ quando se utiliza a janela de dados 1 , só é válida quando se pretende cobrir toda a gama de cargas possíveis de um motor Otto.

Quanto às variáveis independentes utilizadas no modelo $1, a G, N, M_{2}$ e $M_{3}$, entende-se que:

- $a G$ é um coeficiente que estima as condições báricas da carga admitida no motor porque estima a pressão no coletor de admissão. Martins (2006) afirma que quanto menor a pressão no coletor de admissão menor será a pressão no cilindro no início da combustão;

- $\quad N$ representa a rotação real do motor. Além de indicar a velocidade angular da árvore de manivelas do motor, a rotação real interfere na quantidade de pontos de pressão no cilindro coletados por ciclo, considerando uma mesma taxa de amostragem para várias rotações distintas;

- $M_{2}$ é o momento de segunda ordem. Este momento, segundo Mood e Graybill (1963), indica a variância, ou seja, quanto o trecho utilizado do ciclo de pressão no cilindro (em função da janela utilizada) se espalha em relação à média, e

- $M_{3}$ representa o momento de terceira ordem, que de acordo com Mood e Graybill (1963) indica a assimetria. A medida da assimetria indica quanto o trecho utilizado do ciclo de pressão no cilindro se deforma em relação a um trecho simétrico.

O coeficiente de determinação múltipla, $r^{2}$, obtido para o modelo 1 indica que existe uma relação próxima da linear entre as variáveis independentes e o fator $\lambda$, considerando todas as janelas em estudo (Tabelas 25 e 26). 
O coeficiente de determinação múltipla ajustado, $R^{2}$, do modelo 1 será utilizado como parâmetro de comparação para os próximos modelos, indicando se o acréscimo de novas variáveis independentes realmente colabora para o aumento da eficiência na estimativa do fator $\lambda$.

O rms encontrado para o modelo 1 utilizando a janela 1 no presente estudo $(0,0562$ - em plena carga e 0,0505 - em cargas combinadas) foi ligeiramente maior do que o relatado por Gilkey e Powell (1985) para o mesmo modelo e mesma janela, nas condições dos experimentos deles $(0,0487$ desconsiderando a recirculação de gases de exaustão (EGR) e 0,0239 considerando a EGR).

Cabe ressaltar que no presente estudo foi utilizado um motor com diferenças significativas em relação ao motor utilizado por Gilkey e Powell (1985). A primeira diferença se refere ao número de cilindro do motor, neste estudo foi utilizado um motor com 4 cilindros em linha, enquanto que os autores citados empregaram um motor de apenas 1 cilindro. A segunda diferença reside na relação de compressão do motor, Gilkey e Powell (1985) usaram um motor a gasolina com relação de compressão de 6:1, enquanto que no presente estudo foi ensaiado um motor a etanol com relação de compressão de 13,44:1.

\subsubsection{Modelo 2}

Analisando novamente as Tabelas 25 e 26, pode-se constatar que o menor rms para o modelo 2 foi obtido utilizando a janela $1(0,0126)$. A janela 1 também apresentou o menor rms quando utilizando os dados em cargas combinadas $(r m s=0,0230)$.

O modelo 2 apresenta a inclusão do tempo de injeção (TI) como uma variável independente para a estimação do fator $\lambda$. Portanto, a iniciativa foi inédita.

Os estudos relatados até o presente momento não fizeram a inserção do tempo de injeção em conjunto com o método dos momentos para estimativa do fator $\lambda$.

A utilização do tempo de injeção na estimativa do fator $\lambda$ foi motivada:

- pela disponibilidade desta variável em todos os tipos de sistemas eletrônicos de controle de motores, sem a necessidade de adição de novos transdutores ao motor, já que se trata de uma variável de controle do mesmo (para determinar o tempo de abertura das válvulas eletromagnéticas de injeção de combustível);

- pelo fato de o tempo de injeção estar relacionado à quantidade de combustível injetado dentro do motor, e 
- por ser imposto ao motor antes da ocorrência da combustão, ou seja, a pressão no cilindro é influenciada pela quantidade de combustível inserida no motor.

Com a utilização do tempo de injeção, no modelo 2 , o rms $(0,0126)$ sofreu um redução de aproximadamente $77,5 \%$ em relação ao modelo 1 (0,0562), considerando a janela 1 e utilizando os dados em regime de plena carga, como mostra a Tabela 25.

Considerando os dados em cargas combinadas, Tabela 26, para obtenção do modelo 2, a redução do rms $(0,0230)$ em relação ao modelo $1(0,0505)$ foi de aproximadamente $54,4 \%$.

O coeficiente $r^{2}(0,9735)$ obtido para o modelo 2 foi consideravelmente maior que o obtido para o modelo $1(0,8723)$, indicando que existe uma relação mais próxima da linear entre as variáveis independentes do modelo 2 e o fator $\lambda$ (Tabelas 25 e 26).

O valor de $R^{2}$ para o modelo 2 foi superior ao do modelo 1 indicando que o tempo de injeção contribui significativamente para a melhora da estimativa do fator $\lambda$ (Tabelas 25 e 26).

O modelo 2 deve apresentar um pequeno acréscimo computacional na estimativa do fator $\lambda$ em relação ao modelo 1 , pois acrescentou apenas duas operações fundamentais, uma soma e uma multiplicação.

\subsubsection{Modelo 3}

Os resultados obtidos com o modelo 3, apresentados na Tabela 25, indicam que o menor rms $(0,0114)$ ocorreu na janela 1 . Esta janela também apresentou o menor rms quando utilizando os dados em cargas combinadas $(r m s=0,0228)$, como mostra a Tabela 26.

No modelo 3 foi inserida uma nova variável independente, em relação ao modelo 2, o pico de pressão no cilindro $(P C)$. Não foram encontrados relatos sobre a utilização desta variável em conjunto com o método dos momentos para estimação do fator $\lambda$.

O pico de pressão no cilindro foi utilizado como variável independente pelo fato de ser afetado pelo fator $\lambda$ empregado no motor. Para um mesmo avanço da centelha, quando mais pobre for a mistura menor será o pico de pressão no cilindro.

A redução do rms utilizando o modelo $3(0,0114)$ em relação ao modelo $2(0,0126)$ não foi tão significativa quanto à redução do $r m s$ conseguida entre o modelo 2 e o modelo 1 (0,0562). O modelo 3 apresentou uma redução de aproximadamente 9,5\% em relação ao modelo 2, considerando os dados apresentados na Tabela 25, e de apenas $0,9 \%$ (0,0228 contra um rms igual a 0,0230 do modelo 2), considerando os dados apresentados na Tabela 26. 
Se o objetivo for obter um modelo para todas as faixas de operação do motor (cargas combinadas) a redução do $r m s$ alcançada com o modelo 3 não justifica a sua utilização quando comparada ao modelo 2 , pois o requisito computacional será levemente mais elevado sem a contrapartida de uma melhora significativa no resultado da estimativa do fator $\lambda$ (menos de $1 \%$ de redução do $\mathrm{rms})$.

Tanto o $r^{2}$ quanto o $R^{2}$, apresentados nas Tabelas 25 e 26, foram ligeiramente maiores no modelo 3 em relação ao modelo 2, indicando que existe uma relação mais próxima da linear entre as variáveis independentes e que o pico de pressão no cilindro contribui ligeiramente para a estimativa do fator $\lambda$.

\subsubsection{Modelo 4}

De acordo com a Tabela 25, o modelo 4 apresentou o menor rms $(0,0099)$ na janela 1 . Considerando os dados em cargas combinadas as janelas 2 e 3 apresentaram o menor rms $(0,0208$, Tabela 26).

A diferença entre o modelo 4 e o modelo 3 reside na inserção do avanço da centelha $(A V)$ como variável independente.

Durante os testes do motor, com os combustíveis E26, E56, E70 e E100, foi observada a necessidade de aumentar o avanço da centelha à medida que a mistura ar-combustível era empobrecida.

O ponto de ignição precisa avançar quando a mistura empobrece porque a velocidade da queima diminui. $\mathrm{O}$ aumento do avanço da ignição amplia a possibilidade de ocorrência de knocking no motor (Martins, 2006).

A escolha do avanço da centelha como variável independente foi motivada não só por sua influência na ocorrência de knocking, mas também pelo fato de que a posição angular em que ocorre o ponto da centelha determina a localização angular do pico de pressão no cilindro, interferindo na qualidade do torque do motor.

O modelo 4 apresentou uma redução do rms de aproximadamente 21,4\% em relação ao modelo 2 (melhor janela: 1), considerando os dados da Tabela 25, e de aproximadamente 9,6\% considerando os dados da Tabela 26 (melhor janela: 2).

O coeficiente de determinação múltipla ajustado, $R^{2}$, foi maior no modelo 4 do que no modelo 3, indicando que o avanço da centelha contribui significativamente para a estimativa do fator $\lambda$ (Tabelas 25 e 26).

O $r^{2}$ do modelo 4 também foi maior do que o do modelo 3 (Tabelas 25 e 26). 
O modelo 4 apresenta pequeno acréscimo computacional quando comparado ao modelo 2 (aumento de duas somas e duas multiplicações), sendo uma opção para a melhoria da eficiência da estimativa do fator $\lambda$.

\subsubsection{Modelo 5}

O modelo 5 foi criado para verificar a capacidade do método dos momentos em estimar o fator $\lambda$ utilizando não apenas uma janela de dados da pressão no cilindro, mas também a curva gerada pelo método da razão de pressões, relatado por Gassenfeit e Powell (1989).

A descrição do método da razão de pressões encontra-se no Capítulo 2, na seção 2.9.2.

A inovação feita no presente estudo foi aplicar o método dos momentos à curva resultante do método da razão de pressões. Esta curva é obtida pela razão entre a parte da curva de pressão no cilindro com queima (janela 6 de pressão no cilindro: $60^{\circ} \mathrm{DPMS}$ até $120^{\circ} \mathrm{DPMS}$ ) e a parte da curva de pressão no cilindro sem queima (janela 5 de pressão no cilindro: $120^{\circ} \mathrm{APMS}$ até $\left.60^{\circ} \mathrm{APMS}\right)$. A Figura 42 ilustra a curva gerada pelo método da razão de pressões considerando os dados em regime de plena carga para o combustível E26, a 3000 rpm e MBT. 


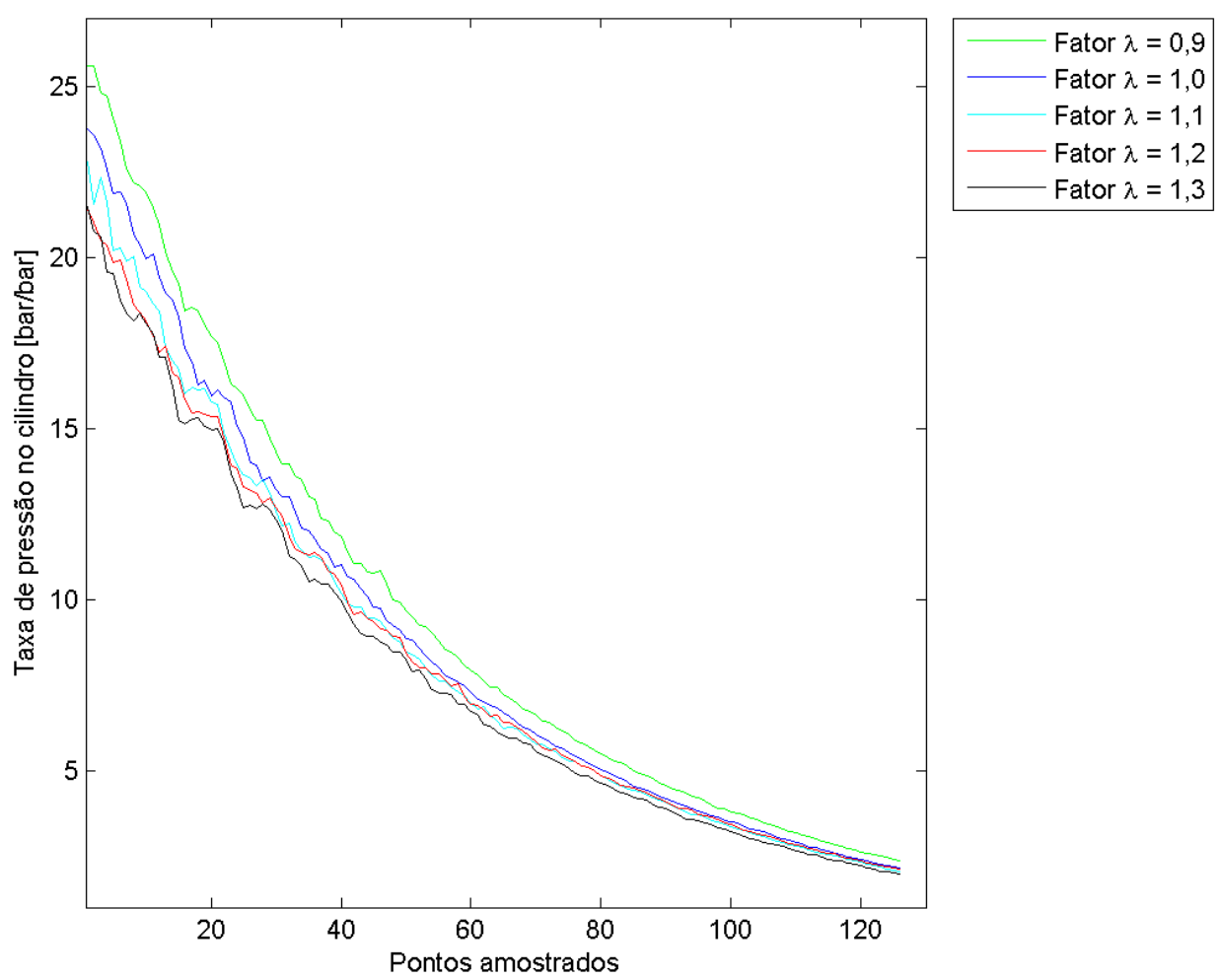

Figura 42 - Curva gerada pelo método da razão de pressões no cilindro (3000 rpm, regime de plena carga, MBT, combustível E26).

Nesta inovação realizada no presente estudo, os momentos de segunda e terceira ordem foram utilizados para reproduzir a curva da razão de pressões no cilindro, com o intuito de obter uma melhor representação desta curva, pois na aplicação do método da razão de pressões, normalmente, são utilizados valores médios da curva ou pontos iniciais e finais para compor os modelos de regressão linear múltipla para estimação do fator $\lambda$.

Os resultados do modelo 5 (considerando os coeficientes $r^{2}, R^{2}$ e o rms) indicam que o método dos momentos aplicado à curva da razão de pressões no cilindro é capaz de estimar o fator $\lambda$ (Tabelas 25 e 26) melhor que os modelos anteriores.

A janela 1 apresentou o menor $r m s$ do modelo 5, mas a melhora em relação ao modelo 4 foi de apenas 7,1\% em condições de plena carga, Tabela 25, e de apenas 3,7\% em condições de cargas combinadas (considerando a janela 1), Tabela 26.

Em condições de regime de cargas combinadas o menor rms ocorreu na janela $4(0,0195$ redução de aproximadamente 6,3\% em relação à janela 2 do modelo 4).

Considerando o aumento da complexidade do modelo 5 em relação ao modelo 4, recomenda-se optar pelo modelo 4 quando o requisito computacional for restritivo. 


\subsubsection{Modelo 6}

Foram inseridos os momentos de quarta e quinta ordem no modelo 6. Cabe ressaltar que a inserção de momentos de ordens superiores facilita o surgimento de matrizes quadradas singulares durante a obtenção dos regressores, ou seja, pelo menos uma linha ou coluna ou diagonal da matriz inversa $\left(X^{\prime} X\right)$ será composta de elementos iguais à zero resultando em um determinante nulo.

O menor rms do modelo 6, de acordo com as Tabelas 25 e 26, ocorreu na janela 4 (0,0081), em condições de plena carga, e na janela $2(0,0200)$, considerando cargas combinadas.

Em relação ao modelo 4, os coeficientes $r^{2}, R^{2}$ e o rms foram melhores indicando que um maior número de momentos, neste caso de quarta e quinta ordem, aumentam a eficiência da estimação do fator $\lambda$ (Tabelas 25 e 26).

Apesar da redução de 18,2\% no valor do $r m s$ do modelo 6 em relação ao modelo 4 (Tabela 25), em condições de cargas combinadas a redução do rms foi de apenas 3,8\% (Tabela 26), portanto, deve-se verificar os requisitos computacionais do sistema eletrônico de controle de motores antes de optar pelo modelo $6 \mathrm{em}$ detrimento do modelo 4, pois os momentos de quarta e quinta ordem aumentam o consumo computacional, além do já mencionado efeito facilitador na geração de matrizes singulares.

\subsubsection{Modelo 7}

No modelo 7 foi inserida a temperatura do ar no coletor de admissão.

A temperatura do ar admitido, segundo Martins (2006), influi na temperatura da mistura no momento anterior à combustão. Temperaturas elevadas na admissão reduzem a quantidade de ar admitida pelo motor, porque reduzem a densidade do ar.

O menor rms do modelo 7 ocorreu na janela $4(0,0081)$, de acordo com a Tabela 25, e na janela 2 (0,0199) considerando os dados de cargas combinadas (Tabela 26).

Em relação ao modelo 6 , houve redução do coeficiente $R^{2}$ indicando que a inclusão da temperatura do ar no coletor de admissão não contribui para o aumento da eficiência na estimação do fator $\lambda$ (Tabelas 25 e 26).

Os resultados do modelo 7 não o qualificam para compor um sistema eletrônico de controle de motores. 
Apesar dos resultados do modelo 7 indicarem que a temperatura de admissão não colabora na estimativa do fator $\lambda$, esta variável foi mantida no modelo 8 com o intuito de comparar, em trabalhos futuros, os resultados de um modelo baseado no método dos momentos com os resultados de um modelo baseado no método dos pesos moleculares, pois este último necessita da temperatura de admissão na sua elaboração.

\subsubsection{Modelo 8}

O modelo 8 apresentou a adição da temperatura dos gases de exaustão, tomada no coletor de exaustão, como variável independente.

Os dados obtidos durante os testes do motor permitiram observar que a temperatura de exaustão é um indicativo do tipo de combustível utilizado (reduz à medida que a quantidade de etanol aumenta) e do fator $\lambda$ empregado (diminui à medida que a relação ar-combustível se afasta da mistura estequiométrica).

O menor rms do modelo 8 ocorreu na janela $4(0,0075)$, como mostra a Tabela 25 , e na janela 2 (0,0186) quando considerando os dados em cargas combinadas (Tabela 26).

Ao contrário da temperatura de admissão, a temperatura de exaustão se mostrou significativa na estimação do fator $\lambda$, ou seja, os valores do coeficiente $R^{2}$ foram maiores em relação aos modelos 6 e 7, em todas as janelas analisadas (Tabelas 25 e 26).

A redução do $r m s$ do modelo 8 em relação ao modelo 6 foi de aproximadamente 7,4\% em condições de plena carga e de $7 \%$ em condições de cargas combinadas.

Os resultados obtidos com o modelo 8 indicam que ele apresenta uma melhora significativa na estimativa do fator $\lambda$, em relação ao modelo 6 , mas a inclusão de um transdutor de temperatura no coletor de escape pode ser um empecilho à sua implementação em um sistema eletrônico de controle de motores, não só pelo custo adicional, mas também, pelos requisitos de manutenção que este transdutor pode vir a exigir.

\subsubsection{Modelo 9}

O modelo 9 foi desenvolvido com o intuito de verificar se um modelo de ajuste mais complexo traria algum benefício na estimativa do fator $\lambda$. Neste caso foram inseridos os quadrados dos momentos de segunda e terceira ordem no modelo 4.

A comparação do modelo 9 deve ser feita com o modelo 4, pois ambos estão baseados apenas na utilização de transdutores de pressão. 
Considerando a janela 1 , os coeficientes $r^{2}, R^{2}$ e o $r m s$ do modelo 9 (Tabelas 25 e 26) foram melhores do que os do modelo 4 , indicando que os quadrados dos momentos aumentam a eficiência da estimação do fator $\lambda$.

A redução do $r m s$ do modelo $9(0,0089)$ foi de aproximadamente $10,1 \%$ em relação ao do modelo $4(0,0099)$, considerando os dados da janela 1 apresentados na Tabela 25 . A redução do rms considerando os dados em cargas combinadas, Tabela 26, foi de aproximadamente $19,7 \%$.

Em condições de cargas combinadas a janela 4 foi a que apresentou o menor rms para o modelo 9 .

Os resultados encontrados para o modelo 9 em cargas combinadas indicam que ele melhora significativamente a estimativa do fator $\lambda$ (considerando os resultados obtidos com a janela 4), sendo que sua implementação depende apenas da disponibilidade computacional do sistema eletrônico de controle de motores, pois apresenta maior requisito computacional do que o modelo 4.

\subsubsection{Síntese dos resultados obtidos com os modelos de estimação do fator $\lambda$ utilizando o combustível E26}

Resumindo os resultados obtidos com todos os modelos para estimação de $\lambda$, com o motor AT1000 8V operando com E26, pode-se afirmar que:

- O modelo 4 apresenta o melhor $r m s$ entre os modelos de menor requisito computacional, tanto em carga plena como em cargas combinadas;

- a melhor janela do modelo 4 em plena carga foi a janela 1 ( $r m s=0,0099)$; enquanto que em cargas combinadas a melhor janela foi a $2(r m s=0,0208)$;

- o modelo 8 foi o que apresentou o menor $r m s$ em plena carga $(0,0075)$, utilizando a janela 4 , e

- o modelo 9 foi o que apresentou o menor rms em cargas combinadas $(0,0167)$, utilizando a janela 4 .

Os coeficientes individuais das regressões lineares múltiplas $\left(a_{n}\right)$ obtidos para os modelos que apresentaram os menores rms em condições de plena carga e de cargas combinadas são apresentados na Tabela 27, considerando uma média de 20 ciclos de pressão no cilindro. 
Tabela 27 - Coeficientes individuais das regressões lineares múltiplas dos modelos que apresentaram os menores rms para o combustível E26.

\begin{tabular}{|c|c|c|c|c|}
\hline \multirow[b]{6}{*}{ Coeficientes $a_{n}$} & \multicolumn{4}{|c|}{ Combustível: E26 (média de 20 ciclos) } \\
\hline & \multirow{2}{*}{\multicolumn{2}{|c|}{$\begin{array}{c}\text { Plena carga } \\
\text { Modelos }\end{array}$}} & \multirow{2}{*}{\multicolumn{2}{|c|}{$\begin{array}{c}\text { Duas cargas combinadas } \\
\text { Modelos }\end{array}$}} \\
\hline & & & & \\
\hline & 4 & 8 & 4 & 9 \\
\hline & \multicolumn{2}{|c|}{ Janelas } & \multicolumn{2}{|c|}{ Janelas } \\
\hline & 1 & 4 & 2 & 4 \\
\hline 1 & $6,943 \mathrm{E}+00$ & $5,011 \mathrm{E}+00$ & $7,759 \mathrm{E}+00$ & $2,543 \mathrm{E}+00$ \\
\hline 2 & $2,009 \mathrm{E}+04$ & $1,401 \mathrm{E}+03$ & $2,144 \mathrm{E}+05$ & $6,313 \mathrm{E}+04$ \\
\hline 3 & $-2,352 \mathrm{E}-01$ & $-2,266 \mathrm{E}-01$ & $-2,212 \mathrm{E}-01$ & $-2,081 \mathrm{E}-01$ \\
\hline 4 & $-4,912 \mathrm{E}-04$ & $2,413 \mathrm{E}-03$ & $-1,400 \mathrm{E}-03$ & $1,788 \mathrm{E}-02$ \\
\hline 5 & $-1,433 \mathrm{E}-02$ & $-8,725 \mathrm{E}-03$ & $-1,878 \mathrm{E}-02$ & $-7,526 \mathrm{E}-03$ \\
\hline 6 & 4,234E-06 & $-3,080 \mathrm{E}-04$ & $-1,890 \mathrm{E}-05$ & $-3,427 \mathrm{E}-05$ \\
\hline 7 & $-5,004 \mathrm{E}-05$ & $6,521 \mathrm{E}-04$ & $-2,320 \mathrm{E}-05$ & $6,868 \mathrm{E}-03$ \\
\hline 8 & 3,909E-06 & $2,334 \mathrm{E}-05$ & $-1,081 \mathrm{E}-06$ & 2,317E-04 \\
\hline 9 & & $-1,662 \mathrm{E}-03$ & & $-9,258 \mathrm{E}-06$ \\
\hline 10 & & $-3,527 \mathrm{E}-03$ & & $-5,808 \mathrm{E}-08$ \\
\hline 11 & & $6,866 \mathrm{E}-06$ & & \\
\hline 12 & & $5,276 \mathrm{E}-06$ & & \\
\hline
\end{tabular}

Para analisar os resíduos do modelo de menor requisito computacional em cargas combinadas, modelo 4, foi utilizada a variável RINT do comando regress do software Matlab $^{\circledR}$. Esta análise foi realizada com nível de $5 \%$ de significância e os resultados são apresentados na Figura 43.

Os resíduos, representados por círculos na Figura 43, indicam a diferença entre o valor do fator $\lambda$ estimado (obtido utilizando o modelo em estudo - modelo 4) e o valor do fator lambda real (que ocorreu no motor nas condições de ensaio utilizadas para a estimação). Os resultados indicam uma pequena variação nos resíduos da estimativa do fator $\lambda$ utilizando o modelo 4 (resíduo médio do fator $\lambda$ estimado igual a 0,0180 ).

Os intervalos de confiança, representados por barras na Figura 43, que não tocam a linha zero indicam que o resíduo é maior do que o esperado em 95\% das observações, ou seja, tratase de um outlier (valor atípico). A retirada dos valores atípicos poderia melhorar a estimativa, mas tal atitude só seria válida se novos experimentos fossem realizados. 


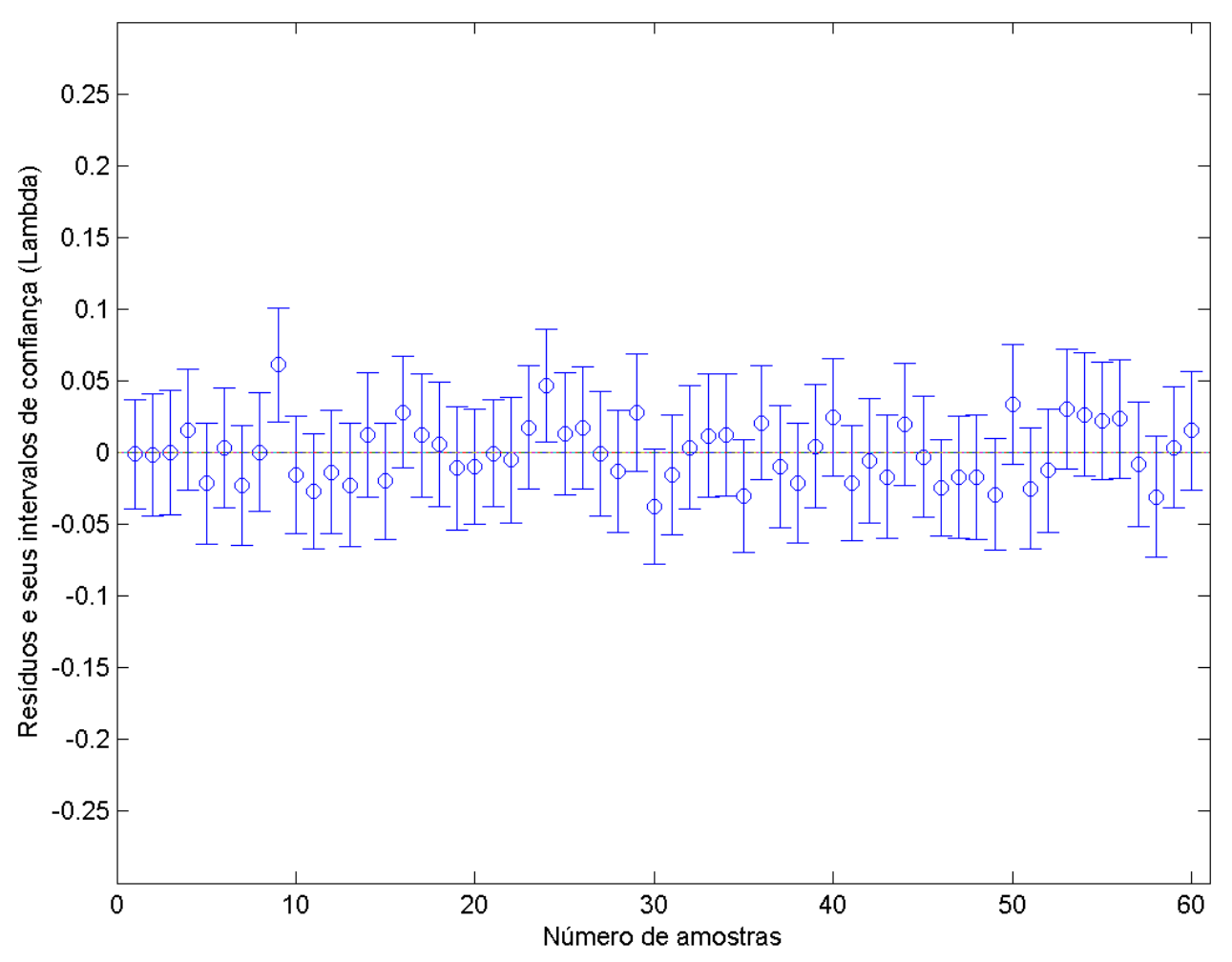

Figura 43 - Resíduos, e seus respectivos intervalos de confiança, resultantes da estimação do fator $\lambda$ utilizando o modelo 4, média dos 20 ciclos de pressão no cilindro e janela 2 para o combustível E26 em condições de cargas combinadas.

Os resultados da estimação do fator $\lambda$ em condições de cargas diversas, utilizando o modelo 4, janela 2 e média de 20 ciclos de pressão no cilindro, são apresentados na Figura 44. A reta apresentada nesta figura indica o modelo ideal de estimação do fator $\lambda$ ( $r m s$ igual à zero).

A título de comparação, os resultados do modelo 9 em condições de cargas combinadas, média de 20 ciclos e janela 4 são apresentados na Figura 45.

Pode-se observar na Figura 45 que os fatores $\lambda$ estimados estão ligeiramente mais próximos dos fatores $\lambda$ reais do que na Figura 44, isto se deve ao menor rms apresentado pelo modelo 9 em relação ao modelo 4 em condições de cargas combinadas.

Os resultados obtidos com o presente trabalho melhoraram consideravelmente a estimativa do fator $\lambda$ em relação ao primeiro modelo proposto por Gilkey e Powell (1985), como pode ser observado na comparação das Figuras 44 e 45 com a Figura 46. Isto se deve a influência que o fator $\lambda$ exerce sobre as variáveis do motor (tempo de injeção, pico de pressão no cilindro e avanço da centelha) inseridas originalmente no presente estudo nas equações dos modelos propostos para a estimação do fator $\lambda$. 


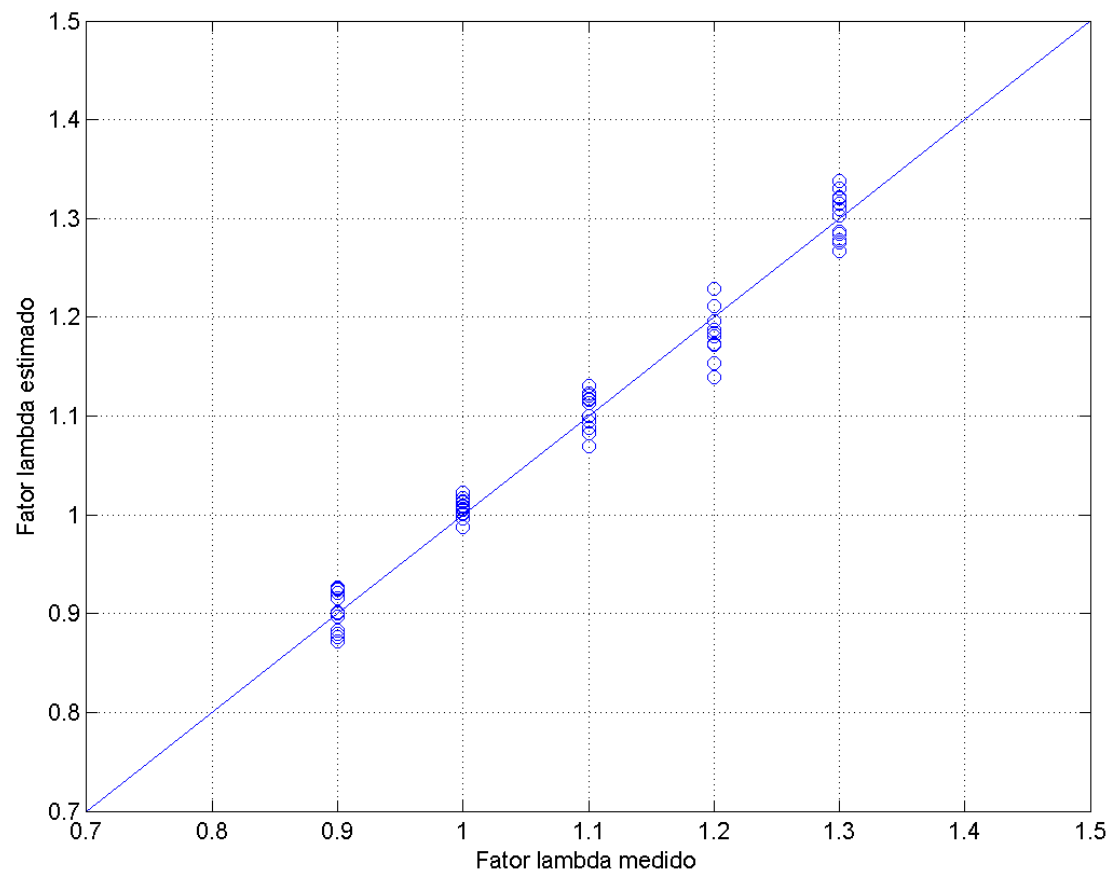

Figura 44 - Resultados obtidos na estimação do fator $\lambda$ utilizando o modelo 4, média de 20 ciclos de pressão no cilindro e janela 2 para o combustível E26 em condições de cargas combinadas.

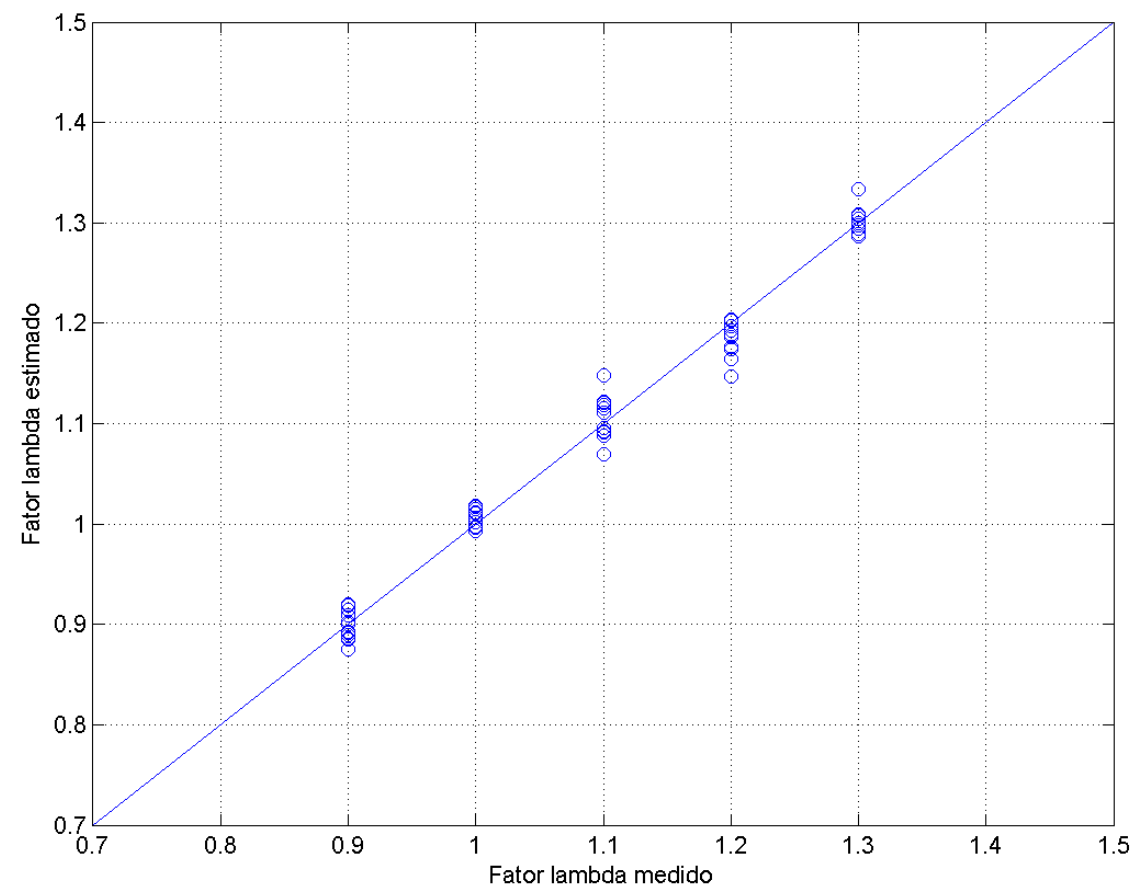

Figura 45 - Resultados obtidos na estimação do fator $\lambda$ utilizando o modelo 9, média de 20 ciclos de pressão no cilindro e janela 4 para o combustível E26 em condições de cargas combinadas. 


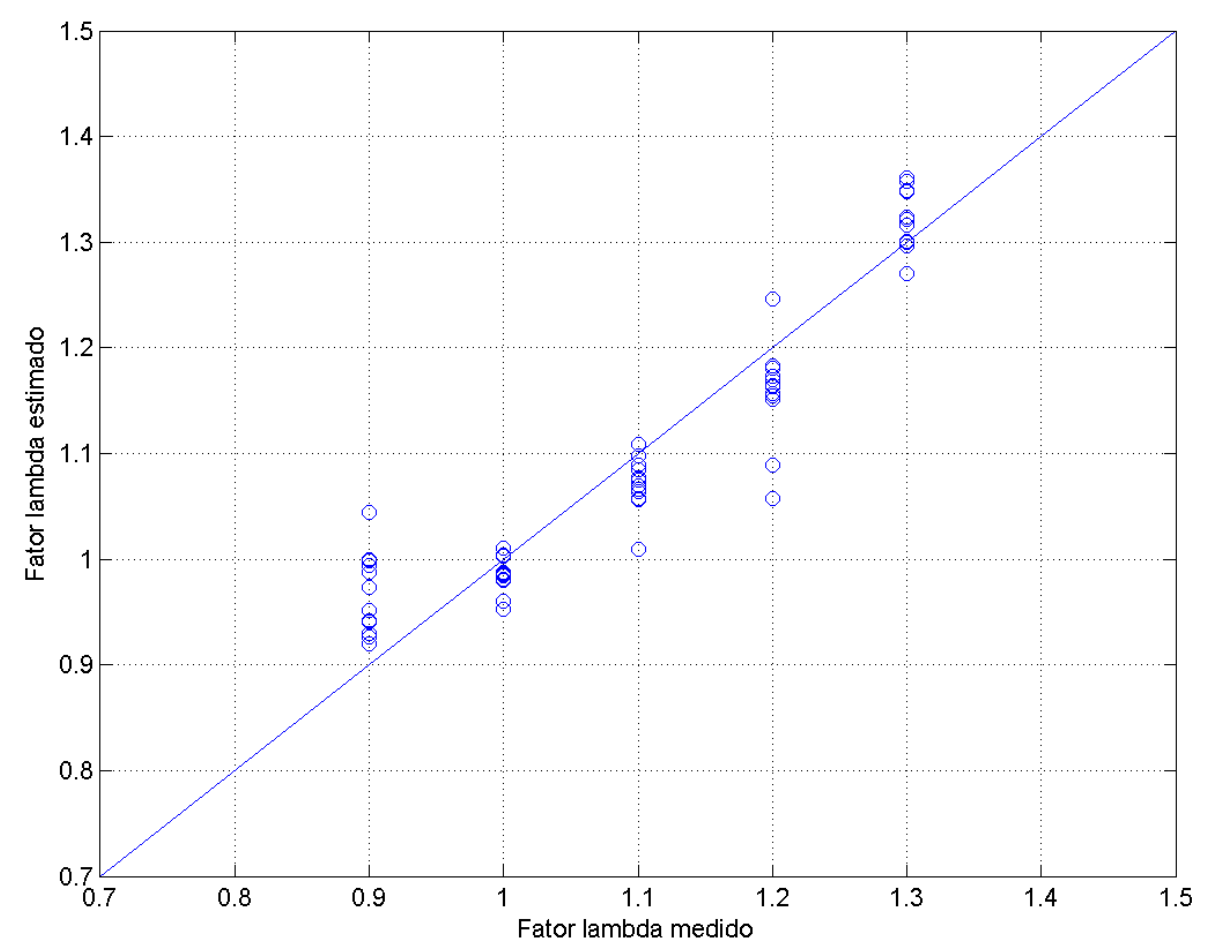

Figura 46 - Resultados obtidos na estimação do fator $\lambda$ utilizando o modelo 1, média de 20 ciclos de pressão no cilindro e janela 1 para o combustível E26 em condições de cargas combinadas.

Nas próximas seções os resultados dos modelos de estimação do fator $\lambda$ serão analisados pontuando o menor requisito computacional e o menor rms possível, evitando assim a repetição das justificativas apresentadas nesta seção para a inclusão de cada variável independente e as comparações entre os diversos modelos obtidos.

\subsubsection{Análise dos modelos obtidos para estimação do fator $\lambda$ utilizando o combustível E56}

Os resultados obtidos com os nove modelos propostos neste estudo são apresentados nas Tabelas 28 e 29, considerando o combustível E56. Os resultados mostrados nestas tabelas foram obtidos utilizando médias de 20 ciclos de pressão no cilindro, condições de plena carga e de cargas combinadas, respectivamente, e considerando as janelas 1, 2, 3 e 4 . 
Tabela 28 - Resultados alcançados com os nove modelos de estimação do fator $\lambda$ utilizando o combustível E56 (regime de plena carga, média de 20 ciclos de pressão no cilindro e janelas 1,2, 3 e 4$)$. (continua)

Combustível: E56 (regime de plena carga)

Média de 20 ciclos de pressão no cilindro

\begin{tabular}{|c|c|c|c|c|c|}
\hline \multirow{2}{*}{ Modelo } & \multirow{2}{*}{ Parâmetros } & \multicolumn{4}{|c|}{ Janelas } \\
\hline & & 1 & 2 & 3 & 4 \\
\hline \multirow{5}{*}{ Modelo 1} & $\mathrm{~F}$ & 128,14 & 12,85 & 27,57 & 189,55 \\
\hline & $\mathrm{F}_{0,05 ; 4 ; 25}$ & 2,76 & 2,76 & 2,76 & 2,76 \\
\hline & $r^{2}$ & 0,9535 & 0,6728 & 0,8152 & 0,9681 \\
\hline & $\mathrm{R}^{2}$ & 0,9461 & 0,6204 & 0,7857 & 0,9630 \\
\hline & rms & 0,0305 & 0,0809 & 0,0608 & 0,0253 \\
\hline \multirow{5}{*}{ Modelo 2} & $\mathrm{~F}$ & 1009,90 & 456,94 & 298,16 & 656,03 \\
\hline & $\mathrm{F}_{0,05 ; 5 ; 24}$ & 2,62 & 2,62 & 2,62 & 2,62 \\
\hline & $r^{2}$ & 0,9953 & 0,9896 & 0,9842 & 0,9927 \\
\hline & $\mathrm{R}^{2}$ & 0,9943 & 0,9874 & 0,9809 & 0,9912 \\
\hline & $\mathrm{rms}$ & 0,0097 & 0,0144 & 0,0178 & 0,0121 \\
\hline \multirow{5}{*}{ Modelo 3} & $\mathrm{~F}$ & 954,77 & 403,80 & 583,76 & 571,89 \\
\hline & $\mathrm{F}_{0,05 ; 6 ; 23}$ & 2,53 & 2,53 & 2,53 & 2,53 \\
\hline & $r^{2}$ & 0,9960 & 0,9906 & 0,9935 & 0,9933 \\
\hline & $\mathrm{R}^{2}$ & 0,9950 & 0,9881 & 0,9918 & 0,9916 \\
\hline & $\mathrm{rms}$ & 0,0089 & 0,0137 & 0,0114 & 0,0115 \\
\hline \multirow{5}{*}{ Modelo 4} & $\mathrm{~F}$ & 1174,13 & 1150,84 & 1142,62 & 1223,90 \\
\hline & $\mathrm{F}_{0,05 ; 7 ; 22}$ & 2,46 & 2,46 & 2,46 & 2,46 \\
\hline & $r^{2}$ & 0,9973 & 0,9973 & 0,9973 & 0,9974 \\
\hline & $\mathrm{R}^{2}$ & 0,9965 & 0,9964 & 0,9964 & 0,9966 \\
\hline & $\mathrm{rms}$ & 0,0073 & 0,0074 & 0,0074 & 0,0072 \\
\hline \multirow{5}{*}{ Modelo 5} & $\mathrm{~F}$ & 882,06 & 826,49 & 847,73 & 894,35 \\
\hline & $\mathrm{F}_{0,05 ; 9 ; 20}$ & 2,39 & 2,39 & 2,39 & 2,39 \\
\hline & $r^{2}$ & 0,9975 & 0,9973 & 0,9974 & 0,9975 \\
\hline & $\mathrm{R}^{2}$ & 0,9964 & 0,9961 & 0,9962 & 0,9964 \\
\hline & $\mathrm{rms}$ & 0,0071 & 0,0073 & 0,0072 & 0,0070 \\
\hline \multirow{5}{*}{ Modelo 6} & F & 925,46 & 1141,88 & 867,18 & 1803,97 \\
\hline & $\mathrm{F}_{0,05 ; 9 ; 20}$ & 2,39 & 2,39 & 2,39 & 2,39 \\
\hline & $r^{2}$ & 0,9976 & 0,9981 & 0,9974 & 0,9988 \\
\hline & $\mathrm{R}^{2}$ & 0,9965 & 0,9972 & 0,9963 & 0,9982 \\
\hline & rms & 0,0069 & 0,0062 & 0,0071 & 0,0050 \\
\hline
\end{tabular}


Tabela 28 - Resultados alcançados com os nove modelos de estimação do fator $\lambda$ utilizando o combustível E56 (regime de plena carga, média de 20 ciclos de pressão no cilindro e janelas 1, 2, 3 e 4). (conclusão)

\begin{tabular}{|c|c|c|c|c|c|}
\hline \multicolumn{6}{|c|}{$\begin{array}{l}\text { Combustível: E56 (regime de plena carga) } \\
\text { Média de } 20 \text { ciclos de pressão no cilindro }\end{array}$} \\
\hline \multirow{2}{*}{ Modelo } & \multirow{2}{*}{ Parâmetros } & \multicolumn{4}{|c|}{ Janelas } \\
\hline & & 1 & 2 & 3 & 4 \\
\hline \multirow{5}{*}{ Modelo 7} & $\mathrm{~F}$ & 985,48 & 1060,93 & 761,36 & 1988,86 \\
\hline & $\mathrm{F}_{0,05 ; 10 ; 19}$ & 2,38 & 2,38 & 2,38 & 2,38 \\
\hline & $r^{2}$ & 0,9981 & 0,9982 & 0,9975 & 0,9990 \\
\hline & $\mathrm{R}^{2}$ & 0,9971 & 0,9973 & 0,9962 & 0,9985 \\
\hline & $\mathrm{rms}$ & 0,0062 & 0,0060 & 0,0071 & 0,0044 \\
\hline \multirow{5}{*}{ Modelo 8} & $\mathrm{~F}$ & 866,71 & 932,36 & 662,61 & 2080,89 \\
\hline & $\mathrm{F}_{0,05 ; 11 ; 18}$ & 2,38 & 2,38 & 2,38 & 2,38 \\
\hline & $\mathrm{r}^{2}$ & 0,9981 & 0,9982 & 0,9975 & 0,9992 \\
\hline & $\mathrm{R}^{2}$ & 0,9970 & 0,9972 & 0,9960 & 0,9987 \\
\hline & $\mathrm{rms}$ & 0,0061 & 0,0059 & 0,0070 & 0,0040 \\
\hline \multirow{5}{*}{ Modelo 9} & $\mathrm{~F}$ & 854,86 & 1128,05 & 1498,58 & 1145,52 \\
\hline & $\mathrm{F}_{0,05 ; 9 ; 20}$ & 2,39 & 2,39 & 2,39 & 2,39 \\
\hline & $r^{2}$ & 0,9974 & 0,9980 & 0,9985 & 0,9981 \\
\hline & $\mathrm{R}^{2}$ & 0,9962 & 0,9971 & 0,9979 & 0,9972 \\
\hline & $\mathrm{rms}$ & 0,0072 & 0,0063 & 0,0054 & 0,0062 \\
\hline
\end{tabular}

Observando os resultados apresentados nas Tabelas 28 e 29 pode-se afirmar que os valores críticos, $F_{\alpha, k, n-p}$, foram menores que as estatísticas de teste, $F$, nos nove modelos estudados, portanto, existe uma relação linear entre os regressores e o fator $\lambda$, e pelo menos um regressor $\left(a_{n}\right)$, em cada um dos modelos analisados, que contribui significativamente para a estimativa do fator $\lambda$.

A janela 2, de acordo com os dados apresentados nas Tabelas 28 e 29, não apresentou o menor valor de $r m s$ em nenhum dos modelos analisados para o combustível E56.

Em condições de plena carga, Tabela 28, o único modelo que apresentou redução do $r^{2} \mathrm{e}$ do $R^{2}$ em relação ao seu antecessor de referência, foi o modelo 5 , indicando que o método dos momentos aplicado à curva da razão de pressões no cilindro não colabora para a estimativa do fator $\lambda$ quando utilizando o combustível E56. Esse resultado não se confirmou em condições de cargas combinadas, pois nestas condições o método dos momentos aplicado à curva da razão de pressões no cilindro colaborou significativamente para a estimativa do fator $\lambda$. 
Tabela 29 - Resultados alcançados com os nove modelos de estimação do fator $\lambda$ utilizando o combustível E56 (duas cargas combinadas, média de 20 ciclos de pressão no cilindro e janelas 1, 2, 3 e 4 ). (continua)

\begin{tabular}{|c|c|c|c|c|c|}
\hline \multicolumn{6}{|c|}{$\begin{array}{l}\text { Combustível: E56 (duas cargas combinadas) } \\
\text { Média de } 20 \text { ciclos de pressão no cilindro }\end{array}$} \\
\hline \multirow{2}{*}{ Modelo } & \multirow{2}{*}{ Parâmetros } & \multicolumn{4}{|c|}{ Janelas } \\
\hline & & 1 & 2 & 3 & 4 \\
\hline \multirow{5}{*}{ Modelo 1} & $\mathrm{~F}_{0,05 ; 4 ; 55}$ & 2,55 & 2,55 & 2,55 & 2,55 \\
\hline & $\mathrm{F}$ & 208,64 & 21,49 & 15,63 & 208,72 \\
\hline & $\mathrm{r}^{2}$ & 0,9382 & 0,6098 & 0,5320 & 0,9382 \\
\hline & $\mathrm{R}^{2}$ & 0,9337 & 0,5815 & 0,4979 & 0,9337 \\
\hline & $\mathrm{rms}$ & 0,0352 & 0,0883 & 0,0968 & 0,0352 \\
\hline \multirow{5}{*}{ Modelo 2} & $\mathrm{~F}_{0,05 ; 5 ; 54}$ & 2,39 & 2,39 & 2,39 & 2,39 \\
\hline & $\mathrm{F}$ & 333,68 & 173,47 & 176,14 & 357,97 \\
\hline & $r^{2}$ & 0,9686 & 0,9414 & 0,9422 & 0,9707 \\
\hline & $\mathrm{R}^{2}$ & 0,9657 & 0,9360 & 0,9369 & 0,9680 \\
\hline & $\mathrm{rms}$ & 0,0250 & 0,0342 & 0,0340 & 0,0242 \\
\hline \multirow{5}{*}{ Modelo 3} & $\mathrm{~F}_{0,05 ; 6 ; 53}$ & 2,28 & 2,28 & 2,28 & 2,28 \\
\hline & $\mathrm{F}$ & 274,92 & 177,44 & 171,84 & 308,73 \\
\hline & $\mathrm{r}^{2}$ & 0,9689 & 0,9526 & 0,9511 & 0,9722 \\
\hline & $\mathrm{R}^{2}$ & 0,9653 & 0,9472 & 0,9456 & 0,9690 \\
\hline & $\mathrm{rms}$ & 0,0250 & 0,0308 & 0,0313 & 0,0236 \\
\hline \multirow{5}{*}{ Modelo 4} & $\mathrm{~F}_{0,05 ; 7 ; 52}$ & 2,20 & 2,20 & 2,20 & 2,20 \\
\hline & $\mathrm{F}$ & 351,33 & 331,85 & 552,85 & 364,27 \\
\hline & $\mathrm{r}^{2}$ & 0,9793 & 0,9781 & 0,9867 & 0,9800 \\
\hline & $\mathrm{R}^{2}$ & 0,9765 & 0,9752 & 0,9850 & 0,9773 \\
\hline & $\mathrm{rms}$ & 0,0204 & 0,0209 & 0,0163 & 0,0200 \\
\hline \multirow{5}{*}{ Modelo 5} & $\mathrm{~F}_{0,05 ; 9 ; 50}$ & 2,08 & 2,08 & 2,08 & 2,08 \\
\hline & $\mathrm{F}$ & 343,15 & 318,97 & 435,90 & 399,28 \\
\hline & $\mathrm{r}^{2}$ & 0,9841 & 0,9829 & 0,9874 & 0,9863 \\
\hline & $\mathrm{R}^{2}$ & 0,9812 & 0,9798 & 0,9852 & 0,9838 \\
\hline & $\mathrm{rms}$ & 0,0179 & 0,0185 & 0,0159 & 0,0166 \\
\hline \multirow{5}{*}{ Modelo 6} & $\mathrm{~F}_{0,05 ; 9 ; 50}$ & 2,08 & 2,08 & 2,08 & 2,08 \\
\hline & $\mathrm{F}$ & 426,53 & 329,48 & 502,30 & 315,24 \\
\hline & $\mathrm{r}^{2}$ & 0,9871 & 0,9834 & 0,9891 & 0,9827 \\
\hline & $\mathrm{R}^{2}$ & 0,9848 & 0,9804 & 0,9871 & 0,9796 \\
\hline & $\mathrm{rms}$ & 0,0160 & 0,0182 & 0,0148 & 0,0186 \\
\hline
\end{tabular}


Tabela 29 - Resultados alcançados com os nove modelos de estimação do fator $\lambda$ utilizando o combustível E56 (duas cargas combinadas, média de 20 ciclos de pressão no cilindro e janelas 1, 2, 3 e 4). (conclusão)

\begin{tabular}{|c|c|c|c|c|c|}
\hline \multicolumn{6}{|c|}{$\begin{array}{l}\text { Combustível: E56 (duas cargas combinadas) } \\
\text { Média de } 20 \text { ciclos de pressão no cilindro }\end{array}$} \\
\hline \multirow{2}{*}{ Modelo } & \multirow{2}{*}{ Parâmetros } & \multicolumn{4}{|c|}{ Janelas } \\
\hline & & 1 & 2 & 3 & 4 \\
\hline \multirow{5}{*}{ Modelo 7} & $\mathrm{~F}_{0,05 ; 10 ; 49}$ & 2,04 & 2,04 & 2,04 & 2,04 \\
\hline & $\mathrm{F}$ & 377,77 & 293,83 & 448,43 & 280,99 \\
\hline & $r^{2}$ & 0,9872 & 0,9836 & 0,9892 & 0,9829 \\
\hline & $\mathrm{R}^{2}$ & 0,9846 & 0,9802 & 0,9870 & 0,9794 \\
\hline & $\mathrm{rms}$ & 0,0160 & 0,0181 & 0,0147 & 0,0185 \\
\hline \multirow{5}{*}{ Modelo 8} & $\mathrm{~F}_{0,05 ; 11 ; 48}$ & 2,01 & 2,01 & 2,01 & 2,01 \\
\hline & $\mathrm{F}$ & 336,50 & 270,43 & 403,00 & 253,97 \\
\hline & $r^{2}$ & 0,9872 & 0,9841 & 0,9893 & 0,9831 \\
\hline & $\mathrm{R}^{2}$ & 0,9843 & 0,9805 & 0,9868 & 0,9792 \\
\hline & $\mathrm{rms}$ & 0,0160 & 0,0178 & 0,0146 & 0,0184 \\
\hline \multirow{5}{*}{ Modelo 9} & $\mathrm{~F}_{0,05 ; 9 ; 50}$ & 2,08 & 2,08 & 2,08 & 2,08 \\
\hline & $\mathrm{F}$ & 287,89 & 283,99 & 455,76 & 406,73 \\
\hline & $r^{2}$ & 0,9811 & 0,9808 & 0,9880 & 0,9865 \\
\hline & $\mathrm{R}^{2}$ & 0,9777 & 0,9774 & 0,9858 & 0,9841 \\
\hline & rms & 0,0195 & 0,0196 & 0,0155 & 0,0164 \\
\hline
\end{tabular}

Em condições de cargas combinadas, Tabela 29, todos os modelos apresentaram aumento do $r^{2}$ e do $R^{2}$ em relação ao seu antecessor de referência, em pelo menos uma das janelas em estudo.

Considerando os dados em cargas combinadas (Tabela 29) pode-se afirmar que todas as variáveis independentes adicionadas a partir do modelo 1 colaboram para a estimativa do fator $\lambda$, exceto a temperatura de admissão.

O modelo 2 (janela 1) apresentou uma redução do rms $(0,0097)$ de aproximadamente 61,7\% em relação ao modelo 1 (janela 4: $r m s=0,0253$ ) considerando os dados em plena carga e de aproximadamente $31,2 \%$ considerando os dados em cargas combinadas.

Em cargas combinadas, Tabela 29, o modelo 2 apresentou os melhores resultados na janela $4(r m s=0,0242)$, enquanto que o modelo 1 apresentou os melhores resultados nas janelas 1 e $4(r m s=0,0352)$.

O modelo 4 foi o que apresentou o menor $r m s(0,0072)$ entre os modelos de menor requisito computacional (modelos 1, 2, 3 e 4). Este resultado ocorreu nas 4 janelas $(r m s=$ $0,0073 \pm 0,0001)$ em condições de plena carga (Tabela 28) e na janela $3(0,0163)$ em condições de cargas combinadas (Tabela 29). 
A redução do $r m s$ do modelo 4 (janela 4: $r m s=0,0072$ ) em relação ao modelo 1 (janela 4: $r m s=0,0253)$ foi de aproximadamente $71,5 \%$ em condições de plena carga e de aproximadamente $53,7 \%$ em condições de cargas combinadas.

Os melhores rms encontrados foram obtidos pelo modelo 8 em plena carga na janela 4 $(r m s=0,0040)$ e em cargas combinadas na janela $3(r m s=0,0146)$. A redução do $r m s$ em relação ao combustível E26 (0,0075), em condições de plena carga, foi de aproximadamente $46,7 \%$, indicando uma menor variação cíclica da pressão no cilindro da mistura E56 em relação à mistura E26.

Como discutido para o combustível E26, o modelo 8 exige a inclusão de transdutores de temperatura nos coletores de admissão e de escape, o que pode ser um empecilho à sua implementação em um sistema eletrônico de controle de motores, não só pelo custo adicional, mas também pelos requisitos de manutenção que estes transdutores podem vir a exigir.

O modelo 6 (com maior número de momentos) apresentou o melhor rms entre os modelos que utilizam apenas o sinal do transdutor de pressão no cilindro (modelos 1, 2, 3, 4, 5, 6 e 9), superando até mesmo o modelo 9 que apresenta o maior requisito computacional.

O modelo 6 apresentou uma redução no rms, em relação ao modelo 4 , de aproximadamente $30,6 \%$ em plena carga e de aproximadamente 9,2\% em condições de cargas combinadas, porém, sua implementação em um sistema eletrônico de controle de motores depende da disponibilidade computacional do mesmo.

Resumindo os resultados obtidos com todos os modelos pode-se afirmar que:

- O modelo 4 apresentou o melhor rms entre os modelos de menor requisito computacional, tanto em plena carga como em cargas combinadas;

- As 4 janelas do modelo 4 em plena carga produziram resultados parecidos $(r m s=$ $0,0073 \pm 0,0001$ ); enquanto que em cargas combinadas a melhor janela foi a 3 $(r m s=0,0163), \mathrm{e}$

- o modelo 8 foi o que apresentou o menor $r m s$ em plena carga $(0,0040)$, utilizando a janela 4 , e em cargas combinadas $(0,0146)$ utilizando a janela 3.

A Tabela 30 exibe os coeficientes individuais das regressões lineares múltiplas $\left(a_{n}\right)$ obtidos para os modelos que apresentaram os menores $r m s$ em condições de plena carga e de cargas combinadas, considerando uma média de 20 ciclos de pressão no cilindro. 
Tabela 30 - Coeficientes individuais das regressões lineares múltiplas dos modelos que apresentaram os menores rms para o combustível E56.

\begin{tabular}{|c|c|c|c|c|}
\hline \multirow[b]{5}{*}{ Coeficientes $a_{n}$} & \multicolumn{4}{|c|}{ Combustível: E56 (média de 20 ciclos) } \\
\hline & \multicolumn{2}{|c|}{$\begin{array}{c}\text { Plena carga } \\
\text { Modelos }\end{array}$} & \multicolumn{2}{|c|}{$\begin{array}{c}\text { Duas cargas combinadas } \\
\text { Modelos }\end{array}$} \\
\hline & 4 & 8 & 4 & 8 \\
\hline & \multicolumn{2}{|c|}{ Janelas } & \multicolumn{2}{|c|}{ Janelas } \\
\hline & 4 & 4 & 3 & 3 \\
\hline 1 & $7,393 \mathrm{E}+00$ & $6,026 \mathrm{E}+00$ & $1,068 \mathrm{E}+01$ & $9,528 \mathrm{E}+00$ \\
\hline 2 & $-6,277 \mathrm{E}+04$ & $-1,355 \mathrm{E}+04$ & $2,106 \mathrm{E}+05$ & $2,064 \mathrm{E}+05$ \\
\hline 3 & $-1,603 \mathrm{E}-01$ & $-1,807 \mathrm{E}-01$ & $-1,503 \mathrm{E}-01$ & $-1,476 \mathrm{E}-01$ \\
\hline 4 & $-3,455 \mathrm{E}-03$ & $-7,933 \mathrm{E}-04$ & $-6,320 \mathrm{E}-03$ & $-5,541 \mathrm{E}-03$ \\
\hline 5 & $-1,422 \mathrm{E}-02$ & $-1,141 \mathrm{E}-02$ & $-2,881 \mathrm{E}-02$ & $-2,529 \mathrm{E}-02$ \\
\hline 6 & $-5,040 \mathrm{E}-06$ & $-2,239 \mathrm{E}-04$ & $-1,357 \mathrm{E}-05$ & $1,603 \mathrm{E}-04$ \\
\hline 7 & $-3,738 \mathrm{E}-04$ & $-2,647 \mathrm{E}-03$ & $3,374 \mathrm{E}-05$ & $1,097 \mathrm{E}-03$ \\
\hline 8 & $2,948 \mathrm{E}-05$ & $1,846 \mathrm{E}-05$ & $-1,991 \mathrm{E}-06$ & $-6,767 \mathrm{E}-06$ \\
\hline 9 & & $-4,990 \mathrm{E}-03$ & & $-2,202 \mathrm{E}-04$ \\
\hline 10 & & $-1,087 \mathrm{E}-03$ & & $-3,581 \mathrm{E}-06$ \\
\hline 11 & & $1,953 \mathrm{E}-05$ & & 2,723E-08 \\
\hline 12 & & $1,811 \mathrm{E}-06$ & & $1,491 \mathrm{E}-10$ \\
\hline
\end{tabular}

Os resíduos em condições de cargas combinadas para o modelo 4 (janela 3) são representados por círculos na Figura 47. Os resultados, com nível de 5\% de significância, indicam uma pequena variação nos resíduos da estimativa do fator $\lambda$ utilizando o modelo 4 (resíduo médio do fator $\lambda$ estimado igual a 0,0131).

A Figura 47 mostra que os resíduos do modelo 4, considerando a janela 3, apresentam alguns intervalos de confiança que não tocam a linha zero, ou seja possuem alguns valores atípicos (outlier). Como mencionado na análise dos modelos para o combustível E26, a retirada dos valores atípicos poderia melhorar a estimativa, mas tal atitude só seria válida se novos experimentos fossem realizados. 


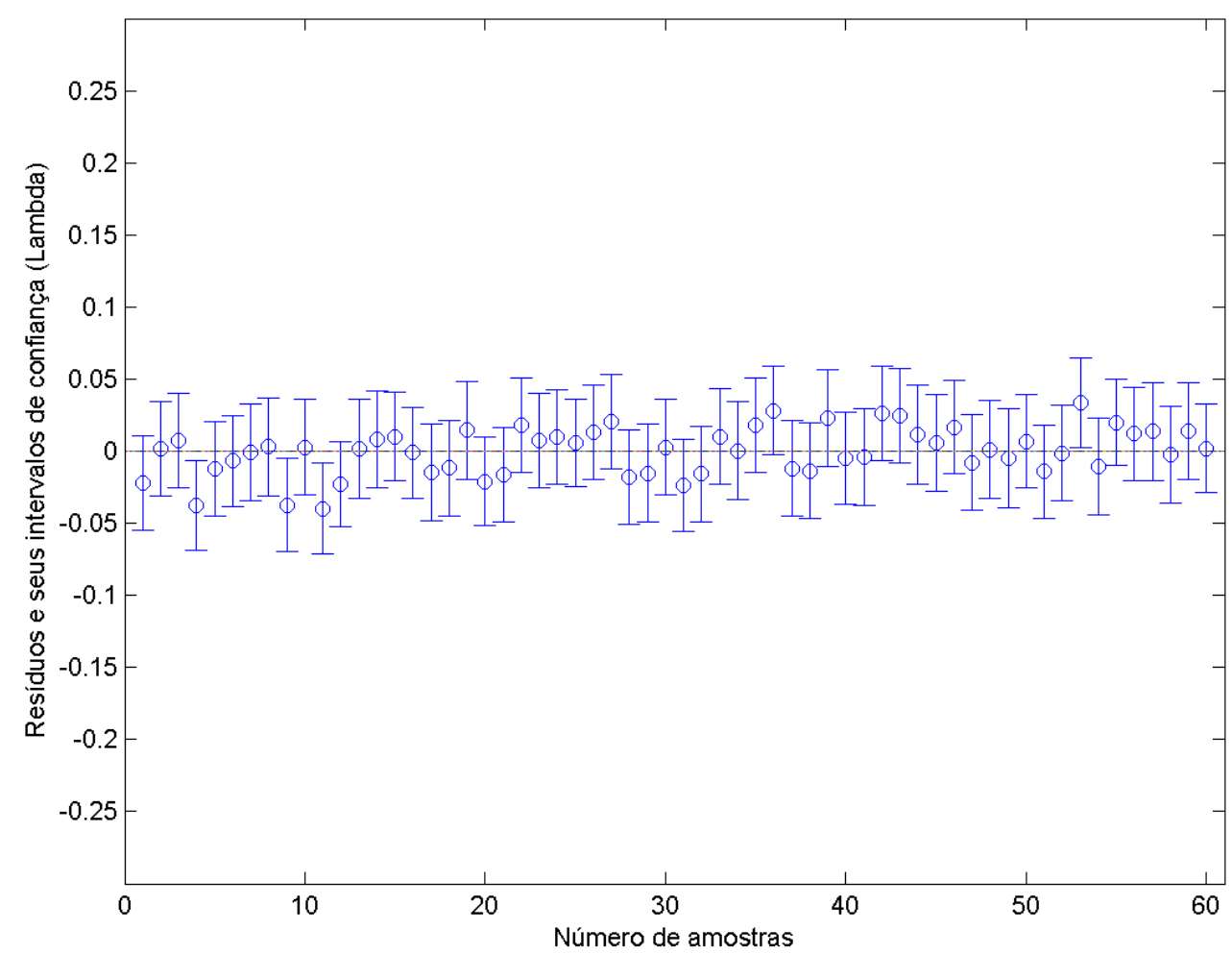

Figura 47 - Resíduos, e seus respectivos intervalos de confiança, resultantes da estimação do fator $\lambda$ utilizando o modelo 4, média de 20 ciclos de pressão no cilindro, e janela 3 para o combustível E56 em condições de cargas combinadas.

A Figura 48 apresenta os resultados da estimação do fator $\lambda$, utilizando o modelo 4, janela 3 e média de 20 ciclos em condições de cargas combinadas.

Os resultados do modelo 8 (janela 4 e média de 20 ciclos) em condições de cargas combinadas são apresentados na Figura 49, com o intuito de permitir uma comparação visual com os resultados obtidos com o modelo 4.

Observando as Figuras 48 e 49 nota-se uma ligeira redução na dispersão dos valores estimados do modelo 8 em relação ao modelo 4, devido à redução do rms apresentada pelo modelo 8 em relação ao modelo 4 em condições de cargas combinadas.

A comparação da Figura 50, que apresenta os resultados obtidos com o modelo 1, proposto por Gilkey e Powell (1985), com as Figura 48 e 49 permite observar a melhora alcançada com o presente estudo na estimativa do fator $\lambda$. 


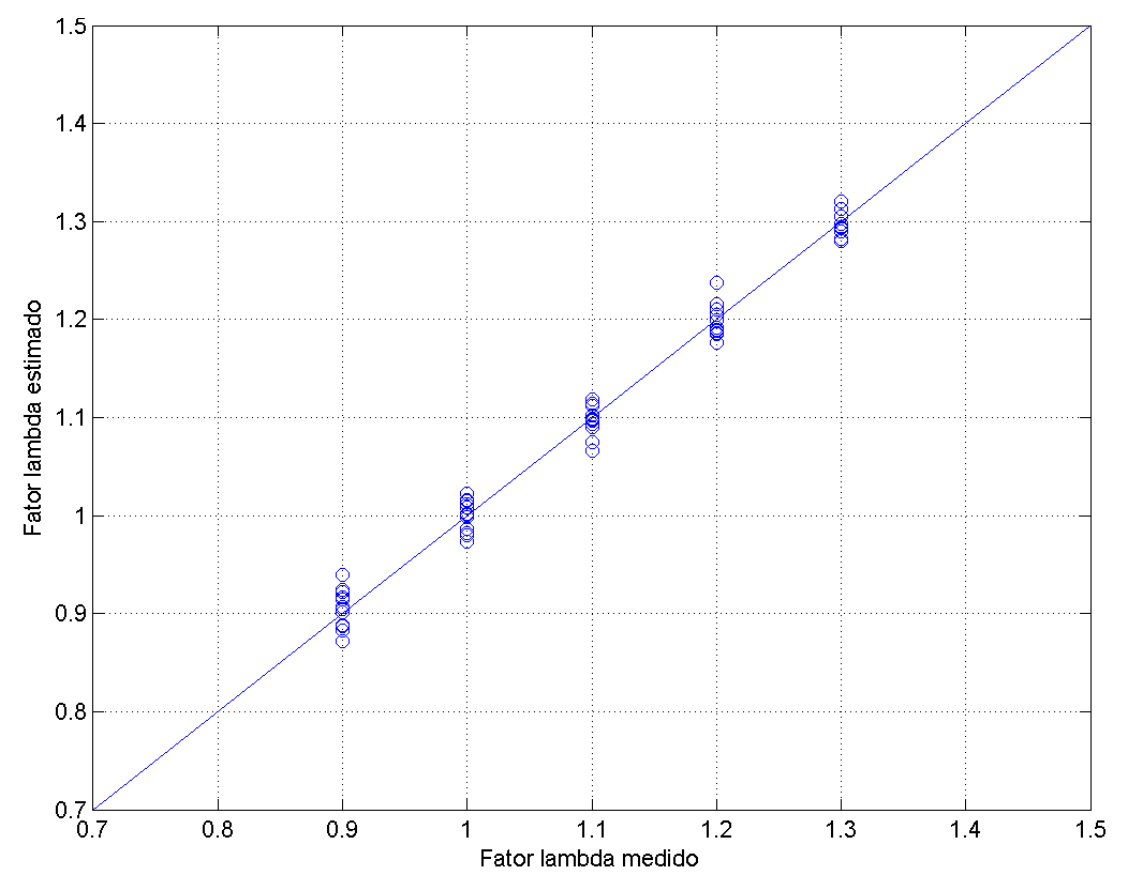

Figura 48 - Resultados obtidos na estimação do fator $\lambda$ utilizando o modelo 4, média de 20 ciclos de pressão no cilindro e janela 3 para o combustível E56 em condições de cargas combinadas.

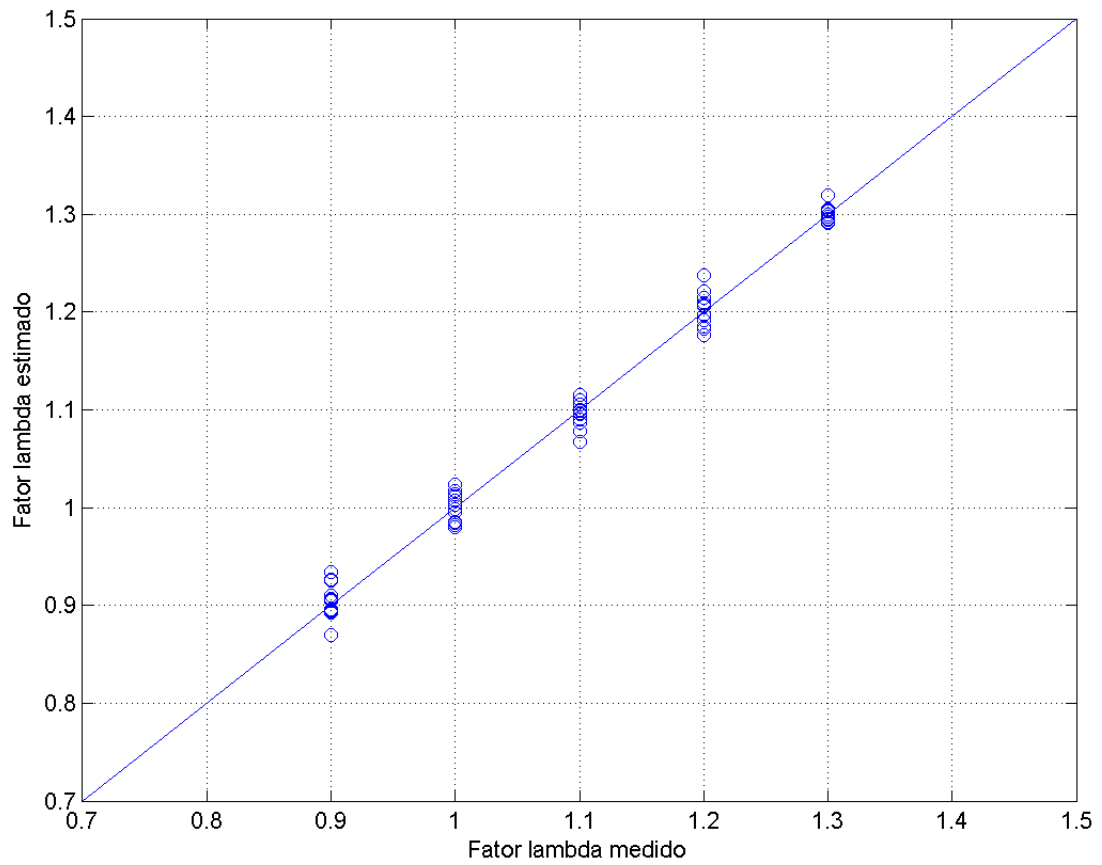

Figura 49 - Resultados obtidos na estimação do fator $\lambda$ utilizando o modelo 8 , média de 20 ciclos de pressão no cilindro e janela 3 para o combustível E56 em condições de cargas combinadas. 


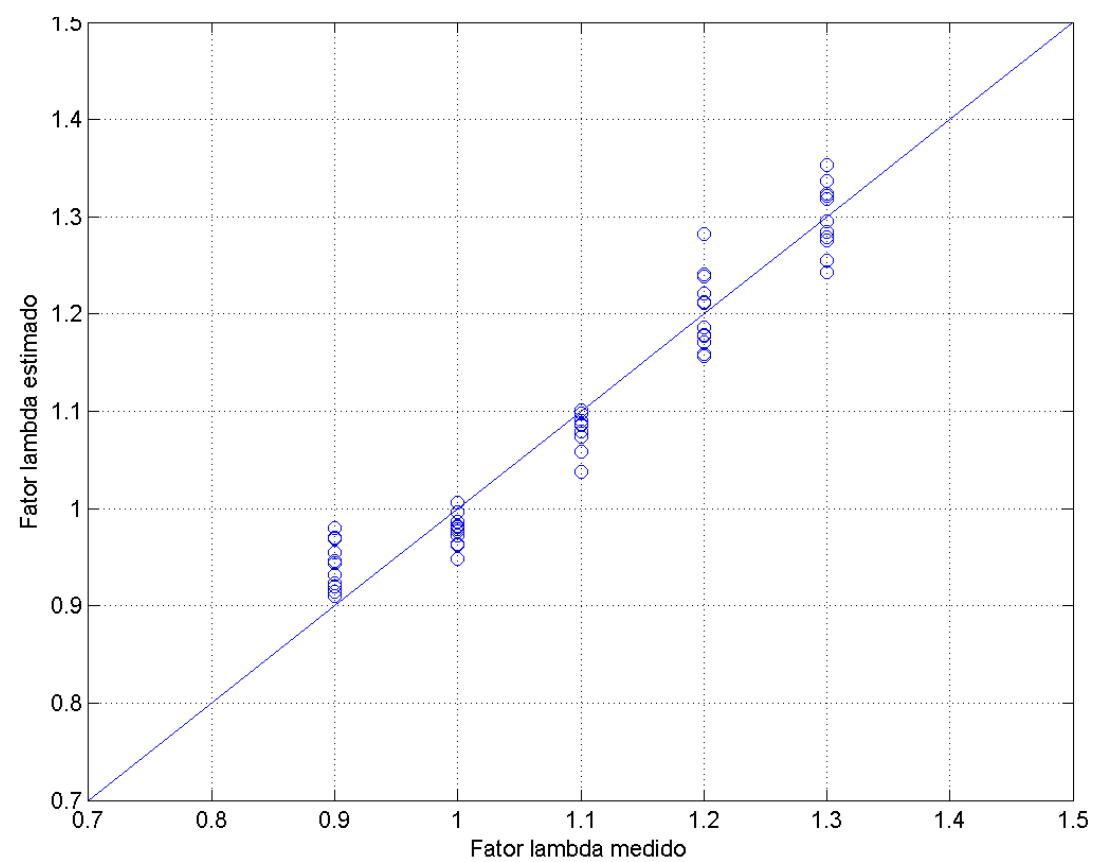

Figura 50 - Resultados obtidos na estimação do fator $\lambda$ utilizando o modelo 1, média de 20 ciclos de pressão no cilindro e janela 1 para o combustível E56 em condições de cargas combinadas.

\subsubsection{Análise dos modelos obtidos para estimação do fator $\lambda$ utilizando o combustível E70}

As Tabelas 31 e 32 exibem os resultados obtidos com os nove modelos propostos neste estudo, considerando o combustível E70.

Os resultados apresentados nas Tabelas 31 e 32 foram obtidos utilizando médias de 20 ciclos de pressão no cilindro, considerando as janelas 1, 2, 3 e 4, condições de plena carga e de cargas combinadas, respectivamente.

Nas Tabelas 31 e 32 pode-se observar que os valores críticos, $F_{\alpha, k, n-p}$, foram menores que as estatísticas de teste, $F$, nos nove modelos estudados, portanto, existe pelo menos um regressor $\left(a_{n}\right)$ em cada um dos modelos analisados que contribui significativamente para a estimativa do fator $\lambda$. 
Tabela 31 - Resultados alcançados com os nove modelos de estimação do fator $\lambda$ utilizando o combustível E70 (regime de plena carga, média de 20 ciclos de pressão no cilindro e janelas 1, 2, 3 e 4$)$. (continua)

\begin{tabular}{|c|c|c|c|c|c|}
\hline \multicolumn{6}{|c|}{$\begin{array}{l}\text { Combustível: E70 (regime de plena carga) } \\
\text { Média de } 20 \text { ciclos de pressão no cilindro }\end{array}$} \\
\hline \multirow{2}{*}{ Modelo } & \multirow{2}{*}{ Parâmetros } & \multicolumn{4}{|c|}{ Janelas } \\
\hline & & 1 & 2 & 3 & 4 \\
\hline \multirow{6}{*}{ Modelo 1} & $\mathrm{~F}$ & 70,04 & 29,25 & 14,34 & 222,98 \\
\hline & $\mathrm{F}_{0,05 ; 4 ; 25}$ & 2,76 & 2,76 & 2,76 & 2,76 \\
\hline & $r^{2}$ & 0,9181 & 0,8239 & 0,6964 & 0,9727 \\
\hline & $\mathrm{R}^{2}$ & 0,9050 & 0,7958 & 0,6478 & 0,9684 \\
\hline & $\mathrm{rms}$ & 0,0405 & 0,0593 & 0,0779 & 0,0234 \\
\hline & $\mathrm{F}$ & 789,08 & 393,91 & 420,13 & 656,25 \\
\hline \multirow{4}{*}{ Modelo 2} & $\mathrm{~F}_{0,05}$ & 2,62 & 2,62 & 2,62 & 2,62 \\
\hline & $r^{2}$ & 0,9940 & 0,9880 & 0,9887 & 0,9927 \\
\hline & $\mathrm{R}^{2}$ & 0,9927 & 0,9855 & 0,9864 & 0,9912 \\
\hline & rms & 0,0110 & 0,0155 & 0,0150 & 0,0121 \\
\hline \multirow{5}{*}{ Modelo 3} & $\mathrm{~F}$ & 860,71 & 468,55 & 648,65 & 591,23 \\
\hline & $\mathrm{F}_{0,05 ; 6 ; 23}$ & 2,53 & 2,53 & 2,53 & 2,53 \\
\hline & $r^{2}$ & 0,9956 & 0,9919 & 0,9941 & 0,9936 \\
\hline & $\mathrm{R}^{2}$ & 0,9944 & 0,9898 & 0,9926 & 0,9919 \\
\hline & rms & 0,0094 & 0,0127 & 0,0108 & 0,0114 \\
\hline \multirow{5}{*}{ Modelo 4} & $\mathrm{~F}$ & 988,94 & 887,90 & 820,83 & 983,51 \\
\hline & $\mathrm{F}_{0,05 ; 7 ; 22}$ & 2,46 & 2,46 & 2,46 & 2,46 \\
\hline & $r^{2}$ & 0,9968 & 0,9965 & 0,9962 & 0,9968 \\
\hline & $\mathrm{R}^{2}$ & 0,9958 & 0,9954 & 0,9950 & 0,9958 \\
\hline & rms & 0,0080 & 0,0084 & 0,0087 & 0,0080 \\
\hline \multirow{5}{*}{ Modelo 5} & $\mathrm{~F}$ & 755,47 & 701,81 & 692,68 & 756,97 \\
\hline & $\mathrm{F}_{0,05 ; 9 ; 20}$ & 2,39 & 2,39 & 2,39 & 2,39 \\
\hline & $r^{2}$ & 0,9971 & 0,9968 & 0,9968 & 0,9971 \\
\hline & $\mathrm{R}^{2}$ & 0,9957 & 0,9954 & 0,9954 & 0,9958 \\
\hline & rms & 0,0077 & 0,0079 & 0,0080 & 0,0077 \\
\hline \multirow{5}{*}{ Modelo 6} & $\mathrm{~F}$ & 760,42 & 670,52 & 723,26 & 821,67 \\
\hline & $\mathrm{F}_{0,05 ; 9 ; 20}$ & 2,39 & 2,39 & 2,39 & 2,39 \\
\hline & $r^{2}$ & 0,9971 & 0,9967 & 0,9969 & 0,9973 \\
\hline & $\mathrm{R}^{2}$ & 0,9958 & 0,9952 & 0,9956 & 0,9961 \\
\hline & rms & 0,0076 & 0,0081 & 0,0078 & 0,0073 \\
\hline
\end{tabular}


Tabela 31 - Resultados alcançados com os nove modelos de estimação do fator $\lambda$ utilizando o combustível E70 (regime de plena carga, média de 20 ciclos de pressão no cilindro e janelas 1, 2, 3 e 4). (conclusão)

\begin{tabular}{|c|c|c|c|c|c|}
\hline \multicolumn{6}{|c|}{$\begin{array}{l}\text { Combustível: E70 (regime de plena carga) } \\
\text { Média de } 20 \text { ciclos de pressão no cilindro }\end{array}$} \\
\hline \multirow{2}{*}{ Modelo } & \multirow{2}{*}{ Parâmetros } & \multicolumn{4}{|c|}{ Janelas } \\
\hline & & 1 & 2 & 3 & 4 \\
\hline \multirow{5}{*}{ Modelo 7} & $\mathrm{~F}$ & 650,66 & 575,98 & 618,87 & 705,80 \\
\hline & $\mathrm{F}_{0,05 ; 10 ; 19}$ & 2,38 & 2,38 & 2,38 & 2,38 \\
\hline & $r^{2}$ & 0,9971 & 0,9967 & 0,9969 & 0,9973 \\
\hline & $\mathrm{R}^{2}$ & 0,9956 & 0,9950 & 0,9953 & 0,9959 \\
\hline & $\mathrm{rms}$ & 0,0076 & 0,0081 & 0,0078 & 0,0073 \\
\hline \multirow{5}{*}{ Modelo 8} & $\mathrm{~F}$ & 661,01 & 641,77 & 608,00 & 807,67 \\
\hline & $\mathrm{F}_{0,05 ; 11 ; 18}$ & 2,38 & 2,38 & 2,38 & 2,38 \\
\hline & $r^{2}$ & 0,9975 & 0,9975 & 0,9973 & 0,9980 \\
\hline & $\mathrm{R}^{2}$ & 0,9960 & 0,9959 & 0,9957 & 0,9967 \\
\hline & $\mathrm{rms}$ & 0,0070 & 0,0071 & 0,0073 & 0,0064 \\
\hline \multirow{5}{*}{ Modelo 9} & $\mathrm{~F}$ & 1040,76 & 794,13 & 717,23 & 804,18 \\
\hline & $\mathrm{F}_{0,05 ; 9 ; 20}$ & 2,39 & 2,39 & 2,39 & 2,39 \\
\hline & $r^{2}$ & 0,9979 & 0,9972 & 0,9969 & 0,9972 \\
\hline & $\mathrm{R}^{2}$ & 0,9969 & 0,9960 & 0,9955 & 0,9960 \\
\hline & $\mathrm{rms}$ & 0,0065 & 0,0075 & 0,0079 & 0,0074 \\
\hline
\end{tabular}

Os resultados apresentados na Tabela 31 permitem afirmar que as janelas 2 e 3 não apresentaram o menor valor de rms em nenhum dos modelos analisados para o combustível E70. Em condições de cargas combinadas, Tabela 32, apenas a janela 2 não foi bem sucedida em nenhum dos nove modelos estudados.

Com exceção do modelo 7, todos os modelos apresentaram aumento dos coeficientes $r^{2} \mathrm{e}$ $R^{2}$ em relação ao seu antecessor de referência ao menos em uma das condições de carga avaliadas (plena carga ou cargas combinadas), conforme mostram as Tabelas 31 e 32.

O método dos momentos aplicado à curva da razão de pressões no cilindro, modelo 5, demostrou que é capaz de estimar o fator $\lambda$ quando utilizando o combustível E70, tanto em condições de plena carga quanto em condições de cargas combinadas.

Todas as variáveis independentes adicionadas ao modelo 1 se mostraram capazes de colaborar para a estimativa do fator $\lambda$, exceto a temperatura de admissão. 
Tabela 32 - Resultados alcançados com os nove modelos de estimação do fator $\lambda$ utilizando o combustível E70 (duas cargas combinadas, média de 20 ciclos de pressão no cilindro e janelas 1, 2, 3 e 4$)$. (continua)

\begin{tabular}{|c|c|c|c|c|c|}
\hline \multicolumn{6}{|c|}{$\begin{array}{l}\text { Combustível: E70 (duas cargas combinadas) } \\
\text { Média de } 20 \text { ciclos de pressão no cilindro }\end{array}$} \\
\hline \multirow{2}{*}{ Modelo } & \multirow{2}{*}{ Parâmetros } & \multicolumn{4}{|c|}{ Janelas } \\
\hline & & 1 & 2 & 3 & 4 \\
\hline \multirow{5}{*}{ Modelo 1} & $\mathrm{~F}_{0,05 ; 4 ; 55}$ & 2,55 & 2,55 & 2,55 & 2,55 \\
\hline & $\mathrm{F}$ & 183,04 & 33,61 & 26,43 & 233,88 \\
\hline & $r^{2}$ & 0,9301 & 0,7096 & 0,6578 & 0,9445 \\
\hline & $\mathrm{R}^{2}$ & 0,9250 & 0,6885 & 0,6329 & 0,9404 \\
\hline & rms & 0,0374 & 0,0762 & 0,0827 & 0,0333 \\
\hline \multirow{5}{*}{ Modelo 2} & $\mathrm{~F}_{0,05 ; 5 ; 54}$ & 2,39 & 2,39 & 2,39 & 2,39 \\
\hline & $\mathrm{F}$ & 553,26 & 301,21 & 271,12 & 334,98 \\
\hline & $\mathrm{r}^{2}$ & 0,9809 & 0,9654 & 0,9617 & 0,9688 \\
\hline & $\mathrm{R}^{2}$ & 0,9791 & 0,9622 & 0,9581 & 0,9659 \\
\hline & $\mathrm{rms}$ & 0,0196 & 0,0263 & 0,0277 & 0,0250 \\
\hline \multirow{5}{*}{ Modelo 3} & $\mathrm{~F}_{0,05 ; 6 ; 53}$ & 2,28 & 2,28 & 2,28 & 2,28 \\
\hline & $\mathrm{F}$ & 487,63 & 254,89 & 239,13 & 296,52 \\
\hline & $\mathrm{r}^{2}$ & 0,9822 & 0,9665 & 0,9644 & 0,9711 \\
\hline & $\mathrm{R}^{2}$ & 0,9802 & 0,9627 & 0,9603 & 0,9678 \\
\hline & $\mathrm{rms}$ & 0,0189 & 0,0259 & 0,0267 & 0,0241 \\
\hline \multirow{5}{*}{ Modelo 4} & $\mathrm{~F}_{0,05 ; 7 ; 52}$ & 2,20 & 2,20 & 2,20 & 2,20 \\
\hline & $\mathrm{F}$ & 418,75 & 448,51 & 708,46 & 419,97 \\
\hline & $\mathrm{r}^{2}$ & 0,9826 & 0,9837 & 0,9896 & 0,9826 \\
\hline & $\mathrm{R}^{2}$ & 0,9802 & 0,9815 & 0,9882 & 0,9803 \\
\hline & $\mathrm{rms}$ & 0,0187 & 0,0181 & 0,0144 & 0,0186 \\
\hline \multirow{5}{*}{ Modelo 5} & $\mathrm{~F}_{0,05 ; 9 ; 50}$ & 2,08 & 2,08 & 2,08 & 2,08 \\
\hline & $\mathrm{F}$ & 340,71 & 381,24 & 543,52 & 350,08 \\
\hline & $\mathrm{r}^{2}$ & 0,9840 & 0,9856 & 0,9899 & 0,9844 \\
\hline & $\mathrm{R}^{2}$ & 0,9811 & 0,9831 & 0,9881 & 0,9816 \\
\hline & $\mathrm{rms}$ & 0,0179 & 0,0169 & 0,0142 & 0,0177 \\
\hline \multirow{5}{*}{ Modelo 6} & $\mathrm{~F}_{0,05 ; 9 ; 50}$ & 2,08 & 2,08 & 2,08 & 2,08 \\
\hline & $\mathrm{F}$ & 469,71 & 379,61 & 647,73 & 544,42 \\
\hline & $\mathrm{r}^{2}$ & 0,9883 & 0,9856 & 0,9915 & 0,9899 \\
\hline & $\mathrm{R}^{2}$ & 0,9862 & 0,9830 & 0,9900 & 0,9881 \\
\hline & $\mathrm{rms}$ & 0,0153 & 0,0170 & 0,0130 & 0,0142 \\
\hline
\end{tabular}


Tabela 32 - Resultados alcançados com os nove modelos de estimação do fator $\lambda$ utilizando o combustível E70 (duas cargas combinadas, média de 20 ciclos de pressão no cilindro e janelas 1, 2, 3 e 4). (conclusão)

\begin{tabular}{clcccc}
\hline \multirow{5}{*}{ Modelo } & \multicolumn{5}{c}{ Combustível: E70 } \\
& \multicolumn{4}{c}{ Média de 20 ciclos de pressão no cilindro } \\
& & \multicolumn{4}{c}{ Janelas } \\
& $\mathrm{F}_{0,05 ; 10 ; 49}$ & 2,04 & 2,04 & 2,04 & 2,04 \\
& $\mathrm{~F}$ & 419,32 & 339,66 & 574,34 & 492,19 \\
Modelo 7 & $\mathrm{r}^{2}$ & 0,9884 & 0,9858 & 0,9915 & 0,9901 \\
& $\mathrm{R}^{2}$ & 0,9861 & 0,9829 & 0,9898 & 0,9881 \\
& $\mathrm{rms}^{2}$ & 0,0152 & 0,0169 & 0,0130 & 0,0140 \\
& $\mathrm{~F}_{0,05 ; 11 ; 48}$ & 2,01 & 2,01 & 2,01 & 2,01 \\
& $\mathrm{~F}$ & 377,73 & 304,68 & 512,15 & 438,32 \\
Modelo 8 & $\mathrm{r}^{2}$ & 0,9886 & 0,9859 & 0,9916 & 0,9901 \\
& $\mathrm{R}^{2}$ & 0,9860 & 0,9826 & 0,9896 & 0,9879 \\
& $\mathrm{rms}^{2}$ & 0,0151 & 0,0168 & 0,0130 & 0,0140 \\
& $\mathrm{~F}_{0,05 ; 9 ; 50}$ & 2,08 & 2,08 & 2,08 & 2,08 \\
& $\mathrm{~F}$ & 377,29 & 380,51 & 567,93 & 544,64 \\
Modelo 9 & $\mathrm{r}^{2}$ & 0,9855 & 0,9856 & 0,9903 & 0,9899 \\
& $\mathrm{R}^{2}$ & 0,9829 & 0,9830 & 0,9886 & 0,9881 \\
& $\mathrm{rms}^{2}$ & 0,0170 & 0,0170 & 0,0139 & 0,0142 \\
\hline
\end{tabular}

A redução do $r m s$ do modelo $2(0,0110)$ foi de aproximadamente $53 \%$ em relação ao modelo $1(0,0234)$ considerando os dados em plena carga e de aproximadamente $41,1 \%$ considerando os dados em cargas combinadas.

Tanto em plena carga quanto em cargas combinadas o modelo 2 apresentou os melhores resultados na janela 1 (cargas combinadas: $r m s=0,0196)$, enquanto que o modelo 1 apresentou os melhores resultados na janela 4 (cargas combinadas: $r m s=0,0333$ ).

Entre os modelos de menor requisito computacional (modelos 1, 2, 3 e 4), o modelo 4 foi o que apresentou o menor rms $(0,0080)$. Este resultado ocorreu nas janelas 1 e 4 em condições de plena carga (Tabela 31$)$ e na janela $3(0,0144)$ em condições de cargas combinadas (Tabela 32).

O modelo 4 apresentou uma redução do rms de aproximadamente 65,8\% (janela 4 menor requisito computacional do que a janela $1: r m s=0,0080)$ em relação ao modelo 1 (janela 4: $r m s=0,0234$ ) em condições de plena carga e de aproximadamente $56,8 \%$ em condições de cargas combinadas.

O menor $r m s$ em plena carga foi obtido pelo modelo 8 (janela 4: $r m s=0,0064$ ). 
Em cargas combinadas os modelos 6, 7 e 8 apresentaram o menor rms $(0,0130$, utilizando a janela 3). Apesar de apresentarem o mesmo rms, o modelo 6 apresenta como vantagem, em relação aos modelos 7 e 8, a menor complexidade na sua obtenção.

Apesar do modelo 6 apresentar uma redução do $r m s$, em relação ao modelo 4, de aproximadamente $9,7 \%$ em cargas combinadas, sua implementação em um sistema eletrônico de controle de motores depende da disponibilidade computacional do mesmo.

Resumindo os resultados obtidos com todos os modelos pode-se afirmar que:

- O modelo 4 apresentou o melhor rms entre os modelos de menor requisito computacional, tanto em plena carga como em cargas combinadas;

- a melhor janela do modelo 4 em plena carga foi a janela 4 ( $r m s=0,0080$, empatada com a janela 1); enquanto que em cargas combinadas a melhor janela foi a $3(r m s=0,0144)$;

- o modelo 8 (janela 4) foi o que apresentou o menor $r m s$ em plena carga $(0,0064)$, e

- os modelos 6,7 e 8, utilizando a janela 3, foram os que apresentaram o menor rms em cargas combinadas $(0,0130)$, porém, o modelo 6 apresenta menor complexidade que os modelos 7 e 8 .

Os coeficientes individuais das regressões lineares múltiplas $\left(a_{n}\right)$ obtidos para os modelos que apresentaram os menores rms em condições de plena carga e de cargas combinadas, considerando uma média de 20 ciclos de pressão no cilindro, são exibidos na Tabela 33.

A Figura 51 exibe os resíduos em condições de cargas combinadas para o modelo 4 (janela 3), os quais são representados por círculos. Os resultados, com nível de 5\% de significância, indicam uma pequena variação nos resíduos da estimativa do fator $\lambda$ utilizando o modelo 4 (resíduo médio do fator $\lambda$ estimado igual a 0,0120).

Como pode ser observado na Figura 51 existem alguns valores atípicos nos resíduos do modelo 4, considerando a janela 3, porém, como mencionado na análise dos modelos para os combustíveis E26 e E56, a retirada dos valores atípicos poderia melhorar a estimativa, mas tal atitude só seria válida se novos experimentos fossem realizados. 
Tabela 33 - Coeficientes individuais das regressões lineares múltiplas dos modelos que apresentaram os menores rms para o combustível E70.

Combustível: E70 (média de 20 ciclos)

Condição de carga do motor

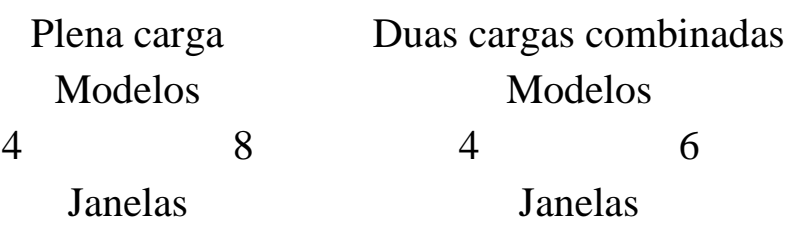

\begin{tabular}{ccccc} 
Coeficientes $\mathrm{a}_{\mathrm{n}}$ & 4 & 4 & 3 & 3 \\
\hline 1 & $5,632 \mathrm{E}+00$ & $4,480 \mathrm{E}+00$ & $9,346 \mathrm{E}+00$ & $7,344 \mathrm{E}+00$ \\
2 & $-2,769 \mathrm{E}+04$ & $-4,843 \mathrm{E}+04$ & $2,044 \mathrm{E}+05$ & $1,863 \mathrm{E}+05$ \\
3 & $-1,636 \mathrm{E}-01$ & $-2,040 \mathrm{E}-01$ & $-1,573 \mathrm{E}-01$ & $-1,647 \mathrm{E}-01$ \\
4 & $-1,301 \mathrm{E}-03$ & $2,040 \mathrm{E}-03$ & $-4,051 \mathrm{E}-03$ & $-1,788 \mathrm{E}-03$ \\
5 & $-9,955 \mathrm{E}-03$ & $-4,848 \mathrm{E}-03$ & $-2,468 \mathrm{E}-02$ & $-1,915 \mathrm{E}-02$ \\
6 & $1,765 \mathrm{E}-05$ & $-3,598 \mathrm{E}-04$ & $-6,915 \mathrm{E}-06$ & $2,949 \mathrm{E}-05$ \\
7 & $-2,645 \mathrm{E}-04$ & $-2,759 \mathrm{E}-04$ & $1,529 \mathrm{E}-05$ & $-3,254 \mathrm{E}-04$ \\
8 & $7,303 \mathrm{E}-05$ & $7,388 \mathrm{E}-05$ & $-2,356 \mathrm{E}-06$ & $-8,688 \mathrm{E}-06$ \\
9 & & $-1,706 \mathrm{E}-03$ & & $4,866 \mathrm{E}-08$ \\
10 & & $6,038 \mathrm{E}-04$ & & $3,789 \mathrm{E}-10$ \\
11 & & $1,001 \mathrm{E}-06$ & & \\
12 & & $-8,934 \mathrm{E}-07$ & & \\
\hline
\end{tabular}

Os resultados da estimação do fator $\lambda$, utilizando o modelo 4 (janela 3 e média de 20 ciclos) em condições de cargas combinadas, são exibidos na Figura 52.

Os resultados do modelo 6, para média de 20 ciclos e janela 3 em condições de cargas combinadas, são apresentados na Figura 53. 


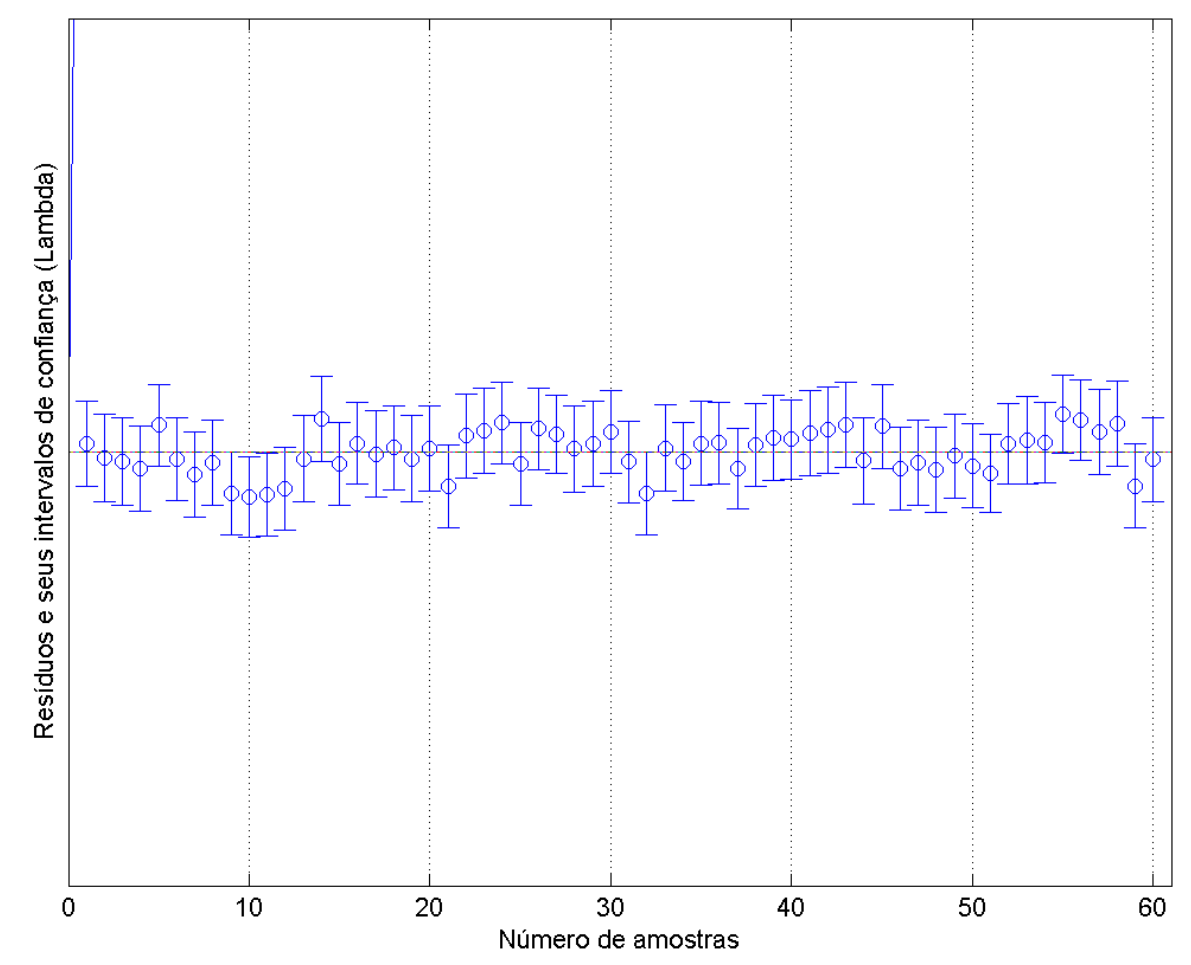

Figura 51 - Resíduos, e seus respectivos intervalos de confiança, resultantes da estimação do fator $\lambda$ utilizando o modelo 4, média de 20 ciclos de pressão no cilindro e janela 3 para o combustível E70 em condições de cargas combinadas.

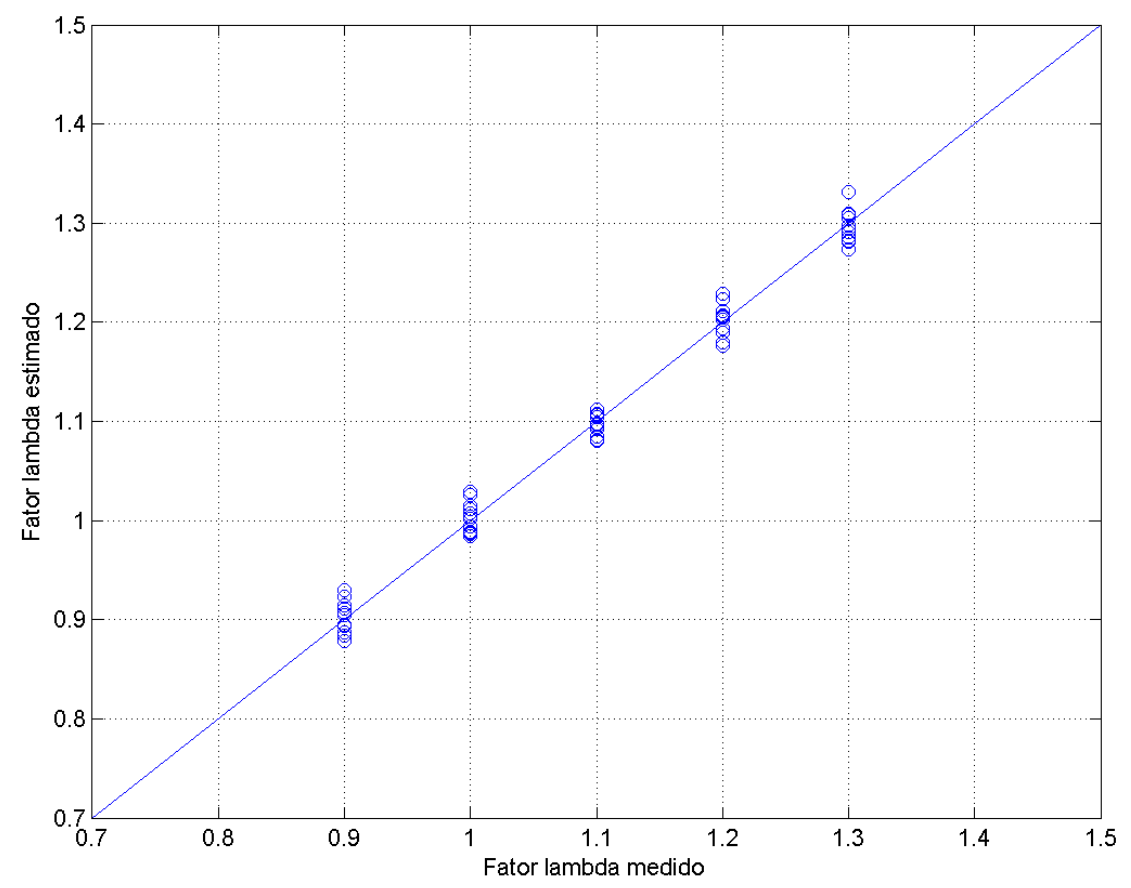

Figura 52 - Resultados obtidos na estimação do fator $\lambda$ utilizando o modelo 4, média de 20 ciclos de pressão no cilindro e janela 3 para o combustível E70 em condições de cargas combinadas. 


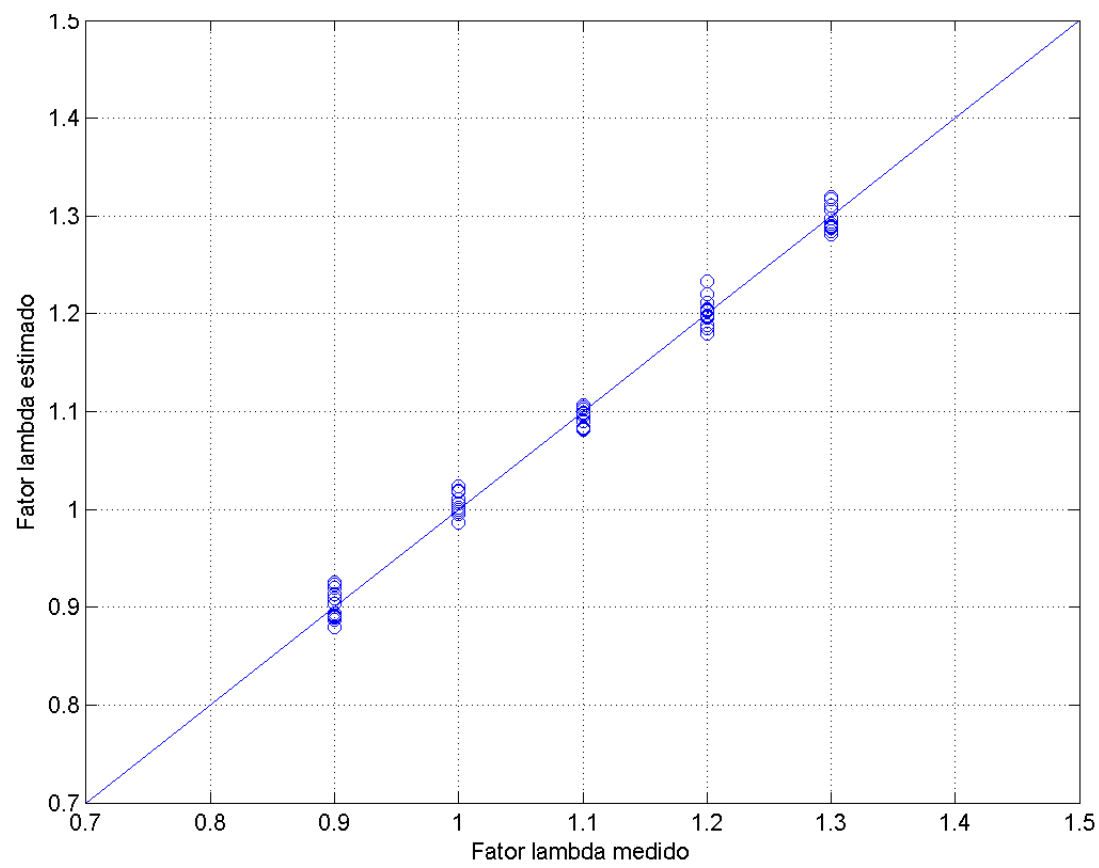

Figura 53 - Resultados obtidos na estimação do fator $\lambda$ utilizando o modelo 6, média de 20 ciclos de pressão no cilindro e janela 3 para o combustível E70 em condições de cargas combinadas.

Na Figura 53 pode-se observar uma pequena redução na dispersão dos valores estimados do fator $\lambda$ pelo modelo 6 em relação aos resultados do modelo 4 apresentados na Figura 52 . Esta redução na dispersão se deve ao menor rms apresentado pelo modelo 6 em relação ao modelo 4 em condições de cargas combinadas.

Comparando a Figura 54, que apresenta os resultados obtidos com o modelo 1, proposto por Gilkey e Powell (1985), com as Figuras 52 e 53 pode-se observar a melhora obtida com o presente estudo na estimativa do fator $\lambda$. 


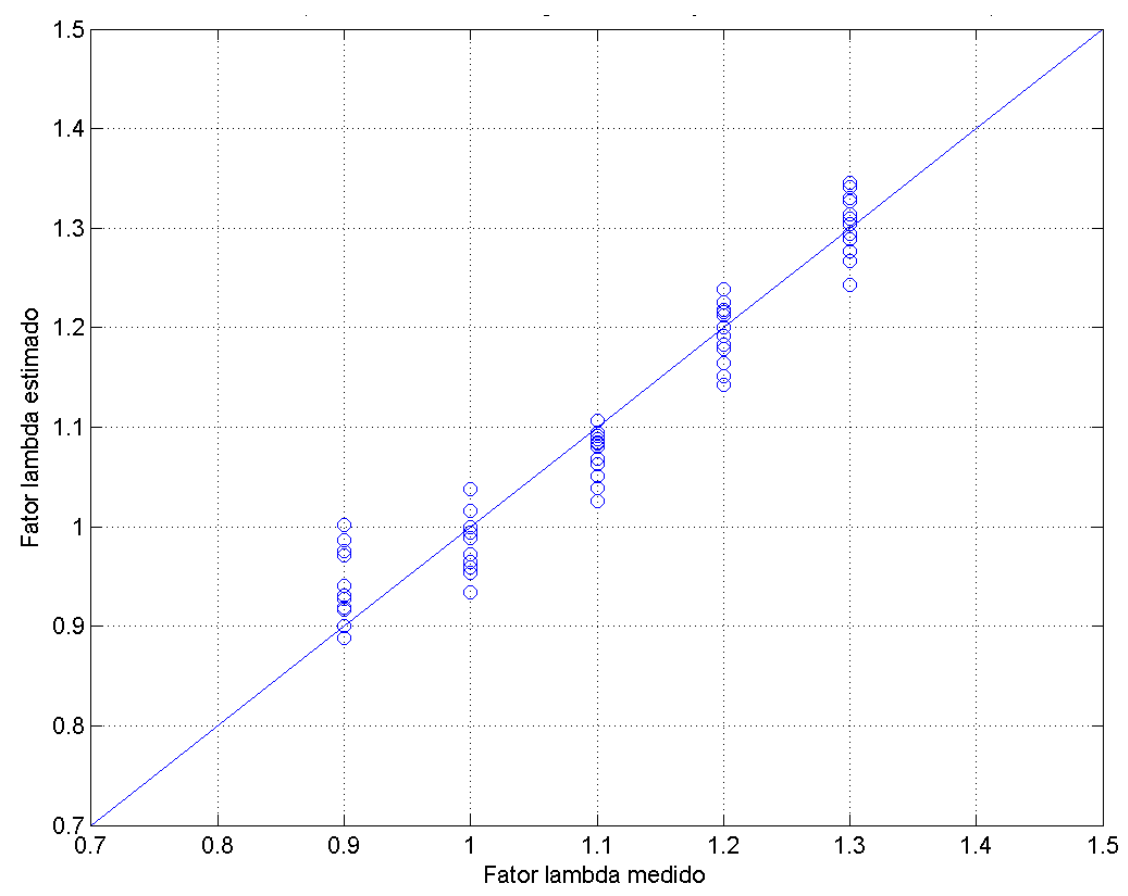

Figura 54 - Resultados obtidos na estimação do fator $\lambda$ utilizando o modelo 1, média de 20 ciclos de pressão no cilindro e janela 1 para o combustível E70 em condições de cargas combinadas.

\subsubsection{Análise dos modelos obtidos para estimação do fator $\lambda$ utilizando o combustível E100}

Os resultados obtidos com os nove modelos propostos neste estudo, considerando o combustível E100, são apresentados nas Tabelas 34 e 35. Estes resultados foram obtidos utilizando médias de 20 ciclos de pressão no cilindro, considerando as janelas 1, 2, 3 e 4, condições de plena carga e de cargas combinadas, respectivamente.

Os valores críticos, $F_{\alpha, k, n-p}$, exibidos nas Tabelas 34 e 35 , foram menores que as estatísticas de teste, $F$, nos nove modelos estudados, portanto, existe pelo menos um regressor $\left(a_{n}\right)$ em cada um dos modelos analisados que contribui significativamente para a estimativa do fator $\lambda$. 
Tabela 34 - Resultados alcançados com os nove modelos de estimação do fator $\lambda$ utilizando o combustível E100 (regime de plena carga, média de 20 ciclos de pressão no cilindro e janelas 1, 2, 3 e 4). (continua)

\begin{tabular}{|c|c|c|c|c|c|}
\hline \multicolumn{6}{|c|}{$\begin{array}{l}\text { Combustível: E100 (regime de plena carga) } \\
\text { Média de } 20 \text { ciclos de pressão no cilindro }\end{array}$} \\
\hline \multirow{2}{*}{ Modelo } & \multirow{2}{*}{ Parâmetros } & \multicolumn{4}{|c|}{ Janelas } \\
\hline & & 1 & 2 & 3 & 4 \\
\hline \multirow{5}{*}{ Modelo 1} & $\mathrm{~F}$ & 129,34 & 28,19 & 17,86 & 197,36 \\
\hline & $\mathrm{F}_{0,05 ; 4 ; 25}$ & 2,76 & 2,76 & 2,76 & 2,76 \\
\hline & $r^{2}$ & 0,9539 & 0,8185 & 0,7408 & 0,9693 \\
\hline & $\mathrm{R}^{2}$ & 0,9465 & 0,7895 & 0,6993 & 0,9644 \\
\hline & $\mathrm{rms}$ & 0,0304 & 0,0602 & 0,0720 & 0,0248 \\
\hline \multirow{5}{*}{ Modelo 2} & $\mathrm{~F}$ & 868,32 & 694,00 & 648,07 & 672,59 \\
\hline & $\mathrm{F}_{0,05 ; 5 ; 24}$ & 2,62 & 2,62 & 2,62 & 2,62 \\
\hline & $r^{2}$ & 0,9945 & 0,9931 & 0,9926 & 0,9929 \\
\hline & $\mathrm{R}^{2}$ & 0,9934 & 0,9917 & 0,9911 & 0,9914 \\
\hline & $\mathrm{rms}$ & 0,0105 & 0,0117 & 0,0121 & 0,0119 \\
\hline \multirow{5}{*}{ Modelo 3} & $\mathrm{~F}$ & 751,99 & 712,52 & 595,67 & 1043,98 \\
\hline & $\mathrm{F}_{0,05 ; 6 ; 23}$ & 2,53 & 2,53 & 2,53 & 2,53 \\
\hline & $r^{2}$ & 0,9949 & 0,9946 & 0,9936 & 0,9963 \\
\hline & $\mathrm{R}^{2}$ & 0,9936 & 0,9933 & 0,9919 & 0,9954 \\
\hline & $\mathrm{rms}$ & 0,0101 & 0,0103 & 0,0113 & 0,0086 \\
\hline \multirow{5}{*}{ Modelo 4} & $\mathrm{~F}$ & 873,09 & 814,47 & 799,66 & 1074,36 \\
\hline & $\mathrm{F}_{0,05 ; 7 ; 22}$ & 2,46 & 2,46 & 2,46 & 2,46 \\
\hline & $r^{2}$ & 0,9964 & 0,9962 & 0,9961 & 0,9971 \\
\hline & $\mathrm{R}^{2}$ & 0,9953 & 0,9949 & 0,9948 & 0,9962 \\
\hline & $\mathrm{rms}$ & 0,0085 & 0,0088 & 0,0088 & 0,0076 \\
\hline \multirow{5}{*}{ Modelo 5} & $\mathrm{~F}$ & 893,44 & 640,23 & 608,44 & 831,96 \\
\hline & $\mathrm{F}_{0,05 ; 9 ; 20}$ & 2,39 & 2,39 & 2,39 & 2,39 \\
\hline & $r^{2}$ & 0,9975 & 0,9965 & 0,9964 & 0,9973 \\
\hline & $\mathrm{R}^{2}$ & 0,9964 & 0,9950 & 0,9947 & 0,9961 \\
\hline & $\mathrm{rms}$ & 0,0070 & 0,0083 & 0,0085 & 0,0073 \\
\hline \multirow{5}{*}{ Modelo 6} & $\mathrm{~F}$ & 858,40 & 581,66 & 755,46 & 777,57 \\
\hline & $\mathrm{F}_{0,05 ; 9 ; 20}$ & 2,39 & 2,39 & 2,39 & 2,39 \\
\hline & $r^{2}$ & 0,9974 & 0,9962 & 0,9971 & 0,9972 \\
\hline & $\mathrm{R}^{2}$ & 0,9963 & 0,9945 & 0,9957 & 0,9959 \\
\hline & $\mathrm{rms}$ & 0,0072 & 0,0087 & 0,0077 & 0,0075 \\
\hline
\end{tabular}


Tabela 34 - Resultados alcançados com os nove modelos de estimação do fator $\lambda$ utilizando o combustível E100 (regime de plena carga, média de 20 ciclos de pressão no cilindro e janelas $1,2,3$ e 4). (conclusão)

\begin{tabular}{|c|c|c|c|c|c|}
\hline \multicolumn{6}{|c|}{$\begin{array}{l}\text { Combustível: E100 (regime de plena carga) } \\
\text { Média de } 20 \text { ciclos de pressão no cilindro }\end{array}$} \\
\hline \multirow{2}{*}{ Modelo } & \multirow{2}{*}{ Parâmetros } & \multicolumn{4}{|c|}{ Janelas } \\
\hline & & 1 & 2 & 3 & 4 \\
\hline \multirow{5}{*}{ Modelo 7} & $\mathrm{~F}$ & 751,74 & 497,56 & 655,61 & 666,99 \\
\hline & $\mathrm{F}_{0,05 ; 10 ; 19}$ & 2,38 & 2,38 & 2,38 & 2,38 \\
\hline & $r^{2}$ & 0,9975 & 0,9962 & 0,9971 & 0,9972 \\
\hline & $\mathrm{R}^{2}$ & 0,9962 & 0,9942 & 0,9956 & 0,9957 \\
\hline & $\mathrm{rms}$ & 0,0071 & 0,0087 & 0,0076 & 0,0075 \\
\hline \multirow{5}{*}{ Modelo 8} & $\mathrm{~F}$ & 759,44 & 450,82 & 567,81 & 666,28 \\
\hline & $\mathrm{F}_{0,05 ; 11 ; 18}$ & 2,38 & 2,38 & 2,38 & 2,38 \\
\hline & $r^{2}$ & 0,9978 & 0,9964 & 0,9971 & 0,9976 \\
\hline & $\mathrm{R}^{2}$ & 0,9965 & 0,9942 & 0,9954 & 0,9961 \\
\hline & $\mathrm{rms}$ & 0,0066 & 0,0085 & 0,0076 & 0,0070 \\
\hline \multirow{5}{*}{ Modelo 9} & $\mathrm{~F}$ & 1709,70 & 888,33 & 829,26 & 864,86 \\
\hline & $\mathrm{F}_{0,05 ; 9 ; 20}$ & 2,39 & 2,39 & 2,39 & 2,39 \\
\hline & $r^{2}$ & 0,9987 & 0,9975 & 0,9973 & 0,9974 \\
\hline & $\mathrm{R}^{2}$ & 0,9981 & 0,9964 & 0,9961 & 0,9963 \\
\hline & $\mathrm{rms}$ & 0,0051 & 0,0071 & 0,0073 & 0,0072 \\
\hline
\end{tabular}

As janelas 2 e 3 não apresentaram o menor valor de rms em nenhum dos modelos analisados para o combustível E100, considerando as condições de plena carga e cargas combinadas.

Apenas o modelo 7, em condições de plena carga não apresentou aumento dos coeficientes $r^{2}$ e $R^{2}$ em relação ao seu antecessor de referência.

O modelo 5, que utiliza como variáveis independentes os momentos de segunda e terceira ordem aplicados à curva da razão de pressões no cilindro, demostrou que é capaz de estimar o fator $\lambda$ quando utilizando o combustível E100, tanto em condições de plena carga quanto em condições de cargas combinadas.

Todas as variáveis independentes adicionadas ao modelo 1 se mostraram capazes de colaborar para a estimativa do fator $\lambda$, ao menos em uma das condições de carga avaliadas. 
Tabela 35 - Resultados alcançados com os nove modelos de estimação do fator $\lambda$ utilizando o combustível E100 (duas cargas combinadas, média de 20 ciclos de pressão no cilindro e janelas 1, 2, 3 e 4$)$. (continua)

\begin{tabular}{|c|c|c|c|c|c|}
\hline \multicolumn{6}{|c|}{$\begin{array}{l}\text { Combustível: E100 (duas cargas combinadas) } \\
\text { Média de } 20 \text { ciclos de pressão no cilindro }\end{array}$} \\
\hline \multirow{2}{*}{ Modelo } & \multirow{2}{*}{ Parâmetros } & \multicolumn{4}{|c|}{ Janelas } \\
\hline & & 1 & 2 & 3 & 4 \\
\hline \multirow{5}{*}{ Modelo 1} & $\mathrm{~F}_{0,05 ; 4 ; 55}$ & 2,55 & 2,55 & 2,55 & 2,55 \\
\hline & $\mathrm{F}$ & 194,69 & 27,10 & 24,57 & 162,61 \\
\hline & $r^{2}$ & 0,9340 & 0,6634 & 0,6411 & 0,9220 \\
\hline & $\mathrm{R}^{2}$ & 0,9292 & 0,6389 & 0,6150 & 0,9164 \\
\hline & $\mathrm{rms}$ & 0,0363 & 0,0821 & 0,0847 & 0,0395 \\
\hline \multirow{5}{*}{ Modelo 2} & $\mathrm{~F}_{0,05 ; 5 ; 54}$ & 2,39 & 2,39 & 2,39 & 2,39 \\
\hline & $\mathrm{F}$ & 199,73 & 145,06 & 110,50 & 203,65 \\
\hline & $r^{2}$ & 0,9487 & 0,9307 & 0,9110 & 0,9496 \\
\hline & $\mathrm{R}^{2}$ & 0,9440 & 0,9243 & 0,9027 & 0,9450 \\
\hline & $\mathrm{rms}$ & 0,0320 & 0,0372 & 0,0422 & 0,0317 \\
\hline \multirow{5}{*}{ Modelo 3} & $\mathrm{~F}_{0,05 ; 6 ; 53}$ & 2,28 & 2,28 & 2,28 & 2,28 \\
\hline & $\mathrm{F}$ & 170,92 & 155,19 & 92,07 & 169,91 \\
\hline & $r^{2}$ & 0,9509 & 0,9461 & 0,9125 & 0,9506 \\
\hline & $\mathrm{R}^{2}$ & 0,9453 & 0,9401 & 0,9025 & 0,9450 \\
\hline & $\mathrm{rms}$ & 0,0313 & 0,0328 & 0,0418 & 0,0314 \\
\hline \multirow{5}{*}{ Modelo 4} & $\mathrm{~F}_{0,05 ; 7 ; 52}$ & 2,20 & 2,20 & 2,20 & 2,20 \\
\hline & $\mathrm{F}$ & 241,94 & 216,98 & 143,00 & 232,37 \\
\hline & $r^{2}$ & 0,9702 & 0,9669 & 0,9506 & 0,9690 \\
\hline & $\mathrm{R}^{2}$ & 0,9662 & 0,9624 & 0,9440 & 0,9649 \\
\hline & $\mathrm{rms}$ & 0,0244 & 0,0257 & 0,0314 & 0,0249 \\
\hline \multirow{5}{*}{ Modelo 5} & $\mathrm{~F}_{0,05 ; 9 ; 50}$ & 2,08 & 2,08 & 2,08 & 2,08 \\
\hline & $\mathrm{F}$ & 182,49 & 167,98 & 173,02 & 187,92 \\
\hline & $r^{2}$ & 0,9705 & 0,9680 & 0,9689 & 0,9713 \\
\hline & $\mathrm{R}^{2}$ & 0,9651 & 0,9622 & 0,9633 & 0,9661 \\
\hline & $\mathrm{rms}$ & 0,0243 & 0,0253 & 0,0249 & 0,0240 \\
\hline \multirow{5}{*}{ Modelo 6} & $\mathrm{~F}_{0,05 ; 9 ; 50}$ & 2,08 & 2,08 & 2,08 & 2,08 \\
\hline & $\mathrm{F}$ & 471,26 & 198,07 & 306,06 & 361,48 \\
\hline & $r^{2}$ & 0,9883 & 0,9727 & 0,9822 & 0,9849 \\
\hline & $\mathrm{R}^{2}$ & 0,9863 & 0,9678 & 0,9790 & 0,9821 \\
\hline & $\mathrm{rms}$ & 0,0153 & 0,0234 & 0,0189 & 0,0174 \\
\hline
\end{tabular}


Tabela 35 - Resultados alcançados com os nove modelos de estimação do fator $\lambda$ utilizando o combustível E100 (duas cargas combinadas, média de 20 ciclos de pressão no cilindro e janelas 1, 2, 3 e 4). (conclusão)

\begin{tabular}{|c|c|c|c|c|c|}
\hline \multicolumn{6}{|c|}{$\begin{array}{l}\text { Combustível: E100 (duas cargas combinadas) } \\
\text { Média de } 20 \text { ciclos de pressão no cilindro }\end{array}$} \\
\hline \multirow{2}{*}{ Modelo } & \multirow{2}{*}{ Parâmetros } & \multicolumn{4}{|c|}{ Janelas } \\
\hline & & 1 & 2 & 3 & 4 \\
\hline \multirow{5}{*}{ Modelo 7} & $\mathrm{~F}_{0,05 ; 10 ; 49}$ & 2,04 & 2,04 & 2,04 & 2,04 \\
\hline & $\mathrm{F}$ & 416,16 & 179,90 & 274,93 & 320,11 \\
\hline & $r^{2}$ & 0,9884 & 0,9735 & 0,9825 & 0,9849 \\
\hline & $\mathrm{R}^{2}$ & 0,9860 & 0,9681 & 0,9789 & 0,9818 \\
\hline & $\mathrm{rms}$ & 0,0153 & 0,0230 & 0,0187 & 0,0174 \\
\hline \multirow{5}{*}{ Modelo 8} & $\mathrm{~F}_{0,05 ; 11 ; 48}$ & 2,01 & 2,01 & 2,01 & 2,01 \\
\hline & $\mathrm{F}$ & 373,09 & 174,86 & 258,93 & 293,23 \\
\hline & $r^{2}$ & 0,9884 & 0,9757 & 0,9834 & 0,9853 \\
\hline & $\mathrm{R}^{2}$ & 0,9858 & 0,9701 & 0,9796 & 0,9820 \\
\hline & $\mathrm{rms}$ & 0,0152 & 0,0221 & 0,0182 & 0,0171 \\
\hline \multirow{5}{*}{ Modelo 9} & $\mathrm{~F}_{0,05 ; 9 ; 50}$ & 2,08 & 2,08 & 2,08 & 2,08 \\
\hline & $\mathrm{F}$ & 191,11 & 180,63 & 110,81 & 288,76 \\
\hline & $r^{2}$ & 0,9718 & 0,9702 & 0,9523 & 0,9811 \\
\hline & $\mathrm{R}^{2}$ & 0,9667 & 0,9648 & 0,9437 & 0,9777 \\
\hline & $\mathrm{rms}$ & 0,0238 & 0,0244 & 0,0309 & 0,0194 \\
\hline
\end{tabular}

O modelo 2 apresentou uma redução do rms (0,0105) de aproximadamente 57,7\% em relação ao modelo $1(0,0248)$ considerando os dados em plena carga e de aproximadamente $12,7 \%$ considerando os dados em cargas combinadas.

Os menores rms do modelo 2 foram obtidos na janela $1(0,0105)$, em plena carga, e na janela 4 (0,0317), em cargas combinadas.

O modelo 4 foi o que apresentou o menor $r m s(0,0076)$ entre os modelos de menor requisito computacional (modelos 1, 2, 3 e 4). Este resultado ocorreu na janelas 4 em condições de plena carga (Tabela 34$)$ e na janela $1(0,0244)$ em condições de cargas combinadas (Tabela 35).

A redução do $r m s$ do modelo 4 foi de aproximadamente 69,4\% (janela 4: $r m s=0,0076$ ) em relação ao modelo 1 (janela 1: rms $=0,0248$ ) em condições de plena carga e de aproximadamente $32,8 \%$ em condições de cargas combinadas.

O modelo 9 (janela 1) foi o que obteve o melhor rms em plena carga $(0,0051)$.

O modelo 8 (janela 1) apresentou o menor rms em condições de cargas combinadas $(0,0152)$. Como mencionado anteriormente o modelo 8 necessita da adição de transdutores de 
temperatura nos coletores de admissão e escape, o que pode ser um empecilho à sua aplicação.

Resumindo os resultados obtidos com todos os modelos pode-se afirmar que:

- O modelo 4 apresentou o melhor rms entre os modelos de menor requisito computacional, tanto em plena carga como em cargas combinadas;

- a melhor janela do modelo 4 em plena carga foi a janela $4(r m s=0,0076)$, enquanto que em cargas combinadas a melhor janela foi a $1(r m s=0,0244)$;

- o modelo 9 (janela 1) foi o que apresentou o menor rms em plena carga $(0,0051)$, $\mathrm{e}$

- o modelo 8 , utilizando a janela 1 , foi o que apresentou o menor $r m s$ em cargas combinadas $(0,0152)$.

A Tabela 36 apresenta os coeficientes individuais das regressões lineares múltiplas $\left(a_{n}\right)$ obtidos para os modelos que apresentaram os menores $r m s$ em condições de plena carga e de cargas combinadas, considerando uma média de 20 ciclos de pressão no cilindro.

Os resíduos para o modelo 4 (janela 1), em condições de cargas combinadas, são representados por círculos na Figura 55. Os resultados, com nível de 5\% de significância, indicam uma pequena variação nos resíduos da estimativa do fator $\lambda$ utilizando o modelo 4 (resíduo médio do fator $\lambda$ estimado igual a 0,0200).

Como pode ser observado na Figura 55 existem alguns valores atípicos nos resíduos do modelo 4, considerando a janela 1, porém, como mencionado na análise dos modelos para os combustíveis E26, E56 e E70, a retirada dos valores atípicos poderia melhorar a estimativa, mas tal atitude só seria válida se novos experimentos fossem realizados. 
Tabela 36 - Coeficientes individuais das regressões lineares múltiplas dos modelos que apresentaram os menores rms para o combustível E100.

\begin{tabular}{|c|c|c|c|c|}
\hline \multirow[b]{5}{*}{ Coeficientes $a_{n}$} & \multicolumn{4}{|c|}{ ombustível: E100 (média de 20 ciclos) } \\
\hline & \multicolumn{2}{|c|}{$\begin{array}{c}\text { Plena carga } \\
\text { Modelos }\end{array}$} & \multicolumn{2}{|c|}{$\begin{array}{c}\text { Duas cargas combinadas } \\
\text { Modelos }\end{array}$} \\
\hline & 4 & 9 & 4 & 8 \\
\hline & \multicolumn{2}{|c|}{ Janelas } & \multicolumn{2}{|c|}{ Janelas } \\
\hline & 4 & 1 & 1 & 1 \\
\hline 1 & $4,907 \mathrm{E}+00$ & $5,116 \mathrm{E}+00$ & $1,706 \mathrm{E}+01$ & $2,264 \mathrm{E}+01$ \\
\hline 2 & $-5,140 \mathrm{E}+04$ & $4,633 \mathrm{E}+04$ & $2,147 \mathrm{E}+05$ & $2,081 \mathrm{E}+05$ \\
\hline 3 & $-1,558 \mathrm{E}-01$ & $-1,775 \mathrm{E}-01$ & $-5,798 \mathrm{E}-02$ & $-1,160 \mathrm{E}-01$ \\
\hline 4 & $4,265 \mathrm{E}-03$ & $-9,305 \mathrm{E}-04$ & $-8,074 \mathrm{E}-03$ & $-1,972 \mathrm{E}-03$ \\
\hline 5 & $-7,003 \mathrm{E}-03$ & $-7,018 \mathrm{E}-03$ & $-4,864 \mathrm{E}-02$ & $-6,724 \mathrm{E}-02$ \\
\hline 6 & $4,306 \mathrm{E}-05$ & $5,040 \mathrm{E}-05$ & $1,639 \mathrm{E}-05$ & $1,154 \mathrm{E}-04$ \\
\hline 7 & $-1,343 \mathrm{E}-03$ & $-5,544 \mathrm{E}-04$ & $-1,200 \mathrm{E}-04$ & $2,825 \mathrm{E}-04$ \\
\hline 8 & $5,251 \mathrm{E}-05$ & $-1,551 \mathrm{E}-05$ & $1,654 \mathrm{E}-05$ & $-1,199 \mathrm{E}-05$ \\
\hline 9 & & $8,280 \mathrm{E}-08$ & & $1,561 \mathrm{E}-03$ \\
\hline 10 & & $3,607 \mathrm{E}-10$ & & $-1,226 \mathrm{E}-04$ \\
\hline 11 & & & & $-7,546 \mathrm{E}-07$ \\
\hline 12 & & & & $3,343 \mathrm{E}-08$ \\
\hline
\end{tabular}

Os resultados da estimação do fator $\lambda$, utilizando o modelo 4, janela 1 e média de 20 ciclos em condições de cargas combinadas, são exibidos na Figura 56.

Os resultados do modelo 8, média de 20 ciclos e janela 1 em condições de cargas combinadas, são apresentados na Figura 57. 


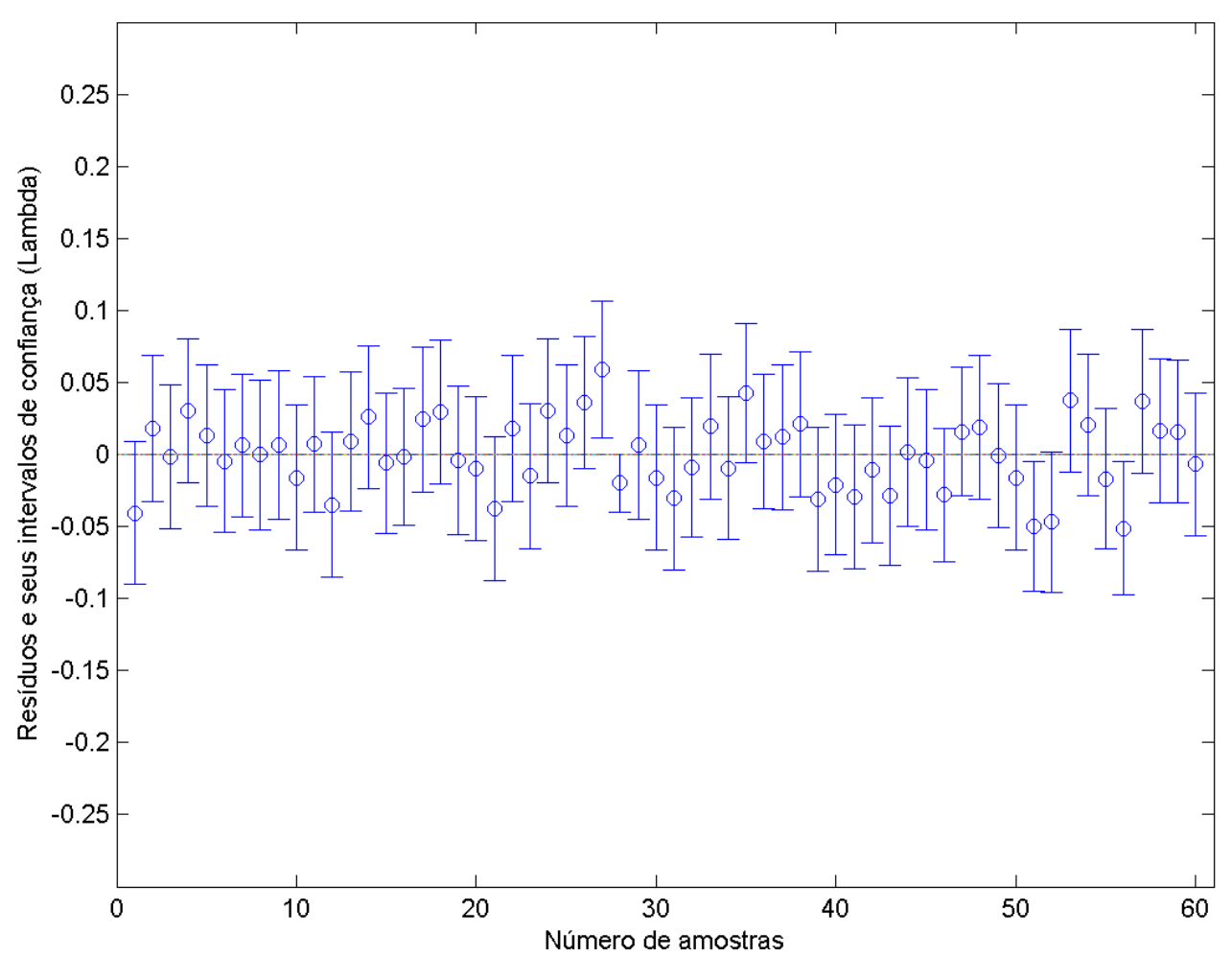

Figura 55 - Resíduos, e seus respectivos intervalos de confiança, resultantes da estimação do fator $\lambda$ utilizando o modelo 4, média de 20 ciclos de pressão no cilindro e janela 1 para o combustível E100 em condições de cargas combinadas.

Na Figura 57 pode-se observar uma pequena redução na dispersão dos valores estimados do fator $\lambda$ pelo modelo 8 em relação aos resultados do modelo 4 apresentados na Figura 56. Esta redução na dispersão se deve ao menor $r m s$ apresentado pelo modelo 8 em relação ao modelo 4 em condições de cargas combinadas.

Comparando a Figura 58, que apresenta os resultados obtidos com o modelo 1, proposto por Gilkey e Powell (1985), com as Figura 56 e 57 pode-se observar a melhora obtida com o presente estudo na estimativa do fator $\lambda$. 


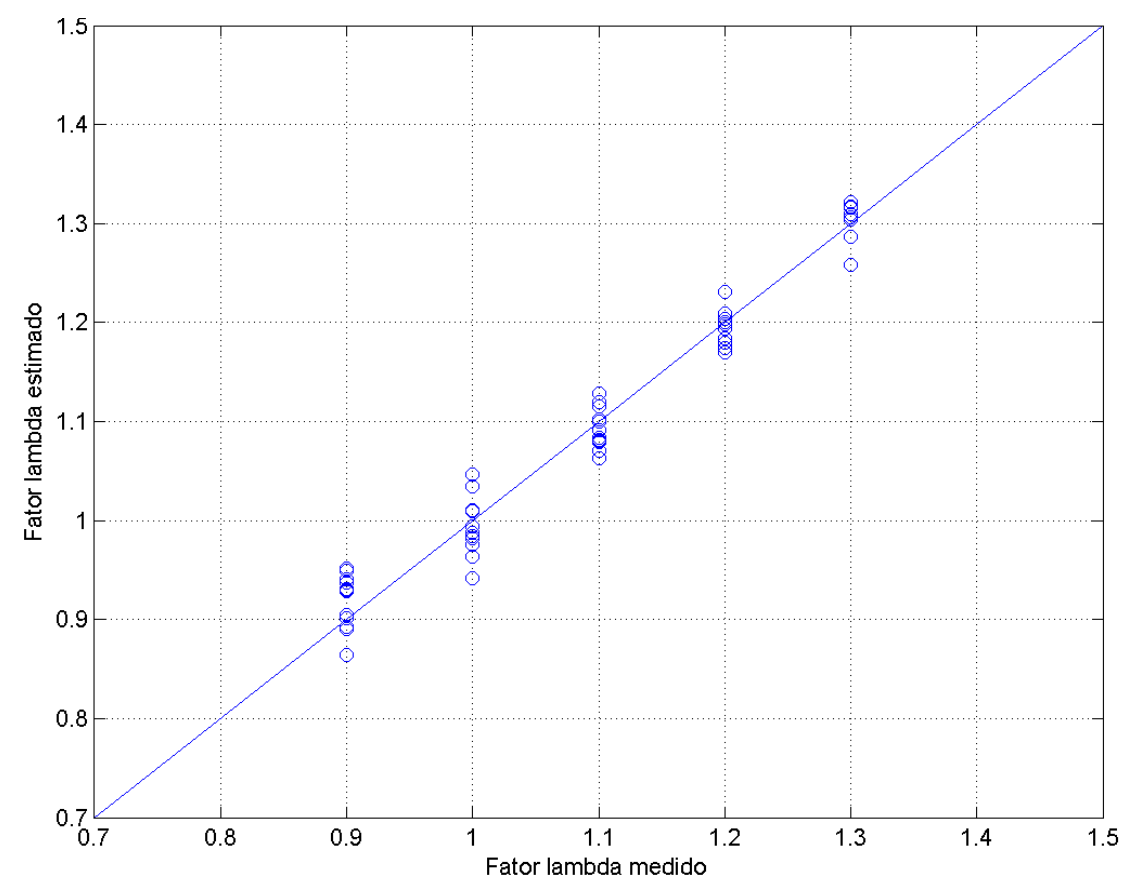

Figura 56 - Resultados obtidos na estimação do fator $\lambda$ utilizando o modelo 4, média de 20 ciclos de pressão no cilindro e janela 1 para o combustível E100 em condições de cargas combinadas.

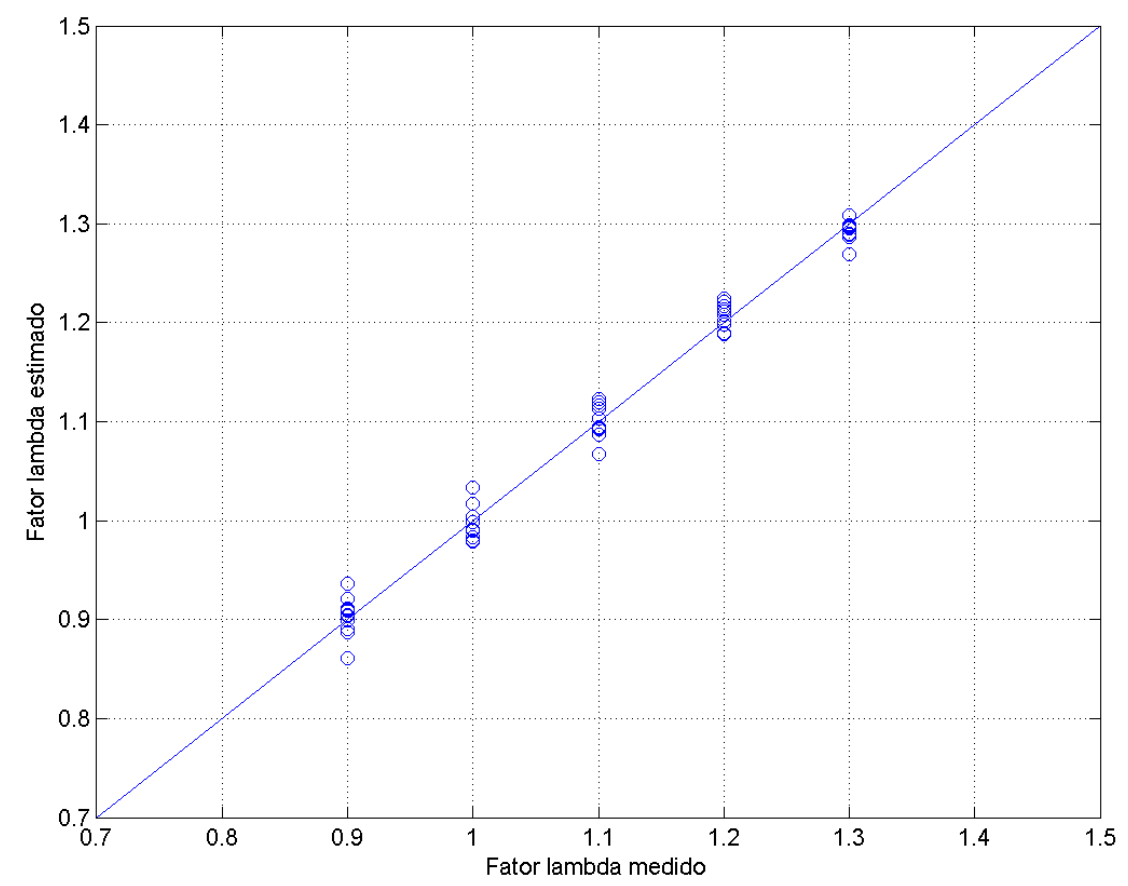

Figura 57 - Resultados obtidos na estimação do fator $\lambda$ utilizando o modelo 8 , média de 20 ciclos de pressão no cilindro e janela 1 para o combustível E100 em condições de cargas combinadas. 


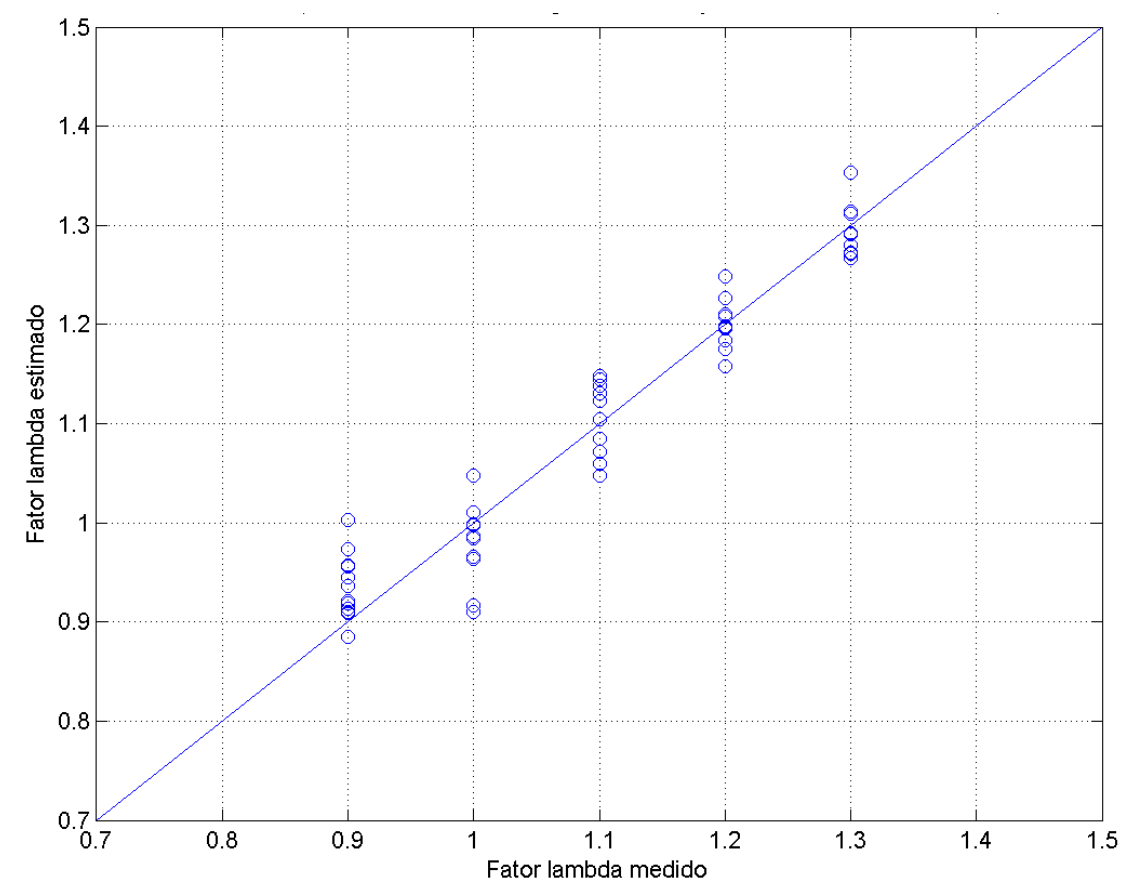

Figura 58 - Resultados obtidos na estimação do fator $\lambda$ utilizando o modelo 1, média de 20 ciclos de pressão no cilindro e janela 1 para o combustível E100 em condições de cargas combinadas.

\subsubsection{Análise dos modelos obtidos para estimação do fator $\lambda$ utilizando todos os combustíveis em estudo (E26, E56, E70 e E100)}

Nas seções anteriores foram desenvolvidos modelos de estimação do fator $\lambda$ dedicados a cada um dos combustíveis em estudo (E26, E56, E70 e E100), mas ainda é necessário verificar se é possível obter um único modelo que seja capaz de estimar o fator $\lambda$ independentemente do tipo de combustível utilizado.

O desenvolvimento de modelos de estimação do fator $\lambda$ utilizando um conjunto de dados composto por todos os combustíveis em estudo permitirá verificar a sensibilidade da estimativa à variação do tipo de combustível.

Os noves modelos propostos nas seções anteriores foram obtidos utilizando todos os dados coletados em regime de plena carga e todos os dados coletados em cargas combinadas.

A Tabela 37 apresenta os resultados obtidos com os nove modelos propostos, considerando todos os dados coletados em regime de plena carga (Etotal $=$ dados dos combustíveis E26, E56, E70 e E100), as médias de 20 ciclos e as janelas 1, 2, 3 e 4 de pressão no cilindro.

Os resultados dos nove modelos em condições de cargas combinadas são apresentados na Tabela 38, considerando todos os dados coletados (Etotal), médias de 20 ciclos de pressão no cilindro e as janelas 1, 2, 3 e 4 . 
De acordo com as Tabelas 37 e 38, os valores críticos, $F_{\alpha, k, n-p}$, foram menores que as estatísticas de teste, $F$, nos nove modelos estudados, portanto, os regressores e o fator $\lambda$ apresentam uma relação próxima da linear e existe pelo menos um regressor $\left(a_{n}\right)$ em cada um dos modelos analisados que contribui significativamente para a estimativa do fator $\lambda$.

Tabela 37 - Resultados alcançados com os nove modelos de estimação do fator $\lambda$ utilizando todos os dados dos combustíveis em estudo (Etotal = E26, E56, E70 e E100, regime de plena carga, média de 20 ciclos de pressão no cilindro e janelas $1,2,3$ e 4). (continua)

\begin{tabular}{|c|c|c|c|c|c|}
\hline \multicolumn{6}{|c|}{$\begin{array}{l}\text { Todos os Combustíveis (regime de plena carga) } \\
\text { Média de } 20 \text { ciclos de pressão no cilindro }\end{array}$} \\
\hline \multirow{2}{*}{ Modelo } & \multirow{2}{*}{ Parâmetros } & \multicolumn{4}{|c|}{ Janelas } \\
\hline & & 1 & 2 & 3 & 4 \\
\hline \multirow{5}{*}{ Modelo 1} & $\mathrm{~F}$ & 83,29 & 40,06 & 36,69 & 68,83 \\
\hline & $\mathrm{F}_{0,05 ; 4 ; 115}$ & 2,46 & 2,46 & 2,46 & 2,46 \\
\hline & $r^{2}$ & 0,7434 & 0,5822 & 0,5606 & 0,7054 \\
\hline & $\mathrm{R}^{2}$ & 0,7345 & 0,5676 & 0,5454 & 0,6951 \\
\hline & $\mathrm{rms}$ & 0,0716 & 0,0914 & 0,0937 & 0,0768 \\
\hline \multirow{5}{*}{ Modelo 2} & $\mathrm{~F}$ & 341,12 & 138,05 & 171,45 & 129,28 \\
\hline & $\mathrm{F}_{0,05 ; 5 ; 114}$ & 2,30 & 2,30 & 2,30 & 2,30 \\
\hline & $\mathrm{r}^{2}$ & 0,9373 & 0,8583 & 0,8826 & 0,8501 \\
\hline & $\mathrm{R}^{2}$ & 0,9346 & 0,8520 & 0,8775 & 0,8435 \\
\hline & $\mathrm{rms}$ & 0,0354 & 0,0532 & 0,0485 & 0,0548 \\
\hline \multirow{5}{*}{ Modelo 3} & $\mathrm{~F}$ & 316,25 & 117,59 & 152,11 & 113,78 \\
\hline & $\mathrm{F}_{0,05 ; 6 ; 113}$ & 2,18 & 2,18 & 2,18 & 2,18 \\
\hline & $\mathrm{r}^{2}$ & 0,9438 & 0,8620 & 0,8898 & 0,8580 \\
\hline & $\mathrm{R}^{2}$ & 0,9408 & 0,8546 & 0,8840 & 0,8504 \\
\hline & $\mathrm{rms}$ & 0,0335 & 0,0525 & 0,0469 & 0,0533 \\
\hline
\end{tabular}


Tabela 37 - Resultados alcançados com os nove modelos de estimação do fator $\lambda$ utilizando todos os dados dos combustíveis em estudo (Etotal = E26, E56, E70 e E100, regime de plena carga, média de 20 ciclos de pressão no cilindro e janelas 1, 2, 3 e 4). (conclusão)

\begin{tabular}{|c|c|c|c|c|c|}
\hline \multicolumn{6}{|c|}{$\begin{array}{l}\text { Todos os Combustíveis (regime de plena carga) } \\
\text { Média de } 20 \text { ciclos de pressão no cilindro }\end{array}$} \\
\hline \multirow{2}{*}{ Modelo } & \multirow{2}{*}{ Parâmetros } & \multicolumn{4}{|c|}{ Janelas } \\
\hline & & 1 & 2 & 3 & 4 \\
\hline \multirow{5}{*}{ Modelo 4} & $\mathrm{~F}$ & 349,49 & 330,72 & 375,61 & 543,44 \\
\hline & $\mathrm{F}_{0,05 ; 7 ; 112}$ & 2,10 & 2,10 & 2,10 & 2,10 \\
\hline & $r^{2}$ & 0,9562 & 0,9539 & 0,9591 & 0,9714 \\
\hline & $\mathrm{R}^{2}$ & 0,9535 & 0,9510 & 0,9566 & 0,9696 \\
\hline & $\mathrm{rms}$ & 0,0296 & 0,0304 & 0,0286 & 0,0239 \\
\hline \multirow{5}{*}{ Modelo 5} & $\mathrm{~F}$ & 320,84 & 394,15 & 301,69 & 442,87 \\
\hline & $\mathrm{F}_{0,05 ; 9 ; 110}$ & 1,97 & 1,97 & 1,97 & 1,97 \\
\hline & $r^{2}$ & 0,9633 & 0,9699 & 0,9611 & 0,9731 \\
\hline & $\mathrm{R}^{2}$ & 0,9603 & 0,9675 & 0,9579 & 0,9709 \\
\hline & $\mathrm{rms}$ & 0,0271 & 0,0245 & 0,0279 & 0,0232 \\
\hline \multirow{5}{*}{ Modelo 6} & $\mathrm{~F}$ & 291,66 & 292,44 & 345,76 & 454,58 \\
\hline & $\mathrm{F}_{0,05 ; 9 ; 110}$ & 1,97 & 1,97 & 1,97 & 1,97 \\
\hline & $r^{2}$ & 0,9598 & 0,9599 & 0,9659 & 0,9738 \\
\hline & $\mathrm{R}^{2}$ & 0,9565 & 0,9566 & 0,9631 & 0,9717 \\
\hline & $\mathrm{rms}$ & 0,0284 & 0,0283 & 0,0261 & 0,0229 \\
\hline \multirow{5}{*}{ Modelo 7} & $\mathrm{~F}$ & 261,01 & 264,06 & 318,14 & 410,93 \\
\hline & $\mathrm{F}_{0,05 ; 10 ; 109}$ & 1,92 & 1,92 & 1,92 & 1,92 \\
\hline & $r^{2}$ & 0,9599 & 0,9604 & 0,9669 & 0,9742 \\
\hline & $\mathrm{R}^{2}$ & 0,9562 & 0,9567 & 0,9638 & 0,9718 \\
\hline & $\mathrm{rms}$ & 0,0283 & 0,0282 & 0,0257 & 0,0227 \\
\hline \multirow{5}{*}{ Modelo 8} & $\mathrm{~F}$ & 235,30 & 237,92 & 286,65 & 370,33 \\
\hline & $\mathrm{F}_{0,05 ; 11 ; 108}$ & 1,89 & 1,89 & 1,89 & 1,89 \\
\hline & $r^{2}$ & 0,9599 & 0,9604 & 0,9669 & 0,9742 \\
\hline & $\mathrm{R}^{2}$ & 0,9559 & 0,9563 & 0,9635 & 0,9715 \\
\hline & $\mathrm{rms}$ & 0,0283 & 0,0282 & 0,0257 & 0,0227 \\
\hline \multirow{5}{*}{ Modelo 9} & $\mathrm{~F}$ & 285,92 & 275,43 & 288,51 & 590,28 \\
\hline & $\mathrm{F}_{0,05 ; 9 ; 110}$ & 1,97 & 1,97 & 1,97 & 1,97 \\
\hline & $r^{2}$ & 0,9590 & 0,9575 & 0,9594 & 0,9797 \\
\hline & $\mathrm{R}^{2}$ & 0,9557 & 0,9540 & 0,9560 & 0,9781 \\
\hline & $\mathrm{rms}$ & 0,0286 & 0,0292 & 0,0285 & 0,0201 \\
\hline
\end{tabular}


Tabela 38 - Resultados alcançados com os nove modelos de estimação do fator $\lambda$ utilizando todos os dados dos combustíveis em estudo (Etotal = E26, E56, E70 e E100, duas cargas combinadas, média de 20 ciclos de pressão no cilindro e janelas 1,2, 3 e 4). (continua)

Todos os combustíveis (duas cargas combinadas)

Média de 20 ciclos de pressão no cilindro

\begin{tabular}{|c|c|c|c|c|c|}
\hline \multirow{2}{*}{ Modelo } & \multirow{2}{*}{ Parâmetros } & \multicolumn{4}{|c|}{ Janelas } \\
\hline & & 1 & 2 & 3 & 4 \\
\hline \multirow{5}{*}{ Modelo 1} & $\mathrm{~F}$ & 168,4448 & 80,6548 & 49,1124 & 119,0171 \\
\hline & $\mathrm{F}_{0,05 ; 4 ; 235}$ & 2,37 & 2,37 & 2,37 & 2,37 \\
\hline & $\mathrm{r}^{2}$ & 0,7414 & 0,5786 & 0,4553 & 0,6695 \\
\hline & $\mathrm{R}^{2}$ & 0,7370 & 0,5714 & 0,4461 & 0,6639 \\
\hline & $\mathrm{rms}$ & 0,0719 & 0,0918 & 0,1044 & 0,0813 \\
\hline \multirow{5}{*}{ Modelo 2} & $\mathrm{~F}$ & 539,1800 & 202,9366 & 192,7512 & 117,8333 \\
\hline & $\mathrm{F}_{0,05 ; 5 ; 234}$ & 2,21 & 2,21 & 2,21 & 2,21 \\
\hline & $r^{2}$ & 0,9201 & 0,8126 & 0,8046 & 0,7157 \\
\hline & $\mathrm{R}^{2}$ & 0,9184 & 0,8086 & 0,8005 & 0,7097 \\
\hline & $\mathrm{rms}$ & 0,0400 & 0,0612 & 0,0625 & 0,0754 \\
\hline \multirow{5}{*}{ Modelo 3} & $\mathrm{~F}$ & 502,2681 & 179,6633 & 167,9076 & 140,1837 \\
\hline & $\mathrm{F}_{0,05 ; 6 ; 233}$ & 2,10 & 2,10 & 2,10 & 2,10 \\
\hline & $r^{2}$ & 0,9282 & 0,8223 & 0,8122 & 0,7831 \\
\hline & $\mathrm{R}^{2}$ & 0,9264 & 0,8177 & 0,8073 & 0,7775 \\
\hline & $\mathrm{rms}$ & 0,0379 & 0,0596 & 0,0613 & 0,0659 \\
\hline \multirow{5}{*}{ Modelo 4} & $\mathrm{~F}$ & 547,5313 & 508,3519 & 474,2825 & 586,4899 \\
\hline & $\mathrm{F}_{0,05 ; 7 ; 232}$ & 2,01 & 2,01 & 2,01 & 2,01 \\
\hline & $r^{2}$ & 0,9429 & 0,9388 & 0,9347 & 0,9465 \\
\hline & $\mathrm{R}^{2}$ & 0,9412 & 0,9369 & 0,9327 & 0,9449 \\
\hline & $\mathrm{rms}$ & 0,0338 & 0,0350 & 0,0361 & 0,0327 \\
\hline \multirow{5}{*}{ Modelo 5} & $\mathrm{~F}$ & 427,6124 & 400,0868 & 380,7870 & 453,4952 \\
\hline & $\mathrm{F}_{0,05 ; 9 ; 230}$ & 1,88 & 1,88 & 1,88 & 1,88 \\
\hline & $r^{2}$ & 0,9436 & 0,9400 & 0,9371 & 0,9467 \\
\hline & $\mathrm{R}^{2}$ & 0,9414 & 0,9376 & 0,9346 & 0,9446 \\
\hline & $\mathrm{rms}$ & 0,0336 & 0,0347 & 0,0355 & 0,0327 \\
\hline \multirow{5}{*}{ Modelo 6} & $\mathrm{~F}$ & 442,3709 & 477,2867 & 484,4680 & 535,0420 \\
\hline & $\mathrm{F}_{0,05 ; 9 ; 230}$ & 1,88 & 1,88 & 1,88 & 1,88 \\
\hline & $r^{2}$ & 0,9454 & 0,9492 & 0,9499 & 0,9544 \\
\hline & $\mathrm{R}^{2}$ & 0,9432 & 0,9472 & 0,9479 & 0,9526 \\
\hline & $\mathrm{rms}$ & 0,0330 & 0,0319 & 0,0317 & 0,0302 \\
\hline
\end{tabular}


Tabela 38 - Resultados alcançados com os nove modelos de estimação do fator $\lambda$ utilizando todos os dados dos combustíveis em estudo (Etotal = E26, E56, E70 e E100, duas cargas combinadas, média de 20 ciclos de pressão no cilindro e janelas 1, 2, 3 e 4). (conclusão)

Todos os combustíveis (duas cargas combinadas)

Média de 20 ciclos de pressão no cilindro

\begin{tabular}{clcccc} 
Modelo & \multirow{2}{*}{ Parâmetros } & \multicolumn{5}{c}{ Janelas } \\
& & 1 & 2 & 3 & 4 \\
\hline & $\mathrm{F}$ & 396,4095 & 431,1529 & 434,2629 & 481,9514 \\
Modelo 7 & $\mathrm{~F}_{0,05 ; 10 ; 229}$ & 1,83 & 1,83 & 1,83 & 1,83 \\
& $\mathrm{r}^{2}$ & 0,9454 & 0,9496 & 0,9499 & 0,9546 \\
& $\mathrm{R}^{2}$ & 0,9430 & 0,9474 & 0,9477 & 0,9527 \\
& $\mathrm{rms}$ & 0,0330 & 0,0318 & 0,0317 & 0,0301 \\
& $\mathrm{~F}$ & 359,2786 & 391,1099 & 393,1185 & 441,9815 \\
& $\mathrm{~F}_{0,05 ; 11 ; 228}$ & 1,79 & 1,79 & 1,79 & 1,79 \\
Modelo 8 & $\mathrm{r}^{2}$ & 0,9455 & 0,9497 & 0,9499 & 0,9552 \\
& $\mathrm{R}^{2}$ & 0,9428 & 0,9472 & 0,9475 & 0,9530 \\
& $\mathrm{rms}$ & 0,0330 & 0,0317 & 0,0316 & 0,0299 \\
& $\mathrm{~F}$ & 443,9027 & 415,9570 & 421,5997 & 479,9208 \\
& $\mathrm{~F}_{0,05 ; 9 ; 230}$ & 1,88 & 1,88 & 1,88 & 1,88 \\
Modelo 9 9 & $\mathrm{r}^{2}$ & 0,9456 & 0,9421 & 0,9428 & 0,9494 \\
& $\mathrm{R}^{2}$ & 0,9434 & 0,9399 & 0,9406 & 0,9475 \\
& $\mathrm{rms}$ & 0,0330 & 0,0340 & 0,0338 & 0,0318 \\
\hline
\end{tabular}

Nas Tabelas 37 e 38, constata-se que as janelas 2 e 3 não apresentaram os menores rms para nenhum dos modelos em estudo.

Todas as variáveis independentes adicionadas a partir do modelo 1 apresentaram uma contribuição significativa na estimativa do fator $\lambda$ em pelo menos uma das janelas de pressão no cilindro em estudo. Esta afirmação pode ser verificada considerando o aumento do coeficiente $R^{2}$ entre os modelos apresentados nas Tabelas 37 e 38, exceto para o modelo 8 em condição de plena carga.

Em condições de plena carga, Tabela 37, e em condições de cargas combinadas o modelo 1 apresentou o menor $r m s$ na janela $1(r m s=0,0716$ em plena carga; $r m s=0,0719$ em cargas combinadas).

Apesar do rms elevado, o modelo 1 se mostrou capaz de estimar o fator $\lambda$ independentemente do combustível utilizado, porém cabe verificar o desvio percentual entre a estimativa do fator $\lambda$ utilizando um modelo único para todos os combustíveis e a estimativa do fator $\lambda$ utilizando um modelo para cada tipo de combustível.

A Tabela 39 apresenta os melhores resultados, considerando o rms, obtidos com o modelo 1 para cada combustível e para todos os combustíveis juntos (Etotal). Para efeito de 
comparação foi calculado o desvio percentual $(d p)$ entre o melhor $r m s$ obtido com o modelo 1 $\left(r m s_{r e l}\right)$ em cada combustível e o rms do modelo 1 para todos os combustíveis (Etotal, $r m s_{r e f}$ ), de acordo com a equação (119).

$$
d p=\frac{r m s_{r e f}-r m s_{r e l}}{r m s_{r e l}}
$$

Tabela 39 - Comparação entre os resultados do modelo 1 na estimativa do fator $\lambda$ (E26, E56, E70,

E100 e Etotal (todos os combustíveis juntos), plena carga e duas cargas combinadas, média de 20 ciclos de pressão no cilindro e melhor janela).

\section{Estimativa do fator $\lambda$ - Modelo 1}

Média de 20 ciclos de pressão no cilindro

dp [\%] - desvio percentual ao se utilizar o modelo único (Etotal) para estimar $\lambda$

Carga Parâmetros Melhor Janela e Combustível

\begin{tabular}{|c|c|c|c|c|c|c|c|c|c|c|c|}
\hline & & $\mathrm{J}$ & E26 & $\mathrm{J}$ & E56 & $\mathrm{J}$ & E70 & $\mathrm{J}$ & E100 & $\mathrm{J}$ & Etotal \\
\hline \multirow{3}{*}{ Plena } & janela e $r$ & 4 & 0,0473 & 4 & 0,0253 & 4 & 0,0234 & 4 & 0,0248 & 1 & 0,0716 \\
\hline & $\mathrm{dp}[\%]$ & & 51,37 & & 183,00 & & 205,98 & & 188,71 & & 0,00 \\
\hline & janela e rms & 1 & 0,0505 & 4 & 0,0352 & 4 & 0,0333 & 1 & 0,0363 & 1 & 0,0719 \\
\hline Combinadas & $\mathrm{dp}[\%]$ & & 42,38 & & 104,26 & & 115,92 & & 98,07 & & 0 \\
\hline
\end{tabular}

De acordo com os dados apresentados na Tabela 39, pode-se afirmar que a utilização do modelo 1 obtido com os dados de todos os combustíveis (Etotal) gera desvios entre $42,38 \%$ a 205,98\% em relação à utilização do modelo 1 obtido para cada combustível separadamente, ou seja, o modelo 1 é significativamente afetado pela variação do tipo de combustível. O modelo 1 utilizando Etotal apresentou o menor desvio percentual na estimativa do fator $\lambda$ para o combustível E26, em cargas combinadas, e o maior desvio percentual para o E70, em plena carga.

Gilkey e Powell (1985) afirmaram que o modelo 1 é pouco afetado pelo tipo de combustível, mas eles não realizaram variações significativas na composição do combustível (utilizaram apenas variações de gasolinas comerciais). Os resultados do presente estudo mostraram que a afirmação feita por Gilkey e Powell (1985) não é válida quando o modelo 1 é utilizado para a estimação do fator $\lambda$ com variações significativas na composição da mistura combustível. 


\subsubsection{Modelo 2}

O modelo 2 apresentou menor rms na janela 1, tanto em plena carga quanto em cargas combinadas, como mostram as Tabelas 37 e 38.

A redução do rms do modelo $2(0,0354)$ foi de aproximadamente 50,6\% em relação ao modelo $1(0,0716)$ considerando os dados em plena carga e de aproximadamente 44,4\% considerando os dados em cargas combinadas.

Os resultados dos melhores rms do modelo 2 obtidos com combustíveis separados e com Etotal são exibidos na Tabela 40.

Tabela 40 - Comparação entre os resultados do modelo 2 na estimativa do fator $\lambda$ (E26, E56, E70, E100 e Etotal (todos os combustíveis juntos), plena carga e duas cargas combinadas, média de 20 ciclos de pressão no cilindro e melhor janela).

\section{Estimativa do fator $\lambda$ - Modelo 2}

Média de 20 ciclos de pressão no cilindro

dp [\%] - desvio percentual ao se utilizar o modelo único (Etotal) para estimar $\lambda$

Carga Parâmetros Melhor Janela e Combustível

\begin{tabular}{|c|c|c|c|c|c|c|c|c|c|c|c|}
\hline & & $\mathrm{J}$ & E26 & $\mathrm{J}$ & E56 & $\mathrm{J}$ & E70 & $\mathrm{J}$ & E100 & $\mathrm{J}$ & Etotal \\
\hline \multirow{3}{*}{ Plena } & janel & 1 & 0,0126 & 1 & 0,0097 & 1 & 0,0110 & 1 & 0,0105 & 1 & 0,0354 \\
\hline & $\mathrm{dp}[\%]$ & & 180,95 & & 264,95 & & 221,82 & & 237,14 & & 0,00 \\
\hline & janela e rms & 1 & 0,0230 & 4 & 0,0242 & 1 & 0,0196 & 4 & 0,0317 & 1 & 0,0400 \\
\hline Combinadas & $\mathrm{dp}[\%]$ & & 73,91 & & 65,29 & & 104,08 & & 26,18 & & 0 \\
\hline
\end{tabular}

Os resultados apresentados na Tabela 40 permitem afirmar que a utilização do modelo 2 obtido a partir de Etotal gera desvios na estimativa do fator $\lambda$ entre $26,18 \%$ a 264,95\% em relação à utilização do modelo 2 obtido para cada combustível separadamente.

A utilização do Etotal para obtenção do modelo 2 apresentou o menor desvio percentual na estimativa do fator $\lambda$ do combustível E100, em cargas combinadas, e o maior desvio percentual na estimativa do fator $\lambda$ do E56, em plena carga.

O modelo 2, assim como o modelo 1 apresentou-se significativamente sensível ao tipo de combustível.

\subsubsection{Modelo 3}

O modelo 3 apresentou redução do $r m s$ em relação ao modelo 2, tanto em plena carga $(5,4 \%)$ quanto em cargas combinadas $(5,2 \%)$, porém, como mencionado anteriormente, o modelo 4 se mostra mais adequado à estimativa do fator $\lambda$ do que o modelo 3 , pois apresenta 
pequeno aumento computacional e redução mais significativa do rms. Os resultados do modelo 3 foram significativamente afetados pela variação do tipo de combustível.

\subsubsection{Modelo 4}

A partir dos dados apresentados nas Tabelas 37 e 38, pode-se calcular que o modelo 4 apresentou uma redução no $r m s$ de aproximadamente $32,5 \%$, em plena carga, e de aproximadamente $18,2 \%$, em cargas combinadas, em relação ao modelo 2 .

A janela 4 apresentou os melhores resultados tanto em plena carga quanto em cargas combinadas.

A Tabela 41 apresenta os resultados dos melhores rms do modelo 4 obtidos com combustíveis separados e com Etotal.

Tabela 41 - Comparação entre os resultados do modelo 4 na estimativa do fator $\lambda$ (E26, E56, E70,

E100 e Etotal (todos os combustíveis juntos), plena carga e duas cargas combinadas, média de 20 ciclos de pressão no cilindro e melhor janela).

Estimativa do fator $\lambda$ - Modelo 4

Média de 20 ciclos de pressão no cilindro

dp [\%] - desvio percentual ao se utilizar o modelo único (Etotal) para estimar $\lambda$

Carga Parâmetros Melhor Janela e Combustível

\begin{tabular}{|c|c|c|c|c|c|c|c|c|c|c|c|}
\hline & & $\mathrm{J}$ & E26 & $\mathrm{J}$ & E56 & $\mathrm{J}$ & E70 & $\mathrm{J}$ & E100 & $\mathrm{J}$ & Etotal \\
\hline \multirow{3}{*}{ Plena } & janela e rms & 1 & 0,0099 & 4 & 0,0072 & 4 & 0,0080 & 4 & 0,0076 & 4 & 0,0239 \\
\hline & $\mathrm{dp}[\%]$ & & 141,41 & & 231,94 & & 198,75 & & 214,47 & & 0 \\
\hline & janela e rms & 2 & 0,0208 & 3 & 0,0163 & 3 & 0,0144 & 1 & 0,0244 & 4 & 0,0327 \\
\hline Combinadas & $\mathrm{dp}[\%]$ & & 57,21 & & 100,61 & & 127,08 & & 34,02 & & 0 \\
\hline
\end{tabular}

Os resultados apresentados na Tabela 41 permitem constatar que o modelo 4 é significativamente sensível a variação do tipo de combustível. O menor desvio percentual com a utilização do modelo 4 obtido a partir de Etotal foi de 34,02\% (para o E100 em regime de cargas combinadas) e o maior foi de $231,94 \%$ (para o E56 em regime de plena carga) em relação à utilização do modelo 4 obtido para cada combustível separadamente.

\subsubsection{Modelo 5}

O modelo 5 apresentou rms menor do que o modelo 4 em plena carga $(0,0232)$. Este resultado mostra que o modelo 5 é capaz de melhorar a estimativa do fator $\lambda$ nesta condição de carga, porém em cargas combinadas o modelo 5 não apresentou melhora significativa na 
estimativa do fator $\lambda$. Os resultados mostraram que o modelo 5 é sensível a variação da composição da mistura combustível.

\subsubsection{Modelo 6}

A redução do rms do modelo 6 em relação ao modelo 4 foi de aproximadamente 4,2\% em plena carga e de aproximadamente 7,6\% em cargas combinadas. A janela 4 foi a que apresentou os melhores resultados nas duas condições de carga analisadas. Este modelo é sensível ao tipo de combustível.

Apesar da melhora na estimativa do fator $\lambda$, se o custo computacional for restritivo, podese optar pela utilização do modelo 4 em detrimento do modelo 6, considerando um pequeno prejuízo na estimativa do fator $\lambda$.

\subsubsection{Modelo 7}

Os resultados do modelo 7 indicam que a redução do $r m s$ em relação ao modelo 6 foi mínima (menor do que $1 \%$ em plena carga e em cargas combinadas), restringindo a sua utilização.

Os resultados obtidos com o modelo 7 permitem afirmar que ele é sensível ao tipo de combustível utilizado.

\subsubsection{Modelo 8}

Em condições de cargas combinadas o modelo 8 foi o que apresentou o menor rms na estimativa do fator $\lambda(0,0299)$, representando uma redução de aproximadamente $1 \% \mathrm{em}$ relação ao modelo 6. Em plena carga a redução do $r m s$ foi de aproximadamente $0,9 \%$ em relação ao modelo 6 .

A Tabela 42 mostra que a utilização do modelo 8 obtido a partir do Etotal acarretou um desvio percentual entre $61 \%$ (E26) e 468\% (E56) em relação à utilização do modelo 8 obtido para cada combustível separadamente. Estes resultados indicam que o modelo 8 é afetado pelas variações do tipo de combustível utilizado no motor VW AT 1000 8V. 
Tabela 42 - Comparação entre os resultados do modelo 8 na estimativa do fator $\lambda$ (E26, E56, E70,

E100 e Etotal (todos os combustíveis juntos), plena carga e duas cargas combinadas, média de 20 ciclos de pressão no cilindro e melhor janela).

Estimativa do fator $\lambda$ - Modelo 8

Média de 20 ciclos de pressão no cilindro

dp [\%] - desvio percentual ao se utilizar o modelo único (Etotal) para estimar $\lambda$

Carga Parâmetros

Melhor Janela e Combustível

\begin{tabular}{clcccccccccc} 
& & J & E26 & J & E56 & J & E70 & J & E100 & J & Etotal \\
\hline \multirow{3}{*}{ Plena } & janela e rms & 4 & 0,0075 & 4 & 0,0040 & 4 & 0,0064 & 1 & 0,0066 & 4 & 0,0227 \\
& dp [\%] & & 204,67 & & 467,50 & & 254,69 & & 243,94 & & 0 \\
Combinadas & janela e rms & 2 & 0,0186 & 3 & 0,0146 & 3 & 0,0130 & 1 & 0,0152 & 4 & 0,0299 \\
& dp [\%] & 60,75 & 104,79 & 130,00 & & 96,71 & 0 \\
\hline
\end{tabular}

O aumento do requisito computacional do modelo 8 aliado à inclusão de transdutores de temperatura nos coletores de admissão e exaustão tornam sua utilização pouco viável em relação aos modelos 4 e 6 .

\subsubsection{Modelo 9}

O modelo 9 apresentou o menor rms na estimativa do fator $\lambda$ em plena carga $(0,0201)$, representando uma redução de aproximadamente $15,9 \%$ em relação ao modelo 4 , enquanto que em cargas combinadas a redução do rms foi de aproximadamente $2,8 \%$.

A utilização do modelo 9 obtido a partir do Etotal gerou em um erro percentual entre 63,92\% (E100 - cargas combinadas) e 294,12\% (E100 - plena carga) em relação à utilização do modelo 8 obtido para cada combustível separadamente. Estes resultados indicam que o modelo 9 é afetado significativamente pelas variações do tipo de combustível utilizado (Tabela 43).

Tabela 43 - Comparação entre os resultados do modelo 9 na estimativa do fator $\lambda$ (E26, E56, E70,

E100 e Etotal (todos os combustíveis juntos), plena carga e duas cargas combinadas, média de 20 ciclos de pressão no cilindro e melhor janela).

Estimativa do fator $\lambda$ - Modelo 9

Média de 20 ciclos de pressão no cilindro

dp [\%] - erro percentual ao se utilizar o modelo único (Etotal) para estimar $\lambda$

Carga Parâmetros Melhor Janela e Combustível

\begin{tabular}{|c|c|c|c|c|c|c|c|c|c|c|c|}
\hline & & $\mathbf{J}$ & E26 & $\mathbf{J}$ & E56 & $\mathrm{J}$ & E70 & J & E100 & $\mathrm{J}$ & Etotal \\
\hline \multirow{3}{*}{ Plena } & janela e rms & 1 & 0,0089 & 3 & 0,0054 & 1 & 0,0065 & 1 & 0,0051 & 4 & 0,0201 \\
\hline & $\mathrm{dp}[\%]$ & & 125,84 & & 272,22 & & 209,23 & & 294,12 & & 0 \\
\hline & janela e rms & 4 & 0,0167 & 3 & 0,0155 & 3 & 0,0139 & 4 & 0,0194 & 4 & 0,0318 \\
\hline Combinadas & $\mathrm{dp}[\%]$ & & 90,42 & & 105,16 & & 128,78 & & 63,92 & & 0 \\
\hline
\end{tabular}


O modelo 9 apresenta maior requisito computacional do que o modelo 4 e sua utilização depende da disponibilidade computacional do sistema eletrônico de controle de motores. Em condições de cargas combinadas o modelo 9 não é recomendado, pois apresenta rms maior do que o modelo 6 (de menor requisito computacional).

\subsubsection{Síntese dos resultados obtidos com os modelos de estimação do fator $\lambda$ utilizando todos os combustíveis em estudo (E26, E56, E70 e E100)}

Resumindo os resultados obtidos com todos os modelos de estimação do fator $\lambda$ pode-se afirmar que:

- O modelo 1 se mostrou muito sensível à variação do tipo de combustível, refutando a afirmação contrária feita por Gilkey e Powell (1985);

- todos os modelos de estimação do fator $\lambda$ foram sensíveis à variação da composição da mistura combustível;

- o modelo 4 apresentou o melhor rms entre os modelos de menor requisito computacional, tanto em plena carga como em cargas combinadas;

- a janela 4 foi a melhor janela do modelo 4 em plena carga $(r m s=0,0239)$ e em cargas combinadas $(r m s=0,0327)$;

- o modelo 9 foi o que apresentou o menor $r m s$ em plena carga (janela 4: $r m s=$ $0,0201), \mathrm{e}$

- o modelo 8, utilizando a janela 4, foi o que apresentou o menor $r m s$ em cargas combinadas $(0,0299)$.

Os coeficientes individuais das regressões lineares múltiplas $\left(a_{n}\right)$ obtidos para os modelos que apresentaram os menores rms em condições de plena carga e de cargas combinadas, considerando uma média de 20 ciclos de pressão no cilindro, são exibidos na Tabela 44. 
Tabela 44 - Coeficientes individuais das regressões lineares múltiplas dos modelos que apresentaram os menores rms para o conjunto de dados com todos os combustíveis (Etotal).

\begin{tabular}{|c|c|c|c|c|}
\hline \multirow[b]{5}{*}{ Coeficientes $a_{n}$} & \multicolumn{4}{|c|}{ dos os combustíveis (média de 20 ciclos) } \\
\hline & \multicolumn{2}{|c|}{$\begin{array}{c}\text { Plena carga } \\
\text { Modelos }\end{array}$} & \multicolumn{2}{|c|}{$\begin{array}{c}\text { Duas cargas } \\
\text { combinadas } \\
\text { Modelos }\end{array}$} \\
\hline & 4 & 9 & 4 & 8 \\
\hline & \multicolumn{2}{|c|}{ Janelas } & \multicolumn{2}{|c|}{ Janelas } \\
\hline & 4 & 4 & 4 & 4 \\
\hline 1 & $8,580 \mathrm{E}+00$ & $1,388 \mathrm{E}+01$ & $9,881 \mathrm{E}+00$ & $8,697 \mathrm{E}+00$ \\
\hline 2 & $4,561 \mathrm{E}+04$ & $2,031 \mathrm{E}+04$ & $1,107 \mathrm{E}+05$ & $9,730 \mathrm{E}+04$ \\
\hline 3 & -7,909E-02 & $-9,060 \mathrm{E}-02$ & $-6,237 \mathrm{E}-02$ & $-6,903 \mathrm{E}-02$ \\
\hline 4 & $-1,936 \mathrm{E}-03$ & $-5,561 \mathrm{E}-03$ & $4,716 \mathrm{E}-05$ & $2,213 \mathrm{E}-03$ \\
\hline 5 & $-2,153 \mathrm{E}-02$ & $-2,745 \mathrm{E}-02$ & $-2,521 \mathrm{E}-02$ & $-2,294 \mathrm{E}-02$ \\
\hline 6 & $-1,862 \mathrm{E}-05$ & $-1,078 \mathrm{E}-05$ & $-1,015 \mathrm{E}-05$ & $-2,526 \mathrm{E}-04$ \\
\hline 7 & 8,943E-04 & $-1,465 \mathrm{E}-02$ & $-7,191 \mathrm{E}-04$ & 1,134E-03 \\
\hline 8 & 1,695E-04 & $-7,756 \mathrm{E}-05$ & $1,092 \mathrm{E}-04$ & $-6,340 \mathrm{E}-06$ \\
\hline 9 & & 1,951E-05 & & $-5,350 \mathrm{E}-03$ \\
\hline 10 & & $-7,137 \mathrm{E}-08$ & & $-1,197 \mathrm{E}-03$ \\
\hline 11 & & & & $2,172 \mathrm{E}-05$ \\
\hline 12 & & & & $2,143 \mathrm{E}-06$ \\
\hline
\end{tabular}

A Figura 59 apresenta, por meio de círculos, os resíduos para o modelo 4, em condições de cargas combinadas. Os resultados, com nível de 5\% de significância, indicam uma pequena variação nos resíduos da estimativa do fator $\lambda$ utilizando o modelo 4 (resíduo médio do fator $\lambda$ estimado igual a 0,0259).

Na Figura 59 pode-se observar que existem alguns valores atípicos nos resíduos do modelo 4, considerando a janela 4, porém, como mencionado anteriormente, a retirada dos valores atípicos poderia melhorar a estimativa, mas tal atitude só seria válida se novos experimentos fossem realizados.

Na Figura 59 os resíduos de 1 a 60 representam o combustível E26, de 61 a 120 o combustível E56, de 121 a 180 o combustível E70 e de 181 a 240 o combustível E100. 


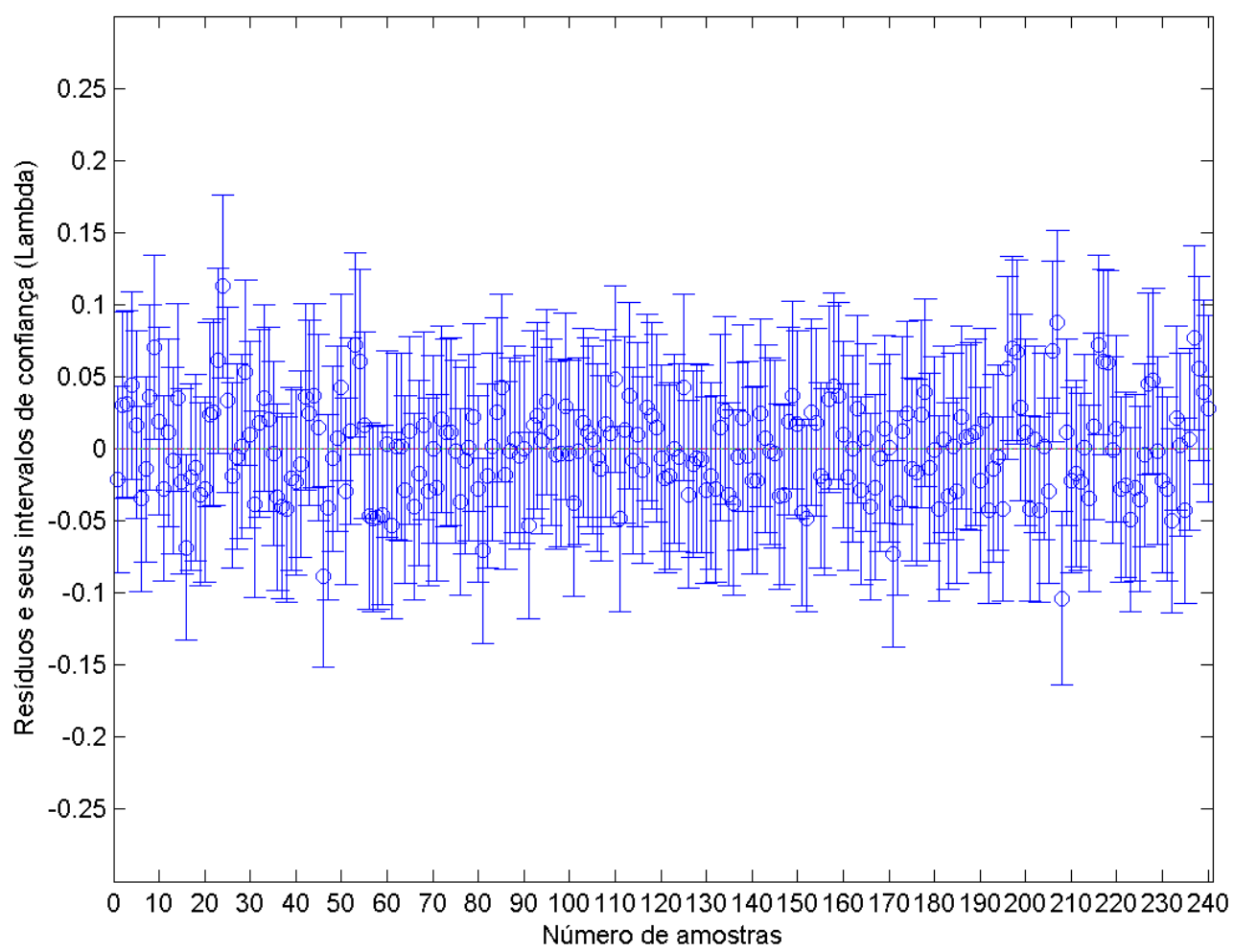

Figura 59 - Resíduos, e seus respectivos intervalos de confiança, resultantes da estimação do fator $\lambda$ utilizando o modelo 4, média de 20 ciclos de pressão no cilindro e janela 4 para o conjunto com todos os combustíveis - Etotal em condições de cargas combinadas, intervalos das amostras: 0-60: E26; 61-120: E56; 121-180: E70; 181-240: E100.

A Figura 60 exibe os resultados da estimação do fator $\lambda$, utilizando o modelo 4 , janela 4 e média de 20 ciclos em condições de cargas combinadas. A reta apresentada nesta figura indica o modelo ideal de estimação do fator $\lambda$ ( $r m s$ igual à zero).

Para título de comparação, os resultados do modelo 8 em condições de cargas combinadas, média de 20 ciclos e janela 4, são apresentados na Figura 61.

Pode-se observar na Figura 61 que os fatores $\lambda$ estimados estão ligeiramente mais próximos dos fatores $\lambda$ reais do que na Figura 60, isto se deve ao menor rms apresentado pelo modelo 8 em relação ao modelo 4 em condições de cargas combinadas.

A comparação das Figuras 60, 61 e 62 permite observar a melhora obtida na estimativa do fator $\lambda$ com os modelos desenvolvidos neste estudo em relação ao primeiro modelo proposto por Gilkey e Powell (1985), Figura 62. 


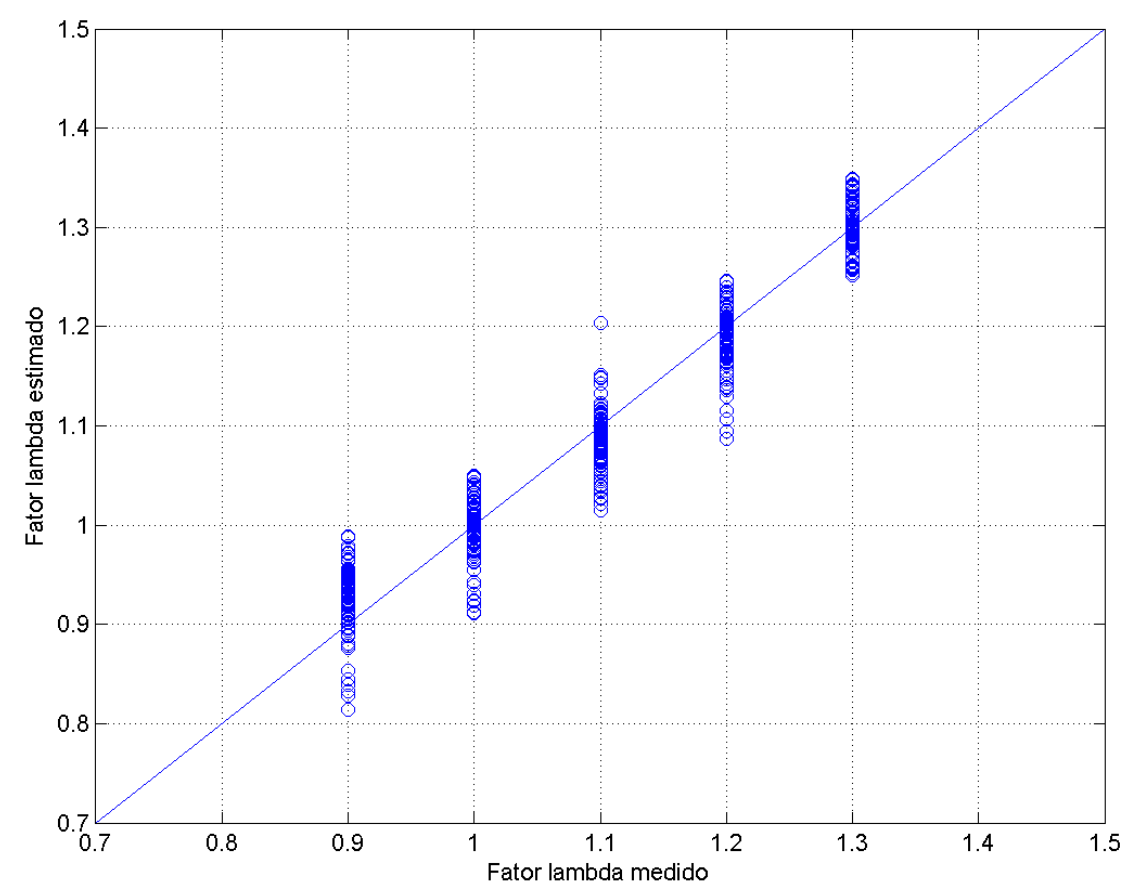

Figura 60 - Resultados obtidos na estimação do fator $\lambda$ utilizando o modelo 4, média de 20 ciclos de pressão no cilindro e janela 4 para o conjunto com todos os combustíveis - Etotal em condições de cargas combinadas.

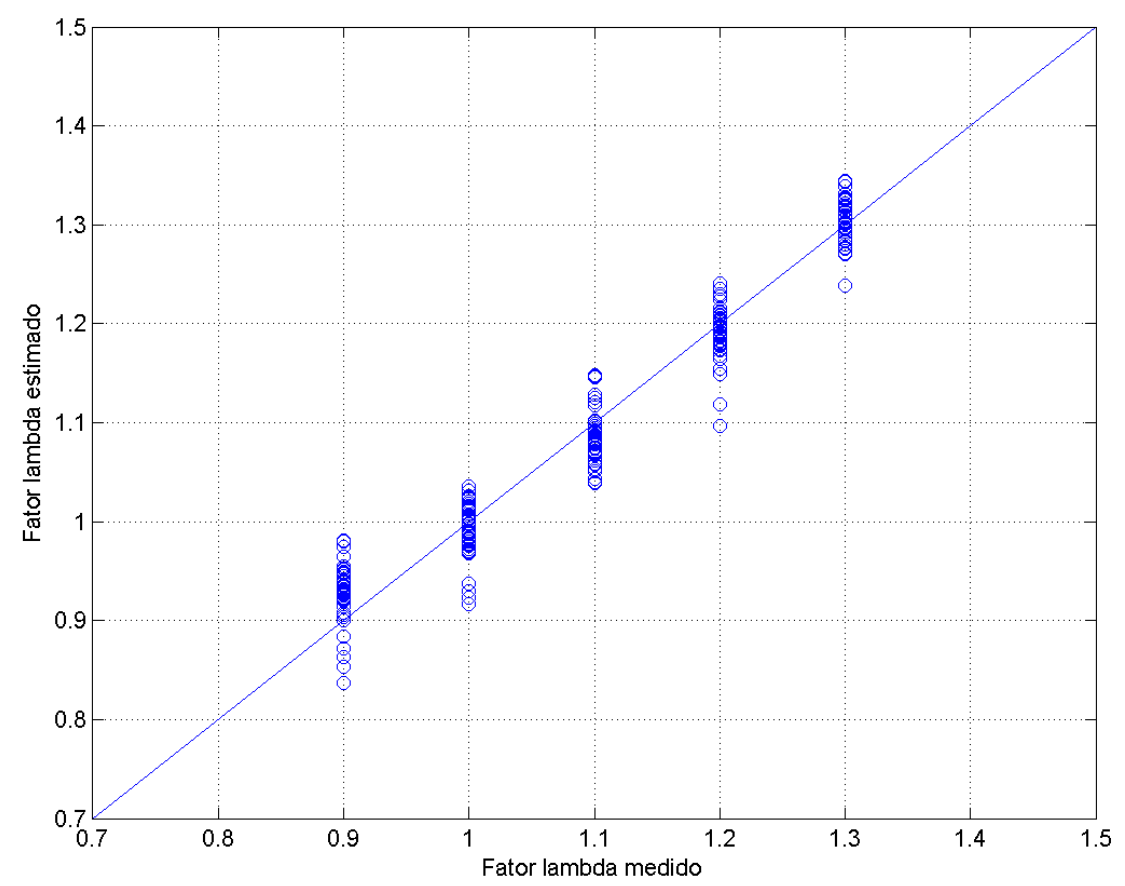

Figura 61 - Resultados obtidos na estimação do fator $\lambda$ utilizando o modelo 8 , média de 20 ciclos de pressão no cilindro e janela 4 para o conjunto com todos os combustíveis - Etotal em condições de cargas combinadas. 


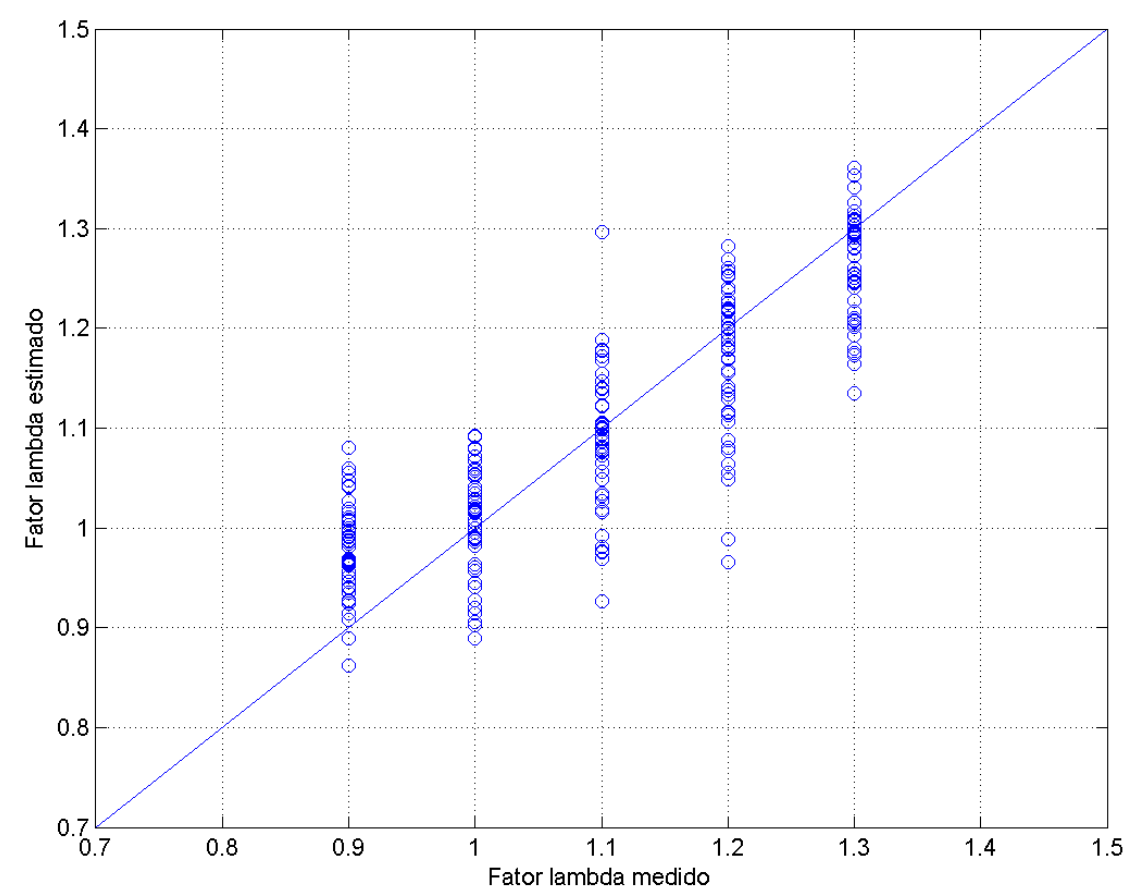

Figura 62 - Resultados obtidos na estimação do fator $\lambda$ utilizando o modelo 1, média de 20 ciclos de pressão no cilindro e janela 1 para o conjunto com todos os combustíveis - Etotal em condições de cargas combinadas.

Os valores de rms obtidos para os nove modelos em estudo considerando todos os combustíveis (Etotal) foram significativamente superiores aos valores de rms obtidos quando considerando individualmente cada combustível, isto demonstra que todos os modelos em estudo são sensíveis a variação do tipo de combustível. Esta afirmação justifica a pesquisa, que será descrita nas próximas seções, sobre a capacidade do método dos momentos e das variáveis independentes, selecionadas neste estudo, para identificar o tipo de combustível em uso no motor.

\subsection{ANÁLISE DOS MODELOS OBTIDOS PARA IDENTIFICAÇÃO DO TIPO DE COMBUSTÍVEL}

Os nove modelos desenvolvidos descritos no Capítulo 3, na seção 3.2.7, serão colocados à prova na identificação do tipo de combustível em uso no motor VW AT1000 8V.

A Tabela 45 indica a fração mássica de etanol em cada mistura combustível utilizada neste estudo. A fração mássica de etanol foi obtida dividindo a porcentagem mássica de etanol (Apêndice B) pela constante de valor cem. 
Tabela 45 - Fração mássica de etanol utilizada nas misturas combustíveis em estudo.

\begin{tabular}{lcccc}
\hline \multicolumn{4}{c}{ Combustíveis } \\
\multicolumn{1}{c}{ Parâmetros } & E26 & E56 & E70 & E100 \\
\hline Porcentagem mássica de $\mathrm{C}_{11} \mathrm{H}_{24}[\%]$ & 73,71 & 44,22 & 29,48 & 0 \\
Fração mássica de etanol & 0,2629 & 0,5578 & 0,7052 & 1 \\
\hline
\end{tabular}

A Tabela 46 apresenta os resultados alcançados com os nove modelos propostos para identificação do tipo de combustível (fração mássica de etanol - FMDE), utilizando a média de 20 ciclos e as janelas 1, 2, 3 e 4 de pressão no cilindro em regime de plena carga, enquanto que a Tabela 47 apresenta os resultados utilizando os dados de cargas combinadas. 
Tabela 46 - Resultados alcançados com os nove modelos de identificação do tipo de combustível utilizando os dados de todos os combustíveis - Etotal (regime de plena carga, MBT, média de 20 ciclos de pressão no cilindro e janelas 1,2,3 e 4) (continua).

\begin{tabular}{|c|c|c|c|c|c|}
\hline \multicolumn{6}{|c|}{$\begin{array}{l}\text { Todos os Combustíveis (dados do experimento } 1 \text { - plena carga) } \\
\text { Identificação do tipo de combustível - MBT - Média de } 20 \text { ciclos }\end{array}$} \\
\hline \multirow{2}{*}{ Modelo } & \multirow{2}{*}{ Parâmetros } & \multicolumn{4}{|c|}{ Janelas } \\
\hline & & 1 & 2 & 3 & 4 \\
\hline \multirow{5}{*}{ Modelo 1} & $\mathrm{~F}$ & 53,70 & 57,30 & 40,18 & 126,59 \\
\hline & $\mathrm{F}_{0,05,4,115}$ & 2,46 & 2,46 & 2,46 & 2,46 \\
\hline & r2 & 0,6513 & 0,6659 & 0,5829 & 0,8149 \\
\hline & $\mathrm{R} 2$ & 0,6392 & 0,6543 & 0,5684 & 0,8085 \\
\hline & $\mathrm{rms}$ & 0,1565 & 0,1532 & 0,1712 & 0,1140 \\
\hline \multirow{5}{*}{ Modelo 2} & $\mathrm{~F}$ & 427,42 & 151,59 & 164,81 & 136,32 \\
\hline & $\mathrm{F}_{0,05,5,114}$ & 2,30 & 2,30 & 2,30 & 2,30 \\
\hline & $\mathrm{r} 2$ & 0,9494 & 0,8693 & 0,8785 & 0,8567 \\
\hline & $\mathrm{R} 2$ & 0,9471 & 0,8635 & 0,8731 & 0,8504 \\
\hline & $\mathrm{rms}$ & 0,0597 & 0,0959 & 0,0924 & 0,1003 \\
\hline \multirow{5}{*}{ Modelo 3} & $\mathrm{~F}$ & 356,44 & 142,26 & 137,73 & 113,07 \\
\hline & $\mathrm{F}_{0,05,6,113}$ & 2,18 & 2,18 & 2,18 & 2,18 \\
\hline & $\mathrm{r} 2$ & 0,9498 & 0,8831 & 0,8797 & 0,8572 \\
\hline & $\mathrm{R} 2$ & 0,9471 & 0,8769 & 0,8733 & 0,8496 \\
\hline & $\mathrm{rms}$ & 0,0594 & 0,0906 & 0,0919 & 0,1002 \\
\hline \multirow{5}{*}{ Modelo 4} & $\mathrm{~F}$ & 330,21 & 345,29 & 326,50 & 423,50 \\
\hline & $\mathrm{F}_{0,05,7,112}$ & 2,10 & 2,10 & 2,10 & 2,10 \\
\hline & r2 & 0,9538 & 0,9557 & 0,9533 & 0,9636 \\
\hline & $\mathrm{R} 2$ & 0,9509 & 0,9529 & 0,9504 & 0,9613 \\
\hline & $\mathrm{rms}$ & 0,0570 & 0,0558 & 0,0573 & 0,0506 \\
\hline \multirow{5}{*}{ Modelo 5} & $\mathrm{~F}$ & 284,08 & 269,34 & 249,52 & 323,66 \\
\hline & $\mathrm{F}_{0,05,9,110}$ & 1,97 & 1,97 & 1,97 & 1,97 \\
\hline & $\mathrm{r} 2$ & 0,9588 & 0,9566 & 0,9533 & 0,9636 \\
\hline & $\mathrm{R} 2$ & 0,9554 & 0,9530 & 0,9495 & 0,9606 \\
\hline & $\mathrm{rms}$ & 0,0538 & 0,0552 & 0,0573 & 0,0506 \\
\hline \multirow{5}{*}{ Modelo 6} & $\mathrm{~F}$ & 260,30 & 280,02 & 263,72 & 352,26 \\
\hline & $\mathrm{F}_{0,05,9,110}$ & 1,97 & 1,97 & 1,97 & 1,97 \\
\hline & r2 & 0,9552 & 0,9582 & 0,9557 & 0,9665 \\
\hline & $\mathrm{R} 2$ & 0,9515 & 0,9548 & 0,9521 & 0,9637 \\
\hline & $\mathrm{rms}$ & 0,0561 & 0,0542 & 0,0558 & 0,0485 \\
\hline
\end{tabular}


Tabela 46 - Resultados alcançados com os nove modelos de identificação do tipo de combustível utilizando os dados de todos os combustíveis - Etotal (regime de plena carga, MBT, média de 20 ciclos de pressão no cilindro e janelas 1,2, 3 e 4) (conclusão).

\begin{tabular}{|c|c|c|c|c|c|}
\hline \multirow{2}{*}{\multicolumn{6}{|c|}{$\begin{array}{l}\text { Todos os Combustíveis (dados do experimento } 1 \text { - plena carga) } \\
\text { Identificação do tipo de combustível - MBT - Média de } 20 \text { ciclos }\end{array}$}} \\
\hline & & & & & \\
\hline Modelo & Parametros & 1 & 2 & 3 & 4 \\
\hline \multirow{5}{*}{ Modelo 7} & $\mathrm{~F}$ & 260,97 & 270,66 & 251,23 & 342,14 \\
\hline & $\mathrm{F}_{0,05,10,109}$ & 1,92 & 1,92 & 1,92 & 1,92 \\
\hline & $\mathrm{r} 2$ & 0,9599 & 0,9613 & 0,9584 & 0,9691 \\
\hline & $\mathrm{R} 2$ & 0,9562 & 0,9577 & 0,9546 & 0,9663 \\
\hline & $\mathrm{rms}$ & 0,0531 & 0,0522 & 0,0541 & 0,0466 \\
\hline \multirow{5}{*}{ Modelo 8} & $\mathrm{~F}$ & 248,24 & 254,08 & 240,22 & 315,83 \\
\hline & $\mathrm{F}_{0,05,11,108}$ & 1,89 & 1,89 & 1,89 & 1,89 \\
\hline & $\mathrm{r} 2$ & 0,9620 & 0,9628 & 0,9607 & 0,9699 \\
\hline & $\mathrm{R} 2$ & 0,9581 & 0,9590 & 0,9567 & 0,9668 \\
\hline & $\mathrm{rms}$ & 0,0517 & 0,0511 & 0,0525 & 0,0460 \\
\hline \multirow{5}{*}{ Modelo 9} & $\mathrm{~F}$ & 256,17 & 266,55 & 270,24 & 330,90 \\
\hline & $\mathrm{F}_{0,05,9,110}$ & 1,97 & 1,97 & 1,97 & 1,97 \\
\hline & r2 & 0,9545 & 0,9562 & 0,9567 & 0,9644 \\
\hline & R2 & 0,9507 & 0,9526 & 0,9532 & 0,9615 \\
\hline & $\mathrm{rms}$ & 0,0566 & 0,0555 & 0,0551 & 0,0500 \\
\hline
\end{tabular}

Os resultados dos valores críticos, $F_{\alpha, k, n-p}$, apresentados nas Tabelas 46 e 47, foram menores que as estatísticas de teste, $F$, nos nove modelos em estudo, portanto, pode-se afirmar que existe pelo menos um regressor $\left(a_{n}\right)$ em cada um dos modelos analisados que contribui significativamente para a estimativa do fator $\lambda$.

Nas Tabelas 46 e 47, pode-se observar que as janelas 2 e 3 não apresentaram os menores rms para nenhum dos modelos em estudo. 
Tabela 47 - Resultados alcançados com os nove modelos de identificação do tipo de combustível utilizando os dados de todos os combustíveis - Etotal (duas cargas combinadas, MBT, média de 20 ciclos de pressão no cilindro e janelas 1,2,3 e 4) (continua).

Todos os combustíveis (duas cargas combinadas)

Identificação do tipo de combustível - MBT - Média de 20 ciclos

\begin{tabular}{|c|c|c|c|c|c|}
\hline \multirow{2}{*}{ Modelo } & \multirow{2}{*}{ Parâmetros } & \multicolumn{4}{|c|}{ Janelas } \\
\hline & & 1 & 2 & 3 & 4 \\
\hline \multirow{5}{*}{ Modelo 1} & $\mathrm{~F}$ & 12,97 & 86,34 & 24,52 & 173,57 \\
\hline & $\mathrm{F}_{0,05,4,235}$ & 2,37 & 2,37 & 2,37 & 2,37 \\
\hline & $\mathrm{r} 2$ & 0,1809 & 0,5951 & 0,2945 & 0,7471 \\
\hline & $\mathrm{R} 2$ & 0,1669 & 0,5882 & 0,2825 & 0,7428 \\
\hline & $\mathrm{rms}$ & 0,2399 & 0,1687 & 0,2227 & 0,1333 \\
\hline \multirow{5}{*}{ Modelo 2} & $\mathrm{~F}$ & 527,87 & 246,06 & 281,28 & 237,50 \\
\hline & $\mathrm{F}_{0,05,5,234}$ & 2,21 & 2,21 & 2,21 & 2,21 \\
\hline & $\mathrm{r} 2$ & 0,9186 & 0,8402 & 0,8574 & 0,8354 \\
\hline & $\mathrm{R} 2$ & 0,9168 & 0,8368 & 0,8543 & 0,8319 \\
\hline & $\mathrm{rms}$ & 0,0757 & 0,1060 & 0,1001 & 0,1076 \\
\hline \multirow{5}{*}{ Modelo 3} & $\mathrm{~F}$ & 444,62 & 207,90 & 233,44 & 218,27 \\
\hline & $\mathrm{F}_{0,05,6,233}$ & 2,10 & 2,10 & 2,10 & 2,10 \\
\hline & $\mathrm{r} 2$ & 0,9197 & 0,8426 & 0,8574 & 0,8490 \\
\hline & $\mathrm{R} 2$ & 0,9176 & 0,8386 & 0,8537 & 0,8451 \\
\hline & $\mathrm{rms}$ & 0,0751 & 0,1052 & 0,1001 & 0,1030 \\
\hline \multirow{5}{*}{ Modelo 4} & F & 471,78 & 478,24 & 452,14 & 646,73 \\
\hline & $\mathrm{F}_{0,05,7,232}$ & 2,01 & 2,01 & 2,01 & 2,01 \\
\hline & $\mathrm{r} 2$ & 0,9344 & 0,9352 & 0,9317 & 0,9513 \\
\hline & $\mathrm{R} 2$ & 0,9324 & 0,9332 & 0,9296 & 0,9498 \\
\hline & $\mathrm{rms}$ & 0,0679 & 0,0675 & 0,0693 & 0,0585 \\
\hline \multirow{5}{*}{ Modelo 5} & $\mathrm{~F}$ & 441,62 & 387,07 & 360,99 & 499,86 \\
\hline & $\mathrm{F}_{0,05,9,230}$ & 1,88 & 1,88 & 1,88 & 1,88 \\
\hline & $\mathrm{r} 2$ & 0,9453 & 0,9381 & 0,9339 & 0,9514 \\
\hline & $\mathrm{R} 2$ & 0,9432 & 0,9356 & 0,9313 & 0,9495 \\
\hline & $\mathrm{rms}$ & 0,0620 & 0,0660 & 0,0682 & 0,0585 \\
\hline \multirow{5}{*}{ Modelo 6} & $\mathrm{~F}$ & 369,65 & 449,54 & 391,80 & 622,07 \\
\hline & $\mathrm{F}_{0,05,9,230}$ & 1,88 & 1,88 & 1,88 & 1,88 \\
\hline & $\mathrm{r} 2$ & 0,9353 & 0,9462 & 0,9388 & 0,9605 \\
\hline & $\mathrm{R} 2$ & 0,9328 & 0,9441 & 0,9364 & 0,9590 \\
\hline & $\mathrm{rms}$ & 0,0674 & 0,0615 & 0,0656 & 0,0527 \\
\hline
\end{tabular}


Tabela 47 - Resultados alcançados com os nove modelos de identificação do tipo de combustível utilizando os dados de todos os combustíveis - Etotal (duas cargas combinadas, MBT, média de 20 ciclos de pressão no cilindro e janelas 1, 2, 3 e 4) (conclusão).

Todos os combustíveis (duas cargas combinadas)

Identificação do tipo de combustível - MBT - Média de 20 ciclos

\begin{tabular}{cccccc} 
Modelo & Parâmetros & \multicolumn{4}{c}{ Janelas } \\
& & 1 & 2 & 3 & 4 \\
\hline \multirow{3}{*}{ Modelo 7 } & $\mathrm{F}$ & 352,10 & 434,21 & 362,63 & 590,43 \\
& $\mathrm{~F}_{0,05,10,229}$ & 1,83 & 1,83 & 1,83 & 1,83 \\
& $\mathrm{r} 2$ & 0,9389 & 0,9499 & 0,9406 & 0,9627 \\
& $\mathrm{R} 2$ & 0,9363 & 0,9477 & 0,9380 & 0,9610 \\
Modelo 8 & $\mathrm{rms}$ & 0,0655 & 0,0593 & 0,0646 & 0,0512 \\
& $\mathrm{~F}$ & 333,17 & 405,25 & 353,96 & 547,00 \\
& $\mathrm{~F}_{0,05,11,228}$ & 1,79 & 1,79 & 1,79 & 1,79 \\
& $\mathrm{r} 2$ & 0,9414 & 0,9513 & 0,9447 & 0,9635 \\
& $\mathrm{R} 2$ & 0,9386 & 0,9490 & 0,9420 & 0,9617 \\
Modelo 9 & $\mathrm{rms}$ & 0,0642 & 0,0585 & 0,0624 & 0,0507 \\
& $\mathrm{~F}$ & 374,65 & 370,64 & 352,64 & 534,39 \\
& $\mathrm{~F}_{0,05,9,230}$ & 1,88 & 1,88 & 1,88 & 1,88 \\
& $\mathrm{r} 2$ & 0,9361 & 0,9355 & 0,9324 & 0,9544 \\
& $\mathrm{R} 2$ & 0,9336 & 0,9330 & 0,9298 & 0,9526 \\
& $\mathrm{rms}$ & 0,0670 & 0,0673 & 0,0689 & 0,0566 \\
\hline
\end{tabular}

O modelo 1 (variáveis independentes: $a G, N, M_{2}$ e $M_{3}$ ) apresentou o menor $r m s$ na janela 4 (e os maiores $r^{2}$ e $R^{2}$ ), tanto em plena carga $(r m s=0,1140)$ quanto em cargas combinadas $(r m s=0,1333)$.

Observando os resultados do modelo 1 pode-se afirmar que ele é capaz de identificar o tipo de combustível, mas seu erro rms, independente da carga analisada, é muito elevado.

\subsubsection{Modelo 2}

Analisando novamente as Tabelas 46 e 47, pode-se observar que o menor rms para o modelo 2 (variáveis independentes: $a G, N, M_{2}, M_{3}$ e $T I$ ) foi obtido utilizando a janela 1 , tanto em plena carga ( $r m s=0,0597)$ quanto em cargas combinadas $(r m s=0,0757)$.

Os resultados do modelo 2 mostram que a inclusão do tempo de injeção (TI) como variável independente permite uma redução no $r m s$, de aproximadamente 47,7\% em plena carga e de aproximadamente 43,2\% em cargas combinadas, em relação ao modelo 1.

Apesar do rms do modelo 2 de identificação do tipo de combustível ser maior do que o rms do modelo 2 de estimação do fator $\lambda$ (considerando o conjunto de todos os combustíveis), pode-se considerá-lo aceitável para uma possível implementação em um sistema eletrônico de 
controle de motores, pois os erros na estimação do tipo de combustível utilizando a atual tecnologia flex fuel (baseada no sinal do sensor de oxigênio) variam entre 9 e 12,5\% (AHN et al., 2010).

Os coeficientes $r^{2}$ e $R^{2}$ obtidos para o modelo 2 foram superiores aos do modelo 1 indicando que o tempo de injeção contribui significativamente para a identificação do tipo de combustível (Tabelas 46 e 47).

\subsubsection{Modelo 3}

Os resultados obtidos com o modelo 3 (variáveis independentes: $a G, N, M_{2}, M_{3}$, TI e PC), apresentados na Tabela 46, indicam que o menor rms $(0,0594)$ ocorreu na janela 1 . Esta janela também apresentou o menor $r m s$ quando utilizando os dados em cargas combinadas ( $r m s=$ 0,0751), como mostra a Tabela 47.

A inclusão do pico de pressão no modelo 3 resultou em uma melhora na identificação do tipo de combustível ( $r^{2}$ e $R^{2}$ maiores do que no modelo 2 ). A redução do $r m s$ ocorreu tanto em plena carga $(0,4 \%)$ quanto em cargas combinadas $(0,7 \%)$, em relação ao modelo 2.

A pequena redução no $r m s$ do modelo 3 em relação ao modelo 2 não justifica sua utilização em um sistema eletrônico de controle de motores devido ao aumento no custo computacional.

\subsubsection{Modelo 4}

Em condições de plena carga o modelo 4 (variáveis independentes: $a G, N, M_{2}, M_{3}, T I, P C$ e $A V)$ apresentou o menor rms $(0,0506)$ na janela 4. Esta mesma janela obteve o menor $r m s$ em condições de cargas combinadas $(0,0585)$.

A adição do avanço da centelha no modelo 4 ajudou a aumentar os coeficientes $r^{2}$ e $R^{2}$ em relação ao modelo 3 e na redução do rms em aproximadamente 14,8\% em plena carga e de aproximadamente $22 \%$ em cargas combinadas.

O modelo 4 apresenta pequeno acréscimo computacional em relação aos modelos anteriores (1, 2 e 3 ) e o melhor rms entre eles, portanto, se trata da melhor opção para implementação em um sistema eletrônico de controle de motores visando menor custo computacional do que outros modelos mais complexos $(5,6,7,8$ e 9$)$. 


\subsubsection{Modelo 5}

A inclusão dos momentos de segunda e terceira ordem aplicados à curva gerada pelo método da razão de pressões no modelo 5 (variáveis independentes: $a G, N, M_{2}, M_{3}$ e $T I, P C$, $A V, M T X_{2}$ e $\left.M T X_{3}\right)$ apresentou melhora nos coeficientes $r^{2}$ e $R^{2}$ em pelo menos uma das janelas de pressão no cilindro, em condições de plena carga e de cargas combinadas.

O menor rms do modelo 5 foi igual ao menor rms do modelo 4 tanto em plena carga quanto em cargas combinadas.

A janela 4 foi a que apresentou os melhores $r m s$ para o modelo 5, tanto em plena carga quanto em cargas combinadas.

Considerando os resultados do modelo 5, pode-se afirmar que ele é capaz de identificar o tipo de combustível, mas não seria a melhor indicação para compor um sistema de controle de motores, pois apresenta maior requisito computacional que o modelo 4 e nenhuma melhora significativa no rms.

\subsubsection{Modelo 6}

Nas Tabelas 46 e 47 pode-se observar que o modelo 6 (variáveis independentes: $a G, N$, $M_{2}, M_{3}$ e $T I, P C, A V, M_{4}$ e $M_{5}$ ) apresentou coeficientes $r^{2}$ e $R^{2}$ maiores do que o modelo 4, indicando que a utilização dos momentos de quarta e quinta ordem auxiliam na identificação do tipo de combustível (ou fração mássica de etanol - FMDE).

A janela 4 apresentou os menores rms em plena carga $(0,0485)$ e em cargas combinadas $(0,0527)$.

A redução do $r m s$ do modelo 6 em relação ao modelo 4 foi de aproximadamente $4 \%$ em plena carga e de aproximadamente $10 \%$ em cargas combinadas.

Se o requisito computacional for restritivo, o modelo 4 seria o escolhido em detrimento ao modelo 6.

Os momentos de quarta e quinta ordem inseridos no modelo 6 permaneceram na composição dos modelos 7 e 8. 


\subsubsection{Modelo 7}

O modelo $7\left(a G, N, M_{2}, M_{3}\right.$ e $T I, P C, A V, M_{4}, M_{5}$ e $\left.T A\right)$ apresentou uma redução de $r m s$ em relação ao modelo 6 de aproximadamente $4 \%$ em plena carga e de aproximadamente 2,7\% em cargas combinadas, ambas obtidas na janela 4.

Os coeficientes $r^{2}$ e $R^{2}$, exibidos nas Tabelas 46 e 47, indicam que a temperatura de admissão (TA), inserida no modelo 7 , colabora significativamente para a identificação da fração mássica de etanol.

Como mencionado nas seções anteriores, o modelo 7 apresenta o empecilho de exigir a inserção de um transdutor de temperatura no coletor de admissão, o que além de aumentar o requisito computacional aumentaria também os requisitos de manutenção e o custo do sistema eletrônico de controle de motores baseado no sinal do transdutor de pressão no cilindro.

\subsubsection{Modelo 8}

De acordo com as Tabelas 46 e 47, o modelo $8\left(a G, N, M_{2}, M_{3}\right.$ e $T I, P C, A V, M_{4}, M_{5}, T A$ e $T E$ ) apresentou coeficientes $r^{2}$ e $R^{2}$ maiores do que o modelo 7 , indicando que a inclusão da temperatura de exaustão $(T E)$ contribui significativamente para a identificação do tipo de combustível.

A redução do $r m s$ do modelo 8 em relação ao modelo 7 foi de aproximadamente 1,2\% em plena carga e de aproximadamente 1,1\% em cargas combinadas. Os menores rms foram obtidos na janela 4 , tanto em plena carga quanto em cargas combinadas.

O modelo 8 foi o que apresentou os menores $r m s$ entre todos os modelos analisados para identificação do tipo de combustível (ou fração mássica de etanol).

Assim como o modelo 7, o modelo 8 também necessita de transdutores de temperatura, um no coletor de admissão e outro no coletor de escape, o que pode ser considerado uma barreira a sua utilização, tanto do ponto de vista do custo do sistema eletrônico de controle do motor quanto do ponto de vista do custo de manutenção.

\subsubsection{Modelo 9}

O modelo 9 ( $a G, N, M_{2}, M_{3}$ e $T I, P C, A V, M_{3}^{2}$ e $\left.M_{4}{ }^{2}\right)$, como apresentado nas Tabelas 46 e 47, apresentou uma redução de $1,1 \%$ no $r m s$ em relação ao modelo 4 em plena carga e de $3,2 \%$ em cargas combinadas, ambas obtidas na janela 4. 
Os coeficientes $r^{2}$ e $R^{2}$ do modelo 9 foram ligeiramente maiores do que os do modelo 4 , indicando que um modelo mais complexo melhora a capacidade de identificar o tipo de combustível, apesar do maior custo computacional. A implementação do modelo 9 depende da disponibilidade computacional.

\subsubsection{Síntese dos resultados obtidos com os modelos de identificação do tipo e combustível}

Resumindo os resultados obtidos com todos os modelos de identificação do tipo de combustível pode-se afirmar que:

- Apenas o modelo 1 apresenta rms muito elevado, sendo descartada a sua utilização em sistema de controle eletrônico de motores;

- os modelos 2, 3, 4, 5, 6, 7, 8 e 9 apresentam rms inferiores aos erros apresentados pela atual tecnologia flex fuel (baseada no sinal do sensor de oxigênio) e que foram descritos na literatura (AHN et al., 2010);

- o modelo 4 apresenta o melhor rms entre os modelos de menor requisito computacional, tanto em carga plena como em cargas combinadas (conjunto de condições de carga plena e parcial);

- a melhor janela do modelo 4 foi a janela 4 tanto em plena carga $(r m s=0,0506)$ quanto em cargas combinadas $(r m s=0,0585)$, e

- o modelo 8 foi o que apresentou o menor $r m s$ em plena carga $(0,0460)$ e em cargas combinadas $(0,0507)$, utilizando a janela 4.

Os coeficientes individuais das regressões lineares múltiplas $\left(a_{n}\right)$ obtidos para os modelos que apresentaram os menores rms em condições de plena carga e de cargas combinadas são apresentados na Tabela 48, considerando uma média de 20 ciclos de pressão no cilindro. 
Tabela 48 - Coeficientes individuais das regressões lineares múltiplas dos modelos que apresentaram os menores $r m s$ na identificação da fração mássica de etanol.

Todos os combustíveis - tipo de combustível (média de 20 ciclos)

Condição de carga do motor (MBT)

\begin{tabular}{ccccc} 
& \multicolumn{2}{c}{$\begin{array}{c}\text { Plena carga } \\
\text { Modelos }\end{array}$} & \multicolumn{2}{c}{$\begin{array}{c}\text { Duas cargas combinadas } \\
\text { Modelos }\end{array}$} \\
& 4 & 8 & 4 & 8 \\
Coeficientes an & 4 & 4 & 4 & 4 \\
\hline 1 & $1,023 \mathrm{E}+01$ & $1,094 \mathrm{E}+01$ & $1,147 \mathrm{E}+01$ & $1,316 \mathrm{E}+01$ \\
2 & $3,107 \mathrm{E}+05$ & $2,432 \mathrm{E}+05$ & $4,903 \mathrm{E}+04$ & $6,983 \mathrm{E}+04$ \\
3 & $2,491 \mathrm{E}-01$ & $2,330 \mathrm{E}-01$ & $2,577 \mathrm{E}-01$ & $2,572 \mathrm{E}-01$ \\
4 & $-1,582 \mathrm{E}-02$ & $-1,696 \mathrm{E}-02$ & $-1,491 \mathrm{E}-02$ & $-1,749 \mathrm{E}-02$ \\
5 & $-3,909 \mathrm{E}-02$ & $-3,928 \mathrm{E}-02$ & $-3,738 \mathrm{E}-02$ & $-4,083 \mathrm{E}-02$ \\
6 & $-1,151 \mathrm{E}-04$ & $5,635 \mathrm{E}-04$ & $-9,830 \mathrm{E}-05$ & $5,733 \mathrm{E}-04$ \\
7 & $5,829 \mathrm{E}-03$ & $4,439 \mathrm{E}-03$ & $4,208 \mathrm{E}-03$ & $4,502 \mathrm{E}-03$ \\
8 & $2,330 \mathrm{E}-04$ & $-1,424 \mathrm{E}-04$ & $1,709 \mathrm{E}-04$ & $-1,208 \mathrm{E}-04$ \\
9 & & $1,151 \mathrm{E}-02$ & & $1,148 \mathrm{E}-02$ \\
10 & & $2,307 \mathrm{E}-03$ & & $3,278 \mathrm{E}-03$ \\
11 & & $-2,663 \mathrm{E}-05$ & & $-3,611 \mathrm{E}-05$ \\
12 & & $-3,307 \mathrm{E}-06$ & & $-4,959 \mathrm{E}-06$ \\
\hline
\end{tabular}

Os resíduos do modelo de menor requisito computacional, modelo 4 - janela 4 , são representados por círculos na Figura 63. Estes resíduos indicam a diferença entre o valor da fração mássica de etanol estimada (obtido utilizando o modelo em estudo - modelo 4) e o valor da fração mássica de etanol real (que ocorreu no motor nas condições de ensaio utilizadas para a identificação).

Os resultados apresentados na Figura 63 indicam uma pequena variação nos resíduos da identificação do tipo de combustível utilizando o modelo 4 (resíduo médio da fração mássica de etanol igual a 0,0450).

Os valores atípicos, visualizados na Figura 63, não foram retirados para melhorar a identificação do tipo de combustível, pois essa atitude só seria válida se novos experimentos fossem realizados. 


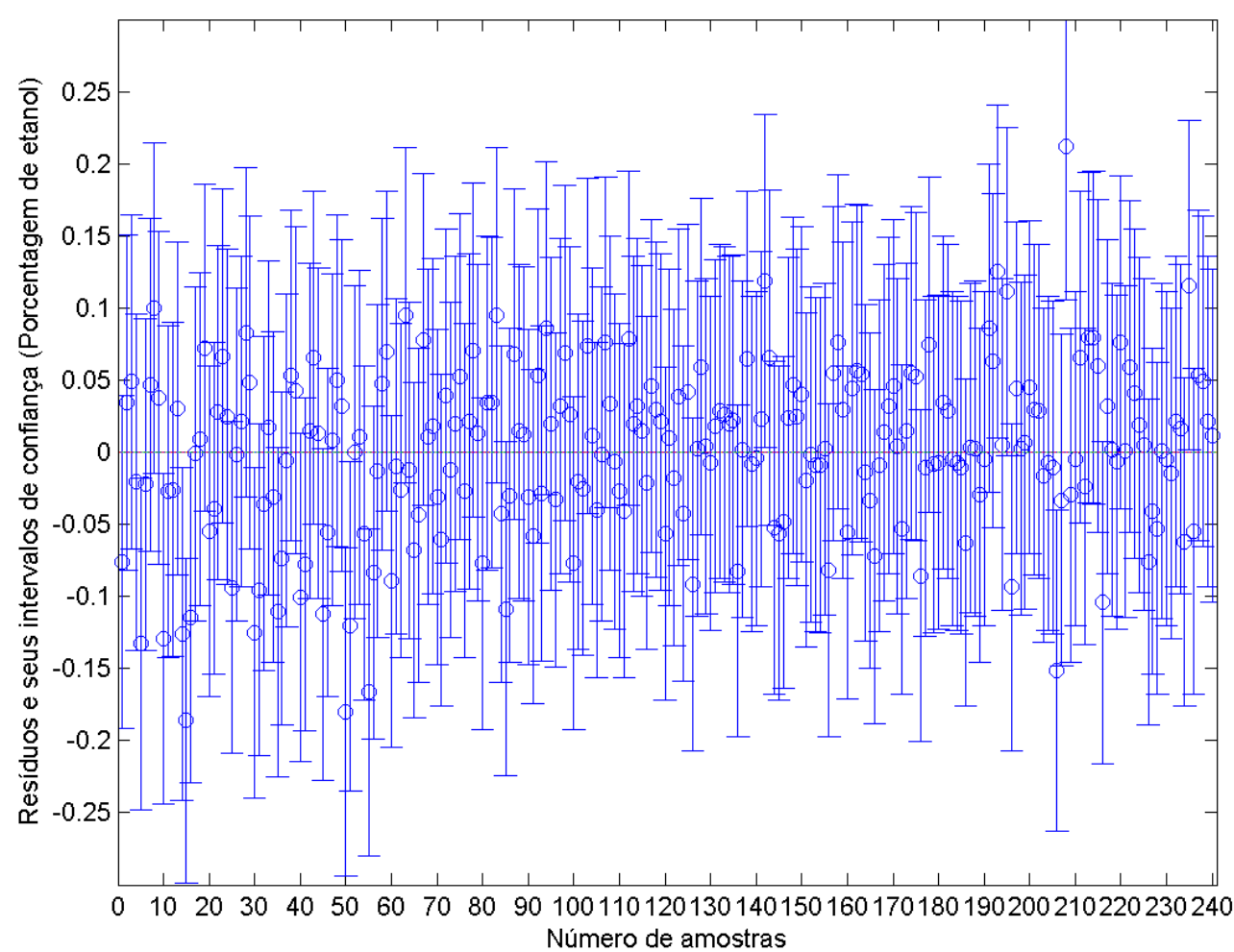

Figura 63 - Resíduos, e seus respectivos intervalos de confiança, resultantes da identificação da fração mássica de etanol utilizando o modelo 4, média de 20 ciclos de pressão no cilindro e janela 4 em condições de cargas combinadas, intervalos das amostras: 0-60: E26; 61-120: E56; 121-180: E70; 181-240: E100.

Na Figura 63 os resíduos de 1 a 60 representam o combustível E26, de 61 a 120 o combustível E56, de 121 a 180 o combustível E70 e de 181 a 240 o combustível E100.

Os resultados da identificação do tipo de combustível, utilizando o modelo $4 \mathrm{em}$ condições de cargas combinadas, janela 4 e média de 20 ciclos, são apresentados na Figura 64. A reta apresentada nesta figura indica o modelo ideal de identificação do tipo de combustível (rms igual à zero). 


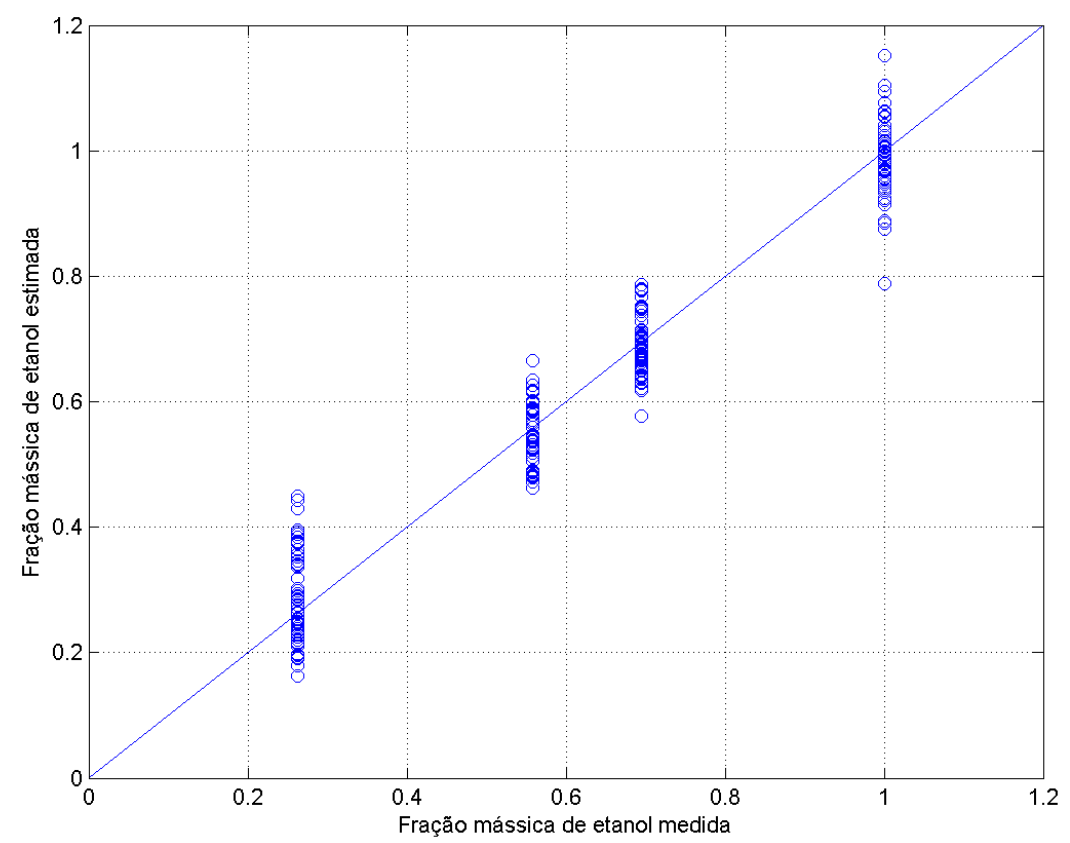

Figura 64 - Resultados obtidos na estimação da fração mássica de etanol utilizando o modelo 4, média de 20 ciclos de pressão no cilindro e janela 4 em condições de cargas combinadas.

Os resultados do modelo 8 em condições de cargas combinadas, média de 20 ciclos e janela 4, são apresentados na Figura 65.

Pode-se observar na Figura 65 que os valores da fração mássica de etanol estimados estão ligeiramente mais próximos dos valores reais do que na Figura 64, isto se deve ao menor rms apresentado pelo modelo 8 em relação ao modelo 4 em condições de cargas combinadas.

Os modelos 4 e 8 apresentaram uma significativa melhora na estimativa da fração mássica de etanol em relação ao modelo 1, como pode ser observado na comparação das Figuras 64, 65 e 66. 


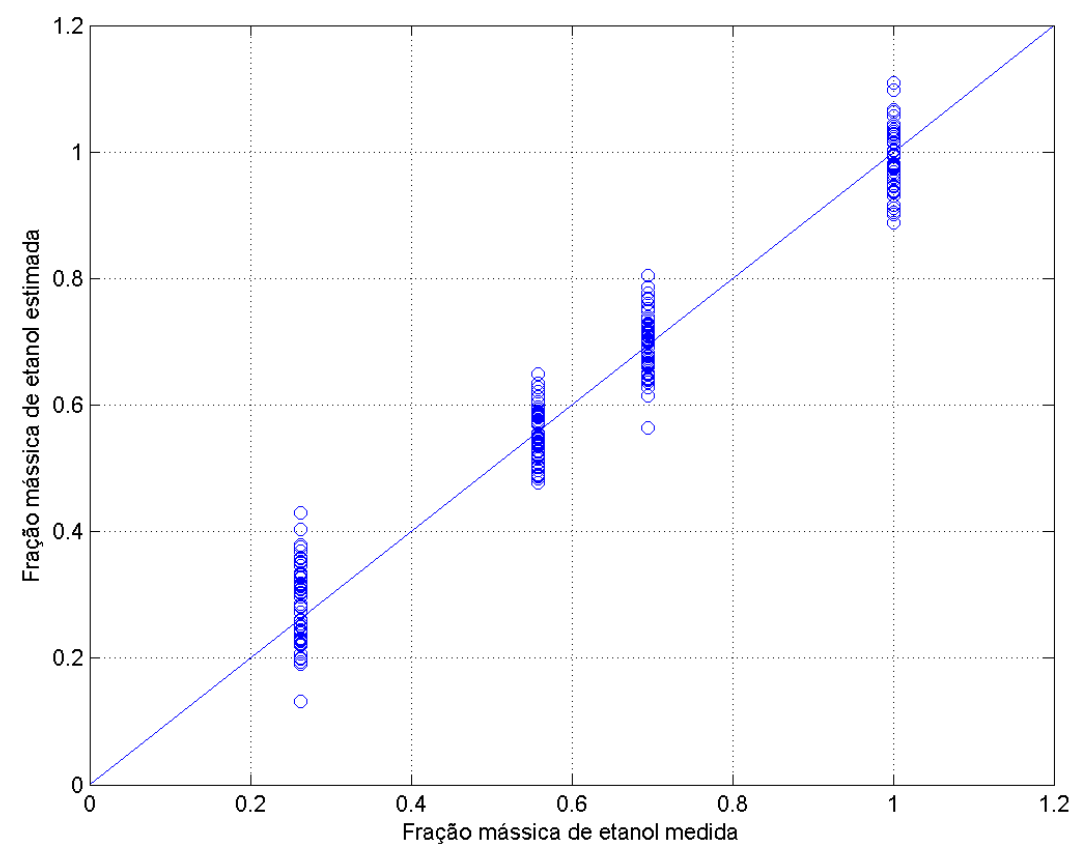

Figura 65 - Resultados obtidos na estimação da fração mássica de etanol utilizando o modelo 8, média de 20 ciclos de pressão no cilindro e janela 4 em condições de cargas combinadas.

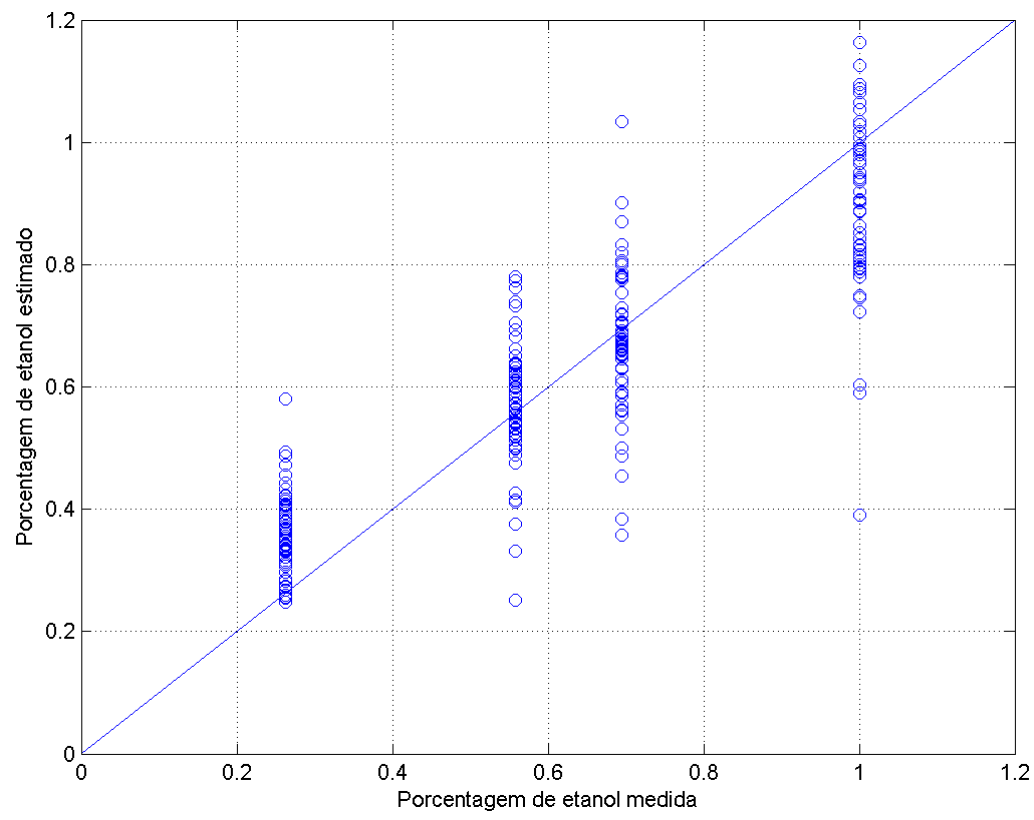

Figura 66 - Resultados obtidos na estimação da fração mássica de etanol utilizando o modelo 1, média de 20 ciclos de pressão no cilindro e janela 4 em condições de cargas combinadas. 


\section{CONCLUSÕES}

Este estudo investigou a estimação da relação ar-combustível, representada pelo fator $\lambda$, e a identificação do tipo de combustível, representada pela fração mássica de etanol (FMDE), utilizando o sinal da pressão no cilindro em um motor Otto alimentado com etanol, gasolina e mistura destes combustíveis.

Foram coletados dados experimentais operando o motor VW AT 1000 8V, originalmente a etanol com relação de compressão de 13,44:1, em condições de plena carga, com MBT (a 2000 e 3000 rpm), e em condições de carga parcial, com MBT (a 2000 e 3000 rpm), utilizando quatro combustíveis distintos (E26, E56, E70 e E100 - 100\% etanol) e até cinco níveis do fator $\lambda(0,9,1,0,1,1,1,2$ e 1,3). O combustível E26 necessitou ter o ponto da centelha mais atrasado porque apresenta menor poder antidetonante, tal como acontece nos veículos flexíveis que possuem motores com relação de compressão mais elevada.

Os resultados das análises das variáveis de desempenho (potência corrigida, consumo específico e eficiência de conversão de combustível) e das emissões de gases de exaustão $\left(\mathrm{CO}, \mathrm{CO}_{2}\right.$ e $\left.\mathrm{HC}\right)$ em regime de plena carga se apresentaram de acordo com o que prevê a literatura.

O modelo 1, composto pelas variáveis independentes $N$ (rotação do motor), $a G$ (estimativa das condições báricas da carga admitida no motor), $M_{2}$ (momento estatístico de segunda ordem) e $M_{3}$ (momento estatístico de terceira ordem), proposto originalmente por Gilkey e Powell (1985), foi capaz de estimar o fator $\lambda$ para todos os combustíveis utilizados, considerando médias de 20 ciclos de pressão no cilindro em condições de plena carga e em duas cargas combinadas (plena carga e 33\% de abertura da válvula borboleta).

O emprego do modelo 1 para estimar o fator $\lambda$ utilizando um conjunto de dados composto por todos os combustíveis testados, em condições de plena carga e em cargas combinadas, mostrou que o mesmo é sensível à variação do tipo de combustível, refutando a afirmação contrária feita por Gilkey e Powell (1985).

O modelo 1 também se mostrou capaz de identificar o tipo de combustível (fração mássica de etanol - FMDE) utilizado no motor em condições de plena carga e em duas cargas combinadas, mas com erros rms elevados (acima de 0,11) o que torna desvantajosa a sua aplicação nos sistemas de controle eletrônico de motores em relação a atual tecnologia flex fuel (baseada no sinal do sensor de oxigênio) que apresenta erros que variam entre 9 e 12,5\% (AHN et al., 2010). Foram incluídas variáveis disponíveis do motor no modelo 1 (tempo de injeção de combustível - $T I$, pico de pressão no cilindro - $P C$, avanço da centelha - $A V$, 
temperatura dos gases tomada no coletor de admissão - TA e temperatura dos gases tomada no coletor de exaustão - TE), além dos momentos de quarta $\left(M_{4}\right)$ e quinta ordem $\left(M_{5}\right)$, dos momentos de segunda e terceira ordem elevados ao quadrado e dos momentos de segunda $\left(M T X_{2}\right)$ e terceira ordem $\left(M T X_{3}\right)$ aplicados originalmente nas curvas das razões de pressões) obtendo mais oito modelos de estimação do fator $\lambda$ e de identificação do tipo de combustível. Estes oito modelos, propostos originalmente neste estudo, foram capazes de estimar o fator $\lambda$, mostraram-se sensíveis à variação do tipo de combustível e foram capazes de identificar o tipo de combustível em condições de plena carga e em cargas combinadas. Os oito modelos propostos neste estudo apresentaram resultados melhores (menores erros rms) do que os obtidos com o modelo 1, proposto originalmente por Gilkey e Powell (1985). Pode-se concluir que a inclusão das variáveis do motor, selecionadas no presente estudo, ao modelo 1 melhora os resultados da estimativa do fator $\lambda$, reduz a sensibilidade à variação do tipo de combustível na estimativa do fator $\lambda$ e melhora os resultados da estimativa do tipo de combustível.

Dentre os modelos com menores requisitos computacionais, propostos neste estudo, o modelo 4 (composto pelas variáveis independentes $N, a G, M_{2}, M_{3}, T I, P C, A V$ ) foi o que apresentou os menores erros rms nas estimativas do fator $\lambda$ e do tipo de combustível, sendo este o modelo recomendado para a aplicação nos sistemas de controle eletrônico de motores flex fuel, quando o requisito computacional for limitado. Para maiores reduções no rms das estimativas do fator $\lambda$ e do tipo de combustível, sem restrições quanto ao custo computacional, recomenda-se o uso dos modelos 8 (composto pelas variáveis independentes $N, a G, M_{2}, M_{3}$, $T I, P C, A V, M_{4}, M_{5}, T A$ e $T E$ ) ou 9 (composto pelas variáveis independentes $N, a G, M_{2}, M_{3}$, $T I, P C, A V, M_{2}^{2}$ e $M_{3}^{2}$ ).

Dentre as quatro janelas do traço da pressão no cilindro utilizadas para o cálculo dos momentos estatísticos, as que apresentam o menor custo computacional são as janelas 1 (início no ponto da centelha e continuando por 120 graus) e 4 (início em $5^{\circ}$ APMS e continuando por $40^{\circ} \mathrm{DPMS}$ ), porém, todas as janelas propostas apresentaram o menor rms em pelo menos uma das estimativas realizadas.

O modelo 5 (composto pelas variáveis independentes $N, a G, M_{2}, M_{3}, T I, P C, A V, M T X_{2} \mathrm{e}$ $M T X_{3}$ ), que propõe a aplicação original do método dos momentos às curvas geradas pelo método da razão de pressões, proposto por Gassenfeit e Powell (1989), foi capaz de estimar o fator $\lambda$ para todos os combustíveis, mostrou-se sensível à variação do tipo de combustível na estimativa do fator $\lambda$ e é capaz de identificar o tipo de combustível (estimar a fração mássica de combustível). Apesar do modelo 5 ser capaz de estimar o fator $\lambda$ e o tipo de combustível, 
ele apresenta maior requisito computacional e melhora pouco significativa na redução do $r m s$ das estimativas em relação ao modelo 4, não sendo a melhor opção entre os modelos propostos para ser implantada em um sistema de controle eletrônico de motores flexíveis.

Os resultados obtidos no presente trabalho, em conjunto com os relatos encontrados na literatura, demonstram que os modelos baseados no sinal da pressão no cilindro para estimação de variáveis do motor (fator lambda e tipo de combustível) podem ser implementados em sistemas de gerenciamento eletrônico de motores, porém, a falta de relatos sobre o comportamento destes modelos ao longo da vida útil dos motores e o custo elevado dos transdutores de pressão no cilindro, ainda produzidos apenas para aplicações científicas, refletem na ausência de sistemas comerciais de gerenciamento eletrônico de motores baseados no sinal da pressão no cilindro.

\subsection{SUGESTÕES DE TRABALHOS FUTUROS}

Entre os apontamentos para trabalhos futuros, destacam-se:

- implementação dos modelos desenvolvidos neste estudo em um sistema eletrônico de controle de motores flex fuel;

- análises estatísticas de experimentos com maior número de variações de carga, rotação e porcentagem de etanol nas misturas combustíveis;

- desenvolvimento de um sistema de controle de temperatura do ar admitido pelo motor, para permitir análises estatísticas entre os dados experimentais coletados em diferentes cargas, tornando desnecessárias as correções propostas pelas normas elaboradas especificamente para regimes de plena carga, e

- desenvolvimento de modelos de identificação do knocking. 


\section{REFERÊNCIAS}

ABDEL-RAHMAN, A. A.; OSMAN, M. M. Experimental investigation on varying the compression ratio of SI engine working under different ethanol-gasoline fuel blends.

International Journal of Energy Research, v. 21, n. 1, p. 31-40, 1997.

AHN, K. et al. Ethanol content estimation in flex fuel direct injection engines using incylinder pressure measurements. Society of Automotive Engineers Inc, 2010. SAE Technical Paper n. 2010-01-0166.

ALVES, M. L. Carro flex fuel: uma avaliação por opções reais. 2007. 47 f. Dissertação (Mestrado em Admisnistração) - Pontifícia Universidade Católica do Rio de Janeiro, Rio de Janeiro, 2007.

ANALOG DEVICES. Monolithic thermocouple amplifiers with cold junction compensation AD294/AD595. Norwoo: [s.n.], 1999.

AGÊNCIA NACIONAL DO PETRÓLEO, GÁS NATURAL E BIOCOMBUSTÍVEIS. 2009. Disponível em: <http://www.anp.gov.br>. Acesso em: 19 nov. 2009.

ARSIE, I et al. Estimation of in-cylinder mass and SFR by cylinder pressure measurement in automotive diesel engines. In: 19th IFAC WORLD CONGRESS, 19., 2014, Cape Town.

Proceedings... Cape Town: IFAC, 2014. p. 11836-11841.

ARSIE, I.; PIANESE, C.; RIZZO, G. Estimation of air-fuel ratio and cylinder wall temperature from pressure cycle in S.I. automotive engines. In: IFAC WORKSHOP ADVANCES IN AUTOMOTIVE CONTROL, 2., 1998, Loundville. Proceedings... Loundville: IFAC, 1998. p. 167-173.

ASSOCIAÇÃO NACIONAL DOS FABRICANTES DE VEÍCULOS AUTOMOTORES. 2014. Anuário da indústria automobilistica brasileira. Disponível em:

<http://www.anfavea.com.br/anuario.html>. Acesso em: 12 jan. 2015.

ATKINS, R. A. et al. Fiber-optic pressure sensors for internal combustion engines. Applied Optics, v. 33, n. 7, p. 1315-1320, Mar. 1994.

BAYRAKTAR, H. Experimental and theoretical investigation of using gasoline-ethanol blends in spark-ignition engines. Renewable Energy, v. 30, n. 11, p. 1733-1747, Sept. 2005.

BENJAMINI, Y.; BRAUN, H. John W. Tukey's contributions to multiple comparisons. The Annals of Statistics, v. 30, n. 6, p. 1576-1594, Dec. 2002.

BERG, J. et al. Measurement of the cylinder pressure in combustion engines with a piezoresistive $\beta$-SIC-on-SOI pressure sensor. In: INTERNATIONAL HIGH TEMPERATURE ELECTRONICS CONFERENCE, 1998, Albuquerque. Proceedings... Albuquerque: HITEC, 1988. p. 245-249.

BORG, J. M.; ALKIDAS, A. C. Cylinder-pressure-based methods for sensing spark-ignition engine knock. International Journal Vehicle Design, v. 45, n. 1-2, p. 222-241, 2007. 
BOSCH. Automotive electric/electronic systems. Warrendale: Society of Automotive Engineers Inc, 1988.

BOSCH. Manual de tecnologia automotiva. 25. ed. São Paulo: Edgard Blücher, 2005.

BOYLESTAD, R.; NASHELSKY, L. Electronic devices and circuit theory. 7th ed. Columbus: Prentice Hall, 1998.

BRECQ, G. et al. Knock prevention of CHP engines by addition of $\mathrm{N}_{2}$ and $\mathrm{CO}_{2}$ to the natural gas fuel. Fuel, v. 23, n. 11, p. 1359-1371, Aug. 2003.

BRECQ, G.; BELLETTRE, J.; TAZEROUT, M. A new indicator for knock detection in gas SI engines. International Journal of Thermal Sciences, v. 42, n. 5, p. 523-532, May 2003.

BRUNETTI, F. Motores de combustão interna. São Paulo: Edgard Blücher, 2012. v. 1.

CARVALHO, J. A.; MCQUARY, M. Q. Princípios de combustão aplicada. Florianópolis: UFSC, 2007.

CELIK, M. B. Experimental determination of suitable ethanol-gasoline blend rate at high compression ratio for gasoline engine. Applied Thermal Engineering, v. 28, n. 5-6, p. 396404, Apr. 2008.

CEVIZ, M. A.; YÜKSEL, F. Effects of ethanol-unleaded gasoline blends on cyclic variability and emissions in an SI engine. Applied Thermal Engineering, v. 25, n. 5-6, p. 917-925, Apr. 2005.

CHAUVIN, J. et al. Kalman filtering for real-time individual cylinder air fuel ratio observer on a diesel engine test bench. In: AMERICAN CONTROL CONFERENCE, 2006, Minneapolis. Proceedings... Minneapolis: IEEE, 2006. p. 1886-1891.

CHEN, R. at al. Cold-start emissions of an SI engine using ethanol-gasoline blended fuel. Applied Thermal Engineering, v. 31, n. 8-9, p. 1463-1467, June 2011.

CONSUMERS, environment and vehicle manufacturers to benefit from advanced engine technology. [S.1.]: Ricardo, 2001. Disponível em: <http://www.ricardo.com>. Acesso em: 12 mar. 2003.

COSTA, R. C.; SODRÉ, J. R. Compression ratio effects on an ethanol/gasoline fuelled engine performance. Applied Thermal Engineering, v. 31, n. 2-3, p. 278-283, Feb. 2011.

COSTA, F. T. M. Estimação da relação ar-combustível utilizando o sinal de pressão no cilindro em um motor ciclo Otto a etanol. 2005. 61 f. Dissertação (Mestrado em Engenharia Mecânica) - Escola de Engenharia de São Carlos, Universidade de São Paulo, São Carlos, 2005.

CRUZ, C. et al. Guia para física experimental: caderno de laboratório, gráficos e erros. Campinas: IFGW-Unicamp, 1997. Versão 1.1, revista por CHBC e HLF em Setembro de 1997. Disponível em: <http://www.ifi.unicamp.br/ brito/graferr.pdf>. Acesso em: 13 jul. 2009. 
DAL BEM, A. J. Análise de desempenho de um motor ciclo Otto alimentado com álcool de 75 INPM. 2008. 116 f. Tese (Doutorado em Engenharia Mecânica) - Escola de Engenharia de São Carlos, Universidade de São Paulo, São Carlos, 2008.

DORINI, F. A.; CUNHA, M. C. C. Statistical moments of the random linear transport equation. Journal of Computational Physics, v. 227, n. 19, p. 8541-8550, Oct. 2008.

DUDEK, K. P.; SAIN, M. K. A control-oriented model for cylinder pressure in internal combustion engines. IEEE Transactions on Automatic Control, v. 34, n. 4, p. 386-397, Apr. 1989.

FAIRCHILD. LM2902, LM324/LM324A, LM224/LM224A: quad operational amplifier. San Jose: [s.n.], 2002.

FIORINI, R. A.; GASSENFEIT, E. H.; POWELL, J. D. A/F estimation from internal combustion engine cylinder pressure using fast Fourier transform descriptors. In: 1988 AMERICAN CONTROL CONFERENCE, 1988, Atlanta. Proceedings... Atlanta: IEEE, 1988. p. 2392-2400.

GASSENFEIT, E. H.; POWELL, J. D. Algorithms for air-fuel ratio estimation using internal combustion engine cylinder pressure. Society of Automotive Engineers Inc, 1989. SAE Technical Paper n. 890300.

GILKEY, J. C.; POWELL, J. D. Fuel-air ratio determination from cylinder pressure time histories. Journal of Dynamic Systems, Measurement, and Control, v. 107, n. 4, p. 252257, Dec. 1985.

GUARINO, A. W. S.; ROJAS, E. G. A. Hidrocarbonetos. 1997. Disponível em: <http://www.unirio.br/laqam/organica/aula_2.pdf>. Acesso em: 1 nov. 2009.

HATA, Y. et al. Engine control system using a cylinder pressure sensor. IEEE Proceedings, v. 136, n. 2, p. 84-88, Mar. 1988.

HE, B. Q. et al. A study on emission characteristics of an EFI engine with ethanol blended gasoline fuels. Atmospheric Environment, v. 37, n. 7, p. 949-957, Mar. 2003.

HEIM, A.; OLEJNIK, P.; PAWLAK, A. Using statistical moments to describe grinding in a ball mill for industrial-scale process. Chemical Engineering and Processing, v. 44, n. 2, p. 263-266, Feb. 2005.

HENRY, R. R. Single-cylinder engine tests of a motor-driven, variable-valve actuator. Society of Automotive Engineers, Inc, 2001. SAE Technical Paper n. 2001-01-0241.

HEYWOOD, J. B. Internal combustion engines fundamentals. New York: McGraw-Hill, 1988.

HOFFMANN, R.; VIEIRA, S. Análise de regressão: uma introdução à econometria. São Paulo: HUCITEC, 1977. 
HSIEH, W. D. et al. Engine performance and pollutant emission of an SI engine using ethanol-gasoline blended fuels. Atmospheric Environment, v. 36, n. 3, p. 403-410, Jan. 2002.

HUCK, S. W. Reading statistics and research. 6nd ed. Boston: Pearson Education, 2012.

HUDSON, C.; GAO, X.; STONE, R. Knock measurement for fuel evaluation in spark ignition engines. Fuel, v. 80, n. 3, p. 395-407, Feb. 2001.

HUNG, V. V.; THANH, L. T. M. Study of elastic properties of $\mathrm{CeO}_{2}$ by statistical moment method. Fhysica B: Condensed Matter, v. 406, n. 21, p. 4014-4018, Nov. 2011.

HUNG, V. V.; HAI, D. T.; BINH, L. T. T. Melting curve of metals with defect: pressure dependence. Computational Materials Science, v. 79, p. 789-794, Nov. 2013.

INSTITUTO NACIONAL DE METROLOGIA, NORMALIZAÇÃO E QUALIDADE INDUSTRIAL. Guia para a expressão da incerteza de medição. 3. ed. Rio de Janeiro: INMETRO, 2003.

JINDO, K. M.; HUNG, V. V.; NISHITANI, S. R. Calcutation of thermodynamic quantities of metals and alloys by estatistical moment method. Intermetallics, v. 11, n. 11-12, p. 12591266, Sept. 2003.

KLEIN, M.; ERIKSSON, L. Models, methods and performance when estimating the compression ratio based on the cylinder pressure. In: CONFERENCE ON COMPUTER SCIENCE AND SYSTEMS ENGINEERING, 4., 2002, Linkõping. Proceedings... Linkõping: CSSE , 2002. p. 1-8.

KUTTATHARMMAKUL, S. et al. Comparasion of methods for the estimation of statistical parameters of censored data. Analytica Chimica Acta, v. 441, n. 2, p. 215-229, Aug. 2001.

KYRIAKIDES, A. et al. Evaluation of gasoline-ethanol-water ternary mixtures used as a fuel for an Otto engine. Fuel, v. 108, p. 208-215, June 2013.

LEONHARDT, S.; MÜLLER, N.; ISERMANN, R. Methods for engine supervision and control based on cylinder pressure information. IEEE/ASME Transactions on Mechatronics, v. 4, n. 3, p. 235-245, Sept. 1999.

LIAO, S. Y. et al. Investigation of the cold-start combustion characteristics of ethanolgasoline blends in a constant-volume chamber. Energy \& Fuels, v. 19, n. 3, p. 813-819, may/june 2005.

MACEDO, I. C.; SEABRA, J. E. A.; SILVA, J. E. A. R. Green house gases emissions in the production and use of ethanol from sugarcane in Brazil: the 2005/2006 averages and a prediction for 2020. Biomass and Bioernergy, v. 32, n. 7, p. 582-595, July 2008.

MANZOLI, F. F. O problema dos momentos. IN: Relação entre o problema dos momentos e a teoria dos jogos estratégicos. São Paulo: FACEA, 1959. cap. 1, p. 1-21.

MARTINS, J. Motores de combustão interna. 2. ed. Porto: Publindústria, 2006. 
MELO, T. C. C. et al. Hydrous ethanol-gasoline blends - Combustion and emission investigations on a flex-fuel engine. Fuel, v. 97, p. 796-804, Mar. 2012.

MONTGOMERY, D. C.; RUNGER, G. C. Estatística aplicada e probabilidade para engenheiros. 2. ed. Rio de Janeiro: LTC, 2003.

MOOD, A. M.; GRAYBILL, F. A. Expected values and moments. In: MOOD, A. M.; GRAYBILL, F. A. Introduction to the theory of statistics. 2nd ed. New York: McGrawHill, 1963. cap. 5, p. 103-121.

MOREIRA, J. R.; GOLDEMBERG, J. The alcohol program. Energy Policy, v. 27, n. 4, p. 229-245, Apr. 1999.

MOTOROLA. Integrated silicon pressure sensor on-chip signal conditioned, temperature compensated and calibrated. Tempe: [s.n.], 2006.

MOTOROLA. High temperature accuracy integrated silicon pressure sensor for measuring absolute pressure, on-chip signal conditioned, temperature compensated and calibrated. Tempe: [s.n.], 2009.

MÜLLER, N.; ISERMANN, R. Control of mixture composition using cylinder pressure sensors. Society of Automotive Engineers Inc, 2001. SAE Technical Paper n. 01ATT-283.

OBERT, E. F. Internal combustion engines. Tradução de Fernando Luiz Carraro. Scranton: International Textbook, 1950.

PATRICK, R. S.; POWELL, J. D. A technique for the real-time estimation of air-fuel ratio using molecular weight ratios. Society of Automotive Engineers Inc, 1990. SAE Technical Paper n. 900260.

PAYRI, et al. Digital signal processing of in-cylinder pressure for combustion diagnosis of internal combustion engines. Mechanical System and Signal Processing, v. 24, n. 6, p. 1767-1784, Aug. 2010.

PENIDO FILHO, P. Os motores a combustão interna. 2. ed. Belo Horizonte: Lemi, 1991. v. 1.

PORTUGAL, M. S. Notas introdutórias sobre o princípio de máxima verossimilhança: estimação e teste de hipóteses. Porto Alegre: Universidade Federal do Rio Grande do Sul, 2009. Disponível em:

<http://www.ufrgs.br/decon/publionline/textosdidaticos/Textodid04.pdf>. Acesso em: 1 nov. 2009.

POWELL, J. D. Engine control using cylinder pressure: past, present, and future. Journal of Dynamic Systems, Measurement, and Control, Berkeley, v. 115, n. 2B, p. 343-350, June 1993.

PUTKO, M. M. et al. Approach for uncertainty propagation and robust design in CFD using sensitivity derivatives. In: COMPUTATIONAL FLUID DYNAMICS CONFERENCE, 15. 2001, Anaheim. Proceedings... Anaheim: AIAA, 2001. 16 p. 
RAHMOUNI, C. et al. Knock rating of gaseous fuels in a single cylinder spark ignition engine. Fuel, v. 83, n. 3, p. 327-336, Feb. 2004.

REGAZZI, R. D.; PEREIRA, P. S.; SILVA JÚNIOR, M. F. Soluções práticas de instrumentação e automação - utilizando programação gráfica LabVIEW. Rio de Janeiro: 3R.KWG, 2005.

RIBBENS, W. B. Understanding automotive electronics. 4th ed. Indianapolis: Sams Publishing, 1993.

ROVAI, F. F. Desgaste e corrosão de bombas de combustível com misturas de álcool e gasohol. 2005. 57 f. Dissertação (Mestrado em Engenharia Mecânica) - Escola Politécnica, Universidade de São Paulo, São Paulo, 2005.

SAMANIEGO, M. R. P. A. J. Uso de biocombustível da pirólise rápida da palha de cana em um motor de ciclo Otto. 2007. 50 f. Dissertação (Mestrado em Planejamento de Sistemas Energéticos) - Faculdade de Engenharia Mecãnica, Universidade Estadual de Campinas, Campinas, 2007.

SANCHES, A. G. Identificação e quantificação do fenômeno de detonação em motores de combustão interna utilizando análise espectral. 2002. 47 f. Dissertação (Mestrado em Engenharia Mecânica) - Escola de Engenharia de São Carlos, Universidade de São Paulo, São Carlos, 2002.

SELLNAU, M. C. et al. Cylinder-pressure-based engine control using pressure-ratiomanagement and low-cost non-intrusive cylinder pressure sensors. Society of Automotive Engineers Inc, 2000. SAE Technical Paper n. 2000-01-0932.

SILVA, J. A. Estudo dos processos de admissão e exaustão utilizando ensaio experimental e simulação de um motor de combustão interna a etanol aspirado e turboalimentado. 2004. 88 f. Tese (Doutorado em Engenharia Mecânica) - Escola de Engenharia de São Carlos, Universidade de São Paulo, São Carlos, 2004.

SOTO PAU, F. Análise do desempenho de motores de combustão interna alimentados com mistura álcool-gasolina. 1999. 62 f. Dissertação (Mestrado em Engenharia Mecânica) Escola de Engenharia de São Carlos, Universidade de São Paulo, São Carlos, 1999.

TABLE: Q scores for Tukey's method. Calgary: University of Calgary, 2006. Disponível em: <http://www.stat.wisc.edu/ st571-1/tables/tableQ.pdf>. Acesso em: 6 jan. 2008.

TAYLOR, C. F. The internal-combustion in theory and practice. Tradução de Mauro Ormeu Cardoso Amorelli. Cambrigde: The MIT Press, 1968. v. 1.

TEIXEIRA, E. C. O desenvolvimento da tecnologia flex-fuel no Brasil. 2005. Disponível em: <http://www.dnabrasil.org.br>. Acesso em: 19 fev. 2006.

TOPGÜL, T. et al. The effects of ethanol-unleaded gasoline blends and ignition timing on engine performance and exhaust emissions. Renewable Energy, v. 31, n. 15, p. 2534-2542, Dec. 2006. 
TUNESTAL, P. et al. In-cylinder measurement for engine cold-start control. In: IEEE INTERNATIONAL CONFERENCE ON CONTROL APPLICATIONS, ThA5-4, 1999, Kohala. Proceedings... Kohala: IEEE, 1999. p. 460-464.

TUNESTAL, P. The use of cylinder pressure for estimation of the in-cylinder air/fuel ratio of an internal combustion engine. $2000.53 \mathrm{f}$. Ph. D. Thesis (Heat and Power Engineering) - University of California, Berkeley, 2000.

TUNESTAL, P. et al. Cylinder air/fuel ratio estimation using net release data. Control Engineering Practic, v. 11, n. 3, p. 311-318, Mar. 2003.

VAN WYLEN, G. J.; SONNTAG, R. E. Fundamentos da termodinâmica clássica. 2. ed. São Paulo: Edgard Bücher, 1976.

VILANOVA, L. C. Efeitos da adição de etanol hidratado no combustível e do sistema de formação da mistura no desempenho e nas emissões de um motor bicombustível brasileiro. 2007. 62 f. Doutorado (Doutorado em Engenharia Mecânica) - Universidade Federal do Rio Grande do Sul, Porto Alegre, 2007.

VOLKSWAGEN DO BRASIL LTDA. Manual de instruções: Gol 1.0 álcool modelo 2003. São Bernardo do Campo: [s.n.], 2003.

WU, C. W. et al. The influence of air-fuel ratio on engine performance and pollutant emission of an SI engine using ethanol-gasoline-blended. Atmospheric Environmentt, v. 38, n. 40, p. 7093-7100, Dec. 2004.

WLODARCZYK, M. T. et al. Embedded fiber-optic pressure sensor for monitoring and control of internal combustion engines. [S.1.: s.n.], 1998. Disponível em:

<http://www.optrand.com/Papers/fisita98/fisita98.htm >. Acesso em: 21 mar. 2003.

YILMAZ, H. Doe merit review: flex fuel vehicle systems. Arlington: Ricardo, 2008.

Disponível em: <http://www1.eere.energy.gov/vehiclesandfuels/pdfs>. Acesso em: 1 nov. 2009.

YOON, P. et al. Closed-loop control of spark advance and air-fuel ratio in SI engines using cylinder pressure. Society of Automotive Engineers Inc, 2000. SAE Technical Paper n. 2000-01-0933.

YÜCESU, H. S. et al. Effect of ethanol-gasoline blends on engine performance and exhaust emissions in different compression ratios. Applied Thermal Engineering, v. 26, n. 17, p. 2272-2278, Dec. 2006. 


\section{APÊNDICE A - Dados coletados no experimentos 1 e algoritmos desenvolvidos no presente trabalho}

\section{A1. DADOS COLETADOS NO EXPERIMENTO 1}

Tabela A1 - Dados coletados durante o experimento 1 a $2000 \mathrm{rpm}$, plena carga e MBT.

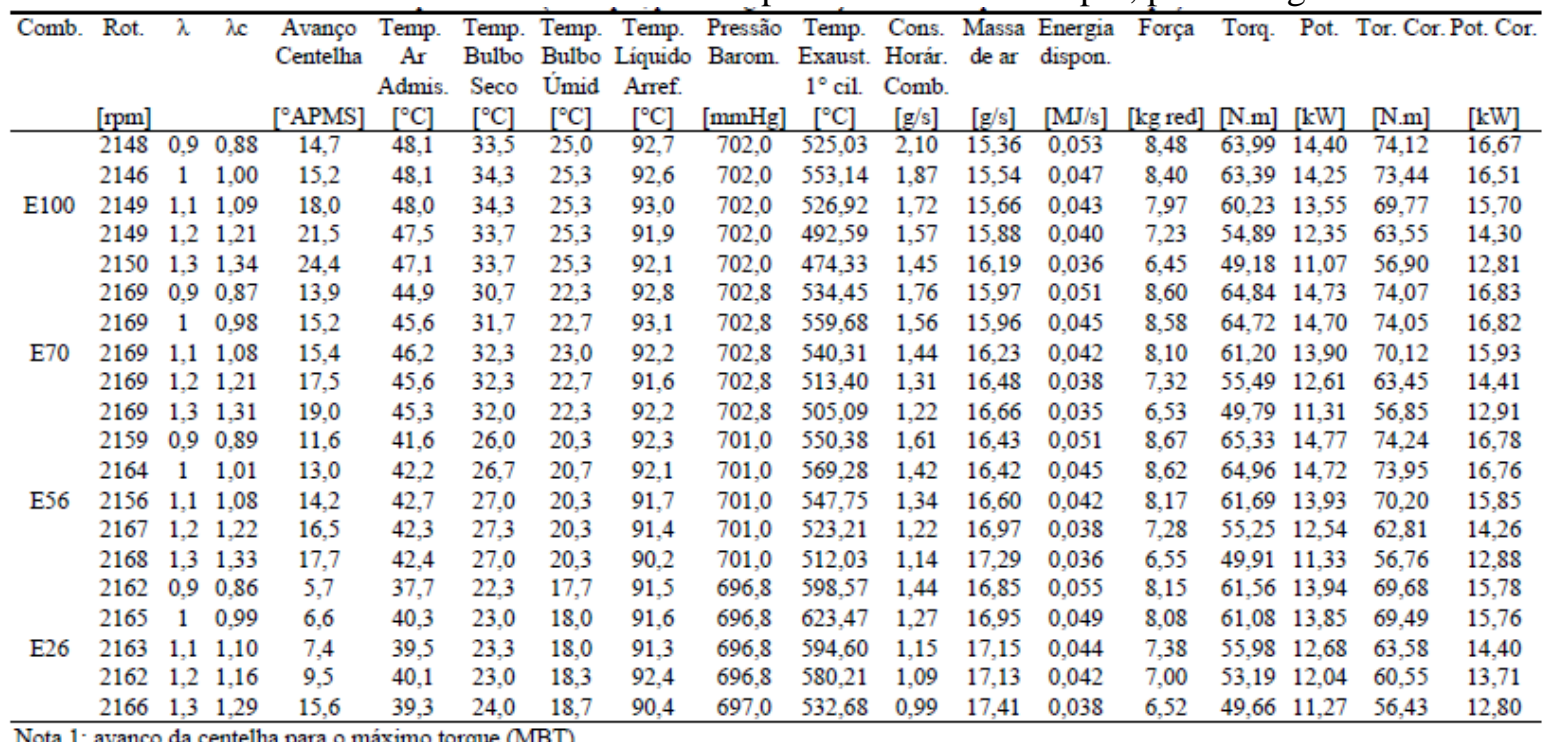

Nota 1: avanço da centelha para o máximo torque (MBT)

Nota 2: dados coletados com rotação de referência em $2000 \mathrm{rpm}$ e plena carga (abertura da válvula borboleta em $100 \%-82,5^{\circ}$ )

Nota 3: dados apresentados referem-se as médias obtidas após a realização de três repetições do experimento em estudo

Nota $4: \lambda$ corresponde ao fator $\lambda$ medido com a sonda lambda de banda larga WB-O2

Nota 5: $\lambda$ c refere-se ao fator lambda calculado a partir dos dados de consumo horário, massa de ar e relação $\mathrm{A} / \mathrm{C}$ estequiométrica

Nota 6: a rotação foi obtida utilizando os dados coletados com o transdutor de rotação-PMS (efeito Hall com 1+3 janelas)

Nota 7: correção da potência (Pot. Cor.) realizada de acordo com a norma NBR ISO 1585 
Tabela A2 - Dados coletados durante o experimento 1 a 3000 rpm, plena carga e MBT.

\begin{tabular}{|c|c|c|c|c|c|c|c|c|c|c|c|c|c|c|c|c|c|c|}
\hline Comb. & {$[\mathrm{rpm}]$} & $\lambda$ & $\lambda c$ & $\begin{array}{l}\text { Avanço } \\
\text { Centelha } \\
\text { ['APMS] }\end{array}$ & $\begin{array}{l}\text { Temp. } \\
\text { Ar } \\
\text { Admis. } \\
{\left[{ }^{\circ} \mathrm{C}\right]}\end{array}$ & $\begin{array}{l}\text { Temp. } \\
\text { Bulbo } \\
\text { Seco } \\
{\left[{ }^{\circ} \mathrm{C}\right]}\end{array}$ & $\begin{array}{l}\text { Temp. } \\
\text { Bulbo } \\
\text { Úmid } \\
{\left[{ }^{\circ} \mathrm{C}\right]}\end{array}$ & $\begin{array}{c}\text { Temp. } \\
\text { Líquido } \\
\text { Arref. } \\
{\left[{ }^{\circ} \mathrm{C}\right]}\end{array}$ & $\begin{array}{l}\text { Pressão } \\
\text { Barom. } \\
\text { [mmHg] }\end{array}$ & $\begin{array}{c}\text { Temp. } \\
\text { Exaust. } \\
1^{\circ} \text { cil. } \\
{\left[{ }^{\circ} \mathrm{C}\right]}\end{array}$ & $\begin{array}{c}\text { Cons. } \\
\text { Horár. } \\
\text { Comb. } \\
{[\mathrm{g} / \mathrm{s}]}\end{array}$ & $\begin{array}{l}\text { Massa } \\
\text { de ar } \\
{[\mathrm{g} / \mathrm{s}]}\end{array}$ & $\begin{array}{l}\text { Energia } \\
\text { dispon. } \\
{[\mathrm{MJ} / \mathrm{s}]}\end{array}$ & [kg red] & Torq. & {$[\mathrm{kW}]$} & Tor. Cor. & Pot. Cor. \\
\hline \multirow{5}{*}{ E100 } & 3168 & 0,9 & 0,93 & 15,9 & 44,8 & 31,3 & 24,7 & 93,0 & 702,2 & 599,8 & 3,23 & 24,88 & 0,081 & 9,22 & 69,34 & 23,00 & 79,81 & 26,48 \\
\hline & 3169 & 1 & 1,03 & 16,1 & 45,6 & 32,3 & 24,7 & 93,1 & 702,2 & 633,5 & 2,91 & 24,96 & 0,073 & 9,17 & 68,97 & 22,89 & 79,44 & 26,36 \\
\hline & 3163 & 1,1 & 1,13 & 18,9 & 46,6 & 32,3 & 24,7 & 93,3 & 702,2 & 599,4 & 2,66 & 25,00 & 0,067 & 8,70 & 65,57 & 21,72 & 75,70 & 25,07 \\
\hline & 3164 & 1,2 & 1,26 & 21,1 & 46,2 & 32,3 & 25,3 & 93,4 & 702,2 & 567,7 & 2,41 & 25,24 & 0,061 & 7,82 & 59,14 & 19,59 & 68,37 & 22,65 \\
\hline & 3163 & 1,3 & 1,37 & 22,6 & 46,4 & 32,0 & 25,0 & 92,0 & 702,2 & 547,0 & 2,24 & 25,55 & 0,056 & 6,97 & 52,94 & 17,54 & 61,18 & 20,27 \\
\hline \multirow{5}{*}{ E70 } & 3167 & 0,9 & 0,91 & 14,3 & 46,5 & 30,7 & 21,3 & 92,4 & 702,3 & 624,5 & 2,67 & 25,43 & 0,078 & 9,18 & 69,09 & 22,91 & 79,00 & 26,20 \\
\hline & 3166 & 1 & 1,03 & 14,4 & 47,5 & 31,3 & 22,0 & 93,0 & 702,3 & 665,5 & 2,38 & 25,43 & 0,069 & 9,07 & 68,24 & 22,63 & 78,28 & 25,96 \\
\hline & 3166 & 1,1 & 1,12 & 14,7 & 47,1 & 31,3 & 22,3 & 92,6 & 702,3 & 642,1 & 2,20 & 25,70 & 0,064 & 8,38 & 63,26 & 20,97 & 72,59 & 24,07 \\
\hline & 3167 & 1,2 & 1,25 & 18,2 & 46,9 & 30,7 & 22,3 & 91,9 & 702,5 & 598,9 & 2,00 & 25,96 & 0,058 & 7,65 & 57,92 & 19,21 & 66,44 & 22,03 \\
\hline & 3168 & 1,3 & 1,35 & 21,0 & 46,3 & 30,0 & 22,0 & 91,9 & 702,5 & 577,6 & 1,86 & 26,11 & 0,054 & 6,80 & 51,73 & 17,16 & 59,25 & 19,65 \\
\hline \multirow{5}{*}{ E56 } & 3160 & 0,9 & 0,92 & 11,4 & 44,1 & 28,3 & 21,3 & 92,9 & 701,0 & 648,6 & 2,46 & 25,79 & 0,078 & 9,10 & 68,49 & 22,66 & 78,27 & 25,90 \\
\hline & 3160 & 1 & 1,03 & 13,0 & 45,1 & 29,3 & 21,3 & 93,0 & 701,2 & 673,7 & 2,18 & 25,79 & 0,069 & 9,00 & 67,76 & 22,42 & 77,50 & 25,64 \\
\hline & 3159 & 1,1 & 1,14 & 14,0 & 45,7 & 29,3 & 21,7 & 93,0 & 700,8 & 647,4 & 1,99 & 25,91 & 0,063 & 8,35 & 63,02 & 20,85 & 72,28 & 23,91 \\
\hline & 3157 & 1,2 & 1,24 & 16,5 & 45,8 & 29,7 & 21,7 & 91,9 & 700,8 & 612,7 & 1,85 & 26,14 & 0,058 & 7,65 & 57,92 & 19,15 & 66,42 & 21,96 \\
\hline & 3157 & 1,3 & 1,34 & 20,5 & 45,5 & 30,0 & 21,7 & 92,0 & 700,8 & 577,1 & 1,71 & 26,29 & 0,054 & 7,02 & 53,31 & 17,63 & 61,09 & 20,20 \\
\hline \multirow{5}{*}{ E26 } & 3163 & 0,9 & 0,88 & 8,6 & 42,2 & 24,7 & 19,3 & 92,7 & 697,7 & 680,7 & 2,19 & 26,15 & 0,084 & 8,80 & 66,30 & 21,96 & 75,75 & 25,09 \\
\hline & 3163 & 1 & 1,00 & 8,5 & 43,3 & 26,0 & 19,7 & 92,8 & 697,7 & 722,7 & 1,93 & 26,19 & 0,074 & 8,58 & 64,72 & 21,44 & 74,09 & 24,54 \\
\hline & 3163 & 1,1 & 1,12 & 9,5 & 43,4 & 26,3 & 20,3 & 93,2 & 697,8 & 696,4 & 1,73 & 26,29 & 0,067 & 7,70 & 58,29 & 19,31 & 66,82 & 22,13 \\
\hline & 3162 & 1,2 & 1,23 & 10,9 & 45,0 & 26,7 & 20,3 & 92,2 & 697,8 & 684,4 & 1,59 & 26,55 & 0,061 & 6,57 & 50,03 & 16,57 & 57,51 & 19,04 \\
\hline & 3163 & 1,3 & 1,32 & 15,5 & 42,7 & 26,7 & 20,3 & 91,5 & 697,8 & 635,8 & 1,50 & 26,64 & 0,057 & 6,50 & 49,54 & 16,41 & 56,71 & 18,79 \\
\hline \multicolumn{19}{|c|}{ Nota 1: avanço da centelha para o máximo torque (MBT) } \\
\hline \multicolumn{19}{|c|}{ Nota 2: dados coletados com rotação de referência em 2000 rpm e plena carga (abertura da válvula borboleta em $100 \%-82,5^{\circ}$ ) } \\
\hline \multirow{2}{*}{\multicolumn{19}{|c|}{$\begin{array}{l}\text { Nota } 3 \text { : dados apresentados referem-se as médias obtidas após a realização de três rep } \\
\text { Nota } 4: \lambda \text { corresponde ao fator } \lambda \text { medido com a sonda lambda de banda larga WB-O2 }\end{array}$}} \\
\hline & & & & & & & & & & & & & & & & & & \\
\hline \multicolumn{19}{|c|}{ Nota 5: $\lambda c$ refere-se ao fator lambda calculado a partir dos dados de consumo horário, massa de ar e relação A/C estequiométrica } \\
\hline \multicolumn{19}{|c|}{ Nota 6: a rotação foi obtida utilizando os dados coletados com o transdutor de rotação-PMS (efeito Hall com 1+3 janelas) } \\
\hline \multicolumn{19}{|c|}{ Nota 7: correção da potência (Pot. Cor.) realizada de acordo com a norma NBR ISO 1585} \\
\hline
\end{tabular}

Tabela A3 - Dados coletados durante o experimento 1 a $2000 \mathrm{rpm}$, carga parcial e MBT.

\begin{tabular}{|c|c|c|c|c|c|c|c|c|c|c|}
\hline \multirow[t]{4}{*}{ Comb. } & \multirow[t]{4}{*}{$\lambda$} & \multirow{3}{*}{$\begin{array}{c}\text { Avanço } \\
\text { Centelha }\end{array}$} & \multirow{3}{*}{$\begin{array}{l}\text { Temp. } \\
\text { Bulbo } \\
\text { Seco }\end{array}$} & \multirow{3}{*}{$\begin{array}{l}\text { Temp. } \\
\text { Bulbo } \\
\text { Úmid }\end{array}$} & \multirow{3}{*}{$\begin{array}{l}\text { Pressão } \\
\text { Barom. }\end{array}$} & \multicolumn{3}{|c|}{ Emissões } & \multirow{4}{*}{$\begin{array}{c}\text { Cons. } \\
\text { Horár. } \\
\text { Comb. } \\
{[\mathrm{g} / \mathrm{s}]}\end{array}$} & \multirow{4}{*}{$\begin{array}{l}\text { Pot. } \\
{[\mathrm{kW}]}\end{array}$} \\
\hline & & & & & & $\mathrm{CO}$ & $\mathrm{CO} 2$ & $\mathrm{HC}$ & & \\
\hline & & & & & & & & & & \\
\hline & & {$\left[{ }^{\circ} \mathrm{APMS}\right]$} & {$\left[{ }^{\circ} \mathrm{C}\right]$} & {$\left[{ }^{\circ} \mathrm{C}\right]$} & {$[\mathrm{mmHg}]$} & {$[\%]$} & {$[\%]$} & [ppm] & & \\
\hline \multirow{5}{*}{ E100 } & 0,9 & 17,6 & 33,3 & 25,0 & 702,0 & 3,11 & 13,3 & 384 & 1,63 & 11,94 \\
\hline & 1 & 19,0 & 33,0 & 24,7 & 702,0 & 0,43 & 14,5 & 336 & 1,47 & 11,91 \\
\hline & 1,1 & 22,2 & 33,3 & 25,0 & 702,0 & 0,13 & 13,3 & 329 & 1,34 & 11,14 \\
\hline & 1,2 & 24,0 & 33,3 & 25,0 & 702,0 & 0,12 & 11,7 & 378 & 1,22 & 10,15 \\
\hline & 1,3 & 26,4 & 33,0 & 25,0 & 702,0 & 0,12 & 10,6 & 407 & 1,13 & 9,08 \\
\hline \multirow{5}{*}{ E70 } & 0,9 & 15,4 & 30,0 & 21,7 & 702,8 & 3,26 & 12,9 & 347 & 1,38 & 12,03 \\
\hline & 1 & 17,1 & 30,3 & 21,7 & 702,8 & 0,23 & 14,3 & 301 & 1,21 & 11,91 \\
\hline & 1,1 & 18,4 & 30,3 & 22,0 & 702,7 & 0,09 & 13,1 & 296 & 1,12 & 11,12 \\
\hline & 1,2 & 21,7 & 30,3 & 22,0 & 702,7 & 0,10 & 11,8 & 323 & 1,03 & 10,25 \\
\hline & 1,3 & 22,8 & 30,3 & 21,7 & 702,7 & 0,10 & 10,7 & 345 & 0,95 & 9,15 \\
\hline \multirow{5}{*}{ E56 } & 0,9 & 15,2 & 30,7 & 22,0 & 701,0 & 2,80 & 13,2 & 320 & 1,27 & 12,75 \\
\hline & 1 & 16,9 & 30,7 & 22,0 & 701,0 & 0,29 & 14,4 & 284 & 1,15 & 12,57 \\
\hline & 1,1 & 16,6 & 31,0 & 22,3 & 701,0 & 0,09 & 12,9 & 260 & 1,03 & 11,53 \\
\hline & 1,2 & 19,4 & 30,7 & 22,3 & 701,0 & 0,09 & 11,8 & 244 & 0,96 & 10,66 \\
\hline & 1,3 & 21,7 & 30,7 & 22,3 & 701,0 & 0,09 & 10,7 & 285 & 0,91 & 9,73 \\
\hline \multirow{5}{*}{ E26 } & 0,9 & 12,3 & 25,3 & 20,0 & 697,8 & 3,34 & 12,6 & 325 & 1,12 & 12,44 \\
\hline & 1 & 11,2 & 25,3 & 20,0 & 697,8 & 0,21 & 14,0 & 262 & 0,98 & 12,09 \\
\hline & 1,1 & 11,5 & 25,7 & 20,0 & 697,8 & 0,08 & 12,7 & 213 & 0,90 & 11,08 \\
\hline & 1,2 & 13,8 & 25,0 & 20,0 & 698,0 & 0,08 & 11,7 & 212 & 0,84 & 10,47 \\
\hline & 1,3 & 18,2 & 25,3 & 20,0 & 698,0 & 0,08 & 10,5 & 246 & 0,78 & 9,36 \\
\hline
\end{tabular}

Nota 1: avanço da centelha para o máximo torque (MBT)

Nota 2: dados apresentados referem-se as médias obtidas após a realização de três repetições

Nota 3: $\lambda$ corresponde ao fator $\lambda$ medido com a sonda lambda de banda larga WB-O2 
Tabela A4 - Dados coletados durante o experimento 1 a $3000 \mathrm{rpm}$, carga parcial e MBT.

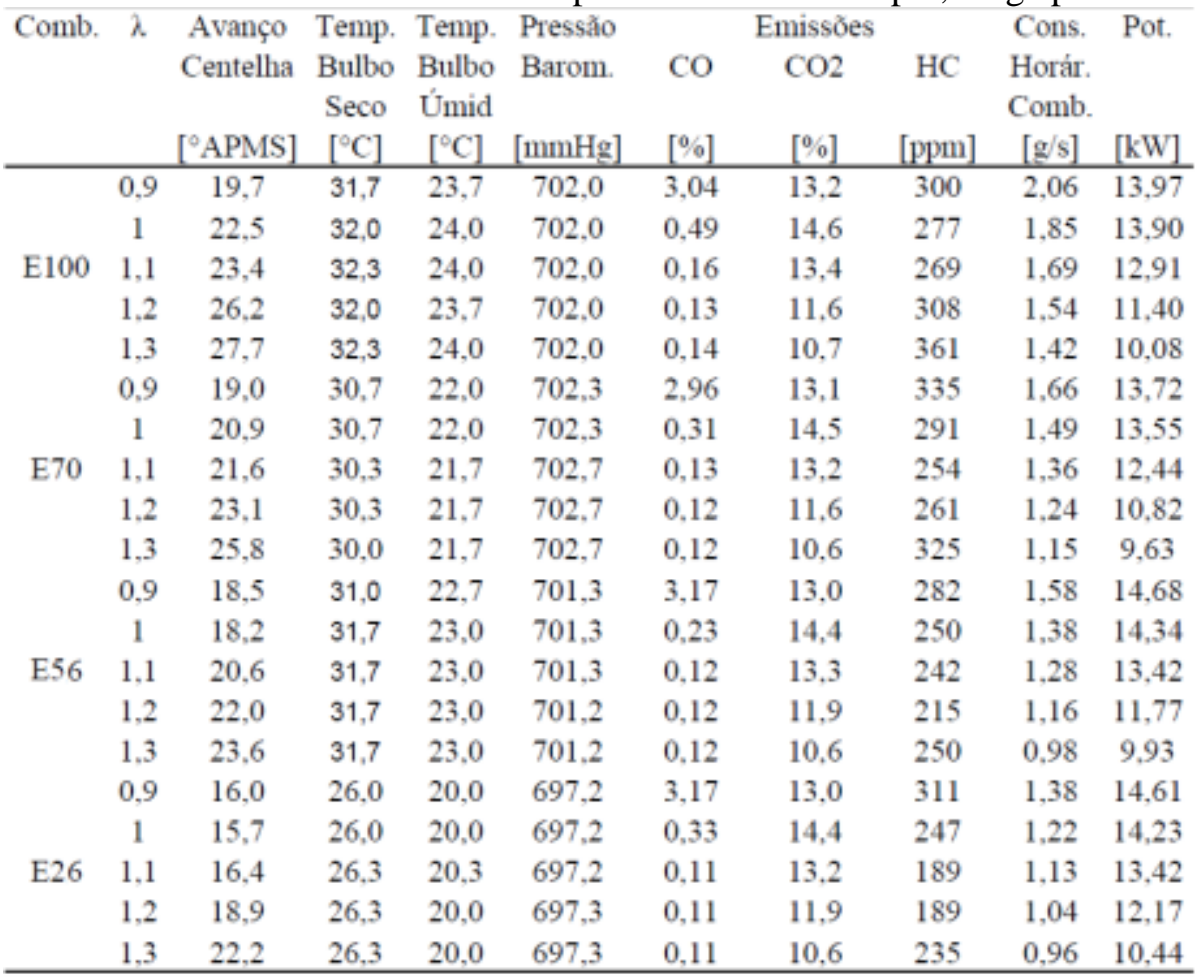

Nota 1: avanço da centelha para o máximo torque (MBT)

Nota 2: dados apresentados referem-se as médias obtidas após a realização de três repetiçð̃es

Nota $3: \lambda$ corresponde ao fator $\lambda$ medido com a sonda lambda de banda larga WB-O2

\section{A2. TABElas DAS ANÁlises ESTATísticas OBTIDAS PARA CADA VARIÁVEL DO MOTOR}

Tabela A5 - ANOVA da potência corrigida do motor (experimento 1: $2000 \mathrm{rpm}$, plena carga e MBT).

\begin{tabular}{lccccc} 
Fonte de variação & SQs & GL & MQs & F & F crítico \\
\hline Fator $\lambda$ & 118,92 & 4 & 29,73 & 641,86 & 2,61 \\
Tipo de & & & & & \\
combustível & 7,54 & 3 & 2,51 & 54,29 & 2,84 \\
Interação & 2,37 & 12 & 0,20 & 4,26 & 2,00 \\
Resíduo (erro) & 1,85 & 40 & 0,05 & & \\
Total & 130,69 & 59 & & & \\
\hline
\end{tabular}


Tabela A6 - Valores de potência corrigida do motor obtidos no experimento 1 a $2000 \mathrm{rpm}$, plena carga e MBT.

\begin{tabular}{|c|c|c|c|c|c|}
\hline \multicolumn{6}{|c|}{ Potência corrigida [kW] } \\
\hline \multirow[b]{2}{*}{ Fator $\lambda$} & \multirow{2}{*}{$\begin{array}{l}\text { Amostras, } \\
\text { médias e U }\end{array}$} & \multicolumn{4}{|c|}{ Tipo de combustível } \\
\hline & & E100 & E70 & E56 & E26 \\
\hline \multirow{5}{*}{0,9} & Am. 1 & 16,64 & 16,87 & 16,39 & 15,90 \\
\hline & Am. 2 & 17,02 & 16,86 & 16,92 & 15,80 \\
\hline & Am. 3 & 16,36 & 16,75 & 17,04 & 15,63 \\
\hline & Média & 16,67 & 16,83 & 16,78 & 15,78 \\
\hline & $\mathrm{U}$ & 0,83 & 0,17 & 0,86 & 0,34 \\
\hline \multirow{5}{*}{1} & Am. 1 & 16,48 & 16,87 & 16,39 & 15,82 \\
\hline & Am. 2 & 16,79 & 16,86 & 16,84 & 15,91 \\
\hline & Am. 3 & 16,24 & 16,73 & 17,03 & 15,53 \\
\hline & Média & 16,51 & 16,82 & 16,76 & 15,76 \\
\hline & $\mathrm{U}$ & 0,68 & 0,19 & 0,83 & 0,49 \\
\hline \multirow{5}{*}{1,1} & Am. 1 & 15,66 & 15,93 & 15,39 & 14,52 \\
\hline & Am. 2 & 15,75 & 15,93 & 16,01 & 14,50 \\
\hline & Am. 3 & 15,70 & 15,93 & 16,15 & 14,19 \\
\hline & Média & 15,70 & 15,93 & 15,85 & 14,40 \\
\hline & $\mathrm{U}$ & 0,11 & 0,01 & 1,00 & 0,45 \\
\hline \multirow{5}{*}{1,2} & Am. 1 & 14,48 & 14,55 & 13,88 & 13,70 \\
\hline & Am. 2 & 14,22 & 14,41 & 14,40 & 13,84 \\
\hline & Am. 3 & 14,20 & 14,29 & 14,49 & 13,58 \\
\hline & Média & 14,30 & 14,41 & 14,26 & 13,71 \\
\hline & $\mathrm{U}$ & 0,38 & 0,33 & 0,82 & 0,32 \\
\hline \multirow{5}{*}{1,3} & Am. 1 & 12,97 & 13,00 & 12,88 & 12,84 \\
\hline & Am. 2 & 12,67 & 12,98 & 12,70 & 12,80 \\
\hline & Am. 3 & 12,78 & 12,76 & 13,08 & 12,76 \\
\hline & Média & 12,81 & 12,91 & 12,88 & 12,80 \\
\hline & $\mathrm{U}$ & 0,37 & 0,33 & 0,47 & 0,10 \\
\hline
\end{tabular}


Tabela A7 - Resumo dos resultados obtidos com a aplicação do método SME - Tukey para a potência

\begin{tabular}{|c|c|c|}
\hline \multicolumn{3}{|c|}{$\begin{array}{c}\text { SME - Tukey - Potência cor., } 2000 \text { rpm, } 100 \% \text {, } \\
\text { MBT }\end{array}$} \\
\hline Nível I & \multicolumn{2}{|r|}{ E100 } \\
\hline Nível II & \multicolumn{2}{|r|}{ E70 } \\
\hline Nível III & \multicolumn{2}{|r|}{ E56 } \\
\hline Nível IV & \multicolumn{2}{|r|}{ E26 } \\
\hline Fator Lambda & Níveis & Diferem entre si \\
\hline \multirow{6}{*}{0,9} & I - II & Não \\
\hline & I -III & Não \\
\hline & I - IV & Sim \\
\hline & II - III & Não \\
\hline & II - IV & Sim \\
\hline & III - IV & Sim \\
\hline \multirow{6}{*}{1} & I - II & Não \\
\hline & I -III & Não \\
\hline & I - IV & Sim \\
\hline & II - III & Não \\
\hline & II - IV & Sim \\
\hline & III - IV & Sim \\
\hline \multirow{6}{*}{1,1} & I - II & Não \\
\hline & I -III & Não \\
\hline & I - IV & Sim \\
\hline & II - III & Não \\
\hline & II - IV & Sim \\
\hline & III - IV & Sim \\
\hline \multirow{6}{*}{1,2} & I - II & Não \\
\hline & I -III & Não \\
\hline & I - IV & Sim \\
\hline & II - III & Não \\
\hline & II - IV & Sim \\
\hline & III - IV & Sim \\
\hline \multirow{6}{*}{1,3} & I - II & Não \\
\hline & I -III & Não \\
\hline & I - IV & Não \\
\hline & II - III & Não \\
\hline & II - IV & Não \\
\hline & III - IV & Não \\
\hline
\end{tabular}


Tabela A8 - ANOVA da potência corrigida do motor (experimento 1: $3000 \mathrm{rpm}$, plena carga e MBT).

\begin{tabular}{lccccc}
\hline Fonte de variação & SQs & GL & MQs & F & F crítico \\
\hline Fator $\lambda$ & 345,66 & 4 & 86,42 & 1317,65 & 2,61 \\
Tipo de & & & & & \\
combustível & 41,75 & 3 & 13,92 & 212,22 & 2,84 \\
Interação & 8,03 & 12 & 0,67 & 10,20 & 2,00 \\
Resíduo (erro) & 2,62 & 40 & 0,07 & & \\
Total & 398,07 & 59 & & & \\
\hline
\end{tabular}

Tabela A9 - Valores de potência corrigida do motor obtidos no experimento 1 a 3000 rpm, plena carga e MBT.

\begin{tabular}{|c|c|c|c|c|c|}
\hline \multicolumn{6}{|c|}{ Potência corrigida [kW] } \\
\hline \multirow[b]{2}{*}{ Fator $\lambda$} & \multirow{2}{*}{$\begin{array}{l}\text { Amostras, } \\
\text { médias e U }\end{array}$} & \multicolumn{4}{|c|}{ Tipo de combustível } \\
\hline & & $\mathrm{E} 100$ & E70 & E56 & E26 \\
\hline \multirow{5}{*}{0,9} & Am. 1 & 26,55 & 25,96 & 25,58 & 25,09 \\
\hline & Am. 2 & 26,57 & 26,40 & 25,98 & 25,19 \\
\hline & Am. 3 & 26,33 & 26,22 & 26,15 & 24,98 \\
\hline & Média & 26,48 & 26,20 & 25,90 & 25,09 \\
\hline & $\mathrm{U}$ & 0,33 & 0,55 & 0,73 & 0,26 \\
\hline \multirow{5}{*}{1} & Am. 1 & 26,49 & 26,07 & 25,47 & 24,50 \\
\hline & Am. 2 & 26,20 & 25,73 & 25,71 & 24,65 \\
\hline & Am. 3 & 26,39 & 26,07 & 25,76 & 24,48 \\
\hline & Média & 26,36 & 25,96 & 25,64 & 24,54 \\
\hline & $\mathrm{U}$ & 0,36 & 0,49 & 0,39 & 0,23 \\
\hline \multirow{5}{*}{1,1} & Am. 1 & 25,34 & 24,27 & 24,05 & 22,08 \\
\hline & Am. 2 & 24,61 & 23,86 & 23,91 & 22,33 \\
\hline & Am. 3 & 25,26 & 24,07 & 23,77 & 22,00 \\
\hline & Média & 25,07 & 24,07 & 23,91 & 22,13 \\
\hline & $\mathrm{U}$ & 1,00 & 0,51 & 0,36 & 0,43 \\
\hline \multirow{5}{*}{1,2} & Am. 1 & 22,92 & 22,33 & 21,93 & 19,19 \\
\hline & Am. 2 & 21,95 & 21,51 & 21,98 & 19,05 \\
\hline & Am. 3 & 23,08 & 22,26 & 21,96 & 18,90 \\
\hline & Média & 22,65 & 22,03 & 21,96 & 19,04 \\
\hline & $\mathrm{U}$ & 1,52 & 1,13 & 0,05 & 0,36 \\
\hline \multirow{5}{*}{1,3} & Am. 1 & 20,65 & 19,54 & 20,14 & 18,85 \\
\hline & Am. 2 & 19,98 & 19,47 & 20,31 & 18,79 \\
\hline & Am. 3 & 20,17 & 19,94 & 20,15 & 18,71 \\
\hline & Média & 20,27 & 19,65 & 20,20 & 18,79 \\
\hline & $\mathrm{U}$ & 0,86 & 0,63 & 0,24 & 0,18 \\
\hline
\end{tabular}


Tabela A10 - Resumo dos resultados obtidos com a aplicação do método SME - Tukey para a potência

\begin{tabular}{|c|c|c|}
\hline \multicolumn{3}{|c|}{$\begin{array}{c}\text { SME - Tukey - Potência cor., } 3000 \text { rpm, 100\%, } \\
\text { MBT }\end{array}$} \\
\hline Nível I & \multicolumn{2}{|r|}{ E100 } \\
\hline Nível II & \multicolumn{2}{|r|}{ E70 } \\
\hline Nível III & \multicolumn{2}{|r|}{ E56 } \\
\hline Nível IV & \multicolumn{2}{|r|}{ E26 } \\
\hline Fator Lambda & Níveis & Diferem entre si \\
\hline \multirow{6}{*}{0,9} & I - II & Não \\
\hline & I -III & Sim \\
\hline & I - IV & Sim \\
\hline & II - III & Não \\
\hline & II - IV & Sim \\
\hline & III - IV & Sim \\
\hline \multirow{6}{*}{1} & I - II & Sim \\
\hline & I -III & Sim \\
\hline & I - IV & Sim \\
\hline & II - III & Não \\
\hline & II - IV & Sim \\
\hline & III - IV & Sim \\
\hline \multirow{6}{*}{1,1} & I - II & Sim \\
\hline & I -III & Sim \\
\hline & I - IV & Sim \\
\hline & II - III & Não \\
\hline & II - IV & Sim \\
\hline & III - IV & Sim \\
\hline \multirow{6}{*}{1,2} & I - II & Não \\
\hline & I -III & Não \\
\hline & I - IV & Sim \\
\hline & II - III & Não \\
\hline & II - IV & Sim \\
\hline & III - IV & Sim \\
\hline \multirow{6}{*}{1,3} & I - II & Sim \\
\hline & I -III & Não \\
\hline & I - IV & Sim \\
\hline & II - III & Não \\
\hline & II - IV & Sim \\
\hline & III - IV & Sim \\
\hline
\end{tabular}


Tabela A11 - ANOVA do consumo específico do motor (experimento 1: $2000 \mathrm{rpm}$, plena carga e MBT).

\begin{tabular}{lccccc}
\hline Fonte de variação & SQs & GL & MQs & F & F crítico \\
\hline Fator $\lambda$ & 19053,69 & 4 & 4763,42 & 352,48 & 2,61 \\
Tipo de & & & & & \\
combustível & 117429,96 & 3 & 39143,32 & 2896,51 & 2,84 \\
Interação & 1097,77 & 12 & 91,48 & 6,77 & 2,00 \\
Resíduo (erro) & 540,56 & 40 & 13,51 & & \\
Total & 138121,98 & 59 & & & \\
\hline
\end{tabular}

Tabela A12 - Valores de consumo horário do motor obtidos no experimento 1 a 2000 rpm, plena carga e MBT.

\begin{tabular}{|c|c|c|c|c|c|}
\hline \multicolumn{6}{|c|}{ Consumo horário $[\mathrm{g} / \mathrm{h}]$} \\
\hline \multirow[b]{2}{*}{ Fator $\lambda$} & \multirow{2}{*}{$\begin{array}{l}\text { Amostras, } \\
\text { médias e U }\end{array}$} & \multicolumn{4}{|c|}{ Tipo de combustível } \\
\hline & & E100 & E70 & E56 & E26 \\
\hline \multirow{5}{*}{0,9} & Am. 1 & 7612,8 & 6424,1 & 5669,3 & 5184,6 \\
\hline & Am. 2 & 7614,3 & 6280,8 & 5841,2 & 5222,7 \\
\hline & Am. 3 & 7433,5 & 6307,0 & 5884,0 & 5159,3 \\
\hline & Média & 7553,6 & 6337,3 & 5798,2 & 5188,9 \\
\hline & $\mathrm{U}$ & 258,1 & 189,5 & 282,1 & 79,3 \\
\hline \multirow{5}{*}{1} & Am. 1 & 6782,4 & 5713,6 & 5050,2 & 4596,4 \\
\hline & Am. 2 & 6813,9 & 5589,9 & 5118,9 & 4563,1 \\
\hline & Am. 3 & 6640,0 & 5594,8 & 5215,7 & 4577,6 \\
\hline & Média & 6745,4 & 5632,7 & 5128,2 & 4579,0 \\
\hline & $\mathrm{U}$ & 230,0 & 173,9 & & 41,5 \\
\hline \multirow{5}{*}{1,1} & Am. 1 & 6222,1 & 5237,3 & 4766,2 & 4175,4 \\
\hline & Am. 2 & 6245,5 & 5135,4 & 4807,1 & 4140,0 \\
\hline & Am. 3 & 6125,3 & 5157,4 & 4877,3 & 4128,8 \\
\hline & Média & 6197,6 & 5176,7 & 4816,9 & 4148,1 \\
\hline & $\mathrm{U}$ & 158,2 & 133,1 & 139,6 & 60,3 \\
\hline \multirow{5}{*}{1,2} & Am. 1 & 5738,5 & 4775,4 & 4356,0 & 3947,6 \\
\hline & Am. 2 & 5694,9 & 4695,4 & 4372,8 & 3947,7 \\
\hline & Am. 3 & 5575,3 & 4703,6 & 4417,1 & 3865,0 \\
\hline & Média & 5669,5 & 4724,8 & 4382,0 & 3920,1 \\
\hline & $\mathrm{U}$ & 209,7 & 109,2 & 78,4 & 118,5 \\
\hline \multirow{5}{*}{1,3} & Am. 1 & 5280,3 & 4445,9 & 4160,6 & 3600,0 \\
\hline & Am. 2 & 5236,5 & 4381,6 & 4044,4 & 3572,3 \\
\hline & Am. 3 & 5149,1 & 4362,2 & 4078,5 & 3568,0 \\
\hline & Média & 5222,0 & 4396,5 & 4094,5 & 3580,1 \\
\hline & $\mathrm{U}$ & 165,9 & 108,8 & 148,3 & 43,0 \\
\hline
\end{tabular}


Tabela A13 - Valores de consumo específico do motor obtidos no experimento 1 a 2000 rpm, plena carga e MBT.

\begin{tabular}{|c|c|c|c|c|c|}
\hline \multicolumn{6}{|c|}{ Consumo específico $[\mathrm{g} / \mathrm{kWh}]$} \\
\hline \multirow[b]{2}{*}{ Fator $\lambda$} & \multirow{2}{*}{$\begin{array}{l}\text { Amostras, } \\
\text { médias e U }\end{array}$} & \multicolumn{4}{|c|}{ Tipo de combustível } \\
\hline & & $\mathrm{E} 100$ & E70 & E56 & E26 \\
\hline \multirow{5}{*}{0,9} & Am. 1 & 457,6 & 380,8 & 345,9 & 326,0 \\
\hline & Am. 2 & 447,3 & 372,6 & 345,2 & 330,6 \\
\hline & Am. 3 & 454,4 & 376,6 & 345,3 & 330,1 \\
\hline & Média & 453,1 & 376,6 & 345,4 & 328,9 \\
\hline & $\mathrm{U}$ & 13,0 & 10,2 & 0,9 & 6,3 \\
\hline \multirow{5}{*}{1} & Am. 1 & 411,5 & 338,8 & 308,2 & 290,5 \\
\hline & Am. 2 & 405,8 & 331,5 & 303,9 & 286,8 \\
\hline & Am. 3 & 408,8 & 334,3 & 306,2 & 294,7 \\
\hline & Média & 408,7 & 334,8 & 306,1 & 290,7 \\
\hline & $\mathrm{U}$ & 7,1 & 9,1 & 5,3 & 9,8 \\
\hline \multirow{5}{*}{1,1} & Am. 1 & 397,4 & 328,9 & 309,7 & 287,6 \\
\hline & Am. 2 & 396,6 & 322,4 & 300,2 & 285,5 \\
\hline & Am. 3 & 390,1 & 323,8 & 302,1 & 290,9 \\
\hline & Média & 394,7 & 325,0 & 304,0 & 288,0 \\
\hline & $\mathrm{U}$ & 9,9 & 8,5 & 12,4 & 6,7 \\
\hline \multirow{5}{*}{1,2} & Am. 1 & 396,4 & 328,3 & 313,9 & 288,1 \\
\hline & Am. 2 & 400,4 & 325,9 & 303,6 & 285,2 \\
\hline & Am. 3 & 392,6 & 329,3 & 304,9 & 284,5 \\
\hline & Média & 396,5 & 327,8 & 307,5 & 285,9 \\
\hline & $\mathrm{U}$ & 9,7 & 4,2 & 13,9 & 4,7 \\
\hline \multirow{5}{*}{1,3} & Am. 1 & 407,1 & 341,9 & 323,0 & 280,3 \\
\hline & Am. 2 & 413,2 & 337,6 & 318,6 & 279,0 \\
\hline & Am. 3 & 402,9 & 341,9 & 311,9 & 279,6 \\
\hline & Média & 407,8 & 340,5 & 317,8 & 279,7 \\
\hline & $\mathrm{U}$ & 12,9 & 6,2 & 13,8 & 1,7 \\
\hline
\end{tabular}


Tabela A14 - Resumo dos resultados obtidos com a aplicação do método SME - Tukey para consumo

\begin{tabular}{|c|c|c|}
\hline \multicolumn{3}{|c|}{$\begin{array}{l}\text { SME - Tukey - Consumo específico, } 2000 \mathrm{rpm} \text {, } \\
100 \%, \text { MBT }\end{array}$} \\
\hline Nível I & \multicolumn{2}{|r|}{ E100 } \\
\hline Nível II & \multicolumn{2}{|r|}{ E70 } \\
\hline Nível III & \multicolumn{2}{|r|}{ E56 } \\
\hline Nível IV & \multicolumn{2}{|r|}{ E26 } \\
\hline Fator Lambda & Níveis & Diferem entre si \\
\hline \multirow{6}{*}{0,9} & I - II & Sim \\
\hline & I -III & Sim \\
\hline & I - IV & Sim \\
\hline & II - III & Sim \\
\hline & II - IV & Sim \\
\hline & III - IV & Sim \\
\hline \multirow{6}{*}{1} & I - II & Sim \\
\hline & I -III & Sim \\
\hline & I - IV & Sim \\
\hline & II - III & Sim \\
\hline & II - IV & Sim \\
\hline & III - IV & Sim \\
\hline \multirow{6}{*}{1,1} & I - II & Sim \\
\hline & I -III & Sim \\
\hline & I - IV & Sim \\
\hline & II - III & Sim \\
\hline & II - IV & Sim \\
\hline & III - IV & Sim \\
\hline \multirow{6}{*}{1,2} & I - II & Sim \\
\hline & I -III & Sim \\
\hline & I - IV & Sim \\
\hline & II - III & Sim \\
\hline & II - IV & Sim \\
\hline & III - IV & Sim \\
\hline \multirow{6}{*}{1,3} & I - II & Sim \\
\hline & I -III & Sim \\
\hline & I - IV & Sim \\
\hline & II - III & Sim \\
\hline & II - IV & Sim \\
\hline & III - IV & Sim \\
\hline
\end{tabular}


Tabela A15 - ANOVA do consumo específico do motor (experimento 1: $3000 \mathrm{rpm}$, plena carga e MBT)

\begin{tabular}{lccccc}
\hline Fonte de variação & SQs & GL & MQs & F & F crítico \\
\hline Fator $\lambda$ & 13739,46 & 4 & 3434,86 & 143,73 & 2,61 \\
Tipo de & & & & & \\
combustível & 98315,00 & 3 & 32771,67 & 1371,28 & 2,84 \\
Interação & 1915,45 & 12 & 159,62 & 6,68 & 2,00 \\
Resíduo (erro) & 955,95 & 40 & 23,90 & & \\
Total & 114925,85 & 59 & & & \\
\hline
\end{tabular}

Tabela A16 - Valores de consumo horário do motor obtidos no experimento 1 a 3000 rpm, plena carga e MBT.

\begin{tabular}{|c|c|c|c|c|c|}
\hline \multicolumn{6}{|c|}{ Consumo horário $[\mathrm{g} / \mathrm{h}]$} \\
\hline \multirow[b]{2}{*}{ Fator $\lambda$} & \multirow{2}{*}{$\begin{array}{l}\text { Amostras, } \\
\text { médias e U }\end{array}$} & \multicolumn{4}{|c|}{ Tipo de combustível } \\
\hline & & E100 & E70 & E56 & E26 \\
\hline \multirow{5}{*}{0,9} & Am. 1 & 11587,9 & 9669,1 & 8725,0 & 7868,2 \\
\hline & Am. 2 & 11717,5 & 9575,6 & 8886,5 & 7884,2 \\
\hline & Am. 3 & 11587,5 & 9644,0 & 8943,4 & 7853,8 \\
\hline & Média & 11631,0 & 9629,6 & 8851,7 & 7868,7 \\
\hline & $\mathrm{U}$ & 186,0 & 120,1 & 281,2 & 37,8 \\
\hline \multirow{5}{*}{1} & Am. 1 & 10495,0 & 8624,4 & 7855,9 & 6937,3 \\
\hline & Am. 2 & 10481,6 & 8540,3 & 7880,0 & 6962,1 \\
\hline & Am. 3 & 10496,7 & 8575,6 & 7861,1 & 6921,8 \\
\hline & Média & 10491,1 & 8580,1 & 7865,7 & 6940,4 \\
\hline & $\mathrm{U}$ & 20,5 & 104,8 & 31,5 & 50,6 \\
\hline \multirow{5}{*}{1,1} & Am. 1 & 9582,3 & 7952,2 & 7176,8 & 6240,9 \\
\hline & Am. 2 & 9587,0 & 7885,2 & 7183,5 & 6256,2 \\
\hline & Am. 3 & 9527,3 & 7899,7 & 7178,5 & 6229,6 \\
\hline & Média & 9565,6 & 7912,4 & 7179,6 & 6242,2 \\
\hline & $\mathrm{U}$ & 82,4 & 87,6 & 8,7 & 33,1 \\
\hline \multirow{5}{*}{1,2} & Am. 1 & 8701,1 & 7258,9 & 6628,7 & 5744,1 \\
\hline & Am. 2 & 8726,9 & 7184,7 & 6646,6 & 5728,1 \\
\hline & Am. 3 & 8629,4 & 7193,9 & 6674,7 & 5714,5 \\
\hline & Média & 8685,8 & 7212,5 & 6650,0 & 5728,9 \\
\hline & $\mathrm{U}$ & 125,4 & 100,4 & 57,5 & 36,7 \\
\hline \multirow{5}{*}{1,3} & Am. 1 & 8004,7 & 6734,6 & 6132,7 & 5390,3 \\
\hline & Am. 2 & 8233,5 & 6682,1 & 6152,1 & 5381,3 \\
\hline & Am. 3 & 7926,1 & 6694,1 & 6179,5 & 5385,6 \\
\hline & Média & 8054,8 & 6703,6 & 6154,8 & 5385,7 \\
\hline & $\mathrm{U}$ & 396,5 & 68,2 & 58,3 & 11,2 \\
\hline
\end{tabular}


Tabela A17 - Valores de consumo específico do motor obtidos no experimento 1 a $3000 \mathrm{rpm}$, plena carga e MBT.

\begin{tabular}{|c|c|c|c|c|c|}
\hline \multicolumn{6}{|c|}{ Consumo específico $[\mathrm{g} / \mathrm{kWh}]$} \\
\hline \multirow[b]{2}{*}{ Fator $\lambda$} & \multirow{2}{*}{$\begin{array}{l}\text { Amostras, } \\
\text { médias e U }\end{array}$} & \multicolumn{4}{|c|}{ Tipo de combustível } \\
\hline & & E100 & E70 & E56 & E26 \\
\hline \multirow{5}{*}{0,9} & Am. 1 & 436,5 & 372,4 & 341,1 & 313,6 \\
\hline & Am. 2 & 441,1 & 362,7 & 342,0 & 312,9 \\
\hline & Am. 3 & 440,1 & 367,8 & 342,0 & 314,4 \\
\hline & Média & 439,2 & 367,6 & 341,7 & 313,7 \\
\hline & $\mathrm{U}$ & 6,1 & 12,1 & 1,3 & 1,8 \\
\hline \multirow{5}{*}{1} & Am. 1 & 396,2 & 330,8 & 308,5 & 283,2 \\
\hline & Am. 2 & 400,1 & 332,0 & 306,5 & 282,5 \\
\hline & Am. 3 & 397,7 & 329,0 & 305,2 & 282,7 \\
\hline & Média & 398,0 & 330,6 & 306,7 & 282,8 \\
\hline & $\mathrm{U}$ & 4,8 & 3,7 & 4,1 & 0,9 \\
\hline \multirow{5}{*}{1,1} & Am. 1 & 378,2 & 327,7 & 298,4 & 282,7 \\
\hline & Am. 2 & 389,6 & 330,5 & 300,4 & 280,2 \\
\hline & Am. 3 & 377,1 & 328,2 & 302,0 & 283,2 \\
\hline & Média & 381,6 & 328,8 & 300,3 & 282,0 \\
\hline & $\mathrm{U}$ & 17,2 & 3,7 & 4,6 & 4,0 \\
\hline \multirow{5}{*}{1,2} & Am. 1 & 379,6 & 325,1 & 302,2 & 299,4 \\
\hline & Am. 2 & 397,6 & 334,0 & 302,4 & 300,7 \\
\hline & Am. 3 & 373,9 & 323,2 & 303,9 & 302,4 \\
\hline & Média & 383,7 & 327,4 & 302,9 & 300,8 \\
\hline & $\mathrm{U}$ & 30,7 & 14,4 & 2,3 & 3,7 \\
\hline \multirow{5}{*}{1,3} & Am. 1 & 387,6 & 344,6 & 304,5 & 285,9 \\
\hline & Am. 2 & 412,1 & 343,2 & 302,9 & 286,4 \\
\hline & Am. 3 & 393,0 & 335,7 & 306,7 & 287,8 \\
\hline & Média & 397,6 & 341,1 & 304,7 & 286,7 \\
\hline & $\mathrm{U}$ & 32,0 & 11,9 & 4,7 & 2,5 \\
\hline
\end{tabular}


Tabela A18 - Resumo dos resultados obtidos com a aplicação do método SME - Tukey para o consumo específico do experimento 1 (3000 rpm, plena carga e MBT).

\begin{tabular}{|c|c|c|}
\hline \multicolumn{3}{|c|}{$\begin{array}{c}\text { SME - Tukey - Consumo específico, } 3000 \mathrm{rpm} \text {, } \\
100 \%, \text { MBT }\end{array}$} \\
\hline Nível I & \multicolumn{2}{|r|}{ E100 } \\
\hline Nível II & \multicolumn{2}{|r|}{ E70 } \\
\hline Nível III & \multicolumn{2}{|r|}{ E56 } \\
\hline Nível IV & \multicolumn{2}{|r|}{ E26 } \\
\hline Fator Lambda & Níveis & Diferem entre si \\
\hline \multirow{6}{*}{0,9} & I - II & Sim \\
\hline & I -III & Sim \\
\hline & I - IV & Sim \\
\hline & II - III & Sim \\
\hline & II - IV & Sim \\
\hline & III - IV & Sim \\
\hline \multirow{6}{*}{1} & I - II & Sim \\
\hline & I -III & Sim \\
\hline & I - IV & Sim \\
\hline & II - III & Sim \\
\hline & II - IV & Sim \\
\hline & III - IV & Sim \\
\hline \multirow{6}{*}{1,1} & I - II & Sim \\
\hline & I -III & Sim \\
\hline & I - IV & Sim \\
\hline & II - III & Sim \\
\hline & II - IV & Sim \\
\hline & III - IV & Sim \\
\hline \multirow{6}{*}{1,2} & I - II & Sim \\
\hline & I -III & Sim \\
\hline & I - IV & Sim \\
\hline & II - III & Sim \\
\hline & II - IV & Sim \\
\hline & III - IV & Não \\
\hline \multirow{6}{*}{1,3} & I - II & Sim \\
\hline & I -III & Sim \\
\hline & I - IV & Sim \\
\hline & II - III & Sim \\
\hline & II - IV & Sim \\
\hline & III - IV & Não \\
\hline
\end{tabular}


Tabela A19 - ANOVA da eficiência de conversão de combustível (experimento 1: 2000 rpm, plena carga e MBT).

\begin{tabular}{lccccc}
\hline Fonte de variação & SQs & GL & MQs & F & F crítico \\
\hline Fator $\lambda$ & 0,017 & 4 & 0,00434 & 299,79 & 2,61 \\
Tipo de & & & & & \\
combustível & 0,019 & 3 & 0,00631 & 435,54 & 2,84 \\
Interação & 0,001 & 12 & 0,00009 & 6,00 & 2,00 \\
Resíduo (erro) & 0,001 & 40 & 0,00001 & & \\
Total & 0,038 & 59 & & & \\
\hline
\end{tabular}

Tabela A20 - Valores de eficiência de conversão de combustível do motor obtidos no experimento 1 a 2000 rpm, plena carga e MBT.

\begin{tabular}{|c|c|c|c|c|c|}
\hline \multicolumn{6}{|c|}{ Eficiência de conversão de combustível } \\
\hline \multirow[b]{2}{*}{ Fator $\lambda$} & \multirow{2}{*}{$\begin{array}{l}\text { Amostras, } \\
\text { médias e U }\end{array}$} & \multicolumn{4}{|c|}{ Tipo de combustível } \\
\hline & & E100 & E70 & E56 & E26 \\
\hline \multirow{5}{*}{0,9} & Am. 1 & 0,314 & 0,326 & 0,329 & 0,288 \\
\hline & Am. 2 & 0,321 & 0,333 & 0,330 & 0,284 \\
\hline & Am. 3 & 0,316 & 0,329 & 0,330 & 0,284 \\
\hline & Média & 0,317 & 0,329 & 0,330 & 0,285 \\
\hline & $\mathrm{U}$ & 0,009 & 0,009 & 0,001 & 0,005 \\
\hline \multirow{5}{*}{1} & Am. 1 & 0,349 & 0,366 & 0,370 & 0,323 \\
\hline & Am. 2 & 0,354 & 0,374 & 0,375 & 0,327 \\
\hline & Am. 3 & 0,351 & 0,371 & 0,372 & 0,318 \\
\hline & Média & 0,351 & 0,370 & 0,372 & 0,323 \\
\hline & $\mathrm{U}$ & 0,006 & 0,010 & 0,007 & 0,011 \\
\hline \multirow{5}{*}{1,1} & Am. 1 & 0,361 & 0,377 & 0,368 & 0,326 \\
\hline & Am. 2 & 0,362 & 0,385 & 0,379 & 0,329 \\
\hline & Am. 3 & 0,368 & 0,383 & 0,377 & 0,323 \\
\hline & Média & 0,364 & 0,382 & 0,375 & 0,326 \\
\hline & $\mathrm{U}$ & 0,009 & 0,010 & 0,015 & 0,008 \\
\hline \multirow{5}{*}{1,2} & Am. 1 & 0,362 & 0,378 & 0,363 & 0,326 \\
\hline & Am. 2 & 0,358 & 0,380 & 0,375 & 0,329 \\
\hline & Am. 3 & 0,365 & 0,377 & 0,374 & 0,330 \\
\hline & Média & 0,362 & 0,378 & 0,371 & 0,328 \\
\hline & $\mathrm{U}$ & 0,009 & 0,005 & 0,017 & 0,005 \\
\hline \multirow{5}{*}{1,3} & Am. 1 & 0,352 & 0,363 & 0,353 & 0,335 \\
\hline & Am. 2 & 0,347 & 0,367 & 0,358 & 0,336 \\
\hline & Am. 3 & 0,356 & 0,363 & 0,365 & 0,336 \\
\hline & Média & 0,352 & 0,364 & 0,359 & 0,336 \\
\hline & $\mathrm{U}$ & 0,011 & 0,007 & 0,016 & 0,002 \\
\hline
\end{tabular}


Tabela A21 - Resumo dos resultados obtidos com a aplicação do método SME - Tukey para a eficiência de conversão de combustível do experimento 1 ( $2000 \mathrm{rpm}$, plena carga e MBT).

\begin{tabular}{cc}
\hline Tukey - Ef. de conv. de comb, 2000 r \\
MBT \\
Nível I & E100 \\
Nível II & E70 \\
Nível III & E56 \\
Nível IV & E26
\end{tabular}

\begin{tabular}{ccc} 
Fator Lambda & Níveis & Diferem entre si \\
\hline \multirow{4}{*}{0,9} & I - II & Sim \\
& I - III & Sim \\
& I - IV & Sim \\
& II - III & Não \\
& II - IV & Sim \\
& III - IV & Sim \\
& I - II & Sim \\
& I - III & Sim \\
& I - IV & Sim \\
& II - III & Não \\
& II - IV & Sim \\
& III - IV & Sim \\
& I - II & Sim \\
& I - III & Não \\
& I - IV & Sim \\
& II - III & Não \\
& II - IV & Sim \\
& III - IV & Sim \\
& I - II & Sim \\
& I - III & Não \\
& I - IV & Sim \\
& II - III & Não \\
& II - IV & Sim \\
& III - IV & Sim \\
& I - II & Sim \\
& I - III & Não \\
& I - IV & Sim \\
& II - III & Não \\
& II - IV & Sim \\
& III - IV & Sim \\
& & \\
& & \\
& &
\end{tabular}


Tabela A22 - ANOVA da eficiência de conversão de combustível (experimento 1: 3000 rpm, plena carga e MBT).

\begin{tabular}{lccccc}
\hline Fonte de variação & SQs & GL & MQs & F & F crítico \\
\hline Fator $\lambda$ & 0,0134 & 4 & 0,00336 & 150,44 & 2,61 \\
Tipo de & & & & & \\
combustível & 0,0220 & 3 & 0,00732 & 327,78 & 2,84 \\
Interação & 0,0017 & 12 & 0,00014 & 6,45 & 2,00 \\
Resíduo (erro) & 0,0009 & 40 & 0,00002 & & \\
Total & 0,0380 & 59 & & & \\
\hline
\end{tabular}

Tabela A23 - Valores de eficiência de conversão de combustível do motor obtidos no experimento 1 a $3000 \mathrm{rpm}$, plena carga e MBT.

\begin{tabular}{|c|c|c|c|c|c|}
\hline \multicolumn{6}{|c|}{ Eficiência de conversão de combustível } \\
\hline \multirow[b]{2}{*}{ Fator $\lambda$} & \multirow{2}{*}{$\begin{array}{l}\text { Amostras, } \\
\text { médias e U }\end{array}$} & \multicolumn{4}{|c|}{ Tipo de combustível } \\
\hline & & E100 & E70 & E56 & E26 \\
\hline \multirow{5}{*}{0,9} & Am. 1 & 0,329 & 0,333 & 0,334 & 0,299 \\
\hline & Am. 2 & 0,325 & 0,342 & 0,333 & 0,300 \\
\hline & Am. 3 & 0,326 & 0,337 & 0,333 & 0,299 \\
\hline & Média & 0,327 & 0,337 & 0,333 & 0,299 \\
\hline & $\mathrm{U}$ & 0,005 & 0,011 & 0,001 & 0,002 \\
\hline \multirow{5}{*}{1} & Am. 1 & 0,362 & 0,375 & 0,369 & 0,331 \\
\hline & Am. 2 & 0,359 & 0,374 & 0,372 & 0,332 \\
\hline & Am. 3 & 0,361 & 0,377 & 0,373 & 0,332 \\
\hline & Média & 0,361 & 0,375 & 0,371 & 0,332 \\
\hline & $\mathrm{U}$ & 0,004 & 0,004 & 0,005 & 0,001 \\
\hline \multirow{5}{*}{1,1} & Am. 1 & 0,379 & 0,378 & 0,382 & 0,332 \\
\hline & Am. 2 & 0,368 & 0,375 & 0,379 & 0,335 \\
\hline & Am. 3 & 0,380 & 0,378 & 0,377 & 0,331 \\
\hline & Média & 0,376 & 0,377 & 0,379 & 0,333 \\
\hline & $\mathrm{U}$ & 0,017 & 0,004 & 0,006 & 0,005 \\
\hline \multirow{5}{*}{1,2} & Am. 1 & 0,378 & 0,381 & 0,377 & 0,313 \\
\hline & Am. 2 & 0,361 & 0,371 & 0,377 & 0,312 \\
\hline & Am. 3 & 0,384 & 0,384 & 0,375 & 0,310 \\
\hline & Média & 0,374 & 0,379 & 0,376 & 0,312 \\
\hline & $\mathrm{U}$ & 0,029 & 0,016 & 0,003 & 0,004 \\
\hline \multirow{5}{*}{1,3} & Am. 1 & 0,370 & 0,360 & 0,374 & 0,328 \\
\hline & Am. 2 & 0,348 & 0,361 & 0,376 & 0,328 \\
\hline & Am. 3 & 0,365 & 0,369 & 0,371 & 0,326 \\
\hline & Média & 0,361 & 0,364 & 0,374 & 0,327 \\
\hline & $\mathrm{U}$ & 0,029 & 0,013 & 0,006 & 0,003 \\
\hline
\end{tabular}


Tabela A24 - Resumo dos resultados obtidos com a aplicação do método SME - Tukey para a eficiência de conversão de combustível do experimento 1 (3000 rpm, plena carga e MBT).

\begin{tabular}{|c|c|c|}
\hline \multicolumn{3}{|c|}{$\begin{array}{c}\text { SME -Tukey - Ef. de conv. de comb, } 3000 \mathrm{rpm} \text {, } \\
100 \%, \text { MBT }\end{array}$} \\
\hline Nível I & \multicolumn{2}{|c|}{ E100 } \\
\hline Nível II & \multicolumn{2}{|c|}{ E70 } \\
\hline Nível III & \multicolumn{2}{|c|}{ E56 } \\
\hline Nível IV & \multicolumn{2}{|c|}{ E26 } \\
\hline Fator Lambda & Níveis & Diferem entre si \\
\hline \multirow{6}{*}{0,9} & I - II & Sim \\
\hline & I -III & Sim \\
\hline & I - IV & Sim \\
\hline & II - III & Não \\
\hline & II - IV & Sim \\
\hline & III - IV & Sim \\
\hline \multirow{6}{*}{1} & I - II & Sim \\
\hline & I -III & Sim \\
\hline & I - IV & Sim \\
\hline & II - III & Não \\
\hline & II - IV & Sim \\
\hline & III - IV & Sim \\
\hline \multirow{6}{*}{1,1} & I - II & Não \\
\hline & I -III & Não \\
\hline & I - IV & Sim \\
\hline & II - III & Não \\
\hline & II - IV & Sim \\
\hline & III - IV & Sim \\
\hline \multirow{6}{*}{1,2} & I - II & Não \\
\hline & I -III & Não \\
\hline & I - IV & Sim \\
\hline & II - III & Não \\
\hline & I I - IV & Sim \\
\hline & III IV & Sim \\
\hline \multirow{6}{*}{1,3} & I - II & Não \\
\hline & I -III & Não \\
\hline & I - IV & Sim \\
\hline & I I - III & Não \\
\hline & II - IV & Sim \\
\hline & III - IV & Sim \\
\hline
\end{tabular}


Tabela A25 - ANOVA da emissão de $C O$ (experimento 1: $2000 \mathrm{rpm}$, plena carga e MBT).

\begin{tabular}{lccccc}
\hline Fonte de variação & SQs & GL & MQs & F & F crítico \\
\hline $\begin{array}{l}\text { Fator } \lambda \\
\text { Tipo de }\end{array}$ & 87,16 & 4 & 21,79 & 4338,95 & 2,61 \\
combustível & 0,07 & 3 & 0,02 & 4,37 & 2,84 \\
Interação & 0,13 & 12 & 0,01 & 2,10 & 2,00 \\
Resíduo (erro) & 0,20 & 40 & 0,01 & & \\
Total & 87,55 & 59 & & & \\
\hline
\end{tabular}

Tabela A26 - Valores de emissão de $C O$ obtidos no experimento 1 a 2000 rpm, plena carga e MBT.

\begin{tabular}{|c|c|c|c|c|c|}
\hline \multicolumn{6}{|c|}{$\mathrm{CO}[\%]$} \\
\hline \multirow[b]{2}{*}{ Fator $\lambda$} & \multirow{2}{*}{$\begin{array}{l}\text { Amostras, } \\
\text { médias e U }\end{array}$} & \multicolumn{4}{|c|}{ Tipo de combustível } \\
\hline & & E100 & E70 & E56 & E26 \\
\hline \multirow{5}{*}{0,9} & Am. 1 & 2,97 & 3,30 & 3,07 & 3,09 \\
\hline & Am. 2 & 3,35 & 3,24 & 3,06 & 3,01 \\
\hline & Am. 3 & 2,91 & 3,46 & 3,13 & 3,27 \\
\hline & Média & 3,08 & 3,33 & 3,09 & 3,12 \\
\hline & $\mathrm{U}$ & 0,59 & 0,28 & 0,09 & 0,33 \\
\hline \multirow{5}{*}{1} & Am. 1 & 0,33 & 0,36 & 0,19 & 0,32 \\
\hline & Am. 2 & 0,34 & 0,39 & 0,29 & 0,25 \\
\hline & Am. 3 & 0,28 & 0,49 & 0,19 & 0,27 \\
\hline & Média & 0,32 & 0,41 & 0,22 & 0,28 \\
\hline & $\mathrm{U}$ & 0,08 & 0,17 & 0,14 & 0,09 \\
\hline \multirow{5}{*}{1,1} & Am. 1 & 0,11 & 0,08 & 0,09 & 0,10 \\
\hline & Am. 2 & 0,12 & 0,09 & 0,09 & 0,09 \\
\hline & Am. 3 & 0,12 & 0,10 & 0,09 & 0,10 \\
\hline & Média & 0,12 & 0,09 & 0,09 & 0,10 \\
\hline & $\mathrm{U}$ & 0,01 & 0,02 & 0,01 & 0,01 \\
\hline \multirow{5}{*}{1,2} & Am. 1 & 0,10 & 0,09 & 0,08 & 0,09 \\
\hline & Am. 2 & 0,14 & 0,09 & 0,09 & 0,09 \\
\hline & Am. 3 & 0,11 & 0,10 & 0,09 & 0,10 \\
\hline & Média & 0,12 & 0,09 & 0,09 & 0,09 \\
\hline & $\mathrm{U}$ & 0,05 & 0,01 & 0,01 & 0,01 \\
\hline \multirow{5}{*}{1,3} & Am. 1 & 0,11 & 0,08 & 0,08 & 0,08 \\
\hline & Am. 2 & 0,12 & 0,09 & 0,09 & 0,08 \\
\hline & Am. 3 & 0,09 & 0,10 & 0,09 & 0,09 \\
\hline & Média & 0,11 & 0,09 & 0,09 & 0,08 \\
\hline & $\mathrm{U}$ & 0,04 & 0,02 & 0,01 & 0,01 \\
\hline
\end{tabular}


Tabela A27 - Resumo dos resultados obtidos com a aplicação do método SME - Tukey para a emissão de $C O$ do experimento 1 (2000 rpm, plena carga e MBT).

\begin{tabular}{|c|c|c|}
\hline \multicolumn{3}{|c|}{ Tukey - CO, $2000 \mathrm{rpm}, 100 \%, \mathrm{MBT}$} \\
\hline Nível I & & E100 \\
\hline Nível II & & E70 \\
\hline Nível III & & E56 \\
\hline Nível IV & & E26 \\
\hline Fator Lambda & Níveis & Diferem entre si \\
\hline \multirow{6}{*}{0,9} & I - II & Não \\
\hline & I -III & Não \\
\hline & I - IV & Não \\
\hline & II - III & Não \\
\hline & II - IV & Não \\
\hline & III - IV & Não \\
\hline \multirow{6}{*}{1} & I - II & Não \\
\hline & I -III & Não \\
\hline & I - IV & Não \\
\hline & II - III & Sim \\
\hline & II - IV & Não \\
\hline & III - IV & Não \\
\hline \multirow{6}{*}{1,1} & I - II & Sim \\
\hline & I -III & Sim \\
\hline & I - IV & Sim \\
\hline & II - III & Não \\
\hline & II - IV & Não \\
\hline & III - IV & Não \\
\hline \multirow{6}{*}{1,2} & I - II & Não \\
\hline & I -III & Não \\
\hline & I - IV & Não \\
\hline & II - III & Não \\
\hline & II - IV & Não \\
\hline & III - IV & Não \\
\hline \multirow{6}{*}{1,3} & I - II & Não \\
\hline & I -III & Não \\
\hline & I - IV & Não \\
\hline & II - III & Não \\
\hline & II - IV & Não \\
\hline & III - IV & Não \\
\hline
\end{tabular}


Tabela A28 - ANOVA da emissão de $C O$ (experimento 1: $3000 \mathrm{rpm}$, plena carga e MBT).

\begin{tabular}{lccccc}
\hline Fonte de variação & SQs & GL & MQs & F & F crítico \\
\hline Fator $\lambda$ & 92,97 & 4 & 23,24 & 1435,29 & 2,61 \\
Tipo de & & & & & \\
combustível & 0,06 & 3 & 0,02 & 1,17 & 2,84 \\
Interação & 0,21 & 12 & 0,02 & 1,09 & 2,00 \\
Resíduo (erro) & 0,65 & 40 & 0,02 & & \\
Total & 93,88 & 59 & & & \\
\hline
\end{tabular}

Tabela A29 - Valores de emissão de $C O$ obtidos no experimento 1 a 3000 rpm, plena carga e MBT.

\begin{tabular}{|c|c|c|c|c|c|}
\hline \multicolumn{6}{|c|}{$\mathrm{CO}[\%]$} \\
\hline \multirow[b]{2}{*}{ Fator $\lambda$} & \multirow{2}{*}{$\begin{array}{l}\text { Amostras, } \\
\text { médias e U }\end{array}$} & \multicolumn{4}{|c|}{ Tipo de combustível } \\
\hline & & E100 & E70 & E56 & E26 \\
\hline \multirow{5}{*}{0,9} & Am. 1 & 3,03 & 3,28 & 2,78 & 3,42 \\
\hline & Am. 2 & 3,57 & 3,38 & 3,44 & 3,37 \\
\hline & Am. 3 & 2,80 & 3,45 & 3,45 & 3,55 \\
\hline & Média & 3,13 & 3,37 & 3,22 & 3,45 \\
\hline & $\mathrm{U}$ & 0,98 & 0,21 & 0,95 & 0,23 \\
\hline \multirow{5}{*}{1} & Am. 1 & 0,57 & 0,32 & 0,29 & 0,41 \\
\hline & Am. 2 & 0,51 & 0,33 & 0,33 & 0,42 \\
\hline & Am. 3 & 0,51 & 0,40 & 0,32 & 0,44 \\
\hline & Média & 0,53 & 0,35 & 0,31 & 0,42 \\
\hline & $\mathrm{U}$ & 0,09 & 0,11 & 0,05 & 0,04 \\
\hline \multirow{5}{*}{1,1} & Am. 1 & 0,14 & 0,12 & 0,10 & 0,13 \\
\hline & Am. 2 & 0,13 & 0,12 & 0,11 & 0,14 \\
\hline & Am. 3 & 0,13 & 0,12 & 0,12 & 0,14 \\
\hline & Média & 0,13 & 0,12 & 0,11 & 0,14 \\
\hline & $\mathrm{U}$ & 0,01 & 0,01 & 0,02 & 0,01 \\
\hline \multirow{5}{*}{1,2} & Am. 1 & 0,15 & 0,12 & 0,10 & 0,16 \\
\hline & Am. 2 & 0,13 & 0,12 & 0,11 & 0,15 \\
\hline & Am. 3 & 0,13 & 0,12 & 0,11 & 0,16 \\
\hline & Média & 0,14 & 0,12 & 0,11 & 0,16 \\
\hline & $\mathrm{U}$ & 0,03 & 0,01 & 0,01 & 0,01 \\
\hline \multirow{5}{*}{1,3} & Am. 1 & 0,11 & 0,12 & 0,10 & 0,13 \\
\hline & Am. 2 & 0,12 & 0,11 & 0,10 & 0,12 \\
\hline & Am. 3 & 0,11 & 0,11 & 0,11 & 0,13 \\
\hline & Média & 0,11 & 0,11 & 0,10 & 0,13 \\
\hline & $\mathrm{U}$ & 0,01 & 0,01 & 0,01 & 0,01 \\
\hline
\end{tabular}


Tabela A30 - Resumo dos resultados obtidos com a aplicação do procedimento de Tukey para análise das médias dos níveis do fator $\lambda$, considerando os dados de emissão de $C O$ (experimento 1 : $3000 \mathrm{rpm}$, plena carga e MBT).

\begin{tabular}{|c|c|c|}
\hline \multicolumn{3}{|c|}{$\begin{array}{l}\text { Procedimento de Tukey para o fator } \lambda(\alpha=0,05) \text { - Emissão de } C O, 3000 \\
\operatorname{rpm}, 100 \%, \text { MBT }\end{array}$} \\
\hline Níveis & Fatores $\lambda$ & Médias dos Níveis \\
\hline I & 0,9 & 3,29 \\
\hline II & 1 & 0,40 \\
\hline III & 1,1 & 0,13 \\
\hline IV & 1,2 & 0,13 \\
\hline $\mathrm{V}$ & 1,3 & 0,11 \\
\hline \multicolumn{2}{|c|}{ k (número de níveis do tratamento em estudo) } & 5 \\
\hline \multicolumn{2}{|c|}{ ka (número de níveis do tratamento A) } & 5 \\
\hline \multicolumn{2}{|c|}{ kb (número de níveis do tratamento B) } & 4 \\
\hline \multicolumn{2}{|c|}{$\mathrm{n}$} & 15 \\
\hline \multirow{2}{*}{\multicolumn{3}{|c|}{$\begin{array}{l}\mathrm{Q}_{0,05, \mathrm{k}, \mathrm{df}}=\mathrm{Q}_{0,05,5,40}(\text { Anexo } \mathrm{D}) \\
\mathrm{df}=\mathrm{ka} * \mathrm{~kb} *(\mathrm{n}-1)=\mathrm{GL} \text { dos resíduos (erro) da anova }\end{array}$}} \\
\hline & & \\
\hline & da ANOVA) & 0,02 \\
\hline & & 0,15 \\
\hline \multicolumn{2}{|c|}{ 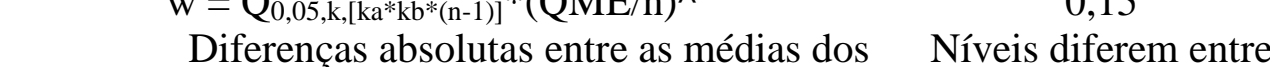 } & Níveis diferem entre \\
\hline Níveis & níveis & si \\
\hline I - II & 2,89 & VERDADEIRO \\
\hline I - III & 3,17 & VERDADEIRO \\
\hline I - IV & 3,16 & VERDADEIRO \\
\hline $\mathrm{I}-\mathrm{V}$ & 3,18 & VERDADEIRO \\
\hline II - III & 0,28 & VERDADEIRO \\
\hline II - IV & 0,27 & VERDADEIRO \\
\hline II - V & 0,29 & VERDADEIRO \\
\hline III - IV & 0,01 & FALSO \\
\hline III - V & 0,01 & FALSO \\
\hline IV - V & 0,02 & FALSO \\
\hline
\end{tabular}

Tabela A31- ANOVA da emissão de $H C$ do motor (experimento 1: $2000 \mathrm{rpm}$, plena carga e MBT).

\begin{tabular}{lccccc}
\hline Fonte de variação & SQs & GL & MQs & F & F crítico \\
\hline Fator $\lambda$ & 69743,33 & 4 & 17435,83 & 7,67 & 2,61 \\
Tipo de & & & & & \\
combustível & 389878,98 & 3 & 129959,66 & 57,17 & 2,84 \\
Interação & 19533,60 & 12 & 1627,80 & 0,72 & 2,00 \\
Resíduo (erro) & 90923,33 & 40 & 2273,08 & & \\
Total & 570079,25 & 59 & & & \\
\hline
\end{tabular}


Tabela A32 - Valores de emissão de $H C$ do motor obtidos no experimento 1 a 2000 rpm, plena carga e MBT.

\begin{tabular}{|c|c|c|c|c|c|}
\hline \multicolumn{6}{|c|}{ Emissão de $H C$ [ppm] } \\
\hline \multirow[b]{2}{*}{ Fator $\lambda$} & \multirow{2}{*}{$\begin{array}{l}\text { Amostras, } \\
\text { médias e U }\end{array}$} & \multicolumn{4}{|c|}{ Tipo de combustível } \\
\hline & & E100 & E70 & E56 & E26 \\
\hline \multirow{5}{*}{0,9} & Am. 1 & 537 & 365 & 411 & 344 \\
\hline & Am. 2 & 511 & 369 & 371 & 369 \\
\hline & Am. 3 & 688 & 398 & 349 & 329 \\
\hline & Média & 579 & 377 & 377 & 347 \\
\hline & $\mathrm{U}$ & 237 & 45 & 78 & 50 \\
\hline \multirow{5}{*}{1} & Am. 1 & 406 & 333 & 352 & 285 \\
\hline & Am. 2 & 404 & 324 & 340 & 302 \\
\hline & Am. 3 & 660 & 345 & 331 & 267 \\
\hline & Média & 490 & 334 & 341 & 285 \\
\hline & $\mathrm{U}$ & 366 & 26 & 26 & 43 \\
\hline \multirow{5}{*}{1,1} & Am. 1 & 350 & 313 & 324 & 233 \\
\hline & Am. 2 & 406 & 308 & 314 & 248 \\
\hline & Am. 3 & 462 & 347 & 318 & 220 \\
\hline & Média & 406 & 323 & 319 & 234 \\
\hline & $\mathrm{U}$ & 139 & 53 & 12 & 35 \\
\hline \multirow{5}{*}{1,2} & Am. 1 & 427 & 349 & 313 & 225 \\
\hline & Am. 2 & 480 & 319 & 301 & 242 \\
\hline & Am. 3 & 532 & 298 & 323 & 216 \\
\hline & Média & 480 & 322 & 312 & 228 \\
\hline & $\mathrm{U}$ & 130 & 64 & 27 & 33 \\
\hline \multirow{5}{*}{1,3} & Am. 1 & 481 & 364 & 331 & 266 \\
\hline & Am. 2 & 476 & 278 & 374 & 289 \\
\hline & Am. 3 & 546 & 285 & 321 & 256 \\
\hline & Média & 501 & 309 & 342 & 270 \\
\hline & $\mathrm{U}$ & 97 & 119 & 70 & 42 \\
\hline
\end{tabular}


Tabela A33 - Resumo dos resultados obtidos com a aplicação do procedimento de Tukey para análise das médias dos níveis do fator $\lambda$, considerando os dados de emissão de $H C$ (experimento 1 : $2000 \mathrm{rpm}$, plena carga e MBT).

Tukey para o fator $\lambda(\alpha=0,05)$ - Emissão de HC, 2000 rpm, 100\%, MBT Níveis

I

II

III

IV

$\mathrm{V}$

k (número de níveis do tratamento em estudo)

ka (número de níveis do tratamento $\mathrm{A}$ )

$\mathrm{kb}$ (número de níveis do tratamento $\mathrm{B}$ )

$\mathrm{n}$

$\mathrm{Q}_{0,05, \mathrm{k}, \mathrm{df}}=\mathrm{Q}_{0,05,5,40}$ (Anexo D)

$\mathrm{df}=\mathrm{ka} * \mathrm{~kb} *(\mathrm{n}-1)=\mathrm{GL}$ dos resíduos (erro) da anova

QME (MQE da ANOVA)

$\mathrm{w}=\mathrm{Q}_{0,05, \mathrm{k},[\mathrm{ka} * \mathrm{~kb} *(\mathrm{n}-1)]} *(\mathrm{QME} / \mathrm{n})^{\wedge} 0,5$

Diferenças absolutas entre as médias dos

Níveis

I - II

I - III

I - IV

I - V

II - III

II - IV

II - V

III -

IV

III - V

IV - V níveis

57,67

99,83

84,67

64,50

42,17

27,00

6,83

15,17

35,33

20,17
Médias dos Níveis

420,08

362,42

320,25

335,42

355,58

5

5

4

15

4,04

2273,08

49,73

Níveis diferem

entre si

VERDADEIRO

VERDADEIRO

VERDADEIRO

VERDADEIRO

FALSO

FALSO

FALSO

FALSO

FALSO

FALSO 
Tabela A34 - Resumo dos resultados obtidos com a aplicação do procedimento de Tukey para análise das médias dos níveis do fator $\lambda$, considerando os dados de emissão de $H C$ (experimento 1: $2000 \mathrm{rpm}$, plena carga e MBT).

\begin{tabular}{|c|c|c|}
\hline \multicolumn{3}{|c|}{$\begin{array}{l}\text { Tukey para o tipo de combustível }(\alpha=0,05) \text { - Emissão de HC, } 2000 \mathrm{rpm} \text {, } \\
\qquad 100 \%, \mathrm{MBT}\end{array}$} \\
\hline Níveis & Fator Tipo de Combustível & Médias dos Níveis \\
\hline I & E100 & 491,07 \\
\hline II & E70 & 333,00 \\
\hline III & E56 & 338,20 \\
\hline IV & E26 & 272,73 \\
\hline \multicolumn{2}{|r|}{ k (número de níveis do tratamento em estudo) } & 4 \\
\hline \multicolumn{2}{|r|}{ ka (número de níveis do tratamento A) } & 4 \\
\hline \multicolumn{2}{|r|}{ kb (número de níveis do tratamento $\mathrm{B}$ ) } & 5 \\
\hline \multicolumn{2}{|r|}{$\mathrm{n}$} & 12 \\
\hline \multicolumn{2}{|r|}{$\mathrm{Q} 0,05, \mathrm{k}, \mathrm{df}=\mathrm{Q} 0,05,4,40($ Anexo D $)$} & 3,79 \\
\hline \multicolumn{3}{|c|}{$\mathrm{df}=\mathrm{ka} * \mathrm{~kb} *(\mathrm{n}-1)=\mathrm{GL}$ dos resíduos (erro) da anova } \\
\hline & QME (MQE da ANOVA) & 2273,08 \\
\hline \multicolumn{2}{|r|}{$\mathrm{w}=\mathrm{Q} 0,05, \mathrm{k},[\mathrm{ka} * \mathrm{~kb} *(\mathrm{n}-1)]^{*}(\mathrm{QME} / \mathrm{n})^{\wedge} 0,5$} & 52,16 \\
\hline \multicolumn{2}{|c|}{ Níveis Diferenças absolutas entre as médias dos níveis } & $\begin{array}{l}\text { Níveis diferem entre } \\
\text { si }\end{array}$ \\
\hline I - II & 158,07 & VERDADEIRO \\
\hline I - III & 152,87 & VERDADEIRO \\
\hline I - IV & 218,33 & VERDADEIRO \\
\hline II - III & 5,20 & FALSO \\
\hline II - IV & 60,27 & VERDADEIRO \\
\hline III - & & \\
\hline IV & 65,47 & VERDADEIRO \\
\hline
\end{tabular}

Tabela A35 - ANOVA da emissão de $H C$ do motor (experimento 1: $3000 \mathrm{rpm}$, plena carga e MBT).

\begin{tabular}{lccccc}
\hline Fonte de variação & SQs & GL & MQs & F & F crítico \\
\hline Fator $\lambda$ & 78727,93 & 4 & 19681,98 & 38,47 & 2,61 \\
Tipo de & & & & & \\
combustível & 123789,78 & 3 & 41263,26 & 80,66 & 2,84 \\
Interação & 29203,80 & 12 & 2433,65 & 4,76 & 2,00 \\
Resíduo (erro) & 20462,67 & 40 & 511,57 & & \\
Total & 252184,18 & 59 & & & \\
\hline
\end{tabular}


Tabela A36 - Valores de emissão de $H C$ do motor obtidos no experimento 1 a 3000 rpm, plena carga e MBT.

\begin{tabular}{|c|c|c|c|c|c|}
\hline \multicolumn{6}{|c|}{$H C$ [ppm] } \\
\hline \multirow[b]{2}{*}{ Fator $\lambda$} & \multirow{2}{*}{$\begin{array}{l}\text { Amostras, } \\
\text { médias e U }\end{array}$} & \multicolumn{4}{|c|}{ Tipo de combustível } \\
\hline & & $\mathrm{E} 100$ & E70 & E56 & E26 \\
\hline \multirow{5}{*}{0,9} & Am. 1 & 373 & 313 & 328 & 296 \\
\hline & Am. 2 & 385 & 297 & 317 & 315 \\
\hline & Am. 3 & 330 & 355 & 326 & 313 \\
\hline & Média & 363 & 322 & 324 & 308 \\
\hline & $\mathrm{U}$ & 72 & 74 & 15 & 26 \\
\hline \multirow{5}{*}{1} & Am. 1 & 348 & 275 & 292 & 206 \\
\hline & Am. 2 & 308 & 225 & 289 & 244 \\
\hline & Am. 3 & 274 & 293 & 306 & 239 \\
\hline & Média & 310 & 264 & 296 & 230 \\
\hline & $\mathrm{U}$ & 92 & 87 & 23 & 51 \\
\hline \multirow{5}{*}{1,1} & Am. 1 & 340 & 230 & 223 & 145 \\
\hline & Am. 2 & 306 & 209 & 235 & 172 \\
\hline & Am. 3 & 241 & 241 & 251 & 167 \\
\hline & Média & 296 & 227 & 236 & 161 \\
\hline & $\mathrm{U}$ & 125 & 40 & 35 & 36 \\
\hline \multirow{5}{*}{1,2} & Am. 1 & 347 & 272 & 240 & 140 \\
\hline & Am. 2 & 331 & 285 & 251 & 150 \\
\hline & Am. 3 & 304 & 261 & 255 & 138 \\
\hline & Média & 327 & 273 & 249 & 143 \\
\hline & $\mathrm{U}$ & 54 & 30 & 19 & 16 \\
\hline \multirow{5}{*}{1,3} & Am. 1 & 425 & 313 & 281 & 224 \\
\hline & Am. 2 & 368 & 338 & 281 & 208 \\
\hline & Am. 3 & 419 & 307 & 281 & 217 \\
\hline & Média & 404 & 319 & 281 & 216 \\
\hline & $\mathrm{U}$ & 78 & 41 & 1 & 20 \\
\hline
\end{tabular}


Tabela A37 - Resumo dos resultados obtidos com a aplicação do método SME - Tukey para a emissão

\begin{tabular}{|c|c|c|}
\hline \multicolumn{3}{|c|}{ SME - Tukey - HC, $3000 \mathrm{rpm}, 100 \%, \mathrm{MBT}$} \\
\hline Nível I & & E100 \\
\hline Nível II & & E70 \\
\hline Nível III & & E56 \\
\hline Nível IV & & E26 \\
\hline Fator Lambda & Níveis & Diferem entre si \\
\hline \multirow{6}{*}{0,9} & I - II & Não \\
\hline & I -III & Não \\
\hline & I - IV & Não \\
\hline & II - III & Não \\
\hline & II - IV & Não \\
\hline & III - IV & Não \\
\hline \multirow{6}{*}{1} & I - II & Não \\
\hline & I -III & Não \\
\hline & I - IV & Sim \\
\hline & II - III & Não \\
\hline & II - IV & Não \\
\hline & III - IV & Não \\
\hline \multirow{6}{*}{1,1} & I - II & Não \\
\hline & I -III & Não \\
\hline & I - IV & Sim \\
\hline & II - III & Não \\
\hline & II - IV & Não \\
\hline & III - IV & Sim \\
\hline \multirow{6}{*}{1,2} & I - II & Sim \\
\hline & I -III & Sim \\
\hline & I - IV & Sim \\
\hline & II - III & Não \\
\hline & II - IV & Sim \\
\hline & III - IV & Sim \\
\hline \multirow{6}{*}{1,3} & I - II & Sim \\
\hline & I -III & Sim \\
\hline & I - IV & Sim \\
\hline & II - III & Não \\
\hline & II - IV & Sim \\
\hline & III - IV & Sim \\
\hline
\end{tabular}


Tabela A38 - ANOVA da emissão de $\mathrm{CO}_{2}$ (experimento 1: $2000 \mathrm{rpm}$, plena carga e MBT).

\begin{tabular}{lccccc}
\hline Fonte de variação & SQs & GL & MQs & F & F crítico \\
\hline $\begin{array}{l}\text { Fator } \lambda \\
\text { Tipo de }\end{array}$ & 97,41 & 4 & 24,35 & 901,92 & 2,61 \\
combustível & 0,02 & 3 & 0,01 & 0,25 & 2,84 \\
Interação & 0,88 & 12 & 0,07 & 2,72 & 2,00 \\
Resíduo (erro) & 1,08 & 40 & 0,03 & & \\
Total & 99,39 & 59 & & & \\
\hline
\end{tabular}

Tabela A39 - Valores de emissão de $\mathrm{CO}_{2}$ obtidos no experimento 1 a $2000 \mathrm{rpm}$, plena carga e MBT.

\begin{tabular}{|c|c|c|c|c|c|}
\hline \multicolumn{6}{|c|}{$\mathrm{CO}_{2}[\%]$} \\
\hline \multirow[b]{2}{*}{ Fator $\lambda$} & \multirow{2}{*}{$\begin{array}{l}\text { Amostras, } \\
\text { médias e U }\end{array}$} & \multicolumn{4}{|c|}{ Tipo de combustível } \\
\hline & & E100 & E70 & E56 & E26 \\
\hline \multirow{5}{*}{0,9} & Am. 1 & 13,2 & 13,0 & 13,1 & 12,9 \\
\hline & Am. 2 & 13,1 & 13,0 & 13,1 & 13,0 \\
\hline & Am. 3 & 13,4 & 12,9 & 13,1 & 13,1 \\
\hline & Média & 13,2 & 13,0 & 13,1 & 13,0 \\
\hline & $\mathrm{U}$ & 0,4 & 0,1 & 0,1 & 0,2 \\
\hline \multirow{5}{*}{1} & Am. 1 & 14,4 & 14,4 & 14,4 & 14,3 \\
\hline & Am. 2 & 14,6 & 14,4 & 14,4 & 14,4 \\
\hline & Am. 3 & 14,2 & 14,5 & 14,3 & 14,5 \\
\hline & Média & 14,4 & 14,4 & 14,4 & 14,4 \\
\hline & $\mathrm{U}$ & 0,5 & 0,1 & 0,1 & 0,2 \\
\hline \multirow{5}{*}{1,1} & Am. 1 & 13,3 & 13,0 & 13,3 & 12,8 \\
\hline & Am. 2 & 13,4 & 13,3 & 13,4 & 13,0 \\
\hline & Am. 3 & 13,0 & 13,4 & 13,4 & 13,2 \\
\hline & Média & 13,2 & 13,2 & 13,4 & 13,0 \\
\hline & $\mathrm{U}$ & 0,5 & 0,5 & 0,1 & 0,5 \\
\hline \multirow{5}{*}{1,2} & Am. 1 & 11,9 & 11,6 & 11,5 & 12,0 \\
\hline & Am. 2 & 11,9 & 11,9 & 11,9 & 12,1 \\
\hline & Am. 3 & 11,9 & 12,0 & 11,8 & 12,3 \\
\hline & Média & 11,9 & 11,8 & 11,7 & 12,1 \\
\hline & $\mathrm{U}$ & 0,1 & 0,5 & 0,5 & 0,4 \\
\hline \multirow{5}{*}{1,3} & Am. 1 & 10,7 & 10,5 & 10,9 & 10,7 \\
\hline & Am. 2 & 10,5 & 10,7 & 10,6 & 10,8 \\
\hline & Am. 3 & 10,0 & 10,8 & 10,6 & 11,0 \\
\hline & Média & 10,4 & 10,7 & 10,7 & 10,8 \\
\hline & $\mathrm{U}$ & 0,9 & 0,4 & 0,4 & 0,4 \\
\hline
\end{tabular}


Tabela A40 - Resumo dos resultados obtidos com a aplicação do procedimento de Tukey para análise das médias dos níveis do fator $\lambda$, considerando os dados de emissão de $\mathrm{CO}_{2}$ (experimento 1: $2000 \mathrm{rpm}$, plena carga e MBT).

\begin{tabular}{|c|c|c|}
\hline \multicolumn{3}{|c|}{$\begin{array}{c}\text { Procedimento de Tukey para o fator } \lambda(\alpha=0,05) \text { - Experimento 1: } 2000 \\
\text { rpm, plena carga e MBT }\end{array}$} \\
\hline Níveis & Fatores $\lambda$ & Médias dos Níveis \\
\hline $\mathrm{I}$ & 0,9 & 13,08 \\
\hline II & 1 & 14,40 \\
\hline III & 1,1 & 13,21 \\
\hline IV & 1,2 & 11,90 \\
\hline $\mathrm{V}$ & 1,3 & 10,65 \\
\hline \multicolumn{2}{|c|}{ k (número de níveis do tratamento em estudo) } & 5 \\
\hline \multicolumn{2}{|c|}{ ka (número de níveis do tratamento A) } & 5 \\
\hline \multicolumn{2}{|r|}{ kb (número de níveis do tratamento $\mathrm{B}$ ) } & 4 \\
\hline \multicolumn{2}{|r|}{$\mathrm{n}$} & 15 \\
\hline & & 4,04 \\
\hline \multicolumn{3}{|c|}{$\mathrm{df}=\mathrm{ka}^{*} \mathrm{~kb}^{*}(\mathrm{n}-1)=\mathrm{GL}$ dos resíduos (erro) da anova } \\
\hline & QME (MQE da ANOVA) & 0,03 \\
\hline \multirow{2}{*}{\multicolumn{2}{|c|}{ 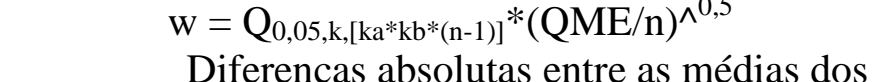 }} & 0,19 \\
\hline & & Níveis diferem entre \\
\hline Níveis & níveis & si \\
\hline I - II & 1,33 & VERDADEIRO \\
\hline I - III & 0,13 & FALSO \\
\hline I - IV & 1,18 & VERDADEIRO \\
\hline $\mathrm{I}-\mathrm{V}$ & 2,43 & VERDADEIRO \\
\hline II - III & 1,19 & VERDADEIRO \\
\hline II - IV & 2,50 & VERDADEIRO \\
\hline II - V & 3,75 & VERDADEIRO \\
\hline III - IV & 1,31 & VERDADEIRO \\
\hline III - V & 2,56 & VERDADEIRO \\
\hline IV - V & 1,25 & VERDADEIRO \\
\hline
\end{tabular}

Tabela A41 - ANOVA da emissão de $\mathrm{CO}_{2}$ (experimento 1: $3000 \mathrm{rpm}$, plena carga e MBT)

\begin{tabular}{lccccc}
\hline Fonte de variação & SQs & GL & MQs & F & F crítico \\
\hline Fator $\lambda$ & 97,91 & 4 & 24,48 & 1027,02 & 2,61 \\
Tipo de & & & & & \\
combustível & 0,67 & 3 & 0,22 & 9,33 & 2,84 \\
Interação & 0,58 & 12 & 0,05 & 2,01 & 2,00 \\
Resíduo (erro) & 0,95 & 40 & 0,02 & & \\
Total & 100,11 & 59 & & & \\
\hline
\end{tabular}


Tabela A42 - Valores de emissão de $\mathrm{CO}_{2}$ obtidos no experimento 1 a $3000 \mathrm{rpm}$, plena carga e MBT.

\begin{tabular}{|c|c|c|c|c|c|}
\hline \multicolumn{6}{|c|}{$\mathrm{CO}_{2}[\%]$} \\
\hline \multirow[b]{2}{*}{ Fator $\lambda$} & \multirow{2}{*}{$\begin{array}{l}\text { Amostras, } \\
\text { médias e U }\end{array}$} & \multicolumn{4}{|c|}{ Tipo de combustível } \\
\hline & & E100 & E70 & E56 & E26 \\
\hline \multirow{5}{*}{0,9} & Am. 1 & 13,4 & 13,1 & 13,2 & 12,7 \\
\hline & Am. 2 & 13,0 & 12,8 & 12,8 & 12,6 \\
\hline & Am. 3 & 13,3 & 12,9 & 12,9 & 12,8 \\
\hline & Média & 13,2 & 12,9 & 13,0 & 12,7 \\
\hline & $\mathrm{U}$ & 0,5 & 0,4 & 0,5 & 0,2 \\
\hline \multirow{5}{*}{1} & Am. 1 & 14,7 & 14,5 & 14,4 & 14,3 \\
\hline & Am. 2 & 14,6 & 14,5 & 14,4 & 14,1 \\
\hline & Am. 3 & 14,4 & 14,5 & 14,4 & 14,5 \\
\hline & Média & 14,6 & 14,5 & 14,4 & 14,3 \\
\hline & $\mathrm{U}$ & 0,4 & 0,1 & 0,1 & 0,5 \\
\hline \multirow{5}{*}{1,1} & Am. 1 & 13,7 & 13,3 & 13,0 & 13,0 \\
\hline & Am. 2 & 13,6 & 13,4 & 13,0 & 12,8 \\
\hline & Am. 3 & 13,3 & 13,4 & 13,1 & 13,2 \\
\hline & Média & 13,5 & 13,4 & 13,0 & 13,0 \\
\hline & $\mathrm{U}$ & 0,5 & 0,1 & 0,1 & 0,5 \\
\hline \multirow{5}{*}{1,2} & Am. 1 & 12,2 & 11,7 & 11,8 & 11,8 \\
\hline & Am. 2 & 11,9 & 11,9 & 11,8 & 11,5 \\
\hline & Am. 3 & 11,7 & 11,8 & 11,9 & 11,9 \\
\hline & Média & 11,9 & 11,8 & 11,8 & 11,7 \\
\hline & $\mathrm{U}$ & 0,6 & 0,2 & 0,1 & 0,5 \\
\hline \multirow{5}{*}{1,3} & Am. 1 & 10,6 & 10,6 & 10,6 & 10,8 \\
\hline & Am. 2 & 10,9 & 10,7 & 10,6 & 10,6 \\
\hline & Am. 3 & 10,5 & 10,7 & 10,8 & 10,9 \\
\hline & Média & 10,7 & 10,7 & 10,7 & 10,8 \\
\hline & $\mathrm{U}$ & 0,5 & 0,1 & 0,3 & 0,4 \\
\hline
\end{tabular}


Tabela A43 - Resumo dos resultados obtidos com a aplicação do método SME - Tukey para a emissão

\begin{tabular}{|c|c|c|}
\hline \multicolumn{3}{|c|}{ SME - Tukey - $\mathrm{CO}_{2}, 3000 \mathrm{rpm}, 100 \%$, MBT } \\
\hline Nível I & \multicolumn{2}{|r|}{ E100 } \\
\hline Nível II & \multicolumn{2}{|r|}{ E70 } \\
\hline Nível III & \multicolumn{2}{|r|}{ E56 } \\
\hline Nível IV & \multicolumn{2}{|r|}{ E26 } \\
\hline Fator Lambda & Níveis & Diferem entre si \\
\hline \multirow{6}{*}{0,9} & I - II & Sim \\
\hline & I -III & Não \\
\hline & I - IV & Não \\
\hline & II - III & Não \\
\hline & II - IV & Não \\
\hline & III - IV & Não \\
\hline \multirow{6}{*}{1} & I - II & Não \\
\hline & I -III & Não \\
\hline & I - IV & Não \\
\hline & II - III & Não \\
\hline & II - IV & Não \\
\hline & III - IV & Não \\
\hline \multirow{6}{*}{1,1} & I - II & Não \\
\hline & I -III & Não \\
\hline & I - IV & Não \\
\hline & II - III & Não \\
\hline & II - IV & Não \\
\hline & III - IV & Não \\
\hline \multirow{6}{*}{1,2} & I - II & Não \\
\hline & I -III & Não \\
\hline & I - IV & Não \\
\hline & II - III & Não \\
\hline & II - IV & Não \\
\hline & III - IV & Não \\
\hline \multirow{6}{*}{1,3} & I - II & Não \\
\hline & I -III & Não \\
\hline & I - IV & Não \\
\hline & II - III & Não \\
\hline & II - IV & Não \\
\hline & III - IV & Não \\
\hline
\end{tabular}

\section{A3. ALGORITMO PARA ANÁLISE DOS DADOS EXPERIMENTAIS}

$\%$ Entrada de dados:

clear all

clc

format long $\mathrm{g}$

[nome,diretorio]=uigetfile('*.txt');

arquivo=[diretorio nome];

disp('Arquivo carregado:') 
disp(arquivo)

$[\mathrm{a}, \mathrm{b}, \mathrm{c}, \mathrm{d}, \mathrm{e}, \mathrm{f}, \mathrm{g}]=$ textread(uigetfile('*.txt'));

$\%$ a=rotação ideal; $\mathrm{b}=$ abertura da válvula borboleta; $\mathrm{c}=$ fator lambda;

$\% \mathrm{~d}=$ variávelem estudo para o combustível E100; e=variável em estudo para o

\% combustível E60; f=variável em estudo para o combustível E40; g=variável

$\%$ em estudo para o combustível E0

vee $=[\mathrm{d}$ e f g];

vee_2000_100_todos_lambdas=vee( $31: 45,1:$ end $)$;

$\%$ Análise de variância para os dois tratamentos

$\%$ (lambda e tipo de combustível)

[p_vee_2000_100_todos_lambdas,anova_vee_2000_100_todos_lambdas,...

stats_vee_2000_100_todos_lambdas]=...

anova2(vee_2000_100_todos_lambdas,3,'off');

figure(1)

\% Gráfico do teste de Tukey-Kramer para as colunas

[c_vee_2000_100_todos_lambdas_comb,m_vee_2000_100_todos_lambdas_comb,...

h_vee_2000_100_todos_lambdas_comb,...

nms_vee_2000_100_todos_lambdas_comb] $=\ldots$

multcompare(stats_vee_2000_100_todos_lambdas,'alpha',...

0.05 ,'ctype','tukey-kramer');

figure(2)

$\%$ Gráfico do teste de Tukey-Kramer para as linhas

[c_vee_2000_100_todos_lambdas_lambda,m_vee_2000_100_todos_lambdas_lambda,..

h_vee_2000_100_todos_lambdas_lambda, ...

nms_vee_2000_100_todos_lambdas_lambda] $=\ldots$

multcompare(stats_vee_2000_100_todos_lambdas,'alpha', 0.05,'ctype',,...

'tukey-kramer','estimate','row');

vee_2000_100_0_9=vee(31:33,1:end);

$\%$ Calcular a incerteza expandida $(\mathrm{U}=\mathrm{k} * \mathrm{u})$

media_vee_2000_100_0_9=mean(vee_2000_100_0_9);

std_vee_2000_100_0_9=std(vee_2000_100_0_9);

var_amostral_vee_2000_100_0_9=std_vee_2000_100_0_9.^2;

var_experimental_vee_2000_100_0_9=var_amostral_vee_2000_100_0_9./...

(length(vee_2000_100_0_9(:,1)));

u_vee_2000_100_0_9=var_experimental_vee_2000_100_0_9.^0.5;

U_vee_2000_100_0_9=u_vee_2000_100_0_9.*4.30;

\% Análise de variância para cada fator lambda

group $=[\{$ 'E100' $\},\{$ 'E70' $\},\{$ 'E56' $\},\{$ 'E26' $\}]$;

[p_vee_2000_100_0_9, anova_vee_2000_100_0_9,stats_vee_2000_100_0_9]=..

anova1(vee_2000_100_0_9,group,'off');

figure(3)

[c_vee_2000_100_0_9_comb,m_vee_2000_100_0_9_comb,h_vee_2000_100_0_9_comb,...

nms_vee_2000_100_0_9_comb] = multcompare(stats_vee_2000_100_0_9, $\ldots$

'alpha', 0.05,'ctype','tukey-kramer');

vee_2000_100_0_9 (4,:)=media_vee_2000_100_0_9;

vee_2000_100_0_9(5,:)=U_vee_2000_100_0_9;

vee_2000_100_1_0=vee(34:36,1:end);

media_vee_2000_100_1_0=mean(vee_2000_100_1_0);

std_vee_2000_100_1_0=std(vee_2000_100_1_0);

var_amostral_vee_2000_100_1_0=std_vee_2000_100_1_0.^2;

var_experimental_vee_2000_100_1_0=var_amostral_vee_2000_100_1_0./...

(length(vee_2000_100_1_0(:,1)));

u_vee_2000_100_1_0=var_experimental_vee_2000_100_1_0.^0.5;

U_vee_2000_100_1_0=u_vee_2000_100_1_0.*4.30;

group $=\left[\left\{\right.\right.$ 'E$\left.^{\prime} 100^{\prime}\right\},\left\{\right.$ 'E70' $\left.^{\prime}\right\},\left\{\right.$ 'E5 $\left.^{\prime}\right\},\left\{\right.$ 'E26' $\left.\left.^{-}\right\}\right]$;

[p_vee_2000_100_1_0,anova_vee_2000_100_1_0,stats_vee_2000_100_1_0]=..

anova1(vee_2000_100_1_0,group,'off');

figure(4)

[c_vee_2000_100_1_0_comb,m_vee_2000_100_1_0_comb,h_vee_2000_100_1_0_comb,...

nms_vee_2000_100_1_0_comb] = multcompare(stats_vee_2000_100_1_0,...

'alpha', 0.05,'ctype','tukey-kramer');

vee_2000_100_1_0(4,:)=media_vee_2000_100_1_0;

vee_2000_100_1_0(5,:)=U_vee_2000_100_1_0;

vee_2000_100_1_1=vee(37:39,1:end);

media_vee_2000_100_1_1=mean(vee_2000_100_1_1);

std_vee_2000_100_1_1=std(vee_2000_100_1_1);

var_amostral_vee_2000_100_1_1=std_vee_2000_100_1_1.^2;

var_experimental_vee_2000_100_1_1=var_amostral_vee_2000_100_1_1./...

(length(vee_2000_100_1_1(:,1)));

u_vee_2000_100_1_1=var_experimental_vee_2000_100_1_1.^0.5;

U_vee_2000_100_1_1=u_vee_2000_100_1_1.*4.30;

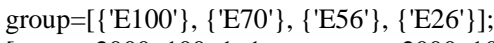

[p_vee_2000_100_1_1,anova_vee_2000_100_1_1,stats_vee_2000_100_1_1] =...

anova1(vee_2000_100_1_1,group,'off');

figure(5)

[c_vee_2000_100_1_1_comb,m_vee_2000_100_1_1_comb,... 
h_vee_2000_100_1_1_comb,nms_vee_2000_100_1_1_comb] $=$... multcompare(stats_vee_2000_100_1_1,'alpha', 0.05 ,'ctype',...

'tukey-kramer');

vee_2000_100_1_1(4,:)=media_vee_2000_100_1_1;

vee_2000_100_1_1(5,:)=U_vee_2000_100_1_1;

vee_2000_100_1_2=vee(40:42,1:end);

media_vee_2000_100_1_2=mean(vee_2000_100_1_2);

std vee 2000_100_1_2=std(vee_2000_100_1_2);

var_amostral_vee_2000_100_1_2=std_vee_2000_100_1_2.^2;

var_experimental_vee_2000_100_1_2=var_amostral_vee_2000_100_1_2./..

(length(vee_2000_100_1_2(:,1)));

u_vee_2000_100_1_2=var_experimental_vee_2000_100_1_2.^0.5;

U_vee_2000_100_1_2=u_vee_2000_100_1_2.*4.30;

group $=[\{$ E100' $\},\{$ 'E70' $\},\{$ 'E56' $\},\{$ 'E26' $\}]$;

[p_vee_2000_100_1_2,anova_vee_2000_100_1_2,stats_vee_2000_100_1_2]=... anova1(vee_2000_100_1_2,group,'off');

figure(6)

[c_vee 2000_100_1_2_comb,m_vee $2000 \_100 \_1 \_2$ comb,..

h_vee_2000_100_1_2_comb,nms_vee_2000_100_1_2_comb] $=$..

multcompare(stats_vee_2000_100_1_2,'alpha', 0.05,'ctype',...

'tukey-kramer');

vee_2000_100_1_2(4,:)=media_vee_2000_100_1_2;

vee 2000_100_1_2(5,:)=U_vee_2000_100_1_2;

vee_2000_100_1_3=vee(43:45, 1 :end);

media_vee_2000_100_1_3=mean(vee_2000_100_1_3);

std_vee_2000_100_1_3=std(vee_2000_100_1_3);

var_amostral_vee_2000_100_1_3=std_vee_2000_100_1_3.^2;

var_experimental vee 2000_100_1 3=var_amostral_vee 2000_100_1 3./...

(length(vee_2000_100_1_3(:,1)) );

u_vee_2000_100_1_3=var_experimental_vee_2000_100_1_3.^0.5;

U_vee_2000_100_1_3=u_vee_2000_100_1_3.*4.30;

group $=[\{$ 'E100' $\},\{$ 'E70' $\},\{$ 'E56' $\},\{$ 'E26' $\}]$;

[p_vee_2000_100_1_3, anova_vee_2000_100_1_3,stats_vee_2000_100_1_3] =... anova1(vee_2000_100_1_3,group,'off');

figure(7)

[c_vee_2000_100_1_3_comb,m_vee_2000_100_1_3_comb,...

h_vee_2000_100_1_3_comb,nms_vee_2000_100_1_3_comb] $=.$.

multcompare(stats_vee_2000_100_1_3,'alpha', 0.05,'ctype',...

'tukey-kramer');

vee_2000_100_1_3(4,:)=media_vee_2000_100_1_3;

vee $2000 \_100 \_1 \_3(5,:)=$ U_vee_2000_100_1_3;

$\%$ VEE: $3000 \mathrm{rpm}$ e $100 \%$

vee_3000_100_todos_lambdas=vee(46:60,1:end);

\% Análise de variância para os dois tratamentos

$\%$ (lambda e tipo de combustível)

[p_vee_3000_100_todos_lambdas,anova_vee_3000_100_todos_lambdas,.. stats_vee_3000_100_todos_lambdas] $=$...

anova2(vee_3000_100_todos_lambdas,3,'off');

figure(8)

$\%$ Gráfico do teste de Tukey-Kramer para as colunas

[c_vee 3000 100 todos_lambdas_comb,m vee 3000_100_todos_lambdas_comb,...

h_vee_3000_100_todos_lambdas_comb,...

nms_vee_3000_100_todos_lambdas_comb] $=$..

multcompare(stats_vee_3000_100_todos_lambdas,'alpha',...

0.05 ,'ctype','tukey-kramer');

figure(9)

$\%$ Gráfico do teste de Tukey-Kramer para as linhas

[c_vee_3000_100_todos_lambdas_lambda,m_vee_3000_100_todos_lambdas_lambda,...

h_vee_3000_100_todos_lambdas_lambda,...

nms_vee_3000_100_todos_lambdas_lambda] $=$...

multcompare(stats_vee_3000_100_todos_lambdas,'alpha', 0.05,'ctype',...

'tukey-kramer','estimate','row');

vee_3000_100_0_9=vee(46:48,1:end);

$\%$ Calcular a incerteza expandida $(\mathrm{U}=\mathrm{k} * \mathrm{u})$

media_vee_3000_100_0_9=mean(vee_3000_100_0_9);

std_vee_3000_100_0_9=std(vee 3000_100_0_9);

var_amostral_vee_3000_100_0_9=std_vee_3000_100_0_9.^2;

var_experimental_vee_3000_100_0_9=var_amostral_vee_3000_100_0_9./...

(length(vee_3000_100_0_9(:,1)));

u_vee_3000_100_0_9=var_experimental_vee_3000_100_0_9.^0.5;

U_vee 3000_100_0_9=u_vee_3000_100_0_9.*4.30;

$\%$ Análise de variância para cada fator lambda

group $=[\{$ 'E100' $\},\{$ 'E70' $\},\{$ 'E56' $\},\{$ 'E26' $\}]$;

[p_vee_3000_100_0_9, anova_vee_3000_100_0_9,stats_vee_3000_100_0_9]=... anova1(vee_3000_100_0_9,group,'off');

figure(10) 
[c_vee_3000_100_0_9_comb,m_vee_3000_100_0_9_comb,h_vee_3000_100_0_9_comb,... nms_vee_3000_100_0_9_comb] = multcompare(stats_vee_3000_100_0_9, ..

'alpha', 0.05,'ctype','tukey-kramer');

vee_3000_100_0_9 $(4,:)=$ media_vee_3000_100_0_9;

vee_3000_100_0_9 (5,:)=U_vee_3000_100_0_9;

vee_3000_100_1_0=vee(49:51,1:end);

media_vee_3000_100_1_0=mean(vee_3000_100_1_0);

std_vee_3000_100_1_0 =std(vee_3000_100_1_0);

var_amostral_vee_3000_100_1_0=std_vee_3000_100_1_0.^2;

var_experimental_vee_3000_100_1_0=var_amostral_vee_3000_100_1_0./...

(length(vee_3000_100_1_0(:,1)));

u_vee_3000_100_1_0=var_experimental_vee_3000_100_1_0.^0.5;

U_vee_3000_100_1_0=u_vee_3000_100_1_0.*4.30;

group $=[\{$ 'E100' $\},\{$ 'E70' $\},\{$ 'E56' $\},\{$ 'E26' $\}]$;

[p_vee_3000_100_1_0,anova_vee_3000_100_1_0,stats_vee_3000_100_1_0]=..

anova1(vee_3000_100_1_0,group,'off');

figure(11)

[c_vee_3000_100_1_0_comb,m_vee_3000_100_1_0_comb,h_vee_3000_100_1_0_comb,...

nms_vee_3000_100_1_0_comb] = multcompare(stats_vee_3000_100_1_0,...

'alpha', 0.05,'ctype','tukey-kramer');

vee_3000_100_1_0(4,:)=media_vee_3000_100_1_0;

vee_3000_100_1_0 $5,:$ : $=$ U_vee_3000_100_1_0;

vee_3000_100_1_1=vee(52:54,1:end);

media_vee_3000_100_1_1=mean(vee_3000_100_1_1);

std_vee_3000_100_1_1=std(vee_3000_100_1_1);

var_amostral_vee_3000_100_1_1=std_vee_3000_100_1_1.^2;

var_experimental_vee_3000_100_1_1=var_amostral_vee_3000_100_1_1./...

(length(vee_3000_100_1_1(:,1)));

u_vee_3000_100_1_1=var_experimental_vee_3000_100_1_1.^0.5;

U_vee_3000_100_1_1=u_vee_3000_100_1_1.*4.30;

group $=\left[\left\{\right.\right.$ E100' $\left.^{\prime}\right\},\left\{\right.$ 'E70' $^{-},\left\{\right.$'E56' $\left.^{\prime}\right\},\left\{\right.$ 'E$\left.\left.^{\prime} 66^{\prime}\right\}\right]$;

[p_vee_3000_100_1_1,anova_vee_3000_100_1_1,stats_vee_3000_100_1_1] =...

anova1(vee_3000_100_1_1,group,'off');

figure(12)

[c_vee_3000_100_1_1_comb,m_vee_3000_100_1_1_comb,...

h_vee_3000_100_1_1_comb,nms_vee_3000_100_1_1_comb] $=$...

multcompare(stats_vee_3000_100_1_1,'alpha', 0.05 ,'ctype',...

'tukey-kramer');

vee_3000_100_1_1(4,:)=media_vee_3000_100_1_1;

vee_3000_100_1_1(5,:)=U_vee_3000_100_1_1;

vee_3000_100_1_2=vee(55:57,1:end);

media_vee_3000_100_1_2=mean(vee_3000_100_1_2);

std_vee_3000_100_1_2=std(vee_3000_100_1_2);

var_amostral_vee_3000_100_1_2=std_vee_3000_100_1_2.^2;

var_experimental_vee_3000_100_1_2=var_amostral_vee_3000_100_1_2./..

(length(vee_3000_100_1_2(:,1)));

u_vee_3000_100_1_2=var_experimental_vee_3000_100_1_2.^0.5;

U_vee_3000_100_1_2=u_vee_3000_100_1_2.*4.30;

group $=[\{$ 'E100' $\},\{$ 'E70' $\},\{$ 'E56' $\},\{$ 'E26' $\}]$;

[p_vee_3000_100_1_2,anova_vee_3000_100_1_2,stats_vee_3000_100_1_2]=..

anova1(vee_3000_100_1_2,group,'off');

figure(13)

[c_vee_3000_100_1_2_comb,m_vee_3000_100_1_2_comb,...

h_vee_3000_100_1_2_comb,nms_vee_3000_100_1_2_comb] $=.$. .

multcompare(stats_vee_3000_100_1_2,'alpha', 0.05,'ctype',...

'tukey-kramer');

vee_3000_100_1_2(4,:)=media_vee_3000_100_1_2;

vee_3000_100_1_2(5,:)=U_vee_3000_100_1_2;

vee_3000_100_1_3=vee(58:60,1:end);

media_vee_3000_100_1_3=mean(vee_3000_100_1_3);

std_vee_3000_100_1_3=std(vee_3000_100_1_3);

var_amostral_vee_3000_100_1_3=std_vee_3000_100_1_3.^2;

var_experimental_vee_3000_100_1_3=var_amostral_vee_3000_100_1_3./..

(length(vee_3000_100_1_3(:,1)));

u_vee_3000_100_1_3=var_experimental_vee_3000_100_1_3.^0.5;

U_vee_3000_100_1_3=u_vee_3000_100_1_3.*4.30;

group $=[\{$ 'E100' $\},\{$ 'E70' $\},\{$ 'E56' $\},\{$ 'E26' $\}]$;

[p_vee_3000_100_1_3,anova_vee_3000_100_1_3,stats_vee_3000_100_1_3] =... anova1(vee_3000_100_1_3,group,'off');

figure(14)

[c_vee_3000_100_1_3_comb,m_vee_3000_100_1_3_comb,...

h_vee_3000_100_1_3_comb,nms_vee_3000_100_1_3_comb] $=.$. .

multcompare(stats_vee_3000_100_1_3,'alpha', 0.05,'ctype',...

'tukey-kramer');

vee_3000_100_1_3(4,:)=media_vee_3000_100_1_3;

vee_3000_100_1_3(5,:)=U_vee_3000_100_1_3; 
$\%$ Gráficos

$\% 2000 \mathrm{rpm} ; 100 \%$

\% E100 (média: círculo verde)

medias_lambdas_2000_100_E100=[vee_2000_100_0_9(4,1),...

vee_2000_100_1_0(4,1),vee_2000_100_1_1 $(4,1)$,...

vee_2000_100_1_2(4,1),vee_2000_100_1_3(4,1)];

i_inf_lambdas_2000_100_E100=[vee_2000_100_0_9 $(4,1)$..

-vee_2000_100_0_9(5,1),vee_2000_100_1_0(4,1)-...

vee_2000_100_1_0(5,1),vee_2000_100_1_1(4,1)-...

vee_2000_100_1_1(5,1),vee_2000_100_1_2(4,1)-...

vee_2000_100_1_2(5,1),vee_2000_100_1_3(4,1)-vee_2000_100_1_3(5,1)];

i_sup_lambdas_2000_100_E100=[vee_2000_100_0_9(4,1)+...

vee $2000 \_100 \quad 0 \quad 9(5,1)$,vee $2000 \_100 \_1 \_0(4,1)+$ vee $2000 \_100 \_1 \_0(5,1) \ldots$.

vee_2000_100_1_1(4,1)+vee_2000_100_1_1(5,1),vee_2000_100_1_2(4,1)+.. vee_2000_100_1_2(5,1),vee_2000_100_1_3(4,1)+vee_2000_100_1_3(5,1)];

$\%$ Obter os intervalos de confiança para cada fator lambda

ic_2000_100_E100_0_9=[i_inf_lambdas_2000_100_E100 $(1,1)$... i_sup_lambdas_2000_100_E100(1,1)];

ic_2000_100_E100_1_0=[i_inf_lambdas_2000_100_E100 $(1,2) \ldots$ i_sup_lambdas_2000_100_E100(1,2)];

ic_2000_100_E100_1_1=[i_inf_lambdas_2000_100_E100 $(1,3) \ldots$ i_sup_lambdas_2000_100_E100(1,3)];

ic_2000_100_E100_1_2=[i_inf_lambdas_2000_100_E100 $(1,4) \ldots$ i_sup_lambdas_2000_100_E100(1,4)];

ic_2000_100_E100_1_3=[i_inf_lambdas_2000_100_E100 $(1,5)$... i_sup_lambdas_2000_100_E100 $(1,5)]$;

$\%$ E70 (média: quadrado azul)

medias lambdas $2000 \quad 100$ E70 $=[$ vee $2000 \quad 100 \quad 0 \quad 9(4,2) \ldots$

vee_2000_100_1_0 $(4,2)$, vee_2000_100_1_1(4,2),vee_2000_100_1_2(4,2),... vee_2000_100_1_3(4,2)];

i_inf_lambdas_2000_100_E70=[vee 2000_100 0 9 9 (4,2)-vee $2000 \_100 \_0-9(5,2), \ldots$ vee_2000_100_1_0(4,2)-vee_2000_100_1_0(5,2),vee_2000_100_1_1(4,2)-... vee $2000 \_100 \_11(5,2)$,vee $2000 \_100 \_1 \_2(4,2)$-vee $2000 \_100 \_12(5,2), \ldots$ vee_2000_100_1_3(4,2)-vee_2000_100_1_3(5,2)];

i_sup_lambdas_2000_100_E70=[vee_2000_100_0_9 $(4,2)+v e e \_2000 \_100 \_0 \_9(5,2), \ldots$ vee_2000_100_1_0 (4,2)+vee_2000_100_1_0(5,2),vee_2000_100_1_1(4,2)+.. vee_2000_100_1_1(5,2),vee_2000_100_1_2(4,2)+vee_2000_100_1_2(5,2),... vee $2000 \quad 100 \_13(4,2)+$ vee $\left.2000 \quad 100 \_13(5,2)\right]$;

ic_2000_100_E70_0_9=[i_inf_lambdas_2000_100_E70 $(1,1)$... i_sup_lambdas_2000_100_E70(1,1)];

ic_2000_100_E70_1_0=[i_inf_lambdas_2000_100_E70 $(1,2) \ldots$ i_sup_lambdas_2000_100_E70(1,2)];

ic_2000_100_E70_1_1=[i_inf_lambdas_2000_100_E70 $(1,3)$... i_sup_lambdas_2000_100_E70(1,3)];

ic_2000_100_E70_1_2=[i_inf_lambdas_2000_100_E70 $(1,4) \ldots$ i_sup_lambdas_2000_100_E70 $(1,4)]$;

ic_2000_100_E70_1_3=[i_inf_lambdas_2000_100_E70 $(1,5)$... i_sup_lambdas_2000_100_E70 (1,5)];

\% E56 (média: triângulo vermelho)

medias_lambdas_2000_100_E56=[vee_2000_100_0_9(4,3),...

vee_2000_100_1_0(4,3),vee_2000_100_1_1(4,3),vee_2000_100_1_2(4,3),... vee_2000_100_1_3(4,3)];

i_inf_lambdas_2000_100_E56=[vee_2000_100_0_9(4,3)-vee_2000_100_0_9(5,3),.. vee_2000_100_1_0(4,3)-vee_2000_100_1_0(5,3),vee_2000_100_1_1(4,3)-... vee_2000_100_1_1(5,3),vee_2000_100_1_2(4,3)-vee_2000_100_1_2(5,3),... vee_2000_100_1_3(4,3)-vee_2000_100_1_3(5,3)];

i_sup_lambdas_2000_100_E56=[vee_2000_100_0_9 (4,3)+vee_2000_100_0_9(5,3),... vee_2000_100_1_0 $(4,3)+$ vee_2000_100_1_0 (5,3),vee_2000_100_1_1 $1(4,3)+\ldots$ vee_2000_100_1_1(5,3),vee_2000_100_1_2(4,3)+vee_2000_100_1_2(5,3),... vee_2000_100_1_3(4,3)+vee_2000_100_1_3(5,3)];

ic_2000_100_E56_0_9=[i_inf_lambdas_2000_100_E56 $(1,1) \ldots$ i_sup_lambdas_2000_100_E56(1,1)];

ic_2000_100_E56_1_0=[i_inf_lambdas_2000_100_E56 $(1,2) \ldots$ i_sup_lambdas_2000_100_E56(1,2)];

ic_2000_100_E56_1_1=[i_inf_lambdas_2000_100_E56 $(1,3) \ldots$ i_sup_lambdas_2000_100_E56(1,3)];

ic_2000_100_E56_1_2=[i_inf_lambdas_2000_100_E56 $(1,4) \ldots$ i_sup_lambdas_2000_100_E56(1,4)];

ic_2000_100_E56_1_3=[i_inf_lambdas_2000_100_E56 $(1,5)$... i_sup_lambdas_2000_100_E56(1,5)];

$\%$ E26 (média: estrela preta)

medias_lambdas_2000_100_E26=[vee_2000_100_0_9(4,4),... vee_2000_100_1_0(4,4),vee_2000_100_1_1(4,4),vee_2000_100_1_2(4,4),... vee_2000_100_1_3(4,4)];

i_inf_lambdas_2000_100_E26=[vee_2000_100_0_9(4,4)-vee_2000_100_0_9(5,4),.. vee_2000_100_1_0(4,4)-vee_2000_100_1_0(5,4),vee_2000_100_1_1(4,4)-... 
vee_2000_100_1_1(5,4),vee_2000_100_1_2(4,4)-vee_2000_100_1_2(5,4),...

vee_2000_100_1_3(4,4)-vee_2000_100_1_3(5,4)];

i_sup_lambdas_2000_100_E26=[vee_2000_100_0_9 (4,4)+vee_2000_100_0_9(5,4),...

vee_2000_100_1_0(4,4)+vee_2000_100_1_0(5,4),vee_2000_100_1_1(4,4)+vee_2000_100_1_1(5,4),vee_2000_100_1_2(4,4)+vee_2000_10 $\left.0 \_1 \_2(5,4), v e e \_2000 \_100 \_1 \_3(4,4)+v e e \_2000 \_100 \_1 \_3(5,4)\right]$;

ic_2000_100_E26_0_9=[i_inf_lambdas_2000_100_E26(1,1)...

i_sup_lambdas_2000_100_E26(1,1)];

ic_2000_100_E26_1_0=[i_inf_lambdas_2000_100_E26 $(1,2)$...

i_sup_lambdas_2000_100_E26(1,2)];

ic 2000_100_E26 1_1 $=$ [i inf lambdas 2000 100_E26(1,3) ..

i_sup_lambdas_2000_100_E26(1,3)];

ic $2000 \_100 \_$E26 $1 \_2=\left[\mathrm{i}\right.$ inf lambdas $2000 \_100 \_$E26 $(1,4) \ldots$

i_sup_lambdas_2000_100_E26(1,4)];

ic_2000_100_E26_1_3=[i_inf_lambdas_2000_100_E26 $(1,5)$...

i_sup_lambdas_2000_100_E26(1,5)];

vetor_pontos_lambdas_2000_100_E100=[i_inf_lambdas_2000_100_E100,...

i_sup lambdas $2000 \_100$ E100,i inf lambdas $2000 \_100 \_$E70,...

i_sup_lambdas_2000_100_E70,i_inf_lambdas_2000_100_E56,...

i_sup_lambdas_2000_100_E56,i_inf_lambdas_2000_100_E26,...

i_sup_lambdas_2000_100_E26];

$\% 3000 \mathrm{rpm} ; 100 \%$

medias_lambdas_3000_100_E100=[vee $3000 \_100 \_0 \quad 9(4,1), \ldots$

vee_3000_100_1_0(4,1),vee_3000_100_1_1 (4,1),vee_3000_100_1_2(4,1),... vee_3000_100_1_3(4,1)];

i_inf_lambdas_3000_100_E100=[vee_3000_100_0_9(4,1)-...

vee_3000_100_0_9(5,1),vee_3000_100_1_0(4,1)-vee_3000_100_1_0(5,1),... vee 3000_100_1_1(4,1)-vee 3000_100_1_1(5,1),vee 3000_100_1_2(4,1)-... vee_3000_100_1_2(5,1),vee_3000_100_1_3(4,1)-vee_3000_100_1_3(5,1)];

i_sup_lambdas_3000_100_E100 $=[$ vee_3000_100_0_9 $(4,1)+\ldots$

vee $3000 \_100 \_9(5,1)$,vee $3000 \_10010(4,1)+$ vee $3000 \_100 \_1 \_0(5,1) \ldots$ vee_3000_100_1_1(4,1)+vee_3000_100_1_1(5,1),vee_3000_100_1_2 $(4,1)+$.. vee 3000_100_1_2(5,1),vee_3000_100_1_3(4,1)+vee_3000_100_1_3(5,1)];

ic_3000_100_E100_0_9=[i_inf_lambdas_3000_100_E100 $(1,1)$...

i_sup_lambdas_3000_100_E100 $(1,1)]$;

ic_3000_100_E100_1_0=[i_inf_lambdas_3000_100_E100 $(1,2) \ldots$ i_sup_lambdas_3000_100_E100(1,2)];

ic 3000_100_E100 1 1 $1=\left[\mathrm{i} \_\right.$inf lambdas 3000 $100 \_$E100 $(1,3) \ldots$ i_sup_lambdas_3000_100_E100(1,3)];

ic_3000_100_E100_1_2=[i_inf_lambdas_3000_100_E100 $(1,4)$... i_sup_lambdas_3000_100_E100(1,4)];

ic_3000_100_E100_1_3 =[i_inf_lambdas_3000_100_E100(1,5) ... i_sup_lambdas_3000_100_E100(1,5)];

medias_lambdas_3000_100_E70=[vee_3000_100_0_9(4,2),.. vee_3000_100_1_0(4,2),vee_3000_100_1_1(4,2),vee_3000_100_1_2(4,2),... vee_3000_100_1_3(4,2)];

i_inf_lambdas_3000_100_E70=[vee_3000_100_0_9 $(4,2)-. .$.

vee 3000_100_0_9(5,2),vee_3000_100_1_0(4,2)-vee_3000_100_1_0(5,2),... vee_3000_100_1_1(4,2)-vee_3000_100_1_1(5,2),vee_3000_100_1_2(4,2)-... vee_3000_100_1_2(5,2),vee_3000_100_1_3(4,2)-vee_3000_100_1_3(5,2)];

i_sup_lambdas_3000_100_E70=[vee_3000_100_0_9 $4(4,2)+.$. vee_3000_100_0_9(5,2),vee_3000_100_1_0(4,2)+vee_3000_100_1_0(5,2),... vee_3000_100_1_1(4,2)+vee_3000_100_1_1(5,2),vee_3000_100_1_2 $(4,2)+$... vee_3000_100_1_2(5,2),vee_3000_100_1_3(4,2)+vee_3000_100_1_3(5,2)];

ic_3000_100_E70_0_9=[i_inf_lambdas_3000_100_E70 $(1,1) \ldots$ i_sup_lambdas_3000_100_E70 $(1,1)$ ];

ic_3000_100_E70_1_0=[i_inf_lambdas_3000_100_E70 $(1,2)$... i_sup_lambdas_3000_100_E70 (1,2)];

ic_3000_100_E70_1_1=[i_inf_lambdas_3000_100_E70 $(1,3)$... i_sup_lambdas_3000_100_E70(1,3)];

ic_3000_100_E70_1_2=[i_inf_lambdas_3000_100_E70 $(1,4) \ldots$ i_sup_lambdas_3000_100_E70(1,4)];

ic_3000_100_E70_1_3=[i_inf_lambdas_3000_100_E70 $(1,5) \ldots$ i_sup_lambdas_3000_100_E70(1,5)];

medias_lambdas_3000_100_E56=[vee_3000_100_0_9(4,3),...

vee $3000 \_100 \_10(4,3)$, vee $3000 \_100 \_11(4,3)$,

vee_3000_100_1_2(4,3),vee_3000_100_1_3(4,3)];

i_inf_lambdas_3000_100_E56=[vee_3000_100_0_9(4,3)-...

vee_3000_100_0_9(5,3),vee_3000_100_1_0(4,3)-vee_3000_100_1_0(5,3),... vee_3000_100_1_1(4,3)-vee_3000_100_1_1(5,3),vee_3000_100_1_2(4,3)-... vee 3000_100_1_2(5,3),vee 3000_100_1_3(4,3)-vee 3000_100_1 3(5,3)];

i_sup_lambdas_3000_100_E56=[vee_3000_100_0_9(4,3)+... vee_3000_100_0_9(5,3),vee_3000_100_1_0(4,3)+vee_3000_100_1_0(5,3),... vee $3000 \_100 \_11(4,3)+$ vee $3000100 \_1$ 1 $1(5,3)$, vee $3000 \_100 \_1 \_(4,3)+$... vee_3000_100_1_2(5,3),vee_3000_100_1_3(4,3)+vee_3000_100_1_3(5,3)];

ic 3000_100_E56_0_9=[i_inf_lambdas_3000_100_E56 $(1,1)$... 


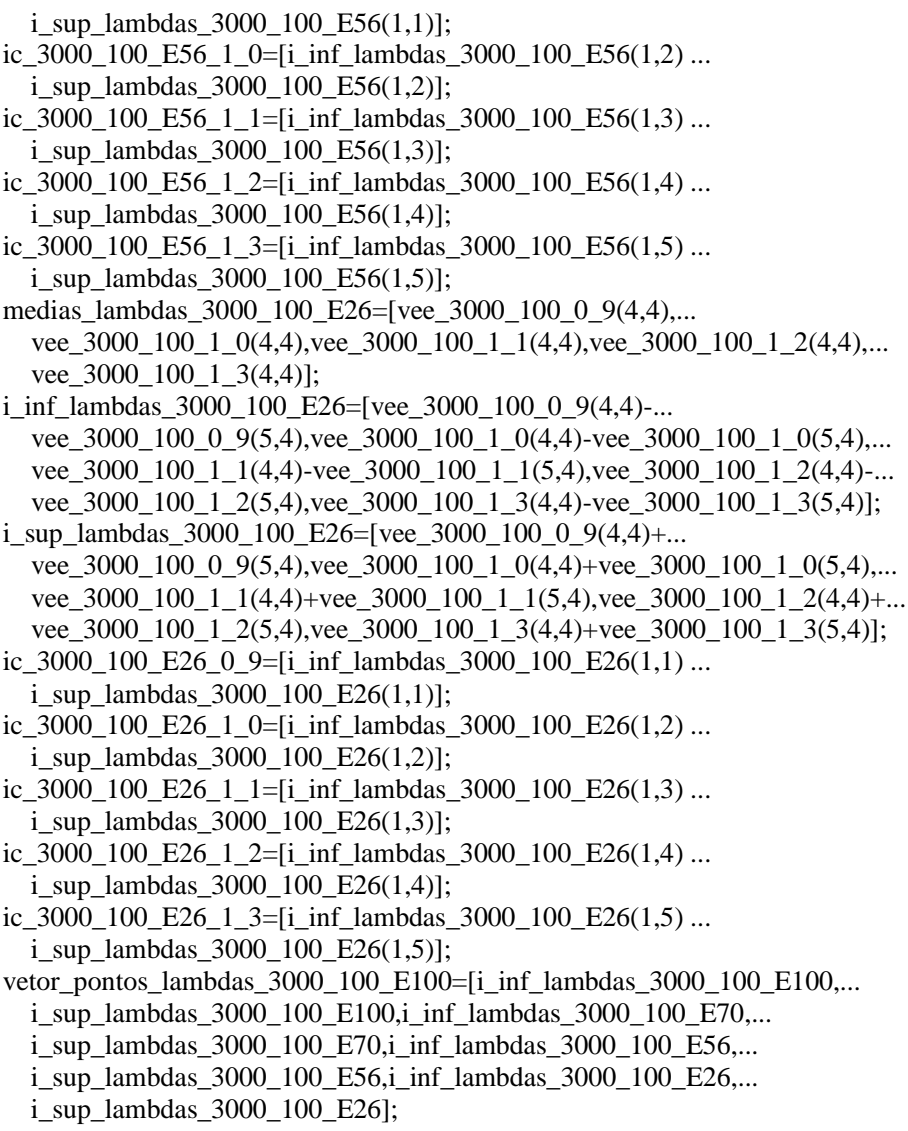

\section{A4. ALGORITMO PARA OBTENÇÃO DOS MODELOS DE ESTIMAÇÃO DA FRAÇÃO MÁSSICA DE ETANOL (OU DO FATOR LAMBDA)}

$\%$ Entrada de dados:

clear all

clc

format long g

load('dados_total_ensaio_2');

nome $=$ dados_total_ensaio_2(:,1);

rotacao $=$ cell2mat $($ dados_total_ensaio_2(:,2));

borboleta $=$ cell2mat (dados_total_ensaio_2 $(:, 3))$;

lambda $=$ cell2mat (dados_total_ensaio_2(:,4));

tbs $=$ cell2mat (dados_total_ensaio_2 $(: \overline{5}))$;

tbu=cell2mat(dados_total_ensaio_2(:,6));

mc $=$ cell2mat(dados_total_ensaio_2(:,7));

torque $=$ cell2mat $($ dados_total_ensaio_2(:,8));

$\mathrm{pb}=$ cell2mat(dados_total_ensaio_2(:,9));

tlambda $=$ cell2mat(dados_total_ensaio_2(:,10));

tempo_inj=cell2mat(dados_total_ensaio_2(:,11));

$\mathrm{HC}=$ cell2mat (dados_total_ensaio_2 $(:, 12))$;

$\mathrm{CO}=$ cell2mat (dados_total_ensaio_2(:,13));

CO2=cell2mat (dados_total_ensaio_2(:,14));

$\mathrm{O} 2=$ cell2mat(dados_total_ensaio_2(:,15));

NOx=cell2mat(dados_total_ensaio_2(:,16))

ma_media=cell2mat(dados_total_ensaio_2(:,17));

tadm_media $=$ cell2mat $($ dados_total_ensaio_2 $(:, 18))$;

tesc_media $=$ cell $2 \mathrm{mat}($ dados_total_ensaio_2 $(:, 19))$;

tla_media $=$ cell2mat(dados_total_ensaio_2 $(:, 20))$;

rpm_real_media $=$ cell2mat(dados_total_ensaio_2(:,21));

$\%$ Criar uma matriz com 1 coluna e uma rotacao real para cada ciclo de cada uma das 36 condições de ensaio.

rpm_real_ciclo_a_ciclo=cell2mat(dados_total_ensaio_2 $(:, 22))$;

angulo_pico=cell2mat (dados_total_ensaio_2 $(:, 24))$;

pico_de_pressao=cell2mat $($ dados_total_ensaio_2 $(:, 25))$;

aG_m3_j0 $=($ dados_total_ensaio_2 $(:, 26))$;

aG_cm3_j0 $=($ dados_total_ensaio_2 $(:, 27))$;

angulo_pico_media=cell2mat (dados_total_ensaio_2(:,28)); 
pico_de_pressao_e_am_medias =cell2mat(dados_total_ensaio_2(:,29));

aG_m3_j0_media=cell2mat(dados_total_ensaio_2 $(:, 30))$;

$\mathrm{aG} \_\mathrm{m} 3 \mathrm{j} 0$ medias $=\mathrm{aG} \mathrm{m} 3 \mathrm{j} 0$ media(: 2 :end);

aG_cm3_j0_media=cell2mat(dados_total_ensaio_2(:,31));

k_cm3_media_j $0=$ cell2mat(dados_total_ensaio_2(:32));

b_cm3_media_j $0=$ cell2mat $($ dados_total_ensaio_2(:,33));

pico_de_pressao_e_am_medias_Perro=cell2mat(dados_total_ensaio_2(:,34));

$\mathrm{k} \_\mathrm{cm} 3$ media $t \mathrm{t} \_\mathrm{j} 2=\operatorname{cell} 2 \mathrm{mat}(\mathrm{dados}$ total ensaio $2(:, 85))$;

b_cm3_media_tx_j2=cell2mat(dados_total_ensaio_2 $(:, 86))$;

momento_pc_Perro_j1_norm=cell2mat(dados_total_ensaio_2(:,88));

momento_pc_Perro_j2_norm=cell2mat(dados_total_ensaio_2 $(:, 89))$;

momento_pc_Perro_j3_norm=cell2mat(dados_total_ensaio_2(:,90));

momento_pc_Perro j4 norm=cell2mat (dados total ensaio_2 $(: 91))$;

momento_pc_Perro_j5_norm=cell2mat(dados_total_ensaio_2(:,92));

momento_taxa_de_pressao_pc_Perro=cell2mat(dados_total_ensaio_2(:,93));

pressao_inicio_da_combustao=cell2mat(dados_total_ensaio_2(:,94));

pc_Perro_i_comb=cell2mat(dados_total_ensaio_2(:,95));

am_i comb $=$ cell2mat(dados total ensaio $2(:, 96))$;

am_i_comb_rad=cell2mat(dados_total_ensaio_2(:,97));

volume_m3_i_comb=cell2mat(dados_total_ensaio_2(:,98));

k_i_comb=cell2mat(dados_total_ensaio_2(:,99));

pressao_final_da_combustao=cell2mat(dados_total_ensaio_2(:,100));

pc_Perro_f_comb=cell2mat(dados_total_ensaio_2(:,101));

am_f_comb=cell2mat(dados_total_ensaio_2(:,102));

am_f_comb_rad=cell2mat(dados_total_ensaio_2(:,103));

volume_m3_f_comb=cell2mat(dados_total_ensaio_2(:,104));

am_xb_10=cell2mat(dados_total_ensaio_2 $(:, 105))$;

pc_Perro_xb_10=cell2mat (dados_total_ensaio_2(:,106));

am_xb_90=cell2mat(dados_total_ensaio_2(:,107));

pc_Perro_xb_90=cell2mat(dados_total_ensaio_2 $(:, 108))$;

duracao_comb_xb=cell2mat(dados_total_ensaio_2(:,109));

duracao_10_ate_90_xb=cel12mat(dados_total_ensaio_2(:,110));

porcentagem massica_de_etanol=cell2mat (dados_total_ensaio_2(:,111));

porcentagem_massica_de_gasolina=cell2mat(dados_total_ensaio_2(:,112));

$\%$ Criar os vetores de cada modelo (considerando que cada linha do vetor_modelos_geral tenha o vetor em questão para cada média, ou seja, cada modelo será representado por uma linha no vetor modelos geral e por 59 colunas (ensaio 2) representando cada média

$\%$ Criação do vetor de dados para o Modelo 1 e Janela $1(\%)$

vetor_modelos_0 01,1$\}=\mathrm{aG} \_\mathrm{m} 3 \mathrm{j} 0 \_$medias;

vetor_modelos_0 $\{1,2\}=$ rpm_real_media;

vetor_modelos_0 $\{1,3\}=$ momento_pc_Perro_medio_j1_norm_ordem_2;

vetor_modelos_0 $\{1,4\}=$ momento_pc_Perro_medio_j1_norm_ordem_3;

vetor_modelos_0 $\{1,5\}=$ porcentagem_massica_de_etanol;

$\%$ Criação do vetor de dados para o Modelo 1 e Janela $2(\%)$

vetor_modelos_0 $\{2,1\}=\mathrm{aG} \_\mathrm{m} 3$ _j0_medias:

vetor_modelos_0 $\{2,2\}=$ rpm_real_media;

vetor_modelos_0 $\{2,3\}=$ momento_pc_Perro_medio_j2_norm_ordem $\_2$;

vetor_modelos_0 $\{2,4\}=$ momento_pc_Perro_medio_j2_norm_ordem_3;

vetor_modelos_0 $\{2,5\}=$ porcentagem_massica_de_etanol;

\% Criação do vetor de dados para o Modelo 1 e Janela 3 (\%)

vetor_modelos_0 $\{3,1\}=\mathrm{aG} \_\mathrm{m} 3 \_j 0 \_$medias;

vetor_modelos_0 $\{3,2\}=$ rpm_real_media;

vetor_modelos_0 $\{3,3\}=$ momento_pc_Perro_medio_j3_norm_ordem_2; vetor_modelos_0 $\{3,4\}=$ momento_pc_Perro_medio_j3_norm_ordem_3;

vetor_modelos_0 $\{3,5\}=$ porcentagem_massica_de_etanol;

$\%$ Criação do vetor de dados para o Modelo 1 e Janela 4 (\%)

vetor_modelos_0 $\{4,1\}=\mathrm{aG} \_\mathrm{m} 3 \_j 0 \_$medias;

vetor_modelos_0 $\{4,2\}=$ rpm_real_media;

vetor_modelos_0 $\{4,3\}=$ momento_pc_Perro_medio_j4_norm_ordem_2;

vetor_modelos_0 $\{4,4\}=$ momento_pc_Perro_medio_j4_norm_ordem_3;

vetor_modelos_0 $\{4,5\}=$ porcentagem_massica_de_etanol;

\% Criação do vetor de dados para o Modelo 1 e Janela 5 (\%)

vetor_modelos_0 $\{5,1\}=\mathrm{aG} \_\mathrm{m} 3$ j0_medias;

vetor_modelos_0 $\{5,2\}=$ rpm_real_media;

vetor_modelos_0 $\{5,3\}=$ momento_pc_Perro_medio_j5_norm_ordem_2;

vetor_modelos_0 $\{5,4\}=$ momento_pc_Perro_medio_j5_norm_ordem_3

vetor_modelos_0 $\{5,5\}=$ porcentagem_massica_de_etanol;

\% Críação do vetor de dados para o Modelo 2 Janela 1 (\%)

vetor_modelos_0 $\{6,1\}=\mathrm{aG} \_\mathrm{m} 3 \_\mathrm{j} 0 \_$medias;

vetor_modelos_0 $\{6,2\}=$ rpm_real_media;

vetor_modelos_0 $\{6,3\}=$ tempo_inj;

vetor_modelos_0 $\{6,4\}=$ momento_pc_Perro_medio_j1_norm_ordem_2;

vetor_modelos_0 $\{6,5\}=$ momento_pc_Perro_medio_j1_norm_ordem_3;

vetor_modelos_0 $\{6,6\}=$ porcentagem_massica_de_etanol;

$\%$ Criação do vetor de dados para o Modelo 2 Janela $2(\%)$

vetor_modelos_0 $\{7,1\}=\mathrm{aG} \_\mathrm{m} 3$ j0_medias;

vetor_modelos_0 $\{7,2\}=$ rpm_real_media; 
vetor_modelos_0 $\{7,3\}=$ tempo_inj;

vetor_modelos_0 $\{7,4\}=$ momento_pc_Perro_medio_j2_norm_ordem_2; vetor_modelos_0 $\{7,5\}=$ momento_pc_Perro_medio_j2_norm_ordem_3; vetor_modelos_0 $\{7,6\}=$ porcentagem_massica_de_etanol;

$\%$ Criação do vetor de dados para o Modelo 2 Janela $3(\%)$ vetor_modelos_0 $\{8,1\}=\mathrm{aG} \_\mathrm{m} 3$ j0_medias;

vetor_modelos_0 $\{8,2\}=$ rpm_real_media;

vetor_modelos_0 $\{8,3\}=$ tempo_inj;

vetor_modelos_0 $\{8,4\}=$ momento_pc_Perro_medio_j3_norm_ordem_2; vetor_modelos_0 $\{8,5\}=$ momento_pc_Perro_medio_j3_norm_ordem_3; vetor_modelos_0 $\{8,6\}=$ porcentagem_massica_de_etanol; $\%$ Criação do vetor de dados para o Modelo 2 Janela 4 (\%) vetor_modelos_0 $\{9,1\}=\mathrm{aG} \_\mathrm{m} 3 \_j 0 \_$medias;

vetor_modelos_0 $\{9,2\}=$ rpm_real_media;

vetor_modelos_0 $\{9,3\}=$ tempo_inj;

vetor_modelos_0 $\{9,4\}=$ momento_pc_Perro_medio_j4_norm_ordem_2; vetor_modelos_0 $\{9,5\}=$ momento_pc_Perro_medio_j4_norm_ordem_3; vetor_modelos_0 $\{9,6\}=$ porcentagem_massica_de_etanol;

$\%$ Criação do vetor de dados para o Modelo 2 Janela $5(\%)$

vetor_modelos_0 $\{10,1\}=\mathrm{aG} \_$m3_j0_medias;

vetor_modelos_0 $\{10,2\}=$ rpm_real_media;

vetor_modelos_0 $\{10,3\}=$ tempo_inj;

vetor_modelos_0 $\{10,4\}=$ momento_pc_Perro_medio_j5_norm_ordem_2

vetor_modelos_0 $\{10,5\}=$ momento_pc_Perro_medio_j5_norm_ordem_3; vetor_modelos_0 $\{10,6\}=$ porcentagem_massica_de_etanol;

\% Criação do vetor de dados para o Modelo 3 Janela 1 (\%)

vetor_modelos_0 $\{11,1\}=\mathrm{aG} \_\mathrm{m} 3 \_j 0 \_$medias;

vetor_modelos_0 $\{11,2\}=$ rpm_real_media;

vetor_modelos_0 $\{11,3\}=$ tempo_inj;

vetor_modelos_0 $\{11,4\}=$ pico_de_pressao_medias;

vetor_modelos_0 $\{11,5\}=$ momento_pc_Perro_medio_j1_norm_ordem_2;

vetor_modelos_0 $\{11,6\}=$ momento_pc_Perro_medio_j1_norm_ordem_3; vetor_modelos_0 $\{11,7\}=$ porcentagem_massica_de_etanol;

$\%$ Criação do vetor de dados para o Modelo 3 Janela 2 (\%)

vetor_modelos_0 $\{12,1\}=\mathrm{aG} \_$m3_j0_medias;

vetor_modelos_0 $\{12,2\}=$ rpm_real_media;

vetor_modelos_0 $\{12,3\}=$ tempo_inj;

vetor_modelos_0 $\{12,4\}=$ pico_de_pressao_medias;

vetor_modelos_0 $\{12,5\}=$ momento_pc_Perro_medio_j2_norm_ordem_2; vetor_modelos_0 $\{12,6\}=$ momento_pc_Perro_medio_j2_norm_ordem_3; vetor_modelos_0 $\{12,7\}=$ porcentagem_massica_de_etanol; $\%$ Criação do vetor de dados para o Modelo 3 Janela $3(\%)$ vetor_modelos_0 $\{13,1\}=\mathrm{aG} \_$m3_j0_medias;

vetor_modelos_0 $\{13,2\}=$ rpm_real_media;

vetor_modelos_0 $\{13,3\}=$ tempo_inj;

vetor_modelos_0 $\{13,4\}=$ pico_de_pressao_medias;

vetor_modelos_0 $\{13,5\}=$ momento_pc_Perro_medio_j3_norm_ordem_2; vetor_modelos_0 $\{13,6\}=$ momento_pc_Perro_medio_j3_norm_ordem_3; vetor_modelos_0 $\{13,7\}=$ porcentagem_massica_de_etanol; $\%$ Criação do vetor de dados para o Modelo 3 Janela $4(\%)$ vetor_modelos_0 $\{14,1\}=\mathrm{aG} \_$m3_j0_medias;

vetor_modelos_0 $\{14,2\}=$ rpm_real_media;

vetor_modelos_0 $\{14,3\}=$ tempo_inj;

vetor_modelos_0 $\{14,4\}=$ pico_de_pressao_medias;

vetor_modelos_0 $\{14,5\}=$ momento_pc_Perro_medio_j4_norm_ordem_2 vetor_modelos_0 $\{14,6\}=$ momento_pc_Perro_medio_j4_norm_ordem_3; vetor_modelos_0 $\{14,7\}=$ porcentagem_massica_de_etanol;

$\%$ Criação do vetor de dados para o Modelo 3 Janela $5(\%)$

vetor_modelos_0 $\{15,1\}=\mathrm{aG} \_\mathrm{m} 3$ j0_medias;

vetor_modelos_0 $\{15,2\}=$ rpm_real_media;

vetor_modelos_0 $\{15,3\}=$ tempo_inj;

vetor_modelos_0 $\{15,4\}=$ pico_de_pressao_medias;

vetor_modelos_0 $\{15,5\}=$ momento_pc_Perro_medio_j5_norm_ordem_2

vetor_modelos_0 $\{15,6\}=$ momento_pc_Perro_medio_j5_norm_ordem_3;

vetor_modelos_0 $\{15,7\}=$ porcentagem_massica_de_etanol;

\% Criação do vetor de dados para o Modelo 4 Janela 1 (\%)

vetor_modelos_0 $\{16,1\}=a G \_m 3 \_j 0 \_$medias;

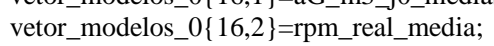

vetor_modelos_0 $\{16,3\}=$ tempo_inj;

vetor_modelos_0 $\{16,4\}=$ pico_de_pressao_medias;

vetor_modelos_0 $\{16,5\}=$ angulo_de_manivelas_picos_medias;

vetor_modelos_0 $\{16,6\}=$ momento_pc_Perro_medio_j1_norm_ordem_2;

vetor_modelos_0 $\{16,7\}=$ momento_pc_Perro_medio_j1_norm_ordem_3;

vetor_modelos_0 $\{16,8\}=$ porcentagem_massica_de_etanol;

$\%$ Criação do vetor de dados para o Modelo 4 Janela $2(\%)$

vetor_modelos_0 $\{17,1\}=\mathrm{aG} \_$m3_j0_medias; 
vetor_modelos_0 $\{17,2\}=$ rpm_real_media;

vetor_modelos_0 $\{17,3\}=$ tempo_inj;

vetor_modelos_0 $\{17,4\}=$ pico_de_pressao_medias:

vetor_modelos_0 $\{17,5\}=$ angulo_de_manivelas_picos_medias;

vetor_modelos_0 $\{17,6\}=$ momento_pc_Perro_medio_j2_norm_ordem_2;

vetor_modelos_0 $\{17,7\}=$ momento_pc_Perro_medio_j2_norm_ordem_3;

vetor_modelos_0 $\{17,8\}=$ porcentagem_massica_de_etanol;

$\%$ Criação do vetor de dados para o Modelo 4 Janela $3(\%)$

vetor_modelos_0 $\{18,1\}=\mathrm{aG} \_\mathrm{m} 3$ j0_medias;

vetor_modelos_0 $\{18,2\}=$ rpm_real_media;

vetor_modelos_0 $\{18,3\}=$ tempo_inj;

vetor_modelos_0 $\{18,4\}=$ pico_de_pressao_medias;

vetor_modelos_0 $\{18,5\}=$ angulo_de_manivelas_picos_medias;

vetor_modelos_0 $\{18,6\}=$ momento_pc_Perro_medio_j3_norm_ordem_2;

vetor_modelos_0 $\{18,7\}=$ momento_pc_Perro_medio_j3_norm_ordem_3;

vetor_modelos_0 $\{18,8\}=$ porcentagem_massica_de_etanol;

\% Criação do vetor de dados para o Modelo 4 Janela 4 (\%)

vetor_modelos_0 $\{19,1\}=\mathrm{aG} \_\mathrm{m} 3 \_\mathrm{j} 0 \_$medias;

vetor_modelos_0 $\{19,2\}=$ rpm_real_media;

vetor_modelos_0 $\{19,3\}=$ tempo_inj;

vetor_modelos_0 $\{19,4\}=$ pico_de_pressao_medias;

vetor_modelos_0 $\{19,5\}=$ angulo_de_manivelas_picos_medias;

vetor_modelos_0 $\{19,6\}=$ momento_pc_Perro_medio_j4_norm_ordem_2;

vetor_modelos_0 $\{19,7\}=$ momento_pc_Perro_medio_j4_norm_ordem_3;

vetor_modelos_0 $\{19,8\}=$ porcentagem_massica_de_etanol;

\% Criação do vetor de dados para o Modelo 4 Janela 5 (\%)

vetor_modelos_0 $\{20,1\}=\mathrm{aG} \_\mathrm{m} 3 \_\mathrm{j} 0 \_$medias;

vetor_modelos_0 $\{20,2\}=$ rpm_real_media;

vetor_modelos_0 $\{20,3\}=$ tempo_inj;

vetor_modelos_0 $\{20,4\}=$ pico_de_pressao_medias;

vetor_modelos_0 $\{20,5\}=$ angulo_de_manivelas_picos_medias;

vetor_modelos_0 $\{20,6\}=$ momento_pc_Perro_medio_j5_norm_ordem_2;

vetor_modelos_0 $\{20,7\}=$ momento_pc_Perro_medio_j5_norm_ordem_3;

vetor_modelos_0 $\{20,8\}=$ porcentagem_massica_de_etanol;

$\%$ Criação do vetor de dados para o Modelo 5 Janela 1 (\%)

vetor_modelos_0 $\{21,1\}=\mathrm{aG} \_\mathrm{m} 3 \_\mathrm{j} 0$ medias;

vetor_modelos_0 $\{21,2\}=$ rpm_real_media;

vetor_modelos_0 $\{21,3\}=$ tempo_inj;

vetor_modelos_0 $\{21,4\}=$ pico_de_pressao_medias;

vetor_modelos_0 $\{21,5\}=$ angulo_de_manivelas_picos_medias;

vetor_modelos_0 $\{21,6\}=$ momento_taxa_de_pressao_pc_Perro_medio_ordem_2;

vetor_modelos_0 $\{21,7\}=$ momento_taxa_de_pressao_pc_Perro_medio_ordem_3;

vetor_modelos_0 $\{21,8\}=$ momento_pc_Perro_medio_j1_norm_ordem_2;

vetor_modelos_0 $\{21,9\}=$ momento_pc_Perro_medio_j1_norm_ordem_3;

vetor_modelos_0 $\{21,10\}=$ porcentagem_massica_de_etanol;

$\%$ Criação do vetor de dados para o Modelo 5 Janela $2(\%)$

vetor_modelos_0 $\{22,1\}=\mathrm{aG} \_\mathrm{m} 3 \_\mathrm{j} 0 \_$medias;

vetor_modelos_0 $\{22,2\}=$ rpm_real_media;

vetor_modelos_0 $\{22,3\}=$ tempo_inj;

vetor_modelos_0 $\{22,4\}=$ pico_de_pressao_medias;

vetor_modelos_0 $\{22,5\}=$ angulo_de_manivelas_picos_medias;

vetor_modelos_0 $\{22,6\}=$ momento_taxa_de_pressao_pc_Perro_medio_ordem_2;

vetor_modelos_0 $\{22,7\}=$ momento_taxa_de_pressao_pc_Perro_medio_ordem_3;

vetor_modelos_0 $\{22,8\}=$ momento_pc_Perro_medio_j2_norm_ordem_2;

vetor_modelos_0 $\{22,9\}=$ momento_pc_Perro_medio_j2_norm_ordem_3;

vetor_modelos_0 $0\{22,10\}=$ porcentagem_massica_de_etanol;

$\%$ Criação do vetor de dados para o Modelo 5 Janela 3 (\%)

vetor_modelos_0 $\{23,1\}=\mathrm{aG} \_\mathrm{m} 3 \_\mathrm{j} 0 \_$medias;

vetor_modelos_0 $\{23,2\}=$ rpm_real_media;

vetor_modelos_0 $\{23,3\}=$ tempo_inj;

vetor_modelos_0 $\{23,4\}=$ pico_de_pressao_medias;

vetor_modelos_0 $\{23,5\}=$ angulo_de_manivelas_picos_medias;

vetor_modelos_0 $\{23,6\}=$ momento_taxa_de_pressao_pc_Perro_medio_ordem_2;

vetor_modelos_0 $\{23,7\}=$ momento_taxa_de_pressao_pc_Perro_medio_ordem_3;

vetor_modelos_0 $\{23,8\}=$ momento_pc_Perro_medio_j3_norm_ordem_2;

vetor_modelos_0 $\{23,9\}=$ momento_pc_Perro_medio_j3_norm_ordem_3;

vetor_modelos_0 $\{23,10\}=$ porcentagem_massica_de_etanol;

\% Criação do vetor de dados para o Modelo 5 Janela 4 (\%)

vetor_modelos_0 $\{24,1\}=\mathrm{aG} \_\mathrm{m} 3 \_\mathrm{j} 0 \_$medias;

vetor_modelos_0 $\{24,2\}=$ rpm_real_media;

vetor_modelos_0 $\{24,3\}=$ tempo_inj;

vetor_modelos_0 $\{24,4\}=$ pico_de_pressao_medias;

vetor_modelos_0 $\{24,5\}=$ angulo_de_manivelas_picos_medias;

vetor_modelos_0 $\{24,6\}=$ momento_taxa_de_pressao_pc_Perro_medio_ordem_2;

vetor_modelos_0 $\{24,7\}=$ momento_taxa_de_pressao_pc_Perro_medio_ordem_3; vetor_modelos_0 $\{24,8\}=$ momento_pc_Perro_medio_j4_norm_ordem_2; 
vetor_modelos_0 $\{24,9\}=$ momento_pc_Perro_medio_j4_norm_ordem_3; vetor_modelos_0 $\{24,10\}=$ porcentagem_massica_de_etanol; vetor_modelos_0 $\{35,11\}=$ porcentagem_massica_de_etanol; \% Criação do vetor de dados para o Modelo 8 Janela 1, 2, 3 e 4 (\%) vetor_modelos_0 $\{36,1\}=\mathrm{aG} \_$m3_j0_medias;

vetor_modelos_0 $\{36,2\}=$ rpm_real_media;

vetor_modelos_0 $\{36,3\}=$ tempo_inj;

vetor_modelos_0 $\{36,4\}=$ pico_de_pressao_medias;

vetor_modelos_0 $\{36,5\}=$ angulo_de_manivelas_picos_medias;

vetor_modelos_0 $\{36,6\}=$ momento_pc_Perro_medio_j5_norm_ordem_2 vetor_modelos_0 $\{36,7\}=$ momento_pc_Perro_medio_j5_norm_ordem_3; vetor_modelos_0 $\{36,8\}=$ momento_pc_Perro_medio_j5_norm_ordem_4; vetor_modelos_0 $\{36,9\}=$ momento_pc_Perro_medio_j5_norm_ordem_5; vetor_modelos_0 $\{36,10\}=$ tadm_media;

vetor_modelos_0 $\{36,11\}=$ tesc_media;

vetor_modelos_0 $\{36,12\}=$ porcentagem_massica_de_etanol;

vetor_modelos_0 $\{37,1\}=\mathrm{aG} \_$m3_j0_medias;

vetor_modelos_0 $\{37,2\}=$ rpm_real_media;

vetor_modelos_0 $\{37,3\}=$ tempo_inj;

vetor_modelos_0 $\{37,4\}=$ pico_de_pressao_medias;

vetor_modelos_0 $\{37,5\}=$ angulo_de_manivelas_picos_medias

vetor_modelos_0 $\{37,6\}=$ momento_pc_Perro_medio_j5_norm_ordem_2; vetor modelos $0\{37,7\}=$ momento pc Perro medio j5 norm ordem 3; vetor_modelos_0 $\{37,8\}=$ momento_pc_Perro_medio_j5_norm_ordem_4; vetor_modelos_0 $\{37,9\}=$ momento_pc_Perro_medio_j5_norm_ordem_5 vetor_modelos_0 $\{37,10\}=$ tadm_media;

vetor_modelos_0 $\{37,11\}=$ tesc_media;

vetor_modelos $0\{37,12\}=$ porcentagem massica_de etanol

vetor_modelos_0 $\{38,1\}=\mathrm{aG} \_$m3_j0_medias;

vetor_modelos_0 $\{38,2\}=$ rpm_real_media;

vetor_modelos_0 $\{38,3\}=$ tempo_inj;

vetor_modelos_0 $\{38,4\}=$ pico_de_pressao_medias;

vetor_modelos_0 $\{38,5\}=$ angulo_de manivelas_picos_medias;

vetor_modelos_0 $\{38,6\}=$ momento_pc_Perro_medio_j5_norm_ordem_2; vetor_modelos_0 $\{38,7\}=$ momento_pc_Perro_medio_j5_norm_ordem_3 vetor_modelos_0 $\{38,8\}=$ momento_pc_Perro_medio_j5_norm_ordem_4; vetor_modelos_0 $\{38,9\}=$ momento_pc_Perro_medio_j5_norm_ordem_5; vetor_modelos $0\{38,10\}=$ tadm_media;

vetor_modelos_0 $\{38,11\}=$ tesc_media;

vetor_modelos_0 $\{38,12\}=$ porcentagem_massica_de_etanol

vetor_modelos_0 $\{39,1\}=a G \_m 3 \_j 0 \_m e d i a s ;$

vetor_modelos_0 $\{39,2\}=$ rpm_real_media;

vetor_modelos_0 $\{39,3\}=$ tempo_inj;

vetor_modelos_0 $\{39,4\}=$ pico_de_pressao_medias;

vetor_modelos_0 $\{39,5\}=$ angulo_de_manivelas_picos_medias

vetor_modelos_0 $\{39,6\}=$ momento_pc_Perro_medio_j5_norm_ordem_2;

vetor_modelos_0 $\{39,7\}=$ momento_pc_Perro_medio_j5_norm_ordem_3;

vetor_modelos_0 $\{39,8\}=$ momento_pc_Perro_medio_j5_norm_ordem_4;

vetor_modelos_0 $\{39,9\}=$ momento_pc_Perro_medio_j5_norm_ordem_5;

vetor_modelos_0 $\{39,10\}=$ tadm_media;

vetor_modelos_0 $\{39,11\}=$ tesc_media;

vetor_modelos_0 $\{39,12\}=$ porcentagem_massica_de_etanol;

vetor_modelos_0 $\{40,1\}=\mathrm{aG} \_$m3_j0_medias;

vetor_modelos_0 $\{40,2\}=$ rpm_real_media;

vetor_modelos_0 $\{40,3\}=$ tempo_inj;

vetor_modelos_0 $\{40,4\}=$ pico_de_pressao_medias;

vetor_modelos_0 $\{40,5\}=$ angulo_de_manivelas_picos_medias;

vetor_modelos_0 $\{40,6\}=$ momento_pc_Perro_medio_j5_norm_ordem_2;

vetor_modelos_0 $\{40,7\}=$ momento_pc_Perro_medio_j5_norm_ordem_3;

vetor_modelos_0 $\{40,8\}=$ momento_pc_Perro_medio_j5_norm_ordem_4; vetor_modelos_0 $\{40,9\}=$ momento_pc_Perro_medio_j5_norm_ordem_5;

vetor_modelos_0 $\{40,10\}=$ tadm_media;

vetor_modelos_0 $\{40,11\}=$ tesc_media;

vetor_modelos_0 $\{40,12\}=$ porcentagem_massica_de_etanol;

$\%$ Criação do vetor de dados para o Modelo 9 Janela 1, 2, 3 e 4 (\%)

vetor_modelos_0 $\{41,1\}=\mathrm{aG} \_\mathrm{m} 3$ j0_medias;

vetor_modelos_0 $\{41,2\}=$ rpm_real_media;

vetor_modelos_0 $\{41,3\}=$ tempo_inj;

vetor_modelos_0 $\{41,4\}=$ pico_de_pressao_medias;

vetor_modelos_0 $\{41,5\}=$ angulo_de_manivelas_picos_medias;

vetor_modelos_0 $\{41,6\}=$ momento_derivada_media_j1_norm_ordem_2;

vetor_modelos_0 $\{41,7\}=$ momento_derivada_media_j1_norm_ordem_3;

vetor_modelos_0 $\{41,8\}=$ momento_derivada_media_j1_norm_ordem_2.^2

vetor_modelos_0 $\{41,9\}=$ momento_derivada_media_j1_norm_ordem_3.^2;

vetor_modelos_0 $\{41,10\}=$ porcentagem_massica_de_etanol;

vetor_modelos_0 $\{42,1\}=\mathrm{aG} \_\mathrm{m} 3 \_j 0 \_$medias; 


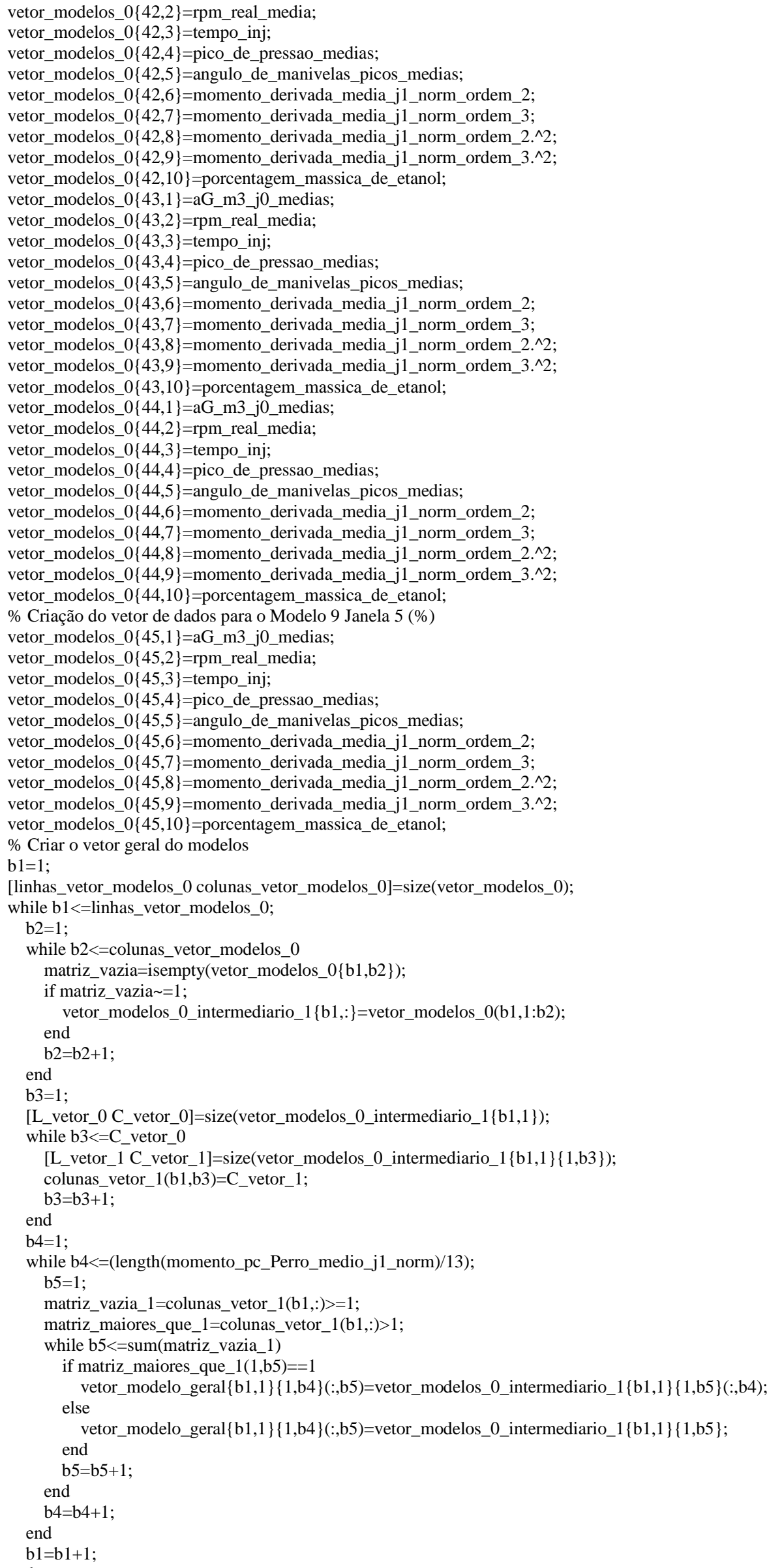




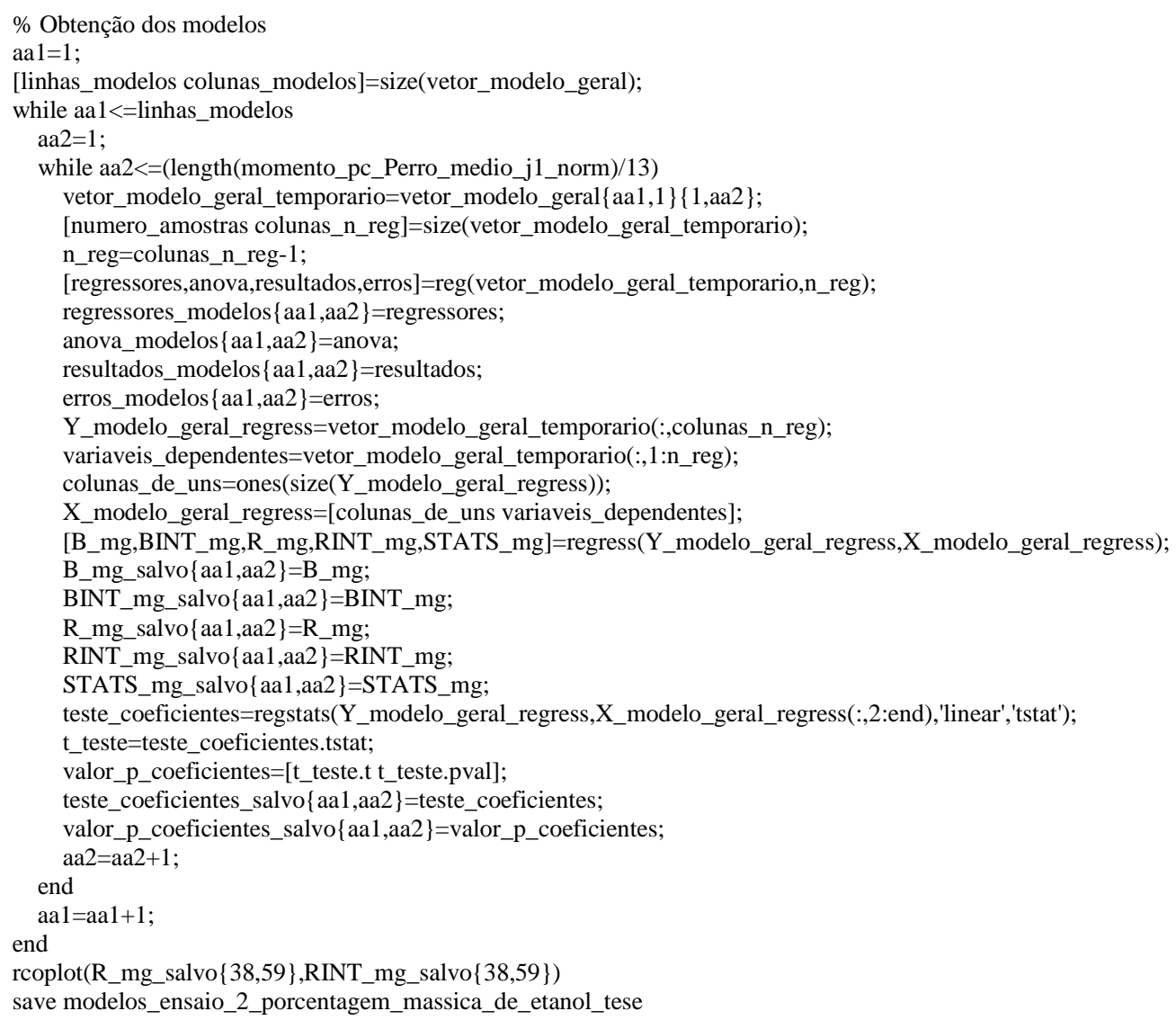




\section{APÊNDICE B - Relações ar-combustível e cálculo da porcentagem em massa de gasolina tipo A em cada tipo de combustível}

Segundo Martins (2006), a relação ar-combustível (A/C) é a razão entre a massa de ar necessária para a combustão completa de uma determinada massa de combustível.

Os quatro combustíveis utilizados nos experimentos são compostos por etanol 92,79 INPM (100\% etanol 92,79 INPM - E100), gasolina tipo $C$ (100\% gasolina tipo $C$ - E26) e duas misturas dos dois primeiros (mistura de 60\% de etanol 92,79 INPM com 40\% de gasolina tipo $C$ - E70, em massa) e mistura de $40 \%$ de etanol 92,79 INPM com $60 \%$ de gasolina tipo $C$ - E56, em massa).

A porcentagem de álcool em massa ou grau alcoólico INPM (quantidade em gramas de álcool absoluto contida em 100 gramas de mistura hidro-alcoólica) do etanol (AEHC - álcool etílico hidratado carburante) foi medida no laboratório de química do grupo Virgolino de Oliveira S.A. Açúcar e Álcool por intermédio do Dr. Armando José Dal Bem. O resultado médio desta medição para todos os lotes de etanol utilizados nos experimentos foi de 92,79 INPM.

Segundo a Agência Nacional do Petróleo, Gás Natural e Bio-combustíveis (2009) desde o

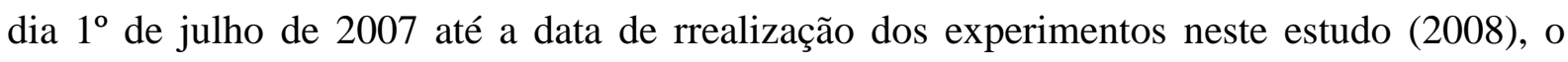
percentual, em volume, obrigatório de álcool etílico anidro carburante (AEAC) na gasolina tipo $C$ é de $25 \%$, sendo que a margem de erro é de $1 \%$ para mais ou para menos. A gasolina tipo $C$ contém gasolina tipo $A$, sem qualquer composto oxigenado, e AEAC.

Samaniego (2007) apresenta a composição da gasolina tipo $C$ com $20 \%$ de álcool etílico anidro, como mostra a Tabela B1.

As unidades de massa atômica do carbono, hidrogênio, nitrogênio e oxigênio, segundo Carvalho e Mcquary (2007), são aproximadamente 12,01 u.m.a, 1,008 u.m.a, 14,01 u.m.a e 16 u.m.a, respectivamente.

Tabela B1 - Composição em massa da gasolina tipo $C$ com 20\% de álcool etílico anidro.

\begin{tabular}{lc}
\hline Componentes & Porcentagem [\%] \\
\hline Carbono & 76,6 \\
Hidrogênio & 15,3 \\
Oxigênio & 8,1 \\
\hline
\end{tabular}

Fonte: Samaniego (2007). 
O número de moles de uma substância química, de acordo com a definição, pode ser obtido pela equação (B1).

$$
n_{m}=\frac{m}{M}
$$

em que:

$n_{m}=$ número de moles de uma substância de massa "m";

$m=$ massa da substância $[\mathrm{g}]$;

$M=$ massa molecular da substância [unidade de massa atômica: u.m.a].

Aplicando a equação (B1) considerando $1 \mathrm{~kg}$ de combustível a cada um dos componentes da gasolina tipo $C$, apresentado por Samaniego (2007), obtém-se o número de moles destes componentes, como mostra a Tabela B2.

Tabela B2 - Número de moles de cada componente em $1 \mathrm{~kg}$ de gasolina tipo $C$ com $20 \%$ de álcool etílico anidro.

\begin{tabular}{lc}
\hline Componente & Número de moles em $1 \mathrm{~kg}$ \\
\hline Carbono & 63,8 \\
Hidrogênio & 151,8 \\
Oxigênio & 5,1 \\
\hline
\end{tabular}

A fórmula química encontrada para a gasolina tipo $C$ é $C_{63,8} H_{151,8} O_{5,1}$, porém a gasolina tipo A contida na gasolina tipo $C$ não contêm compostos oxigenados, portanto, é necessário retirar os átomos de oxigênio por meio da extração da molécula de álcool etílico anidro desta fórmula.

De acordo com Heywood (1988) a fórmula química do álcool etílico anidro é $\mathrm{C}_{2} \mathrm{H}_{5} \mathrm{OH}$. Esta fórmula será utilizada para obtenção de todas as relações ar-combustível dos combustíveis que possuem etanol na sua composição. Não será considerada a porcentagem de água $(\approx 1 \%)$ contida no álcool etílico anidro.

A equação (B2) representa a estrutura da fórmula química da gasolina tipo $C$, com $20 \%$ de álcool etílico anidro, separando a molécula de gasolina tipo A da molécula de álcool etílico anidro.

$$
\mathrm{C}_{x} \mathrm{H}_{y}+\mathrm{zC}_{2} \mathrm{H}_{5} \mathrm{OH}
$$

O valor de $z$ na equação (B3) é igual ao número de moles do oxigênio $(5,1)$. Os valores de $x(53,6)$ e $y(121,4)$ foram obtidos realizando o cálculo estequiométrico das substâncias. Estes 
valores permitem escrever a fórmula química da gasolina tipo $C$ com $20 \%$ de álcool etílico anidro de acordo com a equação (B3).

$$
\mathrm{C}_{53,6} \mathrm{H}_{121,4}+5,1 \mathrm{C}_{2} \mathrm{H}_{5} \mathrm{OH}
$$

Reduzindo a fórmula da gasolina tipo $A$ pelo número de moles de oxigênio $(5,1)$ pode-se escrever a fórmula química mínima aproximada da gasolina tipo $A$ de acordo com a equação (B4).

$$
\text { Gasolina tipo } A=C_{11} H_{24}
$$

O processo de combustão analisado nos experimentos ocorre na presença de ar atmosférico. Segundo Carvalho e Mcquay (2007), a composição teórica do ar é dada pela equação (B5), em que $a$ é o número de moles do gás oxigênio.

$$
a r=a O_{2}+3,76 a N_{2}
$$

A Tabela B3 apresenta as densidades do álcool etílico anidro e do octano $\left(\mathrm{C}_{8} H_{18}\right)$, de acordo com Heywood (1988), a densidade do undecano $\left(\mathrm{C}_{11} \mathrm{H}_{24}\right)$, de acordo com Guarino e Rojas (1997) e a massa molecular aproximada de cada substância

Tabela B3 - Densidades do álcool etílico anidro, do octano e do undecano.

\begin{tabular}{ccc}
\hline Combustível & Densidade $\left[\mathrm{kg} / \mathrm{dm}^{3}=\mathrm{g} / \mathrm{ml}\right]$ & Massa molecular (M) [u.m.a] \\
\hline $\mathrm{C}_{2} \mathrm{H}_{5} \mathrm{OH}$ & 0,792 & 46,068 \\
$\mathrm{C}_{8} \mathrm{H}_{18}$ & 0,785 & 114,224 \\
$\mathrm{C}_{11} \mathrm{H}_{24}$ & 0,74 & 156,302 \\
\hline
\end{tabular}

As relações ar-combustível para os quatro combustíveis utilizados nos experimentos serão apresentadas nas próximas seções. Os resultados finais foram obtidos considerando todos os algarismos significativos dos resultados parciais.

A porcentagem em massa de gasolina tipo $A\left(C_{11} H_{24}\right)$ em cada combustível é obtida no final deste Apêndice. 


\section{B1. RELAÇÃO AR-COMBUSTÍVEL DO COMBUSTÍVEL E100}

O combustível E100 utilizado nos experimentos é constituído por 100\% de AEHC álcool etílico hidratado carburante com teor alcoólico de 92,79 INPM, chamado no presente trabalho de etanol (E100).

Considerando a porcentagem em massa de água no etanol pode-se dizer que em $1 \mathrm{~kg}$ de combustível tem-se 927,9 g de $\mathrm{C}_{2} \mathrm{H}_{5} \mathrm{OH}$ e 72,1 g de água.

O número de moles de cada composto pode ser obtido aplicando a equação (B1). O resultado para $\mathrm{C}_{2} \mathrm{H}_{5} \mathrm{OH}(\mathrm{M}=46,068$ u.m.a) é mostrado na equação (B6) e o resultado para a água $(M=18,016$ u.m.a) é mostrado na equação (B7).

$$
\begin{gathered}
n_{C_{2} H_{6} O}=\frac{m}{M}=\frac{927,9}{46,068}=20,14 \text { moles } \\
n_{H_{2} O}=\frac{m}{M}=\frac{72,1}{18,016}=4,00 \text { moles }
\end{gathered}
$$

A equação (B8) apresenta a combustão completa do combustível E100 obtida pelo equilíbrio de massa entre reagentes e produtos.

$$
\begin{aligned}
20,14 \mathrm{C}_{2} \mathrm{H}_{5} \mathrm{OH}+4,00 \mathrm{H}_{2} \mathrm{O}+60,42 \mathrm{O}_{2} & +227,20 \mathrm{~N}_{2} \rightarrow 40,28 \mathrm{CO}_{2}+64,43 \mathrm{H}_{2} \mathrm{O}+ \\
& +227,20 \mathrm{~N}_{2}
\end{aligned}
$$

A massa de combustível $\left(m_{c}\right)$ na equação (B8) pode ser obtida somando as massas de $\mathrm{C}_{2} \mathrm{H}_{5} \mathrm{OH}$ e $\mathrm{H}_{2} \mathrm{O}$, integrantes dos reagentes da reação de combustão, de acordo com a equação (B9).

$$
m_{c}=n_{H} M_{H}+n_{C} M_{C}+n_{O} M_{O}=128,86.1,008+40,28.12,01+24,14.16=1000 g
$$

A massa de ar $\left(m_{a r}\right)$ na equação (B8) pode ser obtida somando as massas de $\mathrm{O}_{2}$ e $N_{2}$, integrantes dos reagentes da reação de combustão, de acordo com a equação (B10).

$$
m_{a r}=n_{O} M_{O}+n_{N} M_{N}=60,42.32+227,20.28,02=8299,811 g
$$

A relação ar-combustível (A/C) do combustível E100 foi obtida dividindo a massa de ar pela massa de combustível como mostra a equação (B11). 


$$
A / C_{E 100}=\frac{m_{a r}}{m_{c}}=\frac{8299,811}{1000}=8,30: 1
$$

Segundo a equação (B11) a relação ar-combustível do combustível E100 é de 8,30:1 (8,30 partes de ar para uma parte de combustível).

\section{B2. RELAÇÃO AR-COMBUSTÍVEL DO COMBUSTÍVEL E26}

O combustível E26 utilizado nos experimentos é constituído por $100 \%$ de gasolina tipo $C$. A gasolina tipo $C$ é composta por $75 \%$ em volume de gasolina tipo $A\left(C_{11} H_{24}\right)$ e $25 \%$ em volume de álcool etílico anidro carburante (AEAC $\left.-\mathrm{C}_{2} \mathrm{H}_{5} \mathrm{OH}\right)$.

Considerando a porcentagem em volume de $\mathrm{C}_{2} \mathrm{H}_{5} \mathrm{OH}$ na gasolina tipo $\mathrm{C}$ pode-se dizer que em $1000 \mathrm{ml}$ de combustível tem-se $250 \mathrm{ml}$ de $\mathrm{C}_{2} \mathrm{H}_{5} \mathrm{OH}$ e $750 \mathrm{ml} \mathrm{C}_{11} \mathrm{H}_{24}$.

Utilizando a densidade pode-se obter a massa (m) de cada composto da gasolina tipo $C$, como mostram as formulações (B12) e (B13).

$$
\begin{aligned}
250 m l & \rightarrow m_{C_{2} \mathrm{H}_{6} \mathrm{O}}=198 \mathrm{~g} \\
1 \mathrm{ml} & \rightarrow 0,792 \mathrm{~g} / \mathrm{ml} \\
& \\
750 m l & \rightarrow m_{{C_{1} \mathrm{H}_{24}}}=555 \mathrm{~g} \\
1 \mathrm{ml} & \rightarrow 0,74 \mathrm{~g} / \mathrm{ml}
\end{aligned}
$$

O número de moles de cada composto pode ser obtido aplicando a equação (B1). O resultado para $C_{11} H_{24}(M=156,302$ u.m.a) é mostrado na equação (B14) e o resultado para $\mathrm{C}_{2} \mathrm{H}_{5} \mathrm{OH}(\mathrm{M}=46,068$ u.m.a) é mostrado na equação (B15).

$$
\begin{aligned}
& n_{C_{11} H_{24}}=\frac{m}{M}=\frac{555}{156,302}=3,56 \mathrm{~mol} \\
& n_{C_{2} H_{6} O}=\frac{m}{M}=\frac{198}{46,068}=4,30 \mathrm{~mol}
\end{aligned}
$$

A equação (B16) apresenta a combustão completa do combustível E26 obtida pelo equilíbrio de massa entre reagentes e produtos. 


$$
\begin{gathered}
3,55 \mathrm{C}_{11} \mathrm{H}_{24}+4,30 \mathrm{C}_{2} \mathrm{H}_{5} \mathrm{OH}+73,26 \mathrm{O}_{2}+275,45 \mathrm{~N}_{2} \rightarrow 47,65 \mathrm{O}_{2}+55,50 \mathrm{H}_{2} \mathrm{O}+ \\
+275,45 \mathrm{~N}_{2}
\end{gathered}
$$

A massa de combustível $\left(m_{c}\right)$ na equação (B16) pode ser obtida somando as massas de $\mathrm{C}_{11} \mathrm{H}_{24}$ e $\mathrm{C}_{2} \mathrm{H}_{5} \mathrm{OH}$, integrantes dos reagentes da reação de combustão, de acordo com a equação (B17).

$$
m_{c}=n_{H} M_{H}+n_{C} M_{C}+n_{O} M_{O}=111,01.1,008+47,65.12,01+4,30.16=753 g
$$

A massa de ar $\left(m_{a r}\right)$ na equação (B16) pode ser obtida somando as massas de $\mathrm{O}_{2}$ e $\mathrm{N}_{2}$, integrantes dos reagentes da reação de combustão, de acordo com a equação (B18).

$$
m_{a r}=n_{O} M_{O}+n_{N} M_{N}=73,26.32+275,45.28,02=10062,35 g
$$

A relação ar-combustível (A/C) do combustível E26 foi obtida dividindo a massa de ar pela massa de combustível como mostra a equação (B19).

$$
A / C_{E 24}=\frac{m_{a r}}{m_{c}}=\frac{10062,35}{753}=13,36: 1
$$

Segundo a equação (B19) a relação ar-combustível do combustível E26 é de 13,36:1 (13,36 partes de ar para uma parte de combustível).

\section{B3. RELAÇÃO AR-COMBUSTÍVEL DO COMBUSTÍVEL E70}

O combustível E70 utilizado nos experimentos é constituído por $60 \%$ de AEHC - álcool etílico hidratado carburante com teor alcoólico de 92,79 INPM $\left(20,14 . \mathrm{C}_{2} \mathrm{H}_{5} \mathrm{OH}+4,00 \cdot \mathrm{H}_{2} \mathrm{O}\right)$ e $40 \%$ de gasolina tipo $\mathrm{C}\left(3,55 . \mathrm{C}_{11} \mathrm{H}_{24}+4,30 . \mathrm{C}_{2} \mathrm{H}_{5} \mathrm{OH}\right)$. Pode-se dizer que E70 é composto por $60 \%$ em massa de E100 e $40 \%$ em massa de E26.

Considerando a porcentagem em massa de gasolina tipo $C$ no etanol pode-se dizer que em $1 \mathrm{~kg}$ de combustível tem-se 400 g E26 e 600 g de E100.

$\mathrm{O}$ número de moles de cada composto pode ser obtido aplicando a equação (B1). O resultado para E100 ( $M=1000$ u.m.a) é mostrado na equação (B20) e o resultado para a E26 $(M=753$ u.m.a) é mostrado na equação (B21). 


$$
\begin{aligned}
& n_{E 100}=\frac{m}{M}=\frac{600}{1000}=0,6 \mathrm{~mol} \\
& n_{E 24}=\frac{m}{M}=\frac{400}{753}=0,53 \mathrm{~mol}
\end{aligned}
$$

A equação (B22) apresenta a combustão completa do combustível E70 obtida pelo equilíbrio de massa entre reagentes e produtos.

$$
\begin{gathered}
0,6\left[20,14 \mathrm{C}_{2} \mathrm{H}_{5} \mathrm{OH}+4,00 \mathrm{H}_{2} \mathrm{O}\right]+0,53\left[3,55 \mathrm{C}_{11} \mathrm{H}_{24}+4,30 \mathrm{C}_{2} \mathrm{H}_{5} \mathrm{OH}\right]+ \\
+75,17 \mathrm{O}_{2}+282,64 \mathrm{~N}_{2} \rightarrow 49,48 \mathrm{CO}_{2}+68,14 \mathrm{H}_{2} \mathrm{O}+282,64 \mathrm{~N}_{2}
\end{gathered}
$$

A massa de combustível $\left(m_{c}\right)$ na equação (B22) pode ser obtida somando as massas de E100 e E26, integrantes dos reagentes da reação de combustão, de acordo com a equação (B23).

$$
m_{c}=n_{H} M_{H}+n_{C} M_{C}+n_{O} M_{O}=136,28.1,008+49,48.12,01+16,77.16=1000 g(\mathrm{~B} 23)
$$

A massa de ar ( $\left.m_{a r}\right)$ na equação (B22) pode ser obtida somando as massas de $\mathrm{O}_{2}$ e $\mathrm{N}_{2}$, integrantes dos reagentes da reação de combustão, de acordo com a equação (B24).

$$
m_{a r}=n_{O} M_{O}+n_{N} M_{N}=75,17.32+282,64.28,02=10325,09 \mathrm{~g}
$$

A relação ar-combustível (A/C) do combustível E70 foi obtida dividindo a massa de ar pela massa de combustível como mostra a equação (B25).

$$
A / C_{E 70}=\frac{m_{a r}}{m_{c}}=\frac{10325,09}{1000}=10,32: 1
$$

Segundo a equação (B25) a relação ar-combustível do combustível E70 é de 10,32:1 (10,32 partes de ar para uma parte de combustível).

\section{B4. RELAÇÃO AR-COMBUSTÍVEL DO COMBUSTÍVEL E56}

O combustível E56 utilizado nos experimentos é constituído por 40\% de AEHC - álcool etílico hidratado carburante com teor alcoólico de 92,79 INPM $\left(20,14 . \mathrm{C}_{2} \mathrm{H}_{5} \mathrm{OH}+4,00 \cdot \mathrm{H}_{2} \mathrm{O}\right)$ 
e $60 \%$ de gasolina tipo $\mathrm{C}\left(3,55 . \mathrm{C}_{11} \mathrm{H}_{24}+4,30 . \mathrm{C}_{2} \mathrm{H}_{5} \mathrm{OH}\right)$. Pode-se dizer que E56 é composto por $40 \%$ em massa de E100 e $60 \%$ em massa de E26.

Considerando a porcentagem em massa de gasolina tipo $C$ no etanol pode-se dizer que em $1 \mathrm{~kg}$ de combustível tem-se 600 g E26 e 400 g de E100.

O número de moles de cada composto pode ser obtido aplicando a equação (B1). O resultado para E100 ( $M=1000$ u.m.a) é mostrado na equação (B26) e o resultado para a E26 $(M=753$ u.m.a) é mostrado na equação (B27).

$$
\begin{aligned}
& n_{E 100}=\frac{m}{M}=\frac{400}{1000}=0,4 \mathrm{~mol} \\
& n_{E 24}=\frac{m}{M}=\frac{600}{753}=0,80 \mathrm{~mol}
\end{aligned}
$$

A equação (B28) apresenta a combustão completa do combustível E56 obtida pelo equilíbrio de massa entre reagentes e produtos.

$$
\begin{gathered}
0,4\left[20,14 \mathrm{C}_{2} \mathrm{H}_{5} \mathrm{OH}+4,00 \mathrm{H}_{2} \mathrm{O}\right]+0,80\left[3,55 \mathrm{C}_{11} \mathrm{H}_{24}+4,30 \mathrm{C}_{2} \mathrm{H}_{5} \mathrm{OH}\right]+ \\
+82,54 \mathrm{O}_{2}+310,36 \mathrm{~N}_{2} \rightarrow 54,08 \mathrm{CO}_{2}+70,00 \mathrm{H}_{2} \mathrm{O}+310,36 \mathrm{~N}_{2}
\end{gathered}
$$

A massa de combustível $\left(m_{c}\right)$ na equação (B28) pode ser obtida somando as massas de E100 e E26, integrantes dos reagentes da reação de combustão, de acordo com a equação (B29).

$$
m_{c}=n_{H} M_{H}+n_{C} M_{C}+n_{O} M_{O}=139,99.1,008+54,08.12,01+13,08.16=1000 g(\mathrm{~B} 29)
$$

A massa de ar $\left(m_{a r}\right)$ na equação (B28) pode ser obtida somando as massas de $\mathrm{O}_{2}$ e $N_{2}$, integrantes dos reagentes da reação de combustão, de acordo com a equação (B30).

$$
m_{a r}=n_{O} M_{O}+n_{N} M_{N}=82,54.32+310,36.28,01=11337,74 \mathrm{~g}
$$

A relação ar-combustível (A/C) do combustível E56 foi obtida dividindo a massa de ar pela massa de combustível como mostra a equação (B31).

$$
A / C_{E 54}=\frac{m_{a r}}{m_{c}}=\frac{11337,74}{1000}=11,34: 1
$$


Segundo a equação (B31) a relação ar-combustível do combustível E56 é de 11,34:1 (11,34 partes de ar para uma parte de combustível).

\section{B4. PORCENTAGEM EM MASSA DE $C_{11} H_{24}$ EM CADA TIPO DE COMBUSTÍVEL}

A porcentagem em massa de gasolina tipo $A$ foi obtida dividindo a massa de $C_{11} H_{24}$ $\left(m_{C 11 H 24}\right)$ pela massa total de combustível $\left(m_{c}\right)$.

A Tabela B4 apresenta os resultados das porcentagens de gasolina tipo $A$ em cada tipo de combustível utilizado nos experimentos.

Tabela B4 - Porcentagem em massa de $C_{11} H_{24}$ em cada tipo de combustível.

\begin{tabular}{lccc}
\hline Combustível & $\mathrm{m}_{\mathrm{c}}[\mathrm{g}]$ & $\mathrm{m}_{\mathrm{C} 11 \mathrm{H} 24}[\mathrm{~g}]$ & {$[\%]$ em massa de $C_{11} H_{24}$} \\
\hline E100 & 1000 & 0 & 0 \\
E70 & 1000 & 294,82 & 29,48 \\
E56 & 1000 & 442,23 & 44,22 \\
E26 & 753 & 555 & 73,71 \\
\hline
\end{tabular}




\section{APÊNDICE C - Cálculo do poder calorífico inferior}

Segundo Heywood (1988), os combustíveis líquidos são queimados com oxigênio sob pressão em volume constante numa bomba calorimétrica. A amostra de combustível é colocada em um recipiente de aço inoxidável imerso em água de refrigeração a temperatura de referência. $\mathrm{O}$ oxigênio é inserido no recipiente de aço inoxidável a uma pressão de 30 atm. Um pavil de algodão é suspenso sobre a amostra de combustível a partir de um filamento elétrico que age como fonte de ignição. Quando a combustão é completada, a temperatura da água de refrigeração é medida. O poder calorífico medido neste processo é o poder calorífico superior a volume constante.

O termo poder calorífico superior (PCS), segundo Heywood (1988), é usado quando toda a água formada na combustão é totalmente condensada a fase líquida. O termo poder calorífico inferior $(P C I)$ é usado quando toda a água formada na combustão está na fase gasosa.

De acordo com Taylor (1968) os dois poderes caloríficos podem ser relacionados utilizando equação $(\mathrm{C} 1)$.

em que:

$$
P C I=P C S+\frac{m v_{H_{2} O}}{m_{c}} h_{l v}
$$

$m v_{H 2 O}=$ massa de vapor d'água formada como produto da combustão;

$m_{c}=$ massa de combustível, e

$h_{l v}=$ entalpia de condensação de água na temperatura de referência da bomba calorimétrica.

O valor de $h_{l v}$, segundo Van Wylen e Sonntag (1976), é igual a -2,44 MJ/kg.

O poder calorífico superior $(P C S)$ do etanol 92,8 INPM (E100), da gasolina tipo $C$ (E26) e das duas misturas E70 e E56 foram obtidos por meio de ensaios, em um calorímetro da marca IKA ${ }^{\circledR}$, modelo C5000 control, realizados no Núcleo de Engenharia Térmica e Fluídos (NETEF) da Escola de Engenharia de São Carlos. A Tabela C1 apresenta os valores encontrados para cada tipo de combustível. 
Tabela C1 - Poder calorífico superior dos combustíveis E100, E70, E56 e E26.

\begin{tabular}{lc}
\hline Combustível & Poder calorífico superior $[\mathrm{MJ} / \mathrm{kg}]$ \\
\hline E100 & 27,921 \\
E70 & 32,037 \\
E56 & 34,684 \\
E26 & 41,617 \\
\hline
\end{tabular}

As massas $m_{c}$ de cada combustível são apresentadas na Tabela C2. Os valores de $m_{c}$ foram obtidos no Apêndice B.

Tabela C2 - Massas de combustível $\left(m_{c}\right)$.

\begin{tabular}{ll}
\hline Combustível & $\mathrm{m}_{\mathrm{c}}[\mathrm{g}]$ \\
\hline E100 & 1000 \\
E70 & 1000 \\
E56 & 1000 \\
E26 & 753 \\
\hline
\end{tabular}

As massas $m_{\mathrm{H}_{2} \mathrm{O}}$ de cada combustível são apresentadas na Tabela $\mathrm{C} 3$, em que o número de atómos de hidrogênio e oxigênio foram multiplicados por suas respectivas massas atômicas para obter a massa de vapor d'água.

Tabela C3 - Massas de vapor d'água $\left(m v_{H 2 O}\right)$.

\begin{tabular}{lccc}
\hline Combustível & $\mathrm{H}$ & $\mathrm{O}$ & $\mathrm{mv}_{\mathrm{H} 2 \mathrm{O}}$ \\
\hline E100 & 128,86 & 64,43 & 1160,73 \\
E70 & 136,28 & 68,14 & 1227,62 \\
E56 & 139,99 & 70,00 & 1261,07 \\
E26 & 111,01 & 55,50 & 999,96 \\
\hline
\end{tabular}

O cálculo do poder calorífico inferior do combustível E100 é apresentado pela equação (C2).

$$
P C I_{E 100}=27,921+\frac{1160,73}{1000}(-2,44)=25,09 M J / k g
$$

O cálculo do poder calorífico inferior do combustível E70 é apresentado pela equação (C3).

$$
P C I_{E 70}=32,037+\frac{1227,62}{1000}(-2,44)=29,04 M J / k g
$$


O cálculo do poder calorífico inferior do combustível E56 é apresentado pela equação (C4).

$$
P C I_{E 54}=34,684+\frac{1261,07}{1000}(-2,44)=31,61 M J / k g
$$

O cálculo do poder calorífico inferior do combustível E26 é apresentado pela equação (C5).

$$
P C I_{E 24}=41,617+\frac{999,96}{753}(-2,44)=38,38 M J / k g
$$




\section{APÊNDICE D - Calibração do dinamômetro}

A primeira etapa da calibração do dinamômetro foi ajustar o zero da balança dinamométrica (ponteiro no zero), sem qualquer tipo de carga aplicada (cardans desconectados), atuando no seu mecanismo interno.

$\mathrm{Na}$ etapa seguinte, foram conectados os pratos e os braços específicos para realização da calibração, como mostra a Figura D1. O comprimento dos braços instalados é igual a 1,081 metros.

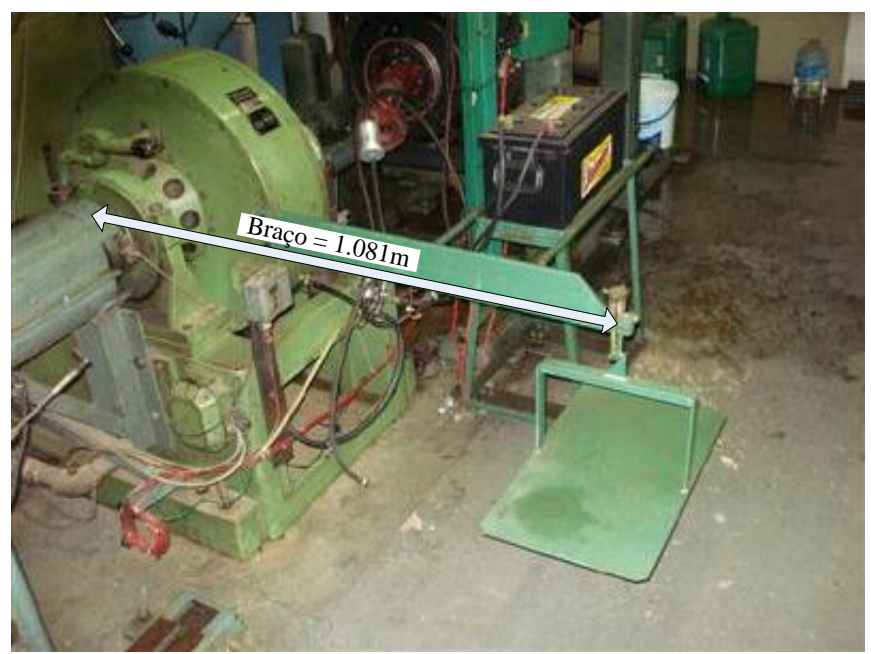

Figura D1 - Instalação dos braços e pratos no dinamômetro.

Para corrigir a diferença entre as massas dos braços e pratos instalados foram aplicados blocos metálicos em um dos pratos para corrigir o zero na balança dinamométrica, como mostra a Figura D2. 


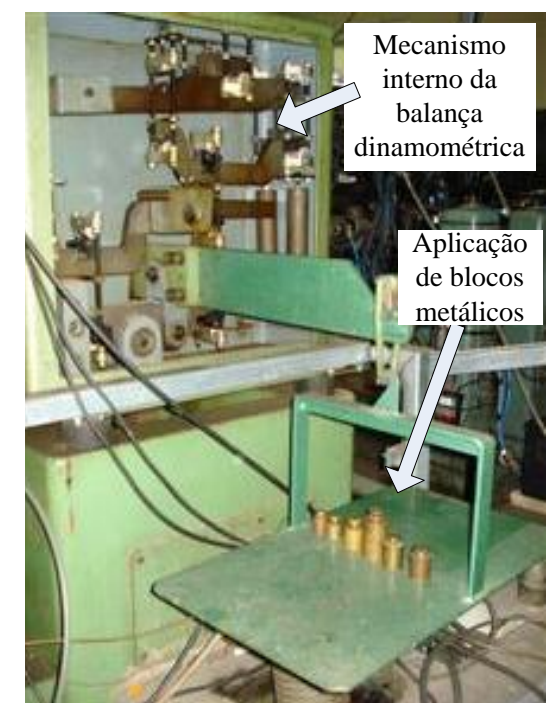

Figura D2 - Correção das diferenças de massas entre os braços e pratos instalados.

A Figura D3 mostra o visor da balança dinamométrica com o ponteiro no zero, após a correção das diferenças entre as massas dos braços e pratos.

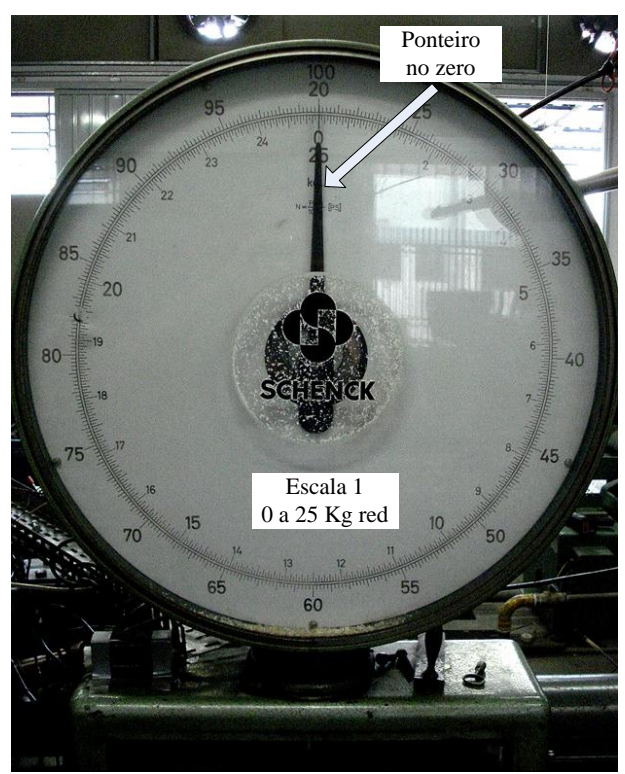

Figura D3 - Visor da balança dinamométrica com o ponteiro no zero da escala 1.

$\mathrm{Na}$ última etapa foram colocados diversos blocos metálicos, no outro prato, com valores de massa obtidos por meio de uma balança digital da marca Toledo, modelo XP32001L, com resolução de 0,1 grama.

Para cada massa aplicada foi observado e anotado o valor indicado pela balança dinamométrica (kg red).

As massas foram variadas trinta vezes, de forma aleatória, com valores entre $0,3997 \mathrm{~kg}$ e $16,1829 \mathrm{~kg}$. 
Foram coletadas três amostras $(A, B$ e $C)$ com 30 observações cada.

Com os dados coletados foram calculados o torque e o fator da potência, definido neste trabalho.

Segundo Heywood (1988) o torque do motor é obtido multiplicando o comprimento do braço do dinamômetro pela força medida, como mostra a equação (D1). A potência do motor é igual ao torque multiplicado pela velocidade de rotação da árvore de manivelas do motor, como mostra a equação (D2), em que RPS significa rotações por segundo.

$$
\begin{aligned}
& \text { Torque }=\text { Força } * \text { Braço } \\
& \text { Potência }=\frac{2 \pi \text { TorqueRPS }}{1000}
\end{aligned}
$$

A Tabela D1 mostra os dados coletados nas três amostras $(A, B$ e $C)$, o torque calculado e o fator da potência, definido neste trabalho, pela equação (D3).

$$
\text { Fator } \quad \text { da Potência }=\frac{(\text { Torque } \pi)}{30}
$$

Utilizando o fator da potência pode-se obter a potência do motor utilizando a equação (D4).

Potência $[k W]=\frac{\text { Fator } \quad d a \quad \text { Potência } * \text { rpm }}{1000}$ 
Tabela D1 - Torque e fator da potência em função da massa aplicada na balança dinamométrica (continua).

\begin{tabular}{|c|c|c|c|c|}
\hline Medidas & $\begin{array}{c}\text { Massa } \\
{[\mathrm{kg}]}\end{array}$ & $\begin{array}{l}\text { Balança } \\
\text { [kg red] }\end{array}$ & $\begin{array}{l}\text { Torque } \\
\text { [N.m] }\end{array}$ & $\begin{array}{l}\text { Fator da } \\
\text { Potência }\end{array}$ \\
\hline $1 \mathrm{~A}$ & 0,3997 & 0,35 & 4,23 & 0,44 \\
\hline $1 \mathrm{~B}$ & 0,3997 & 0,2 & 4,23 & 0,44 \\
\hline $1 \mathrm{C}$ & 0,3997 & 0,3 & 4,23 & 0,44 \\
\hline $2 \mathrm{~A}$ & 0,8174 & 0,95 & 8,65 & 0,91 \\
\hline $2 \mathrm{~B}$ & 0,8174 & 0,8 & 8,65 & 0,91 \\
\hline $2 \mathrm{C}$ & 0,8174 & 0,95 & 8,65 & 0,91 \\
\hline $3 \mathrm{~A}$ & 1,2378 & 1,5 & 13,09 & 1,37 \\
\hline $3 B$ & 1,2378 & 1,45 & 13,09 & 1,37 \\
\hline $3 \mathrm{C}$ & 1,2378 & 1,55 & 13,09 & 1,37 \\
\hline $4 \mathrm{~A}$ & 1,6612 & 2,25 & 17,57 & 1,84 \\
\hline $4 B$ & 1,6612 & 2,05 & 17,57 & 1,84 \\
\hline $4 \mathrm{C}$ & 1,6612 & 2,25 & 17,57 & 1,84 \\
\hline $5 \mathrm{~A}$ & 2,0836 & 2,7 & 22,04 & 2,31 \\
\hline $5 B$ & 2,0836 & 2,7 & 22,04 & 2,31 \\
\hline $5 \mathrm{C}$ & 2,0836 & 2,7 & 22,04 & 2,31 \\
\hline $6 \mathrm{~A}$ & 2,5514 & 3,45 & 26,99 & 2,83 \\
\hline $6 \mathrm{~B}$ & 2,5514 & 3,35 & 26,99 & 2,83 \\
\hline $6 \mathrm{C}$ & 2,5514 & 3,45 & 26,99 & 2,83 \\
\hline $7 \mathrm{~A}$ & 2,9691 & 4,1 & 31,41 & 3,29 \\
\hline $7 \mathrm{~B}$ & 2,9691 & 4,05 & 31,41 & 3,29 \\
\hline $7 \mathrm{C}$ & 2,9691 & 4,2 & 31,41 & 3,29 \\
\hline $8 \mathrm{~A}$ & 3,3895 & 4,7 & 35,86 & 3,75 \\
\hline $8 B$ & 3,3895 & 4,5 & 35,86 & 3,75 \\
\hline $8 \mathrm{C}$ & 3,3895 & 4,7 & 35,86 & 3,75 \\
\hline $9 \mathrm{~A}$ & 3,8129 & 5,2 & 40,33 & 4,22 \\
\hline $9 B$ & 3,8129 & 5,2 & 40,33 & 4,22 \\
\hline $9 \mathrm{C}$ & 3,8129 & 5,3 & 40,33 & 4,22 \\
\hline $10 \mathrm{~A}$ & 4,2353 & 5,75 & 44,80 & 4,69 \\
\hline $10 \mathrm{~B}$ & 4,2353 & 5,8 & 44,80 & 4,69 \\
\hline $10 \mathrm{C}$ & 4,2353 & 6 & 44,80 & 4,69 \\
\hline $11 \mathrm{~A}$ & 4,6047 & 6,25 & 48,71 & 5,10 \\
\hline $11 \mathrm{~B}$ & 4,6047 & 6,3 & 48,71 & 5,10 \\
\hline $11 \mathrm{C}$ & 4,6047 & 6,4 & 48,71 & 5,10 \\
\hline $12 \mathrm{~A}$ & 5,0224 & 6,85 & 53,13 & 5,56 \\
\hline $12 \mathrm{~B}$ & 5,0224 & 6,95 & 53,13 & 5,56 \\
\hline $12 \mathrm{C}$ & 5,0224 & 7,1 & 53,13 & 5,56 \\
\hline $13 \mathrm{~A}$ & 5,4428 & 7,5 & 57,58 & 6,03 \\
\hline $13 \mathrm{~B}$ & 5,4428 & 7,6 & 57,58 & 6,03 \\
\hline
\end{tabular}


Tabela D1 - Torque e fator da potência em função da massa aplicada na balança dinamométrica (continua).

\begin{tabular}{|c|c|c|c|c|}
\hline Medidas & $\begin{array}{c}\text { Massa } \\
{[\mathrm{kg}]}\end{array}$ & $\begin{array}{l}\text { Balança } \\
\text { [kg red] }\end{array}$ & $\begin{array}{l}\text { Torque } \\
\text { [N.m] }\end{array}$ & $\begin{array}{l}\text { Fator da } \\
\text { Potência }\end{array}$ \\
\hline $13 \mathrm{C}$ & 5,4428 & 7,7 & 57,58 & 6,03 \\
\hline $14 \mathrm{~A}$ & 5,8662 & 8,35 & 62,06 & 6,50 \\
\hline 14B & 5,8662 & 8,25 & 62,06 & 6,50 \\
\hline $14 \mathrm{C}$ & 5,8662 & 8,35 & 62,06 & 6,50 \\
\hline $15 \mathrm{~A}$ & 6,2886 & 8,8 & 66,52 & 6,97 \\
\hline $15 B$ & 6,2886 & 8,9 & 66,52 & 6,97 \\
\hline $15 \mathrm{C}$ & 6,2886 & 9 & 66,52 & 6,97 \\
\hline $16 \mathrm{~A}$ & 6,581 & 9,25 & 69,62 & 7,29 \\
\hline $16 \mathrm{~B}$ & 6,581 & 9,2 & 69,62 & 7,29 \\
\hline $16 \mathrm{C}$ & 6,581 & 9,45 & 69,62 & 7,29 \\
\hline $17 \mathrm{~A}$ & 6,9987 & 9,8 & 74,04 & 7,75 \\
\hline 17B & 6,9987 & 10 & 74,04 & 7,75 \\
\hline $17 \mathrm{C}$ & 6,9987 & 10,05 & 74,04 & 7,75 \\
\hline $18 \mathrm{~A}$ & 7,4191 & 10,25 & 78,48 & 8,22 \\
\hline $18 \mathrm{~B}$ & 7,4191 & 10,5 & 78,48 & 8,22 \\
\hline $18 \mathrm{C}$ & 7,4191 & 10,5 & 78,48 & 8,22 \\
\hline $19 \mathrm{~A}$ & 7,8425 & 10,9 & 82,96 & 8,69 \\
\hline $19 B$ & 7,8425 & 11,05 & 82,96 & 8,69 \\
\hline $19 \mathrm{C}$ & 7,8425 & 11,05 & 82,96 & 8,69 \\
\hline $20 \mathrm{~A}$ & 8,2649 & 11,6 & 87,43 & 9,16 \\
\hline $20 B$ & 8,2649 & 11,55 & 87,43 & 9,16 \\
\hline $20 \mathrm{C}$ & 8,2649 & 11,75 & 87,43 & 9,16 \\
\hline $21 \mathrm{~A}$ & 8,7876 & 12,25 & 92,96 & 9,73 \\
\hline $21 B$ & 8,7876 & 12,4 & 92,96 & 9,73 \\
\hline $21 \mathrm{C}$ & 8,7876 & 12,45 & 92,96 & 9,73 \\
\hline $22 \mathrm{~A}$ & 9,2053 & 12,9 & 97,38 & 10,20 \\
\hline $22 \mathrm{~B}$ & 9,2053 & 12,9 & 97,38 & 10,20 \\
\hline $22 \mathrm{C}$ & 9,2053 & 13,15 & 97,38 & 10,20 \\
\hline $23 \mathrm{~A}$ & 9,6257 & 13,45 & 101,83 & 10,66 \\
\hline $23 \mathrm{~B}$ & 9,6257 & 13,6 & 101,83 & 10,66 \\
\hline $23 \mathrm{C}$ & 9,6257 & 13,7 & 101,83 & 10,66 \\
\hline $24 \mathrm{~A}$ & 10,0491 & 14,05 & 106,30 & 11,13 \\
\hline $24 B$ & 10,0491 & 14,25 & 106,30 & 11,13 \\
\hline $24 \mathrm{C}$ & 10,0491 & 14,4 & 106,30 & 11,13 \\
\hline $25 \mathrm{~A}$ & 10,4715 & 14,7 & 110,77 & 11,60 \\
\hline $25 B$ & 10,4715 & 14,8 & 110,77 & 11,60 \\
\hline $25 \mathrm{C}$ & 10,4715 & 14,85 & 110,77 & 11,60 \\
\hline $26 \mathrm{~A}$ & 12,1533 & 17,25 & 128,56 & 13,46 \\
\hline
\end{tabular}


Tabela D1 - Torque e fator da potência em função da massa aplicada na balança dinamométrica (conclusão).

\begin{tabular}{ccccc}
\hline Medidas & $\begin{array}{c}\text { Massa } \\
{[\mathrm{kg}]}\end{array}$ & $\begin{array}{c}\text { Balança } \\
{[\mathrm{kg} \mathrm{red}]}\end{array}$ & $\begin{array}{c}\text { Torque } \\
{[\mathrm{N} . \mathrm{m}]}\end{array}$ & $\begin{array}{c}\text { Fator da } \\
\text { Potência }\end{array}$ \\
\hline 26B & 12,1533 & 17,35 & 128,56 & 13,46 \\
$26 \mathrm{C}$ & 12,1533 & 17,5 & 128,56 & 13,46 \\
$27 \mathrm{~A}$ & 13,1189 & 18,7 & 138,78 & 14,53 \\
$27 \mathrm{~B}$ & 13,1189 & 18,7 & 138,78 & 14,53 \\
$27 \mathrm{C}$ & 13,1189 & 18,9 & 138,78 & 14,53 \\
$28 \mathrm{~A}$ & 14,0312 & 20,1 & 148,43 & 15,54 \\
$28 \mathrm{~B}$ & 14,0312 & 20,2 & 148,43 & 15,54 \\
$28 \mathrm{C}$ & 14,0312 & 20,25 & 148,43 & 15,54 \\
$29 \mathrm{~A}$ & 14,9968 & 21,55 & 158,64 & 16,61 \\
29B & 14,9968 & 21,6 & 158,64 & 16,61 \\
$29 \mathrm{C}$ & 14,9968 & 21,4 & 158,64 & 16,61 \\
$30 \mathrm{~A}$ & 16,1829 & 23,25 & 171,19 & 17,93 \\
$30 \mathrm{~B}$ & 16,1829 & 23,25 & 171,19 & 17,93 \\
$30 \mathrm{C}$ & 16,1829 & 23,3 & 171,19 & 17,93 \\
\hline
\end{tabular}

Os dados da Tabela D1 foram tabelados usando o programa Excel 2003. Este programa também foi usado para encontrar a reta de ajuste por regressão linear para o torque e para o fator da potência em função da massa observada na balança dinamométrica.

Foram obtidos para cada reta ajustada o coeficiente de determinação $r^{2}$ (função RQUAD) e o erro padrão (função $E P A D Y X$ ) do valor $y$ (torque ou fator da potência) previsto para cada $x$ (massa observada na balança dinamométrica) da regressão. O erro padrão é uma medida da quantidade de erro na previsão de um valor de $y$ em função de um valor de $x$.

A função EPADYX utilizada pelo programa Excel 2003 é expressa pela equação (D5).

$$
E P=\sqrt{\frac{1}{n-2}\left[\sum(y-\bar{y})^{2}-\frac{\sum[(x-\bar{x})(y-\bar{y})]^{2}}{\sum(x-\bar{x})^{2}}\right]}
$$

A Figura D4 apresenta a reta de ajuste do torque em função da massa observada na balança dinamométrica. O coeficiente de determinação $\left(r^{2}\right)$ encontrado é igual a 0,9997. 


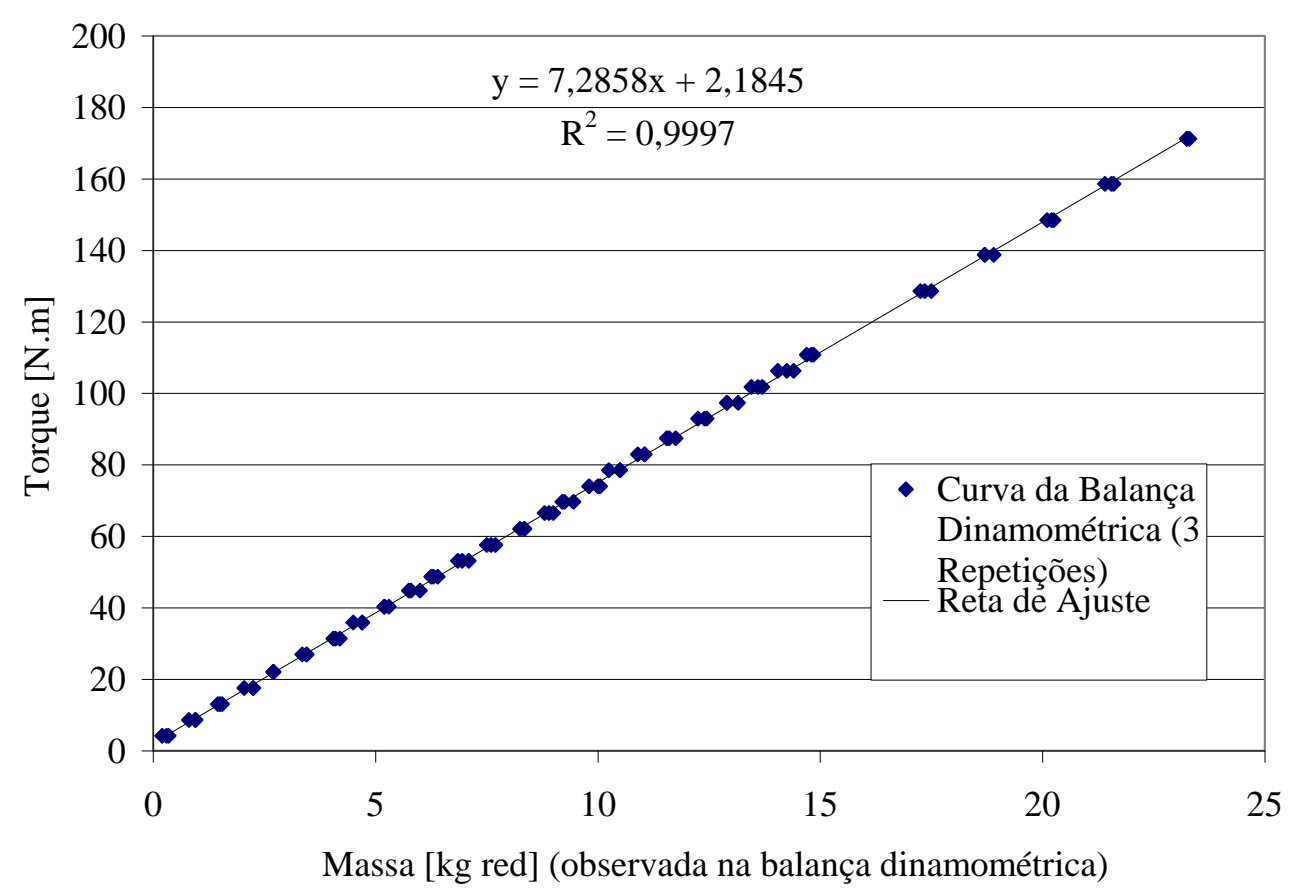

Figura D4 - Torque em função da massa observada na balança dinamométrica (kg red).

Adequando a nomenclatura à equação da reta $y$ apresentada no gráfico da Figura D4, temse a equação D6, em que kg red é o valor observado na balança dinamométrica.

$$
\text { Torque }[\mathrm{Nm}]=7,2858 \mathrm{kgred}+2,1845
$$

O erro padrão encontrado para a equação (D6) é de $0,7831 \mathrm{Nm}$.

A Figura D5 apresenta a reta de ajuste do fator da potência em função da massa observada na balança dinamométrica. O coeficiente de determinação $\left(r^{2}\right)$ encontrado é igual a $0,9997$.

Adequando a nomenclatura à equação da reta $y$ apresentada no gráfico da Figura D5, temse a equação (D7), em que kgred é o valor observado na balança dinamométrica.

Fator da Potência $=0,763$ kgred $+0,2288$

O erro padrão encontrado para a equação (D7) é de 0,082 unidades de fator da potência.

A equação (D7) foi obtida para facilitar os cálculos durante a realização dos experimentos. 


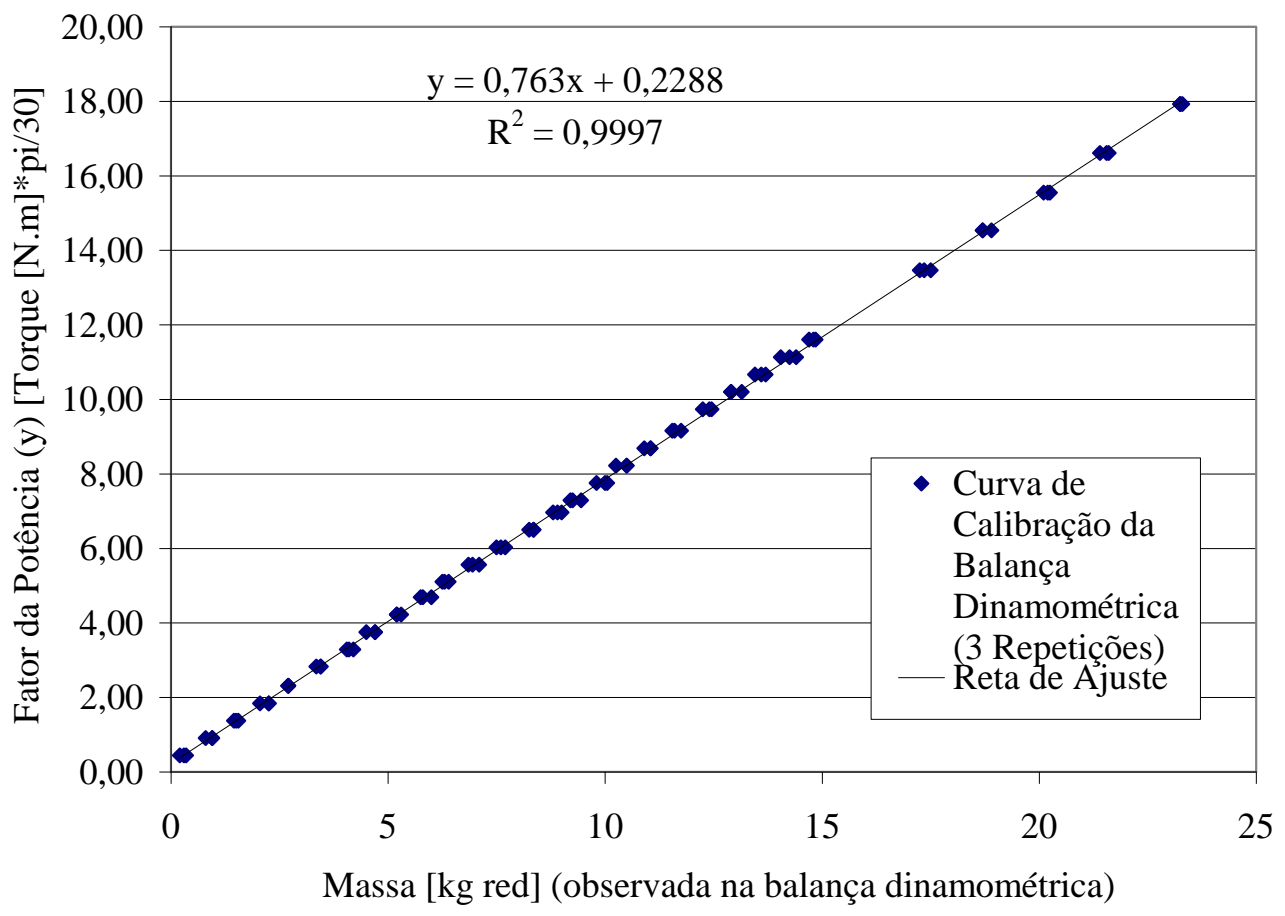

Figura D5 - Fator da potência em função da massa observada na balança dinamométrica (kg red). 


\section{APÊNDICE E - Obtenção da relação de compressão do motor VW AT 1000 8V}

Martins (2006) define a relação de compressão de um motor de acordo com a equação (E1), em que $T_{r}$ é a relação de compressão, $V_{c}$ é o volume do cilindro, $V_{c c}$ é o volume da câmara de combustão e $V_{\text {total }}$ é o volume da câmara de combustão mais o volume do cilindro.

$$
T_{r}=\frac{\left(V_{c}+V_{c c}\right)}{V_{c c}}=\frac{V_{t o t a l}}{V_{c c}}
$$

A Figura E1 mostra um diagrama do conjunto cilindro-pistão-biela de um motor, em que é possível visualizar os volumes utilizados para o cálculo da relação de compressão: o diâmetro do cilindro $\left(D_{C I L}\right)$ e o curso do pistão $\left(C_{P I S}\right)$ entre o ponto morto superior (PMS) e o ponto morto inferior (PMI).

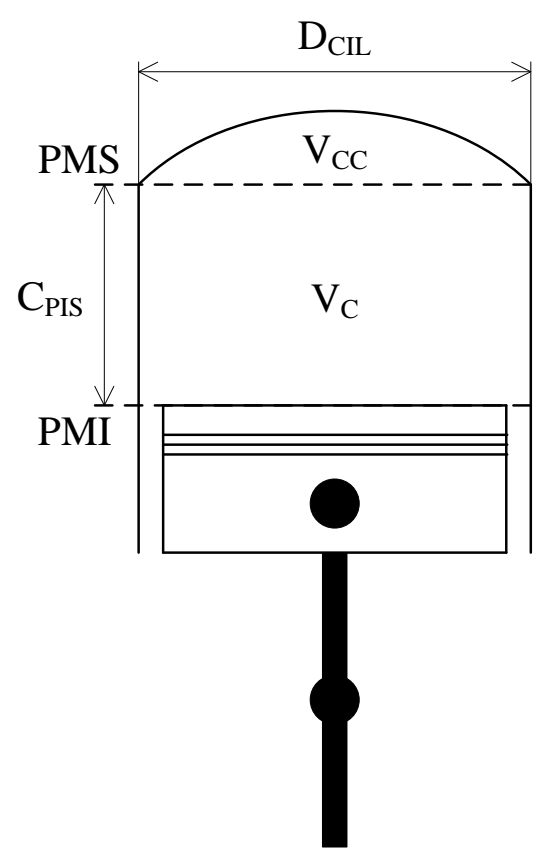

Figura E1 - Diagrama do conjunto cilindro-pistão-biela de um motor.

O volume de um cilindro $\left(V_{c}\right)$ é obtido pela equação (E2).

$$
V_{c}=\frac{\pi D_{C I L}^{2} C_{P I S}}{4}
$$


O volume da câmara de combustão pode ser obtido, segundo Martins (2006), preenchendo o seu volume com óleo ou outro líquido por meio do orifício da vela, com a ajuda de uma proveta ou seringa graduada.

Este procedimento, apesar de facilitar a medida, pois não é necessário desmontar o motor, pode conter desvios devido à ocorrência de vazamentos pelas folgas entre o pistão e o cilindro.

Para evitar estes vazamentos o volume da câmara de combustão foi medido em três etapas (ou volumes) com o motor desmontado, como mostra a Figura E2, em que $V_{c a b}$ é o volume da cavidade do cabeçote, $V_{\text {junta }}$ é o volume da junta do cabeçote (calculado em função da espessura da junta $\left.\left(h_{J}\right)\right)$ e $V_{\text {pis }}$ é o volume composto pelo volume da cavidade do pistão, pelo volume da folga $\left(h_{f}\right)$ entre o topo do pistão e a face superior do bloco do motor e pelo volume entre o primeiro anel de vedação e o topo do pistão.

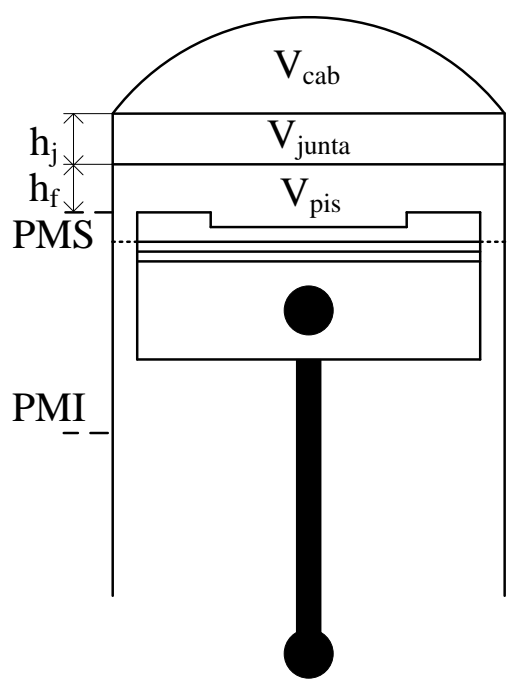

Figura E2 - Volumes que compõem o volume total da câmara de combustão.

A equação (E3) representa o volume da câmara de combustão em função dos três volumes estabelecidos.

$$
V_{c c}=V_{c a b}+V_{j u n t a}+V_{p i s}
$$

\section{E.1 DETERMINAÇÃO DO VOLUME DO CILINDRO $\left(V_{C}\right)$}

Para obter o volume do cilindro $\left(V_{C}\right)$ foi necessário obter o diâmetro do cilindro e o curso do pistão. 


\section{E.1.1 Determinação do diâmetro do cilindro $\left(D_{C I L}\right)$}

A medição do diâmetro foi realizada em quatro raios distintos dos cilindros, como mostra a Figura E3, e dividindo visualmente a altura dos cilindros em três partes: topo, meio e fundo. Os instrumentos de medição empregados foram um súbito e um micrômetro da marca Mitutoyo, com faixa de medição de 50 a $100 \mathrm{~mm}$ e resolução de $0,01 \mathrm{~mm}$.

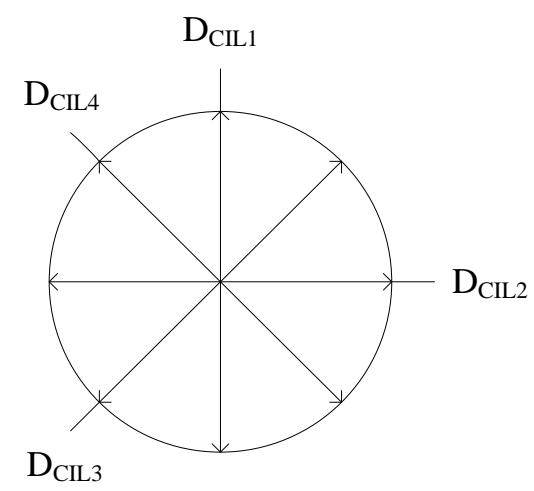

Figura E3 - Direções dos diâmetros medidos nos cilindros.

A Figura E4 mostra o procedimento para realização de uma das medidas do diâmetro do cilindro.

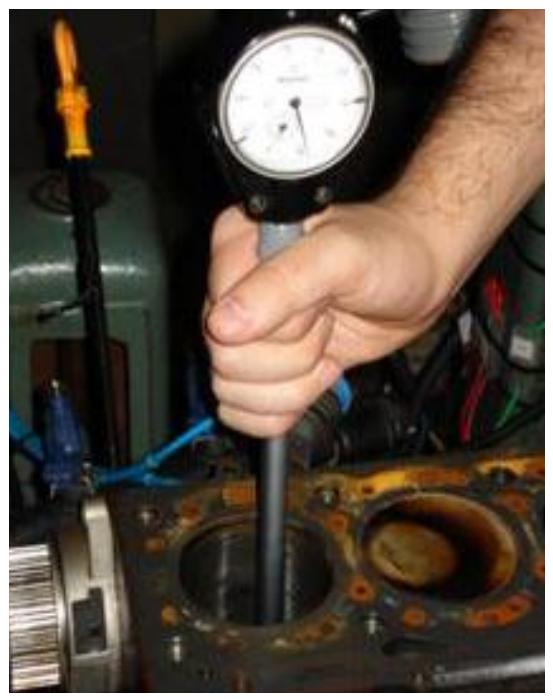

Figura E4 - Procedimento de medição do diâmetro do cilindro.

Este procedimento resultou em 12 medidas em cada cilindro do motor e um total de 48 medidas. A Tabela E1 mostra os diâmetros $\left(D_{C I L}\right)$ encontrados para cada cilindro, as médias das medidas, as incertezas padrão, os intervalos de confiança, obtidos com 95\% de confiança para as médias e a incerteza padrão combinada $\left(u_{c}\right)$. 
Tabela E1 - Diâmetros $\left(D_{C I L}\right)$ referentes a cada cilindro do motor.

\begin{tabular}{|c|c|c|c|c|}
\hline \multirow{2}{*}{ Medidas } & \multicolumn{4}{|c|}{$\mathrm{D}_{\mathrm{CIL}}$ referente a cada cilindro $[\mathrm{mm}]$} \\
\hline & Primeiro & Segundo & Terceiro & Quarto \\
\hline $1^{\mathrm{a}}$ Medida - Topo & 67,11 & 67,11 & 67,12 & 67,12 \\
\hline $2^{\mathrm{a}}$ Medida - Topo & 67,12 & 67,12 & 67,12 & 67,12 \\
\hline $3^{\text {a }}$ Medida - Topo & 67,12 & 67,12 & 67,13 & 67,13 \\
\hline $4^{\mathrm{a}}$ Medida - Topo & 67,11 & 67,11 & 67,11 & 67,11 \\
\hline $5^{\mathrm{a}}$ Medida - Meio & 67,11 & 67,11 & 67,12 & 67,11 \\
\hline $6^{\mathrm{a}}$ Medida - Meio & 67,12 & 67,12 & 67,12 & 67,12 \\
\hline $7^{\text {a }}$ Medida - Meio & 67,12 & 67,12 & 67,12 & 67,12 \\
\hline $8^{\mathrm{a}}$ Medida - Meio & 67,11 & 67,11 & 67,12 & 67,11 \\
\hline $9^{a}$ Medida - Fundo & 67,11 & 67,12 & 67,12 & 67,11 \\
\hline $10^{\mathrm{a}}$ Medida - Fundo & 67,12 & 67,12 & 67,12 & 67,12 \\
\hline $11^{\mathrm{a}}$ Medida - Fundo & 67,12 & 67,12 & 67,12 & 67,12 \\
\hline $12^{\mathrm{a}}$ Medida - Fundo & 67,11 & 67,11 & 67,12 & 67,11 \\
\hline Média & 67,12 & 67,12 & 67,12 & 67,12 \\
\hline Incerteza Padrão [mm] & 0,01 & 0,01 & 0,01 & 0,01 \\
\hline Erro (nível de confiança: $\alpha=0,05$ ) & 0,01 & 0,01 & 0,01 & 0,01 \\
\hline Extremo superior do INCO $(95 \%)$ & 67,13 & 67,13 & 67,13 & 67,13 \\
\hline Extremo inferior do INCO $(95 \%)$ & 67,10 & 67,10 & 67,11 & 67,10 \\
\hline \multicolumn{5}{|c|}{ INCO = Intervalo de confiança; GL $=12-1=11 ; t \alpha / 2=2,201$} \\
\hline Média dos 4 cilindros: $\mathrm{D}_{\mathrm{CIL}}[\mathrm{mm}]$ & \multicolumn{4}{|c|}{67,12} \\
\hline Incerteza padrão combinada $\left(\mathrm{u}_{\mathrm{c}}\right)[\mathrm{mm}]$ & \multicolumn{4}{|c|}{0,02} \\
\hline
\end{tabular}

De acordo com a Tabela E1 pode-se dizer que o diâmetro médio do cilindro $\left(D_{C I L}\right)$ é de $67,12(0,02) \mathrm{mm}$, em que o número expresso entre parênteses é o valor numérico de $\mathrm{u}_{\mathrm{c}}$ (incerteza padrão combinada) expresso na unidade do resultado mencionado. Os valores dos diâmetros foram expressos em mm para facilitar a visualização dos dados obtidos.

A incerteza padrão combinada foi calculada utilizando-se a equação (E4), adaptada da equação apresentada pelo Instituto Nacional de Metrologia, Normalização e Qualidade Industrial (2003), em que $u_{1}(\mathrm{vm}), u_{2}(\mathrm{vm}), u_{3}(\mathrm{vm})$ e $u_{4}(\mathrm{vm})$ são as incertezas padrão (desvios padrão) de cada estimativa do valor mensurado $(\mathrm{vm})$ - neste caso o valor mensurado é o diâmetro referente a cada cilindro $\left(D_{C I L 1}, D_{C I L 2}, D_{C I L 3}\right.$ e $\left.D_{C I L 4}\right)$.

$$
u_{c}=\sqrt{u_{1}^{2}\left(D_{C I L 1}\right)+u_{2}^{2}\left(D_{C I L 2}\right)+u_{3}^{2}\left(D_{C L L 3}\right)+u_{4}^{2}\left(D_{C I L 4}\right)}
$$


Segundo o Instituto Nacional de Metrologia, Normalização e Qualidade Industrial (2003), incerteza padrão é definida como a incerteza do resultado de uma medição determinada pelo desvio padrão das medidas.

A equação (E4) será empregada para o cálculo de todos dos valores de incertezas padrão combinadas apresentadas nas tabelas que constituem este apêndice.

\section{E.1.2 Determinação do curso do cilindro $\left(C_{P I S}\right)$}

Para determinar o curso do pistão foi necessário medir duas alturas: altura $h_{f}$ (folga entre o topo do pistão e a face superior do bloco do motor) e altura total $\left(h_{f}+C_{P I S}\right)$, ambas as medidas nos mesmos quatro raios em que foram medidos os diâmetros do cilindro, de acordo com a Figura E3.

O instrumento utilizado para efetuar as medidas das alturas $h_{f}$ e total foi um paquímetro da marca Mitutoyo, com faixa de medição de 0 a $200 \mathrm{~mm}$ e resolução de $0,05 \mathrm{~mm}$.

A Figura E5 mostra o procedimento de medição da altura $h_{f}$.

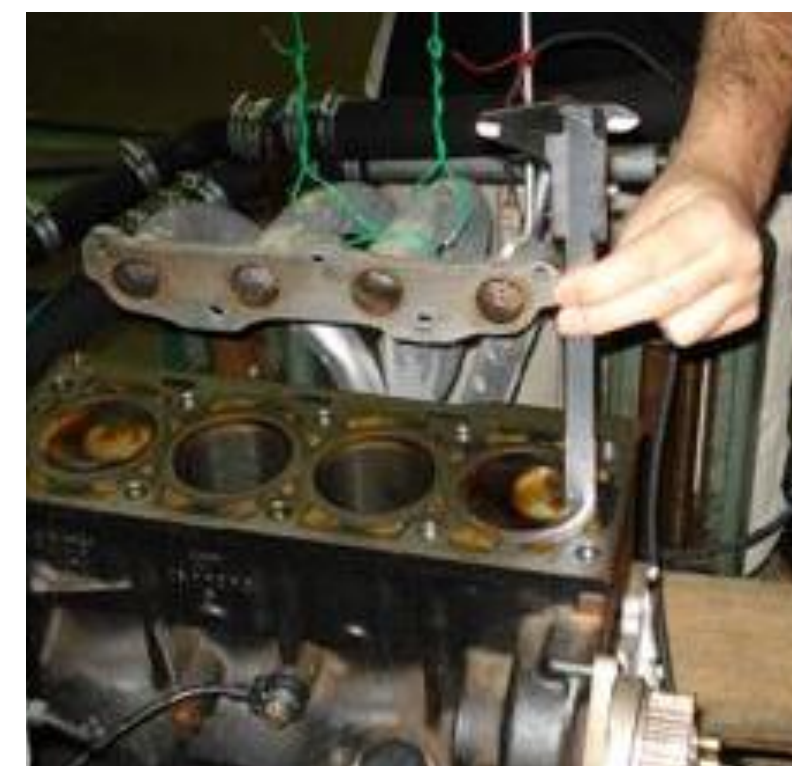

Figura E5 - Procedimento de medição da altura $h_{f}$.

O procedimento de medição da altura $h_{f}$ totalizou 16 medidas. A Tabela E2 mostra os valores de $h_{f}$ encontrados para cada cilindro, as médias das medidas, as incertezas padrão, os intervalos de confiança, obtidos com $95 \%$ de confiança para as médias e a incerteza padrão combinada $\left(u_{c}\right)$. 
Tabela E2 - Alturas $\mathrm{h}_{\mathrm{f}}$ referentes a cada cilindro do motor.

\begin{tabular}{lcccc}
\hline \multirow{2}{*}{\multicolumn{2}{c}{ Medidas }} & \multicolumn{3}{c}{$\mathrm{h}_{\mathrm{f}}$ referente a cada cilindro $[\mathrm{mm}]$} \\
& Primeiro & Segundo & Terceiro & Quarto \\
\hline $1^{\mathrm{a}}$ Medida & 0,30 & 0,20 & 0,30 & 0,30 \\
$2^{\mathrm{a}}$ Medida & 0,30 & 0,30 & 0,40 & 0,40 \\
$3^{\mathrm{a}}$ Medida & 0,25 & 0,40 & 0,40 & 0,40 \\
$4^{\mathrm{a}}$ Medida & 0,30 & 0,30 & 0,25 & 0,40 \\
Média & 0,29 & 0,30 & 0,34 & 0,38 \\
Incerteza Padrão [mm] & 0,01 & 0,04 & 0,04 & 0,02 \\
Erro (nível de confiança: $\alpha=0,05)$ & 0,05 & 0,15 & 0,14 & 0,09 \\
Extremo superior do INCO $(95 \%)$ & 0,35 & 0,50 & 0,52 & 0,50 \\
Extremo inferior do INCO $(95 \%)$ & 0,23 & 0,10 & 0,15 & 0,25 \\
\hline \multicolumn{1}{c}{ INCO = Intervalo de confiança; $\mathrm{GL}=4-1=3 ;$ t $\alpha / 2=3,182$} \\
Média dos 4 cilindros: $\mathrm{h}_{\mathrm{f}}[\mathrm{mm}]$ & \multicolumn{5}{c}{0,33} \\
Incerteza padrão combinada $\left(\mathrm{u}_{\mathrm{c}}\right)[\mathrm{mm}]$ & 0,06 \\
\hline
\end{tabular}

De acordo com a Tabela E2 pode-se dizer que a altura $h_{f}$ média é de $0,33(0,06) \mathrm{mm}$, em que o número expresso entre parênteses é o valor numérico de $\mathrm{u}_{\mathrm{c}}$ (incerteza padrão combinada) expresso na unidade do resultado mencionado. Os valores das alturas foram expressos em mm para facilitar a visualização dos dados obtidos.

O mesmo procedimento apresentado na Figura E5 foi empregado para efetuar a medição da altura total $\left(h_{f}+C_{P I S}\right)$.

O procedimento de medição da altura total totalizou 16 medidas. A Tabela E3 mostra os valores da altura total $\left(h_{f}+C_{P I S}\right)$ encontrados para cada cilindro, as médias das medidas, os intervalos de confiança, obtidos com $95 \%$ de confiança para as médias e a incerteza padrão combinada $\left(u_{c}\right)$.

De acordo com a Tabela E3 pode-se dizer que a altura total média $\left(h_{f}+C_{P I S}\right)$ é de 70,81 $(0,09) \mathrm{mm}$, em que o número expresso entre parênteses é o valor numérico de $\mathrm{u}_{\mathrm{c}}$ (incerteza padrão combinada) expresso na unidade do resultado mencionado. Os valores das alturas foram expressos em mm para facilitar a visualização dos dados obtidos. 
Tabela E3 - Alturas totais $\left(h_{f}+C_{P I S}\right)$ referentes a cada cilindro do motor.

\begin{tabular}{lcccc}
\hline \multirow{2}{*}{ Medidas } & \multicolumn{4}{c}{$\mathrm{h}_{\mathrm{f}}+\mathrm{C}_{\mathrm{PIS}}$ referente a cada cilindro [mm] } \\
& Primeiro & Segundo & Terceiro & Quarto \\
\hline $1^{\mathrm{a}}$ Medida & 70,60 & 70,70 & 70,70 & 70,80 \\
$2^{\mathrm{a}}$ Medida & 70,80 & 70,80 & 70,85 & 70,90 \\
$3^{\mathrm{a}}$ Medida & 70,80 & 71,00 & 70,85 & 70,90 \\
$4^{\mathrm{a}}$ Medida & 70,80 & 70,80 & 70,80 & 70,90 \\
Média & 70,75 & 70,82 & 70,80 & 70,88 \\
Incerteza Padrão [mm] & 0,05 & 0,06 & 0,04 & 0,02 \\
Erro (nível de confiança: $\alpha=0,05)$ & 0,18 & 0,23 & 0,13 & 0,09 \\
Extremo superior do INCO $(95 \%)$ & 71,00 & 71,14 & 70,98 & 71,00 \\
Extremo inferior do INCO $(95 \%)$ & 70,50 & 70,51 & 70,62 & 70,75 \\
\hline \multicolumn{4}{c}{ INCO = Intervalo de confiança; $\mathrm{GL}=4-1=3 ; \mathrm{t} \alpha / 2=3,182$} \\
Média dos 4 cilindros: $\mathrm{h}_{\mathrm{f}}+\mathrm{C}_{\mathrm{PIS}}[\mathrm{mm}]$ \\
Incerteza padrão combinada $\left(\mathrm{u}_{\mathrm{c}}\right)[\mathrm{mm}]$
\end{tabular}

\section{E.1.2.1 Cálculo do curso do cilindro e sua incerteza padrão combinada}

$\mathrm{O}$ curso do cilindro pode ser obtido subtraindo a altura $\mathrm{h}_{\mathrm{f}}$ da altura total $\left(h_{f}+C_{P I S}\right)$, conforme mostra a equação (E5).

$$
C_{P I S}=\text { Altura Total }-h_{f}
$$

Atribuindo os valores de $h_{f}$ e da altura total na equação (E5) pode-se obter o valor do curso do pistão para cada cilindro e também para a média de todos os cilindros. A incerteza padrão combinada pode ser obtida reescrevendo a equação (E4) da forma apresentada pela equação (E6), válida para propagação de incertezas relacionada à adição e subtração de grandezas.

$$
u_{\text {c adição }}=\sqrt{u_{1}^{2}(\text { Altura } \text { Total })+u_{2}^{2}\left(h_{f}\right)}
$$

A Tabela E4 apresenta os valores do curso do pistão $\left(C_{P I S}\right)$ encontrados para cada cilindro, para a média dos quatro cilindros e as incertezas padrões combinadas $\left(u_{c}\right.$ adição $)$.

De acordo com a Tabela E4 pode-se dizer que o curso médio do pistão $\left(C_{P I S}\right)$ é de 70,44 $(0,11) \mathrm{mm}$, em que o número expresso entre parênteses é o valor numérico de $u_{c}$ (incerteza padrão combinada) expresso na unidade do resultado mencionado. Os valores dos cursos dos pistões foram expressos em mm para facilitar a visualização dos dados obtidos. 
Tabela E4 - Valores obtidos dos cursos dos pistões $\left(C_{P I S}\right)$.

\begin{tabular}{lcccc}
\hline \multicolumn{1}{c}{ Valores obtidos } & \multicolumn{4}{c}{ Cilindros } \\
& Primeiro & Segundo & Terceiro & Quarto \\
\hline Curso do pistão $\left(\mathrm{C}_{\mathrm{PIS}}\right)[\mathrm{mm}]$ & 70,46 & 70,52 & 70,46 & 70,50 \\
Incerteza padrão combinada $\left(\mathrm{u}_{\mathrm{c} \text { adição }}\right)[\mathrm{mm}]$ & 0,05 & 0,07 & 0,06 & 0,03 \\
Média dos 4 cilindros: $\mathrm{C}_{\mathrm{PIS}}[\mathrm{mm}]$ & \multicolumn{4}{c}{70,48} \\
Incerteza padrão combinada $\left(\mathrm{u}_{\mathrm{c} \text { adição }}\right)[\mathrm{mm}]$ & \multicolumn{4}{c}{0,11} \\
\hline
\end{tabular}

\section{E.1.3 Cálculo do volume do cilindro e sua incerteza padrão combinada}

A equação que representa o volume do cilindro, equação (E2), pode ser reescrita como mostra a equação (E7).

$$
V_{C}=\frac{\pi D_{C L}^{2} C_{p i s}}{4}=\frac{\pi}{4} D_{C L}^{2} C_{p i s}=c_{1} D_{C L L}^{c_{2}} C_{p i s}
$$

Considerando os valores de $c_{1}$ e $c_{2}$ como constantes numéricas exatas, ou com erros desprezíveis, pode-se obter a incerteza padrão combinada utilizando a equação de propagação de incertezas apresenta por Cruz et al. (1997), que pode ser reescrita segundo a nomenclatura apresentada por Instituto Nacional de Metrologia, Normalização e Qualidade Industrial (2003) como mostra a equação (E8).

$$
u_{c \text { exp }}=\bar{V}_{c} * \sqrt{\left(\frac{2 * u_{c}\left(D_{C I L}\right)}{\bar{D}_{C I L}}\right)^{2}+\left(\frac{u_{c}\left(C_{p i s}\right)}{\bar{C}_{p i s}}\right)^{2}}
$$

em que:

$u_{c \exp }=$ incerteza padrão combinada para funções do tipo da equação (E7)

$u_{c}\left(D_{C I L}\right)=$ incerteza padrão do valor encontrado para o diâmetro do cilindro;

$u_{c}\left(C_{p i s}\right)=$ incerteza padrão do valor encontrado para o curso do pistão;

$\bar{D}_{C L}^{--}=$média dos valores encontrados na medição do diâmetro do cilindro, e

$\overline{C_{p i s}}=$ média dos valores encontrados na medição do curso do pistão.

A Tabela E5 apresenta os valores do volume do cilindro $\left(V_{C}\right)$ encontrados para cada cilindro, para a média dos quatro cilindros e as incertezas padrões combinadas $\left(u_{c} \exp \right)$. 
Tabela E5 - Valores obtidos dos volumes dos cilindros $\left(V_{C}\right)$

\begin{tabular}{lcccc}
\hline \multicolumn{1}{c}{ Valores obtidos } & \multicolumn{4}{c}{ Cilindros } \\
& Primeiro & Segundo & Terceiro & Quarto \\
\hline Volume do Cilindro $\left(\mathrm{V}_{\mathrm{C}}\right)[\mathrm{mL}]$ & 249,280 & 249,507 & 249,317 & 249,425 \\
Incerteza padrão combinada $\left(\mathrm{u}_{\mathrm{c}}\right.$ exp $)[\mathrm{mL}]$ & 0,192 & 0,258 & 0,225 & 0,130 \\
Média dos 4 cilindros: $\mathrm{V}_{\mathrm{C}}[\mathrm{mL}]$ & & 249,382 & \\
Incerteza padrão combinada $\left(\mathrm{u}_{\mathrm{c} \text { adição }}\right)[\mathrm{mL}]$ & & 0,413 \\
\hline
\end{tabular}

De acordo com a Tabela E5 pode-se dizer que o volume médio do cilindro $\left(V_{C}\right)$ é de $249,382(0,413) \mathrm{ml}$, em que o número expresso entre parênteses é o valor numérico de $\mathrm{u}_{\mathrm{c}}$ (incerteza padrão combinada) expresso na unidade do resultado mencionado. Os valores dos volumes dos cilindros foram expressos em $\mathrm{ml}$ para facilitar a visualização dos dados obtidos. Foi adicionado de forma proposital (e incorreta, pois o número correto de algarismos significativos de um resultado é igual ao do elemento somado com menor precisão) mais um algarismo significativo nos resultados do volume do cilindro para permitir a visualização dos valores obtidos das incertezas padrões combinadas.

\section{E.2 DETERMINAÇÃO DO VOLUME DA CÂMARA DE COMBUSTÃO}

\section{E.2.1 Volume da cavidade do cabeçote $\left(V_{c a b}\right)$}

O primeiro volume obtido para compor o volume final da câmara de combustão foi o volume da cavidade do cabeçote.

Uma placa de acrílico, com um furo central de 1/4 de polegada, foi posicionada sobre o centro da cavidade do cabeçote referente a cada cilindro e vedada com uma fina camada de vaselina.

Utilizando-se uma bureta de vidro de $25 \mathrm{ml}$ (resolução de $0,1 \mathrm{ml}$ ) com torneira de teflon, foi inserido querosene pelo orifício da placa até preencher toda a cavidade do cabeçote (em cada cilindro).

A Figura E6 mostra o arranjo para determinação do volume da cavidade do cabeçote. 


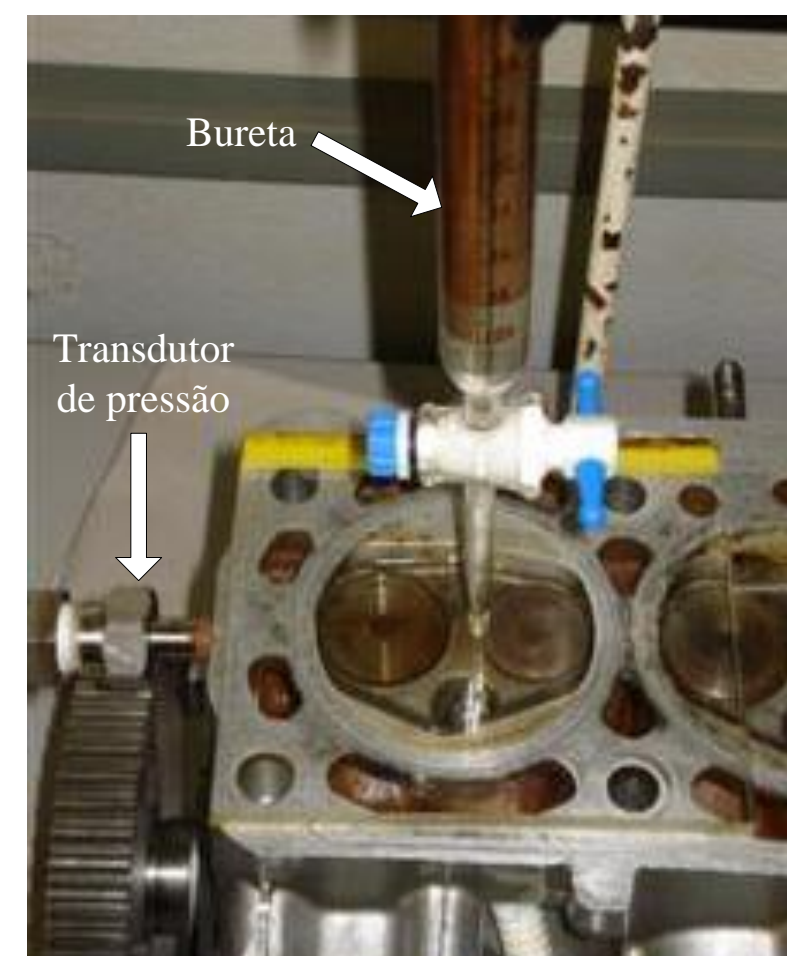

Figura E6 - Arranjo montado para medir o volume da cavidade do cabeçote.

Este procedimento foi repetido três vezes em cada cilindro, totalizando 12 medidas. A Tabela E6 mostra os volumes encontrados para cada cilindro, as médias das medidas, as incertezas padrão, os intervalos de confiança, obtidos com 95\% de confiança para as médias e a incerteza padrão combinada $\left(u_{c}\right)$.

Tabela E6 - Volumes das cavidades do cabeçote referentes a cada cilindro do motor.

\begin{tabular}{|c|c|c|c|c|}
\hline \multirow{2}{*}{ Medidas } & \multicolumn{4}{|c|}{$\mathrm{V}_{\text {cab }}$ referente a cada cilindro $[\mathrm{mL}]$} \\
\hline & Primeiro & Segundo & Terceiro & Quarto \\
\hline $1^{\mathrm{a}}$ Medida & 13,90 & 13,80 & 13,60 & 13,80 \\
\hline $2^{\mathrm{a}}$ Medida & 13,90 & 13,70 & 13,80 & 13,80 \\
\hline $3^{\mathrm{a}}$ Medida & 13,90 & 13,70 & 13,60 & 13,90 \\
\hline Média & 13,90 & 13,73 & 13,67 & 13,83 \\
\hline Incerteza Padrão [ml] & 0,01 & 0,03 & 0,06 & 0,03 \\
\hline Erro (nível de confiança: $\alpha=0,05$ ) & 0,01 & 0,14 & 0,29 & 0,14 \\
\hline Extremo superior do INCO (95\%) & 13,91 & 13,88 & 13,95 & 13,98 \\
\hline Extremo inferior do INCO (95\%) & 13,89 & 13,59 & 13,38 & 13,69 \\
\hline \multicolumn{5}{|c|}{ INCO $=$ Intervalo de confiança; $\mathrm{GL}=3-1=2 ; \mathrm{t} \alpha / 2=4,303$} \\
\hline Média dos 4 cilindros: $\mathrm{V}_{\mathrm{cab}}[\mathrm{ml}]$ & \multicolumn{4}{|c|}{13,78} \\
\hline Incerteza padrão combinada $\left(\mathrm{u}_{\mathrm{c}}\right)[\mathrm{ml}]$ & \multicolumn{4}{|c|}{0,07} \\
\hline
\end{tabular}

Conforme a Tabela E6 pode-se dizer que o volume médio da cavidade do cabeçote é de $13,78(0,07) \mathrm{ml}$, em que o número expresso entre parênteses é o valor numérico de $u_{c}$ 
(incerteza padrão combinada) expresso na unidade do resultado mencionado. Os valores dos volumes foram expressos em $\mathrm{ml}$ para facilitar a visualização dos dados obtidos.

\section{E.2.2 Volume da junta do cabeçote $\left(V_{\text {junta }}\right)$}

O volume da junta do cabeçote foi calculado utilizando o valor da espessura da junta (altura $h_{j}$ ) e supondo que o diâmetro da circunferência da junta é igual ao diâmetro do cilindro $\left(D_{C I L}\right)$. Essa hipótese foi assumida porque não foi possível obter o volume da junta juntamente com o volume da cavidade do cabeçote devido às dificuldades encontradas para vedar o conjunto cabeçote e junta utilizando uma placa de acrílico.

As espessuras da junta $\left(h_{j}\right)$ foram medidas nos quatro raios em que foram medidos os diâmetros dos cilindros, conforme mostra a Figura E3.

O instrumento utilizado para efetuar as medidas de $h_{j}$ foi um paquímetro da marca Mitutoyo, com faixa de medição de 0 a $200 \mathrm{~mm}$ e resolução de $0,05 \mathrm{~mm}$.

O procedimento de medição da espessura da junta totalizou 16 medidas. A Tabela E7 mostra os valores da espessura da junta $\left(h_{j}\right)$ encontrados para cada cilindro, as médias das medidas, os intervalos de confiança, obtidos com 95\% de confiança para as médias e a incerteza padrão combinada $\left(u_{c}\right)$.

Tabela E7 - Espessuras da junta do cabeçote $\left(h_{j}\right)$ referentes a cada cilindro do motor.

\begin{tabular}{|c|c|c|c|c|}
\hline \multirow{2}{*}{ Medidas } & \multicolumn{4}{|c|}{$\mathrm{h}_{\mathrm{j}}$ referente a cada cilindro $[\mathrm{mm}]$} \\
\hline & Primeiro & Segundo & Terceiro & Quarto \\
\hline $1^{a}$ Medida & 0,50 & 0,45 & 0,45 & 0,50 \\
\hline $2^{a}$ Medida & 0,50 & 0,50 & 0,55 & 0,55 \\
\hline $3^{\text {a }}$ Medida & 0,50 & 0,50 & 0,50 & 0,55 \\
\hline $4^{\mathrm{a}}$ Medida & 0,50 & 0,50 & 0,50 & 0,45 \\
\hline Média & 0,50 & 0,49 & 0,50 & 0,51 \\
\hline Incerteza Padrão [mm] & 0,01 & 0,01 & 0,02 & 0,02 \\
\hline Erro (nível de confiança: $\alpha=0,05$ ) & 0,01 & 0,05 & 0,08 & 0,09 \\
\hline Extremo superior do INCO $(95 \%)$ & 0,51 & 0,55 & 0,60 & 0,63 \\
\hline Extremo inferior do INCO (95\%) & 0,49 & 0,43 & 0,40 & 0,39 \\
\hline \multicolumn{5}{|c|}{ INCO = Intervalo de confiança; $\mathrm{GL}=4-1=3 ; \mathrm{t} \alpha / 2=3,182$} \\
\hline Média dos 4 cilindros: $h_{j}[\mathrm{~mm}]$ & \multicolumn{4}{|c|}{0,50} \\
\hline Incerteza padrão combinada $\left(\mathrm{u}_{\mathrm{c}}\right)[\mathrm{mm}]$ & \multicolumn{4}{|c|}{0,03} \\
\hline
\end{tabular}

De acordo com a Tabela E7 pode-se dizer que a espessura média da junta do cabeçote $\left(h_{j}\right)$ é de $0,50(0,03) \mathrm{mm}$, em que o número expresso entre parênteses é o valor numérico de $u_{c}$ 
(incerteza padrão combinada) expresso na unidade do resultado mencionado. Os valores das espessuras foram expressos em mm para facilitar a visualização dos dados obtidos.

\section{E.2.2.1 Cálculo do volume da junta do cabeçote $\left(V_{\text {junta }}\right)$}

O volume da junta do cabeçote foi obtido substituindo o valor de $C_{P I S}$ por $h_{j}$ na equação E2.

A incerteza padrão combinada foi obtida substituindo o valor de $C_{P I S}$ por $h_{j}$ na equação E8.

A Tabela E8 apresenta os valores do volume da junta do cabeçote $\left(V_{\text {junta }}\right)$ encontrados para cada cilindro, para a média dos quatro cilindros e as incertezas padrões combinadas $\left(u_{c}\right.$ exp).

Tabela E8 - Valores obtidos dos volumes da junta do cabeçote $\left(V_{\text {junta }}\right)$.

\begin{tabular}{lcccc}
\hline \multicolumn{1}{c}{ Valores obtidos } & \multicolumn{4}{c}{ Cilindros } \\
& Primeiro & Segundo & Terceiro & Quarto \\
\hline Volume da Junta $\left(\mathrm{V}_{\text {junta }}\right)[\mathrm{mL}]$ & 1,77 & 1,72 & 1,77 & 1,81 \\
Incerteza padrão combinada $\left(\mathrm{u}_{\mathrm{c} \text { exp }}\right)[\mathrm{mL}]$ & 0,04 & 0,04 & 0,07 & 0,07 \\
Média dos 4 cilindros: $\mathrm{V}_{\text {junta }}[\mathrm{mL}]$ & \multicolumn{4}{c}{1,77} \\
Incerteza padrão combinada $\left(\mathrm{u}_{\mathrm{c} \text { adição }}\right)[\mathrm{mL}]$ & \multicolumn{4}{c}{0,11} \\
\hline
\end{tabular}

De acordo com a Tabela E8 pode-se dizer que o volume médio da junta do cabeçote ( $\left.V_{\text {junta }}\right)$ é de $1,77(0,11) \mathrm{ml}$, em que o número expresso entre parênteses é o valor numérico de $\mathrm{u}_{\mathrm{c}}$ (incerteza padrão combinada) expresso na unidade do resultado mencionado. Os valores dos volumes dos cilindros foram expressos em $\mathrm{ml}$ para facilitar a visualização dos dados obtidos.

\section{E.2.3 Volume $V_{p i s}$}

O $V_{p i s}$ é o volume composto pelo volume da cavidade do pistão, pelo volume da folga entre o topo do pistão e a face superior do bloco do motor e pelo volume da folga entre o primeiro anel de vedação e o topo do pistão. A Figura E7 mostra o arranjo montado para medição do $V_{p i s}$.

Para evitar vazamentos foi inserida uma pequena quantidade de vaselina sólida entre o primeiro anel de vedação e a parede do cilindro. 
Uma placa de acrílico, com um furo central de 1/4 de polegada, foi posicionada sobre o bloco do motor no centro de cada cilindro e vedada com uma fina camada de vaselina.

Utilizando-se a mesma bureta do arranjo montado para medir o volume da cavidade do cabeçote, foi inserido querosene pelo orifício da placa até preencher todas as cavidades (pistão e folgas).

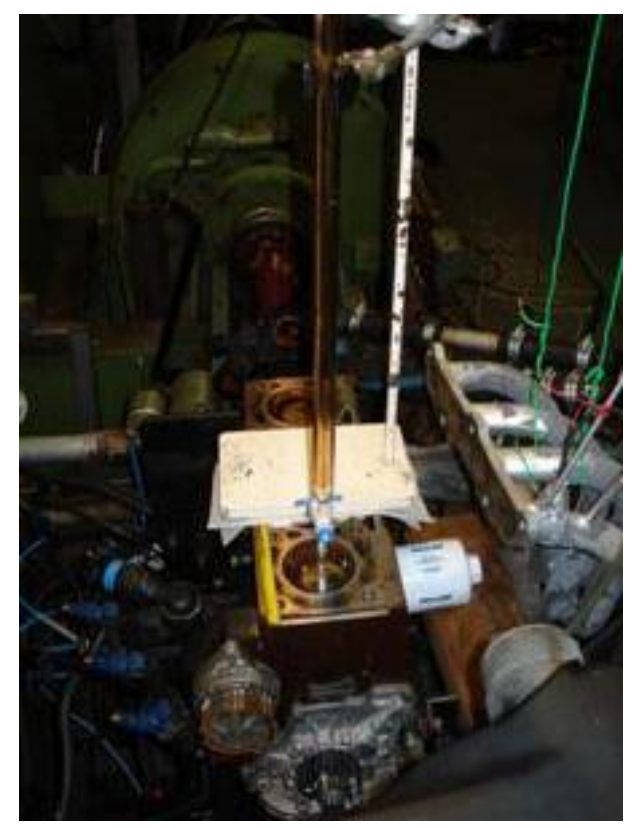

Figura E7 - Arranjo montado para medir o volume $V_{p i s}$.

Este procedimento foi repetido três vezes em cada cilindro, totalizando 12 medidas. A Tabela E9 mostra os volumes encontrados para cada cilindro, as médias das medidas, os intervalos de confiança, obtidos com $95 \%$ de confiança para as médias e a incerteza padrão combinada $\left(u_{c}\right)$.

De acordo com a Tabela E9 pode-se dizer que o volume médio $V_{p i s}$ é de 4,50 $(0,09) \mathrm{ml}$, em que o número expresso entre parênteses é o valor numérico de $u_{c}$ (incerteza padrão combinada) expresso na unidade do resultado mencionado. Os valores dos volumes foram expressos em ml para facilitar a visualização dos dados obtidos. 
Tabela E9 - Volumes das cavidades (pistão e folgas) referentes a cada cilindro do motor.

\begin{tabular}{lcccc}
\hline \multirow{2}{*}{ Medidas } & \multicolumn{4}{c}{$\mathrm{V}_{\text {pis }}$ referente a cada cilindro [mL] } \\
& Primeiro & Segundo & Terceiro & Quarto \\
\hline $1^{\text {a }}$ Medida & 4,40 & 4,40 & 4,30 & 4,70 \\
$2^{\text {a }}$ Medida & 4,40 & 4,50 & 4,50 & 4,60 \\
$3^{\text {a }}$ Medida & 4,40 & 4,50 & 4,60 & 4,70 \\
Média & 4,40 & 4,47 & 4,47 & 4,67 \\
Incerteza Padrão [ml] & 0,01 & 0,03 & 0,08 & 0,03 \\
Erro (nível de confiança: $\alpha=0,05)$ & 0,00 & 0,14 & 0,38 & 0,14 \\
Extremo superior do INCO (95\%) & 4,40 & 4,61 & 4,85 & 4,81 \\
Extremo inferior do INCO $(95 \%)$ & 4,40 & 4,32 & 4,09 & 4,52 \\
\hline
\end{tabular}

INCO = Intervalo de confiança; GL=3-1=2; $\mathrm{t} \alpha / 2=4,303$

Média dos 4 cilindros: $\mathrm{V}_{\text {pis }}[\mathrm{ml}] \quad 4,50$

Incerteza padrão combinada $\left(\mathrm{u}_{\mathrm{c}}\right)[\mathrm{ml}] \quad 0,09$

\section{E.2.4 Cálculo do volume da câmara de combustão}

Como determinado pela equação (E3) o volume da câmara de combustão é a somatória dos volumes da cavidade do cabeçote $\left(V_{c a b}\right)$, da junta do cabeçote $\left(V_{\text {junta }}\right)$ e do volume $V_{\text {pis }}$.

A incerteza padrão combinada do valor medido do volume da câmara de combustão pode ser obtida reescrevendo a equação (E4) da forma apresentada pela equação (E9), válida para propagação de incertezas relacionada à adição (ou subtração) de grandezas.

$$
u_{c \text { adição }}=\sqrt{u_{1}^{2}\left(V_{c a b}\right)+u_{2}^{2}\left(V_{\text {junta }}\right)+u_{1}^{2}\left(V_{p i s}\right)}
$$

A Tabela E10 apresenta os valores do volume da câmara de combustão $\left(V_{C C}\right)$ encontrados para cada cilindro, para a média dos quatro cilindros e as incertezas padrão combinadas $\left(u_{c}\right.$ adição).

Tabela E10 - Valores obtidos dos volumes das câmaras de combustão $\left(V_{C C}\right)$.

\begin{tabular}{lcccc}
\hline \multicolumn{1}{c}{ Valores obtidos } & \multicolumn{4}{c}{ Cilindros } \\
& Primeiro & Segundo & Terceiro & Quarto \\
\hline Volume da Câmara de Combustão $\left(\mathrm{V}_{\mathrm{CC}}\right)$ & 20,07 & 19,92 & 19,91 & 20,31 \\
& 0,02 & 0,02 & 0,04 & 0,04 \\
ImL] & \multicolumn{4}{c}{20,05} \\
Média dos 4 cilindros: $\mathrm{V}_{\mathrm{CC}}[\mathrm{mL}]$ & \multicolumn{4}{c}{0,06} \\
Incerteza padrão combinada $\left(\mathrm{u}_{\mathrm{c} \text { adição }}\right)[\mathrm{mL}]$ & & \multicolumn{4}{c}{} \\
\hline
\end{tabular}


De acordo com a Tabela E10 pode-se expor que o volume médio da câmara de combustão $\left(V_{C C}\right)$ é de 20,05 $(0,02) \mathrm{ml}$, em que o número expresso entre parênteses é o valor numérico de $u_{c}$ (incerteza padrão combinada) expresso na unidade do resultado mencionado. Os valores dos volumes das câmaras de combustão foram expressos em $\mathrm{ml}$ para facilitar a visualização dos dados obtidos.

\section{E.3 CÁlCULO DA RELAÇÃo DE COMPRESSÃO DO MOTOR $\left(T_{R}\right)$}

O volume total $\left(V_{\text {total }}\right)$ utilizado na equação (E1) foi obtido somando os resultados encontrados para o volume da câmara de combustão e para o volume do cilindro.

A incerteza padrão do volume total foi obtida substituindo na equação (E6) os valores da altura total e de $h_{f}$ pelos valores do volume da câmara de combustão $\left(V_{C C}\right)$ e do volume do cilindro $\left(V_{C}\right)$, respectivamente.

A Tabela E11 apresenta os valores do volume total ( $\left.V_{\text {total }}\right)$ encontrados para cada cilindro, para a média dos quatro cilindros e as incertezas padrões combinadas $\left(u_{\text {c adição }}\right)$.

Tabela E11 - Valores obtidos dos volumes totais $\left(V_{\text {total }}\right)$.

\begin{tabular}{lcccc}
\hline \multicolumn{1}{c}{ Valores obtidos } & \multicolumn{4}{c}{ Cilindros } \\
& Primeiro & Segundo & Terceiro & Quarto \\
\hline Volume Total $\left(\mathrm{V}_{\text {total }}\right)[\mathrm{mL}]$ & 269,35 & 269,43 & 269,23 & 269,74 \\
Incerteza padrão combinada $\left(\mathrm{u}_{\mathrm{c} \text { adição }}\right)[\mathrm{mL}]$ & 0,01 & 0,01 & 0,01 & 0,01 \\
Média dos 4 cilindros: $\mathrm{V}_{\text {total }}(\mathrm{mL}]$ & \multicolumn{4}{c}{269,43} \\
Incerteza padrão combinada $\left(\mathrm{u}_{\mathrm{c} \text { adição }}\right)[\mathrm{mL}]$ & \multicolumn{4}{c}{0,02} \\
\hline
\end{tabular}

De acordo com a Tabela E11 pode-se escrever que o volume médio total ( $\left.V_{\text {total }}\right)$ é de 269,43 (0,02) $\mathrm{ml}$, em que o número expresso entre parênteses é o valor numérico de $\mathrm{u}_{\mathrm{c}}$ (incerteza padrão combinada) expresso na unidade do resultado mencionado. Os valores dos volumes totais foram expressos em $\mathrm{ml}$ para facilitar a visualização dos dados obtidos.

De posse de todos os valores obtidos nas medições pode-se calcular o valor da relação de compressão utilizando a equação (E1).

A incerteza padrão combinada ( $u_{c}$ quociente $)$ para a função apresentada pela equação (E1), ou seja, um quociente de grandezas, pode ser calculada utilizando a equação de propagação de incertezas apresenta por Cruz et al. (1997), que pode ser reescrita segundo a nomenclatura apresentada pelo Instituto Nacional de Metrologia, Normalização e Qualidade Industrial (2003) como mostra a equação (E10). 


$$
u_{c \text { quociente }}=\bar{T}_{r} \sqrt{\left(\frac{u_{c}\left(V_{\text {total }}\right)}{\bar{V}_{\text {total }}}\right)^{2}+\left(\frac{u_{c}\left(V_{C C}\right)}{\bar{V}_{C C}}\right)^{2}}
$$

em que:

$u_{c \text { quociente }}=$ incerteza padrão combinada para funções do tipo da equação (E1)

$u_{c}\left(V_{\text {total }}\right)=$ incerteza padrão do valor encontrado para o volume total;

$u_{c}\left(V_{C C}\right)=$ incerteza padrão do valor encontrado para o volume da câmara de combustão;

$\bar{V}_{\text {total }}=$ média dos valores encontrados na medição do volume total;

$\bar{V}_{C C}^{---}$média dos valores encontrados na medição do volume da câmara de combustão.

A Tabela E12 apresenta os valores da relação de compressão $\left(T_{r}\right)$ encontrados para cada cilindro, para a média dos quatro cilindros e as incertezas padrões combinadas $\left(u_{c}\right.$ quociente $)$.

Tabela E12 - Valores obtidos das taxas de compressão do motor $\left(\mathrm{T}_{\mathrm{r}}\right)$.

\begin{tabular}{lcccc}
\hline \multicolumn{1}{c}{ Valores obtidos } & \multicolumn{4}{c}{ Cilindros } \\
& Primeiro & Segundo & Terceiro & Quarto \\
\hline Relação de compressão $\left(\mathrm{T}_{\mathrm{r}}\right)$ & 13,42 & 13,52 & 13,52 & 13,28 \\
Incerteza padrão combinada $\left(\mathrm{u}_{\mathrm{c} \text { quociente }}\right)$ & 0,01 & 0,01 & 0,03 & 0,03 \\
Média dos 4 cilindros: $\mathrm{T}_{\mathrm{r}}$ & \multicolumn{4}{c}{13,44} \\
Incerteza padrão combinada $\left(\mathrm{u}_{\mathrm{c} \text { adição }}\right)$ & \multicolumn{4}{c}{0,04} \\
\hline
\end{tabular}

De acordo com a Tabela E12 pode-se dizer que a relação de compressão média do motor $\left(T_{r}\right)$ é de 13,44 : $1(0,04)$, em que o número expresso entre parênteses é o valor numérico de $u_{c}$ (incerteza padrão combinada) expresso na unidade do resultado mencionado (neste caso adimensional). 


\section{APÊNDICE F - Calibração do transdutor de temperatura do líquido de arrefecimento}

O transdutor de temperatura, modelo MTE-4053, foi utilizado para monitorar a temperatura do líquido de arrefecimento do motor.

Este transdutor é um termistor do tipo NTC (negative temperature coefficient coeficiente de temperatura negativo), que apresenta uma diminuição da sua resistência (resistência variável) com o aumento da temperatura.

Para obter a curva de calibração deste transdutor foi montado um circuito que permite observar os valores de saída (tensão $+V_{s}$ ) do transdutor em função da temperatura aplicada ao seu elemento sensor. Este circuito é um divisor de tensão montado com dois resistores em série, um de resistência constante $\left(R_{1} \approx 2,7 \mathrm{k} \Omega\right)$ e outro de resistência variável (NTC 4053), alimentados por uma fonte de corrente contínua $\left(V_{\text {ref }} \approx 5 \mathrm{~V}\right)$. A Figura F1 mostra os elementos deste circuito.

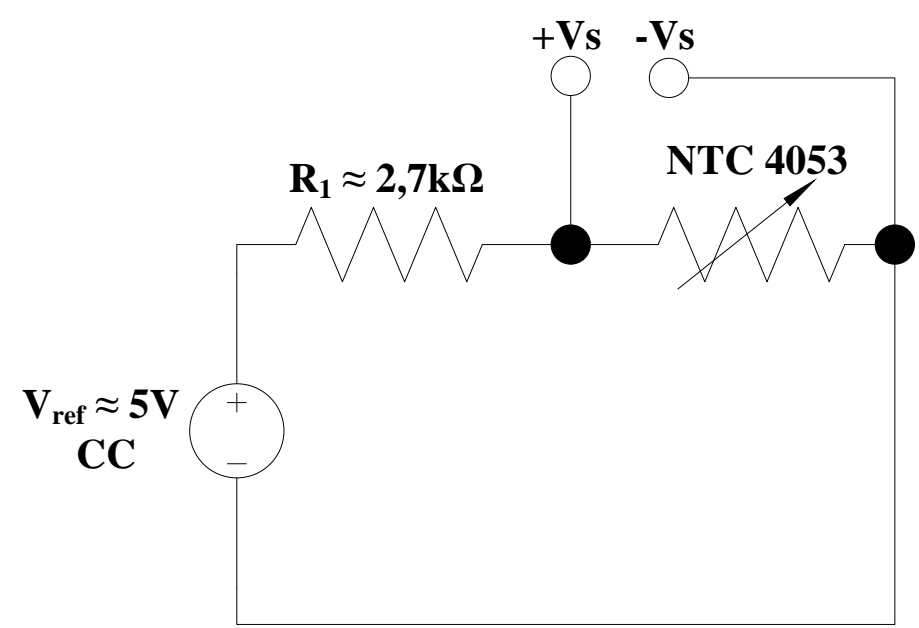

Figura F1 - Circuito do sistema de calibração do transdutor de temperatura NTC 4053.

Diversas temperaturas constantes foram aplicadas ao elemento sensor do transdutor NTC 4053 por meio de sua imersão em um banho termostático da marca Haake, modelo C35\&F6.

A Tabela F1 apresenta dos valores obtidos durante as três repetições da medição da tensão de saída $\left(+V_{s}\right)$ do transdutor NTC4053 em função das temperaturas aplicadas no seu elemento sensor. 
Tabela F1 - Tensões de saída (+Vs) em função das temperaturas atribuídas ao elemento sensor do transdutor NTC 4053.

\begin{tabular}{|c|c|c|c|}
\hline \multirow{2}{*}{ Temperatura $\left[{ }^{\circ} \mathrm{C}\right]$} & \multicolumn{3}{|c|}{ Tensão [V] (+Vs) } \\
\hline & Repetição 1 & Repetição 2 & Repetição 3 \\
\hline 0 & 3,7634 & 3,7755 & 3,7444 \\
\hline 5 & 3,5343 & 3,5486 & 3,5467 \\
\hline 10 & 3,2992 & 3,3084 & 3,3058 \\
\hline 15 & 3,0467 & 3,0508 & 3,0354 \\
\hline 20 & 2,7737 & 2,7793 & 2,7699 \\
\hline 25 & 2,517 & 2,5117 & 2,5057 \\
\hline 30 & 2,2577 & 2,2577 & 2,2505 \\
\hline 35 & 2,0106 & 2,0058 & 2,0005 \\
\hline 40 & 1,7771 & 1,7735 & 1,7737 \\
\hline 45 & 1,5612 & 1,5553 & 1,562 \\
\hline 50 & 1,3713 & 1,3633 & 1,3695 \\
\hline 55 & 1,1966 & 1,1916 & 1,195 \\
\hline 60 & 1,0432 & 1,0354 & 1,0432 \\
\hline 65 & 0,9064 & 0,9014 & 0,9041 \\
\hline 70 & 0,7896 & 0,7828 & 0,7865 \\
\hline 75 & 0,6861 & 0,6789 & 0,6833 \\
\hline 80 & 0,5966 & 0,5902 & 0,5941 \\
\hline 85 & 0,5198 & 0,5124 & 0,5167 \\
\hline 90 & 0,4489 & 0,4458 & 0,4495 \\
\hline 95 & 0,3934 & 0,3887 & 0,3923 \\
\hline 100 & 0,3411 & 0,345 & 0,3484 \\
\hline 101 & 0,3298 & 0,3379 & 0,3256 \\
\hline 102 & 0,3234 & 0,3168 & 0,3248 \\
\hline 103 & 0,3134 & 0,3084 & 0,318 \\
\hline 104 & 0,3051 & 0,3093 & 0,3057 \\
\hline 105 & 0,2993 & 0,2926 & 0,2971 \\
\hline 106 & 0,2901 & 0,2936 & 0,2919 \\
\hline 107 & 0,2839 & 0,2863 & 0,2864 \\
\hline 108 & 0,2711 & 0,2785 & 0,277 \\
\hline 109 & 0,269 & 0,2634 & 0,2699 \\
\hline 110 & 0,2623 & 0,264 & 0,2566 \\
\hline
\end{tabular}

A Tabela F2 apresenta os valores da tensão de alimentação $\left(V_{r e f}\right)$ da fonte de corrente contínua e os valores da resistência $R_{l}$ obtidos durante as três repetições da medição da tensão de saída $\left(+V_{s}\right)$. 
Tabela F2 - Valores de Vref e $R_{l}$ obtidos durante as três repetições da medição de $V_{s}$.

\begin{tabular}{lll}
\hline Repetições & $\mathrm{V}_{\text {ref }}[\mathrm{V}]$ & $\mathrm{R}_{1}[\Omega]$ \\
\hline Repetição 1 & 4,9987 & 2707,5 \\
Repetição 2 & 4,9966 & 2705,3 \\
Repetição 3 & 4,9976 & 2706,4 \\
\hline
\end{tabular}

Pode-se observar na Tabela F2 que não houve variações significativas de $V_{\text {ref }}$ e $R_{l}$ durante a medição que pudessem afetar os resultados obtidos de $V_{s}$.

A Figura F2 apresenta a curva de ajuste da tensão de saída do transdutor $\left(+V_{s}\right)$ em função da temperatura aplicada no banho termostático $(y)$. O coeficiente de determinação $\left(r^{2}\right)$ encontrado é igual a 0,9998. O erro padrão, com nível de confiança de $95 \%$.

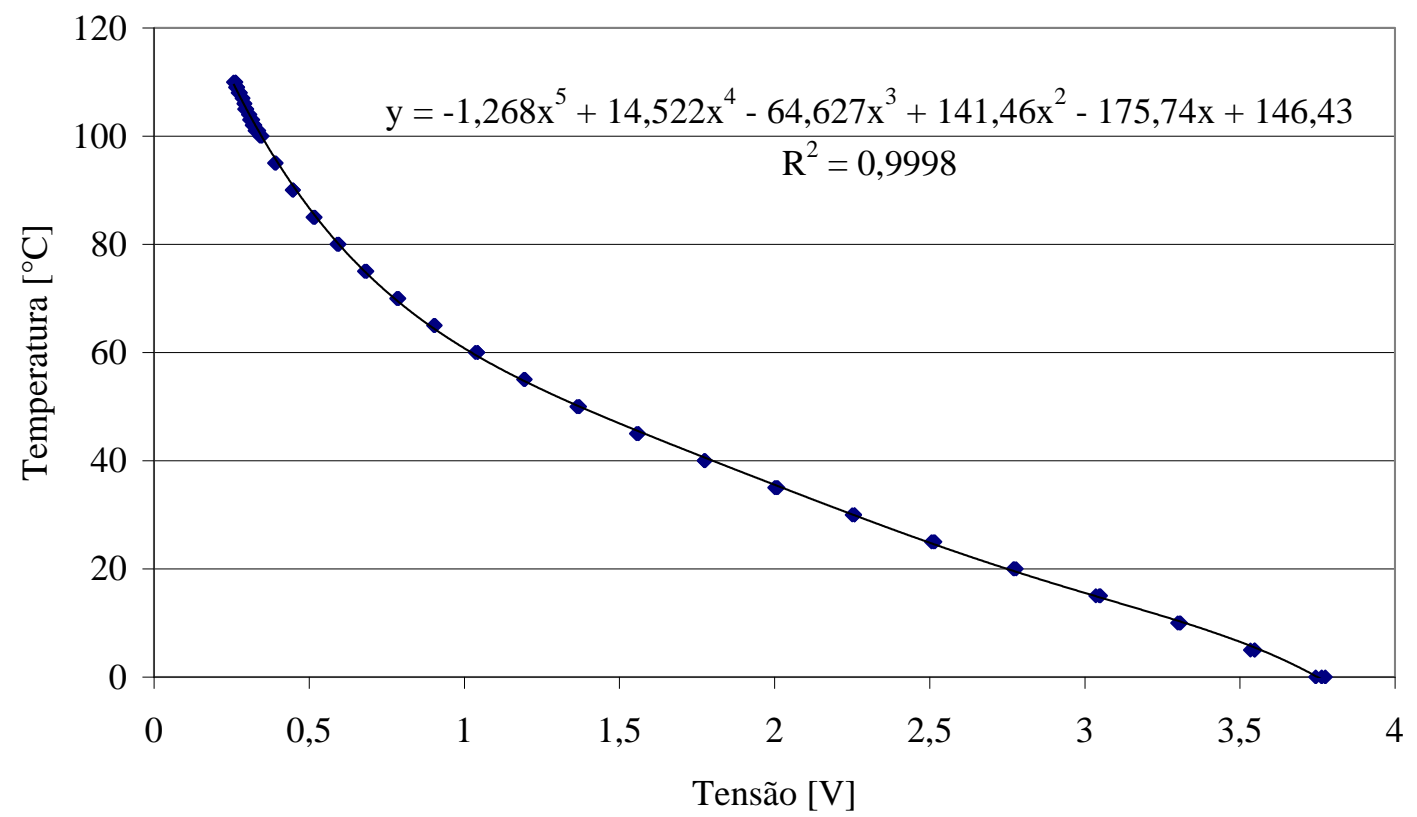

Figura F2 - Tensão de saída $\left(V_{s}\right)$ em função da temperatura $(y)$.

Adequando a nomenclatura à equação da curva y apresentada no gráfico da Figura F2, tem-se a equação (F1).

$$
\text { Temperatura }=-1,268 V_{s}^{5}+14,522 V_{s}^{4}-64,627 V_{s}^{3}+141,46 V_{s}^{2}-175,74 V_{s}+146,43
$$




\section{APÊNDICE G - Procedimentos adotados para preservar os equipamentos da bancada dinamométrica}

As Tabelas G1 e G2 apresentam todos os procedimentos adotados para preservar os equipamentos da bancada dinamométrica antes do início das medições realizadas em cada experimento.

Tabela G1 - Procedimentos preliminares adotados na sala de ensaios.

\begin{tabular}{|l|l|}
\hline \multicolumn{2}{|c|}{ VERIFICAR } \\
\hline \multicolumn{2}{|c|}{ SALA DE ENSAIOS (sala do dinamômetro) } \\
\hline 1 & NÍVEL DO ÓLEO DO MOTOR \\
\hline 2 & NÍVEL DO VASO DE EXPANSÃO DOS RADIADORES \\
\hline 3 & APERTO DOS PARAFUSOS DO CARDAN \\
\hline 4 & APERTO DOS PARAFUSOS DO SUPORTE DO MOTOR \\
\hline 5 & ACIONAMENTO DAS VENTOINHAS \\
\hline 6 & VEDAÇÃO DA REFRIGERAÇÃO DO TRANSDUTOR 8QP 500CA \\
\hline 7 & VEDAÇÃO DO TRANSDUTOR DE PRESSÃO NO COL. DE ADMISSÃO \\
\hline 8 & FILTROS DO TM131 \\
\hline 9 & REGISTROS DA LINHA DE COMBUSTÍVEL \\
\hline 10 & TENSÃO DA BATERIA (ANTES DA PARTIDA) \\
\hline 11 & ALTERNADOR (PÓS-PARTIDA) \\
\hline 12 & CONEXÃO DA SONDA LAMBDA DE BANDA LARGA \\
\hline 13 & REGISTROS D'ÁGUA DOS DINAMÔMETROS \\
\hline 14 & NÍVEL D’ÁGUA DO PSICRÔMETRO \\
\hline
\end{tabular}

Tabela G2 - Procedimentos preliminares adotados na sala de monitoramento.

\begin{tabular}{|c|l|}
\hline \multicolumn{2}{|c|}{ VERIFICAR } \\
\hline \multicolumn{2}{|c|}{ SALA DE MONITORAMENTO (sala do controlador do dinamômetro) } \\
\hline 1 & FLUXO D’ÁGUA DA BOMBA DE REFRIGERAÇÃO DO AVL \\
\hline 2 & NÍVEL DO RESERVATÓRIO DE COMBUSTÍVEL \\
\hline 3 & ACIONAMENTO DO CONTROLADOR WB-O2 (IGNIÇÃO LIGADA) \\
\hline 4 & SINAIS DOS TRANSDUTORES NO VI DE AQUISIÇÃO DE DADOS \\
\hline 5 & SINAL DA BALANÇA NO VI DE MEDIÇÃO DE CONSUMO \\
\hline 6 & SINAL DO TM131 (SOFTGAS) \\
\hline
\end{tabular}




\section{ANEXO A - Especificações técnicas do Amplificador operacional LM224A}

Especificações técnicas do amplificador operacional LM224A da marca Fairchild Semiconductor ${ }^{\circledR}$.

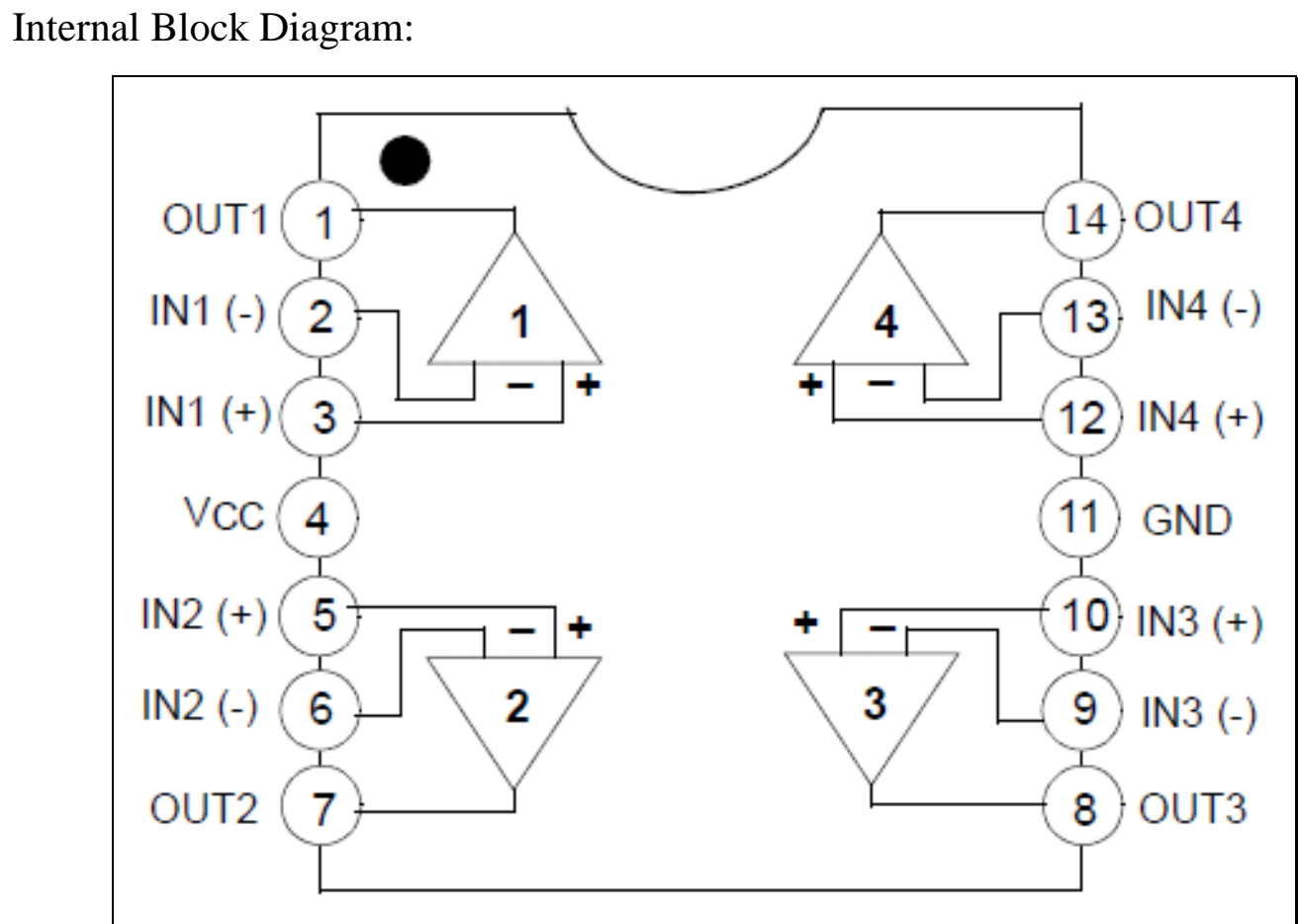

Fonte: FAIRCHILD (2002). 
Absolute Maximum Ratings:

\begin{tabular}{|l|c|c|}
\hline Parameter & Symbol & LM324/LM324A \\
\hline Power Supply Voltage & $V_{C C}$ & \pm 16 or 32 \\
\hline Differential Input Voltage & $V_{\text {I (DIFF) }}$ & 32 \\
\hline Input Voltage & VI & -0.3 to +32 \\
\hline $\begin{array}{l}\text { Output Short Circuit to GND } \\
\text { Vcc } \leq 15 \mathrm{~V}, \mathrm{TA}_{\mathrm{A}}=25^{\circ} \mathrm{C} \text { (one Amp) }\end{array}$ & - & Continuous \\
\hline $\begin{array}{l}\text { Power Dissipation, TA=25 } 5^{\circ} \mathrm{C} \\
\text { 14-DIP } \\
\text { 14-SOP }\end{array}$ & PD & $\begin{array}{c}1310 \\
640\end{array}$ \\
\hline Operating Temperature Range & TOPR & $0 \sim+70$ \\
\hline Storage Temperature Range & TSTG & $-65 \sim+150$ \\
\hline
\end{tabular}

Fonte: FAIRCHILD (2002). 
Voltage Follower Pulse Response:

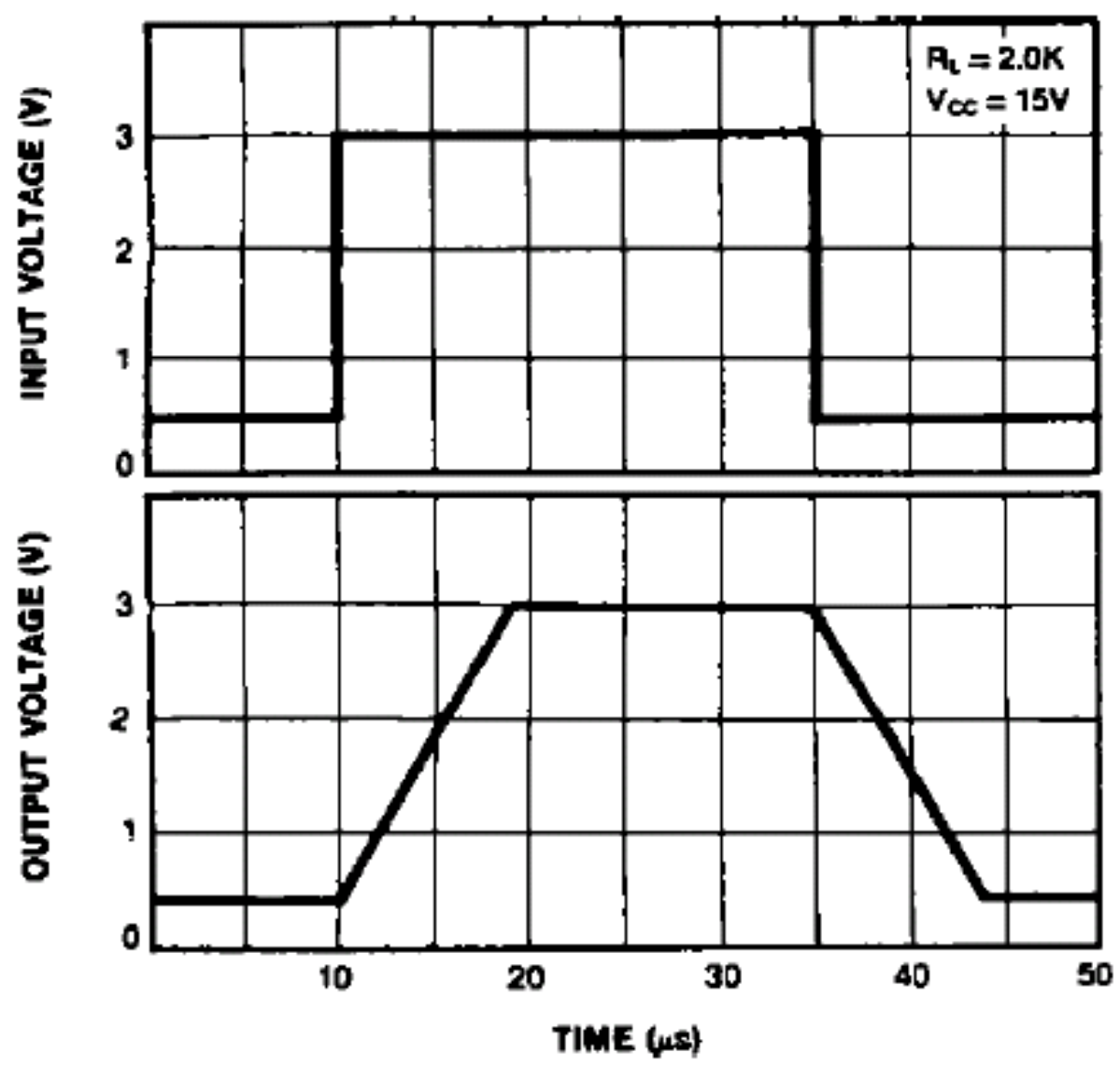

Fonte: FAIRCHILD (2002). 


\section{ANEXO B - Especificações técnicas do amplificador para termopares AD595AQ}

Especificações técnicas do amplificador de termopares com compensação de junta fria AD595AQ da marca Analog Devices ${ }^{\circledR}$.

Functional Block Diagram:

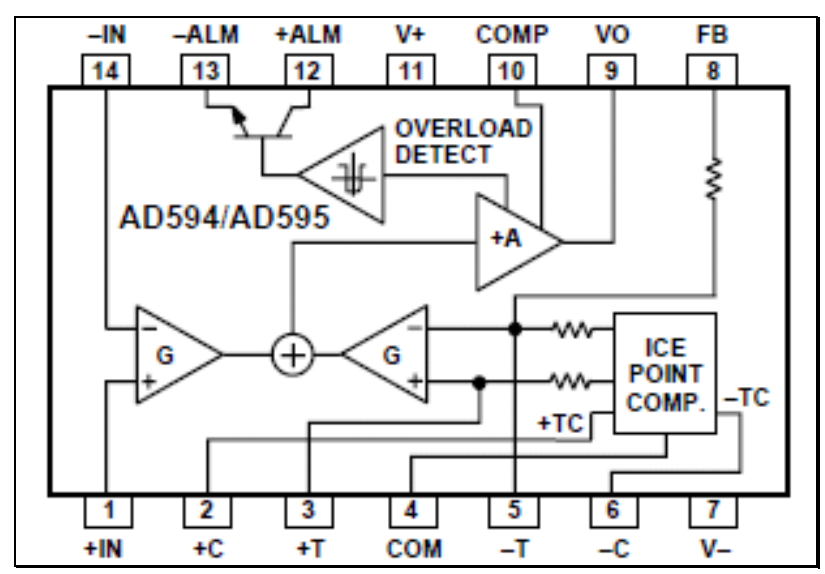

Fonte: ANALOG DEVICES (1999).

Basic connection (single supply operation):

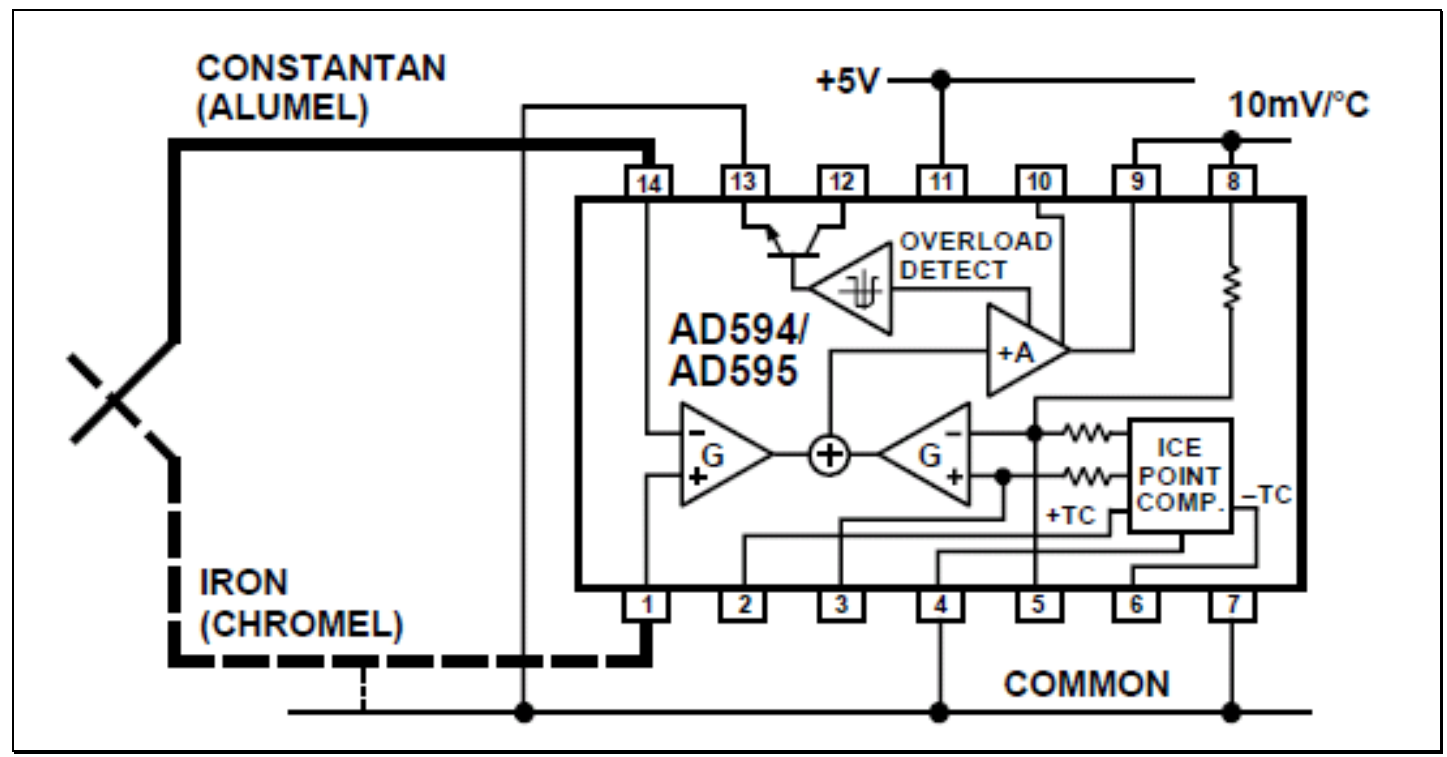

Fonte: ANALOG DEVICES (1999). 
AD595 - Specifications:

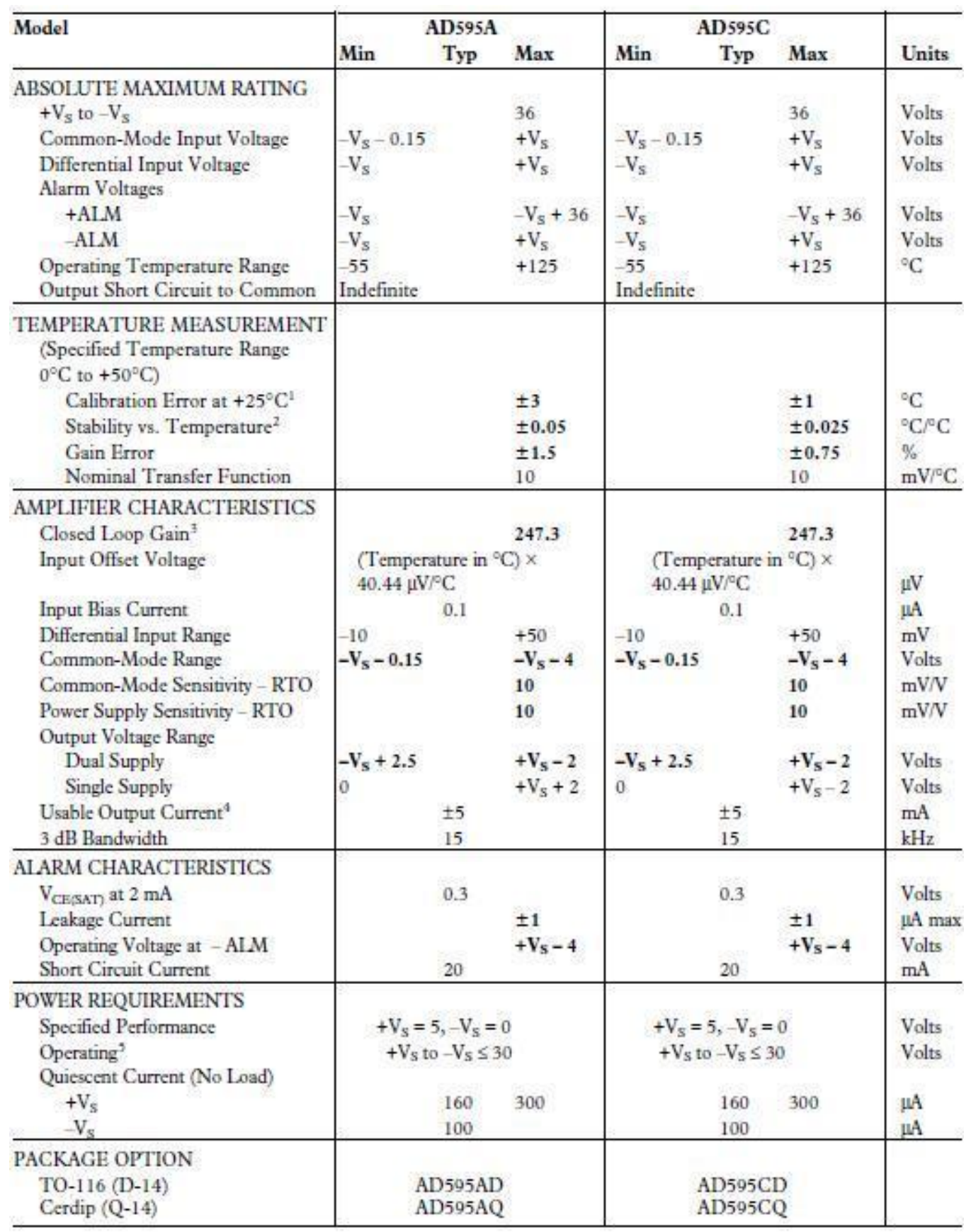

Fonte: ANALOG DEVICES (1999). 


\section{ANEXO C - Especificações técnicas dos transdutores de pressão MPXH6115AC6T1 e MPX4250GP}

Especificações técnicas do transdutor de pressão absoluta da marca Motorola, modelo MPXH6115AC6T1.

Características de operação: $\left(V_{\text {supply }}=5,0 \mathrm{VCC}, T_{\text {Ambiente }}=25^{\circ} \mathrm{C}\right)$

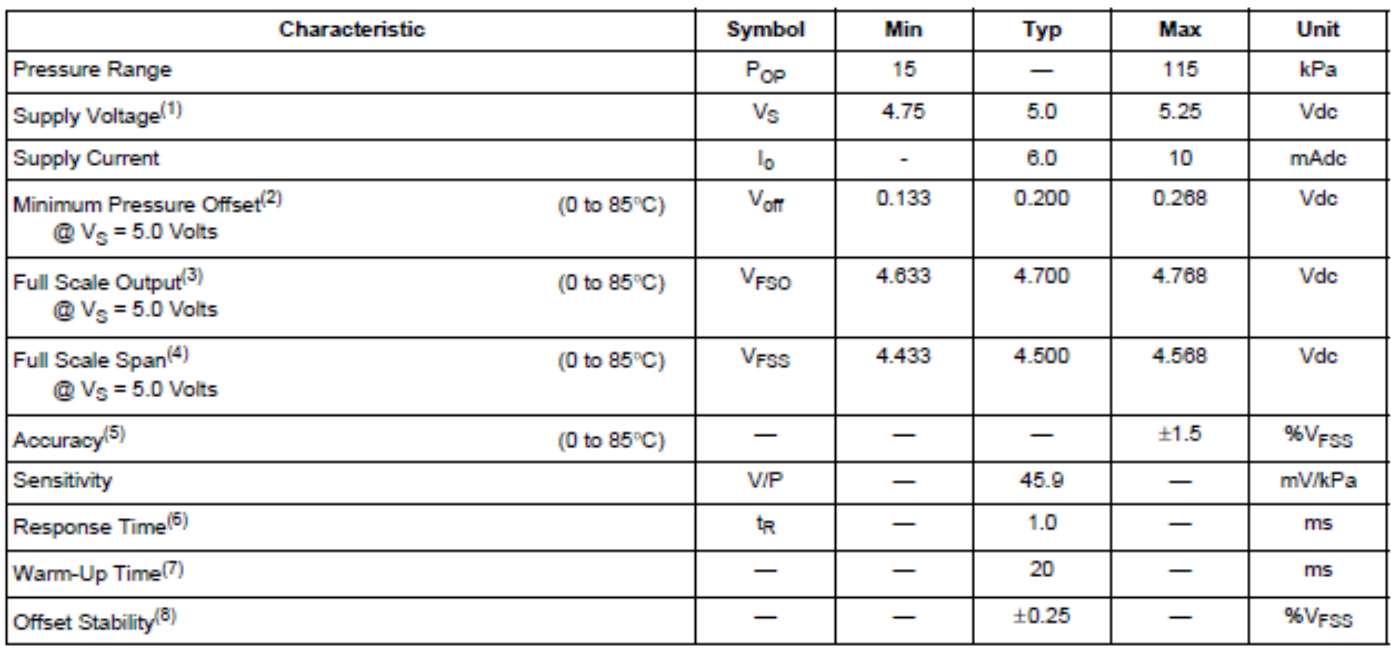

Device is ratiometric within this specified excitation range.

2. Offset $\left(V_{\text {om }}\right)$ is defined as the output voltage at the minimum rated pressure.

3. Full Scale Output $\left(V_{\mathrm{FSO}}\right)$ is defined as the output voltage at the maximum or full rated pressure.

4. Full Scale Span (VFSS) is defined as the algebraic difference between the output voltage at full rated pressure and the output voltage at the minimum rated pressure.

5. Accuracy is the deviation in actual output from nominal output over the entire pressure range and temperature range as a percent of span at $25^{\circ} \mathrm{C}$ due to all sources of error including the following

- Linearity: Output deviation from a straight line relationship with pressure over the specified pressure range.

- Temperature Hysteresis: Output deviation at any temperature within the operating temperature range, after the temperature is cycled to and from the minimum or maximum operating temperature points, with zero differential pressure applied.

- Pressure Hysteresis: Output deviation at any pressure within the specified range, when this pressure is cycled to and from minimum or maximum rated pressure at $25^{\circ} \mathrm{C}$.

- TCSpan: $\quad$ Output deviation over the temperature range of $0^{\circ}$ to $85^{\circ} \mathrm{C}$, relative to $25^{\circ} \mathrm{C}$

- TcOffset: $\quad$ Output deviation with minimum pressure applied, over the temperature range of $0^{\circ}$ to $85^{\circ} \mathrm{C}$, relative to $25^{\circ} \mathrm{C}$

6. Response Time is defined as the time for the incremental change in the output to go from $10 \%$ to $90 \%$ of its final value when subjected to a specified step change in pressure.

7. Warm-up Time is defined as the time required for the product to meet the specified output voltage after the pressure has been stabilized.

8. Offset Stability is the product's output deviation when subjected to 1000 cycles of Pulsed Pressure, Temperature Cycling with Bias Test.

Fonte: Motorola (2009). 
Resposta versus pressão absoluta:

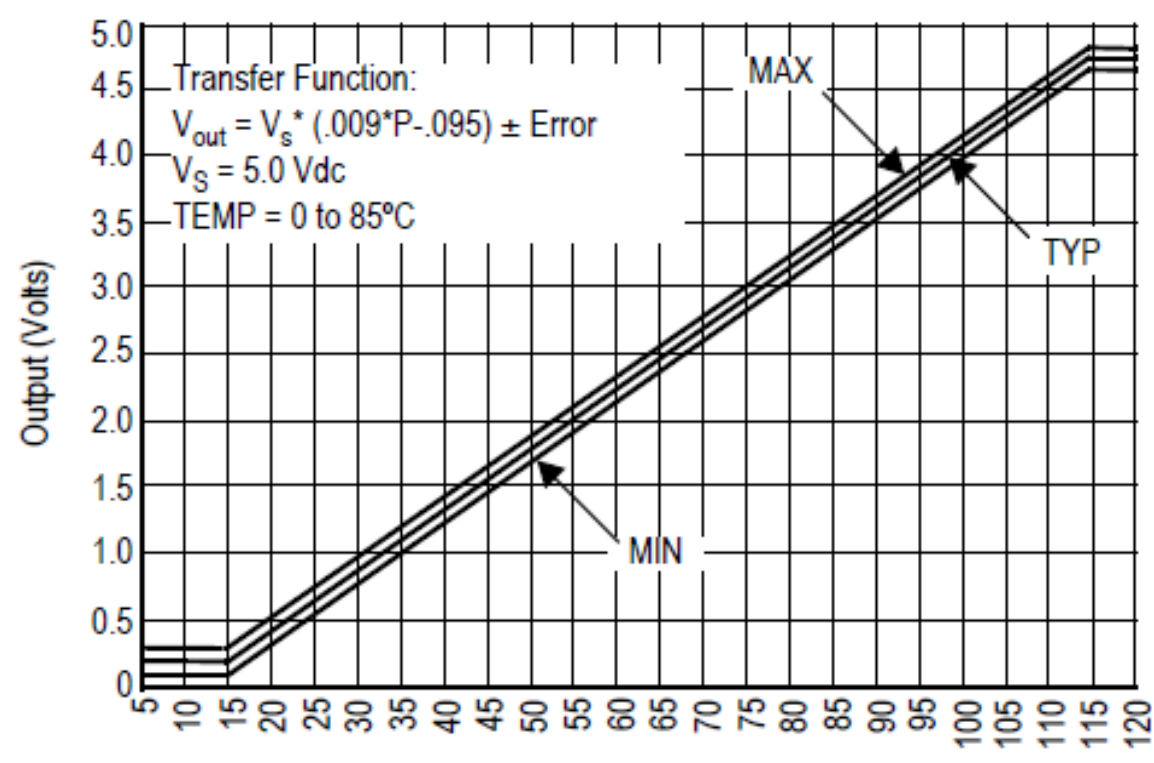

Pressure (ref: to sealed vacuum) in $\mathrm{kPa}$

Fonte: Motorola (2009).
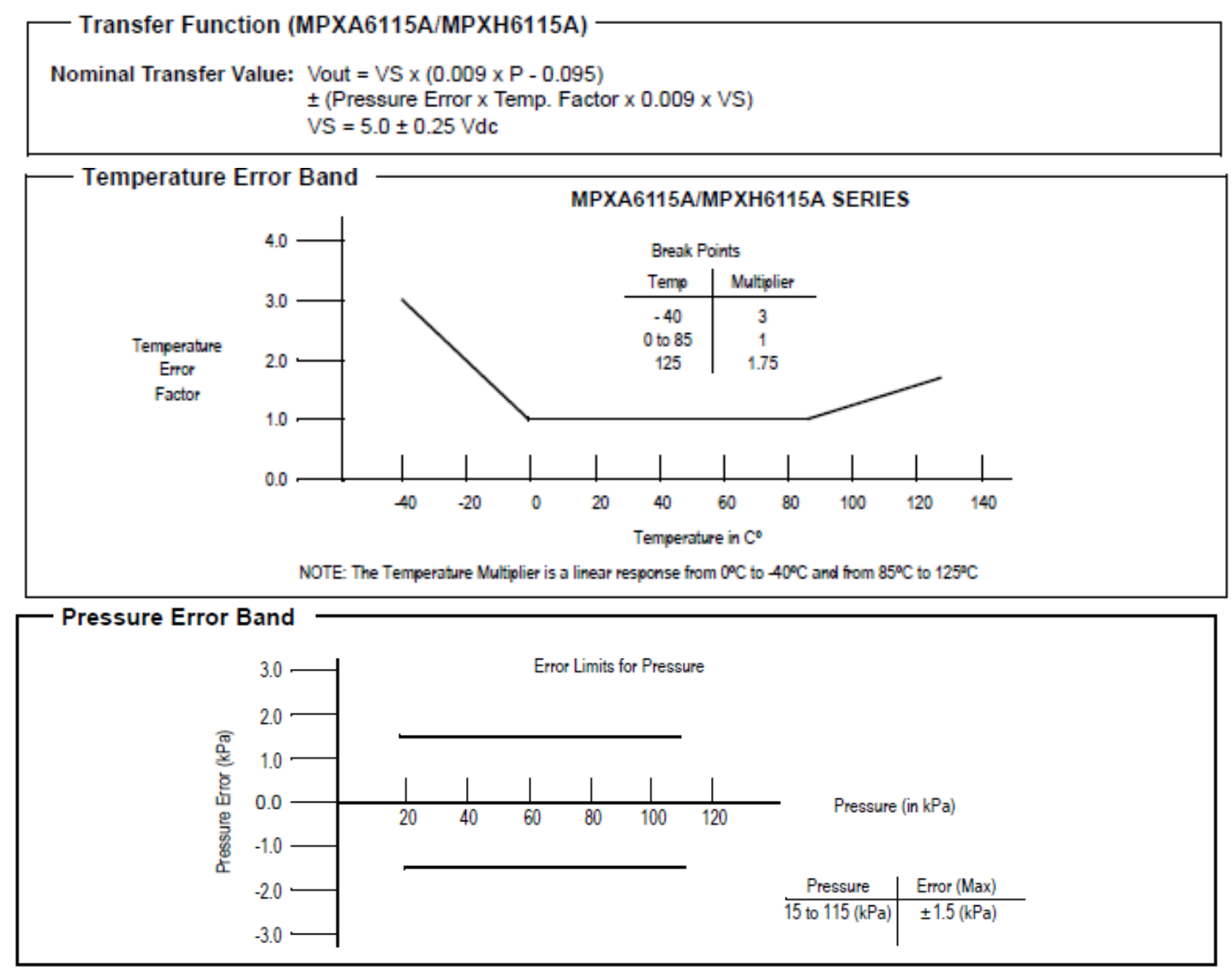

Fonte: Motorola (2009). 
Descrição dos pinos deste tansdutor:

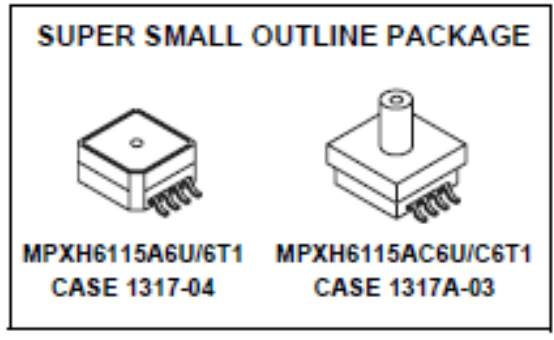

\begin{tabular}{|c|c|c|c|}
\hline \multicolumn{4}{|c|}{ SUPER SMALL OUTLINE PACKAGE } \\
PIN NUMBERS \\
${ }^{(1)}$
\end{tabular}

1. Pins $1,5,6,7$, and 8 are internal device connections. Do not connect to external circuitry or ground. Pin 1 is denoted by the notch in the lead

Fonte: Motorola (2009).

Especificações técnicas do transdutor de pressão relativa da marca Motorola, modelo MPX4250GP.

Descrição dos pinos deste tansdutor:

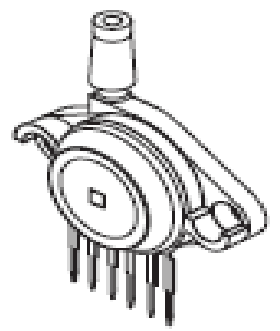

\begin{tabular}{|c|c|c|c|}
\hline \multicolumn{4}{|c|}{ PIN NUMBER } \\
\hline 1 & Vout $_{\text {out }}$ & 4 & N/C \\
\hline 2 & Gnd & 5 & N/C \\
\hline 3 & VS & 6 & N/C \\
\hline
\end{tabular}

NOTE: Pins 4,5 , and 6 are internal device connections. Do not connect to external circuitry or ground. Pin 1 is noted by the notch in the lead.

Fonte: Motorola (2006). 
Características de operação: $\left(V_{\text {supply }}=5,1 \mathrm{VCC}, T_{\text {Ambiente }}=25^{\circ} \mathrm{C}\right)$

\begin{tabular}{|c|c|c|c|c|c|}
\hline Characteristic & Symbol & Min & Typ & Max & Unit \\
\hline Pressure Range ${ }^{(1)}$ & $P_{O P}$ & 0 & - & 250 & $\mathrm{kPa}$ \\
\hline Supply Voltage ${ }^{(2)}$ & $v_{S}$ & 4.85 & 5.1 & 5.35 & Vdc \\
\hline Supply Current & $\mathrm{I}_{0}$ & - & 7.0 & 10 & mAdc \\
\hline Minimum Pressure Offset @ $V_{S}=5.1$ Volts ${ }^{(3)}$ & $\mathrm{V}_{\text {off }}$ & 0.139 & 0.204 & 0.269 & Vdc \\
\hline Full Scale Output @ V $\mathrm{S}_{\mathrm{S}}=5.1 \mathrm{Volts}^{(4)}$ & $\mathrm{V}_{\mathrm{FSO}}$ & 4.844 & 4.909 & 4.974 & Vdc \\
\hline Full Scale Span @ V $\mathrm{S}=5.1$ Volts $^{(5)}$ & $\mathrm{V}_{\mathrm{FSS}}$ & - & 4.705 & - & Vdc \\
\hline$\left(0\right.$ to $\left.85^{\circ} \mathrm{C}\right)$ & - & - & - & \pm 1.4 & $\% V_{F S S}$ \\
\hline Sensitivity & $\Delta V / \Delta P$ & - & 18.8 & - & $\mathrm{mV} / \mathrm{kPa}$ \\
\hline Response Time ${ }^{(7)}$ & $t_{R}$ & - & 1.0 & - & $\mathrm{ms}$ \\
\hline Output Source Current at Full Scale Output & $\mathrm{I}_{\mathrm{o}+}$ & - & 0.1 & - & mAdc \\
\hline Warm-Up Time ${ }^{(8)}$ & - & - & 20 & - & $\mathrm{ms}$ \\
\hline Offset Stability ${ }^{\left({ }^{(\theta)}\right.}$ & - & - & \pm 0.5 & - & $\% V_{\text {FSS }}$ \\
\hline
\end{tabular}

1. $1.0 \mathrm{kPa}$ (kiloPascal) equals $0.145 \mathrm{psi}$.

2. Device is ratiometric within this specified excitation range.

3. Offset $\left(V_{\text {off }}\right)$ is defined as the output voltage at the minimum rated pressure.

4. Full Scale Output $\left(\mathrm{V}_{\mathrm{FSO}}\right)$ is defined as the output voltage at the maximum or full rated pressure.

5. Full Scale Span $\left(V_{F S S}\right)$ is defined as the algebraic difference between the output voltage at full rated pressure and the output voltage at the minimum rated pressure.

6. Accuracy (error budget) consists of the following:

Linearity: $\quad$ Output deviation from a straight line relationship with pressure over the specified pressure range.

Temperature Hysteresis: Output deviation at any temperature within the operating temperature range, after the temperature is cycled to and from the minimum or maximum operating temperature points, with zero differential pressure applied.

Pressure Hysteresis: $\quad$ Output deviation at any pressure within the specified range, when this pressure is cycled to and from the

TcSpan: minimum or maximum rated pressure, at $25^{\circ} \mathrm{C}$

Output deviation over the temperature range of 0 to $85^{\circ} \mathrm{C}$, relative to $25^{\circ} \mathrm{C}$.

$\begin{array}{ll}\text { TcOffset: } & \text { Output deviation with minimum rated pressure applied, over the temperature range of } 0 \text { to } 85^{\circ} \mathrm{C} \text {, relative to } 25^{\circ} \mathrm{C} \text {. } \\ \text { Variation from Nominal: } & \text { The variation from nominal values, for Offset or Full Scale Span, as a percent of } V_{F S S} \text {, at } 25^{\circ} \mathrm{C} \text {. }\end{array}$

7. Response Time is defined as the time for the incremental change in the output to go from $10 \%$ to $90 \%$ of its final value when subjected to a specified step change in pressure.

8. Warm-up Time is defined as the time required for the product to meet the specified output voltage after the Pressure has been stabilized.

9. Offset Stability is the product's output deviation when subjected to 1000 hours of Pulsed Pressure, Temperature Cycling with Bias Test.

Fonte: Motorola (2006). 
Resposta versus pressão relativa:

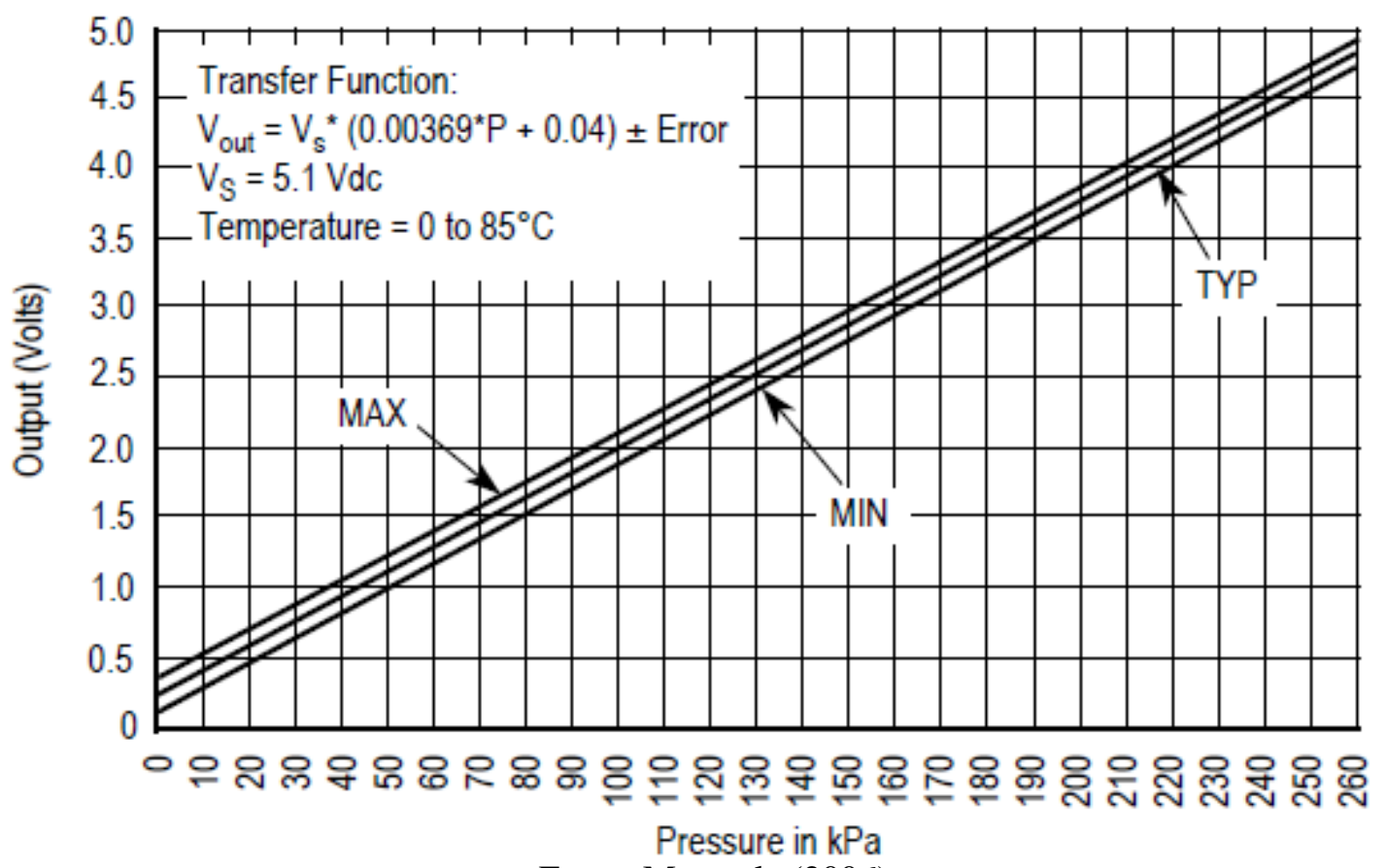

Fonte: Motorola (2006).

Transfer Function (MPX4250)

Nominal Transfer Value: $V_{\text {out }}=V_{S} \times(0.00369 \times P+0.04)$

\pm (Pressure Error $\times$ Temp. Factor $\left.\times 0.00369 \times V_{S}\right)$

$V_{S}=5.1 \pm 0.25 \mathrm{Vdc}$

Temperature Error Band

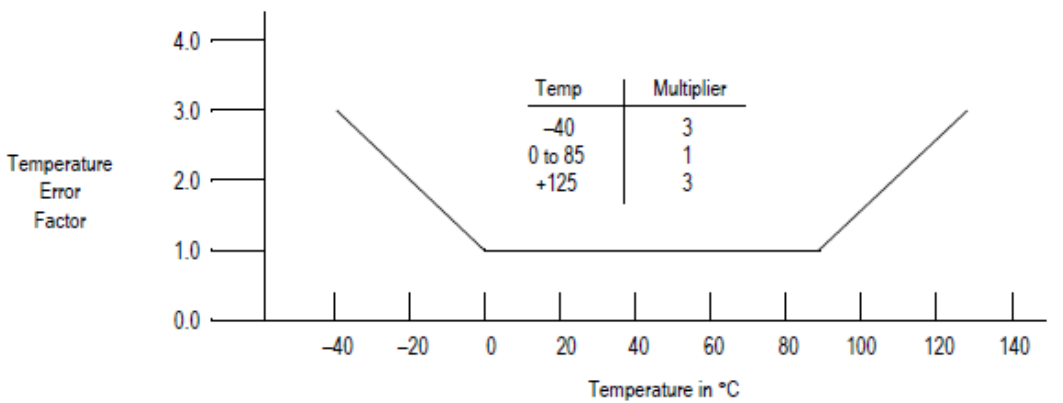

NOTE: The Temperature Multiplier is a linear response from $0{ }^{\circ} \mathrm{C}$ to $-40^{\circ} \mathrm{C}$ and from $85^{\circ} \mathrm{C}$ to $125^{\circ} \mathrm{C}$.

Fonte: Motorola (2006). 


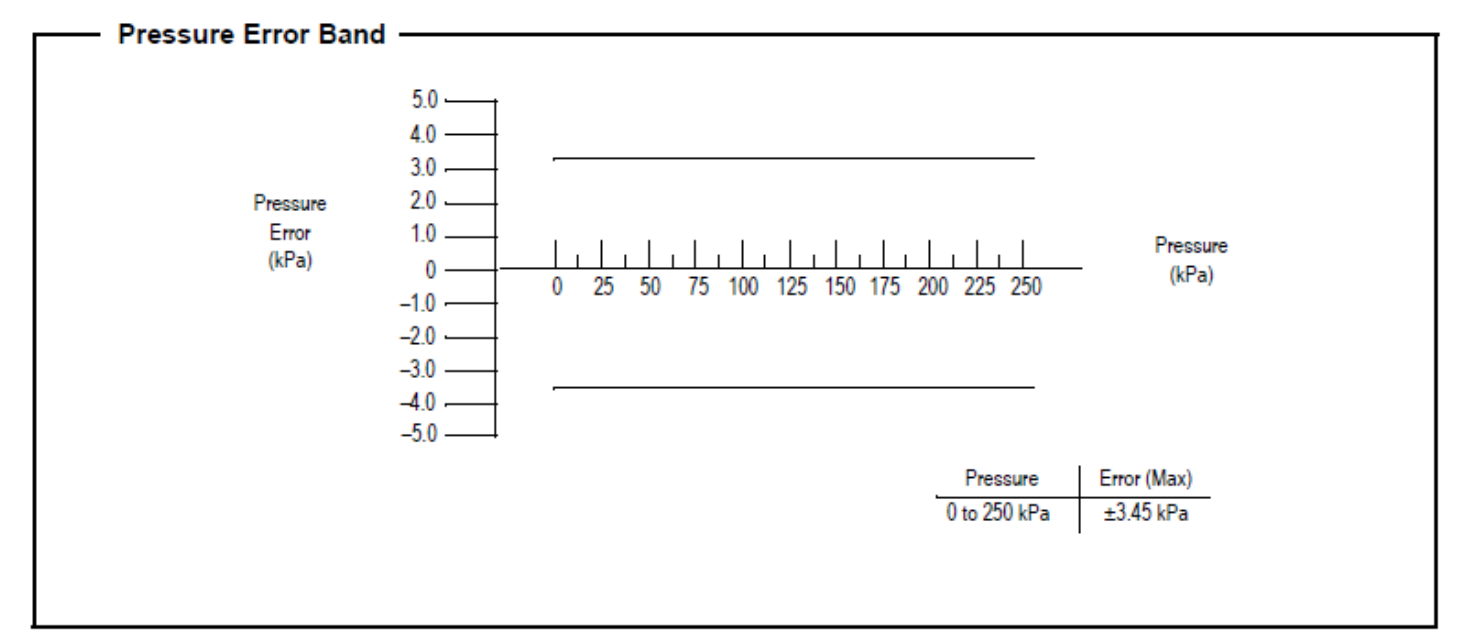

Fonte: Motorola (2006). 


\section{ANEXO D - Tabela para o procedimento de Tukey}

TABLE: Q SCORES FOR TUKEY'S METHOD

\begin{tabular}{r|rrrrrrrrr}
\multicolumn{10}{c}{$\alpha=0.05$} \\
\hline$k$ & 2 & 3 & 4 & 5 & 6 & 7 & 8 & 9 & 10 \\
df & & & & & & & & & \\
\hline 1 & 18.0 & 27.0 & 32.8 & 37.1 & 40.4 & 43.1 & 45.4 & 47.4 & 49.1 \\
2 & 6.08 & 8.33 & 9.80 & 10.88 & 11.73 & 12.43 & 13.03 & 13.54 & 13.99 \\
3 & 4.50 & 5.91 & 6.82 & 7.50 & 8.04 & 8.48 & 8.85 & 9.18 & 9.46 \\
4 & 3.93 & 5.04 & 5.76 & 6.29 & 6.71 & 7.05 & 7.35 & 7.60 & 7.83 \\
5 & 3.64 & 4.60 & 5.22 & 5.67 & 6.03 & 6.33 & 6.58 & 6.80 & 6.99 \\
6 & 3.46 & 4.34 & 4.90 & 5.30 & 5.63 & 5.90 & 6.12 & 6.32 & 6.49 \\
7 & 3.34 & 4.16 & 4.68 & 5.06 & 5.36 & 5.61 & 5.82 & 6.00 & 6.16 \\
8 & 3.26 & 4.04 & 4.53 & 4.89 & 5.17 & 5.40 & 5.60 & 5.77 & 5.92 \\
9 & 3.20 & 3.95 & 4.41 & 4.76 & 5.02 & 5.24 & 5.43 & 5.59 & 5.74 \\
10 & 3.15 & 3.88 & 4.33 & 4.65 & 4.91 & 5.12 & 5.30 & 5.46 & 5.60 \\
11 & 3.11 & 3.82 & 4.26 & 4.57 & 4.82 & 5.03 & 5.20 & 5.35 & 5.49 \\
12 & 3.08 & 3.77 & 4.20 & 4.51 & 4.75 & 4.95 & 5.12 & 5.27 & 5.39 \\
13 & 3.06 & 3.73 & 4.15 & 4.45 & 4.69 & 4.88 & 5.05 & 5.19 & 5.32 \\
14 & 3.03 & 3.70 & 4.11 & 4.41 & 4.64 & 4.83 & 4.99 & 5.13 & 5.25 \\
15 & 3.01 & 3.67 & 4.08 & 4.37 & 4.59 & 4.78 & 4.94 & 5.08 & 5.20 \\
16 & 3.00 & 3.65 & 4.05 & 4.33 & 4.56 & 4.74 & 4.90 & 5.03 & 5.15 \\
17 & 2.98 & 3.63 & 4.02 & 4.30 & 4.52 & 4.70 & 4.86 & 4.99 & 5.11 \\
18 & 2.97 & 3.61 & 4.00 & 4.28 & 4.49 & 4.67 & 4.82 & 4.96 & 5.07 \\
19 & 2.96 & 3.59 & 3.98 & 4.25 & 4.47 & 4.65 & 4.79 & 4.92 & 5.04 \\
20 & 2.95 & 3.58 & 3.96 & 4.23 & 4.45 & 4.62 & 4.77 & 4.90 & 5.01 \\
24 & 2.92 & 3.53 & 3.90 & 4.17 & 4.37 & 4.54 & 4.68 & 4.81 & 4.92 \\
30 & 2.89 & 3.49 & 3.85 & 4.10 & 4.30 & 4.46 & 4.60 & 4.72 & 4.82 \\
40 & 2.86 & 3.44 & 3.79 & 4.04 & 4.23 & 4.39 & 4.52 & 4.63 & 4.73 \\
60 & 2.83 & 3.40 & 3.74 & 3.98 & 4.16 & 4.31 & 4.44 & 4.55 & 4.65 \\
120 & 2.80 & 3.36 & 3.68 & 3.92 & 4.10 & 4.24 & 4.36 & 4.47 & 4.56 \\
$\infty$ & 2.77 & 3.31 & 3.63 & 3.86 & 4.03 & 4.17 & 4.29 & 4.39 & 4.47 \\
\hline
\end{tabular}

\begin{tabular}{r|rrrrrrrrr}
\multicolumn{10}{c}{$\alpha=0.01$} \\
\hline$k$ & 2 & 3 & 4 & 5 & 6 & 7 & 8 & 9 & 10 \\
$\mathrm{df}$ & & & & & & & & & \\
\hline 1 & 90.0 & 135 & 164 & 186 & 202 & 216 & 227 & 237 & 246 \\
2 & 13.90 & 19.02 & 22.56 & 25.37 & 27.76 & 29.86 & 31.73 & 33.41 & 34.93 \\
3 & 8.26 & 10.62 & 12.17 & 13.32 & 14.24 & 15.00 & 15.65 & 16.21 & 16.71 \\
4 & 6.51 & 8.12 & 9.17 & 9.96 & 10.58 & 11.10 & 11.54 & 11.92 & 12.26 \\
5 & 5.70 & 6.98 & 7.80 & 8.42 & 8.91 & 9.32 & 9.67 & 9.97 & 10.24 \\
6 & 5.24 & 6.33 & 7.03 & 7.56 & 7.97 & 8.32 & 8.61 & 8.87 & 9.10 \\
7 & 4.95 & 5.92 & 6.54 & 7.00 & 7.37 & 7.68 & 7.94 & 8.17 & 8.37 \\
8 & 4.75 & 5.64 & 6.20 & 6.62 & 6.96 & 7.24 & 7.47 & 7.68 & 7.86 \\
9 & 4.60 & 5.43 & 5.96 & 6.35 & 6.66 & 6.91 & 7.13 & 7.33 & 7.49 \\
10 & 4.48 & 5.27 & 5.77 & 6.14 & 6.43 & 6.67 & 6.87 & 7.05 & 7.21 \\
11 & 4.39 & 5.15 & 5.62 & 5.97 & 6.25 & 6.48 & 6.67 & 6.84 & 6.99 \\
12 & 4.32 & 5.05 & 5.50 & 5.84 & 6.10 & 6.32 & 6.51 & 6.67 & 6.81 \\
13 & 4.26 & 4.96 & 5.40 & 5.73 & 5.98 & 6.19 & 6.37 & 6.53 & 6.67 \\
14 & 4.21 & 4.89 & 5.32 & 5.63 & 5.88 & 6.08 & 6.26 & 6.41 & 6.54 \\
15 & 4.17 & 4.84 & 5.25 & 5.56 & 5.80 & 5.99 & 6.16 & 6.31 & 6.44 \\
16 & 4.13 & 4.79 & 5.19 & 5.49 & 5.72 & 5.92 & 6.08 & 6.22 & 6.35 \\
17 & 4.10 & 4.74 & 5.14 & 5.43 & 5.66 & 5.85 & 6.01 & 6.15 & 6.27 \\
18 & 4.07 & 4.70 & 5.09 & 5.38 & 5.60 & 5.79 & 5.94 & 6.08 & 6.20 \\
19 & 4.05 & 4.67 & 5.05 & 5.33 & 5.55 & 5.73 & 5.89 & 6.02 & 6.14 \\
20 & 4.02 & 4.64 & 5.02 & 5.29 & 5.51 & 5.69 & 5.84 & 5.97 & 6.09 \\
24 & 3.96 & 4.55 & 4.91 & 5.17 & 5.37 & 5.54 & 5.69 & 5.81 & 5.92 \\
30 & 3.89 & 4.45 & 4.80 & 5.05 & 5.24 & 5.40 & 5.54 & 5.65 & 5.76 \\
40 & 3.82 & 4.37 & 4.70 & 4.93 & 5.11 & 5.26 & 5.39 & 5.50 & 5.60 \\
60 & 3.76 & 4.28 & 4.59 & 4.82 & 4.99 & 5.13 & 5.25 & 5.36 & 5.45 \\
120 & 3.70 & 4.20 & 4.50 & 4.71 & 4.87 & 5.01 & 5.12 & 5.21 & 5.30 \\
$\infty$ & 3.64 & 4.12 & 4.40 & 4.60 & 4.76 & 4.88 & 4.99 & 5.08 & 5.16 \\
\hline
\end{tabular}

Fonte: TABLE... (2006). 